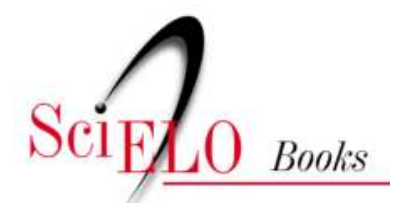

\title{
Segurança do paciente conhecendo os riscos nas organizações de saúde
}

\author{
Paulo Sousa \\ Walter Mendes \\ (orgs.)
}

SOUSA, P., and MENDES, W., comps. Segurança do paciente: conhecendo os riscos nas organizações de saúde [online]. 2nd ed. rev. updt. Rio de Janeiro, RJ : CDEAD, ENSP, Editora FIOCRUZ, 2019, 524 p. ISBN 978-85-7541-641-9. https://doi.org/10.7476/9788575416419.

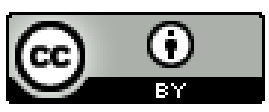

All the contents of this work, except where otherwise noted, is licensed under a Creative Commons Attribution 4.0 International license.

Todo o conteúdo deste trabalho, exceto quando houver ressalva, é publicado sob a licença Creative Commons Atribição $\underline{4.0}$. 


\section{Segurança do Paciente: \\ conhecendo os riscos nas organizações de saúde}




\section{Fundação Oswaldo Cruz - Fiocruz}

PRESIDENTE

Nísia Trindade Lima

VICE-PRESIDENTE DE EDUCAÇÃO, INFORMAÇÃO E COMUNICAÇÃO

Cristiani Vieira Machado

\section{Editora Fiocruz}

DIRETORA

Cristiani Vieira Machado

EDITOR EXECUTIVO

João Carlos Canossa Mendes

EDITORES CIENTÍFICOS

Carlos Machado de Freitas

Gilberto Hochman

CONSELHO EDITORIAL

Denise Valle

José Roberto Lapa e Silva

Kenneth Rochel de Camargo Jr.

Lígia Maria Vieira da Silva

Marcos Cueto

Maria Cecília de Souza Minayo

Marilia Santini de Oliveira

Moisés Goldbaum

Rafael Linden

Ricardo Ventura Santos
Escola Nacional de Saúde Pública Sergio Arouca

DIRETOR

Hermano Albuquerque de Castro

VICE-DIRETORA DE ENSINO

Lúcia Maria Dupret

COORDENADOR DE DESENVOLVIMENTO EDUCACIONAL E EDUCAÇÃO A DISTÂNCIA

Mauricio De Seta 


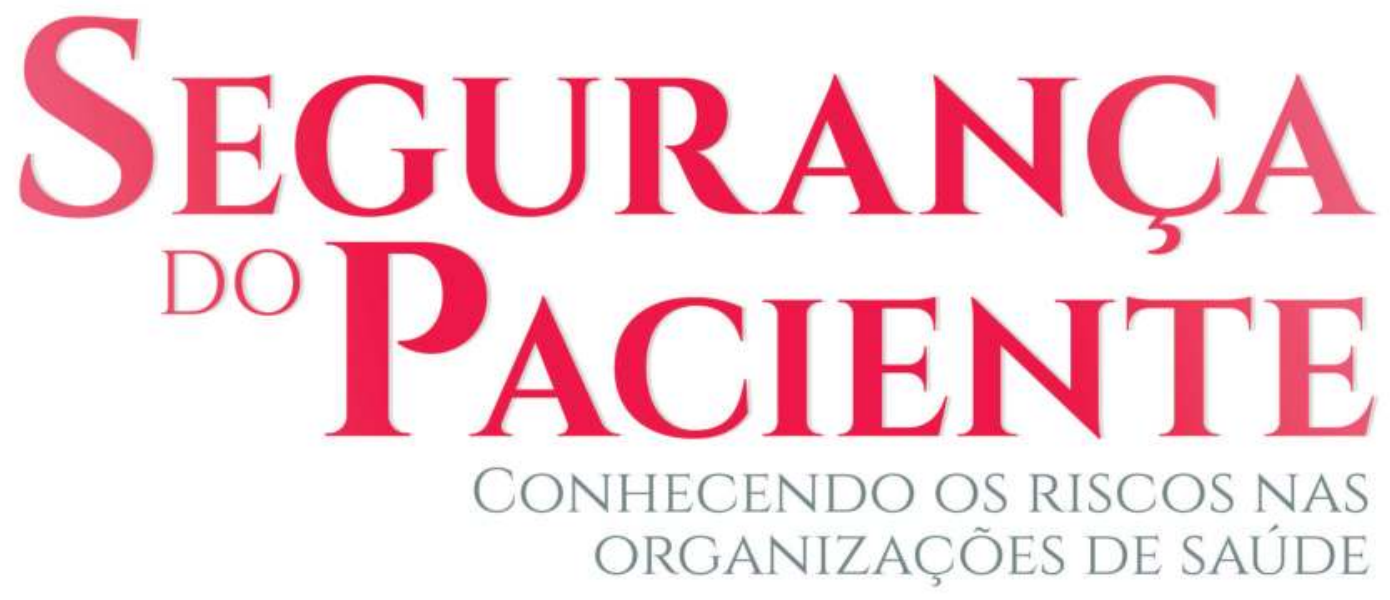

$2^{\mathrm{A}}$ EDIÇÃO REVISTA E AMPLIADA

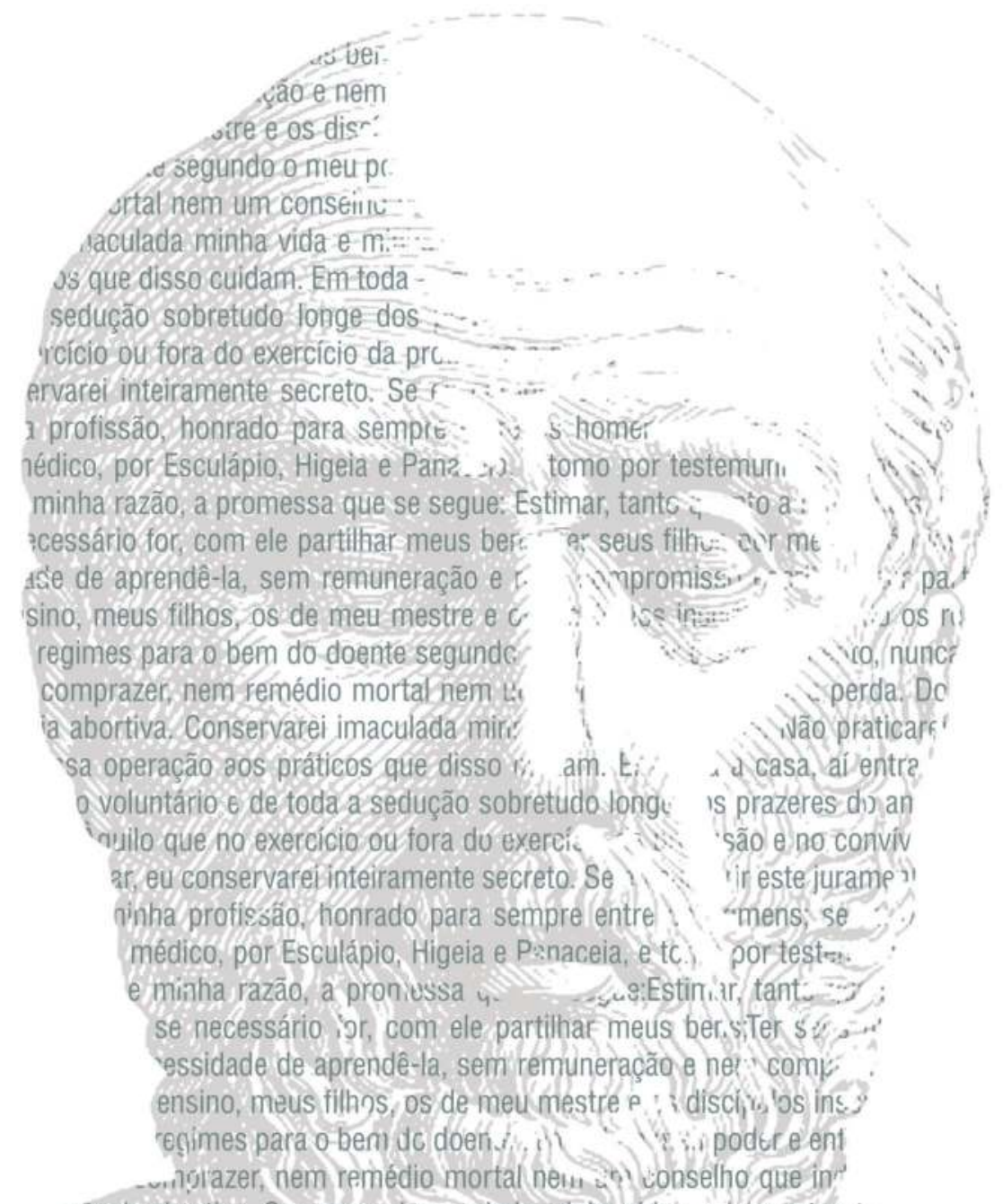

PAULO SOUSA

WALTER MENDES

ORGANIZADORES

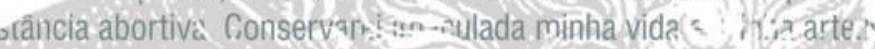

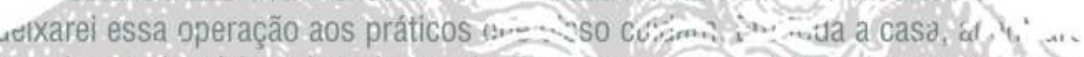

todo 0 dano voluntário e de toda a sedução s. bretuc a dos prazerés cil, thor, u

uu escravizados. Àquilo que no exercício ou fora do exercicis ? rofissa. e no corvi a da socier

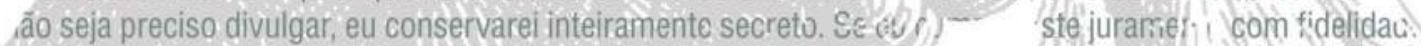

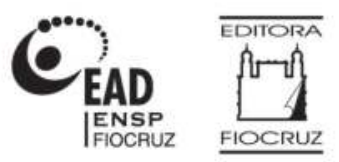


Copyright (C2014 dos autores

Todos os direitos de edição reservados à Fundação Oswaldo Cruz - Editora Fiocruz e ENSP/CDEAD

$1^{\text {a }}$ edição (2014)

$1^{\text {a }}$ reimpressão (2016)

$2^{\text {a }}$ edição revista e ampliada (2019)

\section{SUPERVISÃO EDITORIAL}

Maria Leonor de M. S. Leal

\section{ASSESSORIA PEDAGÓGICA}

Ana Paula Abreu-Fialho

Henriette dos Santos (2014)

Moacyr Torres Junior

Cleide Figueiredo Leitão (2019)

Suely Guimarães Rocha

Diogo César Nunes (2019)

\section{REVISÃO METODOLÓGICA}

Ana Paula Abreu-Fialho

Katlheen Gonçalves

REVISÃO TÉCNICA

Bárbara do Nascimento Caldas
REVISÃO E NORMALIZAÇÃO

Alda Maria Lessa Bastos

Ana Lucia Normando

Andréia Amaral

Christiane Abbade

Maria Auxiliadora Nogueira

Simone Teles

CAPA E PROJETO GRÁFICO

Jonathas Scott

\section{ILUSTRAÇÕES}

Luiz Marcelo Resende

EDITORAÇÃO ELETRÔNICA E TRATAMENTO DE IMAGEM

Quattri Design (2014)

Leevro, Design Editorial

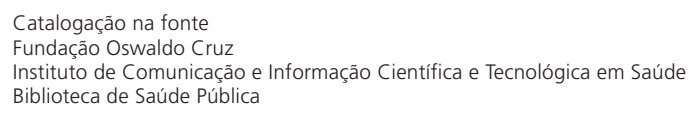

S725s Sousa, Paulo (Org.)

Segurança do paciente: conhecendo os riscos nas organizações de saúde. / organizado por Paulo Sousa e Walter Mendes. - 2.ed (revista e ampliada) - Rio de Janeiro, RJ : CDEAD, ENSP, Fiocruz, 2019.

524 p. : il. color

ISBN: 978-85-8432-063-9

1. Segurança do Paciente. 2. Qualidade da Assistência à Saúde. 3. Classificação. 4. Sistema Único de Saúde. 5. Gestão de Riscos. 6.

Organizações em Saúde. 7. Aprendizagem. 8. Educação a Distância. I. Mendes, Walter (Org.). II. Título.

CDD -362.104258

\section{9}

\section{Editora Fiocruz}

Avenida Brasil, 4.036 - Sala 112

Manguinhos - Rio de Janeiro - RJ

CEP: 21041-210

Tels.: (21) 3882-9039/ 3882-9041

Telefax: (21) 3882-9006

www.fiocruz.br/editora
Coordenação de Desenvolvimento Educacional e Educação a Distância da Escola Nacional de Saúde Pública Sergio Arouca

Rua Leopoldo Bulhões, 1.480 - Prédio Professor Joaquim Alberto Cardoso de Melo

Manguinhos - Rio de Janeiro - RJ

CEP: 21041-210

www.ead.fiocruz.br 


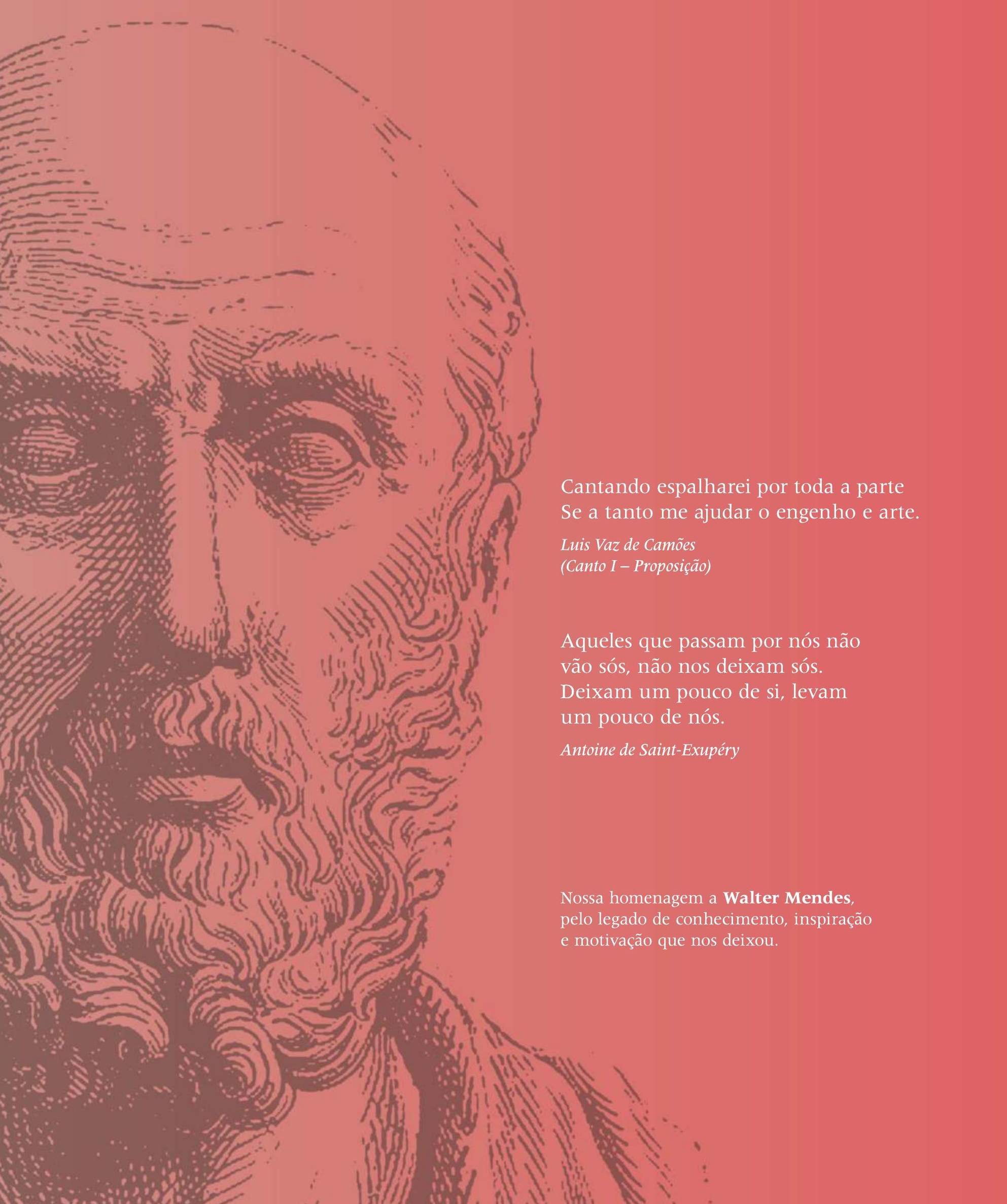




\section{Autores}

Adriana Carla Bridi

Enfermeira intensivista pela Universidade do Estado do Rio de Janeiro (Facenf-Uerj) e pela Associação Brasileira de Enfermagem em Terapia Intensiva (Abenti); doutora em enfermagem e biociências pela Universidade Federal do Estado do Rio de Janeiro (Unirio); mestre em enfermagem pela Universidade Federal do Estado do Rio de Janeiro (Unirio); pós-graduação em prevenção e controle de infecções hospitalares pela Universidade Gama Filho (UGF). Enfermeira do Centro de Terapia Adulto do Hospital Universitário Pedro Ernesto (Hupe-Uerj).

Ana Alves

Mestre em gestão da saúde pela ENSP-UNL. Autora do trabalho de Projeto Caracterização Clínica e Económica das Úlceras por Pressão em Ambiente Hospitalar: contributos para a melhoria da segurança do doente e da qualidade dos cuidados. Técnica especialista da Direção Comercial da Luz Saúde.

Ana Teles

Mestre em gestão de unidades de saúde; pós-graduada em imuno-hemoterapia, frequentou vários cursos de especialização na área da medicina transfusional. Técnica superior de análises clínicas e saúde pública no IPST-CSTL. Desenvolveu um projeto de investigação/pesquisa para obtenção do grau de mestre em caracterização e avaliação do impacto dos erros nos serviços de medicina transfusional. Áreas de interesse: segurança do doente e medicina transfusional.

António Tavares

Doutorado em saúde pública; médico especialista em saúde pública. Consultor de saúde pública. Assistente graduado sénior de saúde pública da Administração Regional de Saúde de Lisboa e Vale do Tejo. Autoridade de saúde da cidade da Amadora. Professor associado convidado na ENSP-UNL das unidades curriculares de saúde ambiental, de planeamento da saúde e de vigilância epidemiológica e gestão do risco. Dois prémios científicos na área da saúde pública; autor e coautor de livros, capítulos de livros e artigos científicos na área de saúde pública. Coordenou o Curso de Especialização em Saúde Pública da ENSP-UNL.

Barbara Ventura Fontes

Enfermeira intensivista; MBA em qualidade e acreditação hospitalar pelo Consórcio Brasileiro de Acreditação (CBA). Atual membro da Assessoria da Qualidade do Instituto Nacional de Traumatologia e Ortopedia Jamil Haddad (Into) e membro do Núcleo de Segurança do Paciente.

Candida Pité-Madeira

Mestre em engenharia sanitária; engenheira química. Exerce funções como técnica superior de saúde do ramo de engenharia sanitária na Administração Regional de Saúde de Lisboa e Vale do Tejo, IP, desenvolvendo trabalhos no âmbito do planeamento/ planejamento e execução da vigilância sanitária, monitorização, investigação/pesquisa e controlo dos factores de risco para a saúde (físicos, químicos e biológicos). Preletora de várias unidades curriculares na área de saúde ambiental na ENSP-UNL. Autora de livros, capítulos de livros e vários artigos científicos de saúde pública.

Carla Barreiros

Mestre em engenharia sanitária. Técnica superior de saúde do ramo de engenharia sanitária na Administração Regional de Saúde de Lisboa e Vale do Tejo, IP, desenvolvendo trabalhos no âmbito do planeamento/planejamento e execução da vigilância sanitária, monitorização, investigação/pesquisa e controlo dos factores de risco para a saúde (físicos, químicos e biológicos). 
Claudia Dolores Trierweiler Sampaio de Oliveira Corrêa

Cirurgiã-dentista; mestre e especialista em saúde pública pela Escola Nacional de Saúde Pública Sergio Arouca (ENSP-Fiocruz); especialista em odontologia legal pela Universidade Federal do Rio de Janeiro (UFRJ); especialista em gestão em saúde (Coppead-UFRJ); especialista em endodontia pela Odontoclínica Central da Marinha (OCM); pós-graduada em qualidade do cuidado e segurança do paciente pela Escola Nacional de Saúde Pública da Universidade Nova de Lisboa (ENSP-UNL).

Elaine da Hora dos Santos

Enfermeira; mestre em avaliação pela Fundação Cesgranrio (UFRJ). Membro da Assessoria da Qualidade do Instituto Nacional de Traumatologia e Ortopedia Jamil Haddad (Into); educadora para a qualidade e segurança em instituições de saúde pelo Consórcio Brasileiro de Acreditação (CBA).

Elaine Pina

Licenciada em medicina e cirurgia pela Universidade Clássica de Lisboa. Provida como especialista de microbiologia no Laboratório de Bacteriologia do Hospital de Santa Maria. Desde 1988, trabalha na área do controlo de infeção. Foi coordenadora do Programa Nacional de Controlo de Infeção até a criação do Programa de Prevenção e Controlo das Infeções e Resistência aos Antimicrobianos, em fevereiro de 2013, integrando a coordenação desse novo programa prioritário até 2015.

Elsa Soares

Mestre em saúde comunitária; pós-graduada em medicina do trabalho. Médica e consultora de saúde pública.

Etelvina Ferreira

Mestre em segurança do doente pela ENSP-UNL; enfermeira de prevenção e controlo de infeção com experiência no sector público e no sector privado em Portugal. Atualmente, trabalha para Nuffield Health, The Manor Hospital em Oxford, Reino Unido, como enfermeira coordenadora do programa de prevenção e controlo de infeção, sendo ainda cluster lead para a região central e País de Gales. Membro do Oxfordshire Joint Infection Control Committee. Formadora na área de prevenção e controlo de infeção em diversos contextos de saúde.

Irene Rêgo Haddad

Enfermeira; especialista em controle de infecção pelo Inesp-SP e em gerência de saúde pela FGV-RJ. Responsável pela Gestão Ambiental e Manejo de Resíduos de Serviços de Saúde do HFSE-MS- RJ. Membro do Projeto Hospitais Saudáveis. Educadora de projetos de avaliação e educação em melhoria da qualidade e segurança em saúde pelo CBA-JCI.

Isabela Ribeiro Simões de Castro

Médica; mestrado em medicina (pneumologia) pela Universidade Federal Fluminense; doutoranda do Instituto de Medicina Social da Universidade do Estado do Rio de Janeiro. Coordenadora da Assessoria de Qualidade do Instituto Nacional de Traumatologia e Ortopedia. Intensivista do Instituto Nacional de Câncer.

Joana Barata Tavares

Mestrado integrado em medicina, com tema de investigação na área da epidemiologia e prevenção da saúde pela Faculdade de Medicina de Lisboa (FML); médica especialista em neurorradiologia, certificada pelo European Board of Neurorradiology (EBNR); e especialista em medicina do trabalho. Trabalha no Hospital Egas Moniz, Centro Hospitalar Lisboa Ocidental (CHLO). 
Jorge Pontes

Licenciatura e doutorando em gestão no ISCTE-Lisboa. Foi gestor da qualidade e coordenador da acreditação hospitalar pela Joint Commission International no CHAA. Consultor e auditor de sistemas de gestão da qualidade em hospitais e clínicas em Portugal, Angola e Moçambique. Coordenou a pós-graduação de gestão da qualidade e auditoria na saúde - Cespu.

Laura Souza Pinto

Administradora e advogada, graduada pela Universidade Federal de Santa Maria (Brasil) e Faculdade de Direito de Santa Maria (Brasil), respectivamente; pós-graduada em nível de especialização em administração hospitalar e negócios em saúde, pelo Instituto de Administração Hospitalar e Ciências da Saúde (IAHCS), em gestão em saúde e em engenharia - área de concentração em produção com ênfase em qualidade e gerência de serviços - pela Universidade Federal do Rio Grande do Sul, e em direito médico e hospitalar, pela Faculdade Escola Paulista de Direito. Atuante nas áreas de gestão hospitalar pública e privada e do direito da saúde. Atualmente trabalha na Empresa Brasileira de Serviços Hospitalares.

Lenice Gnocchi da Costa Reis

Médica; doutora em saúde coletiva pela Escola Nacional de Saúde Pública Sergio Arouca da Fundação Oswaldo Cruz (ENSP-Fiocruz). Pesquisadora/investigadora da Escola Nacional de Saúde Pública Sergio Arouca. Suas atividades concentram-se nas áreas de planeamento em saúde, avaliação de tecnologias em saúde, avaliação da qualidade de serviços de saúde, segurança do paciente e vigilância sanitária.

Lucas Santos Zambon

Médico; residência em clínica médica e doutorado em ciências médicas, ambos pela Faculdade de Medicina da Universidade de São Paulo (FMUSP). Supervisor do ProntoSocorro do Hospital das Clínicas da FMUSP; diretor do Instituto Brasileiro para Segurança do Paciente; editor geral do website de atualização médica MedicinaNET. Consultor e organizador de cursos sobre segurança do paciente e gerenciamento de risco em assistência à saúde; palestrante em cursos e autor de diversos capítulos e livros na área de emergências clínicas.

Luciana Santos de Carvalho

Mestre em sistema musculoesquelético pelo Instituto Nacional de Traumatologia e Ortopedia Jamil Haddad (Into); especialista em auditoria de sistemas de saúde pela Faculdade São Camilo (Fasc); graduada em letras (português/inglês) pela Faculdade de Filosofia de Além Paraíba (Fafi). Enfermeira da Unidade de Educação Permanente (Into).

Luis Antonio dos Santos Diego

Médico; doutor em anestesiologia pela Universidade Estadual Paulista (Unesp-Botucatu). Autor de livros e artigos sobre anestesiologia, medicina perioperatória e segurança do paciente. Professor da Faculdade de Medicina da Universidade Federal Fluminense; coordenador do módulo de anestesiologia e da disciplina segurança do paciente. Tesoureiro da Sociedade Brasileira para a Qualidade do Cuidado e Segurança do Paciente (Sobrasp).

Lurdes Trindade

Licenciada em enfermagem; pós-graduação em gestão da qualidade na saúde, do Instituto Superior de Economia e Gestão; mestranda do II Curso de Mestrado de Segurança do Doente da Escola Nacional de Saúde Pública. Enfermeira no Hospital de Santa Marta, Centro Hospitalar Universitário de Lisboa Central-EPE, onde faz parte do Gabinete de Segurança do Doente e Auditoria Clínica. Participou do grupo de trabalho do estudo nacional de eventos adversos dos hospitais portugueses. Publicou, em coautoria, artigos sobre o risco na área da transfusão sanguínea, gestão do risco e segurança do doente. 
Mafalda de Sousa-Uva

Doutorada em saúde pública na especialidade de epidemiologia pela ENSP-UNL. Bolseira de investigação/pesquisa científica no Departamento de Epidemiologia do Instituto Nacional Doutor Ricardo Jorge, no âmbito dos Programas Nacionais Prioritários. Docente nas disciplinas de microbiologia e saúde pública no Instituto Superior de Educação e Ciências desde 2009. Autora de alguns artigos nas áreas da microbiologia e segurança do doente.

Marcio Curi Rondinelli

Médico acupunturista com titulação em área de tratamento da dor. Membro da Comissão de Dor da Associação Médica Brasileira (AMB); coordenador do Serviço de Registro e Controle da Dor do Instituto Nacional de Traumatologia e Ortopedia (Into).

Maria Celia Andrade

Médica; residência médica em clínica médica pela Universidade Federal do Rio de Janeiro (UFRJ). Médica intensivista do Instituto Nacional de Traumatologia e Ortopedia - Ministério da Saúde (Into); autora de artigos sobre nefropatia renal na síndrome antifosfolipídeo e manifestações gastrintestinais na síndrome antifosfolipídeo. Experiência na área de clínica médica, terapia intensiva e profilaxia do tromboembolismo venoso.

Maria de Lourdes Oliveira Moura

Médica; mestre em saúde pública pela Escola Nacional de Saúde Pública Sergio Arouca da Fundação Oswaldo Cruz (ENSP-Fiocruz). Autora de livros e artigos sobre vigilância sanitária e segurança do paciente. Coordenadora da Coordenação de Segurança do Paciente e Gestão de Risco da Suvisa/SVS/SES-RJ; coordenadora adjunta do Comitê Estadual de Segurança do Paciente da SES-RJ (Cesp) e coordenadora do Subcomitê de Ensino e Pesquisa do Cesp. Assessora técnico-científica do Centro Colaborador para a Qualidade do Cuidado e a Segurança do Paciente (Proqualis/lcict/Fiocruz).

Maria João Lage

Mestrado (MSc) em quality and patient safety no Imperial College, Londres, sob orientação do prof. Charles Vincent. Neonatologista no Hospital Dona Estefania em Lisboa e responsável pela Gestão do Risco desde 2007. Assistente convidada de pediatria na Faculdade de Ciências Médicas de Lisboa. Colaboradora no módulo de erros de medicação no mestrado de segurança do doente e no mestrado de saúde pública - relato e análise de incidentes e medidas de melhoria. Tutora do CIQSSP nas edições promovidas pela ENSP-UNL.

Mauricio Diuana Saud

Médico pneumologista. Intensivista do Instituto Nacional de Traumatologia e Ortopedia.

Mônica Martins

Nutricionista-sanitarista; doutora (Université de Montreal) e mestre (ENSP-Fundação Oswaldo Cruz) em saúde pública. Estágio sênior na École de Hautes Études et Santé Publique (França). Pesquisador/investigador titular do Departamento de Administração e Planejamento em Saúde da ENSP-Fiocruz desde 1989. Docente do programa de pósgraduação em saúde pública da ENSP-Fiocruz. Áreas de interesse: avaliação de serviços de saúde, qualidade do cuidado, utilização, avaliação de desempenho de sistema e serviços de saúde, segurança do paciente e ajuste de risco.

Nádia Bomfim Nascimento

Psicóloga; doutora em saúde pública pela Escola Nacional de Saúde Pública (ENSP-Fiocruz); especialista em saúde mental. Gestora de processos de trabalho nas áreas de segurança do paciente, atenção primária e promoção da saúde. Colaboradora do portal Proqualis. 
Paula Lobato de Faria

Doutora em direito pela Universidade Montesquieu; mestre em direito da saúde pela Universidade de Bordéus; licenciada em direito no ramo jurídico-económico. Professora associada da Escola Nacional de Saúde Pública da UNL. Desde 2004, coordena o projeto de intercâmbio académico nas áreas do direito da saúde, bioética e direitos humanos com a Boston School of Public Health, da Universidade de Boston. Tem publicado artigos em revistas nacionais e estrangeiras sobre os aspetos jurídicos e legais do sistema de saúde, da responsabilidade de profissionais e unidades de saúde, da segurança do doente, da proteção e confidencialidade da informação de saúde, dos direitos e deveres dos doentes e dos biobancos.

Paula Perdigão

Mestre em saúde pública pela ENSP-UNL; licenciada em ciências farmacêuticas (FF-UL). Encontra-se a desenvolver investigação/pesquisa na área da segurança do doente, em particular no erro medicamentoso e conciliação medicamentosa. Professora na ESTeSL e na ESSL nas áreas de farmacologia e saúde pública. Responsável pelo serviço de Aconselhamento Terapêutico do Serviço Linha Saúde 24, do Ministério da Saúde de Portugal.

Paulo Sousa

Doutorado em saúde pública; professor na ENSP-UNL. Perito da ISQua para as questões da qualidade e segurança do paciente. Tem colaborado com a OMS e com o IHI em várias iniciativas de melhoria da qualidade em saúde e da segurança do doente, em larga escala. Membro do corpo editorial e reviewer de algumas revistas científicas nacionais e internacionais. Autor de vários artigos científicos e capítulos de livros sobre avaliação da qualidade em saúde, gestão do risco e segurança do doente. Atualmente é o coordenador do mestrado em saúde pública e coordenador adjunto do curso de especialização em saúde pública, ambos da ENSP-UNL. Colaborador do portal Proqualis.

Pedro Sá Moreira

Doutorado em saúde pública pela Universidade de Alicante, em regime de cotutela internacional pela Escola Nacional de Saúde Pública - Universidade Nova de Lisboa (ENSP). Detentor de formação pós-graduada em gestão da qualidade em saúde pela Universidad Pompeu Fabra e Johns Hopkins University. Habilitado com formação avançada especializada em direito da saúde, biodireito e bioética pelo Centro de Estudos Sociais da Universidade de Coimbra e pela ENSP-UNL. Colaborador do Departamento da Qualidade na Saúde da Direção-Geral da Saúde.

Ricardo Alcoforado Maranhão Sá

Engenheiro eletricista pela Universidade Federal de Engenharia de Itajubá (Unifei); mestre em saúde pública pela Escola Nacional de Saúde Pública Sergio Arouca (ENSPFiocruz); especialista em engenharia clínica pela Universidade Estadual de Campinas (Unicamp). Professor auxiliar na Escola de Engenharia da Pontifícia Universidade Católica de Goiás (PUC-GO). Coordenador do curso de especialização de engenharia clínica na RTG Especialização e sócio-diretor na empresa Orbis Engenharia Clínica.

Rita Palmeira de Oliveira

Doutorada em ciências farmacêuticas pela Universidade da Beira Interior, na área de tecnologia farmacêutica; especialista em farmácia hospitalar pela Ordem dos Farmacêuticos. É professora auxiliar convidada da Faculdade de Ciências da Saúde na Universidade da Beira Interior e cofundadora da Labfit (HPRD, Lda).

Roberto José Bittencourt

Médico cardiologista do Hospital de Base do DF; doutor em saúde pública na área de planejamento e gestão pela ENSP-Fiocruz, com ênfase na melhoria do desempenho da gestão hospitalar e soluções para resolver a superlotação dos serviços de emergência; mestre em medicina pela UFMG. Consultor do Ministério da Saúde (2003-2008). Subsecretário de Atenção à Saúde do DF e professor da Escola de Medicina da Universidade Católica de Brasília. 
Ronaldo Franklin de Miranda

Médico; doutorado e mestrado em medicina, com área de concentração em cardiologia na UFRJ; residência em clínica médica no Hospital Universitário Clementino Fraga Filho, Universidade Federal do Rio de Janeiro; especialização em medicina desportiva pela PUC-RJ. Médico do Serviço de Cardiologia da UFRJ. Atua na Coordenação de Ensino e Pesquisa/Investigação do Into. Professor do mestrado profissional do Into.

Sandra Regina Ferreira Vasconcelos

Enfermeira; mestre em ciências aplicadas ao sistema musculoesquelético pelo Instituto Nacional de Traumatologia e Ortopedia (Into); especialista em unidade de cuidados intensivos adulto/idoso pela UFF; MBA em gestão em saúde pela Fundação Getúlio Vargas; MBA em qualidade e acreditação hospitalar pelo CBA. Membro da equipe da Assessoria da Qualidade do Into e membro do Núcleo de Segurança do Paciente.

Sílvia Carla da Silva André

Mestre em saúde pública e doutoranda em enfermagem em saúde pública, ambos pela Escola de Enfermagem de Ribeirão Preto da Universidade de São Paulo; especialista em saúde pública e gestão pela Universidade de Alfenas (2009); graduada em enfermagem pela Universidade do Estado de Minas Gerais (2006). Experiência na área de ensino e pesquisa/investigação, atuando principalmente nos temas saúde pública, saúde ambiental e resíduos de serviços de saúde.

Sílvia Oliveira

Mestre em gestão da saúde, tendo desenvolvido seu trabalho projeto na área da qualidade em saúde, segurança do doente e gestão do risco; curso de póslicenciatura em enfermagem de saúde infantil e pediatria e curso de especialização em administração hospitalar. Autora e coautora de artigos publicados na área da neonatologia; enfermeira no Hospital Dona Estefânia - Centro Hospital de Lisboa Central.

Simone Grativol Marchon

Nutricionista-sanitarista; doutora em saúde pública pela ENSP-Fiocruz; mestre em saúde da família (Unesa). Desenvolve atividades na área de saúde pública, gestão e organização de serviços de saúde e segurança do paciente na atenção primária à saúde. Atuou na gestão da atenção primária em saúde.

Susana Ramos

Mestre em infeção em cuidados de saúde. Enfermeira chefe, coordenadora do Gabinete de Segurança do Doente do Centro Hospitalar Universitário de Lisboa Central e membro da Comissão da Qualidade e Segurança. Autora de vários artigos científicos relacionados com as áreas de gestão do risco, segurança do doente, controlo da infeção e auditoria. Coautora de vários artigos científicos relacionados com as áreas de gestão do risco, segurança do doente, controlo da infeção e auditoria. Tutora do CIQSSP nas edições promovidas pela ENSP-UNL.

Vanessa Rodrigues

Mestre em segurança do doente pela ENSP-UNL, tendo desenvolvido sua dissertação na área da medição e avaliação de eventos adversos em hospitais. Cardiopneumologista no Centro de Medicina Desportiva de Lisboa. Colaboradora do portal Proqualis. Colaborou no estudo-piloto dos eventos adversos em hospitais portugueses e na tradução e adaptação do curso on-line da OMS, Introdutory Course of Patient Safety Research.

Victor Grabois

Médico; mestre e doutorando em saúde coletiva. Docente da ENSP-Fiocruz; coordenador-executivo do Proqualis; representante da Fiocruz no Comitê de Implantação do Programa Nacional de Segurança do Paciente; e presidente da Sociedade Brasileira para a Qualidade do Cuidado e Segurança do Paciente (Sobrasp). 
Walter Mendes (in memoriam)

Médico; doutor em saúde coletiva pela ENSP-Fiocruz. Autor de livros e artigos sobre avaliação da qualidade em serviços de saúde, segurança do paciente e atendimento domiciliar.

Wilson Shcolnik

Médico; patologista clínico; doutorando em medicina pela USP. Autor de artigos e capítulos sobre qualidade laboratorial e segurança do paciente em laboratórios clínicos. Presidente da Sociedade Brasileira de Patologia Clínica/Medicina Laboratorial (SBPC/ML2018/19). Gerente de Relações Institucionais do Grupo Fleury.

\section{Organizadores}

Paulo Sousa

Walter Mendes 


\section{Apreciação analítica}

Adelia Quadros Farias Gomes

Adriana Carla de Miranda Magalhaes

Adriana Dias Silva

Alexandre Souza Morais

Alice Eulália Chaga Ribeiro

Ana Luiza Braz Pavão

Andrea Donato Drumond da Silva

Anne Caroline Oliveira dos Santos

Arminda Rezende de Pádua Del Corona

Arnaldo Sala

Betina Barbedo Andrade

Carlos Renato Alves da Silva

Catalina Kiss

Celia Maria de Andrade Bruno

Eliane Werneck Abrantes

Fernanda Cristina Manzini Sleutjes

Francis Solange Vieira Tourinho

Geovanna Cunha Cardoso

Helaine Carneiro Capucho

Helen Cristiny Teodoro Couto Ribeiro

Ivanise Arouche Gomes de Souza

Janaina Ferro Pereira

Janine Koepp

Josélia Giordani Hespanhol Duarte

Karla Crozeta Figueiredo

Keroulay Estebanez Roque

Lidia Maria Feitosa Guedes

Liliana Rodrigues do Amaral

Lúcia de Fátima Neves da Silva

Luciana Barcellos Teixeira

Luciana Regina Ferreira da Mata

Luciana Tricai Cavalini

Luciana Venhofen Martinelli Tavares

Margarete Perez Machado

Maria João Lajes Leitão

Maria Lucia de Souza Monteiro

Mário Borges Rosa
Marisa Peter Silva

Michele Santos Malta

Moisés Kogien

Natália Custódio Almeida Akamine

Patricia Eliane de Melo

Renata Galvão Diniz

Rosane Cohen

Rosimeyre Correia Costa

Sebastiana Shirley de Oliveira Lima

Sergio Gelbvaks

Silvana Abrantes Vivacqua

Simara Lopes Cruz Damázio

Sonia Maria Cezar Goes

Sonia Maria Dias de Lima

Suiane Chagas de Freitas Baptista

Susana Ramos

Suzinara Beatriz Soares de Lima

Tatiana dos Santos Borso

Teresa Cristina Gioia Schimidt

Valeria Rodrigues de Lacerda

Vera Lucia Neves Marra

Viviane Euzébia Pereira Santos

Waldir Viana das Neves Junior 


\section{Sumário}

Prefácio da $2^{\mathrm{a}}$ edição

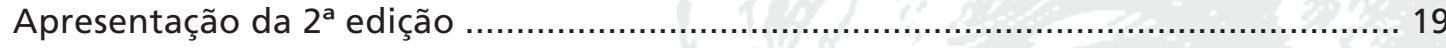

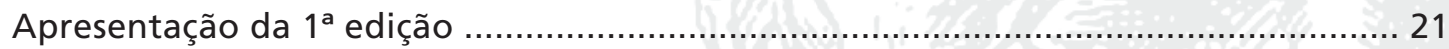

\section{Qualidade em saúde e segurança do paciente: aspectos fundamentais}

1. Qualidade do cuidado de saúde

Mônica Martins

2. A perspectiva histórica e principais desenvolvimentos da segurança do paciente Lurdes Trindade e Maria João Lage

3. Taxonomia em segurança do paciente Walter Mendes

4. O erro e as violações no cuidado de saúde Nádia Bomfim Nascimento

5. Magnitude do problema e os factores contribuintes do erro e dos eventos adversos

Paulo Sousa, Maria João Lage e Vanessa Rodrigues

6. Direito e segurança do paciente

Paula Lobato de Faria, Pedro Sá Moreira e Laura Souza Pinto

\section{Avaliação e gestão do risco em organizações de saúde}

7. Infeções associadas aos cuidados de saúde

Elaine Pina, Etelvina Ferreira e Mafalda Sousa-Uva

8. Erros relacionados aos medicamentos

Susana Ramos, Paula Perdigão e Rita Palmeira de Oliveira

9. Cirurgia segura

Maria de Lourdes de Oliveira Moura e Luis Antonio dos Santos Diego

10. A segurança do paciente e o diagnóstico

Lucas Santos Zambon

11. Erros relacionados ao laboratório

Wilson Shcolnik

12. Gestão do risco de quedas, úlceras por pressão e de incidentes relacionados com transfusão de sangue e hemoderivados

Paulo Sousa, Silvia Oliveira, Ana Alves e Ana Teles

13. Segurança do paciente na Atenção Primária à Saúde

Simone Grativol Marchon e Walter Mendes

14. Superlotação dos serviços de emergência 
15. Gestão do risco não clínico

António Tavares, Elsa Soares, Silvia Carla da Silva André, Carla Barreiros,

Cândida Pité-Madeira, Ricardo Alcoforado Maranhão Sá e Irene Rêgo Haddad

16. Maternidade segura

Lenice Gnocchi da Costa Reis

17. Segurança do paciente e imagiologia

18. A segurança do paciente no cuidado odontológico

Claudia Dolores Trierweiler Sampaio de Oliveira Corrêa

\section{Anexos}

Anexo A - Diretriz clínica para prevenção de tromboembolismo venoso

Isabela Ribeiro Simões de Castro, Maria Celia Andrade,

Maurício Diuana Saud e Ronaldo Franklin de Miranda

Anexo B - Diretriz clínica de avaliação pré-operatória para

prevenção de complicações cardiológicas

Isabela Ribeiro Simões de Castro e Ronaldo Franklin de Miranda

Anexo C - Diretriz clínica para prevenção de Acidente Vascular Cerebral

perioperatório em cirurgias que não sejam cardíacas, carotídeas ou neurológicas

Isabela Ribeiro Simões de Castro e Ronaldo Franklin de Miranda

Anexo D - Diretriz clínica para gerenciamento/gestão da dor

Elaine da Hora dos Santos, Isabela Ribeiro Simões de Castro e Marcio Curi Rondinelli

Anexo E - Uso único para os dispositivos de injeção

Bárbara Ventura Fontes e Sandra Regina Ferreira Vasconcelos

Anexo F - Diretriz clínica para a prevenção de falhas relacionadas a

conexões de linhas de infusão e cabos

Bárbara Ventura Fontes e Sandra Regina Ferreira Vasconcelos

Anexo G - Diretriz clínica para prevenção e tratamento do delirium em pacientes internados em serviços de pacientes em condições agudas e de cuidados gerais

Luciana Santos de Carvalho e Isabela Ribeiro Simões de Castro

Anexo $\mathrm{H}$ - Fadiga de alarmes

Adriana Carla Bridi

Anexo I - Interrupções do trabalho da equipe de enfermagem

Adriana Carla Bridi 


\section{Prefácio da $2^{\circ}$ edição}

Esta nova edição do livro Segurança do Paciente: conhecendo os riscos nas organizações de saúde, publicado há já cinco anos, reveste-se de uma importância extraordinária por três ordens de razões: pela atualidade do seu conteúdo, pela sua natureza colaborativa e pela capacidade que tem para unir culturas.

Com efeito, o conteúdo desta nova edição tem uma enorme atualidade, por tratar de um tema emergente da saúde à escala global, o da segurança dos doentes. Tema com implicações técnicas, morais, de reputação e económicas, e sobre o qual a Organização Mundial de Saúde (OMS) tem protagonizado inúmeras iniciativas. Este livro inspirado, em parte, num curso também apoiado pela OMS, vem nessa mesma linha, olhando a segurança dos doentes duma perspectiva integrada e colocando a ênfase para a sua promoção, nos sistemas de saúde.

Pela mão de investigadores e experts, o livro aborda sucessivamente o papel das organizações, as consequências económicas, o papel da acreditação, a importância da cultura de segurança, os indicadores, a ergonomia e a segurança dos profissionais de saúde, a comunicação e o papel do doente na promoção da sua segurança - este, um tema bem recente no contexto internacional.

Este livro tem uma missão definida, a de ensinar sobre a segurança dos doentes e ensiná-la em português.

Não menos importante, esta edição, originada num Curso Internacional de Qualidade em Saúde e Segurança do Paciente, reflete um meritório esforço colaborativo por parte de duas reputadas escolas: a Escola Nacional de Saúde Pública da Universidade Nova de Lisboa, em Portugal, e a Escola Nacional de Saúde Pública Sergio Arouca, da Fundação Oswaldo Cruz, no Brasil. Esta iniciativa fez convergir investigadores notáveis de ambos os lados do Atlântico, uma verdadeira diáspora da língua portuguesa, centrada num tema comum que beneficia os leitores na Europa, na África e na América e onde mais alcance a cultura e a língua do português. 
Por isso, esse esforço colaborativo encerra, verdadeiramente, uma missão de unir culturas, globalizando um tema que é em si mesmo global, o tema da segurança do doente. Muito a propósito, esta comunhão de culturas, feita a pretexto da união da língua, aborda um dos mais importantes vetores da segurança dos doentes - a cultura de segurança - que o livro tão bem trata, e que tanto contribuirá para que os pacientes ao nosso cuidado corram cada vez menos riscos.

Este fantástico livro publicado pela Editora Fiocruz constitui um elo forte de ligação entre essas duas escolas congéneres. Enquanto Vice-Reitor da Universidade Nova de Lisboa, com o pelouro da saúde, é com enorme gosto que escrevo este prefácio. Prefácio de um livro sobre um tema que, como médico e investigador, tão grato me é, um livro para a qual a minha escola contribuiu em paridade distinta com uma reputada escola brasileira, interpretando aquilo que é, afinal, a missão da Universidade Nova: busca do talento, iniciativas académicas de índole colaborativa, internacionalização e criação de valor social sobre temas com aplicação e de utilidade pública. Este não poderia ser um tema mais ilustrativo para a missão da Nova, universidade que acolhe no seio da sua muito proeminente investigação em saúde, precisamente um ativo grupo sobre qualidade e segurança do doente, grupo que é, aliás, liderado por um dos principais impulsionadores desta obra.

Felicito os autores, felicito as escolas, felicito a editora e faço votos para que esta obra possa continuar a unir, pela língua portuguesa, os esforços dos muitos que somos empenhados na promoção de cuidados de saúde mais seguros. Notável!

José Fragata

Vice-Reitor da Universidade Nova de Lisboa 


\section{Apresentação da $2^{a}$ edição}

As razões que nos levaram a proceder à atualização e alargamento do conteúdo do livro Segurança do Paciente: conhecendo os riscos nas organizações de saúde nesta $2^{\mathrm{a}}$ edição surgiram, também, da convergência de três fatores, assim como a ideia inicial de organizar esse livro.

O primeiro tem a ver com a velocidade a que o conhecimento tem evoluído na ciência e tecnologia em geral e, em particular, na área da Qualidade em Saúde e Segurança do Paciente. Tal evolução é expressa no aumento exponencial de pesquisas/estudos que têm sido feitos e publicados em revista com significativo fator de impacto; no crescente número de iniciativas de avaliação, melhoria e garantia da qualidade e segurança dos cuidados que temos assistido, um pouco por todo o mundo, e pela quantidade cada vez maior de profissionais de saúde que têm demonstrado interesse e "paixão" pelo conhecimento, pesquisa/ investigação e ação em qualidade em saúde e segurança do paciente.

O segundo fator se relaciona com a circunstância de considerarmos importante refletir sobre a experiência que as três instituições parceiras - o Instituto de Comunicação e Informação Científica e Tecnológica em Saúde (Icict), a Escola Nacional de Saúde Pública Sergio Arouca (ENSP), ambos da Fundação Oswaldo Cruz (Fiocruz) e a Escola Nacional de Saúde Pública da Universidade Nova de Lisbia (UNL) - têm vindo a acumular ao longo dos últimos cinco anos e das cinco edições (duas no Brasil e três em Portugal) do Curso Qualidade em Saúde e Segurança do Paciente. Neste livro foram atualizados, praticamente, todos os capítulos, em termos dos conteúdos propostos, dos exemplos apresentados e das referências utilizadas. Foram ainda acrescentados dois novos capítulos que se debruçam sobre a importância da qualidade e segurança dos cuidados, em áreas específicas "Segurança do paciente e imagiologia" e "A segurança do paciente no cuidado odontológico".

O terceiro e último fator tem a ver com o nosso reconhecimento a todos os profissionais de saúde que, diariamente, em suas organizações se esforçam por prestar cuidados de saúde seguros e de elevada 
qualidade aos seus pacientes - por vezes, desenvolvendo suas funções em condições/contextos que não são os mais adequados ou desejáveis, mas, com elevada resiliência, dedicação e profissionalismo, conseguem ultrapassar as dificuldades com que se vão deparando.

Este é, também, o momento para homenagear e agradecer a todos que contribuíram para o sucesso deste livro: aos autores, aos revisores, à equipa de CDEAD da Fiocruz, à Bárbara Caldas (Brasil) e à Sónia Rodrigues (Portugal) pelo apoio na gestão do processo de revisão e atualização.

Paulo Sousa

Organizador 


\section{Apresentação da $1^{\text {a }}$ edição}

A ideia de organizar o livro Segurança do Paciente: conhecendo os riscos nas organizações de saúde surgiu da convergência de três fatores.

O primeiro relaciona-se com a importância do tema. Até o início deste século XXI, com a publicação do relatório Errar é Humano, do Institute of Medicine (IOM), as referências às questões da segurança do paciente ou aos eventos adversos eram relativamente escassas. À medida que se começou a avaliar a frequência (incidência e prevalência) com que os pacientes sofriam danos provenientes do cuidado de saúde, a magnitude do problema atraiu a atenção de profissionais e gestores da saúde, pesquisadores/investigadores, decisores políticos, grupos de direitos dos pacientes e da sociedade em geral. Hoje, os sistemas e organizações de saúde, um pouco por todo o mundo, buscam alternativas e soluções que objetivam melhorar a qualidade e a segurança do paciente.

O segundo fator diz respeito à escassez de publicações, principalmente em língua portuguesa, que integrem temas da qualidade em saúde e da segurança do paciente de uma forma sistémica e estruturada. Podemos encontrar conteúdos sobre esses temas, a maioria em língua inglesa, em várias revistas científicas, livros ou em documentos políticos e estratégicos, oficiais, de países ou organizações internacionais, tais como a Organização Mundial de Saúde (OMS), Joint Commission International, Agency for Healthcare Research and Quality (AHRQ), Institute for Healthcare Improvement (IHI) ou Health Foundation (HF), para citar apenas alguns.

O terceiro fator resulta da experiência acumulada pelas três instituições, parceiras em várias iniciativas - a Escola Nacional de Saúde Pública Sergio Arouca (ENSP), o Instituto de Comunicação e Informação Científica e Tecnológica (Icict) da Fundação Oswaldo Cruz (Fiocruz) e a Escola Nacional de Saúde Pública (ENSP) da Universidade Nova de Lisboa (UNL). Dentre as diversas iniciativas que ocorreram em conjunto, recebem destaque: i) o curso introdutório, na modalidade de ensino a distância (on-line), sobre Investigação em Segurança do Paciente. Esse curso foi realizado a convite, sob a chancela da OMS e a colaboração 
do e-Portuguese. Em cada uma das oito sessões, ministradas por professores do Brasil e de Portugal, assistiram cerca de 400 participantes, dos quatro cantos do mundo; ii) a participação em um portal de disseminação de conhecimento sobre segurança do paciente - Proqualis; iii) a tradução e adaptação para a língua portuguesa de um conjunto de aulas e cursos integrados no projeto Open School, do Institute for Healthcare Improvement; iv) a larga experiência adquirida pelas duas ENSP em ensino e investigação no campo da qualidade em saúde e da segurança do paciente, o que já resultou em várias publicações em revistas, nacionais e internacionais, com arbitragem científica.

Mediante as práticas anteriormente descritas e apoiadas na evidência da demanda existente, as instituições se articularam para promover o Curso Internacional de Qualidade em Saúde e Segurança do Paciente, na modalidade de ensino a distância, direcionado a profissionais de saúde do Brasil, de Portugal e da Comunidade de Países de Língua Portuguesa (CPLP).

O livro foi elaborado com a finalidade não só de apoiar esse curso tornando-se o referencial, o ponto de partida e de chegada de conteúdos, de questões, dúvidas e reflexões -, como também ter vida própria, independente dele. Essa publicação reúne contributos de um vasto conjunto de autores brasileiros e portugueses, com extensa experiência em termos clínicos, investigação/pesquisa e operacional do terreno, além de conhecimentos muito sólidos. Dessa diversidade, riqueza e expertise dos autores resultou, estamos certos, uma obra que, baseada na mais recente evidência científica, constitui importante contributo para quem se dedica e se preocupa com a melhoria contínua da qualidade em saúde, da segurança dos cuidados e da excelência clínica.

Este livro está estruturado em duas partes.

A Parte I, “Qualidade em saúde e segurança do paciente: aspectos fundamentais", tem o propósito de introduzir os alunos no universo da segurança do paciente, como uma dimensão da qualidade em organizações de saúde. Pautados na concepção de que o erro é humano e pode ocorrer em qualquer ramo de atividade, inclusive na saúde, pretende-se apresentar a segurança do paciente em um contexto histórico, com arcabouço teórico, uma taxonomia robusta, estratégias e ações propostas em escala mundial. A culpa e punição do(s) profissional(ais) envolvidos com o erro serão discutidas sob os pontos de vista da teoria da qualidade em saúde e jurídico. O conteúdo da Parte I está distribuído em seis capítulos: 1. Qualidade do cuidado de saúde; 2. Perspectiva 
histórica e principais desenvolvimentos da segurança do paciente; 3 . Taxonomia em segurança do paciente; 4 . O erro e as violações no cuidado de saúde; 5. Magnitude do problema e os fatores contribuintes do erro e dos eventos adversos; 6. Direito e segurança do paciente.

A Parte II, "Avaliação e gestão do risco em organizações de saúde", pretende discutir os vários tipos de riscos específicos em uma organização de saúde e as soluções já conhecidas, sustentadas em evidências científicas que contribuem para a prestação de cuidados mais seguros em sua prática de trabalho. O conteúdo da Parte II está distribuído em dez capítulos: 7. Infecções associadas aos cuidados de saúde; 8. Erros relacionados aos medicamentos; 9. Cirurgia segura; 10. A Segurança do paciente e o diagnóstico; 11. Erros relacionados ao laboratório; 12. Gestão do risco de quedas, úlceras por pressão e de incidentes relacionados com transfusão de sangue e hemoderivados; 13. Segurança do paciente na atenção primária à saúde. 14. Superlotação dos serviços de emergência; 15. Gestão do risco não clínico; 16. Maternidade segura.

Alguns temas relacionados aos riscos específicos em organizações de saúde não foram deliberadamente abordados nos capítulos da Parte II, como o tromboembolismo venoso, as falhas relacionadas a conexões de linhas de infusão e cabos, o delirium em pacientes internados, o acidente vascular cerebral pós-operatório, as complicações cardiológicas pós-operatórias, o gerenciamento/gestão da dor, o uso único de dispositivos de injeção, a fadiga de alarmes, as interrupções do trabalho da equipe de enfermagem. No entanto, por considerarmos sua relevância para a segurança do paciente, optamos por incluí-los de forma sucinta em nove anexos ao final do livro.

Escrito conforme as normas do Acordo Ortográfico da Língua Portuguesa (1990), que passou a vigorar no início de 2009, a publicação, entretanto, contempla termos consagrados tanto no Brasil como em Portugal, como exemplos: prontuário ou processo clínico; plantão ou turno; leito ou cama; entre outros. Os leitores irão se deparar, ao longo do livro, com tais nomenclaturas separadas por uma barra como representação de que elas são utilizadas em cada país, por exemplo: prontuário/processo clínico.

Consideramos que este livro, no geral, apresenta-se com uma linguagem de fácil entendimento, além disso, nos capítulos, estão disponíveis diversas referências bibliográficas atuais, que permitem o aprofundamento de qualquer tema abordado no âmbito do curso. 
O sonho dos organizadores desta obra é poder encontrá-la nas "estantes" de cada serviço ou organização de saúde espalhados pelo mundo lusófono - um livro com o propósito de difundir o tema na língua portuguesa, escrito por autores do Brasil e de Portugal, que se destina aos profissionais de saúde de três continentes.

Os Organizadores 


\section{Qualidade em saúde e segurança do paciente: \\ -17. aspectos fundamentais}




\section{Qualidade do cuidado de saúde}

Mônica Martins

Abordar o tema segurança do paciente como um atributo da qualidade sublinha a intenção dos autores do livro. Neste capítulo, veremos que buscar qualidade no cuidado de saúde do paciente não é só garantir um cuidado seguro, porque envolve também atributos (ou dimensões) como acesso, efetividade, entre outros. Procuramos, aqui, introduzir os principais conceitos na área de avaliação da qualidade do cuidado de saúde, além de apresentar a definição de qualidade do cuidado, suas dimensões constituintes e a relação com a segurança do paciente.

\section{O contexto da discussão sobre qualidade do cuidado e sua relação com outras temáticas no campo da avaliação de serviços de saúde}

O contexto atual é marcado por pressões relacionadas ao alto custo do cuidado de saúde associado à incorporação tecnológica, ao aumento da carga de trabalho dos profissionais de saúde e ao envelhecimento da população com múltiplas doenças crônicas. Desse contexto, emergem preocupações voltadas para a qualidade do cuidado e das organizações de saúde, com ênfase em ações direcionadas à melhoria contínua e à prestação de contas (accountability - responsabilização) (Elliott et al. 2010; Kohn et al. 2000; Wennberg 2010).

Essas ações, com vistas ao aprimoramento da qualidade do cuidado de saúde e do desempenho do sistema, já foram postas em prática e

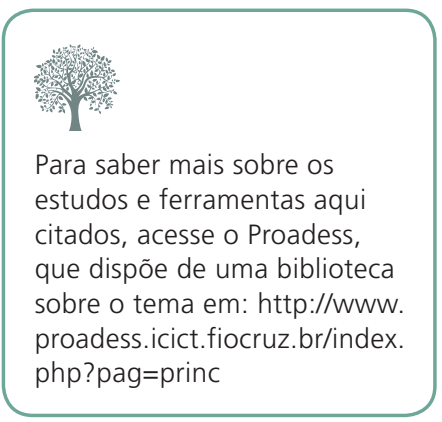


A variação injustificável geográfica da prática é definida como uma variação não explicada por variação na doença (tipo ou gravidade) ou preferência do paciente. incluem tanto o desenvolvimento de estudos como ferramentas para a gestão cotidiana das organizações de saúde (Smith et al. 2009).

Em linhas gerais, essas ações buscam minimizar as consequências dos problemas prevalentes na qualidade do cuidado. Tais problemas podem ser decorrentes do uso excessivo (overuse), do uso insuficiente (underuse) e do uso inadequado (misuse) de serviços, procedimentos e tecnologia em saúde (Grol 2001; Kohn et al. 2000; Wennberg 2010). Especificamente sobre esse ponto, embora haja volume considerável de estudos produzidos ao longo de décadas, no campo da variação geográfica da prática, ainda persiste ampla e injustificável variação na prática médica e na prestação de cuidados, com evidências científicas insuficientes sobre a efetividade de determinados procedimentos (Kale et al. 2013; Mulley 2009; Wennberg 2011). A variação injustificável na prática médica é classificada em três grupos:

1. Na efetividade do cuidado e segurança do paciente, relacionada ao uso insuficiente de intervenções baseadas em evidência.

2. No cuidado sensível à preferência do paciente, relacionada à tomada de decisão partilhada entre médico e paciente.

3. No cuidado sensível à oferta, relacionado à prestação de cuidado desnecessário e ao uso excessivo.

Para refletir

Você já teve contato, em sua prática, ou já ouviu falar de casos relacionados ao uso excessivo (overuse), uso insuficiente (underuse) e uso inadequado (misuse)? Quais foram as consequências? Que medidas podem ser tomadas para reduzir sua ocorrência?

É difícil mensurar globalmente o impacto das iniciativas no campo da melhoria da qualidade face à multidimensionalidade do conceito de qualidade e ao contexto. Aliam-se a esse fator questões relacionadas à complexidade do cuidado médico na atualidade, envolvendo inúmeros processos especializados, com intensa incorporação tecnológica (Blumenthal 2012; Smith et al. 2009). Embora tradicionalmente o foco central da discussão da qualidade do cuidado fossem os atributos eficiência e efetividade, ao longo do tempo, outras preocupações foram agregadas, como a segurança, a centralidade do cuidado no paciente e o respeito ao seu direito. 


\section{Qualidade do cuidado: conceitos, atributos/dimensões e abordagens}

A ideia de qualidade está presente em todos os tipos de avaliação em saúde, cuja característica nuclear é fazer um juízo de valores, que, quando positivo, significa ter qualidade. Em virtude do caráter multidimensional e subjetivo do conceito de qualidade, sua definição e os elementos que a constituem, tal questão apresenta significados distintos para autores e os diversos atores/intervenientes (pacientes, profissionais de saúde, gestores, financiadores e autoridades governamentais) (Donabedian 1980, 2003).

O conceito de qualidade do cuidado vem se modificando ao longo do tempo e passou a incluir novas dimensões, cuja evolução e diversidade são exemplificadas no Quadro 1. Essas modificações espelham, ainda, a relevância dos problemas em uma conjuntura específica. Por exemplo, a dimensão acessibilidade recebe destaque quando há barreiras ao uso de serviços de saúde; já a segurança do paciente passa a ser mais relevante quando a magnitude de erros e riscos evitáveis é reconhecida.

Quadro 1 - Dimensões da qualidade do cuidado

\begin{tabular}{|c|c|c|c|c|c|}
\hline $\begin{array}{l}\text { Brook et al. } \\
1977\end{array}$ & $\begin{array}{l}\text { Donabedian } \\
1980\end{array}$ & $\begin{array}{l}\text { Holland } 1983 \\
\text { Long } 1985\end{array}$ & $\begin{array}{l}\text { Donabedian } \\
1990\end{array}$ & $\begin{array}{l}\text { Aday et al. } \\
1993\end{array}$ & $\begin{array}{l}\text { IOM } \\
2001\end{array}$ \\
\hline $\begin{array}{l}\text { Componente } \\
\text { técnico } \\
\text { Processo } \\
\text { diagnóstico } \\
\text { Processo } \\
\text { terapêutico } \\
\text { "Arte" do } \\
\text { cuidado } \\
\text { Interação médico } \\
\text { e paciente }\end{array}$ & $\begin{array}{l}\text { Qualidade técnico- } \\
\text { científica } \\
\text { Acessibilidade e } \\
\text { disponibilidade } \\
\text { Relações } \\
\text { interpessoais } \\
\text { Continuidade }\end{array}$ & $\begin{array}{l}\text { Eficiência } \\
\text { Efetividade }\end{array}$ & $\begin{array}{l}\text { Eficiência } \\
\text { Efetividade } \\
\text { Equidade } \\
\text { Eficácia } \\
\text { Relação médico } \\
\text { paciente } \\
\text { Otimização } \\
\text { Aceitabilidade } \\
\text { Acessibilidade } \\
\text { Amenidades } \\
\text { Conformidade } \\
\text { com as } \\
\text { preferências dos } \\
\text { pacientes } \\
\text { Legitimidade }\end{array}$ & $\begin{array}{l}\text { Eficiência } \\
\text { Efetividade } \\
\text { Equidade }\end{array}$ & $\begin{array}{l}\text { Eficiência } \\
\text { Efetividade } \\
\text { Equidade } \\
\text { Centralidade no } \\
\text { paciente } \\
\text { Segurança } \\
\text { Oportunidade }\end{array}$ \\
\hline
\end{tabular}

Fonte: Holland (1983); Long (1985); Donabedian (1990); Aday et al. (1993); Institute of Medicine (2001). 


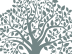

(3)

Avedis Donabedian (1919-

2000), autor seminal no

campo da qualidade do cuidado de saúde, considera a melhoria da qualidade uma abordagem para avaliar e melhorar continuadamente o processo de produção de serviços de saúde, a fim de responder adequadamente às necessidades dos pacientes (Donabedian 2003). Para conhecer mais sobre esse autor, visite a La Fundación Avedis Donabedian no endereço http://www.fadq.org/.
Para Donabedian, um dos autores precursores dessa área, cuidado de qualidade era aquele que maximizava o bem-estar do paciente, após considerar o balanço entre os ganhos e perdas esperados em todas as etapas do processo de cuidado (Quadro 2). Em 2003, esse mesmo autor definiu a qualidade do cuidado de saúde como produto de dois fatores:

a ciência (conhecimento científico) e a tecnologia de saúde disponíveis;

躒 sua aplicação no cuidado ao paciente (Donabedian 2003).

Dentro dessa perspectiva, a qualidade do cuidado seria produto desses dois fatores e poderia ser caracterizada por diversas dimensões que incluem: eficácia, efetividade, eficiência, otimização, aceitabilidade, legitimidade e equidade.

Blumenthal (1996) alertou para a variedade de definições existentes sobre o cuidado de qualidade e destacou a proposta do Institute of Medicine (IOM) dos Estados Unidos, apresentada no Quadro 2, como a mais frequentemente empregada (Blumenthal 1996).

Quadro 2 - Definições disponíveis do conceito de qualidade do cuidado

\begin{tabular}{|l|l|}
\hline Autor & Definições \\
\hline Donabedian, 1980 & $\begin{array}{l}\text { Cuidado de alta qualidade: tipo de cuidado do qual é esperado maximizar o } \\
\text { bem-estar do paciente (medida inclusiva), após considerar o balanço entre } \\
\text { os ganhos e perdas esperados em todas as etapas do processo de cuidado. }\end{array}$ \\
\hline $\begin{array}{l}\text { Associação Médica } \\
\text { Americana, 1984 }\end{array}$ & $\begin{array}{l}\text { Qualidade do cuidado: contribui de forma consistente para melhorar ou } \\
\text { manter a qualidade e/ou duração da vida. }\end{array}$ \\
\hline $\begin{array}{l}\text { Office of } \\
\text { Aechnology }\end{array}$ & $\begin{array}{l}\text { Qualidade de um prestador: grau em que o processo de assistência } \\
\text { aumenta a probabilidade de resultados desejados pelos pacientes e reduz } \\
\text { a probabilidade de resultados não desejados, em razão do estado do } \\
\text { conhecimento médico. }\end{array}$ \\
\hline Palmer, 1991 & $\begin{array}{l}\text { Qualidade da assistência é medida pela produção de uma melhora da } \\
\text { saúde do paciente depois de ajustado pelas restrições da tecnologia e pela } \\
\text { gravidade da doença. } \\
\text { Qualidade é a capacidade do prestador (médico) de coordenar a tecnologia } \\
\text { disponível, habilidades e julgamento para melhorar a saúde dos pacientes. }\end{array}$ \\
\hline $\begin{array}{l}\text { Institute of } \\
\text { Medicine (IOM), } \\
1990\end{array}$ & $\begin{array}{l}\text { Qualidade da assistência é o grau em que as organizações de saúde para } \\
\text { indivíduos e populações aumentam a probabilidade de resultados desejados } \\
\text { e são consistentes em conhecimento profissional corrente. }\end{array}$ \\
\hline
\end{tabular}

Fonte: Blumenthal (1996). 
A noção de qualidade em saúde, ao longo do tempo, foi aplicada ora com sentido amplo, ora com sentido restrito do termo. A apreensão da qualidade, no primeiro caso, pode ser ilustrada nos textos de Vuori (1982), em que a qualidade englobava as seguintes dimensões:

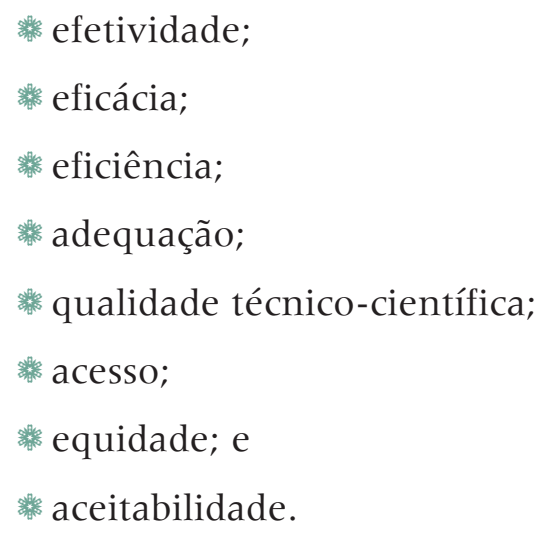

Em sentido restrito, o conceito de qualidade é sinônimo de qualidade técnico-científica, atributo nuclear da atenção médica. Qualidade técnico-científica pode ser compreendida como uma dimensão do conceito de qualidade, apresentada por Donabedian em suas primeiras obras (Quadro 1, coluna 2). De acordo com essa lógica, qualidade técnico-científica, por sua vez, é constituída de duas subdimensões essenciais:

1. A aplicação dos conhecimentos científicos e recursos tecnológicos para resolver o problema clínico do paciente, isto é, fazer a coisa certa de forma correta requer que médicos tomem decisões certas sobre o cuidado de cada paciente. Alcançar esse patamar requer ainda habilidade, julgamento e oportunidade de execução em termos de tempo (Donabedian 1980).

2. A relação interpessoal, que diz respeito à qualidade da relação individual estabelecida entre o profissional e o paciente, está associada a elementos como respeito ao paciente, capacidade de comunicação, e habilidade do profissional em obter a confiança do paciente (Donabedian 1980).

Posteriormente, o próprio Donabedian (1990) considerou a qualidade do cuidado em uma perspectiva mais ampla que a anterior, englobando sete atributos (ou dimensões), denominados "os sete pilares", nomeadamente: eficácia, efetividade, eficiência, otimização, aceitabilidade, legitimidade e equidade (Quadro 3). 
Quadro 3 - Definição dos sete pilares segundo Donabedian

\begin{tabular}{|c|c|}
\hline Sete Pilares & Definição \\
\hline Eficácia & $\begin{array}{l}\text { Diz respeito à capacidade de determinada intervenção produzir impacto } \\
\text { potencial em uma situação ideal. Ou a capacidade da ciência e tecnologia } \\
\text { empregadas no cuidado de trazer melhorias à saúde, quando usadas em } \\
\text { circunstâncias mais favoráveis. }\end{array}$ \\
\hline Efetividade & $\begin{array}{l}\text { Grau de melhoria na saúde alcançado de fato. É a relação entre o impacto } \\
\text { real (prática cotidiana) de um serviço ou programa em funcionamento e o } \\
\text { impacto potencial em uma situação ideal (estudos de eficácia). }\end{array}$ \\
\hline Eficiência & $\begin{array}{l}\text { Capacidade de diminuir os custos sem comprometer o nível atingível de } \\
\text { melhoria da saúde. É a relação entre o impacto real de um serviço ou } \\
\text { programa em funcionamento e seu respectivo custo. }\end{array}$ \\
\hline Otimização & $\begin{array}{l}\text { Balanço entre melhorias na saúde e custos envolvidos para o alcance dessas } \\
\text { melhorias. O processo de aumentar benefícios pode ser desproporcional aos } \\
\text { custos acrescidos. }\end{array}$ \\
\hline Aceitabilidade & $\begin{array}{l}\text { Conformidade aos desejos, expectativas e valores dos pacientes e membros } \\
\text { de suas famílias (depende da efetividade, eficiência e otimização, além da } \\
\text { acessibilidade, relação médico-paciente e amenidade do cuidado). }\end{array}$ \\
\hline Legitimidade & $\begin{array}{l}\text { Conformidade com as preferências sociais expressas nos princípios éticos, } \\
\text { valores, normas, leis e regulação. }\end{array}$ \\
\hline Equidade & $\begin{array}{l}\text { Conformidade a princípios que determinam o que é justo e legítimo } \\
\text { na distribuição equânime, ou seja, sem distinções, discriminações ou } \\
\text { preferências, para o cuidado e concessão de benefícios entre os membros } \\
\text { da população. }\end{array}$ \\
\hline
\end{tabular}

Fonte: Tradução livre com base em Donabedian (1990).

O IOM, em 2001, publicou o texto Crossing the Quality Chasm: A New Health System for the 21st Century e destacou as seguintes dimensões da qualidade: segurança, efetividade, centralidade no paciente, oportunidade, eficiência e equidade (Quadro 4). Nesse e no relatório anterior, National Healthcare Quality Report, também publicado pelo instituto, a segurança do paciente aparece, pela primeira vez, como dimensão constituinte do conceito de qualidade do cuidado. Vale ressaltar que os atributos propostos pelo IOM (2001) ganharam ampla adesão internacional.

Quadro 4 - Dimensões da qualidade no cuidado

\begin{tabular}{|l|l|}
\hline $\begin{array}{l}\text { Atributos/ } \\
\text { Dimensões }\end{array}$ & Definição \\
\hline Oportunidade & $\begin{array}{l}\text { Redução do tempo de espera e de atrasos potencialmente danosos tanto } \\
\text { para quem recebe como para quem presta o cuidado. }\end{array}$ \\
\hline Segurança & $\begin{array}{l}\text { Evitar lesões e danos nos pacientes decorrentes do cuidado que tem como } \\
\text { objetivo ajudá-los. }\end{array}$ \\
\hline
\end{tabular}


Quadro 4 - Dimensões da qualidade no cuidado (cont.)

\begin{tabular}{|l|l|}
\hline $\begin{array}{l}\text { Atributos/ } \\
\text { Dimensões }\end{array}$ & Definição \\
\hline Efetividade & $\begin{array}{l}\text { Cuidado baseado no conhecimento científico para todos que dele possam } \\
\text { se beneficiar, evitando seu uso por aqueles que provavelmente não se } \\
\text { beneficiarão (evita subutilização e sobreutilização, respectivamente). }\end{array}$ \\
\hline Eficiência & $\begin{array}{l}\text { Cuidado sem desperdício, incluindo o desperdício associado ao uso de } \\
\text { equipamentos, suprimentos, ideias e energia. }\end{array}$ \\
\hline nuidado centrado paciente & $\begin{array}{l}\text { Cuidado respeitoso e responsivo às preferências, necessidades e valores } \\
\text { individuais dos pacientes, assegurando que os valores do paciente orientem } \\
\text { todas as decisões clínicas. }\end{array}$ \\
\hline Equidade & $\begin{array}{l}\text { Qualidade do cuidado que não varia em decorrência de características } \\
\text { pessoais, como gênero, etnia, localização geográfica e condição } \\
\text { socioeconômica. }\end{array}$ \\
\hline
\end{tabular}

Fonte: Institute of Medicine 2001. Tradução livre dos conceitos.

\section{A tríade: estrutura, processo e resultado}

Embora não seja o foco deste capítulo, mas considerando sua importância do ponto de vista da mensuração, avaliação e compreensão do processo de cuidado, algumas breves considerações sobre os tipos de abordagem da qualidade são aqui apresentadas. Também é oriunda da obra de Donabedian (1980) a clássica classificação dos estudos ou abordagens da qualidade do cuidado em termos do foco na tríade: estrutura, processo e resultado.

A estrutura compreende fatores referentes às condições sob as quais o cuidado é prestado e engloba:

繁 estrutura física e recursos materiais, como equipamentos ou tecnologias;

* recursos humanos, como número, variedade e qualificação da equipe profissional, além de características organizacionais do corpo médico e de enfermagem, atividades de ensino e pesquisa, tipo de supervisão, disponibilidade de protocolos clínicos e ferramentas para avaliação de desempenho;

*arsocursos financeiros envolvidos na assistência, além de formas de pagamento do cuidado e dos profissionais.

O processo compreende as etapas que constituem o cuidado de saúde em si, incluindo diagnóstico, tratamento, reabilitação e educação do paciente. Em geral, o conceito se refere ao conjunto de atividades 
desenvolvidas pelos profissionais que participam diretamente do cuidado prestado ao paciente.

O conceito de resultado refere-se às mudanças (desejáveis ou indesejáveis) no estado de saúde dos indivíduos ou populações. Elas podem ser atribuídas à atenção recebida anteriormente, incluindo: mudanças no estado de saúde; no nível de conhecimento ou comportamento adquirido pelos pacientes ou sua família, que podem influenciar a saúde futura; na satisfação dos pacientes e familiares com o cuidado e seus resultados. Os resultados podem ser adversos ou indesejáveis (morte, incapacidade, doença ou insatisfação) ou favoráveis (cura, sobrevida, recuperação do estado fisiológico, físico e emocional, ou satisfação com o serviço).

Essa tríade não pode ser confundida como dimensões ou atributos da qualidade. Esses três componentes são abordagens para obter informações a respeito da presença ou ausência dos atributos (isto é, efetividade, adequação etc.). A avaliação da qualidade do cuidado pressupõe a existência de uma inter-relação entre estrutura, processo e resultado, ou seja, um recurso ou tecnologia (estrutura) que contribui para o diagnóstico e tratamento adequado (processo), do qual resulta um estado de saúde favorável (resultado) (Brook et al. 1977).

Obviamente, esse modelo representa a simplificação de uma realidade mais complexa, mas estabelece que há uma relação de causalidade entre estrutura, processo e resultado. A força dessa relação dependerá da validade causal e validade atribuível. A validade causal diz respeito à intensidade, baseada na evidência científica, da associação entre processo e resultado. Em outras palavras, a validade causal se refere à capacidade de alguns processos de cuidados específicos produzirem resultados específicos em condições específicas (Donabedian 1980 apud Portela, Martins 2008).

Como exemplo, para facilitar o entendimento desse conceito: há evidências científicas de que o uso de ácido acetilsalicílico (aspirina - AAS), utilizado logo após a ocorrência de episódios isquêmicos recorrentes, traz como consequência a redução de reoclusão das artérias coronárias (um novo infarto/enfarte do miocárdio) e da mortalidade subsequente em 3,5 a 4,0\% dos pacientes. Vários protocolos clínicos recomendam que pacientes com suspeita de infarto/enfarte agudo do miocárdio (IAM) devem receber prescrição de aspirina imediatamente após sua chegada à emergência, desde que não haja contraindicação (Portela, Martins 2008). 
Figura 1 - Resultados, sejam bons ou ruins, têm relação direta com os processos que o determinaram. Por exemplo, um bom escritor pode ser aquele que lê bons livros.

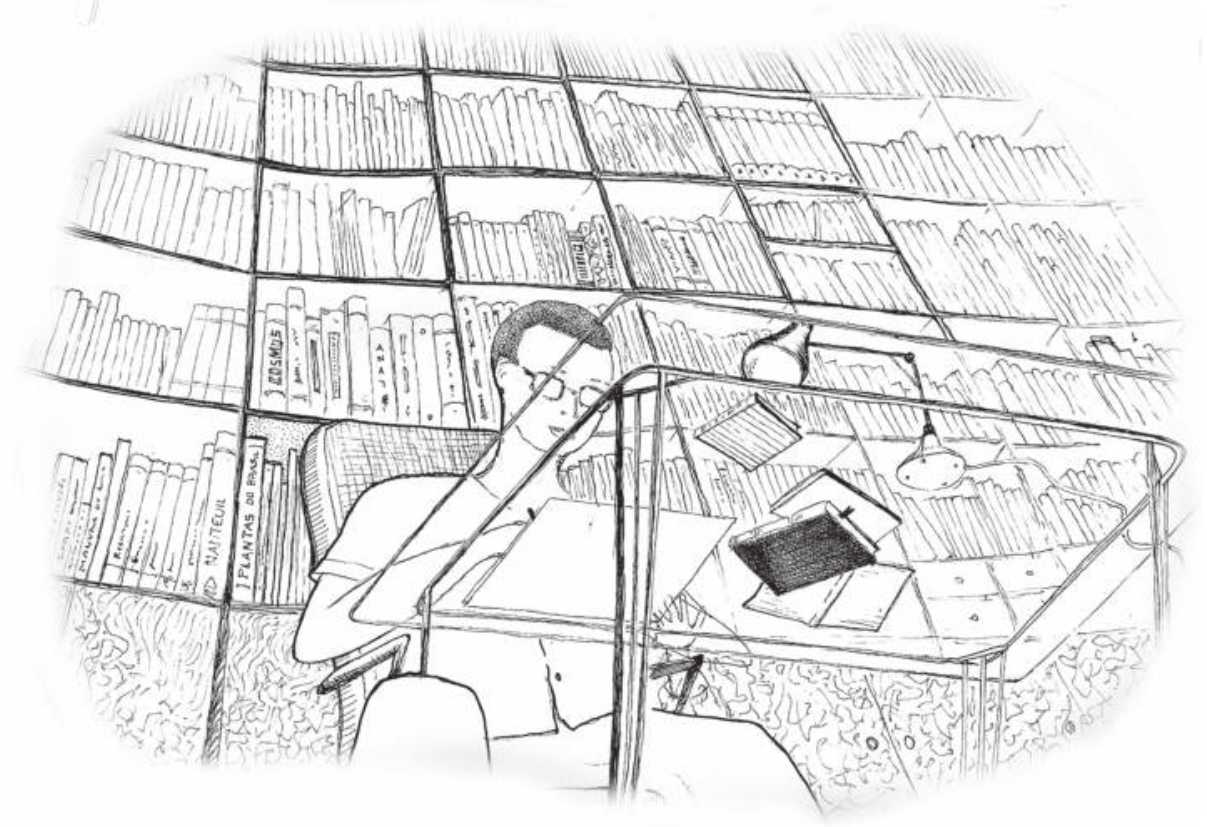

A validade atribuível é a inferência de que determinada medida de processo ou resultado contém as mesmas características que definem a existência de validade causal (Donabedian 1980). Escrito de outro modo, a validade atribuível refere-se à inferência de que, em qualquer situação, a relação causal entre o processo e o resultado é responsável pelos resultados observados. Particularmente com relação à abordagem de resultado, eles, em qualquer situação, podem ou não ser fruto do processo de cuidado prestado. O resultado do tratamento de determinada patologia depende da gravidade do caso ou da capacidade fisiológica do paciente.

Logo, quando se usa uma abordagem de resultado para avaliar a qualidade do cuidado, é imprescindível saber se os resultados são realmente decorrentes do cuidado recebido. Esse aspecto diz respeito à validade atribuível. A avaliação de resultados é mais suscetível a problemas de perda de "validade atribuível", porque eles sofrem influência de fatores intervenientes, como a gravidade do paciente e da patologia, que modificam as condições específicas sob as quais a relação processo-resultado foi determinada (Donabedian 1980). Como exemplo, para facilitar o entendimento desse conceito: um paciente com diabetes tem prognóstico de risco maior ao sofrer intervenções cirúrgicas do que outro não portador de diabetes (Portela, Martins 2008). 
O debate científico a respeito do mérito das três abordagens é intenso e aponta na direção de que nem a estrutura, nem mesmo o processo ou o resultado deveria ser a única abordagem sobre a qualidade. Importa por isso estabelecer a relação entre os três conceitos-chave, como já afirmava Lohr no final da década de 1980 (Lohr 1988).

\section{Intersecções entre qualidade do cuidado e segurança do paciente}

A preocupação com a segurança do paciente, compreendida como "a redução, a um mínimo aceitável, do risco de um dano desnecessário associado ao cuidado de saúde" (Runciman et al. 2009), assumiu espaço privilegiado como um obstáculo superável para buscar melhorar a qualidade no cuidado prestado ao paciente nos diversos níveis de atenção.

Embora exista um estudo anterior, o Harvard Medical Practice Study é considerado pioneiro por seu escopo e desenho (Brennan et al. 1991; Leape 2008). Esse estudo gerou o relatório Errar é humano (To Err is Human), publicado em 1999 pelo IOM, que chamou a atenção para a magnitude do problema da segurança do paciente, medido nesse estudo pela ocorrência de eventos adversos (Kohn et al. 2000; Leape 2008). Apesar da conceituação específica do campo da segurança do paciente, incluindo termos como erro, evento adverso e modelos explicativos, ser tratada nos capítulos seguintes, vale uma pontuação breve do que seja evento adverso. Para tal, faremos um paralelo com o conceito de resultado proposto por Donabedian (1980, já mencionado neste capítulo). Ou seja, um evento adverso, considerado um problema de qualidade do cuidado relacionado à dimensão segurança do paciente, pode ser compreendido como mudança indesejável no estado de saúde do paciente, que, por sua vez, pode ser atribuída à atenção recebida anteriormente, e não ao problema de saúde desse paciente e à gravidade. Essas mudanças, isto é, resultados adversos ou indesejáveis, podem ocasionar morte, incapacidade, doença ou insatisfação com o serviço.

Assim, retomando a publicação Errar é humano, a inquietação que orientou esse relatório foi a busca por responder às razões pelas quais eram toleradas altas taxas de erros (resultados indesejáveis como morte ou incapacidades) no cuidado de saúde comparativamente a outras indústrias. As estimativas produzidas indicaram, entre outras, mortalidade associada a eventos adversos no cuidado de saúde comparativamente maior que aquelas decorrentes de câncer/cancro de mama e Aids. 
A publicação desse relatório gerou mobilização dos profissionais de saúde e do público em geral, que transcendeu o contexto dos EUA e chamou a atenção para o problema da segurança do paciente em diversos países. No âmbito da Organização Mundial de Saúde (OMS), um programa voltado para a segurança do paciente foi consolidado e se tornou responsável por várias iniciativas no campo educacional, na pesquisa, no desenvolvimento de uma taxonomia específica e de ferramentas e no lançamento de campanhas, tais como a de "Higienização das mãos" e "Cirurgia segura salva vidas" (Runciman et al. 2009; Brown et al. 2008).

Após o estudo de Harvard, muitos outros foram desenvolvidos em vários países, inclusive no Brasil (Mendes et al. 2009) e em Portugal (Sousa et al. 2014). O panorama descrito, com base nesses estudos, indica que a incidência de eventos adversos relacionados ao cuidado hospitalar está em torno de 10\%; estima-se, ainda, que entre 4,4\% e $20,8 \%$ dos eventos adversos foram associados à morte dos pacientes (Zeger et al. 2009).

É nesse cenário que a segurança do paciente passa a ser um atributo da qualidade do cuidado de saúde tão importante quanto a efetividade, por exemplo. Isso porque os eventos adversos envolvem custos sociais e econômicos consideráveis, podendo implicar danos irreversíveis aos pacientes e suas famílias, constituindo sério problema de saúde pública (Brown et al. 2008). No entanto, há, na literatura, dois principais olhares sobre a relação entre qualidade do cuidado e segurança do paciente.

Sob um olhar, a segurança do paciente é tratada como atributo da qualidade do cuidado (IOM, 2001); já sob outro, como um constructo em si, independentemente da qualidade ou mesmo incluindo-a como atributo da segurança. (Runciman et al. 2009; Brown et al. 2008; Wismar et al. 2011). No modelo de Brown et al. (2008), é reconhecida uma polarização entre qualidade e segurança com gradientes, mas indicando que segurança é um elemento sine qua non para prestar o cuidado de qualidade seguro. Apesar desse debate, não há dúvidas sobre a importância do tema e da adoção de práticas efetivas para a segurança do paciente voltadas para a prestação de um cuidado seguro (Shekelle et al. 2013).

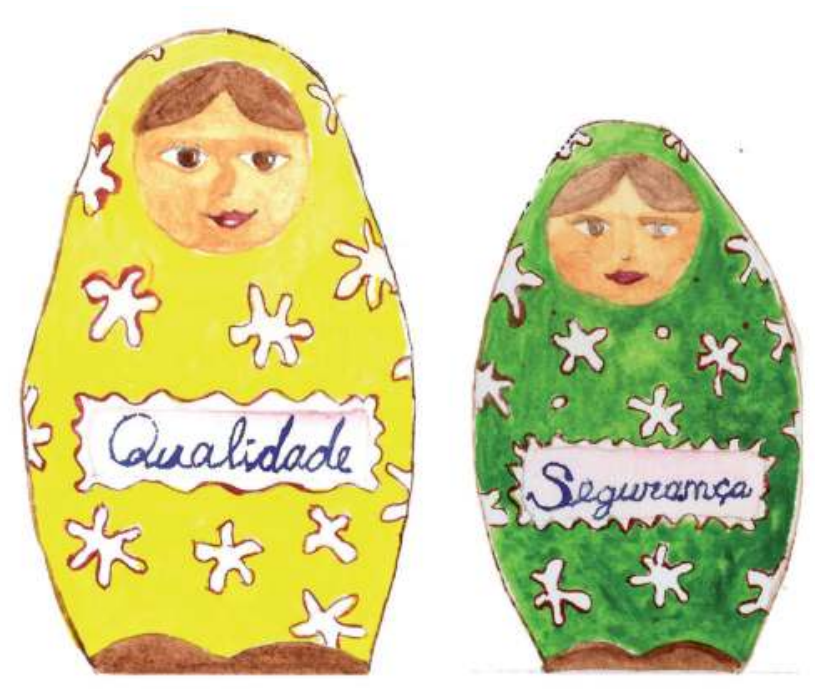




\section{Considerações finais}

Estratégias dirigidas para a melhoria da qualidade e do desempenho das organizações de saúde estão presentes nas agendas governamentais, acadêmicas e das próprias organizações de saúde em diversos países. Ao longo do tempo, houve mudanças no foco central e nas dimensões da qualidade que eram privilegiados. Atualmente, observam-se a priorização da segurança e o respeito ao direito dos pacientes conjugados à preocupação com a ocorrência de eventos adversos, decisão partilhada e com prestação de contas (Leape 2008; Chassin et al. 2010; Mcclellan et al. 2010; Shortell, Casalino 2010).

Contudo, a melhoria da qualidade do cuidado e da segurança do paciente é tarefa difícil, com resultados a longo prazo que exigem envolvimento de todos os membros da organização. A avaliação das organizações de saúde é um elemento chave, mas acrescem custos não desprezíveis e ainda apresentam lacunas e desafios. Avanços são necessários, entretanto os resultados das avaliações devem ser interpretados mais como oportunidades de melhoria, em vez de considerados consequência da excelência ou insuficiência da ação de um indivíduo (Brown et al. 2008; Reason 2000).

Avaliação é essencial, mas não é suficiente. É preciso agir na correção dos problemas encontrados

\section{Referências}

Aday LA, Begley CE, Lairson DR, Balkrishnan R. Evaluating the medical care system effectiveness, efficiency, and equity. Ann Arbor (MI): Health Administration Press; 1993.

Blumenthal D. Performance improvement in health care: seizing the moment. N Engl J Med. 2012; 366(21):1953-55.

Blumenthal D. Quality of care: what is it?N Engl J Med.1996;335(17):891-94.

Brennan TA, Leape LL, Laird NM, Hebert L, Localio R, Lawthers AG et al. Incidence of adverse events and negligence in hospitalized patients - results of the Harvard Medical Practice Study I. N Engl J Med. 1991;324(6):370-77.

Brook RH, Davies-Avery A, Greenfield S, Harris LJ, Lelah T, Solomon NE et al. Assessing the quality of medical care using outcome measures: an overview of the methods. Med. Care, 1977;15(9 Suppl):1-106.

Brown C, Hofer T, Johal A, Thomson R, Nicholl J, Franklin BD et al. An epistemology of patient safety research: a framework for study design and interpretation. Part 1. Conceptualizing and developing interventions. QualSaf Health Care.2008;17(3):158-62. 
Chassin MR, Loeb JM, Schmaltz SP, Wachter RM. Accountability measures: using measurement to promote quality improvement. N Engl J Med. 2010; 363(7):683-88.

Donabedian A. The definition of quality and approaches to its assessment. Ann Arbor (MI): Health Administration Press, 1980.

Donabedian A. An introduction to quality assurance in health care. New York: Oxford University Press, 2003.

Donabedian A. The seven pillars of quality. Arch. Pathol. Lab. Med. 1990;114(11):1115-18.

Elliott SF, FisherES, Shortell SM. Accountable care organizations: accountable for what, to whom, and how. JAMA 2010; 304(15):1715-16.

Grol RP. Improving the quality of medical care: building bridges among professional pride, payer profit, and patient satisfaction. JAMA 2001;286(20):2578-85.

Holland W. Evaluation of health care. New York: Oxford University Press; 1983.

Institute of Medicine [IOM]. Committee on Quality of Health Care in America. Crossing the quality chasm: a new health system for the 21st Century. Washington, DC: National Academy Press, 2001.

Kale MS, Bishop TF, Federman AD, Keyhani S. Trends in the overuse of Ambulatory Health Care Services in the United States. JAMA Intern Med. 2013;173 (2):142-48.DOI:10.1001/2013. jamainternmed. 1022.

Kohn LT, Corrigan JM, Donaldson MS. To err is human: building a safer health system: a report of the Committee on Quality of Health Care in America, Institute of Medicine. Washington, DC: National Academy Press; 2000.

Leape LL. Scope of problem and history of patient safety. Obstet Gynecol Clin North Am. 2008; 35(1):1-10.

Lohr KN. Outcome measurement: concepts and questions. Inquiry 1988;25(1):37-50.

Long AF. Health services performance. New Hampshire: Groom Helm; 1985.

McClellan M, McKethan AN, Lewis JL, Roski J, Fisher ES. A national strategy to put accountable care into practice. Health Aff (Millwood). 2010;29(5):982-90.

Mendes W, Martins M, Rozenfeld S, Travassos C. The assessment of adverse events in hospitals in Brazil. Int J Qual Health Care. 2009 [citado 2013 ago. 20];21(4): 279-84. Disponível em: http:// intqhc.oxfordjournals.org/content/21/4/279.long.

Mulley AG. Inconvenient truths about supplier induced demand and unwarranted variation in medical practice. BMJ. 2009; 339:b4013.

Portela MC, Martins M. Caderno de estudo: gestão da qualidade em saúde. In: Lopes CMB, Barbosa PR, Silva VC, organizadores. Rio de Janeiro: Ensp/Fiocruz; 2008. Programa de Gestão em Saúde, Ensino a distância da ENSP/Fiocruz e Universidade aberta do Brasil. (Desenvolvimento de material didático ou instrucional - Material didático de curso de educação a distância).

Reason J. Human error: models and management. BMJ.2000;320(7237):768-70.

Runciman W, Hibbert P, Thomson R, Van Der Schaaf T, Sherman H, Lewall P. Towards an international classification for patient safety: key concepts and terms. Int J Qual Health Care.2009;21(1):18-20.

Shekelle P G, Pronovost P, Wachter RM, McDonald KM, Schoelles K, Dy SM et al. The top patient safety strategies that can be encouraged for adoption now. Ann Intern Med. 2013;158 (5 Pt 2):365-68. 
Shortell SM, Casalino LP. Implementing qualifications criteria and technical assistance for accountable care organizations. JAMA.2012;303(17):1747-48.

Smith P, Mossialos E, Papanicolas I, Leatherman S. Principles of performance measurement: introduction. In: Smith P, Mossialos E, Papanicolas I, Leatherman S, editors. Performance measurement for health system improvement: experiences, challenges and prospects. New York: Cambridge University Press; 2009. p. 3-23.

Sousa P, Uva AS, Serranheira F, Nunes C, Leite ES. Estimating the incidence of adverse events in Portuguese hospitals: a contribution to improving quality and patient safety. BMC Health Services Research. 2014;14:311. doi:10.1186/1472-6963-14-311.

Travassos C, Caldas B. A qualidade do cuidado e a segurança do paciente: histórico e conceitos. In: ANVISA. Assistência segura: uma reflexão teórica aplicada à prática. Série Segurança do paciente e qualidade em serviços de saúde. Brasília; 2013. Capítulo 2, p. 19-27.

U.S. Department of Health and Human Services, Agency for Healthcare Research and Quality (AHRQ). National healthcare quality report [internet]. Rockville (MD): Agency for Healthcare Research and Quality; 2005 [citado 2012 Maio 28]. (AHRQ Publication n. 06-0018). Disponível em: http://archive.ahrq.gov/qual/nhqr05/nhqr05.htm.

Vuori H. Quality assurance of health services. Copenhagen: World Organization; 1992.

Wennberg JE. Time to tackle unwarranted variations in practice. BMJ 2011; 342:d1513.

Wennberg JE. Tracking medicine a researcher's quest to understand health care. New York: Oxford University Press; 2010.

Wismar M, Palm W, Figueras J, Ernst K, van Ginneken E. Cross-border health care in the European Union Mapping and analyzing practices and policies. Copenhagen (DK): European Observatory on Health Systems and Policies, [2011].

Zegers M, Bruijne MC, Wagner C, Hoonhout LHF, Waaijman R, Smits Metal.Adverse events and potentially preventable deaths in Dutch hospitals: results of a retrospective patient record review study.Qual. Saf. Health Care.2009;18(4): 297-302. 


\section{A perspetiva histórica e principais desenvolvimentos da segurança do paciente}

Lurdes Trindade e Maria João Lage

Apresentam-se, neste capítulo, alguns dos principais contributos/colaboradores (autores, movimentos, publicações, instituições, estudos, descobertas etc.) relevantes para a forma como as questões relacionadas com qualidade e, principalmente, a segurança do paciente são interpretadas e valorizadas nos dias de hoje. Na história da prestação de cuidados de saúde, poderemos ver, nalguns casos, determinadas descobertas fundamentais para o conhecimento que temos atualmente. Noutras situações, constatamos também que algumas figuras importantes foram colocadas de parte por apresentarem ideias/pensamentos, muitas vezes, contra a corrente dominante e, nalguns casos, em oposição à maioria dos seus pares (veja, mais à frente, os casos de Semmelweis e Codman).

Serão também descritos, de forma sucinta, os contributos/colaboradores de vários estudos e relatórios, entre eles o relatório do IOM que, na segunda metade do século XX, alertava para o elevado número de incidentes nos hospitais (e suas consequências). De acordo com vários autores, em virtude dele, as questões da segurança do paciente e dos eventos adversos (EAs) viriam a ter grande relevo nos anos seguintes.

\section{Conceitos de doença na Antiguidade}

Na Pré-História e na Antiguidade, a vida dos homens estava sempre em risco, à mercê da violência e de inúmeras doenças infecciosas para as quais se dispunha de poucos tratamentos eficazes. Não é de estranhar o recurso frequente à intercessão dos deuses. A doença era, muitas vezes, encarada como uma punição ou mal de origem divina, sendo o sacerdote/mágico um dos instrumentos para a cura, atuando em con- 
Segundo a lenda, Manú era filho de Brahma e pode ser considerado o mais antigo legislador do mundo - segundo estudiosos, seu código data, aproximadamente, entre os anos 1300 e 800 a.C.

O Código de Hamurabi, mais antigo, tecnicamente não é um código no sentido técnico da palavra, já que se tratava de uma coletânea de normas que abrange vários assuntos e preceitos. junto com o curandeiro responsável pelas drogas, poções e ligaduras. No Egito dos anos 500 antes de Cristo (a.C.), existia já a distinção entre as doenças que estariam ao alcance do curandeiro e de suas poções divididas em especialidades como abdômen, olho, ouvido etc. - e aquelas, particularmente as crônicas, que, por não terem resposta previsível à ação das drogas e intervenções cirúrgicas disponíveis, necessitariam da intervenção divina (Porter 2006).

Há evidências de que, ainda na Antiguidade, na Mesopotâmia, eram já efetuados alguns procedimentos cirúrgicos e outros tratamentos a que Pita (2007) chama de medicina pré-técnica.

O Código de Hammurabi, na Babilónia dos anos 1792-50 a.C., contém alguns artigos relacionados com o tratamento médico, reconhecendo que seu resultado também dependia da ação do médico e responsabilizando-o de forma dura: se, em razão de determinado tratamento, um paciente perdesse a mão, o médico poderia perder a sua. Também na antiga Índia, segundo as leis de Manú, os médicos podiam ser castigados se fizessem um diagnóstico errado, ou se tentassem tratar os casos considerados incuráveis; a falha não era atribuída à vontade divina, mas a um engano ou má prática do médico.

Na Grécia antiga, a cura da doença era uma prática aberta, procurada no templo ou na diversidade de outras propostas terapêuticas, dependendo do tratamento escolhido e da preferência individual. Coexistiam várias escolas de medicina, entre elas a escola de Cós, da qual fez parte Hipócrates, que viveu entre 460 e 377 a.C. considerado o pai da medicina. Para ele, a doença era um desequilíbrio dos humores, cabendo ao médico perceber qual e auxiliar a natureza no seu restabelecimento. Hipócrates afirmava que, em sua prática, o médico deve dirigir os cuidados com a finalidade da recuperação do paciente, abstendo-se de toda a maldade e dano (Pita 2007). "Primum non nocere"- que significa: primeiro não cause o dano - é reconhecida como uma das primeiras referências explícitas à segurança do paciente. 


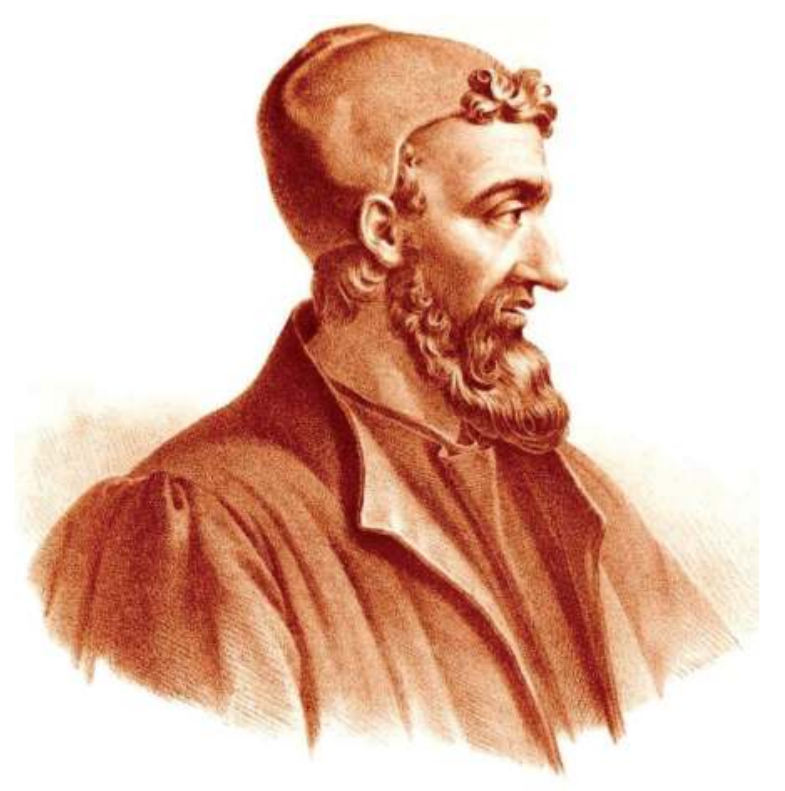

Fonte: Wikipedia

Galeno, cuja influência na Europa chegou ao século XVIII, escreveu sobre anatomia e fisiologia, mas também deontologia médica, advogando que a medicina devia ter o rigor da geometria.

Na Europa, durante a Idade Média, a medicina baseava-se no respeito pela tradição e pelos mestres da Antiguidade como Galeno e, como em outras áreas do saber, ficou em grande parte a cargo das ordens religiosas. Essas fundaram os primeiros hospitais e foram os principais agentes da preservação e difusão da prática e do ensino médico, tanto no nível assistencial como, mais tarde (século XII), na criação das primeiras universidades (Porter 2006).

\section{Figuras históricas relevantes para a promoção da qualidade e segurança dos cuidados de saúde}

No final do século XIX, a comunidade médica e a sociedade em geral assumiam que os incidentes se deviam ao comportamento de alguns raros profissionais e tinham pouco peso no resultado do tratamento do paciente.

O pensamento dominante, à época, era que o profissional cumprisse seu papel sem errar; cada incidente era gerido individualmente por ele, que não o partilhava com o paciente nem com seus pares. Essa atitude 
devia muito à formação profissional, mas estava também enraizada na cultura da sociedade e na forma como o homem conviveu com a doença desde sempre.

No século XIX, a enfermeira inglesa Florence Nightingale, além de revolucionar a enfermagem e o seu ensino, incentivou mudanças dos cuidados, no sentido da melhoria da segurança do paciente, com sua análise das condições dos hospitais ingleses. Durante a Guerra da Crimeia e a convite do governo britânico, chefiou as primeiras enfermeiras em hospitais de campanha e, por meio da introdução de mudanças simples na higiene e alimentação dos soldados, provocou diminuição significativa no número de infeções e mortes.

Nas várias obras publicadas ao longo da sua vida, Florence afirma que a estrutura e a organização dos hospitais influenciam a saúde e recuperação do paciente.

Figura 2 - A enfermeira britânica Florence Nightingale (1820-1910)

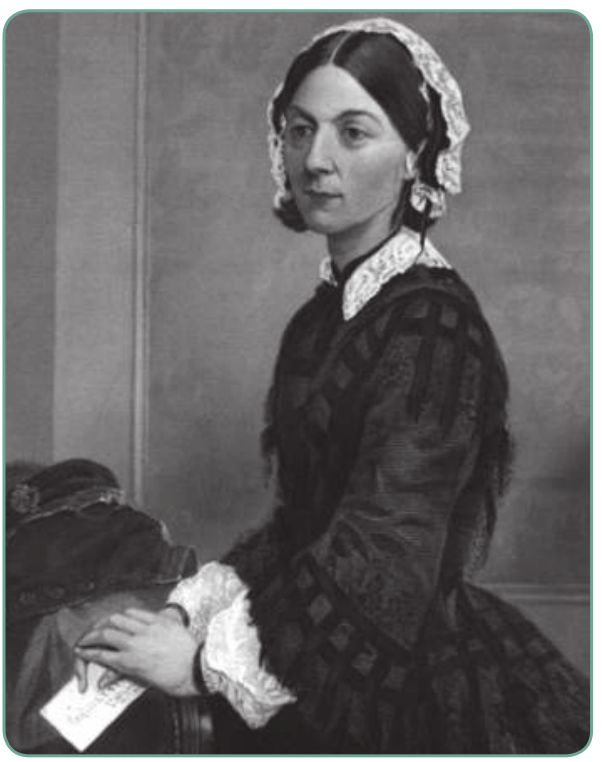

Fonte: Wikimedia Commons (2009).

A enfermeira britânica Florence Nightingale era também conhecida pela alcunha "A dama da lamparina", pois usava este instrumento para iluminar o atendimento que realizava aos feridos durante a noite.

Ao analisar as condições dos soldados na Índia, demonstrou que os problemas de saneamento, a contaminação da água, superlotação dos espaços e ventilação incorreta eram responsáveis pelos maus resultados. Avança mais e alarga as recomendações de melhoria das condições sanitárias ao país em sua totalidade, como forma de melhorar a saúde do exército e da população em geral.

Apesar de demonstrar estatisticamente os dados que deram suporte às suas conclusões e ter conseguido algumas modificações nos hospitais ingleses, suas recomendações não foram bem acolhidas pela maioria da classe médica (Lopes 2010).

Para saber mais sobre Florence Nightingale, sugerimos que assista ao filme Florence Nightingale - História da Enfermagem, que conta sua história. Você poderá encontrálo nas locadoras ou em versões legendadas na Internet.
Outro exemplo de não aceitação de novas teorias, por desconhecimento dos seus fundamentos científicos, ocorreu com as propostas de Ignaz Semmelweis. Só após os trabalhos de Pasteur, Koch e Lister e das teorias de microrganismos e técnicas antissépticas, elas foram compreendidas e aceitas. 
Figura 3 - Ignaz Philipp Semmelweis (1818-1865)

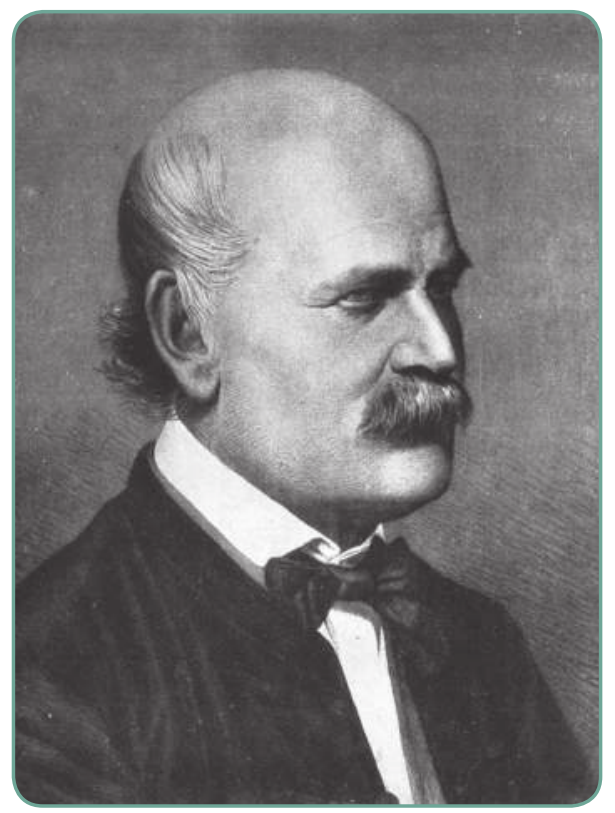

Fonte: Wikimedia Commons (2014).

Ignaz Philipp Semmelweis nasceu na Hungria.

Mais tarde foi para Viena completar seus estudos em advocacia, mas acabou se tornando médico.
Semmelweis era responsável pela maternidade de um hospital universitário, onde verificou que a taxa de morte por infeção após o parto era superior nas enfermarias em que as mulheres eram cuidadas pelos estudantes em relação àquelas nas quais os partos eram feitos por enfermeiras parteiras. Ao estudar essa diferença, identificou como causa o facto de os estudantes passarem de procedimentos de autópsias para a observação das parturientes, sem procederem à lavagem das mãos.

Ao introduzir a obrigação de lavagem das mãos dos estudantes e médicos, verificou que a taxa de mortalidade desceu para valores idênticos aos das enfermarias das parteiras. No entanto, essas conclusões não foram aceitas pelos responsáveis do hospital, e não lhe foi renovado o contrato como professor. Semmelweis voltou para seu país natal, onde conseguiu obter resultados de mortalidade muito baixos com a introdução da lavagem sistemática das mãos, numa maternidade pela qual era responsável. Publicou esses resultados em 1861, mas o livro não foi bem aceito pela comunidade científica, e acabou por morrer aos 47 anos num asilo para pacientes mentais (Best 2004).

Ernest Amory Codman (1869-1940), cirurgião em Boston, é outra figura incompreendida pelos seus pares durante sua vida e percurso profissional. Para ele, o trabalho desenvolvido pelos médicos era limitado, faltando-lhe a avaliação do resultado das suas cirurgias. Descontente com o hospital onde trabalhava, fundou um hospital privado em que acompanhou, de forma sistemática, os pacientes que operava, marcando erros de diagnóstico e tratamento e monitorizando os resultados alcançados. Num período de cinco anos, houve o registo do número e do tipo de erros ocorridos, classificando-os em: falta de conhecimento ou habilidade técnica, julgamento cirúrgico, falta de cuidados ou equipamento e falta de competências para diagnosticar. Em seus estudos, também foram incluídas situações que classificou como calamidades 
Esses conceitos foram abordados no capítulo anterior. Reveja também seu conceito de qualidade em saúde e sua proposta de avaliação da qualidade baseada na tríade: estrutura, processos e resultados. cirúrgicas e complicações que fogem ao controlo, recomendando que essas últimas fossem conhecidas dos profissionais e do público e estudadas de forma a serem prevenidas.

Segundo Codman, os artigos científicos habitualmente publicados só davam a conhecer as experiências positivas, e era importante que os resultados reais fossem conhecidos. Suportou os custos da publicação dos seus resultados e divulgou-os aos outros hospitais, instando-os a fazer o mesmo, sem sucesso. Estudante e cirurgião brilhante, fundador do Colégio Americano de Cirurgiões (ACS), foi rejeitado pelos seus pares, e seus esforços reformadores só lhe valeram censura, terminando seus dias na pobreza. No entanto, em 1917, o ACS acabou por publicar um grupo de padrões mínimos baseados nas categorias de Codman, que viriam a ser alicerces dos padrões de acreditação hospitalar (Neuhauser 2002).

Avedis Donabedian (1919-2000), médico e professor que estudou a qualidade na saúde, propõe a decomposição do conceito de qualidade em eficácia, efetividade, eficiência, otimização, aceitabilidade, legitimidade e equidade. Cada uma dessas dimensões pode ser medida e avaliada, isolada ou em conjunto, permitindo fazer uma avaliação objetiva da qualidade.

Donabedian prova, no estudo "Epidemiologia da qualidade", publicado em 1985, que os atributos estruturais convertem-se em medidas indiretas da qualidade dos cuidados, assim como em indicadores de uma possível assistência deficiente. Outros estudos publicados sobre a avaliação da qualidade dos cuidados descrevem a existência de variações geográficas da prática, como discutido no capítulo anterior.

Essa linha de estudo foi aprofundada pelo médico americano Wennberg, que, no início do século XXI, comparou os cuidados médicos em diferentes zonas geográficas a pacientes com a mesma patologia. Ele encontrou uma variação nos tratamentos administrados que não dependia do tipo de doença, da evidência médica ou preferência dos pacientes, levando-o a atribuir essa responsabilidade ao comportamento do médico.

\section{Para refletir}

Ao refletir sobre suas experiências, você consegue imaginar de que forma o comportamento do médico pode interferir na variação dos tratamentos administrados? Você já viu pacientes com as mesmas características e patologia serem tratados de forma diferente pelo facto de serem atendidos em centros diferentes ou por médicos diferentes? 
As causas e soluções para essas variações indesejáveis são diferentes dependendo da categoria de cuidado de saúde prestado: cuidado efetivo, cuidado sensível às preferências dos pacientes e cuidado sensível à oferta.

O cuidado efetivo tem, comprovadamente, melhor resultado que as suas alternativas, cujos benefícios ultrapassam os efeitos secundários e o risco de possíveis danos e que assenta em evidência científica sólida. O problema de qualidade encontrado nos cuidados efetivos é a subutilização, de que a falha na administração de vacinas é exemplo.

O cuidado sensível às preferências dos pacientes refere-se aos casos em que existem várias opções de cuidado, com resultados que variam segundo a opção escolhida. Habitualmente, o paciente delega ao médico grande parte das decisões terapêuticas, e a escolha dos cuidados acaba por não ser aquela que o paciente escolheria se tivesse acesso à informação detalhada sobre o tipo de qualidade de vida proporcionada por esse cuidado. Nesse caso, é fundamental mudar a relação médico-paciente e aumentar o poder de decisão do paciente, informando-o para que possa fazer as suas escolhas.

Por fim, o cuidado sensível à oferta resulta habitualmente na sobreutilização dos recursos, sendo muito influenciado pela disponibilidade do mercado local de cuidados de saúde; na ausência de orientações baseadas na evidência científica, a tendência é utilizar ao máximo os recursos existentes.

Segundo Wennberg (2010), com a organização dos sistemas de cuidados, a qualidade aumentaria, haveria ganhos significativos e poupança dos sistemas de saúde, com melhores resultados para o paciente. Essa reorganização passaria pela determinação, como norma ética e legal, da escolha informada do paciente para decisões relativas a alguns atos, nomeadamente a cirurgia eletiva, a sustentação dos cuidados em evidências científicas e impedindo o crescimento indisciplinado da capacidade e custos dos serviços de saúde.

Mais tratamento não significa necessariamente melhores cuidados, pelo que esse autor recomenda uma gestão inteligente dos cuidados envolvendo os pacientes, sobretudo no decurso da doença crônica, como forma de aumentar a qualidade (Wennberg 2010). 
Figura 4 - John E. Wennberg

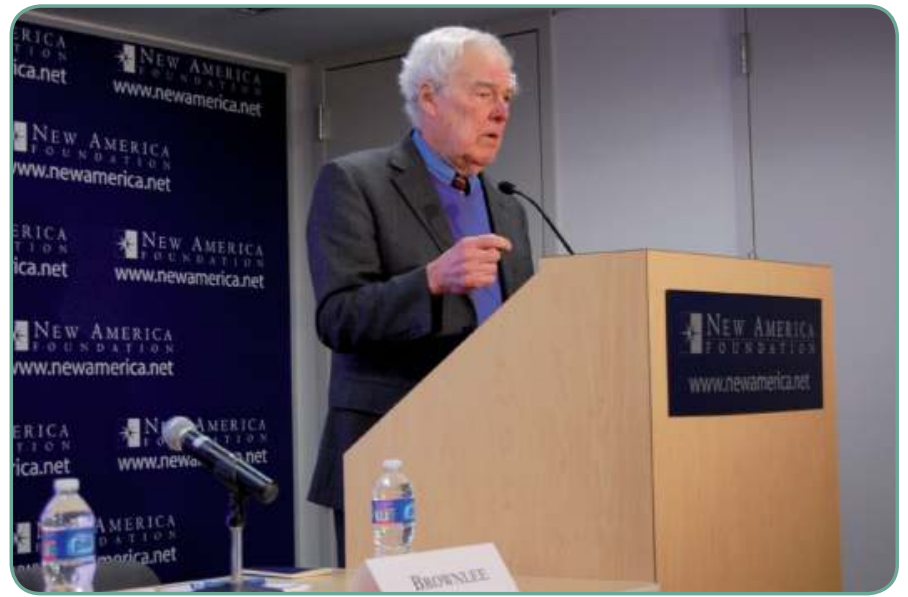

Fonte: Flick (2011).

John E. Wennberg é fundador e diretor emérito do Instituto de Dartmouth para a Política de Saúde e Prática Clínica. Também é professor no Departamento de Medicina da Família e Comunidade e no Departamento de Medicina da Escola de Medicina de Dartmouth.

Archie Cochrane (1909-1988), epidemiologista, também preocupado com as escolhas nos cuidados de saúde, sugeriu que dada a escassez de recursos, esses deveriam ser utilizados para proporcionar os cuidados que se comprovaram eficazes e efetivos por meio de estudos científicos bem desenhados. Sobretudo estudos controlados e randomizados, que têm mais hipótese de fornecer informação de maior rigor que outro tipo de fontes.

Figura 5 - Archibald Leman Cochrane (1909-1988)

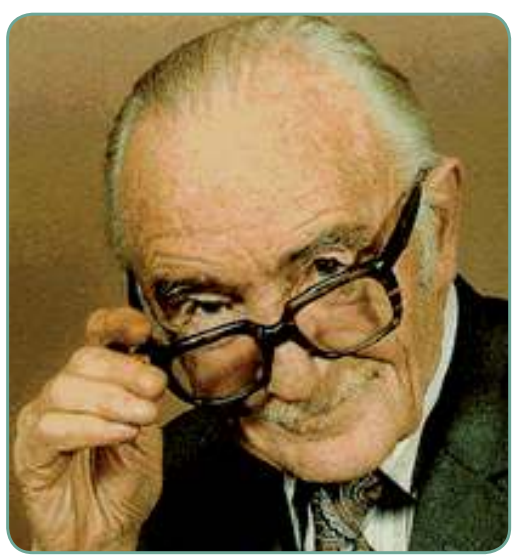

Fonte: Wikimedia Commons (2013).

Archibald Leman Cochrane nasceu na Escócia e como médico se tornou um defensor da utilização do método científico para investigar a eficiência e eficácia de tratamentos e doenças. É um dos pioneiros e fundadores da medicina baseada em evidências. 
O ritmo de publicação de estudos, no entanto, é tão elevado que impossibilita que os profissionais se mantenham a par de todas as edições. Por isso, Cochrane sugere que é imprescindível “...um sumário crítico, revisto periodicamente de todos os estudos controlados..." publicados diariamente.

Em resposta a esse desafio, foi criada, inicialmente, a base de dados de estudos perinatais de Oxford, alargada mais tarde, que deu origem à colaboração de Cochrane, em 1993. Com o contributo/apoio de equipas de investigadores/pesquisadores em todo o mundo, ela organiza e classifica uma imensa quantidade de informação, disponibilizando essas revisões sistemáticas aos profissionais, para que suas decisões clínicas sejam apoiadas por estudos robustos.

\section{Os primeiros estudos, relatórios, organizações e campanhas que lançaram as bases da segurança do paciente}

O estudo pioneiro que empregou o método de revisão retrospetiva de processos clínicos/prontuários para avaliar a incidência de eventos adversos em hospitais foi The Medical Insurance Feasibility Study (MIFS), realizado na Califórnia em 1974 (Mills, 1978). Contudo, foi The Havard Medical Practice Study (HMPS), realizado em 1984 em hospitais do Estado de Nova Iorque, que tornou conhecida a magnitude dos problemas de segurança do paciente internado. O estudo de Harvard (HMPS) teve como objetivo obter mais e melhor informação sobre a incidência de eventos adversos e negligência entre os pacientes hospitalizados. Baseou-se no estudo retrospetivo de uma amostra aleatória de mais de 30 mil processos clínicos/prontuários de pacientes internados em 51 hospitais no ano de 1984 . Seus resultados mostraram que cerca de $3,7 \%$ dos pacientes sofreram algum tipo de incidente, e a maioria poderia ter sido prevenida. Apesar de a maioria resultar em lesões menores, aproximadamente $2,6 \%$ tiveram problemas que implicaram incapacidade total e permanente ou morte (Leape et al. 1991).

A repetição do estudo de Harvard na Austrália, com a revisão de mais de 14 mil processos de pacientes admitidos em 28 hospitais no ano de 1995, revela que $16,6 \%$ dos pacientes sofreram algum tipo de incidente, incapacidade permanente em $13,7 \%$ e morte em 4,9\%. Também, nesse caso, $51 \%$ dos incidentes foram classificados como evitáveis. A diferença dos resultados é atribuída a diferenças metodológicas (Weingart et al. 2000).

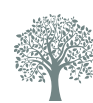

Saiba mais sobre esse projeto de pesquisa no endereço do sítio da organização Cochrane: http://www.cochrane.org/ cochrane-reviews 


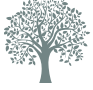

Você pode ter acesso a um resumo do relatório To Err is Human em: http://www. iom.edu/ /media/Files/ Report\%20Files/1999/To-Erris-Human/To\%20Err\%20is\% 2 Humam $\% 201999 \% 20 \% 20$ report\%20brief.pdf.
A mesma metodologia foi aplicada no estudo realizado no Reino Unido e em outros países, incluindo Portugal e Brasil (Mendes et al. 2009; Sousa et al. 2014), tendo-se obtido resultados semelhantes.

\section{Para refletir}

As estatísticas encontradas nos diversos estudos descritos correspondem ao que você vivencia em sua região? Que importância você vê nesse tipo de levantamento e por quê?

O relatório To Err is Human, elaborado pelo IOM em 2000, estimava a ocorrência de 44 mil a 98 mil mortes anuais nos Estados Unidos da América, causadas por eventos adversos decorrentes da prestação de cuidados de saúde, e dessas cerca de metade seria evitável. O custo associado a esses eventos foi estimado entre 17 e 29 biliões de dólares em razão dos custos de cuidados adicionais, mas também pela perda de rendimento e incapacidade resultante (Kohn et al. 1999). Essa constatação alertou os profissionais de saúde, gestores da saúde, pacientes, organizações e decisores políticos para a dimensão do problema e dos seus custos sociais e económicos, além do óbvio sofrimento dos pacientes e famílias.

No Reino Unido, um relatório sobre a análise dos EAs, An organisation with a memory, publicado no mesmo ano (Expert Group on Learning 2000) revelou uma incidência desses eventos de cerca de $10 \% \mathrm{em}$ pacientes internados, que, extrapolados para o total de pacientes admitidos por ano, significaria cerca de 850 mil internamentos/internações com custos diretos acima dos 2 milhões de libras.

Ambos os relatórios sugeriam algumas estratégias para fazer face a essa problemática. Entre essas estratégias destaca-se a mudança de cultura das organizações de saúde. A passagem de uma cultura de culpabilização do indivíduo para a cultura de segurança e de aprendizagem com o erro, por meio da criação de sistemas de notificação confidencial de eventos adversos, incentivando os profissionais a reportá-los, proceder à sua análise sistemática e divulgar os resultados dessa análise para que outros profissionais e pacientes se beneficiem com as recomendações. A notificação voluntária dos incidentes, algumas vezes em plataformas nacionais, foi assim implementada como medida de melhoria e de prevenção de incidentes em diversos países.

Alguns países criaram instituições próprias para desenvolver as estratégias de prevenção a nível nacional, com a missão de melhorar a qualidade, a segurança, a eficiência e a efetividade dos cuidados de saúde: no Reino 
Unido, a National Patient Safety; a Danish Society for Patient Safety, na Dinamarca; a Australian Patient Safety Agency, na Austrália; e nos EUA, a Agency for Healthcare Research and Quality (Sousa et al. 2011).

Em 2004, a OMS lançou o desafio da campanha para a segurança do paciente "Patient Safety" com o objetivo de coordenar, disseminar e promover a melhoria na segurança do paciente a nível mundial. Essa campanha propõe a segurança do paciente como uma prioridade de saúde pública, procurando integrar a perspetiva do paciente e família aos seus cuidados. No entanto, uma década depois da publicação do relatório do IOM, os números de eventos adversos não diminuíram como esperado e desejável (Consumers Union 2010; Levinson 2012), apesar da implementação de algumas estratégias recomendadas, nomeadamente a do relato e análise do incidente como forma a promover a aprendizagem pelo erro.

A consciência desse problema levou ao desenvolvimento de campanhas para envolver o paciente nessas questões de segurança, sendo disso exemplo a campanha da OMS - "Patients for Patient Safety" (PFPS), que procura dar voz ao paciente e família após a ocorrência de incidentes relacionados aos cuidados de saúde.

Recomenda-se às instituições que procurem o ponto de vista do paciente nos aspetos que podem melhorar sua segurança e usem a análise das reclamações como uma forma de melhorar a prática. É encorajado o feedback e o envolvimento do paciente utilizando inquéritos de satisfação e sítios electrónicos para exposição das suas preocupações, assim como o envolvimento da população em geral por meio das suas associações, com encontros para discussão sobre segurança do paciente.

Em 2005, da parceria entre a OMS e a Joint Commission International (JCI), surgiram as "Soluções de Segurança do Paciente" (Patient Safety Solutions) que pretendem ser um contributo/apoio para a sistematização de medidas preventivas e a implementação de políticas em áreas identificadas como problemáticas na segurança do paciente. As soluções criadas a partir desse trabalho foram publicadas em 2007 e descrevem o(s) problema(s) em questão; apresentam a evidência que suporta a(s) solução(ões) proposta(s); identificam as potenciais barreiras à sua implementação; descrevem os riscos potenciais; e fazem referência ao papel do paciente e da família para cada uma das nove soluções (são nove as áreas definidas - conforme você poderá ver a seguir). Esse conjunto de soluções, que passam por mudanças simples das práticas, mas podem evitar incidentes graves, pretendem ser uma boa referência para os profissionais e instituições que prestam cuidados de saúde.
Os aspetos que podem melhorar a segurança do paciente serão focados com maior profundidade no livro Segurança do paciente: criando organizações de saúde seguras. Mais precisamente nos Capítulos 7, Comunicação entre os profissionais de saúde e a segurança do paciente, e 8 , Envolvimento e segurança do paciente: desafios e estratégias.

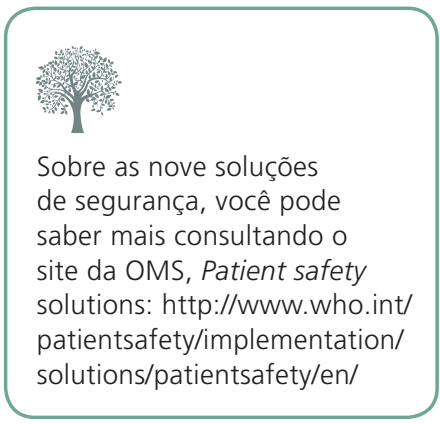


As nove soluções de segurança propostas são as seguintes:

Gestão de medicamentos de aspecto e nome semelhante (medicamentos LASA -"Look Alike, Sounds Alike")

Identificação do paciente

Comunicação durante a transição de cuidados

Realização do procedimento correto no local correto

Controlo das soluções concentradas de eletrólitos

Conciliação medicamentosa

Evitar erros nas conexões de cateteres e tubos

Uso único de dispositivos injetáveis

Melhorar a higiene das mãos para prevenir infecções associadas aos cuidados de saúde

O projeto High 5s, lançado pela OMS em 2006, na mesma linha das soluções de segurança, passa pela implementação e disseminação de protocolos simples (Standard Operating Protocols - SOP's), cuja intenção era reduzir a frequência de cinco dos problemas identificados, em cinco países, num horizonte temporal de cinco anos, daí o nome High 5 s.

\section{Para refletir}

Na sua prática clínica, quais os problemas que poderiam ser resolvidos com estas recomendações? Pense em exemplos concretos.

Você pode consultar essa plataforma on-line no website da OMS: https://www.high5s. org/pub/Main/WebHome/ High_5s_Overview_Sheet.pdf.

Além da criação dos protocolos padronizados na intenção de resolver os problemas, foram definidos os mecanismos de avaliação do seu impacte; da colheita e análise dos dados e, igualmente, estabelecida uma plataforma on-line de ensino, aprendizagem e monitorização dessas ações. 
A implementação do projeto foi iniciada em 2009 e sua timeline de implementação é até 2014, estando, atualmente, três SOP's a ser implementadas em vários hospitais aderentes, quer na Europa, quer na Ásia e América. As três SOP'S são:

橉 a reconciliação do medicamento na transição dos cuidados;

滕 a realização do procedimento correto no local correto do corpo; e

橉 a gestão de soluções concentradas injetáveis.

Como reação ao relatório de 2001 do IOM, Crossing the Quality Chasm: A New Health Care System for the $21^{\text {st }}$ Century, que chamava a atenção para a necessidade de melhoria urgente do sistema de saúde americano, nomeadamente nos aspetos da sua efetividade, eficiência, equidade e segurança do paciente, o Institute for Healthy Improvement (IHI) abraçou esse desafio, traduzindo-o em seis objetivos para combater:

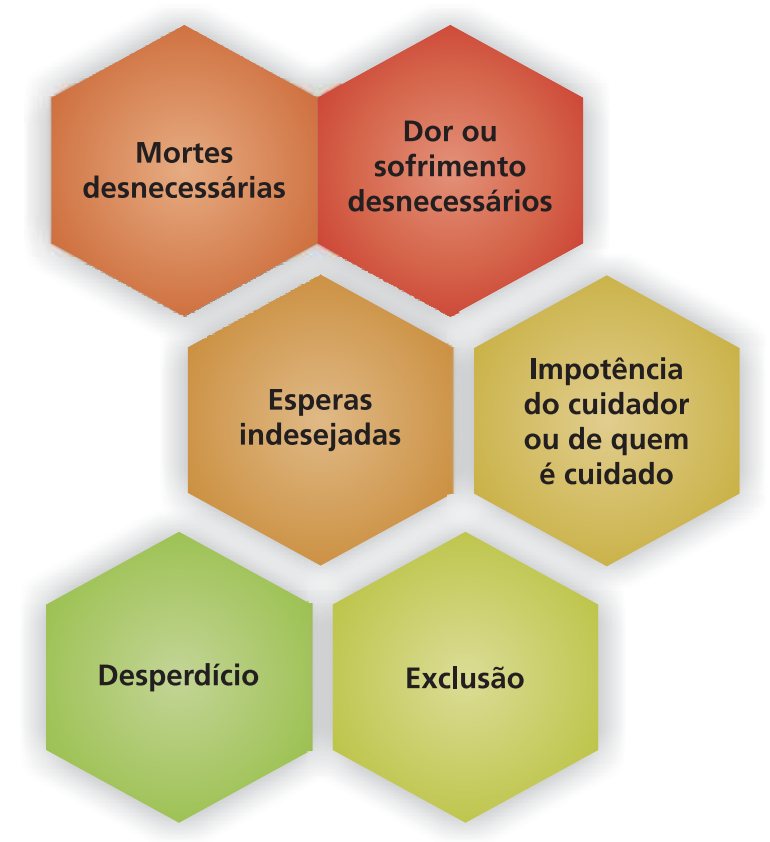

Fonte: Institute for Healthy Improvement (2006).

A campanha das "100 mil vidas" do IHI decorreu de 2004 a 2006, estendendo-se a uma rede vasta de hospitais aderentes. A esses hospitais era pedido que implementassem um conjunto de intervenções, cuja eficácia em impedir mortes desnecessárias era conhecida, cabendo ao IHI a disponibilização de algumas ferramentas e a participação na formação dos profissionais envolvidos. 


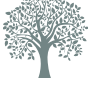

Conheça mais sobre essa nova campanha do IH no endereço: http://www.ihi.org/about/Docu ments/5MillionLivesCampaignC aseStatement.pdf
As intervenções recomendadas pelo IHI passavam por um conjunto de ações focalizadas, como sejam:

ativação de equipas de resposta imediata ao primeiro sinal de agravamento da situação do paciente;

踭 providenciar o tratamento eficaz e baseado na melhor evidência às mortes por EAM/IAM;

prevenir incidentes adversos relacionados com a medicação, implementando a reconciliação do medicamento;

* prevenindo a infeção de cateteres centrais e a pneumonia associada à ventilação, implementando algumas medidas com evidência comprovada; e

prevenindo a infeção do local cirúrgico por meio da administração da profilaxia antibiótica em tempo correto.

No final do período da campanha, foi estimado que mais de $120 \mathrm{mil}$ mortes tinham sido evitadas com o cumprimento dessas medidas pelos hospitais aderentes.

O sucesso inspirou o IHI a lançar uma nova campanha: "5 milhões de vidas". Nela, mais que a redução do número de mortes, o objetivo era proteger os pacientes de cinco milhões de lesões causadas por eventos adversos. Para isso, além de desejar a adesão do dobro dos hospitais, a intenção das intervenções foi alargada. Pretendia-se atuar também em áreas com a prevenção de todas as infeções relacionadas aos cuidados de saúde e das lesões associadas aos medicamentos de alto risco; nas complicações cirúrgicas; nas úlceras por pressão, para dar, apenas, alguns exemplos.

Os custos dos serviços de saúde tendem a aumentar exponencialmente, o que resulta da ampliação da procura (em razão, entre outros factores, ao envelhecimento da população e aumento da esperança média de vida, à inovação e conhecimento biomédico e desenvolvimento de novos fármacos e novas técnicas terapêuticas etc.), mas também ao custo elevado dos procedimentos e medicamentos que vão sendo disponibilizados. Coloca-se, neste momento, a questão, em vários sistemas de saúde a nível mundial, de saber como controlar esses custos sem reduzir os níveis de segurança para o paciente.

Refere-se aqui um exemplo recente de como a preocupação de alcançar os objetivos financeiros pode afetar a segurança do paciente: um hospital inglês, o Stafford Hospital, durante anos sucessivos, apresentou uma taxa de mortalidade acima do esperado. As sucessivas queixas 
dos pacientes e familiares foram sendo ignoradas, e o número insuficiente de enfermeiros, assim como uma cultura de tolerância e de não cumprimento das boas práticas, pôs em causa cuidados básicos, como a higiene e hidratação dos pacientes, por exemplo. Esse caso foi conhecido e tornado público, estando todo o processo bem descrito (desde as causas até as consequências) no relatório Francis (2013). Esse relatório público do inquérito que foi efetuado avança como uma das principais causas para prestação de cuidados inseguros e das consequências que daí resultaram; o enfoque da gestão do hospital apenas no cumprimento dos objetivos financeiros, descurando os sinais e indicadores de falta de qualidade e de falhas na segurança que iam sendo referidos por pacientes e familiares.

Figura 6 - Stafford Hospital

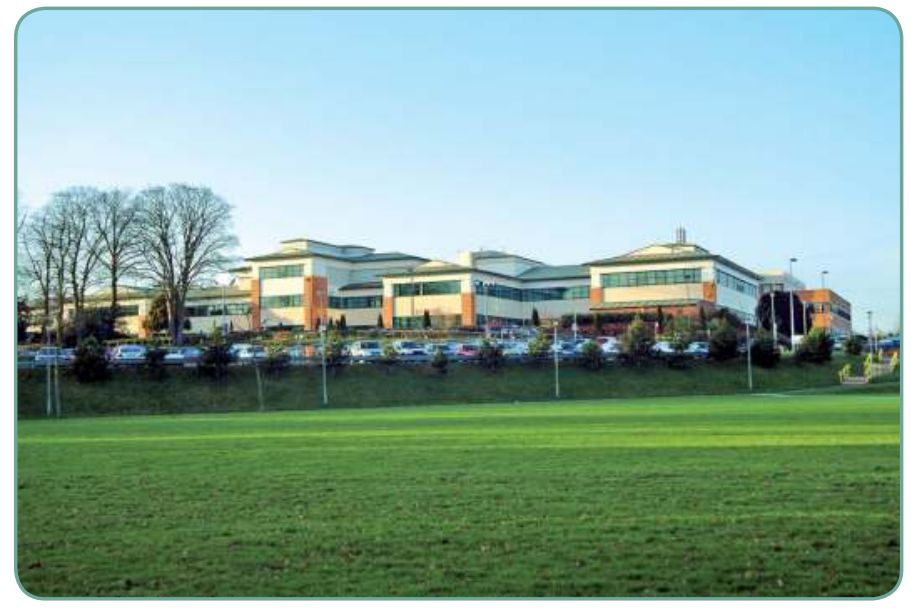

Fonte: Wikimedia Commons - Alistair Rose (2011).

O caso do Hospital de Stafford nos mostra a importância de

implementação nas organizações de saúde de uma cultura de segurança

do paciente. Muitos eventos adversos poderiam ter sido evitados, além de processos judiciais.

\section{Considerações finais}

O caminho para o desenvolvimento da segurança do paciente, da sua integração no trabalho diário das instituições e na cultura de todos os profissionais tem sido lento, com alertas ignorados ao longo do tempo.

Apesar do ritmo lento e da dimensão do problema, inúmeras estratégias para a avaliação, melhoria e garantia da segurança do paciente estão identificadas, e, em muitos casos, já existe um conjunto significativo de evidências que comprovam sua efetividade e eficiência. 
Passará sempre pelo esforço individual e das equipas a aceitação da necessidade de mudança da sua prática (com vista a potenciar a segurança do paciente), mas é fundamental que as organizações de saúde procedam também a alterações organizacionais que incentivem e possibilitem essas práticas mais seguras - daí que o enfoque deva incidir sempre, simultaneamente, nos indivíduos e no sistema.

Muito vem sendo feito, ao longo da história, para que os cuidados de saúde prestados tenham o nível de desenvolvimento que hoje apresentam, bem como a qualidade e a segurança que os caracteriza.

\section{Referências}

Best M., Neuhauser D. Ignaz Semmelweis and the birth of infection control. Qual Saf Health Care. 2004 [citado 2013ago. 20];13:233-34. Disponível em: http://qualitysafety.bmj.com/ content/13/3/233.full.pdf+html.

Consumers Union. To err is human: to delay is deadly. [Local desconhecido]: Safe Patient Project; 2009 [citado 2012 jan. 20]. Disponível em: http://safepatientproject.org/safepatientproject.org/pdf/ safepatientproject.org-ToDelaylsDeadly.pdf .

Donabedian A. La calidad de la atención médica. Rev Calid Asist. 2001; 16:529-538 [citado 2013 set. 12]. Disponível em: http://www.calidadasistencial.es/images/gestion/biblioteca/251.pdf.

Donabedian A. Epidemiología de la calidad. Rev Calid Asist. 2001;16:S54-S62 [citado 2013set. 12]. Disponível em: http://www.calidadasistencial.es/images/gestion/biblioteca/251.pdf.

Donabedian A. The quality of care: how can it be assessed? JAMA. 1988; 260:1743-48.

Expert Group on Learning from Adverse Events in the NHS. An organisation with a memory. London: Stationery Office; 2000 [citado 2011 ago 23]. Disponível em: http://webarchive. nationalarchives.gov.uk/20130107105354/http:/www.dh.gov.uk/prod_consum_dh/groups/dh_ digitalassets/@dh/@en/documents/digitalasset/dh_4065086.pdf.

Flick. John E. Wennberg. [Local desconhecido]: New American Foundation, 2011 [citado 2014 jun. 14]. Disponível em: http://www.flickr.com/photos/newamerica/5387871543/.

Francis R. Report of the Mid Staffordshire NHS Foundation Trust Public Inquiry. London: The Stationery Office; 2013 [citado 2013 set. 21]. Dísponível em: http://www.midstaffspublicinquiry. com/sites/default/files/report/Executive\%20summary.pdf

Institute for Healthcare Improvement. 5 million lives campaign. Cambridge (MA): The Institute; 2006 [citado 2013 set. 3]. Disponível em: http://www.ihi.org/about/Documents/5MillionLivesCampa ignCaseStatement.pdf.

Institute for Healthcare Improvement. The Triple Aim:optimizing health, care and cost. Cambridge (MA): The Institute; 2009[citado 2013 set. 3].Disponível em: http://www.ihi.org/offerings/ Initiatives/TripleAim/Pages/default.aspx.

Institute of Medicine [IOM]. Crossing the quality chasm: a new health system for the 21 st Century. Washington, DC: National Academy Press, 2001.

Kohn L, Corrigan J, Donaldson M. To err is human: building a safer health system. Washington (DC): National Academy Press; 1999. 
Leape LL, Brennan TA, Laird NM, Lawthers AG, Localio AR, Barnes BA et al. The nature of adverse events in hospitalized patients: results from the Harvard Medical Practice Study II. N Engl J Med. 1991 [citado 2011 out. 6]; 324(6): 377-84. Disponivel em: http://www.nejm.org/doi/pdf/10.1056/ NEJM199102073240605.

Levinson DR. Hospital incident reporting systems do not capture most patient harm. Department of Health and Human Services, Office of Inspector General; 2012 [citado 2012 jan 18]. Disponível em: http://oig.hhs.gov/oei/reports/oei-06-09-00091.pdf.

Lopes LMM, Santos SMP. Florence Nightingale: apontamentos sobre a fundadora da Enfermagem Moderna. Rev Enferm Referência. 2010 dez [citado 2013 ago. 20];3.série(2):181-9. Disponível em: http://www.scielo.oces.mctes.pt/pdf/ref/v3n2/v3n2a19.pdf.

Lyons AS. et al. Historia de la medicina medicine: an illustrated history. Barcelona: Doyma; 1984.

Mendes V. Qualidade no Sistema Nacional de Saúde, evolução recente e perspectivas futuras. Lisboa: Universidade Nova de Lisboa, Escola Nacional de Saude Pública; 2012.

Mendes W, Martins M, Rozenfeld S, Travassos C. The assessment of adverse events in hospitals in Brazil. Int J Qual Health Care. 2009 [citado 2013 ago. 20];21(4): 279-84. Disponível em: http:// intqhc.oxfordjournals.org/content/21/4/279.long.

Mills DH. Medical insurance feasibility study: a technical summary. West J Med. 1978;128: 360-5.

Neuhauser D. Heroes and martyrs of quality and safety: Ernest Amory Codman MD. Qual Saf Health Care. 2002 [citado 2013 ago. 20];11:104-5, 2002. Disponível em http://qualitysafety.bmj.com/ content/11/1/104.full.pdf+html.

Pita JR. História da farmácia. Coimbra: Minerva; 2007.

Porter R., editor. The Cambridge history of medicine. New York: Cambridge University; 2006.

Serapioni M. Avaliação da qualidade em saúde: a contribuição da sociologia da saúde para a superação da polarização entre a visão dos usuários e a perspectiva dos profissionais de saúde. Saúde Debate. 1999 set./dez.;23(53):81-92.

Sousa P, Uva AS, Serranheira F, Leite E, Nunes C. Segurança do doente: eventos adversos em hospitais portugueses: estudo piloto de incidência, impacte e evitabilidade. Lisboa: Ed. Escola Nacional de Saúde Pública; 2011.

Sousa P, Uva AS, Serranheira F, Nunes C, Leite ES. Estimating the incidence of adverse events in Portuguese hospitals: a contribution to improving quality and patient safety. BMC Health Services Research. 2014;14:311. doi:10.1186/1472-6963-14-311.

Weingart S. et. al. Epidemiology of medical error. BMJ 2000 [citado em 2008 set. 17];320:774-7. Disponível em: http://bmj.com.

Wennberg J. Tracking medicine: a researcher's quest to understand health care. New York: Oxford University; 2010 [citado 2013 ago. 20]. Disponível em: http://sgh.org.sa/Portals/0/Articles/Tracking $\%$ Medicine\%Researcher's\%Quest\%0to\%Understand\%Health\%Care.pdf .

Wikimedia Commons. File:Florence Nightingale.png. 2009 [citado 2014 jun. 14]. Disponível em: http://commons.wikimedia.org/wiki/File:Florence_Nightingale.png

Wikimedia Commons. File:Ignaz Semmelweis 1860.jpg. 2014 [citado 2014 jun. 14]. Disponível em: http://commons.wikimedia.org/wiki/File:Ignaz_Semmelweis_1860.jpg?uselang=pt-br

Wikimedia Commons. File:Professor Archibald Leman Cochrane (Dr. Archie Cochrane).gif. 2013 [citado 2014 jun. 14]. Disponível em: http://commons.wikimedia.org/wiki/File:Professor_Archibald_ Leman_Cochrane_\%28Dr._Archie_Cochrane\%29.gif. 
Wikipedia. Ficheiro: Galen detail.jpg. [citado 2014 jun. 18]. 1 reprodução de original de arte bidimensional. Disponível em: http://pt.wikipedia.org/wiki/Ficheiro:Galen_detail.jpg.

World Health Organization, Patient Safety Programme. Evaluation of the WHO Patient Safety solutions aides. Donna O. Failey, evaluation consultant. [Genebra: WHO], Aug. 31, 2011 [citado 2013 set. 3]. Disponível em: http://www.who.int/patientsafety/implementation/solutions/ patientsafety/PSP_H5-Solutions_Report-Final_Apr-2012.pdf.

World Health Organization, Patient Safety Programme. High 5s: action on Patient Safety. [Genebra: WHO], 2013[citado 2013 set. 3]. Disponível em: http://www.who.int/patientsafety/implementation/ solutions/high5s/ps_high5s_project_overview_fs_Oct_2011.pdf. 


\section{Taxonomia em segurança do paciente}

Walter Mendes

Neste capítulo, estudaremos a taxonomia em segurança do paciente. Apresentaremos os motivos que levaram a Organização Mundial de Saúde (OMS) a classificar e organizar os conceitos e definições sobre o tema. Ao final do capítulo, serão conhecidos alguns termos e conceitos habitualmente utilizados, que não estão na classificação proposta pela OMS, mas serão encontrados ao longo deste livro.

\section{A torre de Babel}

O Conselho Australiano para Segurança e Qualidade em Saúde, por meio do projeto denominado Shared Meanings, criou, em 2001, um endereço eletrônico para incentivar pesquisadores/investigadores e outros profissionais de saúde a informar os termos e definições utilizadas no campo da segurança do paciente (Australian Council for Safety and Quality in Health Care 2001). O objetivo era conceber uma linguagem com significados comuns para facilitar a discussão e a pesquisa (Ruciman, Moller 2001). Foram listados 149 termos com 296 definições diversas; registradas 16 definições para erro, 14 para evento adverso e 5 para evento adverso relacionado a medicamentos (Runciman 2006).

Essa profusão de definições tem várias origens. Entre elas a compreensão dos profissionais de saúde, em geral, e dos médicos, em particular, sobre o que é erro no cuidado à saúde. A definição de erro para o médico é influenciada pelas consequências desse no paciente. Durante

No próximo capítulo, "O erro e as violações no cuidado de saúde", será discutido de forma mais detalhada o erro no cuidado à saúde. um estudo, ao ser apresentado a médicos de família o cenário em que um médico tinha registrado como resultado normal um exame com resultado anormal, todos relataram que houve um erro ou engano. 
Como já abordado no capítulo anterior, "A perspetiva histórica e principais desenvolvimentos da segurança do paciente", os estudos de incidência de eventos adversos e, particularmente, a publicação do relatório Errar é Humano, do Instituto de Medicina dos Estados Unidos, estimularam a OMS a criar a Aliança Mundial para a Segurança do Paciente (Ruciman et al. 2009).
Entretanto, quando o cenário apresentado foi a queda de um tubo com sangue, apenas parte deles $(47 \%)$ considerou que houve um erro. Ou seja, há falta de consenso entre os médicos sobre o que constitui erro. Essa constatação é importante, pois os médicos são convidados para fazer relatórios de erros a fim de determinar o foco de atenção da segurança do paciente e intervenções (Elder et al. 2006).

Adicionalmente, existe, ainda, a dificuldade de transpor alguns termos ou palavras do inglês para o português, como medical error, near miss, entre outros (Mendes 2012). É fácil, portanto, compreender por que essa situação tem sido comparada a uma "Torre de Babel".

Figura 1 - Torre de Babel

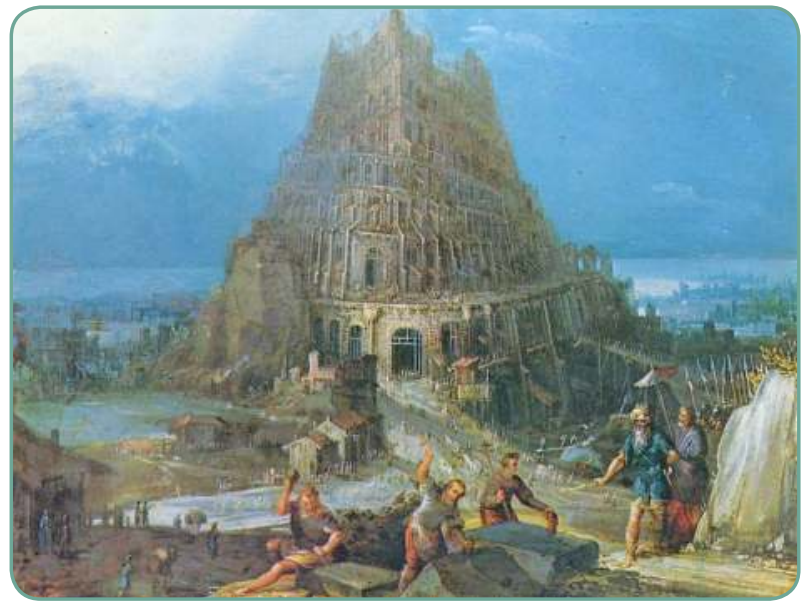

Fonte: Wikimedia Commons (2013)

Essa pintura em óleo sobre tela de Pieter Brueghel, O Velho, de 1563, retrata a torre que, segundo o Antigo Testamento, foi construída na Babilônia pelos homens para atingir o céu. Deus considerou esse fato uma afronta e, para castigá-los, confundiulhes as línguas e os espalhou por toda a Terra.

\section{A Organização Mundial de Saúde entra em cena}

A OMS criou, em 2004, a Aliança Mundial para a Segurança do Paciente (renomeada, em 2009, como Segurança do Paciente). Uma das primeiras iniciativas da Aliança foi o desenvolvimento de uma classificação para segurança do paciente. Um grupo de trabalho, cuja coordenação entregou-se a William Ruciman, que havia participado do projeto australiano Shared Meanings (Ruciman et al. 2009), desenvolveu a Classificação Internacional de Segurança do Paciente (International Classification for Patient Safety - ICPS) (WHO 2009). 
Essa classificação apresenta um conjunto de conceitos ligados por relações semânticas para organizar a informação a ser utilizada para vários objetivos, incluindo estatísticas nacionais, estudos descritivos e a investigação de avaliação. A classificação foi organizada em uma estrutura que realça a identificação, a prevenção, a detecção e a redução do risco, bem como a recuperação do incidente e a resiliência do sistema. A resiliência, no contexto dessa estrutura conceitual, é "o grau com que um sistema continuamente impede, detecta, atenua o dano ou reduz os perigos ou incidentes" (WHO 2009). A Figura 2 apresenta a estrutura da ICPS.

Figura 2 - Estrutura conceitual da Classificação Internacional sobre Segurança do Paciente

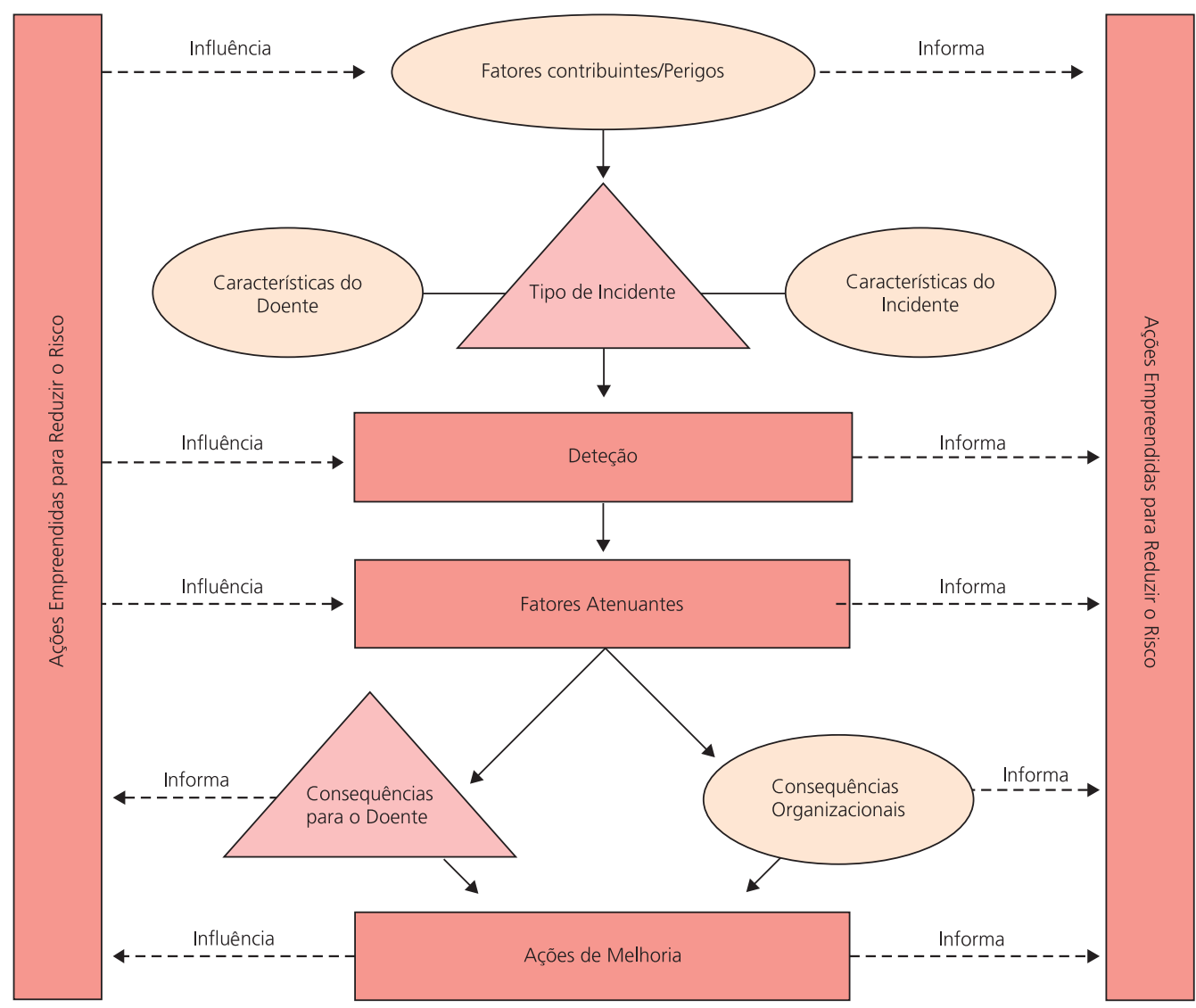

Resiliência do Sistema (Avaliação de Riscos Pró-Ativa \& Reativa

Categorias clinicamente significativas e reconhecíveis para identificação e recuperação de incidentes

Informação descritiva

As linhas a cheio representam as relaçôes semânticas entre as classes. As linhas a tracejado representam o fluxo de informação.

Fonte: Classificação Internacional para a Segurança do Doente (ICPS) (WHO 2009).

A estrutura da ICPS não só demonstra a taxonomia, como também organiza a forma de raciocinar a maneira que se estabelecem as relações entre as causas e consequências dos incidentes e de que forma as ações podem prevenir ou reduzi-los, na lógica de uma organização que aprende com os erros. Recomenda-se que leiam a ICPS, disponível na página da OMS, para melhor entender as relações existentes.

Nota: Traduzido para o português por Divisão de Segurança do Doente, Departamento da Qualidade na Saúde, Direção-Geral da Saúde do Ministério de Saúde de Portugal, 2011. 
A negligência tem significado disciplinar específico e será desenvolvida no Capítulo 6, "Direito e segurança do paciente", deste livro, que trata do direito e da segurança do paciente.

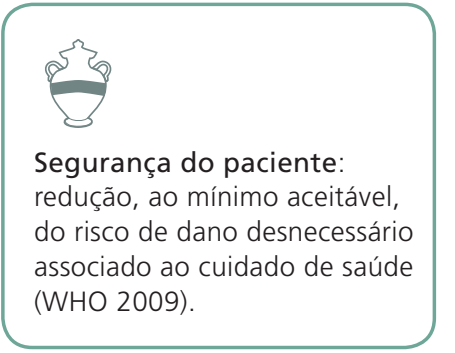

Alguns termos e conceitos, utilizados na literatura e na comunicação cotidiana dos profissionais de saúde, não foram incluídos na ICPS porque seu significado varia de acordo com o contexto (WHO 2009). Negligência, danos iatrogênicos e nosocomiais são exemplos de termos não relacionados. Os danos iatrogênicos e nosocomiais são, respectivamente, associados a médicos e hospitais. O termo iatrogênico ainda é muito utilizado e definido como um dano originado ou provocado por atos de comissão ou omissão do profissional de saúde (Aspden et al. 2004). Um erro pode ser oriundo de um ato de omissão - quando se deixa de agir - ou de um ato de comissão (ação) - quanto se erra durante a ação.

A opção da ICPS por "dano associado aos cuidados de saúde" engloba cuidados de saúde prestados por diferentes profissionais (não só o médico), em uma variedade de ambientes de cuidado (não só o hospital).

A ICPS parte da premissa que a lista de conceitos é dinâmica e deverá sofrer revisões futuras. Para compreender a ICPS, é preciso conhecer as dez classes que a compõem (WHO 2009):

\section{Tipos de incidentes}

Consequências para o paciente

Características do paciente

Características do incidente

Fatores contribuintes/perigos

Consequências organizacionais

Detecção

Fatores atenuantes do dano

Ações de melhoria 


\section{Tipos de incidente e as consequências para o paciente}

Os tipos de incidentes e as consequências para o paciente são categorias consideradas, na estrutura conceitual, clinicamente significativas e reconhecíveis para identificação e recuperação de incidentes (WHO 2009).

Incidente (relacionado ao cuidado de saúde) é um evento ou circunstância que poderia ter resultado, ou resultou, em dano desnecessário ao paciente. A palavra "desnecessário", nessa definição, significa implicitamente que, erros, transgressões, abuso de pacientes e atos deliberadamente perigosos podem ocorrer em cuidados de saúde. Ao contrário, certos danos, tais como uma incisão para laparotomia, são necessários e, nesse caso, não são considerados incidentes, Os incidentes podem ser oriundos de atos intencionais (violações) ou atos não intencionais.

A seguir, são apresentadas as definições para os principais termos relacionados na ICPS:

- Evento: algo que ocorre com ou envolve o paciente.

- Circunstância: situação ou fator que pode influenciar um evento, agente ou pessoa.

- Agente: substância, objeto ou sistema que age para produzir mudança.

- Dano: dano da estrutura ou função do corpo e/ou qualquer efeito deletério dele oriundo. Inclui doenças, dano ou lesão, sofrimento, incapacidade ou disfunção e morte. O dano pode, assim, ser físico, social ou psicológico.

- Dano associado ao cuidado de saúde: dano surgido por, ou associado a, planos ou ações realizadas durante o cuidado de saúde em vez de uma doença de base ou lesão.

- Paciente/doente: pessoa que recebe cuidados de saúde. O termo paciente é mais utilizado no Brasil, enquanto doente é mais utilizado em Portugal.

- Cuidados de saúde: serviços recebidos por indivíduos ou comunidades para promover, manter, monitorizar ou restaurar a saúde.

- Saúde: estado de bem-estar físico, mental e social completo, e não apenas ausência de doença ou enfermidade.

- Doença: disfunção fisiológica ou psicológica.

- Erro: falha em executar um plano de ação como pretendido ou aplicação de um plano incorreto. Pode ocorrer por fazer a coisa errada (erro de ação ou comissão) ou por falhar em fazer a coisa certa (erro de omissão) na fase de planejamento ou na fase de execução. Os erros são, por definição, não intencionais. 
- Violação: divergência deliberada de um procedimento cirúrgico, um padrão ou regra. São de forma habitual intencionais, apesar de raramente maliciosas; e, em determinado contexto, podem se tornar rotineiras ou automáticas. Um exemplo de violação é a não adesão à higienização das mãos por profissionais de saúde.

A seguir, serão apresentados quatro casos para facilitar o entendimento dos tipos de incidentes (WHO 2009):

Caso 1 - Um profissional observou que o frigorífico que guarda unidades de sangue estava com problema técnico, e, por isso, a temperatura estava alta. Essa é uma circunstância notificável: circunstância em que houve potencial significativo para o dano.

*aso 2 - Uma unidade de sangue foi conectada ao paciente errado, mas o erro foi detectado antes do início da transfusão. Isso é um near miss: incidente que não atingiu o paciente.

膦 Caso 3 - Uma unidade de sangue foi conectada ao paciente errado, houve transfusão, mas não houve reação. Isso é um incidente sem danos: evento que atingiu o paciente, mas não causou dano discernível.

Caso 4 - Uma unidade de sangue foi conectada ao paciente errado, houve transfusão, e o paciente morreu por reação hemolítica. Isso é um incidente com dano, ou um evento adverso: incidente que resulta em dano ao paciente.

Figura 3 - Tipos de incidentes

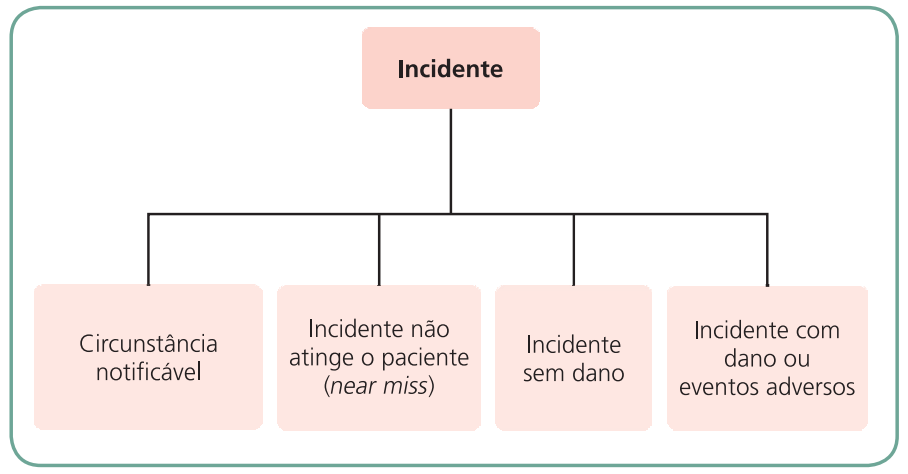




\section{Características do paciente e do incidente, fatores contribuintes e consequências organizacionais}

Considere agora o seguinte caso: Um paciente do sexo masculino, de 27 anos, procurou um serviço de emergência, em função de hemorragia causada por acidente automobilístico. Houve a necessidade de reposição de sangue. Uma unidade de sangue prescrita para outro paciente foi transfundida, e ele morreu por reação hemolítica.

A partir desse caso, vamos entender como as características do paciente e do incidente, os fatores contribuintes e as consequências organizacionais são conceituados na ICPS.

As características do paciente englobam os dados demográficos e o motivo original do contato do paciente com o serviço de saúde, além do diagnóstico clínico principal. No caso relatado, sabemos as seguintes características do paciente: sexo masculino, 27 anos, procurou um serviço de emergência em função de hemorragia causada por acidente automobilístico.

Já as características do incidente representam as circunstâncias do incidente - o que ocorreu, quem esteve envolvido, quem o comunicou, como ocorreu, onde ocorreu, quando ocorreu e o trajeto do paciente pelo "sistema de saúde". Sabemos que, em nossa história fictícia "houve a necessidade de reposição de sangue. Uma unidade de sangue prescrita para outro paciente foi transfundida, e ele morreu por reação hemolítica".

Os fatores contribuintes são as circunstâncias, ações ou influências que desempenham papel na origem ou no desenvolvimento de um incidente ou no aumento do risco de incidente, e vários podem ter sido os fatores - não seguir um protocolo, falta de habilitação do profissional que cuida, falta de comunicação entre a equipe e dessa com o paciente etc.

O risco, por sua vez, é a probabilidade de um incidente ocorrer, diferente do perigo, que é a circunstância, agente ou ação que pode causar dano. O perigo é uma percepção, e o risco um cálculo.

Os fatores contribuintes para o desenvolvimento de um incidente ou aumento do risco podem ser:

Fatores humanos ligados ao comportamento, ao desempenho ou à comunicação da equipe de saúde entre si e com os pacientes. 


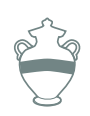

Um único incidente no paciente pode ser causado por mais de um fator contribuinte.
O conceito de resiliência voltará a ser discutido no Capítulo 1, "Organizações de saúde seguras e confiáveis/fiáveis", do livro Segurança do paciente: criando organizações de saúde seguras.
Fatores do sistema como o ambiente de trabalho. Os fatores do sistema estão relacionados aos fatores latentes.

* Fatores externos para além do controle da organização, como o ambiente natural ou a legislação.

滕 Fatores relacionados ao paciente, por exemplo, a não adesão ao tratamento.

Existe uma relação complexa entre incidente e fatores contribuintes. A mesma situação pode ser entendida como um incidente ou fator contribuinte, dependendo do contexto, circunstância ou resultado. Exemplo (WHO 2009): considere um paciente com fibrilação auricular, medicado com warfarina, que se levanta à noite para ir ao banheiro/casa de banho, e cai sem um dano visível. Isso poderia ser um incidente sem dano (queda). Entretanto, se esse mesmo paciente tivesse sido encontrado na manhã seguinte inanimado no chão, com lesão na cabeça, poderia ser considerado um incidente com dano (evento adverso), e a queda considerada um fator contribuinte.

As consequências organizacionais referem-se ao impacto na organização atribuível, inteira ou parcialmente, a um incidente. Esses impactos podem ser o aumento da utilização de recursos para cuidar do paciente, o desgaste na imagem institucional ou consequências legais.

\section{Para refletir}

De acordo com o caso relatado no início dessa seção, observe as características do paciente e do incidente, os fatores contribuintes e que tipos de consequências organizacionais devem ter ocorrido.

Você acha que teria sido possível evitar o incidente? De que maneira?

\section{Gestão do risco}

A detecção, os fatores de mitigação, as ações de melhoria e as ações empreendidas para reduzir o risco são categorias consideradas, na ICPS, de recuperação do incidente e resiliência do sistema.

A detecção é a descoberta de um incidente. Os mecanismos de detecção podem ser parte do sistema (como o alarme de baixa saturação de oxigênio no monitor multiparamétrico) ou resultar de uma postura de maior "consciência" da situação, que envolve o conhecimento do profissional responsável pelo cuidado sobre o risco e a forma de preveni-lo. 
O fator de mitigação é a ação ou circunstância que objetiva prevenir ou moderar a progressão de um incidente. Em conjunto, a detecção e a mitigação do dano podem impedir a progressão de um incidente e que ele atinja e/ou prejudique o paciente.

Se o incidente resultar em dano, podem ser introduzidas ações de melhoria. Essas ações, realizadas ou circunstanciais, são alteradas para melhorar o desempenho da organização ou compensar qualquer dano depois de um incidente.

Ações empreendidas para reduzir o risco são tomadas para reduzir, gerenciar ou controlar qualquer dano futuro ou a probabilidade de dano associado a um incidente. Essas ações podem ser proativas ou reativas. A detecção, os fatores atenuantes do dano e as ações de melhoria influenciam e informam simultaneamente as ações empreendidas para reduzir o risco.

Figura 4 - Um fator de mitigação pode ser um ato simples, como lavar as mãos

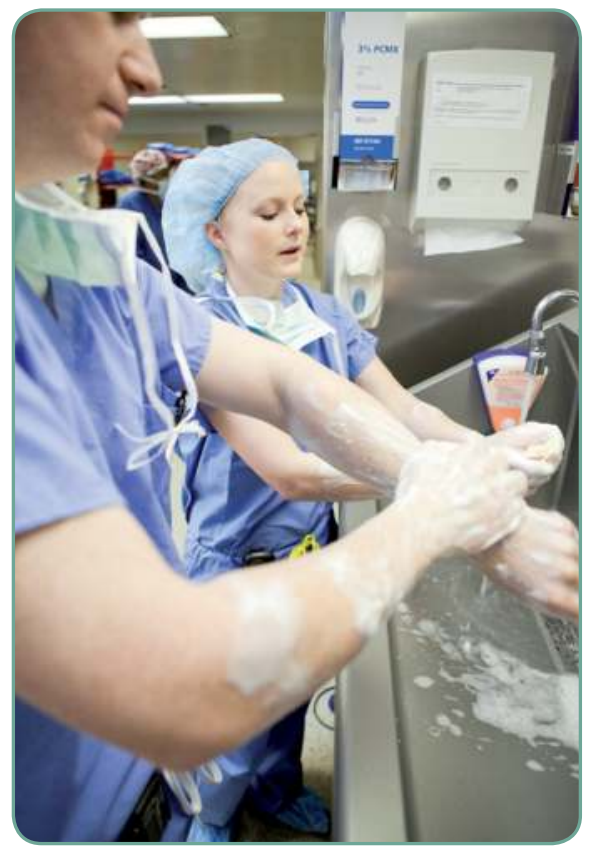

Fonte: Flickr (2012)

\section{Termos e conceitos polêmicos habitualmente utilizados}

Alguns termos causam muita confusão pela incorreta tradução do inglês para o português ou pelo uso rotineiro do seu conceito na literatura ou na comunicação entre os profissionais que trabalham nas organizações de saúde (Mendes 2012). 
No Capítulo 16, deste livro, o termo near miss materno será mais bem contextualizado.
O termo medical error, cujo significado, em vários contextos, é erro de qualquer profissional de saúde, não raro é traduzido como erro médico.

Outro termo de uso comum que carrega certa confusão é near miss, traduzido no Manual de Acreditação Hospitalar, da Joint Commmission International, versão em português, como quase erro. Essa tradução embute um problema conceitual, já que o erro existiu, mas não se concretizou no paciente. O Departamento da Qualidade na Saúde, Direção-Geral da Saúde do Ministério de Saúde de Portugal, em 2011, na tradução que fez do documento da OMS, traduziu near miss como quase evento. Talvez, a melhor forma de traduzir near miss seja a utilização do seu conceito - incidente que não atingiu o paciente.

O termo near miss, na área da saúde maternoinfantil, tem sido utilizado pelos profissionais muito antes da publicação da ICPS. Nesses casos, ele é usado para fazer referência às situações em que mulheres apresentam complicações potencialmente letais durante a gravidez, o parto ou puerpério, e só sobrevivem em razão do acaso ou ao cuidado de saúde prestado.

Existe um conjunto de termos - evento adverso, evento adverso evitável, reação adversa a medicamentos, efeito secundário, evento sentinela e acidente - que provocam muita discussão sobre seu uso e, por esse motivo, serão discutidos a seguir.

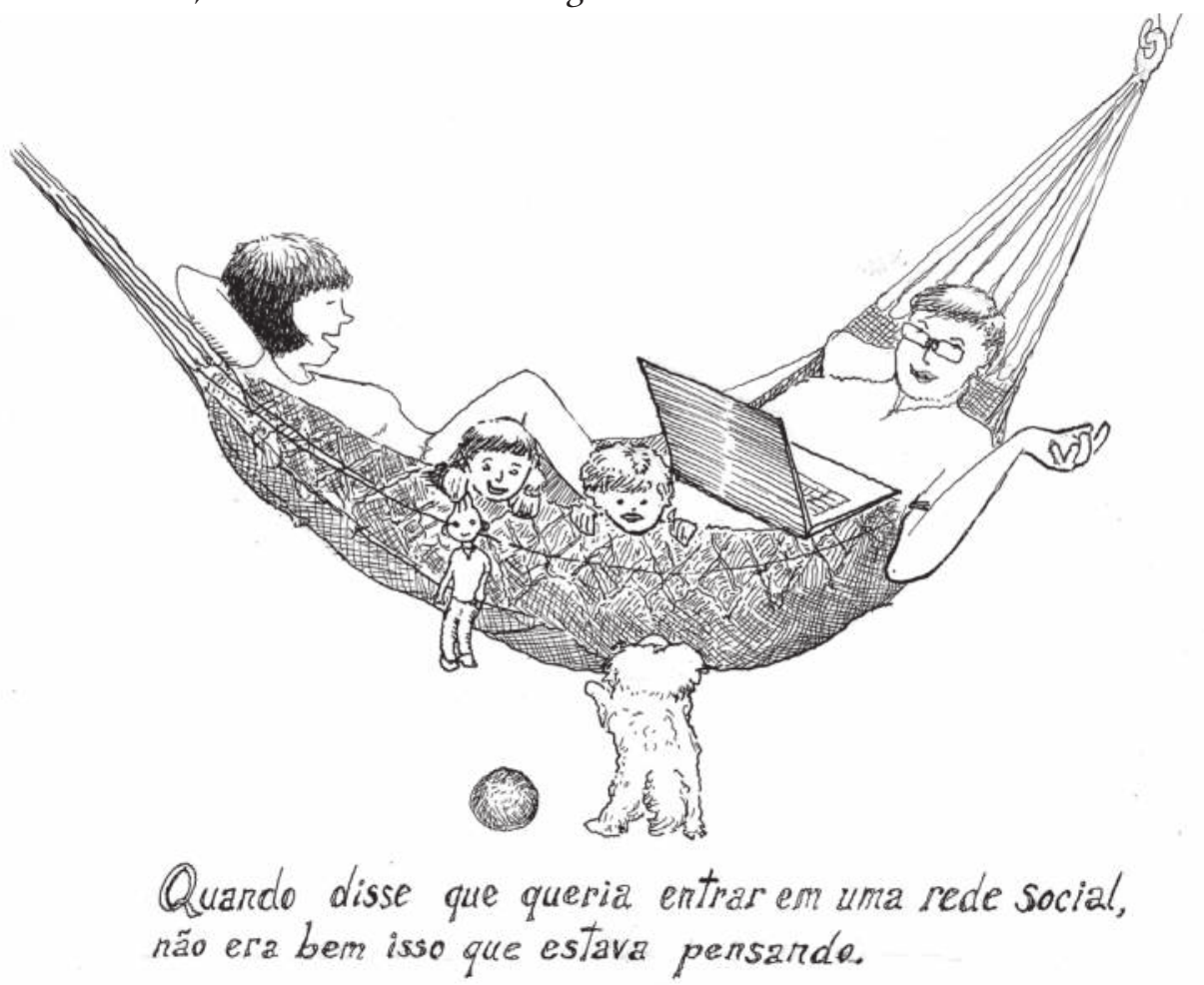




\section{Evento adverso evitável}

Com base nas definições da ICPS, é uma redundância utilizar termo evitável para se referir a um evento adverso. Pela ICPS, o evento adverso é um incidente com lesão, e incidente é um evento ou circunstância que poderia ter resultado, ou resultou, em dano desnecessário ao paciente. Em função disso, não são considerados os danos necessários (caso da laparotomia). Portanto, para a ICPS, todos os eventos adversos são evitáveis.

A maioria dos estudos pioneiros para avaliar a frequência de eventos adversos foi realizada antes da publicação da ICPS. Esses estudos se basearam no estudo de Harvard (Leape et al. 1991), inclusive o estudo brasileiro e o português (Mendes et al. 2009; Sousa et al. 2014). Eles utilizaram a seguinte definição para eventos adversos: “dano não intencional que resulta em incapacidade ou disfunção, temporária ou permanente, e/ou prolongamento do tempo de permanência ou morte como consequência do cuidado de saúde prestado" (Mendes et al. 2005). A avaliação dos eventos adversos, nesses estudos, é realizada por médicos, que, inicialmente, julgam se o evento adverso existe ou não e, posteriormente, se é evitável ou não.

Portanto, de acordo com a maioria dos estudos (realizados antes da publicação da ICPS), o evento adverso pode ou não ser evitável. Como exemplo, mencionamos o caso de um paciente que desenvolve uma complicação hemorrágica após o uso de um quimioterápico. Mesmo que ele tenha sido alertado sobre os riscos e benefícios do tratamento e assinado de forma livre e consciente o termo de consentimento informado para realização do procedimento, a hemorragia é considerada um evento adverso (utilizando a definição de Harvard). Entretanto, essa complicação é compreendida como não evitável. Nesse caso hipotético, o médico, a enfermeira e o farmacêutico que cuidaram desse paciente tinham a capacidade técnica necessária, todo o arsenal terapêutico, os materiais médico-cirúrgicos estavam disponíveis, e a estrutura do hospital estava adequada. Pela ICPS, não houve um incidente, mas, pela definição dos estudos pioneiros, houve um evento adverso não evitável. Quando a ICPS incluiu o termo "dano desnecessário ao paciente" na definição de incidente, eliminou o termo evitável, de modo que todo evento adverso é evitável.

\section{Reação adversa ao medicamento e efeito secundário}

São termos bem conhecidos pelos farmacêuticos e técnicos de farmácia, mas, muitas vezes, não tão bem compreendidos pelos demais profissio- 
nais de saúde. Segundo a ICPS, reação adversa ao medicamento é um dano inesperado que resulta de uma ação ou tratamento justificado em que o processo correto, para o contexto em que o evento ocorreu, foi implementado. Por exemplo, a diminuição anormal e inesperada do número de glóbulos brancos no sangue pela utilização de um medicamento em que se desconhecia esse efeito é uma reação adversa.

Um efeito secundário é um efeito conhecido, para além do principalmente desejado, relacionado com as propriedades farmacológicas de um medicamento, tais como náusea após a administração de morfina para alívio das dores.

\section{Para refletir}

Em sua organização, quando são usados os termos "reações adversas"

e "efeito secundário", os profissionais de todas as categorias

compreendem? O termo "efeito colateral" é também utilizado?

\section{Evento sentinela}

O dano é o elemento comum na definição de evento adverso, presente nos estudos acadêmicos pioneiros e na ICPS. Não há evento adverso sem dano. Uma queda de leito/cama sem nenhum dano ao paciente, por exemplo, é um incidente, mas não é um evento adverso.

Entretanto, há o registro de uma definição diferente para evento adverso no glossário do último manual Padrão de Acreditação da Joint Commission International (JCI) para Hospitais, $4^{\mathrm{a}}$ edição (Joint Commission International. Padrões de acreditação da Joint Commission International para hospitais. Editado por Consórcio Brasileiro de Acreditação de Sistemas e Serviços de Saúde. Rio de Janeiro: CBA; 2010). Segundo ele, evento adverso é a "ocorrência imprevista, indesejável ou potencialmente perigosa na organização de saúde". Pela definição da JCI, não há uma vinculação conceitual do dano com evento adverso. Dessa forma, uma queda do leito/cama é um evento adverso, independentemente de ter causado ou não um dano.

No mesmo manual, há a definição de evento sentinela: ocorrência inesperada que implique morte ou perda grave e permanente de função. Essas duas denominações sugerem existir uma escala de gravidade sobre a consequência indesejável para o paciente - o evento adverso uma ocorrência mais branda, e o evento sentinela ocorrência mais grave. Entretanto são definições muito semelhantes e geram confusão. 


\section{Acidente}

James Reason, um autor de referência na área, utiliza o termo acidente em seus textos sobre o erro em saúde - assunto que será aprofundado no próximo capítulo, "O erro e as violações no cuidado de saúde". Com a publicação do ICPS, o termo foi substituído por incidente.

No campo da saúde e segurança do trabalho ou saúde ocupacional, ou ainda saúde do trabalhador, existem, há muitos anos, os conceitos de "acidente" e de "incidente". O conceito de incidente é mais restrito e não engloba as situações com dano. No caso de existir dano corporal, perturbação funcional ou doença, designa-se por acidente (de trabalho) (Faria, Uva 1988; Sousa-Uva, Graça 2004). A denominação de incidente pode também ser aplicada à existência apenas de danos materiais, e, por isso, alguns autores também o distinguem do quase-acidente. Por sua vez, o conceito de acontecimento (ou evento) adverso, muito usado em segurança do paciente, é generalista e engloba o incidente e o acidente, isto é, o incidente sem dano para o trabalhador, e o acidente com consequências negativas para o trabalhador.

\section{Considerações finais}

A divulgação da ICPS por meio do relatório de 2009 (WHO 2009) é o início da discussão sobre a taxonomia no domínio da segurança do paciente. Esse documento ressalta a importância que a classificação pode ter para a segurança do paciente, nomeadamente porque:

滕 Facilita a descrição, comparação, medição, monitoramento, análise e interpretação da informação para melhorar os cuidados ao paciente.

Pode ser utilizada para epidemiologia e para fins de planejamento de políticas elaboradas pelos profissionais de saúde, pesquisadores/ investigadores, responsáveis pelo desenvolvimento de sistemas de notificação para a segurança do paciente, legisladores e grupos de defesa do paciente ou consumidores.

膦 Desenvolve um enquadramento para instituir um currículo para a segurança do paciente, pelo estabelecimento de um conjunto de elementos essenciais que descrevem o conhecimento atual no âmbito da segurança do paciente.

Essa iniciativa da OMS/ICPS é um passo importante para que o tema segurança do paciente deixe de estar associado a uma Torre de Babel (Mendes 2012) e possa contribuir para maior consenso no âmbito das definições, dos conceitos e das terminologias utilizadas nessa área. 


\section{Referências}

Aspden P, Corrigan J, Wolcott J, Erickson S, editors. Patient Safety: achieving a new standard for care. Washington DC: National Academies of Sciences, Institute of Medicine, Committee on Data Standards for Patient Safety, Board on Health Care Services; 2004.

Australian Council for safety and Quality in Health Care. Safety in practice. Canberra: ACSQHC; 2001. p. 8.

Elder NC, Pallerla H, Regan S. What do family physicians consider an error? A comparison of definitions and physician perception. BMC Fam Pract 2006; 7:73.

Faria M., Uva AS. Diagnóstico e prevenção das doenças profissionais: algumas reflexões. J Cienc Med Lisb 1988; 9(10):360-371.

Joint Commission International. Padrões de acreditação da Joint Commission International para hospitais. Editado por Consórcio Brasileiro de Acreditação de Sistemas e Serviços de Saúde. Rio de Janeiro: CBA; 2010.

Leape LL, Brennan TA, Laird NM, Lawthers AG, Localio AR, Barnes BA et al. The nature of adverse events in hospitalized patients: results from the Harvard Medical Practice Study II. N Engl J Med. 1991; 324(6): 377-84.

Mendes W. Torre de Babel. Acreditação. 2012 [citado em 2014 jun. 14]; 2:1. Disponível em: https://www.researchgate.net/publication/236839872_Ttulo_de_Babel

Mendes W, Martins M, Rozenfeld S, Travassos C. The assessment of adverse events in hospitals in Brazil. Int J Qual Health Care. 2009;21(4):279-84.

Mendes W, Travassos C, Martins M, Noronha JC. Revisão dos estudos de avaliação da ocorrência de eventos adversos em hospitais. Rev Bras Epidemiol. 2005; 8(4): 393-406.

Runciman WB. Shared meanings: preferred terms and definitions for safety and quality concepts. Med J Aust. 2006; 184(10 Suppl):S41-S43.

Runciman WB, Hibbert P, Thomson R, Van Der Schaaf T, Sherman H, Lewall P. Towards an international classification for patient safety: key concepts and terms. Int J Qual Health Care. 2009;21(1):18-20.

Ruciman WB, Moller J. latrogenic injury in Australia. Adelaide: Australian Patient Safety Foundation; 2001. p. 9.

Rutstein DD, Berenberg W, Chalmers TC, Child CG 3rd, Fishman AP, Perrin EB . Measuring the quality of medical care: a clinical method. N Engl J Med. 1976 Mar 11; 294(11):582-8.

Rutstein DD, Mullan RJ, Frazier TM, Halperin WE, Melius JM, Sestito JP. Sentinel health events (occupational): a basis for physician recognition and public health surveillance. Am J Public Health. 1983 Sept.; 73(9):1054-62.

Sousa P, Uva AS, Serranheira F, Nunes C, Leite ES. Estimating the incidence of adverse events in Portuguese hospitals: a contribution to improving quality and patient safety. BMC Health Services Research. 2014;14:311. doi:10.1186/1472-6963-14-311.

Uva AS, Graça L. Saúde e segurança do trabalho: glossário. Lisboa: Sociedade Portuguesa de Medicina do Trabalho; 2004. (Caderno avulso, 4).

Wikimedia Commons. File:Pieter Bruegel d. Ä. 074.jpg. 2013 [citado 2014 jun. 14]. Disponível em: http://commons.wikimedia.org/wiki/File:Pieter_Bruegel_d._\%C3\%84._074.jpg 
World Health Organization, World Alliance for Patient Safety. The conceptual framework for the international classification for patient safety: final technical report.Version 1.1. [Genebra]: WHO, Jan. 2009.

\section{Nota de tradução}

Nesse capítulo, o autor utilizou estas fontes para as traduções para o português do The Conceptual Framework for the International Classification for Patient Safety:

1. Centro Colaborador para a Qualidade do Cuidado e a Segurança do Paciente (Proqualis), em 2010. Disponível em: http://proqualis.net/

2. A qualidade do cuidado e a segurança do paciente: histórico e conceitos do livro Assistência segura: uma reflexão teórica aplicada à prática da Agência Nacional de Vigilância Sanitária. cap. 2.

3. Assistência segura: uma reflexão teórica aplicada à prática. Disponível em: http://www.anvisa. gov.br/hotsite/segurancadopaciente/documentos/junho/Modulo\%201\%20-\%20Assistencia\%20 Segura.pdf

4. Divisão de Segurança do Doente, Departamento da Qualidade na Saúde, Direção-Geral da Saúde do Ministério de Saúde de Portugal, 2011. 


\section{O erro e as violações no cuidado de saúde}

Nádia Bomfim Nascimento

Neste capítulo, discutiremos a importância da identificação precoce das situações vulneráveis à ocorrência do erro. Para tal, apresentaremos referencial teórico que ajudará a compreender esse fenômeno. A distinção conceitual entre erro e violação tem sido considerada um caminho para entender os processos envolvidos na ocorrência do erro, já que a identificação e a compreensão dos atos de violação possibilitariam identificar de forma precoce situações vulneráveis à ocorrência do erro. A violação de normas prescritas é definida como a etapa inicial de um processo progressivo, que irá culminar em erro.

Como discutido no Capítulo 2,"A perspectiva histórica e principais desenvolvimentos da segurança do paciente", a área de segurança do paciente, uma dimensão importante da qualidade em saúde, tornou-se foco de relatórios e pesquisas desde a virada do século. Os incidentes que resultam em dano para o paciente, decorrentes do cuidado hospitalar, são, em mais da metade dos casos, ocasionados pela equipe de profissionais de saúde, em especial pelos médicos (Kohn, Corrigan, Donaldson 2000). Dentre os vários fatores indicados como fomentadores das condições de insegurança dos pacientes, registramos: o excesso de carga de trabalho dos profissionais de saúde, equipe de trabalho reduzida e material insuficiente ou inadequado para execução de procedimentos. Mas o silêncio que cerca a questão também é indicado como fator importante para a falta de elucidação sobre um tema tão complexo como a natureza do cuidado de saúde. 
Incidentes acarretados pela assistência à saúde dos pacientes dentro dos hospitais, ambulatórios e rede de atenção básica vêm sendo discutidos nas duas últimas décadas em todo o mundo. Paulatinamente, o silêncio que cerca essas questões é quebrado em prol da criação de estratégias que aumentem a segurança do paciente. O fato de os médicos serem uma fatia expressiva dos profissionais de saúde a ocasionar esses riscos faz com que se tornem objeto de observação e pesquisa, como nos apresenta o estudo realizado recentemente na Itália que aponta os seguintes resultados:

Os conhecimentos dos médicos sobre práticas de segurança do paciente baseadas em evidências foram inconsistentes. Mais de $90 \%$ disseram que a contagem de itens cirúrgicos durante um procedimento invasivo representava uma prática de segurança do paciente. As respostas revelaram atitudes positivas em relação à segurança do paciente; porém, 44,5 e $44,1 \%$, respectivamente, concordaram ou tiveram dúvidas sobre a ideia de informar a ocorrência de erros aos pacientes. No que diz respeito ao comportamento, 7,6\% dos médicos afirmaram nunca terem estado envolvidos em erros no cuidado de saúde; já em relação às falhas de sistema, o item classificado como o mais importante foi o "excesso de trabalho, estresse ou fadiga dos profissionais da saúde"(Flotta et al. 2012).

Para além da culpabilização desses profissionais, os resultados obtidos nesses estudos devem se reverter em ações educativas e reflexivas para todo o corpo de profissionais da área de saúde.

\section{Teorias para a compreensão do erro e dos atos de violação}

Algumas teorias sobre o erro foram propostas na tentativa de compreender e lidar com o fenômeno. James Reason, professor inglês de psicologia, por meio de seus estudos na área de psicologia cognitiva, procurou entender os mecanismos do comportamento humano na ocorrência do erro. Inicialmente, esses estudos foram direcionados a área de aviação e, depois, voltaram-se para as outras grandes indústrias das décadas de 1970 a 1990. Recentemente, foram orientados para a área de saúde. Seu trabalho mais conhecido é Human Error, livro editado em 1990. A proposta de Reason (2003), nessa obra, é apresentar uma teoria voltada à análise da questão ultrapassando a mera descrição de princípios gerais sobre a ocorrência e tipos de erros.

William Runciman, médico anestesista australiano e pesquisador/ investigador na área de segurança do paciente, e seus colaboradores basearam-se na teoria proposta por Reason (2003) para entender como esse processo que resulta em erro ocorre na área de saúde, com desta- 
que para a complexidade e a especificidade desse sistema. Por especificidade, eles apontam o fato de que os profissionais de saúde têm de lidar invariavelmente com grande diversidade de tarefas e meios para executá-las. A clientela atendida envolve pessoas vulneráveis e, por consequência, com maior risco de ocorrência de danos por conta da execução de atos inseguros. Por fim, a condição de que a maioria das ações executadas em áreas críticas de segurança é realizada por mãos humanas, o que ocasiona diminuir a padronização das atividades e em consequência incertezas. A partir daí, Runciman e seus colaboradores estabeleceram a necessidade de haver distinção entre erros e violações.

Christophe Dejours, médico psiquiatra francês, especialista em medicina do trabalho e ergonomista, voltou sua atenção para a dimensão dinâmica do trabalho e o microcosmo em que ele ocorre. Dejours utilizou achados dos estudos em ergonomia da segunda metade do século XX que possibilitaram a construção de conceitos centrais em sua teoria - trabalho real, trabalho prescrito. Iremos conhecê-los melhor mais à frente neste capítulo. O médico francês partiu do pressuposto de que o trabalho, em sua execução diária, está intrinsecamente ligado ao fracasso e, em razão da complexidade das organizações do trabalho, é necessário criar condições sociais e psicoafetivas favoráveis para que o indivíduo possa enfrentar e sobrepor as situações imprevistas. Dejours (2005) enfatiza, ainda, que a rapidez e a complexidade das transformações contemporâneas do trabalho tornaram ultrapassado o conhecimento científico armazenado e compartimentado em diferentes disciplinas.

Com o intuito de obter maior compreensão sobre o tema e com a perspectiva de intervenção na realidade laboral, a seguir, faremos, de forma sucinta, uma exposição do trabalho dos autores já mencionados, seguida de breve discussão.

\section{Errar é humano}

Os conceitos de fator humano e posteriormente erro humano foram muitíssimo utilizados por James Reason (2000, 2003, 2008). A proposta da teoria sobre o erro humano é apresentar uma análise profunda sobre o tema, no nível teórico, e a criação de instrumentos para manejo do ato inseguro, como aplicação prática dos seus achados. São objetivos funcionais desses estudos tornar o sistema robusto e praticável em face de situações que envolvam riscos humanos e operacionais e, como resultado, a ocorrência de erro humano. 
Reason (2003) definiu que o termo erro só pode ser aplicado às ações em que o indivíduo tem a intenção de realizar a tarefa a contento. Ele acrescenta que os tipos de erro dependem de duas espécies de falhas:

䟕 A primeira delas envolve falha na execução das ações que caminham de acordo com a intenção pretendida, são os lapsos (lapses) e os deslizes (slips).

A segunda diz respeito à falha no planejamento/planeamento das ações intencionais para alcançar os resultados desejados, são os enganos (mistakes).

Pelo fato de sua teoria estar intrinsecamente voltada para a prática, Reason propõe algumas definições operacionais.

O erro é um termo geral que abrange todas aquelas ocasiões em que uma sequência traçada de atividades mentais ou físicas falha em alcançar o resultado esperado e quando essas falhas não podem ser atribuídas à intervenção do acaso (Reason 2003).

A distinção entre ações que não ocorrem conforme a intenção pretendida daquelas em que há inadequação do planejamento/planeamento aponta para duas definições operacionais subsequentes. Os deslizes e lapsos são ambos determinados como

erros que resultam de alguma falha na execução e/ou no estágio de armazenagem de uma sequência de ação, independentemente se o plano que os guia é ou não adequado para alcançar o objetivo (Reason 2003).

O lapso é, em geral, relacionado a formas de erro mais encobertas, não observável por meio do comportamento, como o erro na dose de um medicamento, que rotineiramente é prescrito pelo mesmo profissional. O deslize está mais relacionado a ações observáveis e à habilidade na execução de um procedimento, por exemplo, a falha no ato de puncionar uma veia.

O engano tem como definição operacional: "Deficiência ou falha no processo de julgamento ou inferência envolvida na seleção de um objetivo, ou na especificação dos meios para alcançá-lo, independente das ações dirigidas ao esquema de decisão ocorrer ou não de acordo com o planejado" (Reason 2003). Podemos apontar como exemplo a execução de procedimentos em determinado tratamento incompatíveis ao protocolo adequado à patologia em questão. 


\section{Para refletir}

Deslizes e enganos são comuns em qualquer prática laboral. Você lembra-se de tê-los cometidos? Como foi? O que sentiu? O que poderia tê-los evitado?

As definições operacionais assinaladas são as bases para identificar e delinear as diversas categorias de erros: classificação, tipos e formas. Os erros se apresentam com forma e mecanismos semelhantes ao longo de amplo espectro de atividades mentais. Assim, é possível identificar formas comparáveis de erros nas mais diversas atividades, tais como a fala, a percepção, as ações, julgamento, solução de problemas e similares.

Os mecanismos básicos e os processos que geram recorrentes formas de variada gama ou tipos de erros são descritos sob a forma do sistema de modelos gerais de erros. No Quadro 1, podemos ver a delimitação das origens dos tipos básicos de erro humano e a apresentação de um modelo integrado e dinâmico dos mecanismos operativos do erro e, ainda, de maneira específica, a busca de integração de duas áreas aparentemente distintas: deslizes e lapsos; e enganos. O modelo permite a identificação de três mecanismos básicos de erro:

1. deslize e lapso com base na habilidade;

2. engano com base nas normas;

3. engano com base no conhecimento.

Nesse modelo, vemos três níveis de execução das tarefas. A primeira é baseada na habilidade, a segunda está inserida dentro das normas estabelecidas, e a última, em nível de maior complexidade, envolve o conhecimento acumulado. 
Quadro 1 - Dinâmica do Sistema de Modelos Gerais de Erros (Gems)

\section{Nível baseado na habilidade}

Deslizes e lapsos

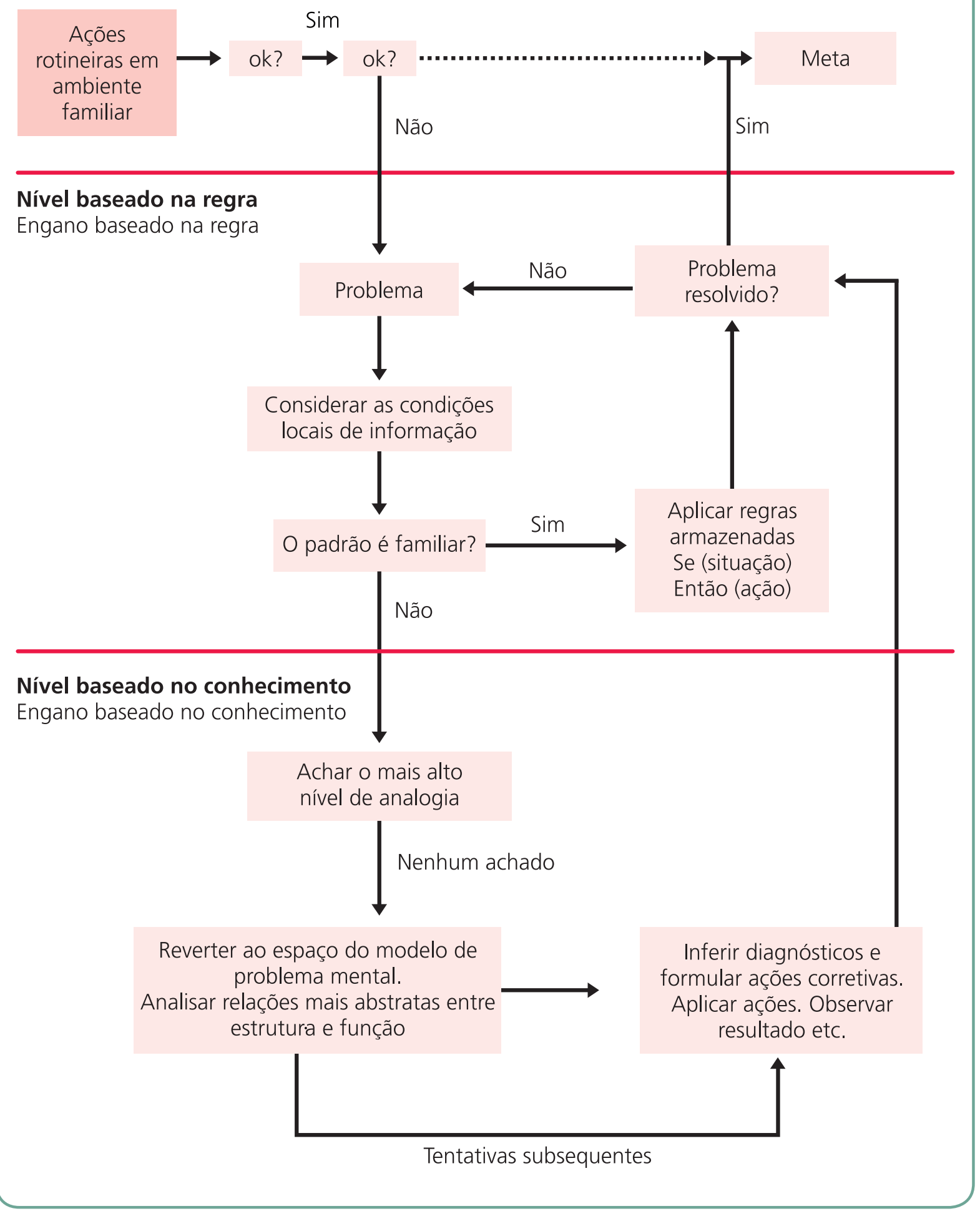

Fonte: Reason (2003, p. 64). 
Os erros ocorridos nessas etapas dizem respeito, em sua ordem de progressão, a falhas de monitoramento de uma ação rotineira ou contínua por causa de desatenção ou excessiva concentração, que podem ser denominadas falha no modo de controle. Veja bem: não se trata de um caso de atenção e desatenção, e sim da forma como se realiza uma ação rotineira. Ela pode ser executada de modo displicente ou ater-se somente à execução mecânica da ação sem perceber outras variáveis, que podem ocorrer paralelamente e fazer com que essa ação seja modificada.

Na etapa seguinte - engano baseado na regra -, a falha está associada à resolução de problemas, tendo em vista ser necessário revisar ações correntes que têm por base normas ou conhecimentos relativos à sua execução. Erros nesse nível envolvem tanto a má aplicação de boas normas como a aplicação de más normas.

Os erros no nível baseado em conhecimento têm raízes em dois aspectos da cognição humana. O primeiro deles está relacionado ao processo de raciocínio lento, sequencial e laborioso e com recursos limitados frente ao problema apresentado - racionalidade limitada. O segundo reside no fato de que o conhecimento disponível é insuficiente, até aquele momento, em face da resolução do problema.

Para avançarmos, nesse nível, é necessário saber com que tipo de configuração de problema estamos lidando. Segundo Reason, há três tipos de configurações: estática, dinâmica reativa e dinâmica-múltipla. Elas envolvem um grau crescente de complexidade e caminham no sentido da menor para maior plasticidade em função das ações utilizadas e as respectivas reações do sistema diante dessas ações. Podemos usar os exemplos a seguir para caracterizar cada uma das configurações apontadas:

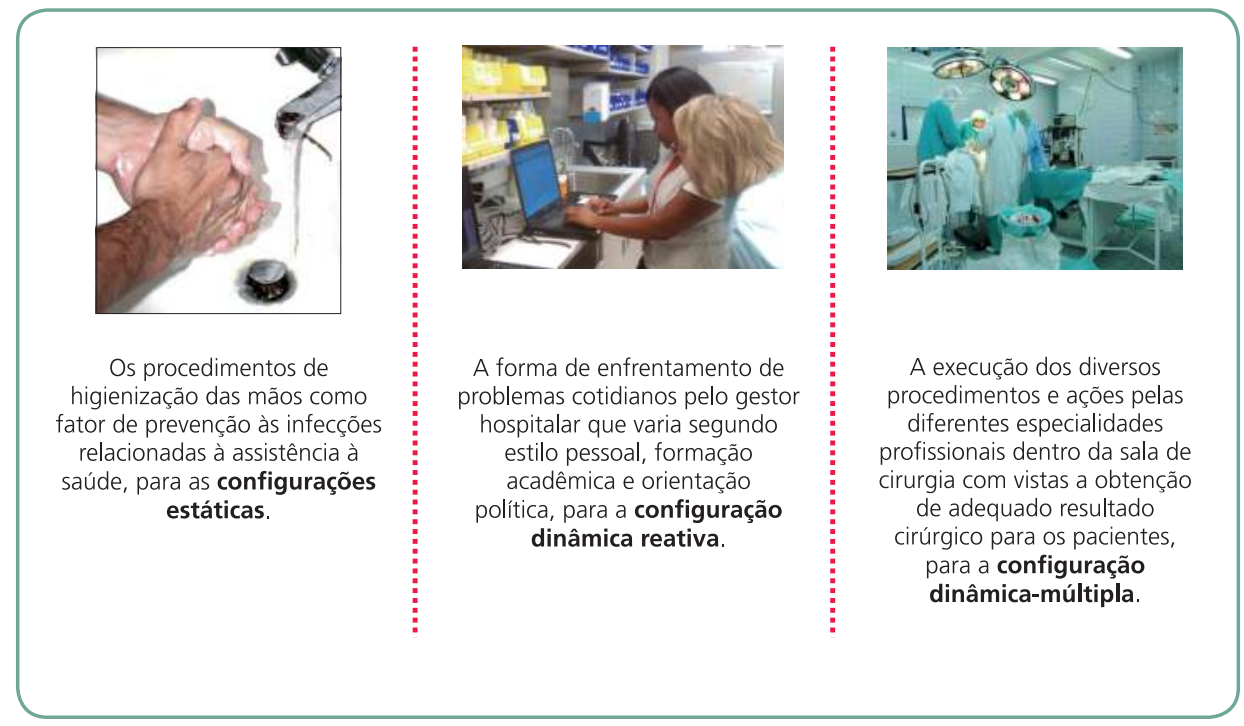

Fonte: Wikipedia $(2005,2008, \ldots)$
Boas normas são aquelas com comprovada utilidade em uma situação particular, todavia podem ser aplicadas de forma inadequada em situações que possuem não só características comuns, mas também elementos ou circunstâncias que demandam outro tipo de ação.

Más normas ou normas fortes, porém erradas, referem-se à ação errada, que se trata de mais uma conservação de práticas passadas do que a demanda da circunstância corrente, e a força é determinada pela relativa frequência de execução bem-sucedida de referida ação. 
Quando os erros não são corrigidos, por repetição e/ou revisão, dentro do nível em que ele ocorre, é necessário buscar recursos no nível seguinte para reordenar todo o processo de execução da tarefa. Reason (2003) menciona que a passagem do nível baseado nas normas para o nível baseado no conhecimento possui fatores determinantes menos distintos, e os fatores emocionais provavelmente desempenham aspecto importante.

\section{Para refletir}

Você já percebeu influências de fatores emocionais durante o desempenho de sua atividade profissional?

James Reason, por ter genuína preocupação com a aplicação prática da teoria e conceitos por ele formulados, sustenta que há, ainda, um vasto campo para argumentação e aprofundamento sobre o tema. Em sua face prática, o autor propõe duas formas de abordagem do erro: a individual e a sistêmica.

A primeira - abordagem individual - se detém em atos inseguros dos indivíduos que trabalham na ponta do sistema, ou seja, nos erros e violações de procedimentos adotados por pilotos de avião, controladores de voo, médicos, enfermeiras, cirurgiões e outros a partir de um processo mental fora do padrão desejável para a tarefa, tais como: esquecimento, desatenção, descuido, pouca motivação, negligência e imprudência.

A abordagem sistêmica tem como premissa básica a falibilidade dos seres humanos e, portanto, erros são esperados mesmo nas organizações de excelência. Essa abordagem não enfatiza a perversidade humana, nem a culpabilização e a responsabilização do indivíduo como única causa do erro. Aspectos morais também são colocados em segundo plano. Reason (2003) assume a premissa de que não se pode mudar a natureza humana, mas é possível mudar as condições em que os indivíduos trabalham. Os sistemas de defesa são o eixo dessa abordagem. Na ocorrência do erro, a questão importante é identificar como e porque as defesas falharam. 


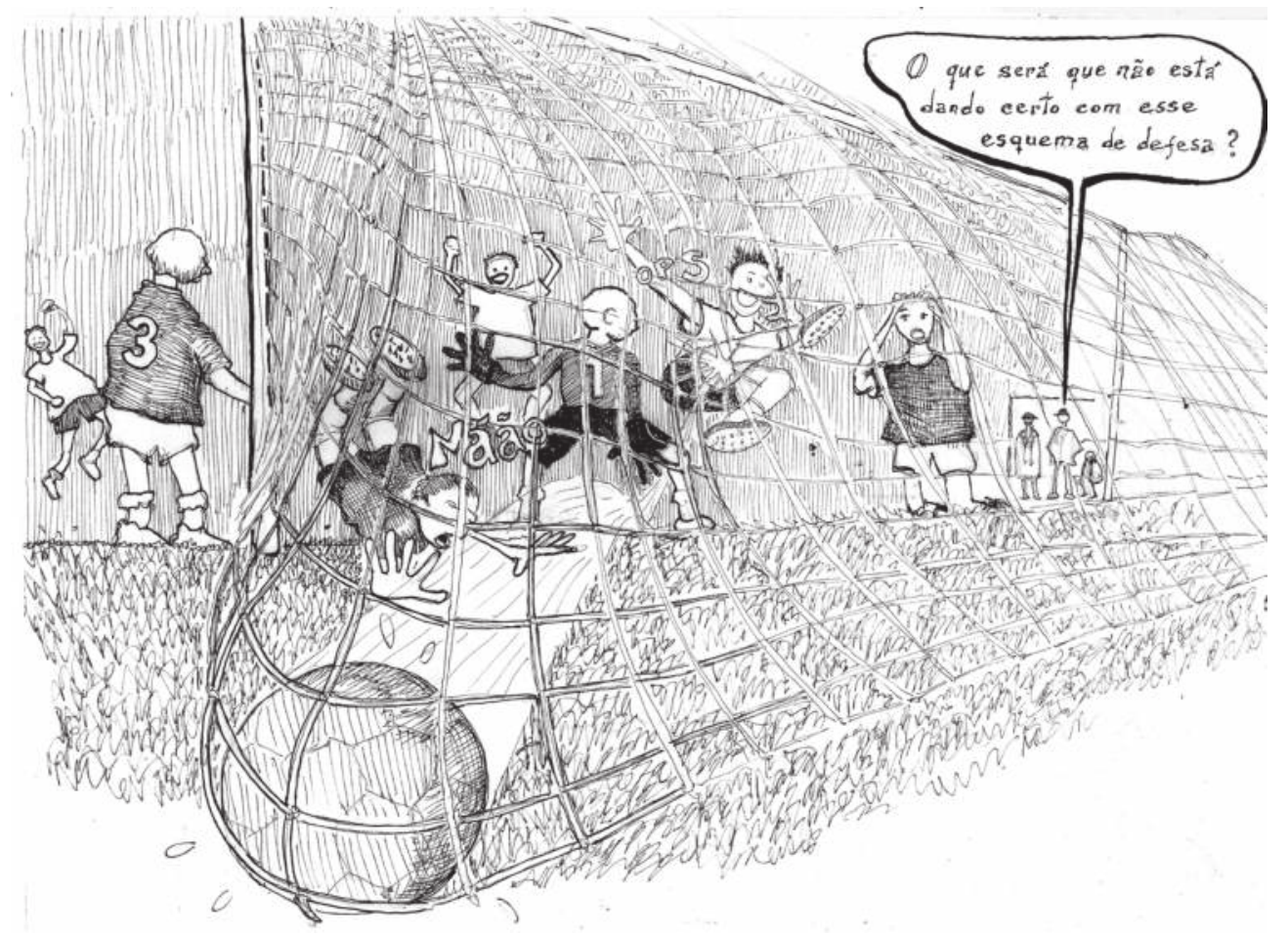

A falha latente - ato ou ação evitável existente dentro do sistema e que surge a partir de decisões feitas por analistas, gerentes e o alto nível gerencial - e a falha ativa - ato inseguro cometido por uma pessoa que está em contato direto com o sistema e pode assumir variadas formas - são conceitos utilizados para justificar a forma de manejo defendida pelo autor, a abordagem sistêmica.

Reason (2000) propõe o Modelo do Queijo Suíço no sistema de acidentes - também chamado modelo epidemiológico -, apresentado na Figura 1, que se adéqua especialmente aos sistemas de alta tecnologia por terem várias barreiras ou camadas defensivas. Algumas são construídas como alarmes, umas são focadas nos indivíduos que trabalham nas ações finalistas ou de ponta (cirurgiões, pilotos etc.), e outras dependem de procedimentos e dos controles gerenciais. Sua função é proteger.

Figura 1 - Modelo de queijo suíço com defesas e barreiras que podem ser penetradas pela trajetória de um acidente.

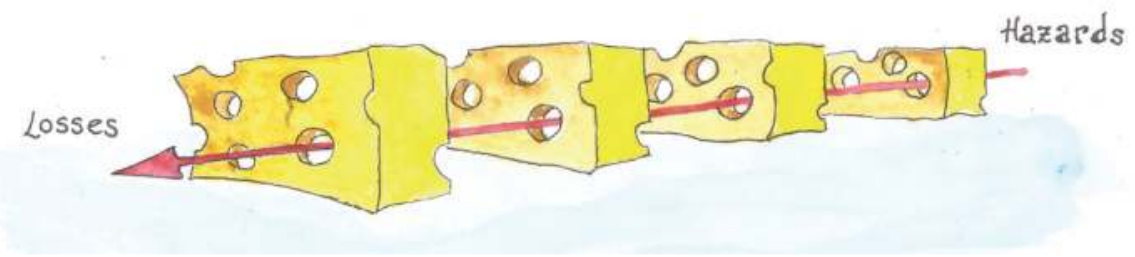


Na prática, as barreiras defensivas são como fatias de queijo suíço, pois apresentam muitos furos. Somente quando os furos, nas várias camadas defensivas, estão momentaneamente dispostos em uma mesma linha, permite-se que a trajetória do acidente venha a ocorrer.

Os "furos" nas camadas de defesa sucedem em função de falhas ativas e de falhas ou condições latentes. Diferenciar falhas ativas e latentes permite a distinção da contribuição humana na ocorrência dos acidentes. As falhas latentes, inevitáveis dentro do sistema, são geradas por decisões tomadas pelos responsáveis pelo desenho de seu funcionamento. Esse fato possibilita a ocorrência de dois tipos de efeitos diversos:

* aqueles que podem provocar erro no ambiente de trabalho como: equipamento inadequado, fadiga e inexperiência do profissional que cuida; e

aqueles que podem criar fragilidades e lacunas no sistema e se mantêm por longos períodos, tais como: alarmes e indicadores que não são fidedignos, desenho e construção de processos de trabalho deficientes etc.

Condições latentes podem permanecer imperceptíveis por anos a fio até que se combine com uma falha ativa no sistema, de modo a criar uma oportunidade de acidente. Nesse caso, são acidentes de grande monta, como acidentes aéreos, vazamentos em usinas nucleares etc. Diferentemente da falha ativa, as falhas ou condições latentes podem ser remediadas e/ou identificadas antes que o acidente ocorra. Ao advogar pela abordagem sistêmica como forma de prevenir o erro, Reason propõe ações pautadas em distintos objetos: no indivíduo, na equipe, na tarefa, no local de trabalho e na organização em sua totalidade. A criação e manutenção de um sistema resiliente é o principal objetivo.

\section{Você sabia?}

Em setembro de 2006, ocorreu, no Brasil, um acidente aéreo entre um avião de empresa comercial e um jato de pequeno porte em que desapareceram 145 passageiros. Os grandes acidentes, como esse, que acarretam significativo número de óbitos, na maioria das vezes são atribuídos a uma sequência de erros advindos de diversas fontes e/ou áreas de atuação. Essa questão aponta para a configuração dinâmica-múltipla de um problema ou ação em que há alto grau de complexidade na realização da tarefa, bem como a necessidade de mecanismos sofisticados ou camadas defensivas bem elaboradas que possam restringir a um número menor possível a ocorrência de acidentes. 


\section{Violação de procedimentos}

William Runciman e colaboradores (2007), ao focar os cuidados de saúde, propõem uma extensão do sistema de modelos gerais de erros, descrito por James Reason (2003), para ampliar operacionalmente a capacidade de planejamento/planeamento e execução de estratégias corretivas a fim de lidar com o erro. Runciman e seus colaboradores (2007) ampliam e sistematizam os três tipos de erros descritos por Reason. Além desses, são propostos os tipos de erro por informação, por aquisição de conhecimento, de percepção, de combinação, de armazenamento do conhecimento como esquema, entre outros.

Os conceitos de erro e violação e suas respectivas aplicações possuem definições que são distintas dentro dos sistemas classificatórios propostos por Reason (2003) e Runciman e colaboradores (2007). As violações, para Runciman e colaboradores, diferem de erros pelo fato de os primeiros envolverem um elemento de escolha e em geral implicarem ações que fogem ao prescrito nas normas, ações essas que reconhecidamente incorrem em risco. Também ressalta que a violação não se aplica a situações em que haja intenção de dano. Reason, por sua vez, apresenta duas definições, para erro e violação, diferentes que podem ser conjugadas.

A primeira delas afirma que "violação é um desvio deliberado, mas não necessariamente repreensível, de procedimentos operacionais seguros, padrões ou normas".

A segunda definição, com a qual Runciman e colaboradores (2007) se contrapõem de forma mais clara, afirma que "o limite entre erro e violação não é tão rigoroso e palpável nem em termos conceituais nem dentro da sequência de ocorrência de um acidente em particular".

A diferença entre as definições estabelecidas pelos dois autores ocorre em pontos sutis. Para Runciman, as violações são atos repreensíveis, com clara intenção. Reason suaviza essa questão e, por isso, acredita não haver uma delimitação nítida e palpável entre os dois.

William Runciman, ao fazer a distinção entre violação e erro, propõe uma classificação específica, na qual destacamos o tipo violação de rotinas. Ele ocorre na execução das atividades diárias na maioria dos ambientes de trabalho, com o objetivo de "aparar as arestas" para se levar a cabo determinada tarefa proposta.

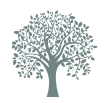

Caso queira aprofundar seus conhecimentos sobre os diversos tipos de erro, procure, nas referências, pelo texto de Runciman, Merry e Walton (2007). 
Runciman argumenta em favor da distinção entre esses dois tipos de comportamento, violação e erro, uma vez que a ocorrência diária da violação também a diferencia do erro, já que tanto para ele como para James Reason, esse último só ocorre excepcionalmente. Ele acrescenta que:

a existência de escolha em violações rotineiras pode existir apenas nas primeiras vezes em que a violação é cometida. Apesar disso, é geralmente possível mudar o comportamento com relação à violação através de uma decisão de parar de violar. No caso do erro, a decisão por si só não é capaz de prevenir a sua recorrência (Runciman et al. 2007).

\section{Para refletir}

Responda com base na observação em sua prática diária: as violações ocorrem com frequência?

- Se a resposta for afirmativa, a quais fatores você credita essa frequência?

- No caso de resposta negativa, que tipo de medidas você acredita impedirem sua ocorrência?

A análise do processo de ocorrência do erro dentro do sistema cognitivo, como também a análise da ocorrência de acidentes nos mais diversos ambientes de trabalho contribuem de forma significativa para a prevenção e o desenho de medidas voltadas à melhoria da segurança, com a consequente diminuição dos riscos. O conhecimento dessa matéria é de vital importância para a área da saúde no que diz respeito à formulação de novas estratégias para o aperfeiçoamento das várias camadas defensivas do complexo processo de cuidado do paciente dentro do sistema hospitalar. Entretanto, parece-nos que as barreiras ou camadas defensivas - mecanismos essenciais introduzidos pelo modelo epidemiológico apresentado por Reason - somadas às contribuições trazidas por Runciman, relativas à questão da violação, não parecem apresentar todas as respostas. Por exemplo, como explicar problemas envolvendo as múltiplas correlações existentes entre o ambiente em que o trabalho se realiza, a tarefa a ser executada e seus executores?

O modelo explicativo de ocorrência do erro e da violação trazidos por Reason $(2003,2008)$ e Runciman e colaboradores (2007) trabalha na lógica de decomposição das atividades de trabalho executadas para sua melhor compreensão. Esse modelo propõe como prevenção à ocorrência de erro o enfraquecimento das barreiras ou falhas latentes inerentes ao sistema por meio da criação de camadas defensivas complexas, mas 
lineares na tentativa de responder à questão relativa aos fatores que estariam envolvidos na escolha inicial, que levaria ao afastamento da execução de uma tarefa conforme a prescrição das normas, sua dinâmica de ocorrência e manutenção da escolha.

Explicaremos as contribuições teóricas aportadas por Christophe Dejours $(1999,2005,2007)$, que propõe um modelo sistêmico de compreensão das ações e tarefas executadas pelo indivíduo para realizar suas atividades profissionais dentro do contexto de trabalho e consideram essas múltiplas inserções envolvidas, cuja compreensão ocorre no microcosmo em que o trabalho é realizado.

\section{O erro como fator inerente à execução da tarefa}

Os conceitos centrais da teoria de Dejours são o trabalho real e o trabalho prescrito, os quais se contrastam e se opõe. O trabalho real "é aquilo que no mundo se faz conhecer por sua resistência ao domínio técnico e ao conhecimento científico" (Dejours 2005).

O trabalho real é tudo aquilo que, durante a realização da tarefa, não pode ser obtido pela observação rigorosa das leis, normas e regras técnicas existentes para sua execução, isto é, o trabalho prescrito. O que é real no trabalho está intrinsecamente ligado ao fracasso, visto que a organização do trabalho apresenta inúmeras contradições e não é completamente absorvida por aqueles que a executam. A execução de tarefas torna-se, então, um enigma a decifrar, já que o trabalho prescrito nunca é suficiente.

Esses dois conceitos centrais se desdobram em outros para que seja possível compreender a dinâmica existente no triângulo tecnológico do trabalho (Figura 2). A técnica passa a ser um ato que incide sobre o real e tem, em sua origem, os traços da cultura em que ela é desenvolvida, sendo sancionada a partir do julgamento daqueles envolvidos, o outro, que, ao mesmo tempo, produz cultura para dar respostas às exigências de uma sociedade historicamente datada. O trabalho (real) é uma atividade julgada e reconhecida pelo outro não somente por sua eficácia técnica, mas também por sua utilidade social e econômica, em que "os limites do saber, do conhecimento e da concepção, [...] se chocam com os atos técnicos e as atividades de trabalho" (Dejours 2005). E ainda mais: "todo trabalho é sempre trabalho de concepção. A definição de trabalho corrente insiste na dimensão humana do trabalho. O trabalho é, por definição, humano, uma vez que é mobilizado justamente ali
Esse tema será desenvolvido mais detalhadamente no Capítulo 6, "Saúde do trabalhador, ergonomia e segurança do paciente", do livro Segurança do paciente: conhecendo os riscos nas organizações de saúde. 
onde a ordem tecnológica-maquinal é insuficiente" (Dejours 2005). As interações entre o sujeito - o ego - e o outro estão submetidas a uma exigência suplementar, a coordenação das atividades no trabalho.

Analisaremos o triângulo tecnológico do trabalho criado por Dejours (2007), apresentado na Figura 2 e cujos vértices são o real, o ego e o outro. Esse modelo nos fala das interações entre o sujeito que trabalha e aqueles que compartilham do mesmo contexto de trabalho - o ego e o outro.

Figura 2 - Triângulo tecnológico do trabalho

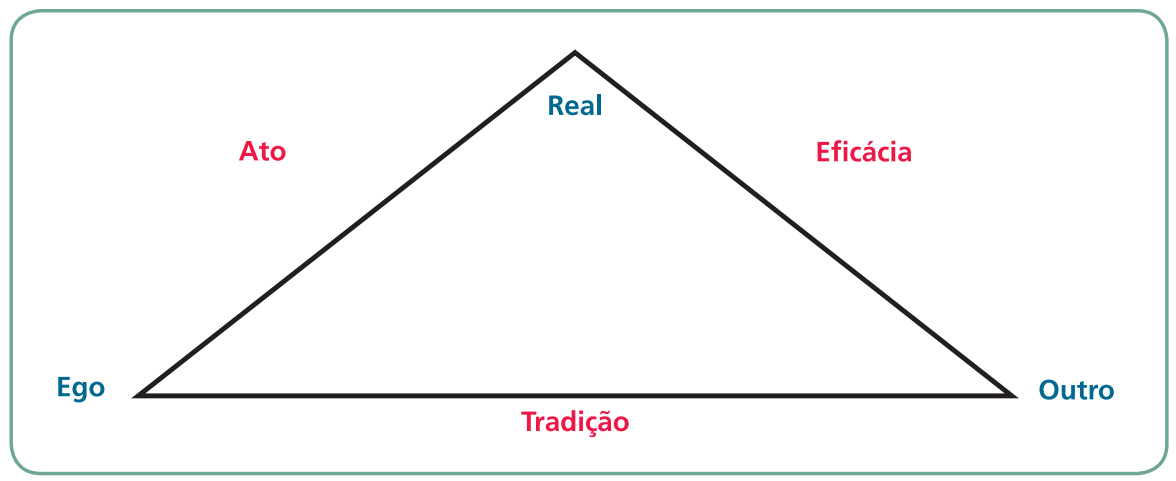

Fonte: Dejours (2007, p. 37).

A tradição, nesse contexto, constitui-se em uma condição sobre a possibilidade de coordenação, que incorpora o cognitivo-instrumental, as relações e interações no registro da compreensão e do sentido e as relações sociais de trabalho. O triângulo tecnológico é atravessado pelo ato na relação entre o ego e o real, pela tradição na relação entre o ego e o outro e pela eficácia na relação entre o real e o outro.

O ato se propõe a uma mudança no mundo real. Para ser considerado técnico, o ato necessita da homologação de um grupo de sujeitos capacitados para julgar se há sua continuidade ou ruptura em relação à tradição, forma de sedimentação das rotinas praticadas até então. O ato técnico, após ser considerado como tal e passar a fazer parte da tradição, contribui para que a própria tradição se torne renovada. A eficácia, nesse sentido, é a capacidade que o ato técnico tem de transformar o mundo real. A eficácia não existe em si, ela passa por um julgamento, que tem por fundamento ser uma atribuição do outro ao qual o ego está ligado pela tradição. A complexidade desse processo faz-nos entrever que é impossível prever tudo e ter o domínio sobre tudo de forma antecipada no trabalho; portanto, a falha humana frente à tarefa, no trabalho real, é inevitável. 
Para Christophe Dejours (2007), a tradição tem papel capital na realização do ato técnico dentro do que por ele foi denominado triângulo tecnológico do trabalho. Assim, o autor atribui à tradição ou ato tradicional uma forma de sedimentação das rotinas práticas. O ato técnico, mesmo novo, deve tornar-se tradicional e contribuir assim com a evolução de toda tradição, para uma tradição renovada. Mas, aquém mesmo do reconhecimento ou da homologação do ato como ato técnico, é impossível produzir um ato regulado do corpo em um agir instrumental novo que não seja ele próprio um broto mutante da tradição (...) a dimensão tradicional é a parte propriamente intersubjetiva, social ou cultural da construção de uma conduta técnica. Portanto, a técnica é não somente uma técnica do corpo, mas também uma técnica cultural (Dejours 2007, p. 36).

A tradição, portanto, é a construção histórica de uma corporação profissional e traz em si o percurso de determinado grupo e suas crenças quanto a melhor forma de atuar para fazer parte dessa corporação. Como captar e perceber os aspectos dessa tradição que não se adéquam ao trabalho real, que exige cada vez mais ações inovadoras?

\section{Para refletir}

Você seria capaz de identificar qual é a tradição presente em seu ambiente de trabalho? Ela tem influência sobre o ato (técnico) realizado? Em caso positivo: quais são as influências?
A distância entre a organização do trabalho prescrito e o trabalho real é dinâmica; ora oferece margens para a liberdade criadora, ora é restritiva e faz com que os sujeitos envolvidos na execução da tarefa temam ser surpreendidos cometendo erros. E esses dois processos podem ocorrer de forma concomitante. O espaço de manobra entre eles possibilita, por meio da inteligência astuciosa, ao profissional lidar com os reveses do real de forma criativa e transformá-los, incluindo-os no repertório das ações prescritas. Processo que pode se realizar infinitamente.

A inteligência astuciosa ou inteligência prática, que é a disponibilidade de iniciativa, criatividade e de formas de inteligência específicas capazes de ajustar a tarefa real à organização prescrita do trabalho, possui paradoxos em razão de comportar dois lados. A astúcia em relação ao real pode introduzir tricherie, que implica digressão à norma e à tradição, como também pode criar espaço privativo para a realização das ações que ficam ao abrigo do controle e da segurança, no segredo. $\mathrm{O}$ segredo e o tricherie trazem riscos à coordenação das atividades e
Tricherie significa quebrar galho, improvisar, desenrascar. 
dos profissionais. Por esse motivo, as engenhosidades e inovações, para não se incorrer no risco de provocarem incoerências e incompreensões, devem ser coordenadas, uma vez que destruiriam as potenciais vantagens da inteligência prática, tendo em vista a qualidade e a segurança do trabalho.

Sigamos na análise de outro processo indicado por Christophe Dejours (2004), o triângulo dinâmico do trabalho, apresentado na Figura 3.

Figura 3 - Triângulo dinâmico do trabalho

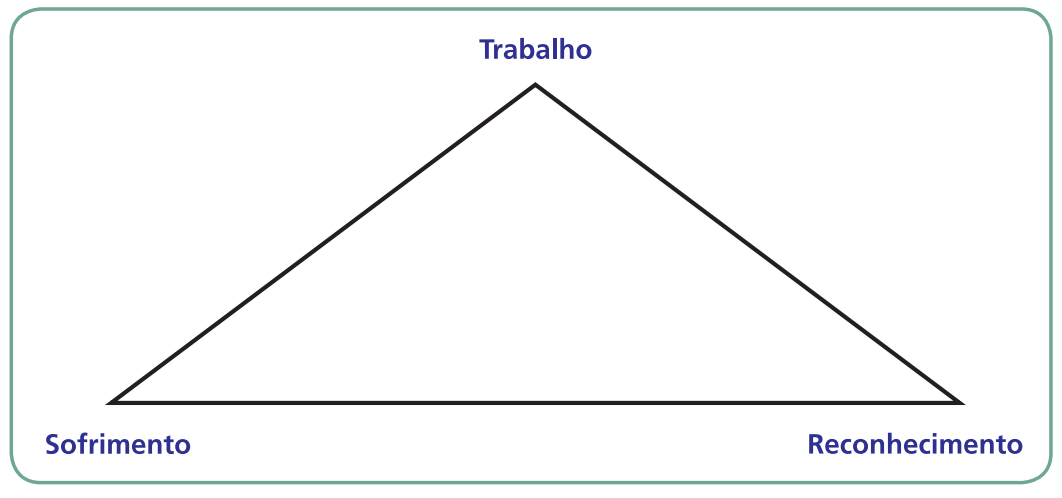

Fonte: Lancman e Sznelwar (2004, p.74)

Visibilidade é a condição de passagem do estatuto subjetivo de engenhosidade à objetivação dos achados, enquanto confiança é a promessa de equidade nos julgamentos proferidos pelo outro sobre a conduta do ego. Eles se tornam requisito e, também, condição precípua à coordenação das atividades e cooperação nas tarefas. Ambos têm papel determinante no processo (do triângulo) dinâmico do trabalho indicado por Dejours (2004). Nesse processo, ocorrem as dinâmicas e inter-relações entre o trabalho, o sofrimento e o reconhecimento inerentes à execução da tarefa no real (do trabalho).

O reconhecimento é uma forma específica da retribuição moral-simbólica dada ao ego, como modo de engajamento de sua subjetividade e inteligência. Para que a cooperação ocorra, é necessário colocar os achados técnicos à prova de discussão, das vantagens e inconvenientes de sua adoção e, posteriormente, estabilizá-los ou integrá-los à tradição da empresa ou do ofício. A psicodinâmica do reconhecimento tem papel fundamental no destino do sofrimento no trabalho, advindo das dificuldades práticas encontradas face ao real, e na possibilidade de transformar sofrimento em prazer. 
O triângulo da psicodinâmica do trabalho nos aponta que o acesso ao reconhecimento é feito pela via do sofrimento no trabalho, que, por sua vez, é proveniente de toda a situação laboral em que o ego se encontra diante de vários constrangimentos. A construção de sentido no ato da execução da tarefa pode transformar sofrimento em prazer. A subjetividade, então, é substituída pela identidade singular na esfera do trabalho, que possibilita enfrentar os ataques direcionados à saúde mental. A conquista da identidade está especialmente relacionada à prática no campo das relações sociais, que, por sua vez, favorece a construção da identidade em outros campos da vida subjetiva. Fechando o triângulo dinâmico, a conquista da identidade no campo social, mediada pela atividade do trabalho, passa pela dinâmica do reconhecimento, que, por sua vez, gera a mobilização da racionalidade subjetiva frente ao sofrimento.

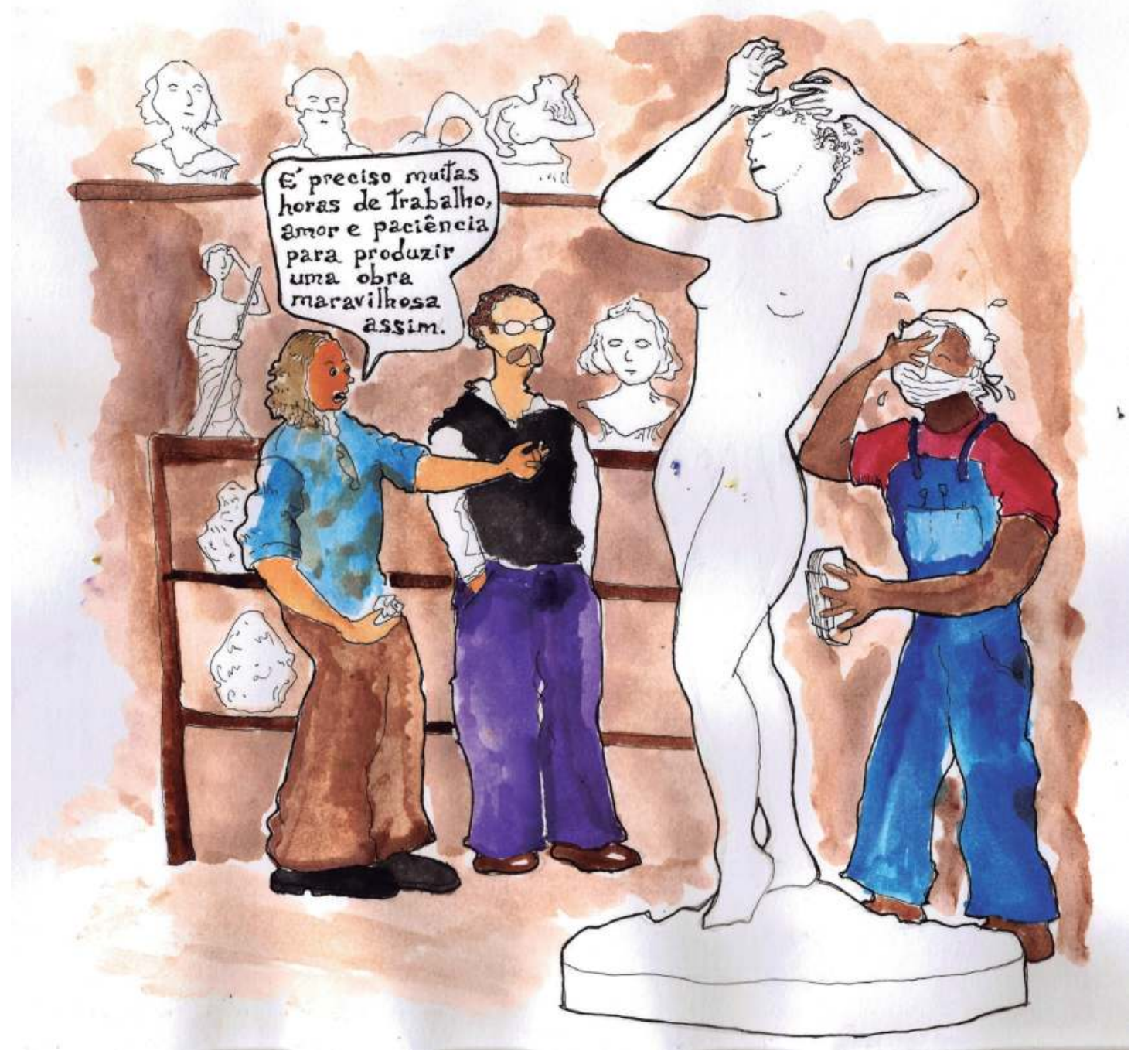


Mas, na realidade, o reconhecimento é com pouca frequência satisfatório. Espera-se, então, que o sofrimento no trabalho gere uma série de manifestações psicopatológicas, e, para não produzir descompensações psicopatológicas, os sujeitos empregam defesas que lhe permitem controlá-lo. Além das estratégias de defesa individuais descritas pela psicanálise, existem as coletivas (Dejours 1999, 2007). As defesas coletivas dos trabalhadores são de forma peculiar marcadas pelas pressões reais do trabalho relacionadas às especificidades de cada contexto profissional, e o funcionamento dessas estratégias mostra que elas podem igualmente contribuir para tornar aceitável aquilo que não deveria sê-lo.

\section{Para refletir}

Você reconhece, em seu dia a dia, que tipos de defesa criou para lidar com suas insatisfações frente às frustrações? De que maneira elas impactam na qualidade do seu trabalho?

Necessárias à proteção da saúde mental contra os efeitos deletérios do sofrimento, “as estratégias defensivas também podem funcionar como armadilha que insensibiliza contra aquilo que faz sofrer. Permite, às vezes, tornar tolerável o sofrimento ético, aquele que pode experimentar ao cometer, por causa do seu trabalho, atos que condena moralmente" (Dejour 2007).

\section{Questões da teoria na prática}

Os modelos explicativos para a compreensão do erro e da violação, já mencionados, trazem inúmeras contribuições teóricas passíveis de aplicação direta à prática. As contribuições de Reason (2000) relativas ao Modelo do Queijo Suíço no sistema de acidentes já são amplamente difundidas e também utilizadas em algumas instituições por serem voltadas para a prevenção e o desenho de medidas direcionadas à segurança e à diminuição de riscos. Essa implementação das ideias de Reason propicia, na área de saúde, a criação de estratégias nas várias camadas defensivas, no complexo processo de cuidado ao paciente que se encontra em tratamento dentro do sistema hospitalar.

As contribuições de Runciman e colaboradores (2007) são menos conhecidas, mas nos aproximam dos problemas relacionados à adesão a procedimentos padronizados dentro da área de saúde por sua comprovada efetividade. A detecção do elemento de escolha com relação às ações a serem realizadas pelos indivíduos, no que diz respeito ao 
desvio ou fuga às normas prescritas, possibilita criar instrumentos para observação e análise dos processos em curso.

Aparar arestas, indicado por Runciman (2007), e tricherie, trazido por Dejours (Lancman, Sznelwar 2004), contribuem de forma significativa no cotidiano laboral para o aumento da ocorrência de violações. Essas ações também põem em risco a execução das tarefas por provocar incoerências e incompreensões. Mas, se utilizadas de forma visível e compartilhada frente às dificuldades e impasses do cotidiano, podem gerar saídas criativas e trazer soluções aos impasses. Ao trazer soluções, abrem um novo caminho ao indivíduo e seu coletivo para lidar de forma criativa com os reveses do real do trabalho e diminuir o sofrimento que ele gera.

Alertamos para a contribuição teórica, trazida por Dejours (Lancman, Sznelwar 2004), no que diz respeito aos mecanismos de defesa coletivos e a possibilidade de compreender a passividade e o alheamento dos profissionais de saúde em relação às evidências que se referem aos procedimentos preconizados na área de saúde. O papel paradoxal desses mecanismos na dinâmica do contexto laboral, uma vez que protegem os profissionais de saúde dos efeitos deletérios do sofrimento, mas podem também insensibilizá-los contra aquilo que faz sofrer, poderá propiciar a identificação dos fatores que se encontram em jogo e incidem diretamente sobre a segurança do paciente.

\section{Referências}

Dejours C. A banalização da injustiça social. 7ª ed. Rio de Janeiro: FGV; 2007.

Dejours C. Conferências brasileiras: identidade, reconhecimento e transgressão no trabalho. São Paulo: Fundap: EAESP/FGV; 1999.

Dejours C. O fator humano. 5a ed. Rio de Janeiro: FGV; 2005.

Flotta D, Rizza P, Bianco A, Pileggi C, Pavia M. Patient safety and medical errors: knowledge, attitudes and behavior among Italian hospital physicians. Int J Qual Health Care. 2012; 24(3): 258-65.

Kohn LT, Corrigan JM, Donaldson MS. To err is human: building a safer health system: a report of the Committee on Quality of Health Care in America, Institute of Medicine. Washington, DC: National Academy Press; 2000.

Lancman S, Sznelwar LI, organizadores. Christophe Dejours: da psicopatologia do trabalho à psicodinâmica do trabalho. Rio de Janeiro: Fiocruz; Brasília: Paralelo 15; 2004.

Reason J. The human contribution: unsafe acts, accidents and heroic recoveries. Ashgate, 2008.

Reason J. Human error. London: Cambridge University Press; 2003.

Reason J. Human error: models and management. Brit Med J. 2000; 320:768-70. 
Runciman B, Merry A, Walton M. Safety and ethics in healthcare: a guide to getting it right. London: British Library; 2007. p. 109-34.

Wikipedia. File:OCD handwash.jpg. 2008 [citado 2014 jul 14]. Disponível em: http://en.wikipedia. org/wiki/File:OCD_handwash.jpg.

Wikipedia. File:Operating theatre.jpg. 2005 [citado 2014 jul 14]. Disponível em: http://en.wikipedia. org/wiki/File:Operating_theatre.jpg.

World Health Organization, World Alliance for Patient Safety. The conceptual framework for the international classification for patient safety: final technical report. Version 1.1. [Genebra]: WHO, Jan. 2009. 


\section{Magnitude do problema e os factores contribuintes do erro e dos eventos adversos}

Paulo Sousa, Maria João Lage e Vanessa Rodrigues

Este capítulo aborda a importância em avaliar a frequência e tipologia dos eventos adversos (EAs); a caracterização dos principais factores que contribuem para a ocorrência de erros e de EAs; e os principais aspetos a serem considerados na implementação de um sistema de notificação de incidentes, bem como dos objetivos e características que lhes devem estar subjacentes.

Assim, as perguntas de partida para este capítulo são:

蹸 Qual a importância em se conhecer a frequência e tipologia dos EAs decorrentes da prestação de cuidados de saúde?

Quais os principais métodos existentes e as vantagens e limitações mais importantes de cada um?

滕 Quais os principais factores que contribuem para a ocorrência de erros e de EAs?

煞 Qual a importância de um sistema de notificação de incidentes para uma cultura de aprendizagem e de melhoria da segurança do paciente?

曗 Os cuidados de saúde que prestamos são seguros para o paciente? Como podemos saber?

\section{A importância em avaliar a frequência e tipologia dos eventos adversos}

O dano e até mesmo a morte do paciente, decorrentes da prestação deficiente ou omissão dos cuidados de saúde adequados, podem surgir 
como notícia de abertura nas televisões ou ocupar a primeira página dos jornais. Esses casos correspondem a situações raras e excepcionais ou são apenas a ponta de um iceberg? Importa assim colocar a questão: A prestação de cuidados de saúde é uma atividade segura?

Em outras áreas como a aviação, podemos determinar o nível de segurança, por exemplo, baseado no número e gravidade dos incidentes ocorridos, considerando o número de operações ou de utentes/usuários desses serviços. Essa estratégia pode ser aplicada aos cuidados de saúde, tendo em conta, no entanto, uma série de limitações e dificuldades.

Uma vez definida a ocorrência de um incidente é útil determinar se esse constituiu um EA, ou seja, se ocorreu dano no paciente causado pelos cuidados de saúde, ou se foi suficientemente grave para prolongar o tempo de internamento/internação ou causar algum grau de incapacidade temporária ou permanente (Baker et al. 2004).

Como podemos medir a ocorrência desses EAs, traduzi-los sob a forma de indicadores e fazer comparações?

Nos últimos 25 anos, realizaram-se, em vários países do mundo, diversos estudos sobre a frequência e a natureza dos EAs em pacientes internados em hospitais utilizando diferentes metodologias. Em sua maioria, foram estudos de incidência e de prevalência, baseados em informação contida nos processos clínicos/prontuários, cujos resultados têm possibilitado conhecer a dimensão do problema e desenvolver soluções para sua prevenção (Baker et al. 2004; Sousa 2006; Zegers 2009; Aranaz-Andrés et al. 2008, Wilson et al. 2012).

Como se pode verificar no Quadro 1, as taxas de incidência de EAs em hospitais atingem valores que variam entre os 3,7\% e os 16,6\% (com consequente impacte clínico, económico e social), e desses a maior fatia (40\% a $70 \%$ ) é considerada evitável (Mills 1978; Leape et al. 1991; Thomas et al. 2000; Baker et al. 2004; Schioler et al. 2001; Michel et al. 2004; Wilson et al. 1995; Davis et al. 2001; Vincent 2001; Aranaz-Andrés et al. 2008; Mendes et al. 2009; Soop et al. 2009; Zegers et al. 2009; Sousa et al. 2014; Letaief et al. 2011; Mendes et al. 2013). 
Quadro 1- Pesquisas sobre incidência de eventos adversos em hospitais realizadas em vários países

\begin{tabular}{|c|c|c|c|c|}
\hline $\begin{array}{l}\text { Local/ano de } \\
\text { publicação/autor } \\
\text { do estudo }\end{array}$ & $\begin{array}{l}\text { Ano a que diz } \\
\text { respeito a informação } \\
\text { analisada }\end{array}$ & $\begin{array}{l}\text { N. de processos } \\
\text { clínicos/prontuários } \\
\text { analisados }\end{array}$ & $\begin{array}{l}\text { Incidência de } \\
\text { pacientes com } \\
\text { EAs (\%) }\end{array}$ & $\begin{array}{l}\text { Proporção de } \\
\text { EAs evitáveis }\end{array}$ \\
\hline $\begin{array}{l}\text { Califórnia } \\
\text { Mills et al. } 1978\end{array}$ & 1974 & 20.864 & 4,65 & Não relatada \\
\hline $\begin{array}{l}\text { Nova York (HMPS) } \\
\text { Breman et al. } 1991 \\
\text { Leape et al. } 1991\end{array}$ & 1984 & 30.195 & 3,7 & Negligência* \\
\hline $\begin{array}{l}\text { Utah/Colorado } \\
\text { Thomas et al. } 2000\end{array}$ & 1992 & 14.700 & 2,9 & Negligência* \\
\hline $\begin{array}{l}\text { Austrália } \\
\text { Wilson et al. } 1995\end{array}$ & 1992 & 14.179 & 16,6 & 50,3 \\
\hline $\begin{array}{l}\text { Reino Unido } \\
\text { Vincent et al. } 2001\end{array}$ & 1999 & 1.014 & 10,8 & 52,0 \\
\hline $\begin{array}{l}\text { Nova Zelândia } \\
\text { Davis et al. } 2001\end{array}$ & 1998 & 6.579 & 11,3 & 61,6 \\
\hline $\begin{array}{l}\text { Dinamarca } \\
\text { Schioler et al } 2001\end{array}$ & & 1.097 & 9,0 & 40,4 \\
\hline $\begin{array}{l}\text { França } \\
\text { Michel et al. } 2004\end{array}$ & & 778 & 14,5 & 27.6 \\
\hline $\begin{array}{l}\text { Canadá } \\
\text { Baker et al. } 2004\end{array}$ & 2004 & 3.745 & 7,5 & 36,9 \\
\hline $\begin{array}{l}\text { Brasil } \\
\text { Mendes et al. } 2009\end{array}$ & 2003 & 1.628 & 7,6 & 66,7 \\
\hline $\begin{array}{l}\text { Holanda } \\
\text { Zegers et al. } 2009\end{array}$ & 2004 & 7.926 & 5.7 & 39.6 \\
\hline $\begin{array}{l}\text { Suécia } \\
\text { Soop et al. } 2009\end{array}$ & $2003 / 2004$ & 1.967 & 12,3 & 70 \\
\hline $\begin{array}{l}\text { Espanha } \\
\text { Aranaz et al. } 2008\end{array}$ & 2005 & 5.624 & 8,4 & 42.8 \\
\hline $\begin{array}{l}\text { Tunísia } \\
\text { Letaief et al. } 2010\end{array}$ & 2005 & 620 & 10 & 60 \\
\hline $\begin{array}{l}\text { Portugal } \\
\text { Sousa et al. } 2014\end{array}$ & 2009 & 1.669 & 11,1 & 53,2 \\
\hline
\end{tabular}

Fonte: Proqualis(http://proqualis.net/eventos-adversos).

* Percentual de EAs em virtude de negligência - HMPS - 27,6. Utah - 32,6. Colorado - 27,4. 
Na Parte II deste livro, Segurança do paciente: conhecendo os riscos nas organizações de saúde, será dada particular atenção a cada um desses grupos de EAs, e, em capítulos individualizados, por conta de sua importância, cada um desses grupos será aprofundado.
No Capítulo 13, o tema "Segurança do paciente na Atenção Primária à Saúde".
Nos vários estudos descritos no Quadro 1, as tipologias de EAs mais frequentes foram aquelas relacionadas com:

粼 o medicamento (nas diferentes fases do circuito do medicamento, desde a prescrição até a administração);

橉 a cirurgia (por exemplo, cirurgia no local errado, deiscência);

橉 as infeções;

噒 os danos por quedas;

喼 as úlceras por pressão; e

踭 o atraso ou falha no diagnóstico ou no tratamento.

Na última década, começaram a ser dados os primeiros passos no sentido de reunir todo o conjunto de evidências de vários estudos realizados no campo dos cuidados primários, com o objetivo de definir prioridades a partir da frequência e tipologias dos erros e dos EAs. Estudos que incidam na frequência, tipologia ou impacte dos EAs nos cuidados de saúde continuados, de forma geral, têm sido muito residuais. Apresenta-se como exceção o investimento feito pelos países do norte da Europa (Suécia, Dinamarca, Noruega, por exemplo), que sempre dedicaram particular atenção a essa área (long term care; home care). A visibilidade desses resultados é diminuta (face ao seu interesse), pois, na maioria dos casos, esses estudos não foram publicados em revistas internacionais (em língua inglesa). Para aprofundar mais esse tema, sugere-se o recente artigo de Sears e colaboradores (Sears et al. 2013).

Para conhecer a frequência de EAs ocorridos, podemos recorrer a diferentes fontes de informação, nomeadamente:

踌 dados administrativos;

procedimentos efetuados;

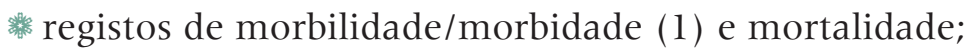

滕 reclamações dos pacientes; e

蝶 processos litigiosos referentes a queixas de má prática.

Essa informação é dependente da qualidade dos registos, da limitada abrangência da codificação de diagnósticos relacionados com a iatrogenia e da perceção do erro pelos pacientes no caso das reclamações. Quando são reunidos, apresentam habitualmente números inferiores aos obtidos por outras metodologias mais específicas, como a revisão de processos clínicos/prontuários, os sistemas de notificação voluntária de incidentes ou os estudos observacionais prospetivos. 
Existem diversos métodos para avaliar a frequência de erros, incidentes ou de EAs, e esses apresentam diferentes caraterísticas, já que uns se adequam preferencialmente a estudar falhas latentes e/ou falhas ativas, e outros a analisar EAs. A observação direta dos cuidados de saúde prestados ao paciente e os estudos de coorte são métodos que apresentam uma abordagem prospetiva na avaliação da frequência dos EAs. No entanto, a análise de reclamações por má prática clínica, os sistemas de notificação de incidentes, as conferências de morbilidade/morbidade e mortalidade (com ou sem análise de autópsias), e a revisão de processos clínicos/prontuários são métodos que utilizam uma abordagem retrospetiva para medir os EAs. Na Figura 1, encontra-se esquematizada a utilidade das abordagens para medir a frequência dos EAs.

Figura 1 - Utilidade relativa dos métodos para medir falhas latentes, falhas ativas e eventos adversos

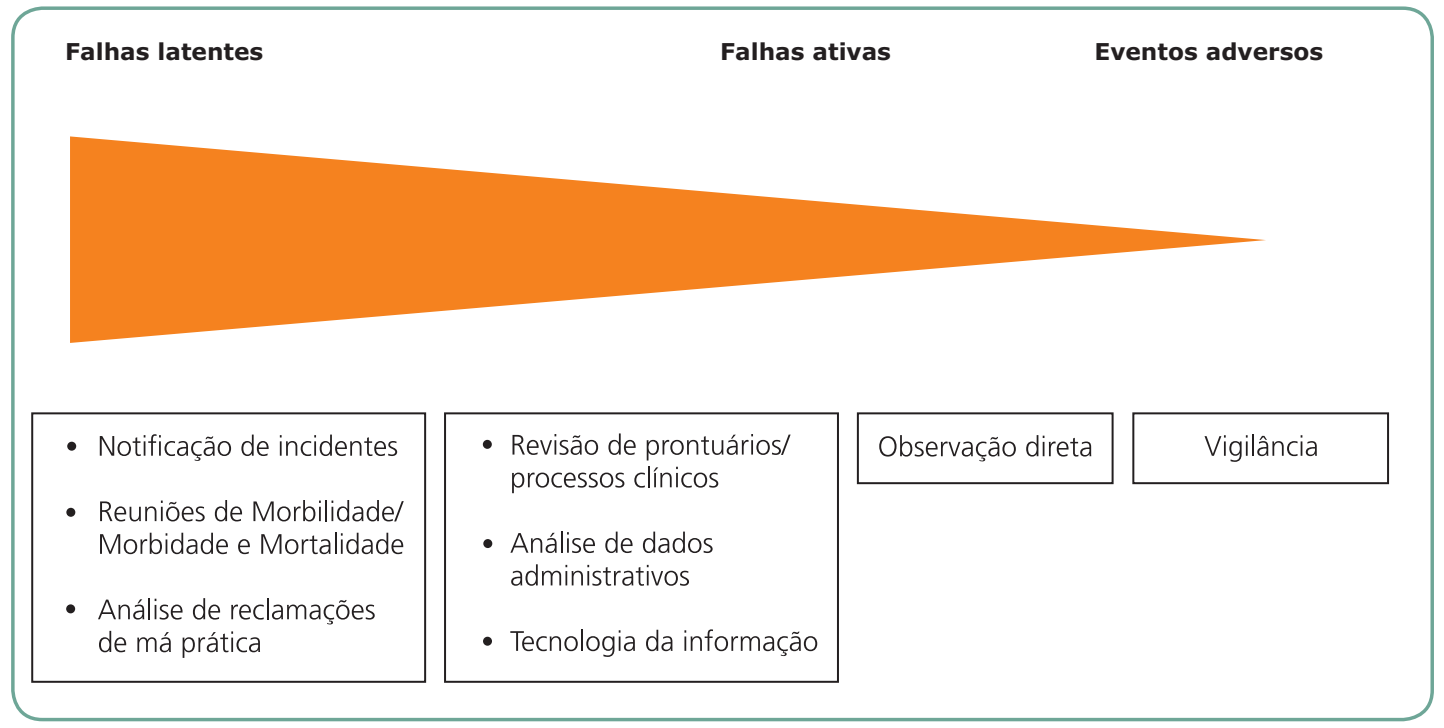

Fonte: Thomas, Petersen (2003, p. 64).

A figura nos mostra como os diferentes métodos (mencionados nos retângulos da parte de baixo) de medir as falhas e os EAs são mais adequados na deteção de diferentes falhas (latentes ou ativas) e EAs (mencionados nos retângulos da parte de cima). Por exemplo, as Notificações de Incidentes são adequadas para captar falhas latentes; no oposto, a Vigilância parece ser o método ideal, o mais preciso para detetar EAs, apresentando como desvantagem o facto de ter custos significativos e não ser bom para detetar falhas latentes.

A observação direta da prestação dos cuidados de saúde é um dos métodos utilizados para identificar as falhas ativas, pois se refere a um conjunto de técnicas de observação em tempo real de todos os aspetos do processo de prestação de cuidados ao paciente (Lepée 2012; Wallace et al. 2013). A observação direta ou por meio de gravação de vídeo tem sido utilizada em salas de cirurgia (Helmreich, Schaefer 1994; Morgan et al. 2013), unidades de cuidados intensivos (Donchin et al., 2003) e para avaliar a ocorrência de EAs durante a administração de medicamentos. Após a realização de estudos em que foi aplicada essa metodo- 
O Efeito de Hawthorne foi percebido a partir de uma experiência que tinha como objetivo melhorar a produtividade dos trabalhadores a partir da observação de sua produção em diferentes níveis de luminosidade. O resultado foi surpreendente, pois, independentemente das condições de trabalho, os trabalhadores passaram a produzir mais. A conclusão do pesquisador foi a de que essa melhoria na produtividade deveu-se ao facto de os funcionários se sentirem lisonjeados e motivados pela simples situação de receberem atenção durante o estudo. logia, foram registados várias falhas ativas e EAs que não tinham sido documentados até então e, de outra forma, não seriam conhecidos, demonstrando ser esse um método com potencialidades.

A observação direta é considerada uma metodologia inadequada para identificar condições ou falhas latentes e apresenta algumas limitações práticas e metodológicas, nomeadamente, a dificuldade em respeitar a confidencialidade implícita na prestação dos cuidados, uma vez que esses dados podem ser utilizados pelos supervisores a fim de punir os prestadores de cuidados de saúde. Esse processo de observação dos cuidados de saúde requer um observador experiente e bastante treinado para assegurar a precisão dos dados obtidos, o que normalmente corresponde a um processo dispendioso.

Como você explicaria a afirmação de que a observação direta não é adequada para a identificação de falhas latentes?

Outra das limitações associadas ao método de observação direta é o enviesamento dos dados em razão da sobrecarga de informação disponível durante o processo de observação e da dificuldade normalmente sentida pelo observador em se distanciar dos resultados e consequências da prestação de cuidados ao paciente (Morgan et al. 2013).

Finalmente, podemos classificar o Efeito de Hawthorne como outra das limitações desse método, já que ele ocorre na maioria das situações em que os intervenientes/atores sabem que estão a ser observados e alteram, geralmente de forma positiva ou benéfica, suas atitudes e seu comportamento normal (Morgan et al. 2013).

A análise de reclamações por má prática clínica é um dos métodos utilizados na avaliação dos EAs em hospitais (Wallace et al. 2013).

Nos últimos tempos, tem sido registado um crescimento exponencial do número de queixas e reclamações contra os prestadores de cuidados de saúde (Leape et al. 1991; Wallace et al. 2013) e, consequentemente, dos montantes monetários decorrentes de indenizações concedidas aos queixosos (Kohn, Corrigan, Donaldson 2000; Thomas, Petersen 2003; Wallace et al. 2013).

Os elementos que constituem os ficheiros das reclamações, como os depoimentos, relatórios e os testemunhos judiciais, integram uma 
quantidade significativa de informação disponível para ser utilizada pelos investigadores/pesquisadores a fim de analisar qualitativamente os erros e EAs (Thomas, Petersen 2003).

Esse é o método apropriado para identificar falhas latentes e apresenta diversas vantagens como o facto de providenciar a descrição detalhada dos cuidados prestados em casos específicos; identificar os custos reais das reclamações; obter múltiplas perspetivas, conseguindo uma descrição dos eventos ocorridos pela óptica dos pacientes ou, por vezes, dos prestadores de cuidados; e obter mais informação sobre os EAs considerados mais graves.

A análise dessas reclamações, no entanto, também apresenta algumas limitações, uma vez que representam apenas uma pequena parte dos EAs (pois são casos específicos), dificultando a generalização. Outra desvantagem desse método são as condições e circunstâncias reais em que ocorrem os EAs, que podem não ser as refletidas no relato, sujeitando os dados a enviesamento. Além disso, a fonte desse tipo de dados não é padronizada, não sendo possível estudar e analisar a informação em tempo real.

A análise desses arquivos de reclamações tem conduzido à criação de importantes normas relativas à segurança do paciente, como ocorre por exemplo na área da anestesia (Wu 2010). No entanto, Thomas e Petersen (2003) referem que, apesar de esse ser um método que pode identificar potenciais causas de EAs, não deve ser utilizado para estimar a incidência ou prevalência, nem para estimar o efeito de uma intervenção na redução deles.

As conferências ou reuniões sobre morbilidade/morbidade e mortalidade com ou sem resultados de autópsias são um elemento essencial na educação e no treino cirúrgico e, por isso, devem ser aperfeiçoadas e destacadas (Higginson, Walters, Fulop 2013).

O objetivo dessas conferências ou reuniões é a aprendizagem com os erros e EAs cirúrgicos, por meio da análise e discussão (entre pares) das situações, e, consequentemente, a definição de ações de melhoria da qualidade dos cuidados. Apesar desse último objetivo não ter sido comprovado cientificamente, os investigadores/pesquisadores e intervenientes/atores nessa área acreditam na sua efetividade (Thomas, Petersen 2003). 
Figura 2 - A tela The Gross Clinic, do pintor realista Thomas Eakins (1844-1916)

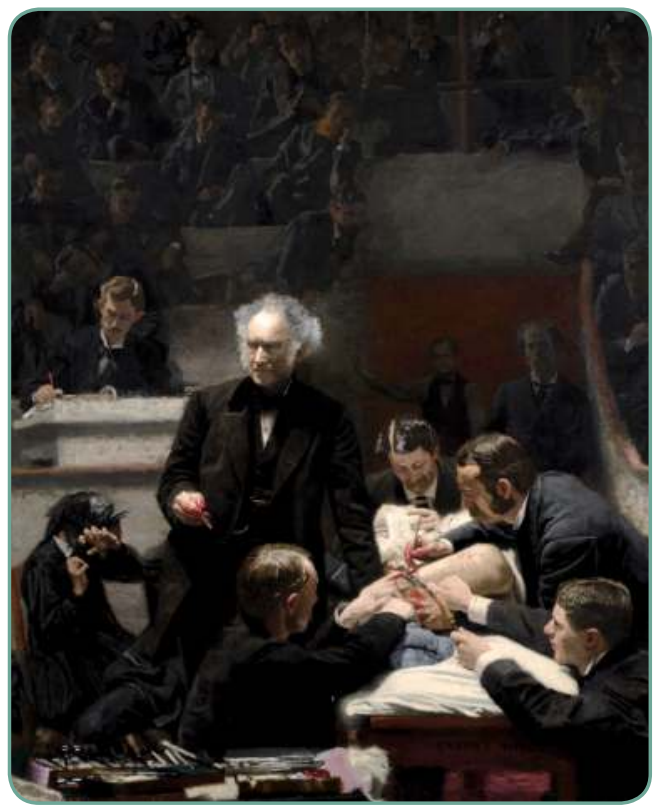

Fonte: Wikipedia Enciclopedia (2010).

Essa tela mostra um renomado cirurgião (Dr. Samuel

Gross) presidindo uma operação durante uma

palestra em um anfiteatro repleto de alunos.

Alguns estudos sugerem que, em razão da análise dos resultados das autópsias, foi possível confirmar que os diagnósticos incorretos potencialmente fatais ocorrem em $20 \%$ a $40 \%$ dos casos (Higginson, Walters, Fulop 2013).

Embora esse método possa ser aplicado à medição de falhas ativas e latentes, é mais adequado utilizá-lo na avaliação de falhas latentes. No entanto, Sackett e colaboradores e Higginson e colaboradores (Sackett et al. 1991; Higginson, Walters, Fulop 2013) consideram que, pelo facto de as autópsias e de o número de casos debatidos em conferências ou reuniões sobre morbilidade/morbidade e mortalidade ser tão reduzido, não deve ser um método utilizado para avaliar a incidência ou prevalência de erros ou EAs, sendo considerado com nível de precisão baixo a moderado.

Que argumento (ou argumentos) você usaria para explicar a afirmação de que as análises dos resultados das autópsias são mais adequadas para avaliação de falhas latentes?

Os métodos que recorrem à análise da informação de tipo administrativo surgem, ao que tudo indica, como fonte de informação atrativa 
(potencialmente útil e fácil de se obter) no que diz respeito à avaliação de EAs. No entanto, são dados que podem ser pouco fiáveis/confiáveis e sujeitos à influência de políticas de incentivo, bem como condicionados por problemas de codificação (Mansoa et al. 2011).

Thomas e Petersen (2003) consideram que os dados administrativos são menos suscetíveis de algum tipo de enviesamento do que os métodos de análise das reclamações por má prática clínica, dos sistemas de notificação de incidentes e das conferências de morbilidade/morbidade e mortalidade (com ou sem autópsias).

A revisão de processos clínicos/prontuários (em papel ou eletrónicos) é considerado o método que estabeleceu a investigação sobre erros e EAs, e sua utilidade continua a ser demonstrada, uma vez que é um dos métodos mais utilizados no mundo para avaliar os EAs em hospitais (Thomas, Petersen 2003; Zegers et al. 2011; Vlayen et al. 2012). Esse método retrospetivo de revisão sistemática de registos clínicos permite determinar a natureza, incidência e impacte económico dos Eas, procurando ainda perceber suas causas. Na maioria dos estudos que utilizaram esse tipo de metodologia, os EAs mais frequentes foram os associados a atos cirúrgicos, infeção associada aos cuidados de saúde, os erros relacionados com o medicamento (nas diferentes fases do circuito) e as quedas.

Apesar de serem evidentes os benefícios e as vantagens do método de revisão dos processos clínicos/prontuários e de esse ser o método mais utilizado na avaliação dos EAs, ele não é isento de limitações. A principal limitação apontada a esse método relaciona-se com a qualidade da informação dos registos clínicos (informação incompleta ou ausência de informação).

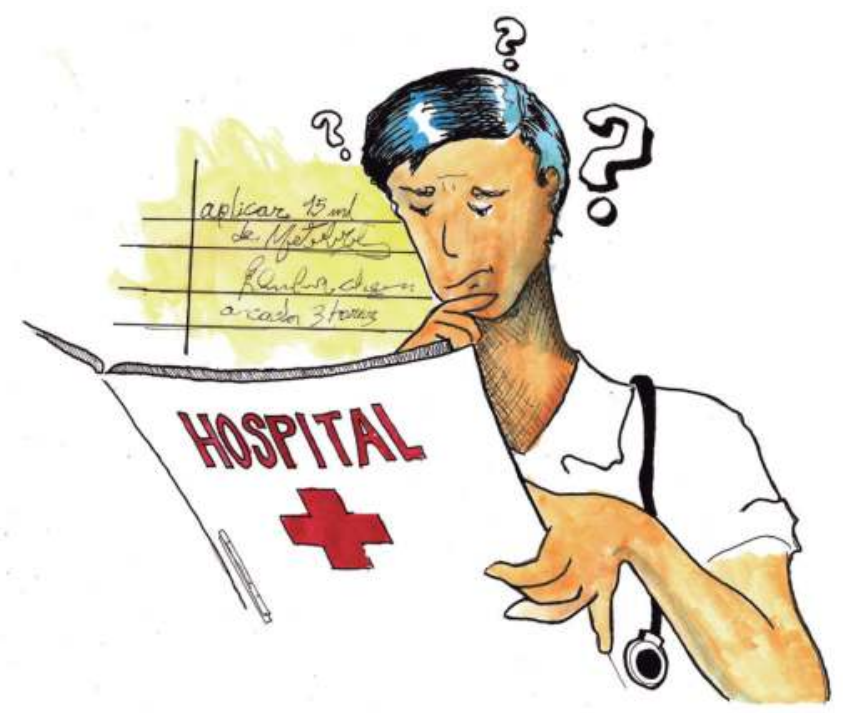




\section{Para refletir}

Em seu local de trabalho, qual o problema mais comum relacionado com os registos clínicos: Não haver registos?

Registos incompletos?

Uso de abreviaturas?

Não colocação de data, hora ou assinatura?

Letra ilegível nos registos manuais?

Que sugestões você implementaria para diminuir esse problema?

Em estudos realizados em vários países, constatou-se que entre 3,7\% a 16,6\% de pacientes admitidos em hospitais experienciaram um ou mais EAs (Zegers et al. 2009). Esses estudos divulgaram dados importantes sobre aspetos críticos da atividade hospitalar e contribuíram para promover o desenvolvimento de iniciativas em segurança do paciente (Letaief et al. 2010).

De acordo com vários autores (Thomas, Studdert, Brennan 2002; Sari et al. 2007), existe consensualidade entre os revisores de que o método de revisão dos registos clínicos é altamente sensível e de confiança na deteção de EAs.

De acordo com Sousa e colaboradores (2014), apesar de a natureza retrospetiva dos estudos baseados na análise de registos clínicos apresentar algumas dificuldades, essa metodologia continua a ser considerada a mais adequada para caracterizar a ocorrência, a tipologia e as consequências dos EAs em contexto hospitalar.

A identificação dos critérios de positividade para a ocorrência de EAs é a forma mais utilizada para detetar os EAs nesse método, no qual o auditor verifica a presença de um ou mais critérios dos inicialmente definidos e que indiciam a presença de potenciais EAs. Em vários estudos (Leape et al. 1991; Baker et al. 2004; Mendes et al. 2009; Sousa et al. 2014), foram utilizados 18 critérios de positividade para a ocorrência de EAs (esses estudos se basearam no Harvard Medical Practice Study, 1991). Outro exemplo de uso de critérios (triggers) é o caso do estudo desenvolvido por Landrigan e colaboradores (2010), realizado em hospitais do Estado da Carolina do Norte, nos EUA, em que foram utilizados os 52 critérios de positividade definidos pelo Institute for Healthcare Improvement (IHI), designados Global Trigger Tool for Measuring Adverse Events (Landrigan et al. 2010).

Mais recentemente, com a utilização de "processos clínicos/prontuários eletrónicos" assistiu-se a uma melhoria nesse tipo de metodologia, na medida 
em que tornou possível integrar múltiplas fontes de informação num único sistema informático, tais como os registos farmacêuticos e laboratoriais, dados administrativos, obviando dessa forma o que era considerado a principal limitação (qualidade e quantidade de informação) (Thomas, Petersen 2003; Landrigan et al. 2010). A utilização de registos eletrónicos faculta informação sobre incidentes e EAs que, muitas vezes, não é detetada pelos meios mais tradicionais, como a revisão de processos clínicos/prontuários em papel ou a análise dos sistemas de notificação de EAs.

Não obstante algumas fragilidades, esse método (revisão de processos clínicos/prontuários) continua a ser considerado por vários autores como o gold-standard para avaliar a frequência de EAs em contexto hospitalar.

Existem outros métodos de avaliação da frequência de EAs que não foram descritos no presente capítulo, e cuja aplicação tem sido feita de forma muito residual (experiências pontuais) e quase sempre numa perspetiva académica. São exemplos disso, o método de vigilância clínica, os questionários por telefone, entre outros. Tendo em consideração tais factos, não nos parece oportuno proceder, aqui, à sua caracterização.

\section{Avaliação de EAs em pediatria}

As crianças estão na linha da frente quando consideramos os factores de risco para a ocorrência de incidentes, sendo três vezes mais afetadas que os adultos pelos incidentes relacionados com a medicação (National Patient Safety Agency 2009).

A revisão de processos clínicos/prontuários num hospital pediátrico (Matlow 2011) mostrou que 15\% das crianças hospitalizadas são vítimas de um EA, ou seja, sofrem um dano relacionado com os cuidados aos quais são submetidas. As características da população pediátrica que a tornam mais vulnerável são:

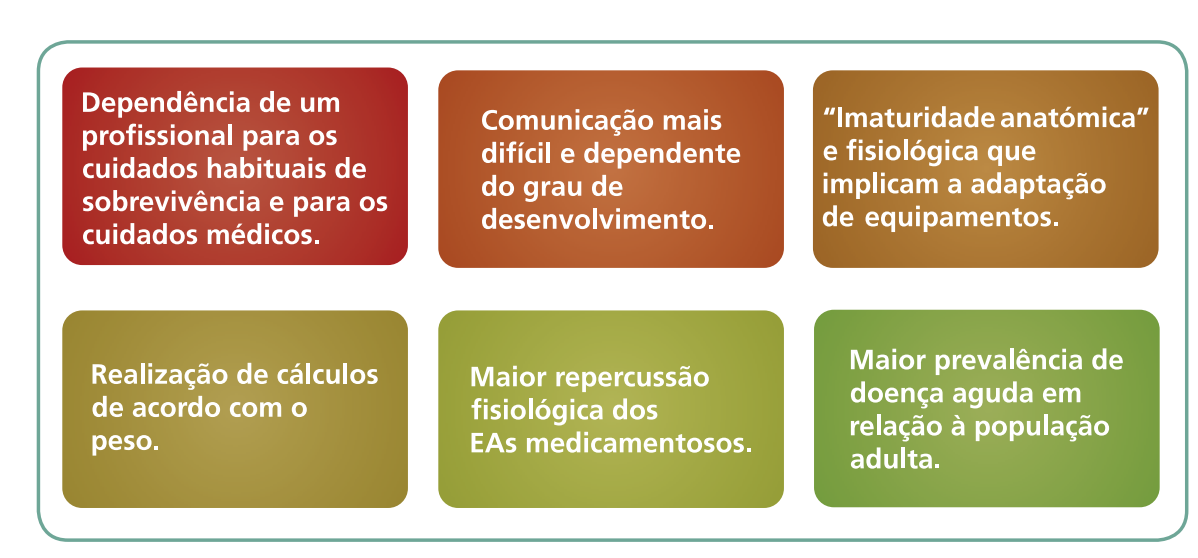

Fonte: Frey (2010); American Academy of Pediatrics (2011).
No final do capítulo, estão disponibilizadas algumas referências que permitirão aprofundar mais nos métodos que não foram discutidos aqui.

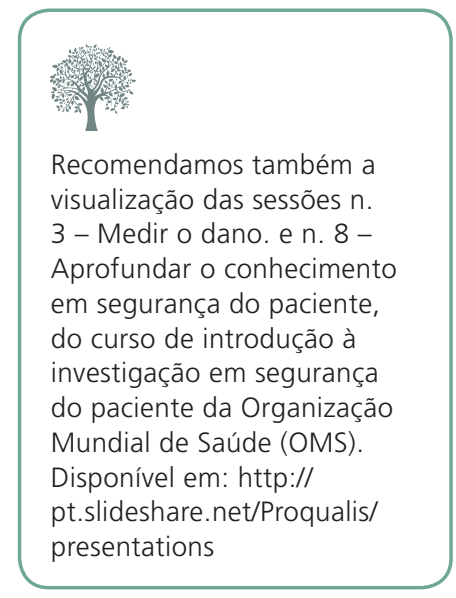

드. 
As especificidades da população pediátrica exigem ainda que, por exemplo, a metodologia de deteção de EAs pela revisão de registos clínicos recorra a critérios de positividade diferentes daqueles já validados na população adulta. Esses novos critérios terão de abordar a avaliação do período neonatal precoce com as especificidades da adaptação à vida extrauterina, a reanimação neonatal, o traumatismo de parto e algumas patologias próprias do recém-nascido pré-termo, como a enterocolitenecrosante e a doença pulmonar crónica (Matlow 2011).

\section{Que factores contribuintes estão implicados na ocorrência de erros, incidentes e EAs e como analisá-los}

Você já pensou em quanto tempo gastam os profissionais de saúde a registar os erros, incidentes e EAs? E a analisá-los?

A análise dos incidentes relatados e a determinação dos factores contribuintes podem originar informação útil sobre problemas existentes no sistema, detetando quebras de segurança na prestação de cuidados. $\mathrm{O}$ modelo de investigação de incidentes mais conhecido foi desenvolvido a partir do estudo dos factores humanos implicados no erro (Reason 1990) e adaptado por Charles Vincent e Sally Adams, com a elaboração do London Protocol em 2004 (Taylor-Adams, Vincent 2004). A análise abrange:

a deteção de factores organizacionais e culturais (decisões administrativas e processos);

粼 factores contribuintes (local, tarefa, paciente, indivíduo, equipa);

* problemas na prestação de cuidados (omissões, lapsos, violações, atos inseguros) e;

粕 defesas e barreiras do sistema.

Invariavelmente, para cada incidente que ocorre, as falhas são múltiplas, simultâneas e tanto originadas no sistema (condições latentes sempre presentes) como na ação ou inação (omissão) dos profissionais (erros ou falhas ativas - nem sempre presentes).

Um dos aspetos mais importantes na análise de um incidente é uma boa descrição dos factores que contribuíram para sua ocorrência e sua classificação de acordo com as várias categorias. Poderemos identificar factores relacionados com:

o paciente (idade, diagnóstico, tratamento, factores pessoais);

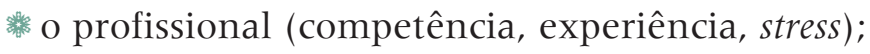


滕 a equipa (comunicação, supervisão, ajuda mútua);

繗 a tarefa (concepção, protocolos e normas disponíveis);

滕 o ambiente de trabalho (horários, sobrecarga, treino, equipamento); e

橉 a organização (liderança, cultura de segurança, recursos, políticas).

Da análise do incidente decorre obrigatoriamente a definição de um plano de ação, com propostas de melhoria tendo em conta os factores contribuintes e os problemas detetados. Tais propostas devem incluir a designação concreta de um responsável, um tempo adequado de implementação e uma forma de monitorização e, consequentemente, avaliação dos resultados.

Algumas medidas de melhoria podem interessar apenas a uma equipa ou serviço, como o uso mais adequado do equipamento ou a sistematização da passagem de turno/plantão (Handover). Outras podem abranger a organização, caso da necessidade de formação ou de contratar pessoal para o bloco operatório. Há também medidas que podem constituir uma proposta de âmbito nacional, tais como a rotulagem segura da medicação ou a alteração no design de uma bomba infusora.

\section{Para praticar}

Reflita sobre o caso descrito a seguir e tente identificar quais factores contribuíram para este incidente (administração de medicação ao paciente errado) utilizando as várias categorias descritas neste capítulo até agora.

"Um lactente de quatro meses com bronquiolite e hipersecreção bronquica encontra-se na sala de tratamentos de um serviço de urgência pediátrico a fazer um aerossol com soro fisiológico. Ao seu lado, está outro lactente de dois meses com vómitos. Ambos têm um acesso venoso. Nesse hospital, por ter elevada afluência de pacientes à urgência, não é colocada pulseira de identificação na criança se ela não for admitida ao internamento/internação. No corredor, o médico informa oralmente a enfermeira: "É para dar 3 mg de furosemide endovenoso (diurético) à criança que está na sala dos aerossois". Na sala de aerossois, a criança com bronquiolite é levada pela mãe ao banheiro para trocar a fralda. A enfermeira administra o furosemide à criança de dois meses com vómitos (paciente errado)". 
Para além de contribuir e, simultaneamente, ser promotor de uma cultura justa ("aberta") de aprendizagem e de não culpabilização, os sistemas de notificação constituem uma importante "ferramenta" de diagnóstico de situações de risco e, em consequência, podem ser uma fonte de recomendações que visem aumentar a segurança e as boas práticas em saúde.

\section{Sistemas de notificação: objetivos e principais características}

Como denominador comum entre as estratégias que diversos países ou organizações de saúde definiram para melhorar a segurança dos pacientes, destaca-se a implementação de sistemas de notificação de incidentes, voluntários ou obrigatórios (sendo os primeiros mais frequentes) e cuja escala pode ser a nível local (determinado serviço ou departamento ou a organização de saúde em sua totalidade), regional ou nacional. Também aqui a aprendizagem com outras áreas (nomeadamente a aviação e a indústria de maior complexidade e risco, como a de energia nuclear) foi fundamental.

Segundo a OMS (World Health Organization 2005), o principal objetivo dos sistemas de notificação de incidentes é investigar e analisar os dados obtidos (ocorrências notificadas e consequente informação recolhida durante a análise da situação), com base nisso, disseminar e implementar recomendações que promovam mudanças nas organizações de saúde, com vista à redução ou eliminação de ocorrências semelhantes no futuro. Do exposto, decorre que os sistemas de notificação devem ser considerados uma forma de aprendizagem e de melhoria contínua da segurança e da qualidade dos cuidados prestados.

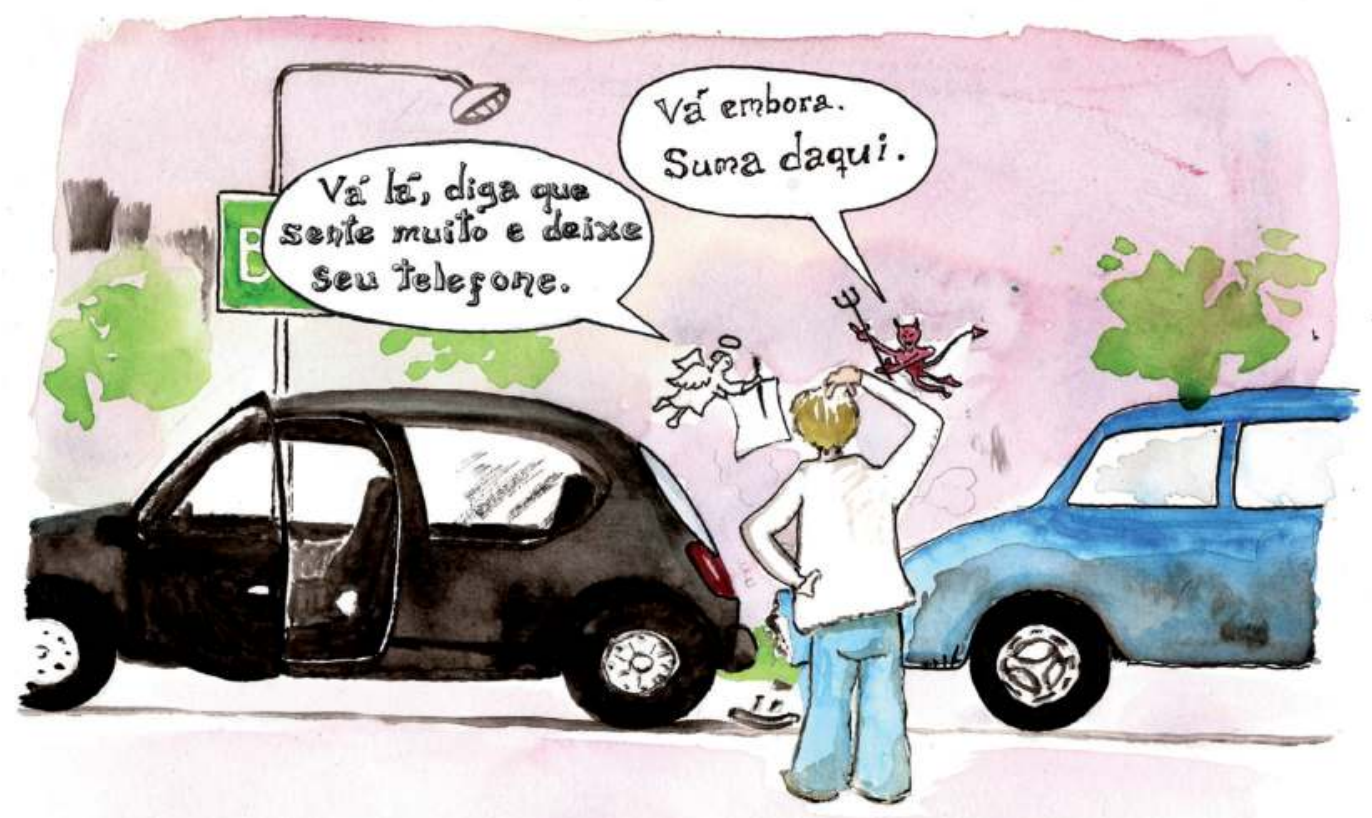

Notificar uma ocorrência nem sempre é fácil, pois muitas vezes significa assumir um erro. Mas é importante incentivar esse comportamento. Lembre-se de que essa atitude pode evitar novos erros. 
O sistema de notificação de incidentes permite que os profissionais de saúde exponham e registem, normalmente de forma voluntária e confidencial, a ocorrência de incidentes ou de qualquer preocupação de segurança detetada no trabalho (Meyer-Masseti et al. 2011). Esse relato tem dois objetivos:

1. aumentar o conhecimento sobre os erros e os riscos inerentes à tarefa e ao tipo e local de trabalho e;

2. por meio da investigação do incidente e da análise de vários incidentes agregados, gerar informação útil para corrigir as fragilidades ou falhas identificadas.

O relato dos profissionais constitui, essencialmente, uma oportunidade oferecida através do seu relato para conhecermos o funcionamento de um sistema no quotidiano, das suas fragilidades e riscos latentes.

\section{Para refletir}

Na organização em que você trabalha, existe algum tipo de estímulo ao registo de notificações? Você se preocupa em registar os incidentes que ocorrem? Por quê?

Em alguns países europeus, como a Inglaterra e o País de Gales, a Dinamarca e a Escócia, foi implementado um sistema centralizado a nível nacional, associado necessariamente a uma vasta estrutura para a análise, divulgação, informação de retorno (feed-back) e intervenção, face aos problemas detetados. Esses sistemas nacionais foram rapidamente confrontados com um volume considerável de relatos, sendo os valores divulgados no Reino Unido pela National Patient Safety Agency (NPSA), desde outubro de 2003 até dezembro de 2012, de 8.166.871 relatos de incidentes relacionados com os cuidados de saúde.

Os níveis de dano, para o paciente, associados aos incidentes, apenas no período de um ano (outubro 2011 a setembro 2012), são preocupantes: 3.496 mortes e 8.067 lesões, e maior gravidade em 1.364 .465 incidentes relatados provenientes de cerca de 371 instituições de saúde no Reino Unido. A estimativa de custos de EAs no Reino Unido aponta para um bilião de libras por ano, tendo em conta apenas os custos diretos decorrentes do prolongamento da hospitalização.

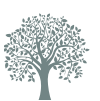

Para conhecer mais sobre esses relatos, consulte o NRLS Quarterly Data Work book up to December 2012. Acessível em: http://www.nrls.npsa. nhs.uk/resources/type/datareports/?entryid45=135213.

Esses dados estão acessíveis para consulta no endereço:http:// www.nrls.npsa.nhs.uk/ resources/?Entryld45=135212

Se você quiser saber mais sobre os sistemas de âmbito nacional existentes na Europa e a sua caracterização, pode consultar o relatório National Reporting Systems for Patient Safety Incidents, elaborado por P. Doupi em 2009. Acessível em http://www.thl.fi/thl-client/ pdfs/254c52fb-95d0-4ddea8ab-bd0df41e0c57. 
Quando se utiliza a informação recolhida pelos sistemas de notificação para estimar a frequência de EAs, devemos ter em atenção que, em comparação com a revisão de processos clínicos, a estratégia de notificação é menos sistemática e objetiva, mas, por outro lado, permite conhecer falhas que não chegaram a atingir o paciente (near miss) ou não foram registadas no processo clínico/prontuário.

Uma das razões que podem levar os profissionais de saúde a evitar a notificação é o incómodo e a demora no preenchimento dos formulários disponibilizados nesses sistemas, que, muitas vezes, são longos e exigem demasiada informação, podendo provocar atrasos na realização das tarefas e/ou atividades dos profissionais de saúde. As razões para a não notificação podem também estar relacionadas com o facto de os profissionais estarem preocupados com a sua reputação ou mesmo com a possibilidade de uma ação judicial.

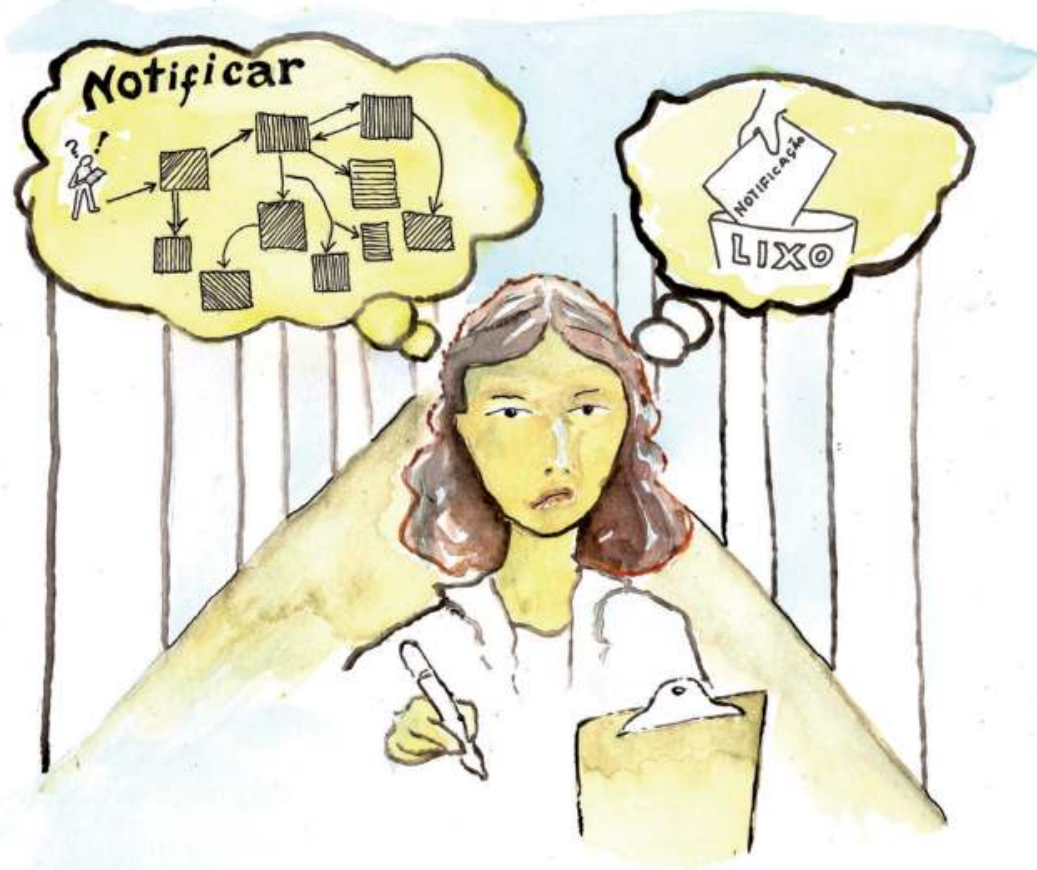

Em virtude desses e outros factores, as organizações devem ser cuidadosas ao interpretar os dados provenientes dos sistemas de notificação. Uma taxa elevada de notificação de EAs poderá indicar uma cultura organizacional assente no compromisso de identificar e reduzir os erros e EAs, e não um mau desempenho dos profissionais ou da organização em sua totalidade. Apesar das suas limitações, esse método identifica EAs que não seriam considerados por meio de outros métodos (Florea et al. 2010). 
Quando se pensa em implementar um sistema de notificação, várias questões se devem colocar, entre as quais poderemos destacar:

滕 se a escala deve ser local, regional ou nacional;

繙 se deve ser de caráter obrigatório ou voluntário;

滕 como é que se garante a confidencialidade da informação que é notificada;

滕 anonimato - o profissional que notifica pode fazê-lo de forma anónima ou não; e por fim;

羭 qual o grau de envolvimento que o paciente e seus familiares devem ter no processo de desenvolvimento e implementação e acompanhamento do sistema de notificação.

\section{Para refletir}

Reflita se um sistema de notificação deve ser de âmbito nacional ou local (cada hospital ter o seu próprio registo) e se deve preservar o anonimato e a confidencialidade.

Várias podem ser as razões que levam uma organização de saúde a implementar um sistema de notificação de incidentes e EAs. Em certos países, foi definido, a nível do Ministério da Saúde, que tal iniciativa seria obrigatória (o caso da Dinamarca), outros determinaram que a notificação de erros, incidentes e EAs deve ser de caráter voluntário (o caso de Inglaterra e do País de Gales, por exemplo).

\section{Considerações finais}

Atualmente, parece existir forte consenso no facto de que o conhecimento da magnitude (frequência) dos EAs e sua natureza e impacte é um factor crucial para a implementação de estratégias com vistas à melhoria da segurança do paciente (nomeadamente em países onde esse conhecimento não existe, ou é escasso). Essa ideia é consubstanciada no facto de que só com base nesse conhecimento se podem definir as mais adequadas estratégias de intervenção (só se gere o que se conhece) e estabelecer prioridades de atuação.

De igual forma, a identificação dos factores que contribuem ou potenciam a ocorrência de erros ou incidentes é fundamental para que se possa atuar no sentido da mitigação dessas ocorrências. 
Paralelamente, a implementação de sistemas de notificação nas organizações de saúde tem sido uma das ações comuns a vários países, apresentando múltiplas vantagens.

A identificação e compreensão dos EAs (sua frequência, tipologia e impacte), o conhecimento sobre os principais factores que estão em sua origem, bem como a implementação de um sistema de notificação (que permite o registo, classificação e investigação das causas que estiveram subjacentes a essas ocorrências) constituem, nos dias de hoje, uma parte fundamental do processo, mais amplo, de avaliação e melhoria contínua da segurança do paciente e da qualidade em saúde.

\section{Referências}

American Academy of Pediatrics. Policy statement: principles of pediatric patient safety: reducing harm due to medical care. Pediatrics May 29, 2011; 127 (6):1199-1212. DOI: 10.1542/peds.2011-0967.

Aranaz-Andrés JM, Albar-Remón C, Vitaller-MurilloJ,Ruiz-López P, Limón-Ramírez R, Terol-Garcia $E$, et al. Incidence of adverse events related to health carein Spain: results of the Spanish National Study of Adverse Events. J Epidemiol Community Health. 2008;62:1022-9.

Baker GR, et al. The Canadian adverse events study: the incidence of adverse events among hospital patients in Canada. CMAJ. 2004;170(11):1678-86.

Brennan TA, Leape LL, Laird NM, Hebert L, Localio AR, LawthersAG.Incidence of adverse events and negligence care in hospitalized patients: results of the Harvard Medical Practice Study I.N Engl J Med.1991;324:370-6.

Davis P, Lay-Yee R, Schug S, Briant R, Scott A, Johnson S. Adverse events regional feasibility study: indicative findings.N Z Med J. 2001;114:203-5.

Donchin $Y$ et al. A look into the nature and causes of human errors in the intensive care unit. QualSaf Health Care. 2003;12:143-7.

Doupi P. National reporting systems for patient safety incidents: a review of the situation in Europe. Helsinki: National Institute for Health and Welfare; 2009. (Report 13/2009). Disponível em: http:// www.thl.fi/thl-client/pdfs/254c52fb-95d0-4dde-a8ab-bd0df41e0c57

Florea A, et al. The Ottawa hospital quality incident notification system for capturing adverse events in obstetrics. J ObstetGynaecol Can. 2010 Jul;32(7):657-62.

Frey B, Schwappach D. Critical incident monitoring in paediatric and adult critical care: from reporting to improved patient outcomes? CurrOpinCrit Care. 2010 Dec;16(6):649-53.

Helmreich RL, Schaefer HG. Team performance in the operating room. In: Bogner MS, editor. Human error in medicine. Hillside: Lawrence Erlbaum and Associates, 1994. p. 225-53.

Higginson J, Walters R, Fulop N. Mortality and morbidity meetings: an untapped resource for improving the governance of patient safety? BMJ QualSaf.2012 Jul; 21(7):576-85. doi: 10.1136/ bmjqs-2011-000603. Epub 2012 May 3.

Kohn LT, Corrigan JM, Donaldson MS. To err is human: building a safer health system: a report of the Committee on Quality of Health Care in America, Institute of Medicine. Washington, DC: National Academy Press; 2000. 
Landrigan CP, Parry GJ, Bones CB, Hackbarth AD, Goldmann DA, Sharek PJ. Temporal trends in rates of patient harm resulting from medical care. N Engl J Med. 2010 Nov 25;363(22): 2124-34.

Leape LL, Brennan TA, Laird N, et al. The nature of adverse events in hospitalized patients: results of the Harvard Medical Practice Study II. N Engl J Med. 1991; 324(6):377-84.

Lepée C, Klaber RE, Benn J, Fletcher PJ, Cortoos P, Jacklin A et al. The use of a consultant-led ward round checklist to improve paediatric prescribing: An interrupted time series study. Eur J Pediatr. 2012 Aug;171(8):1239-45.

Letaief M, Mhamdi SE, El-Asady R, Siddiqi S, Abdullatif A. Adverse events in a Tunisian hospital: results of a retrospective cohort study. Int J Qual Health Care. 2010 Oct;22(5):380-5.

Mansoa A, Vieira C, Ferrinho P, Nogueira P, Varandas L. Eventos adversos na prestação de cuidados hospitalares em Portugal no ano de 2008. Rev Port Saúde Pública. 2011 Jul;29(2):116-22.

Matlow AG, Cronin CM, Flintoft V, Nijssen-Jordan C, Fleming M, Brady-Fryer B et al. Description of the development and validation of the Canadian Paediatric Trigger Tool. BMJ QualSaf. 2011 May;20:416-23.

Mendes W, Martins M, Rozenfeld S, Travassos C. The assessment of adverse events in hospitals in Brazil. Int J Qual Health Care. 2009;21(4):279-84.

Mendes W, Pavão ALB, Martins M, Moura MLO, Travassos C. Características de eventos adversos evitáveis em hospitais do Rio de Janeiro. Rev Assoc Med Bras. 2013;59:421-8.

Meyer-Massetti C, Cheng CM, Schwappach DL, Paulsen L, Ide B, Meier CR et al. Systematic review of medication safety assessment methods.Am J Health Syst Pharm.2011 Feb 1 [citadoem 2011 out. 20];68(3):227-40. doi: 10.2146/ajhp100019. Disponívelem: http://www.medscape.com/ viewarticle/736427.

Michel P, Quenon JL, Sarasqueta AM, Scemama O. Comparison of three methods for estimating rates of adverse events and rates of preventable adverse events in acute carehospitals. BMJ. 2004;328:199-202.

Mills DH. Medical insurance feasibility study: a technical summary. West J Med. 1978;128:360-5.

Morgan L, Robertson E, Hadi M, Catchpole K, Pickering S, New S et al. Capturing intraoperative process deviations using a direct observational approach: the glitch method. BMJ Open. 2013 Nov 25;3(11):e003519.

National Patient Safety Agency (UK). Review of patient safety for children and young people. 2009. Disponível em:http://www.nrls.npsa.nhs.uk/resources/?entryid45=59864. Acesso em: 23 jan. 2013.

Sackett D. et al. Clinical epidemiology. Boston: Little Brown and Company; 1991.

Sari AB, Sheldon TA, Cracknell A, Turnbull A, Dobson Y, Grant $C$ et al. Extent, nature and consequences of adverse events: results of a retrospective case note review in a large NHS hospital. QualSaf Health Care. 2007 Dec;16(6):434-9.

Schioler T, Lipczak H, Pedersen BL, Mogensen TS, BechKB,Stockmarr A, et al. Incidence of adverse events in hospitals: a retrospective study of medical records. UgeskrLaeger. $2001 \mathrm{Sep}$ 24;163(39):5370-8.

Sears N, Baker GR, Barnsley J, Shortt, S. The incidence of adverse events among home care patients. Int J Qual Health Care. 2013; 25(1):16-28.

Soop M, Fryksmark U, Koster M, Haglund B. The incidence ofadverse events in Swedish hospitals: a retrospective medicalrecord review study. Int J Qual Health Care. 2009;21:285-91.

Sousa P. Patient safety: a necessidade de uma estratégia nacional. Acta Med Port. 2006;19:309-18. 
Sousa P, Uva AS, Serranheira F, Nunes C, Leite ES. Estimating the incidence of adverse events in Portuguese hospitals: a contribution to improving quality and patient safety. BMC Health Services Research. 2014;14:311. doi:10.1186/1472-6963-14-311.

Taylor-Adams S, Vincent C. Systems analysis of clinical incidents: the London protocol. Clin Risk. 2004;10:211-20

Thomas EJ, Petersen LA. Measuring errors and adverse events in healthcare. J Gen Intern Med. 2003;18:61-7.

Thomas EJ, Studdert DM, Brennan, T. The reliability of medical record review for estimating adverse event rates. Ann Intern Med. 2002;136:812-6.

Thomas EJ, Studdert DM, Burstin HR, Orav EJ, Zeena T, Williams EJ et al. Incidence and types of adverse events and negligent care in Utah and Colorado. Med Care. 2000;38:261-71.

Vincent C. Patient safety. London: Wiley Blackwell; 2010.

Vincent C, Neale G, Woloshynowych M. Adverse events in British hospitals: preliminary retrospective record review. BMJ. 2001;322:517-9.

Vlayen A, Marquet K, Schrooten W, Vleugels A, Hellings J, De Troy E, et al. Design of a medical record review study on the incidence and preventability of adverse events requiring a higher level of care in Belgian hospitals. BMC Res Notes.2012;5:468.

Wallace E, Lowry J, Smith SM, Fahey T. The epidemiology of malpractice claims in primary care: a systematic review. BMJ Open. 2013;3(7).DOI:10.1136/bmjopen-2013-002929.

Wikipedia. File: EakinsTheGrossClinic.jpg. 2010 [citado 2014jun 24]. Disponível em: http:// en.wikipedia.org/wiki/File:EakinsTheGrossClinic.jpg

Wilson RM, Michel P, Olsen S, Gibberd RW, Vincent C, El-Assady R, et al. Patient safety in developing countries: retrospective estimation of scale and nature of harm to patients in hospital. BMJ2012;344.

Wilson RM, Runciman WB, Gibbert RW, Harrison BT, Newby L, Hamilton JD. The Quality in Australian health care study. Med J Aust. 1995;163:458-71.

World Health Organisation. World Alliance for Patient Safety. Who draft guidelines for adverse event reporting and learning systems. Geneva: WHO; 2005.

Wu AW. Session 4: understanding causes. In: World Health Organization. Patient Safety research introductory course, April and May 2010. Geneva: WHO; 2010.

Zegers M, Bruijne MC, Spreeuwenberg P, Wagner C, Groenewegen PP, van der Wal G. Quality of patient record keeping: an indicator of the quality of care? BMJ QualSaf. 2011;20(11): 314-318. doi:10.1136/bmjqs.2009.038976.

Zegers M, Bruijne MC, Wagner C, Hoonhout LHF, Waaijman R, Smits M, et al. Adverse events and potentially preventable deaths in Dutch hospitals: results of a retrospective patient record review study. Qual Saf Health Care. 2009;18:297-302. 


\section{Direito e segurança do paciente}

Paula Lobato de Faria, Pedro Sá Moreira e Laura Souza Pinto

Este capítulo tem por objetivo fornecer elementos de análise e bibliografia internacional quanto aos seguintes tópicos dentro do tema do direito e segurança do paciente:

* interações entre o direito e a segurança do paciente;

滕 dilemas legais na segurança do paciente;

滕 soluções legais apontadas para melhorar a segurança do paciente;

problemas jurídico-legais resultantes do evento adverso.

\section{Interações entre o direito e a segurança do paciente}

O tema deste capítulo é muito complexo, o que exige uma abordagem multidisciplinar; por isso, não nos limitamos à análise puramente jurídico-legal, tentando antes estudar as questões sob o olhar mais abrangente da saúde pública.

Por ser a lei o mais forte instrumento de intervenção na sociedade, sobretudo quando se trata da proteção contra situações que colocam em perigo os bens essenciais vida e integridade física e psíquica, o direito pode ser considerado um mecanismo central no desenvolvimento e implementação de cuidados de saúde com qualidade e segurança. Esse facto é tanto mais relevante se tivermos em conta que existem diversos factores que contribuem para um crescente número de erros e incidentes na área da saúde. Dentre esses factores, citaremos o crescimento do número de pacientes e de atos de cuidados de saúde, em virtude do

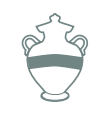

Num ambiente em que se sabe que os eventos adversos têm tendência a aumentar nas organizações de saúde, o papel do direito e a utilização inteligente e eficaz dos instrumentos legais são muito importantes. 
No domínio do direito, a segurança do paciente ainda é um campo emergente em que os dilemas tendem a superar as soluções.
Esses factos mostram, visivelmente, que a segurança do paciente não tem sido fácil de se concretizar em organizações de saúde e como uma estratégia eficiente, nesse campo, ainda está para ser encontrada. aumento da longevidade da população, e as atuais políticas de contenção de custos em saúde que implicam aumento dos eventos adversos em organizações de saúde, causados pela escassez de recursos humanos e materiais e estresse profissional acrescido (Faria 2010).

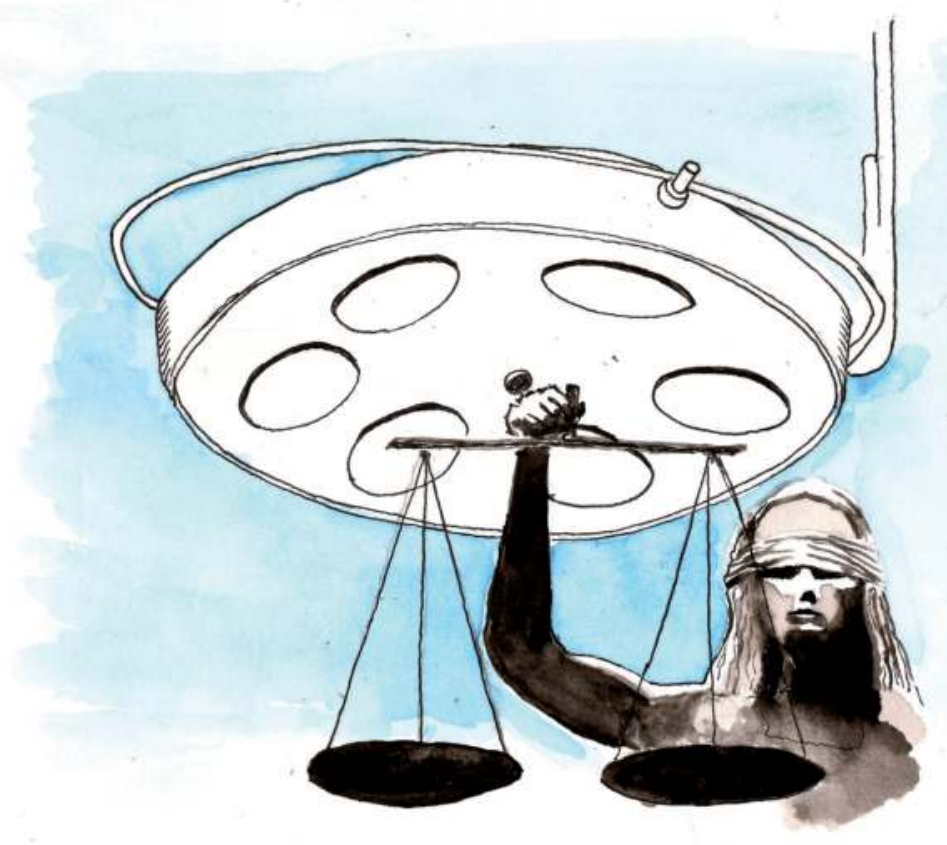

Como sabemos, o relatório To Err is Human, do Institute of Medicine (Kohn et al. 2000), despertou o mundo para a necessidade de melhorar os sistemas de qualidade clínica e de gestão do risco em organizações de saúde, contendo diversas recomendações de ação nesse sentido, muitas delas exigindo sua legislação adequada, tais como os relatórios de eventos adversos, a proteção da confidencialidade dos profissionais envolvidos, o respeito pelos direitos dos pacientes e o cumprimento de deveres por parte de gestores e profissionais.

Apesar de a segurança do paciente ter se tornado, em todo o mundo, num campo de trabalho multidisciplinar, em que se congregam os esforços de especialistas em saúde pública, juristas, gestores de saúde, médicos, enfermeiros e outros profissionais de saúde, os progressos na disseminação de uma cultura de qualidade e prevenção de erros em organizações de saúde não têm sido os desejados. Nos EUA, tal como o artigo de Robert Wachter (2004) claramente descreve, há inúmeras deficiências ainda por corrigir. Além disso, em 2009, uma nova "nota de reprovação" foi dada aos progressos verificados em segurança do paciente num longo relatório assinado pela União dos Consumidores (Safe Patient Project) (McGiffert 2009). 
Na Europa, um relatório datado de julho de 2013 também não trouxe boas notícias. Os resultados do primeiro inquérito europeu - realizado em mais de mil hospitais de 30 países europeus sobre a prevalência de infeções associadas aos cuidados de saúde e uso de antimicrobianos divulgados pelo ECDC (Centro Europeu de Prevenção e Controlo de Doenças) estima que, todos os dias, dos cerca de 80 mil pacientes dos hospitais europeus, ou 1 em cada 18 pacientes, têm, pelo menos, uma infeção associada aos cuidados de saúde. Esse relatório cumpre a Recomendação do Conselho de 9 de junho de 2009 sobre a segurança dos pacientes, incluindo a prevenção e o controlo de infeções associadas aos cuidados de saúde e um relatório de 2012 sobre a aplicação daquela mesma recomendação, cujas conclusões são bastante otimistas, assinalando que a maioria dos Estados-membros reportou ter tomado uma série de ações conducentes à segurança dos pacientes, tal como previsto pela recomendação. No entanto, o mais recente relatório de 2013 parece mostrar que essas etapas ainda não foram suficientes para impedir o grande número de lesões e mortes evitáveis nas organizações de saúde europeias.

Em Portugal, um estudo piloto realizado pela Escola Nacional de Saúde Pública da Universidade Nova de Lisboa sobre três hospitais públicos da região de Lisboa, tendo por base a informação contida nos processos clínicos/prontuários de uma amostra de 1.669 pacientes internados, de um total de 47.783 admissões referentes ao período de $1^{\circ}$ de janeiro de 2009 a 31 de dezembro 2009, apurou a ocorrência de 11,1\% de incidentes adversos, dos quais 53,2\% foram considerados preveníveis. Tais resultados são semelhantes aos encontrados em países como, nomeadamente, o Reino Unido, Canadá, Dinamarca, entre outros (Sousa et al. 2014).

\section{Para refletir}

Como é o nível de infeção hospitalar na organização em que você trabalha? Existe algum tipo de regulamentação interna no sentido de melhorar os índices verificados?

Há várias áreas da recomendação da União Europeia (UE), que foram mencionadas no relatório de 2012, como tendo considerável "espaço para melhorias". Essas áreas incluem, ao nível dos Estados-membros, envolver mais ativamente os pacientes em questões de segurança, em especial para lhes fornecer informação sobre medidas de segurança, procedimentos de reclamação e direitos dos pacientes a fim de permitir trabalhar num projeto conjunto para o desenvolvimento de compe-

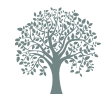

Conheça mais sobre os relatórios citados neste parágrafo consultando os seguintes endereços:

European Centre for Disease Prevention and Control. Point prevalence survey of healthcare-associated infections and antimicrobial use in European acute care hospitals 2011-2012. Stockholm: ECDC; 2013 [citado 2014 jun 22]. Disponível em: http://www.ecdc.europa. eu/en/press/news/_layouts/ forms/News_DispForm. aspx $? \mid \mathrm{D}=718 \&$ List $=8 \mathrm{db} 7286 \mathrm{c}$ fe2d-476c-9133-

$18 f f 4 c b 1 b 568$.

União Europeia, Conselho. Recomendação do Conselho, de 9 de junho de 2009, sobre a segurança dos pacientes, incluindo a prevençãoe o controlo de infeções associadas aos cuidados da saúde (2009/C 151/01). J Oficial União Europeia. 2009 Jul 3. Disponível em: http:// ec.europa.eu/health/patient_ safety/docs/council_2009_ ro.pdf

European Commission. Report from the Commission to the Council: on the basis of Member States' reports on the implementation of the Council Recommendation (2009/C 151/01) on patient safety, including the prevention and control of healthcare associated infections. Brussels: EC; 2012 [citado 2014 jun 22]. Disponível em: http:// ec.europa.eu/health/patient_ safety/docs/council_2009_ report_en.pdf. 
tências essenciais aos pacientes, encorajando-os, bem como aos seus familiares a relatar e a recolher informação sobre eventos adversos, garantindo um contexto não punitivo nessa área (Sousa et al. 2011).

Para praticar

Leia a recomendação da UE sobre segurança do paciente em: http:// ec.europa.eu/health/patient_safety/docs/council_2009_ro.pdf

Após a leitura, liste quais são as medidas mais importantes aí previstas para implementar a segurança do paciente em organizações de saúde.

Em face dessa situação, a Comissão Europeia propôs a extensão do monitoramento da implementação das disposições gerais de segurança do paciente estabelecidas na Recomendação de 2009 para um período adicional de dois anos. Um segundo relatório está previsto para junho de 2014.

Que papel caberá ao direito no melhoramento da situação de segurança do paciente em organizações de saúde?

Sobre essa questão, há, primeiramente, de se constatar que a segurança do paciente, no domínio do direito, ainda é um campo emergente, no qual os dilemas tendem a superar as soluções. De facto, o interesse dos juristas pela temática da segurança do paciente de uma forma interdisciplinar e pró-ativa, no sentido de analisar como é que a lei pode ajudar a melhorar a segurança dos utentes/usuários de organizações e serviços de saúde, é algo recente.

Normalmente, os problemas da segurança do paciente só chegam aos profissionais do direito pela via das reações aos danos ocorridos nos serviços de saúde, isto é, quando os pacientes ou suas famílias interpõem queixa contra os profissionais ou suas administrações. De facto, os próprios programas de gestão do risco em unidades de saúde nasceram nos Estados Unidos da América nos anos de 1970, como resposta a uma explosão de ações em tribunal contra médicos (malpractice crisis), em que, só no Estado de Nova Iorque, verificou-se o aumento de 564 (em 1970) para 1.200 novos casos/ano em 1974 (Faria 1991, 2010). Aliás, o objetivo essencial desses programas iniciais de gestão do risco em organizações de saúde era essencialmente o de prevenir 
o risco financeiro institucional (proteção do património), proveniente de ações em tribunal contra elas, quer por meio de uma gestão reativa em relação às ações já interpostas, quer de uma gestão preventiva no sentido de acautelar futuras ações em tribunal (Balsamo, Brown 2004). As características dos programas e dos departamentos clássicos de gestão de unidades de saúde eram as seguintes:

natureza base essencialmente jurídico-legal (o gestor do risco era sempre um jurista);

滕 necessidade de cooperação estreita com departamentos e serviços clínicos;

multidisciplinaridade, isto é, envolvendo toda a atividade da organização de saúde: clínica (prestação de cuidados) e não clínica (edifícios, refeições etc.).

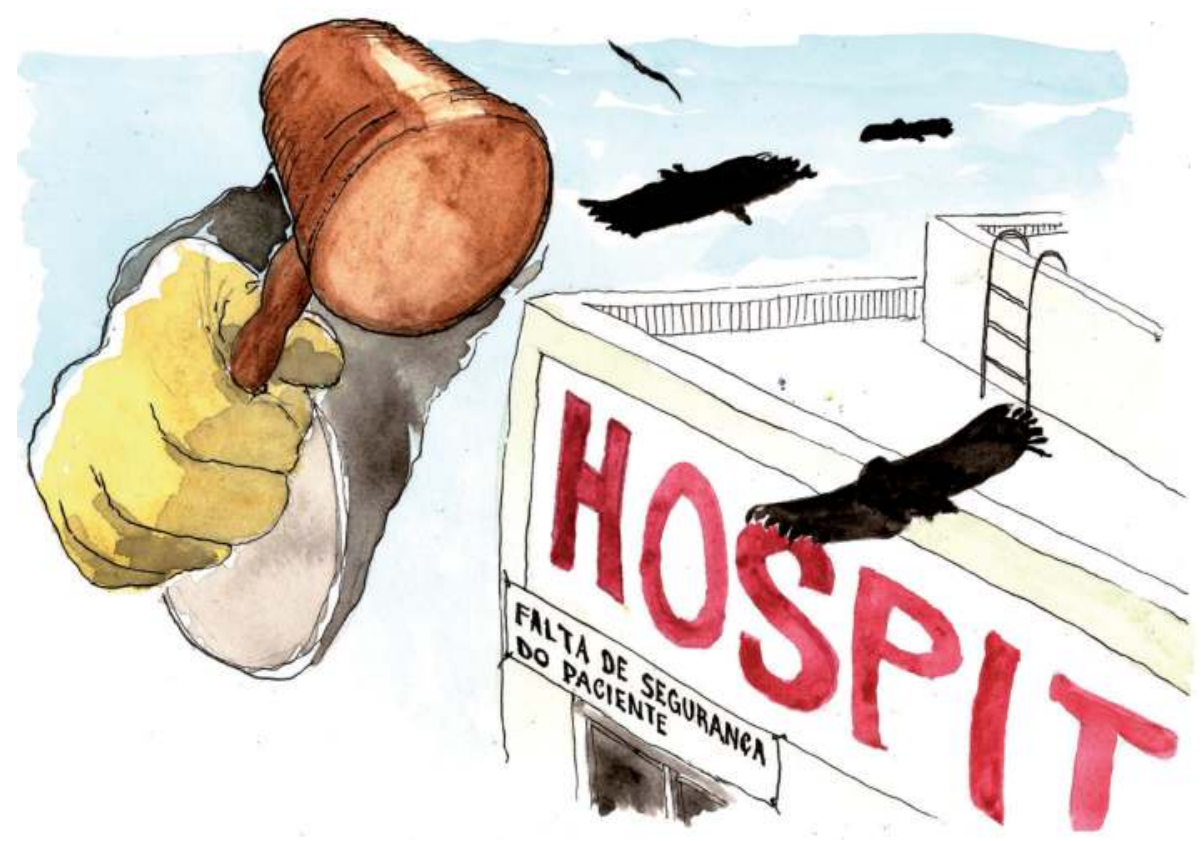

Só a partir do já citado relatório do IOM (Kohn et al. 2000) em 2000 ocorre uma mudança de paradigma nesse estado de coisas, passando o conceito de gestão do risco a estar aliado ao conceito da gestão da qualidade e do risco clínico. Essa nova abordagem da gestão do risco em organizações de saúde passa a ter como objetivo essencial a segurança do paciente e a prevenção do evento clínico adverso, e já não apenas de evitar o risco financeiro das queixas em tribunal. Passa-se para o objetivo de tornar o sistema de saúde mais seguro. 
Essa lei francesa versa sobre a reforma das instituições hospitalares e sobre os pacientes e determina, em seu artigo $1^{\circ}$ que "as instituições de saúde participam na realização da política de saúde pública e dos dispositivos de vigilância para garantir a segurança sanitária, elaborando e implementando uma política de melhoria contínua da qualidade e da segurança dos cuidados de saúde e uma gestão de riscos visando prevenir e responder aos eventos adversos ligados às suas atividades [...] Neste contexto, organizarão a luta contra os eventos adversos, infeções hospitalares e iatrogenia, definindo uma política do medicamento e dos dispositivos médicos esterilizados, implementando um sistema que permita garantir a qualidade da esterilização dos dispositivos médicos." (Hauté Autorité de Santé 2011, tradução nossa). Disponível em: http://www.has-sante.fr/portail/ jcms/c_1098725/lois.
O sucesso da gestão do risco em organizações de saúde, até ao virar do milênio, apurava-se pelo menor número de ações em tribunal contra aquelas instituições, o que tinha uma natureza essencialmente jurídico-legal. Hoje, o principal eixo da gestão do risco nas unidades de saúde é a promoção da segurança clínica por meio da qualidade dos cuidados prestados, exigindo-se, pois, novas e mais complexas formas de avaliação da sua eficácia.

A atuação dos juristas continua muito associada à gestão das queixas em tribunal, enquanto os "gestores da qualidade" são normalmente profissionais de saúde, havendo todo o interesse numa intercolaboração intensa entre essas duas áreas (Balsamo, Brown 2004).

Daí que, por regra, a temática da segurança do paciente só seja analisada pelos juristas quando os incidentes já provocaram danos, e é necessário litigar em tribunal sobre o ressarcimento das vítimas ou sobre a punição dos presumíveis culpados. No entanto, existem hoje, a nível internacional, especialistas do direito da saúde, juristas e académicos da área da saúde que se vêm interessando pela área da segurança do paciente, numa perspetiva de criação de mecanismos jurídicos de concretização do direito à segurança por parte dos pacientes em organizações de saúde.

São ainda poucos, também, os países que possuem leis específicas sobre a qualidade dos serviços de saúde ou a segurança do paciente, tal como Healthcare Quality Improvement Act of 1986 (HCQIA) norte-americano ou leis que, apesar de não serem específicas sobre a questão, a preveem de forma genérica, como é o caso da França na Lei n. 2.009-879, de 21 de julho (no original: Loi n. 2009-879 du 21 juillet 2009 portant réforme de l'hôpital et relative aux patients, à la santé et aux territoire).

\section{Para refletir}

A partir da observação da sua prática, você acredita que o direito pode ser um elemento-chave para melhorar a segurança do paciente nos serviços de saúde?

Em Portugal, não existe uma lei específica sobre segurança do paciente, mas, nos termos do Decreto-Lei n. 124/2011, de 29 de dezembro, que aprovou a Lei Orgânica do Ministério da Saúde, a Direção-Geral da Saúde (DGS) tem como uma das suas atribuições promover o desenvolvimento, implementação, coordenação e avaliação de instrumentos, atividades e programas de segurança dos pacientes e de melhoria contí- 
nua da qualidade clínica e organizacional das unidades de saúde. Essas atividades são implementadas por meio do Departamento da Qualidade na Saúde pela emissão de normas e orientações, quer clínicas quer organizacionais. Essas normas não têm caráter de lei, situando-se no âmbito das normas de natureza administrativa ou mesmo técnica, mas são muito importantes para orientar os serviços de saúde na área da segurança do paciente.

Em 2009, a Estratégia Nacional para a Qualidade na Saúde foi aprovada por despacho ministerial, novamente uma norma de natureza administrativa (Faria, Moreira 2009). Para dar continuidade a essa estratégia, um despacho publicado a 7 de março de 2013 determina que:

todos os serviços e entidades públicas prestadoras de cuidados de saúde [...] devem elaborar um plano de ação anual, que explicite as atividades e o planejamento que a instituição pretende desenvolver atentas às prioridades estratégicas e ações definidas na Estratégia Nacional para a Qualidade na Saúde, segundo um modelo definido pelo Departamento da Qualidade na Saúde.

No Brasil, o Ministério da Saúde criou o Programa Nacional de Segurança do Paciente (PNSP) por meio da publicação da Portaria n. 529 de $1^{\circ}$ de abril de 2013 e da Resolução (RDC 36) da Agência Nacional de Vigilância Sanitária (Anvisa), com objetivo primordial de melhorar a segurança dos pacientes atendidos pelas organizações de saúde. O PNSP prevê:

镂 Nos serviços de saúde: implantar os núcleos, planos locais de segurança do paciente e os protocolos de cirurgia segura; prevenção de úlcera por pressão; higienização das mãos; identificação do paciente; medicação segura e prevenção de queda (os protocolos foram publicados pelo Ministério da Saúde, por meio das Portarias n. 1.377, de 9 de julho de 2013 e n. 2.095, de 24 de setembro de 2013).

噒 No campo regulatório: participar ativamente do sistema de notificações de incidentes do Sistema Nacional de Vigilância Sanitária.

噄 Envolver o cidadão.

䠌 No ensino: atividades de pós-graduação - educação permanente e especialização e de graduação.

瞵 Aumentar a pesquisa em segurança do paciente.

Podemos dizer que, no cômputo geral, o direito está ainda subaproveitado na luta por serviços de saúde mais seguros, não existindo consenso sobre quais as medidas legais que podem realmente melhorar a

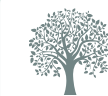

Para ler na íntegra a Portaria n. 529 da Anvisa, acesse: http://bvsms.saude.gov.br/ bvs/saudelegis/gm/2013/ prt0529_01_04_2013.html.

E para conhecer mais sobre o PNSP, acesse: http:// bvsms.saude.gov.br/bvs/ saudelegis/gm/2013/ prt0529_01_04_2013.html 
segurança das organizações de saúde. Maior interesse pela interação do direito com a segurança do paciente deve, no entanto, ser cultivado, dado que a lei é o mais forte instrumento de intervenção na sociedade, sendo única em suas competências para:

Criar direitos e obrigações

Estabelecer princípios e padrões de comportamento pró-segurança

Resolver conflitos de interesse

Criar equilíbrios no confronto inevitável entre os interesses dos gestores e os direitos individuais dos pacientes

Promover as medidas necessárias de alocação de recursos para as áreas da gestão do risco e da qualidade e segurança dos cuidados de saúde

Por conseguinte, a procura das medidas legais adequadas e eficientes no combate ao flagelo do erro clínico surge como uma das preocupações mais prementes na área da governação em saúde.

Sobre a terminologia "erro clínico": A expressão "erro médico" ou "erro em medicina", tradução literal da expressão medical error, utilizada nomeadamente em 1994, no famoso estudo de Lucian Leape, tem sido muitíssimo contestada pela carga negativa que contém em relação à profissão médica, pelo que recentemente se vem tentando substituí-la por outras designações mais pró-ativas e abrangentes, tais como "erro em cuidados de saúde", "risco iatrogénico" ou mesmo "segurança do paciente". Não há uma aceitação consensual, e a comunidade médica prefere falar de "risco clínico" ou "risco iatrogénico", enquanto os profissionais da saúde pública preferem a expressão "gestão do risco clínico" ou "segurança do paciente". Não existe literatura específica sobre essa ainda recente discussão terminológica, mas, nos próximos anos, espera-se, pelo menos, abolir a expressão "erro médico", que se apresenta indubitavelmente errónea e pejorativa. 


\section{Dilemas legais na segurança do paciente}

Em 2004, na prestigiada revista Health Affairs, o autor R. M. Wachter, identificou, de forma sistematizada e clara, alguns dos problemas que, numa perspetiva geral, ainda subsistem e impedem que se possa afirmar que hoje, nas organizações de saúde, existe já uma verdadeira segurança do paciente. Apesar disso, segundo alguns estudos citados pelo mesmo autor, observa-se que a perceção dos profissionais em relação ao evoluir dessa questão é de otimismo. Assim, os problemas que ainda subsistem, segundo Wachter e, também, George J. Annas (2004, 2010), autores que seguimos e com os quais concordamos, são:

\section{A existência de um modelo mental desatualizado sobre eventos adversos nas organizações de saúde, o qual leva à recusa em aceitar o erro e a agir no sentido de o evitar.}

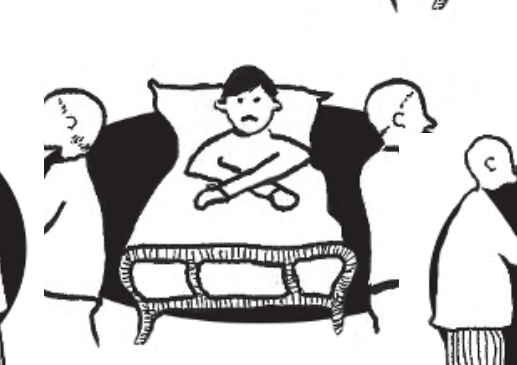

A desatenção coletiva a que é voltada a segurança do paciente, começando pelas administrações dos hospitais e restantes organizações de saúde, as quais dão mais importância à contenção de custos e gestão financeira do que à segurança dos seus pacientes.
A estrutura fragmentada das organizações de saúde em que existem várias hierarquias profissionais paralelas.

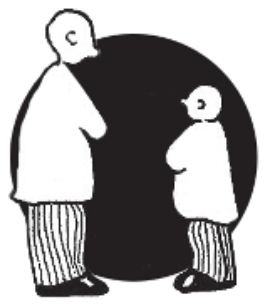

O regime jurídico da responsabilidade civil baseado na culpa, o qual deveria ser substituído no sector da saúde por um regime de responsabilidade objectiva, tal como existe, por exemplo, na Finlândia desde 1987 (Faria 1991, 2010). Nesse regime, o sistema de indenização das vítimas de erro clínico potencia o relato e o melhor conhecimento do que falhou, pois o ressarcimento dos danos é apurado independentemente de ter que se provar a culpa dos profissionais em tribunal.

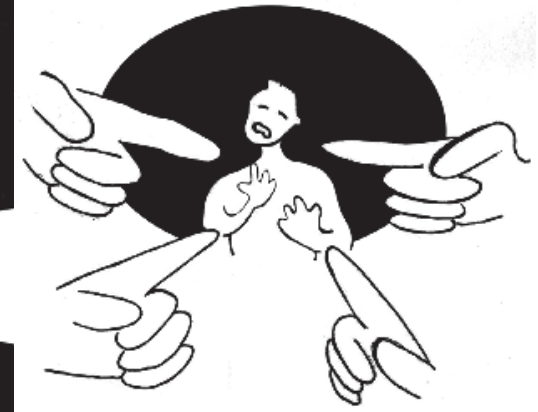

A inexistência de um sistema de incentivos para organizações de saúde que cumpram e observem os parâmetros de qualidade exigidos e cujos índices de segurança sejam mais elevados.

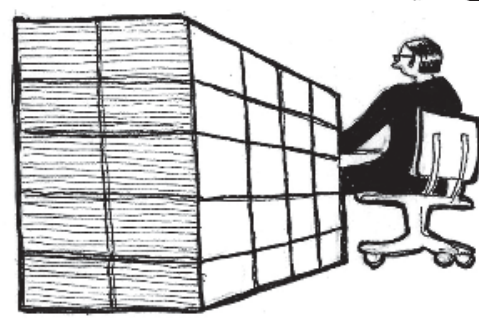

A ausência de sistemas obrigatórios para relatar eventos adversos e, mesmo quando existem, a dificuldade em levar os profissionais a cumprir a obrigação de elaborar os relatórios. Além da sensação de inutilidade dos relatórios de eventos adversos, na medida em que, na maior parte das vezes, esses apenas se amontoam numa gaveta, sem que sejam tomadas verdadeiras medidas pró-ativas no sentido de corrigir as falhas detetadas, Wachter (2004) refere que há evidência que muitos hospitais nova-iorquinos não estão a cumprir a lei que os obriga a relatar todos os eventos adversos ocorridos. O autor afirma que "este é o calcanhar de Aquiles do sistema de relatório de erros: a noção errónea de que a comunicação tem valor intrínseco em si mesma" (Watcher 2004, tradução nossa). E não se pode dizer que, nos Estados Unidos, aquele incumprimento se deva ao medo de represálias pelo relato de eventos adversos, pois, naquele país, a lei protege a confidencialidade dos peer-reviews, realizados para analisar esse tipo de relatório. 
Todos os casos em que um "evento adverso", numa unidade de cuidados, gera danos graves, a comunicação social dá-lhes cobertura de primeira página ou de abertura de tele (ou rádio) jornais. O exemplo mais recente e mais mediatizado em Portugal foi um caso de troca de medicamentos no Hospital de Santa Maria, que levou a danos nos olhos de seis pacientes. Veja, por exemplo, a base de dados do jornal Expresso sobre esse assunto em: http://aeiou.expresso.pt/ cegueira-em-santa-maria=s25185 [citado 2014 jan. 10]

\section{Para refletir}

A partir da sua vivência profissional, você concorda que os problemas citados por Wachter subsistem nas organizações de saúde e impedem a construção de uma verdadeira cultura de segurança do paciente?

Sob o ponto de vista estritamente jurídico, não se vislumbra uma solução pronta e fácil para os problemas já descritos; muito pelo contrário, apresentam-se como verdadeiros dilemas nessa área. De facto, existem alguns desafios que se colocam permanentemente ao direito no campo da segurança clínica, os quais enunciamos em seguida:

蹸 Como promover uma cultura de "não culpabilização" para que haja um relato de eventos adversos nas organizações de saúde, sem medo do processo em tribunal, ao mesmo tempo que é também necessário identificar e punir os profissionais que agem com negligência ou desrespeitam as regras?

橉 Como compensar celeremente as vítimas de injúrias em saúde, sem o peso da máquina judicial, quando a maior parte dos regimes jurídicos é baseada na culpa que deve ser provada em tribunal?

粼 Como tornar as unidades de saúde responsáveis por reportarem seus erros, evitando que esse facto se transforme numa imediata sentença condenatória por parte da imprensa e dos média ou numa ação em tribunal?

镂 Como responsabilizar os gestores de saúde pelo cumprimento das normas e parâmetros de qualidade e segurança em situações de crise e cortes orçamentais?

A seguir, analisaremos algumas das soluções que têm sido apontadas para dar resposta aos problemas e dilemas expostos anteriormente.

\section{Para praticar}

Descreva os dilemas legais que se colocam no domínio da segurança do paciente e as soluções que você preconizaria para eles.

\section{Soluções legais apontadas para melhorar a segurança do paciente}

Quais seriam, então, as soluções possíveis para melhorar a segurança do paciente? Wachter (2004), por exemplo, cita as recomendações do relatório do IOM, isto é: 
A necessidade de regulamentação

A melhoria dos sistemas de relatos de eventos adversos

A maximização da utilização das tecnologias de informação

A punição da conduta negligente (malpractice) e outros mecanismos de responsabilização (accountability), bem como

A necessidade de formar os profissionais de saúde no trabalho em equipe

Outros autores consideram que, a fim de criar medidas mais eficazes nas organizações de cuidados de saúde para evitar eventos adversos, o sector da saúde deveria desenvolver parcerias com sectores em que a segurança é a regra, como a indústria da aviação, nomeadamente na adoção de normas de segurança e monitorização tão rígidas quanto as que existem naquela atividade (Pronovost et al. 2009; Romano 2005). No entanto, alguns autores argumentam que os melhores exemplos de como diminuir o risco médico vêm de dentro da própria medicina, como é o caso do sucesso na redução do risco de morte associado à anestesia, em que, nos EUA, em apenas 25 anos, passou de 1 para 5 mil a 1 para 250 mil (Annas 2010, p.165-173). Têm sido também apontadas algumas soluções mais específicas, as quais apresentaremos em seguida.

Figura 1 - Tela de Ernest Board (1877-1934)

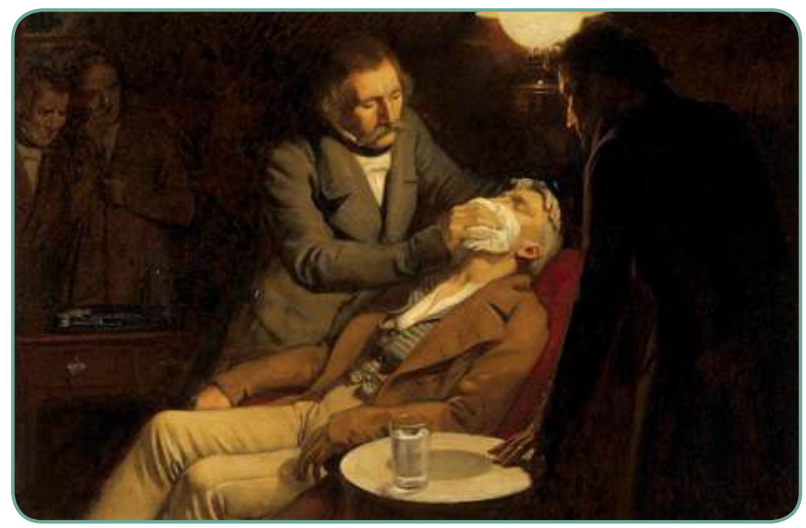

Fonte: Wikipedia.

Do uso do éter aos procedimentos mais modernos da anestesia, a evolução das questões de segurança nesta área da medicina nos oferece um bom exemplo a ser estudado. 


\section{O Patient's Rights Advocate}

Os autores Jay Healey e George J. Annas, baseados na evidência de que um paciente, quando acompanhado por alguém que possa ir observando os cuidados e em particular os medicamentos que lhe são administrados, fica mais protegido de erros clínicos ou medicamentosos (Annas 2010), sobretudo os pacientes mais fragilizados, propõem que se crie uma nova entidade nas organizações de saúde, o "patient's rights advocate" (expressão que traduzimos aqui livremente por "defensor do paciente"). Seria uma pessoa da confiança do paciente, por ele proposto ou mesmo, na ausência dessa possibilidade, alguém contratado especialmente para o efeito, pelo paciente, seus familiares ou pela organização, com o objetivo de acompanhar o paciente durante sua permanência na unidade de saúde, ajudando-o e representando-o, de forma a tornar suas escolhas verdadeiramente informadas, a exercer melhor seus direitos e a protegê-lo de erros clínicos (Annas 2004).

\section{Dar voz ao paciente: o caso Betsy Lehman (1993)}

Betsy Lehman, de 37 anos, jornalista do jornal Boston Globe, tinha duas filhas. Em 1993, em tratamento de quimioterapia para um cancro/câncer da mama, recebeu, durante quatro dias, por engano, uma dose muito mais elevada que a prescrita. Apesar das suas inúmeras e repetidas queixas aos clínicos de dores e mal-estar, sua situação não foi avaliada por exames ou análises. Seu coração, entre outros órgãos, estava já acometido, e um eletrocardiograma feito a tempo depois das primeiras queixas teria mostrado que algo estava errado. O facto de ter falecido após ter telefonado a uma amiga a dizer que se sentia muito mal e de se ter apurado que, desde esse telefonema até ser encontrada morta, mediaram 45 minutos sem que ninguém tivesse respondido aos seus apelos, tornou o caso Betsy Lehman no caso-estudo mais paradigmático para análise dos factos e eventos desencadeantes de um incidente adverso de enorme gravidade, com consequências dramáticas.

Pelo facto de Betsy Lehman ser jornalista, casada com um médico (curiosamente do mesmo hospital onde ocorreu seu tratamento e posterior falecimento) e viver perto de Harvard concorreu, certamente, para a mediatização desse caso.

Se, sob o ponto de vista legal, nunca houve um processo contra os médicos que assistiram Betsy Lehman, e ninguém foi julgado ou condenado pelos erros fatais cometidos, o caso dessa jornalista teve con- 
sequências diretas não só para um incremento do estudo da segurança dos pacientes, mas também na concretização da criação, em 2004, do Betsy Lehman Center for Patient Safety and Medical Error Reduction no Departamento de Saúde Pública do Estado do Massachusetts (Annas 2004). Esse caso ajudou, definitivamente, a que se considerasse a segurança do paciente como uma prioridade de saúde pública (Balsamo, Brown 2004; Annas 2004, 2010).

\section{O direito à segurança do paciente}

Apesar de haver unanimidade em torno da necessidade de implementar, urgentemente, normas legais que darão prioridade à segurança do paciente, como é o caso de criar um verdadeiro direito à segurança em organizações de saúde da pessoa doente (Annas 2010), tal ainda não ocorreu. De facto, a consagração da segurança do paciente como um direito da pessoa é algo que, sob o ponto de vista legal, se enquadra muito facilmente no quadro dos princípios fundamentais do direito, dado que tem como objetivo proteger o interesse legítimo das pessoas em prevenir a morte ou injúrias físicas decorrentes de cuidados de saúde, sendo ainda uma questão de proteção de direitos humanos, integrando os direitos fundamentais à vida e à integridade física.

\section{Para refletir}

Você já observou, na prática, casos semelhantes ao de Betsy Lehman?

Pela sua vivência, acredita que a consagração na lei de um direito à segurança do paciente poderia representar maior proteção para evitar casos como esse?

\section{Leis de incentivo à qualidade em organizações de saúde}

Dada a falência das medidas legais tradicionais para melhorar os níveis de segurança dos cuidados de saúde, novos horizontes se abriram nos EUA com base na ideia de que a estratégia ideal para conseguir essa segurança será uma nova filosofia político-legal, isto é, a de que o financiamento das organizações de saúde e o pagamento dos atos de cuidados de saúde devem ser estimados de acordo com seu nível de qualidade, e não sem ter em conta tais elementos como ocorre no presente (Leatherman et al. 2003). A criação de leis de incentivo fiscal ou financeiro para as organizações de saúde com bons níveis de segurança é mencionada como mecanismo legal idóneo para melhorar a segurança do paciente. 


\section{O direito a conhecer quem cuida de nós}

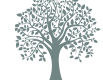

Para conhecer mais sobre o National Practicioner Data Bank, acesse: http://www. npdb-hipdb.hrsa.gov/
Para mais informações sobre evento iatrogênico, reveja o Capítulo 3 deste livro Segurança do paciente: conhecendo os riscos nas organizações de saúde.
A criação de mecanismos idóneos para o conhecimento, por parte das instituições e pacientes, do nível de experiência e competência dos profissionais de saúde é considerada pelo IOM uma medida de segurança de grande relevância. Todos os países deveriam ter uma entidade análoga ao National Practicioner Data Bank norte-americano.

\section{Para praticar}

O que deveria ser feito, a nível legal, para promover uma boa gestão do risco e promoção da segurança nas organizações de saúde? Realize essa análise a partir das seguintes medidas:

- dar prioridade à segurança do paciente como objetivo da gestão do risco em organizações de saúde;

- elaborar uma lei de bases sobre gestão do risco e implementação da qualidade em organizações de saúde;

- considerar a segurança do paciente uma prioridade de saúde pública;

- publicar normas legais de segurança em organizações de saúde e mecanismos de avaliação do seu cumprimento;

- criar mecanismos idóneos para o conhecimento, por parte das organizações e pacientes, do nível de experiência e competência dos profissionais de saúde;

- reforçar os direitos dos pacientes por meio da instituição de uma figura semelhante ao "patients rights advocate";

- criar mecanismo eficaz e obrigatório de relatório de ocorrências anómalas;

- garantir a confidencialidade sobre as informações prestadas, impedindo represálias para os seus autores - permitir o mero relatório oral desses factos;

- criar incentivos para as organizações de saúde com bons níveis de segurança e para implementação de sistemas informáticos eficazes.

\section{Problemas jurídico-legais resultantes do evento adverso}

O "evento iatrogénico" é uma realidade incontornável em medicina, facto que deveria ter relevância no direito, por exemplo, na adoção de um sistema de responsabilidade objetiva (isto é, não baseado na culpa 
dos agentes) para a compensação por danos em organizações de saúde, tal como já referido. Outra opção seria criar um sistema mais justo e menos penoso judicialmente para pacientes e profissionais, tal como o regime francês de compensação arbitral de alguns danos mais graves ocorridos em pacientes.

Existem, aliás, uma série de factores que indiciam que haverá, certamente, tendência para o crescimento das ações em tribunal por danos causados em organizações de saúde:
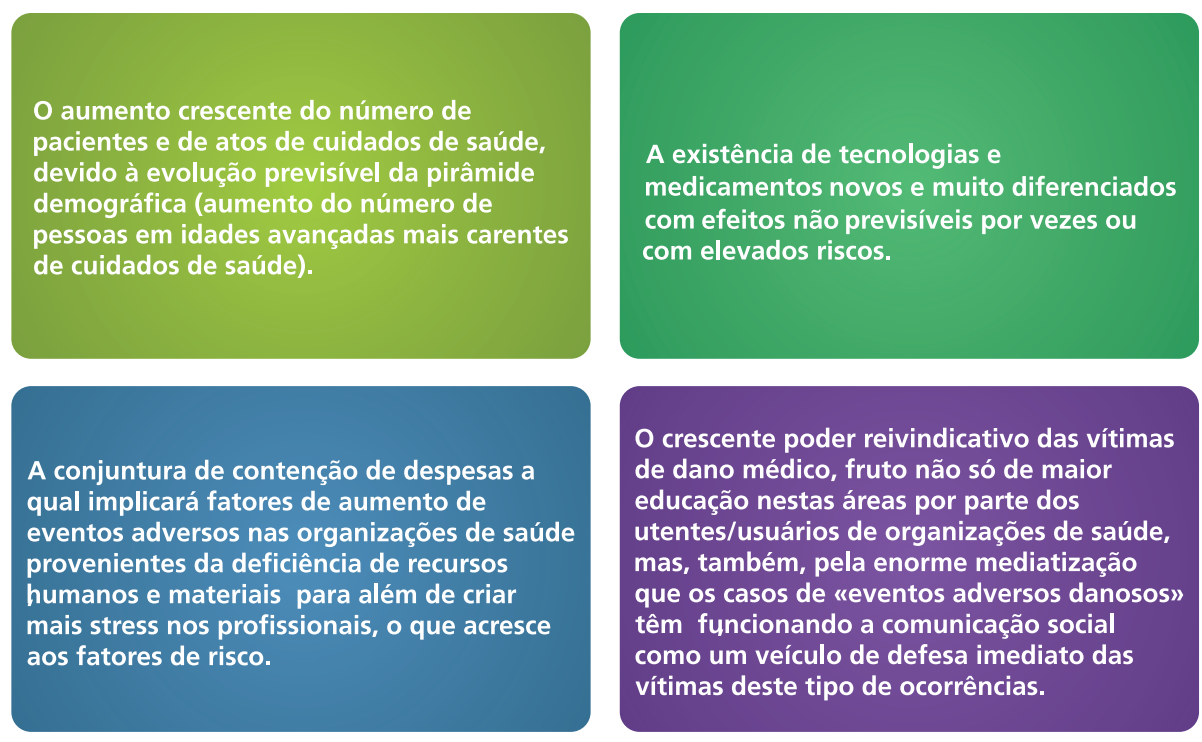

Mesmo não sendo habitualmente fruto de negligência, como o demonstrou o famoso relatório Harvard Medical Practice Study III (Localio et al. 1992), os "incidentes adversos", sobretudo quando graves, podem sempre vir a dar origem a uma ação em tribunal contra o profissional de saúde e/ou a organização, o que poderá culminar, eventualmente, numa obrigação por parte desses em indenizar o(s) pacientes(s) lesado(s). Daí que a questão da segurança do paciente e da gestão do risco em unidades de organizações de saúde para a prevenção dos incidentes adversos tenha passado a ser, a partir de 2000, um dos temas de debate obrigatório na área do direito da saúde.

No Brasil, também, a partir da década de 1990 verificou-se considerável crescimento no número de ações judiciais contra profissionais e organizações de saúde. Isso se deveu a diversos factores, podendo-se destacar o aumento da regulação e a regulamentação da prestação de cuidado, em que é definida a responsabilização dos envolvidos no "insucesso" de algum
O sistema francês conhecido por Oniam (Office national d'indemnisation des accidents médicaux) foi criado pela Lei de 4 de março de 2002, relativa aos direitos dos pacientes e à qualidade do sistema de saúde (no original: Loi du 4 mars 2002 relative aux droits des malades et à la qualité du système de santé). Para saber mais: http://www.oniam.fr/ dispositif.php 
procedimento. Segundo levantamento realizado em 2008 pelo Superior Tribunal de Justiça (STJ), o número de processos ajuizados em decorrência de evento adverso aumentou 200\% em seis anos (Cavalieri 2007).

Esse levantamento do STJ está disponível em: http:// www.stj.gov.br/portal_stj/ publicacao/engine.wsp?tmp. area $=398 \&$ tmp.texto $=89920$
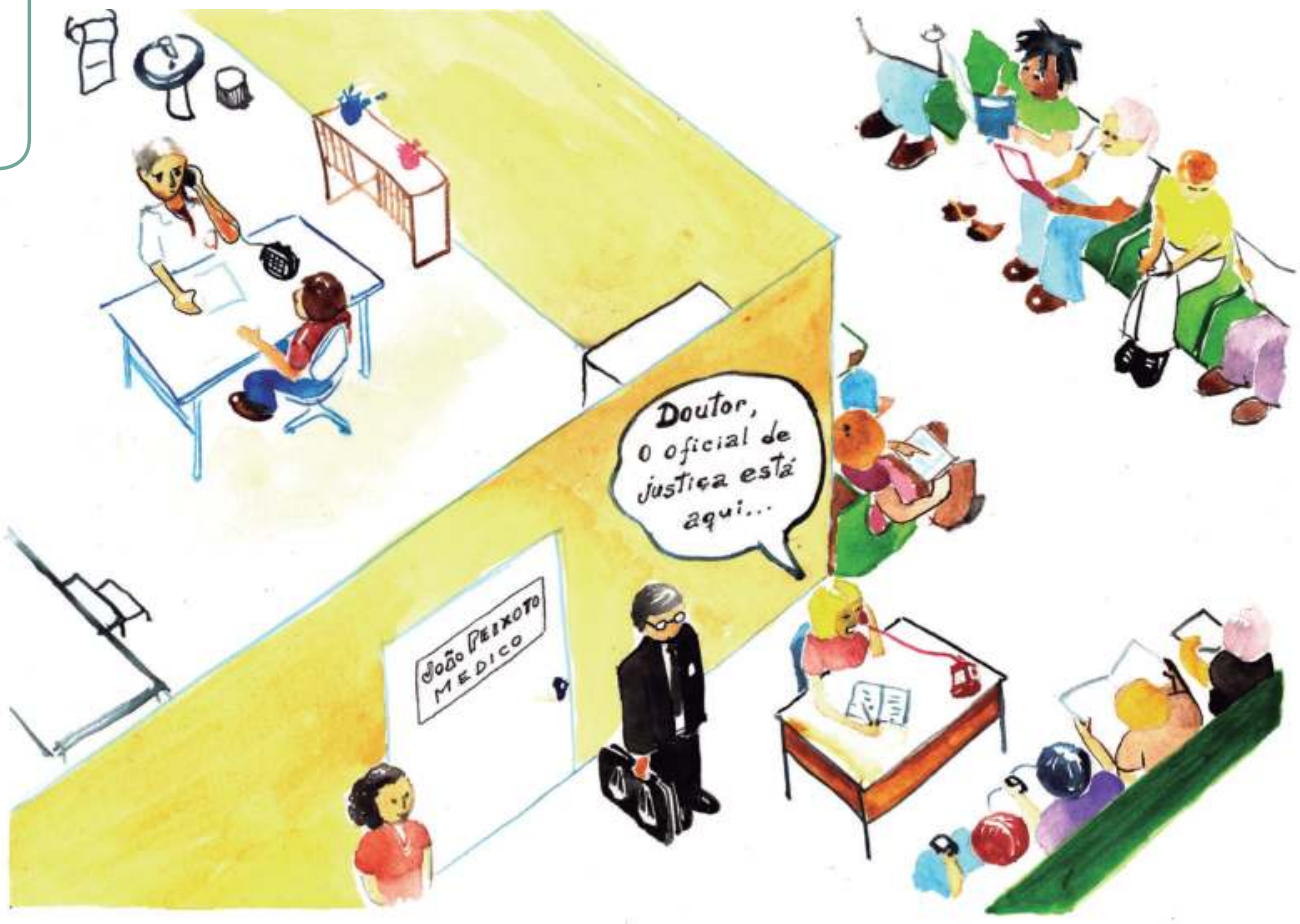

A responsabilidade proveniente de evento adverso grave para os profissionais envolvidos pode ser de natureza civil, penal, disciplinar (Portugal) ou administrativa (Brasil) e é regida pelos Códigos Civil, Penal, de Defesa do Consumidor (Brasil), para além dos Códigos Disciplinares, de Ética, de Deontologia e de Processos Ético-Profissionais que possam existir relativamente a cada categoria profissional.

\section{Para que haja obrigação de indenizar}

A responsabilidade civil implica quatro pressupostos quer no direito brasileiro, quer no direito português: a ação ou omissão do agente; o resultado danoso causado por ele; a relação existente entre a ação e a omissão e o resultado obtido; e a imputação ao agente do dano. A ação de um agente refere-se à conduta que o profissional teve e contribuiu para a ocorrência de um dano ao paciente. Já a omissão é aquela conduta que o profissional deveria ter realizado, isto é, quando houve falta de ação no tratamento do paciente levando ao dano. O dano é condição essencial para que haja a possibilidade de responsabilização civil de um profissional, pois, não havendo nenhum resultado danoso, isto é, não tendo sido violado nenhum direito do paciente que seja juridicamente 
tutelado, não há o porquê de se falar em dever de indenizar, muito menos em responsabilização pelo dano. Outro pressuposto fundamental para a responsabilização civil de um profissional é o nexo causal ou nexo de causalidade adequado. É necessário que o dano sofrido pelo paciente seja diretamente decorrente da ação ou omissão do profissional, isto é, deve haver uma relação de causa e efeito entre a conduta (ou falta dela) tomada pelo agente e o resultado obtido pelo paciente (dano).

\section{Responsabilidade civil}

O instituto da responsabilidade civil tem, basicamente, como objetivo, buscar a reparação de um dano, e quem tiver dado causa a ele terá o dever de repará-lo, a fim de restaurar o equilíbrio violado.

A imputação tem a função de determinar a legitimidade ou não do agente do dano, isto é, identificar se a pessoa que deu causa ao dano tinha, efetivamente, a obrigação de cuidar e não o fez (podendo fazê-lo), devendo, assim, responder pelo resultado e o dever de indenizar o paciente.

Mas o que é negligência, imprudência e imperícia?

(Direito brasileiro)

A negligência está ligada ao descuido, desídia, inação, inércia, passividade, desleixo, falta de cuidado daquele que deveria agir. Trata-se de um ato omissivo, isto é, o agente deixou de fazer algo que deveria ter praticado. Na área da saúde, é aquela situação em que há o abandono do paciente, a omissão de tratamento.

Já a imprudência está diretamente relacionada com o agir da pessoa causadora do dano, isto é, a alguma ação comissiva do agente. Se refere a atitudes não justificadas, ou descuidadas, precipitadas, de maneira intempestiva, sem uso de cautela e precaução que o profissional deveria ter.

E a imperícia ocorre quando não há a observação das normas por parte daquele que deveria tê-las e segui-las, incluindo-se aqui a ignorância técnica dos profissionais, inexperiência, incompetência, desconhecimento e despreparo prático do agente.

\section{Considerações finais}

Tratar a questão da gestão do risco clínico, em particular do tratamento medicamentoso ou a gestão da qualidade em organizações de saúde, é falar de direitos fundamentais da pessoa como paciente ou utente/ 
usuário de organizações de saúde, isto é, dos direitos à vida e à integridade física e psíquica. Sabemos, porém, que o direito à segurança não está ainda acautelado nas organizações de saúde. "Gerir o risco" deverá significar evitar o erro e não evitar a ação em tribunal contra a organização ou o profissional, mas há que sedimentar algumas premissas básicas de uma cultura de segurança do paciente:

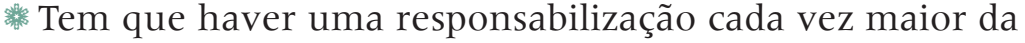
organização na área da prevenção de eventos adversos por meio do reforço dos deveres de velar pela segurança do paciente; controlar a qualidade dos cuidados e assistência prestados; analisar e avaliar de forma idónea as credenciais e qualidade profissional do seu staff.

* Há que proteger e dar voz ao paciente, ou seja, dar primazia ao princípio de que o paciente tem sempre razão sobre seu corpo até prova em contrário (caso Betsy Lehman).

Deve ser criada a existência de um defensor do paciente (patient's advocate) a fim de proteger e representar o paciente.

* Devem ser reconhecidos aos pacientes o direito à segurança e o direito a saber o nível de experiência e competência de quem o trata.

* Os relatórios de ocorrência de erros ou situações anómalas (Error Reporting Systems) devem ser obrigatórios por lei, mas tendo em atenção que, para que tal sistema resulte, haverá que educar os profissionais de saúde no sentido de cumprirem essa norma; proteger os profissionais de represálias pelo relato de eventos adversos; mostrar que os relatórios de erros servem para melhorar e corrigir falhas na prestação de cuidados aos pacientes e não irão amontoar-se numa gaveta.

Diversos estudos têm vindo a ser feitos, nomeadamente ao nível da OMS (WHO 2008), no sentido de encontrar evidências do que funciona ou não na implementação de uma verdadeira cultura de segurança no sistema de saúde. Devemos acompanhar todo esse movimento, de forma a podermos tomar as medidas legais mais certas e testadas como eficazes na batalha contra as evitáveis mortes e incapacidades causadas pelo risco iatrogénico em organizações de saúde.

\section{Referências}

Annas GJ. The rights of patients. Carbondale (IL): ACLU; 2004

Annas GJ. Worst case bioethics: death, disaster, and public health. Oxford: Oxford University Press; 2010.

Balsamo RR, Brown MD. Risk management. In: Sanbar SS, editor. Legal medicine. Philadelphia: American College of Legal Medicine; 2004. 
Cavalieri S. Programa de responsabilidade civil. 7. ed.. São Paulo: Atlas; 2007.

European Centre for Disease Prevention and Control. Point prevalence survey of healthcareassociated infections and antimicrobial use in European acute care hospitals 2011-2012.

Stockholm: ECDC; 2013 [citado 2014 jun 22]. Disponível em: http://www.ecdc.europa.eu/en/press/ news/_layouts/forms/News_DispForm.aspx?ID=718\&List=8db7286c-fe2d-476c-9133-18ff4cb1b568.

European Commission. Report from the Commission to the Council: on the basis of Member States' reports on the implementation of the Council Recommendation (2009/C 151/01) on patient safety, including the prevention and control of healthcare associated infections. Brussels: EC, 2012 [citado 2014 jun 22]. Disponível em: http://ec.europa.eu/health/patient_safety/docs/council_2009_ report_en.pdf

Faria PL. Perspectivas do direito da saúde em segurança do doente com base na experiência norteamericana. Rev Port Saúde Pública. 2010; Vol Temat(10); 81-88.

Faria PL. Responsabilidade civil médica: o futuro do regime jurídico na década de 90 . Rev Port Saúde Pública. 1991 Jan-Mar;9(1): 9-21.

Faria PL, Jardim SV, Costa JP. O novo regime da responsabilidade civil extracontratual do Estado: repercussões no sistema de saúde. Rev Port Saúde Pública. 2008 Jan-Jun; 26(1): 89-93.

Faria PL, Kleefield S. Intensive Course on International Trends in Clinical Quality, Risk Management and Patient Safety: Proven Strategies. Lisboa: Escola Nacional de Saúde Pública; 2008. Curso realizado em Lisboa, pela Escola Nacional de Saúde Pública da Universidade Nova de Lisboa (ENSPUNL), em parceria com a Universidade de Harvard, nos dias 25 e 26 de Janeiro de 2008. Todas as apresentações do curso se encontram num CD que está depositado no Centro de Documentação e Informação da ENSP-UNL em Lisboa, Portugal.

Faria PL, Moreira PS. Estratégia nacional para a qualidade na saúde: notas em torno do Despacho n. 14 223/2009, de 24 de junho de 2009 da Ministra da Saúde. Rev Port Saúde Pública. 2009;27:103-6.

Furrow RB, Breaney SH, Jost TS, Schwartz RL. Health law: cases, materials and problems.St. Paul, Minn: West Group; 2001. p. 29-64.

Hauté Autorité de Santé. Lois relatives à la sécurité du patient: sélection de la réglementation effectuéeen. Saint-Denis La Plaine Cedex, 2011 [citado 6 jan 2014]. Disponível em: http://www.hassante.fr/portail/jcms/c_1098725/lois.

Heffernan M. The Health Care Quality Improvement Act of 1986 and the National Practitioner Data Bank: the controversy over practitioner privacy versus public access. Bull Med Libr Assoc. 1996 April;84(2):263-69.

Kohn LT, Corrigan JM, Donaldson MS. To err is human: building a safer health system. Washington, DC: National Academy Press; 1999.

Kohn LT, Corrigan JM, Donaldson MS. To err is human: building a safer health system: a report of the Committee on Quality of Health Care in America, Institute of Medicine. Washington, DC: National Academy Press; 2000.

Leape L. Error in medicine. JAMA. 1994 Dec 21;272(23):1851-57.

Leatherman S, et al. The business case for quality: case studies and an analysis. Health Aff. 2003; 22(2):17-30.

Localio AR, et al. Relation between malpractice claims and adverse events due to negligence: results of the Harvard Medical Practice Study III. N Engl J Med. 1991;325(4):245-51.

McGiffert L.Consumers Union: Policy \& Action from Consumer Reports, 2009 [citado 2014 jul 14]. Disponível em: http://consumersunion.org/experts/lisa-mcgiffert/ 
Palmer LI. Patient safety, risk reduction, and the law. Houst Law Rev. 1999;36:1609-61.

Pronovost Peter J. et al. Reducing health care hazards: lessons from the commercial aviation safety team. Health Affairs. 2009 Apr 7;28(3):w479-w489.

Romano PS. Improving the quality of hospital care in America. N Engl J Med. 2005; 353(3):302-4.

Sousa P, et al. Segurança do doente: eventos adversos em hospitais portugueses: estudo piloto de incidência, impacte e evitabilidade. Lisboa: Escola Nacional de Saúde Pública da Universidade Nova de Lisboa, 2011.

Sousa P, Uva AS, Serranheira F, Nunes C, Leite ES. Estimating the incidence of adverse events in Portuguese hospitals: a contribution to improving quality and patient safety. BMC Health Services Research. 2014;14:311. doi:10.1186/1472-6963-14-311.

União Europeia, Conselho. Recomendação do Conselho, de 9 de junho de 2009, sobre a segurança dos pacientes, incluindo a prevenção e o controlo de infeções associadas aos cuidados da saúde (2009/C 151/01). J Oficial União Europeia 2009 Jul 3. Disponível em: http://ec.europa.eu/health/ patient_safety/docs/council_2009_ro.pdf

Wachter RM. The end of the beginning: patient safety five years after to err is human. Health Aff (Millwood). 2004 Jul-Dec;Suppl Web Exclusives:W4-534-45.

Wikipedia. File:Morton Ether 1846.jpg [citado 2014 jun 24]. Disponível em: http://en.wikipedia.org/ wiki/File:Morton_Ether_1846.jpg.

World Health Organization, World Alliance for Patient Safety. Summary of the evidence on Patient Safety: implications for research. Copenhagen: WHO; 2008. 


\section{TI Avaliação e gestão do risco em organizações de saúde}

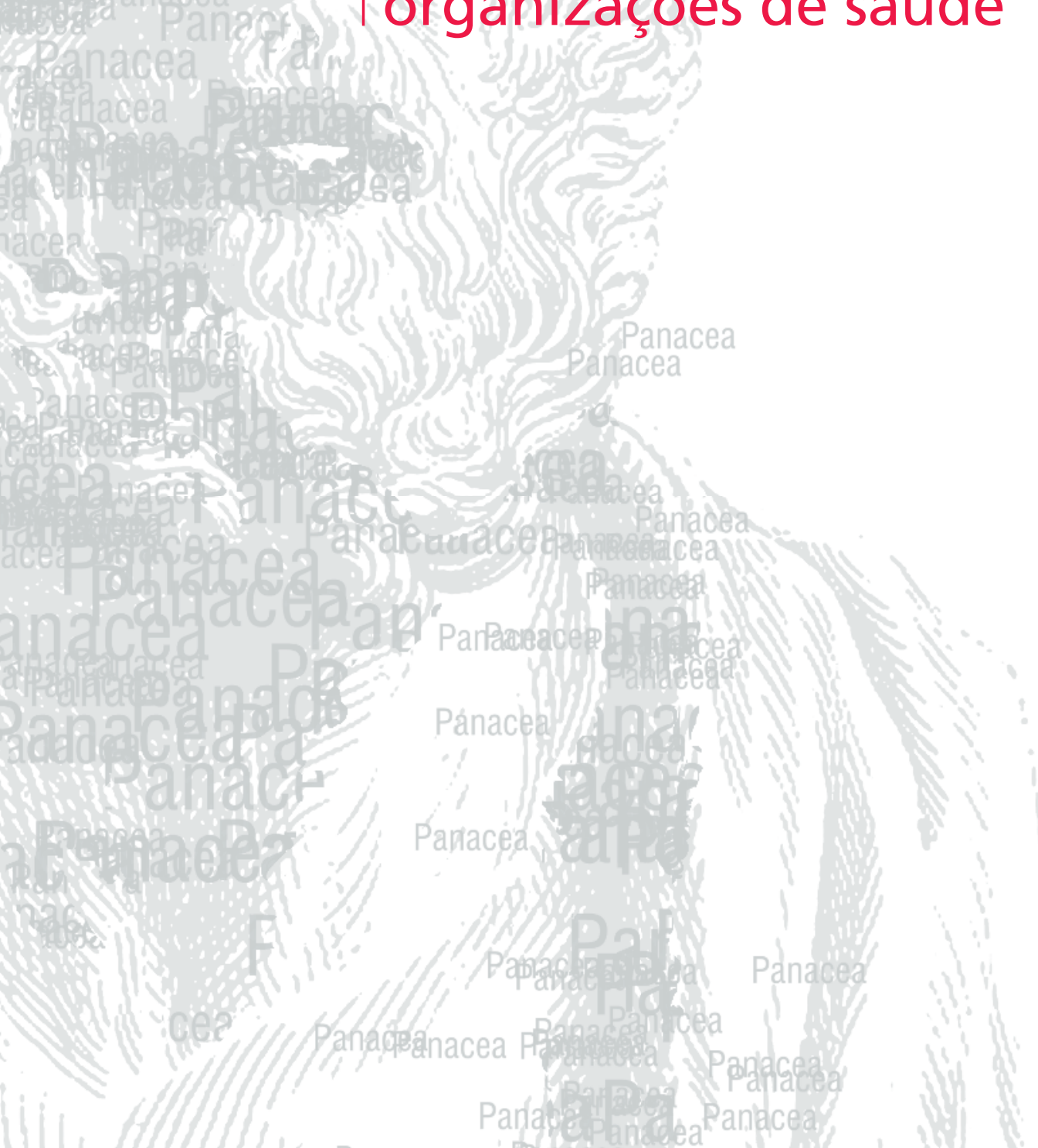




\section{Infeções associadas aos cuidados de saúde}

Elaine Pina, Etelvina Ferreira e Mafalda de Sousa-Uva

O presente capítulo aborda as seguintes questões:

* Será que as infeções associadas aos cuidados de saúde constituem um evento adverso evitável na prestação de cuidados de saúde?

粼 Em caso afirmativo, quais as principais medidas para evitar, controlar ou minimizar esse evento adverso?

\section{Definição da infeção associada aos cuidados de saúde (IACS)}

Segundo a definição de 2002 da Organização Mundial da Saúde, uma infeção nosocomial ou infeção hospitalar (IH) "é uma infeção que ocorre num paciente durante a prestação de cuidados no hospital", a qual não estava presente em incubação no momento da admissão. Estão também incluídas as infeções adquiridas no hospital e que só se manifestam após a alta, bem como "as infeções adquiridas pelos profissionais, relacionadas com a prestação de cuidados (ocupacionais)" (WHO 2002).

Na atualidade, esse conceito foi alargado e fala-se em infeções associadas aos cuidados de saúde (IACS) abrangendo situações relacionadas com a prestação de cuidados de saúde, onde quer que elas ocorram como resultado (Pina et al. 2010):

direto da prestação de cuidados de saúde, tais como tratamentos médicos ou intervenções cirúrgicas, ou como consequência do contacto com locais onde se prestam esses cuidados;

絴 direto de cuidados prestados na comunidade (atenção primária, cuidados continuados); 
A contribuição de Semmelweis para a melhoria da qualidade em saúde foi apresentada no Capítulo 2 do livro Segurança do paciente: Criando organizações de saúde seguras.
* de transmissão de uma infeção adquirida na comunidade e introduzida em instituições de saúde por pacientes, profissionais ou visitantes.

\section{Enquadramento da problemática das IACS}

A infeção tem sido uma complicação e preocupação sempre presente desde as épocas antigas. Durante muito tempo, foi encarada como um castigo divino. Mais tarde, pensou-se que era transmitida por miasmas, que surgiam espontaneamente dos maus ares produzidos em ambientes insalubres. Em 1847, Ignaz Semmelweis apercebeu-se de que os profissionais de saúde podem transmitir infeções e descreveu o modo de transmissão da sépsis puerperal, que afeta o aparelho genital feminino após o parto. Também demonstrou a eficácia de uma medida de prevenção: a desinfeção das mãos antes da prestação de cuidados. No entanto, essa medida não foi bem aceita pelos pares. Em 1864, Louis Pasteur propôs a Teoria Microbiana da Infeção; mas, só em 1890, os postulados de Koch vieram tornar plausível essa teoria proposta por Semmelweis e Pasteur.

Outro marco importante na história do controlo de infeção foi o conceito de antissepsia introduzido por Joseph Lister. Esse cirurgião conseguiu reduzir significativamente as infeções e a mortalidade após a realização de cirurgias com uso de ácido carbólico para antissepsia (Lister 1867).

No início do século XX (1928), Alexander Fleming descobriu a Penicilina (Aldridge 1999). A descoberta dos antimicrobianos veio revolucionar a prática da medicina, permitindo salvar muitas vidas durante a Segunda Grande Guerra. Pensou-se mesmo que o problema das infeções teria ficado resolvido definitivamente. Contudo, veio a verificar-se rápido que as bactérias podem criar resistências aos antimicrobianos e, na atualidade, algumas delas são pan-resistentes, ou seja, resistentes a todos os antimicrobianos disponíveis, podendo dizer-se que nos encontramos hoje em dia em uma era pós-antibiótica. A esse facto está também associada a escassez de novos antibióticos em estudo ou desenvolvimento. 
Figura 1 - Alexander Fleming recebendo o Prêmio Nobel de Medicina (1945) por sua descoberta da penicilina e suas propriedades antibióticas

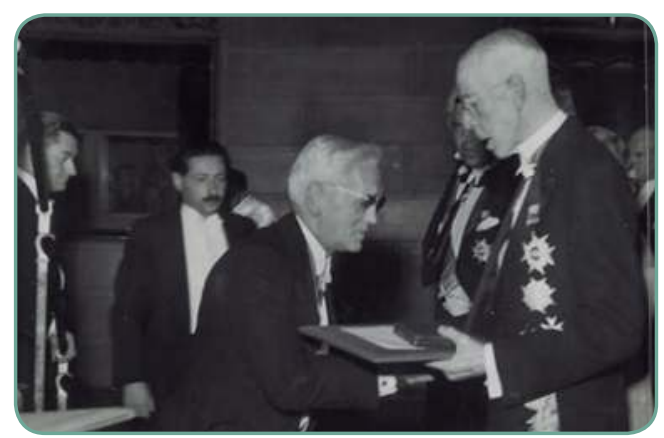

Fonte: Wikipedia (2007).

Foi Florence Nightingale quem associou as infeções nosocomiais à prestação de cuidados nos hospitais e insistiu na necessidade de intervenção para preveni-las.

\section{Para praticar}

"It may seem a strange principle to enunciate as the very first requirement in a Hospital that it should do the sick no harm" (Nightingale 1863).

Tradução... "Pode parecer um princípio estranho afirmar-se que a primeira exigência no Hospital é de não fazer mal ao paciente."

Faça uma análise crítica dessa afirmação a partir do seu contexto de trabalho.

As IACS afetam grande número de indivíduos em todo o mundo e constituem um risco significativo para pacientes, profissionais e visitantes, representando custos adicionais para o sistema de saúde. Numa revisão sistematizada da literatura, que incluiu estudos publicados entre 1995 e 2008, verificou-se a prevalência de IACS nos países em vias de desenvolvimento de 15,5\% (Allegranzi et al. 2011).

O último estudo de prevalência realizado pelo European Center for Disease Prevention and Control (ECDC) identificou uma taxa global de IACS, a nível europeu, de 6,1\%, sendo em Portugal esse valor de 10,6\% (Direção Geral da Saúde 2012). No Brasil, não há números nacionais confiáveis; num estudo estima-se que a taxa possa ser de 15,5\% (Oliveira 2005). Não se conhece a dimensão do problema das IACS na prestação de cuidados fora dos hospitais. Segundo a Organização Mundial da Saúde, as IACS constituem hoje uma epidemia silenciosa (Pittet et al. 2008). 
É provável que não seja possível evitar algumas dessas infeções, e esse seja o valor a pagar pelos avanços tecnológicos e terapêuticos. Contudo, um número significativo de infeções pode ser prevenido. O estudo do Senic, Study on the Efficacy of Nosocomial Infection Surveillance, conduzido por Haley et al. (1985), demonstrou que, com algumas medidas simples de prevenção como higiene das mãos, descontaminação correta do material, entre outros (que não incluíam a vigilância epidemiológica), era possível a redução de $6 \%$ das IH, enquanto programas com componentes de prevenção e de controlo baseados em dados de vigilância epidemiológica conseguiam reduções de cerca de 32\%. Em uma revisão sistematizada de publicações que descrevem estudos de intervenção multimodal e de transmissão ocorridas nos 12 anos anteriores, Harbarth et al. (2003) encontraram reduções de 10 a 70\% dependendo do tipo de organização, desenho do estudo, taxas de infeção anteriores ao estudo e tipo de IH. Concluíram que, pelo menos, $20 \%$ de todas as IH seriam provavelmente evitáveis. As IACS mais comuns podem ser encontradas no Quadro 1.

Quadro 1 - IACS mais frequentes e factores de risco associados

\begin{tabular}{|l|l|l|}
\hline Principais IACS & $\begin{array}{l}\text { Principais factores de risco } \\
\text { associados }\end{array}$ & Microrganismos \\
\hline $\begin{array}{l}\text { Infeção das Vias } \\
\text { Urinárias (IVU) }\end{array}$ & $\begin{array}{l}\text { Exposição ao cateter urinário (e } \\
\text { duração da exposição) }\end{array}$ & $\begin{array}{l}\text { Microrganismos Gram-negativos } \\
- \text { por exemplo, E. coli e } \\
\text { Enterobacter spp. }\end{array}$ \\
\hline $\begin{array}{l}\text { Infeção do Local } \\
\text { Cirúrgico (ILC) }\end{array}$ & $\begin{array}{l}\text { Contaminação durante o procedimento } \\
\text { e duração da operação }\end{array}$ & $\begin{array}{l}\text { S. aureus - frequentemente } \\
\text { resiste à meticilina (MRSA). } \\
\text { Coliformes fecais, no caso de } \\
\text { operação ao intestino. }\end{array}$ \\
\hline $\begin{array}{l}\text { Infeção da } \\
\text { Corrente } \\
\text { Sanguínea (ICS) }\end{array}$ & $\begin{array}{l}\text { Exposição ao cateter venoso central (e } \\
\text { duração da exposição) }\end{array}$ & $\begin{array}{l}\text { Staphylococcus coagulase } \\
\text { negativa. Caso se trate de uma } \\
\text { infeção secundária à IVU poderá } \\
\text { ser por coliformes fecais. }\end{array}$ \\
\hline Pneumonia & $\begin{array}{l}\text { Exposição ao ventilador (e duração da } \\
\text { exposição) }\end{array}$ & $\begin{array}{l}\text { Microrganismos provenientes } \\
\text { da flora das vias respiratórias } \\
\text { superiores. }\end{array}$ \\
\hline
\end{tabular}

Fonte: Adaptado de Pratt et al. (2001).

\section{Para refletir}

Que infeções você considera evitáveis no seu contexto de prestação de cuidados (na sua organização de saúde)? 
De modo geral, os profissionais de saúde não encaram o problema das IACS da mesma forma como encaram os erros de medicação, quedas e outros problemas de segurança do paciente, e as iniciativas para a abordagem desse problema têm sido poucas (O’Boyle et al. 2001). Isso ocorre porque, enquanto as outras situações são claramente vistas como evitáveis, no caso das IACS, considera-se que:

粼 São "ossos do ofício", consequência da sofisticação e complexidade dos cuidados prestados na atualidade.

䟕 São mais do que um evento adverso evitável, são entendidas como uma "complicação". Sendo, portanto, registadas nos programas de vigilância epidemiológica como dados estatísticos, e não são reportadas como um evento adverso.

滕 Há uma crença generalizada de que os antibióticos resolvem o problema.

Acresce que, de modo geral, as evidências para apoiar as recomendações de prevenção nem sempre são suficientemente convincentes.

Numa análise teórica realizada em 2013, Storr et al. abordam um aspeto associado à ergonomia humana de grande impacte. Os autores referem que se verifica uma tendência, entre os profissionais de saúde, de considerar as medidas de prevenção e controlo de infeção como tarefas extras, não integradas nas suas atividades diárias. No entanto, as medidas de prevenção e controlo de infeção são a boa prática, mas, por se considerar como "sobrecarga", essas atividades são, por vezes, descuradas, levando a riscos evitáveis.

\section{Para refletir}

Você verifica, na sua prática, essa tendência de se considerar as medidas de prevenção e controlo de infeção como atividades não integradas à rotina dos profissionais de saúde? E você, como trata essa questão na sua rotina de trabalho?

As IACS recebem atenção pública quando ocorrem surtos ou epidemias. No entanto, o problema endémico é muito mais grave e mais difícil de solucionar.

A prevenção e controlo desse problema representa um grande desafio, porque, para além de se observar o aumento dessas infeções, os agentes microbianos implicados vão sendo progressivamente mais difíceis 
de tratar (Pittet 2005). No entanto, o aumento de esperança de vida, a sobrevivência de recém-nascidos de muito baixo peso e o recurso cada vez maior a terapêuticas imunossupressoras levam ao aumento de suscetibilidade à infeção. Acresce, também, a isso questões que se relacionam com o financiamento dos serviços de saúde (agravados com a falência do "Estado Social" e com a crise económica que teve início em 2008, principalmente nos sistemas em que o financiamento público é predominante, como é o caso de Portugal, ou com crônico subfinanciamento da saúde, como no Brasil) e com a globalização (facilitando a circulação de pessoas, alimentos, materiais, fazendo com que as IACS se disseminem rapidamente). Todos esses factores contribuem para uma morbilidade/morbidade e mortalidade por IACS. Os custos para os sistemas de saúde associados a essas infeções estão relacionados com o prolongamento de internamento/internação, exames complementares de diagnóstico, terapêuticas adicionais e consultas externas. Para os pacientes e sua família, representam ausência do trabalho, deslocações para as visitas e custos não calculáveis, tais como: as sequelas residuais, dor, desconforto, ansiedade, podendo mesmo levar à morte.

Por todas essas razões, nos últimos anos, as IACS surgem como parte importante da agenda da segurança do paciente, sendo abordadas como prioritárias pelos organismos internacionais e governos de diversos países. Essa preocupação teve origem na publicação do relatório To Err is Human, nos EUA, em 1999, pelo Institute of Medicine, que identificou elevada frequência de erros médicos na prestação de cuidados (entre eles as IH/ IACS) e concluiu que já existe o conhecimento necessário para a prevenção, estabelecendo, assim, metas e prazos para as atingir, propondo uma estratégia nacional que abrange os decisores políticos, os prestadores de cuidados, a indústria e os consumidores de cuidados de saúde.

\section{Para praticar}

Leia, atentamente:

- o documento sobre segurança do paciente da União Europeia,

"Recomendação do Conselho de 9 de Junho de 2009" (2009/C 151/01), que pode ser encontrado em:

http://ec.europa.eu/health/patient_safety/docs/council_2009_pt.pdf 
- o Segundo Relatório ao Conselho Europeu relativo à implementação da Recomendação do Conselho de 9 de Junho de 2009 sobre a segurança dos pacientes, incluindo a prevenção e o controlo de infeções associadas aos cuidados de saúde (2009/C 151/01). Report from the Commission to the Council June 2014 que pode ser encontrado em: https://ec.europa. eu/health//sites/health/files/patient_safety/docs/ec_2ndreport_ps_ implementation_en.pdf

Depois de ler a recomendação e o relatório, responda: Quais os níveis de organização em que considera ser necessário intervir no seu país para um programa de controlo de infeção eficaz?

Em 2005/2006, a Organização Mundial da Saúde (OMS), por intermédio da World Alliance for Patient Safety, estabeleceu como desafio a redução do problema da infeção associada aos cuidados de saúde, tendo como principal mensagem Clean Care is Safer Care (que o Proqualis traduz como "Assistência Limpa é Assistência Mais Segura"). Este programa teve uma adesão enorme em nível mundial (WHO 2015).

Também, nos EUA, o Institute for Healthcare Improvement incluiu a segurança do paciente (abrangendo as IACS) na sua agenda, propondo um leque alargado de métodos de melhoria. Nesse âmbito, desenvolveu uma campanha de grande impacte, designada 5 Millions Lives, que visava melhorar a qualidade da assistência à saúde nos EUA por meio da prevenção da ocorrência de 5 milhões de incidentes entre 2006 e 2008 (IHI). A meta para as IH foi a prevenção de infeções da corrente sanguínea associadas ao uso do Cateter Venoso Central (CVC). Em Portugal, temos bastantes UCI (Unidades de Cuidados Intensivos), que têm tido zero bacteriemias associadas ao CVC. E, globalmente, essas taxas também estão diminuindo, representando bons resultados para essa campanha.

Também, a nível nacional, vários governos de diferentes países (nomeadamente dos denominados desenvolvidos) têm vindo a criar estruturas para a coordenação dos programas nacionais.

\section{Epidemiologia das IACS}

A cadeia de transmissão das IACS é um modelo usado para compreender o processo de transmissão de infeção, em que cada elo representa um componente de um círculo. Cada elo deve estar presente, e nessa ordem sequencial, para que ocorra a infeção. Compreender as características de cada um desses elos fornece informação fundamental para 
a implementação de medidas de proteção do hospedeiro suscetível, de prevenção e controlo da transmissão cruzada de infeção e de proteção dos profissionais de saúde.

Figura 2 - Cadeia de transmissão das IACS e intervenções específicas (em vermelho) em alguns elos da cadeia de transmissão

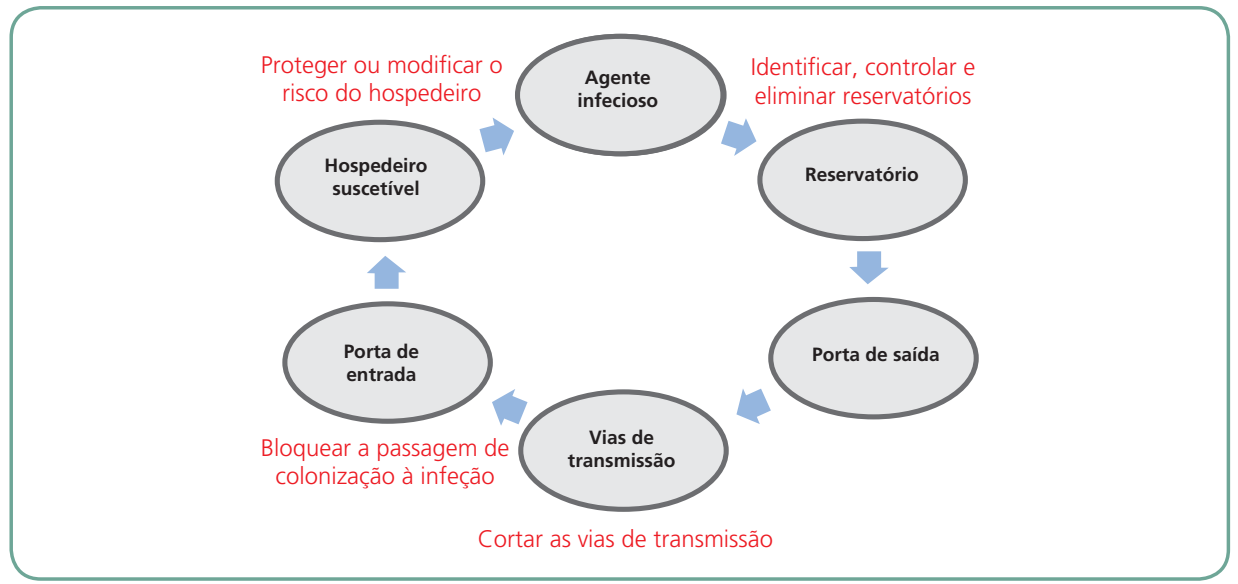

Fonte: Elaboração dos autores.

Definições de conceitos envolvidos na compreensão da cadeia de transmissão das IACS:

Agente infecioso - microrganismo com capacidade de produzir doença no hospedeiro. Quanto maior for sua virulência (capacidade de se multiplicar, invadir os tecidos do hospedeiro, produzir toxinas etc.) e patogenicidade (capacidade de produzir doença) maior a probabilidade de o microrganismo provocar infeção. Os agentes infeciosos podem ser bactérias, vírus, fungos ou parasitas.

Reservatório - o local onde os microrganismos sobrevivem e se reproduzem. Por exemplo, seres humanos, materiais e equipamentos, água, alimentos etc.

Porta de saída - a via através da qual os microrganismos deixam o seu reservatório. Por exemplo, o ato de espirrar faz com que as bactérias infeciosas possam sair do reservatório pelo nariz (porta de saída).

Via de transmissão - método de transferência de microrganismos de um local para outro. As mãos dos profissionais de saúde podem ser uma via de transmissão. Outra possível via de transmissão podem ser as gotículas, produzidas quando se espirra ou tosse, que se depositam noutro local ou ficam no ar e podem ser inaladas. A transmissão pode dar-se por transferência direta e essencialmente imediata de agentes infeciosos para uma porta de entrada, ou por transmissão indireta, por meio de um veículo intermédio: superfícies, equipamentos etc. 
Porta de entrada - local por onde o microrganismo entra no corpo humano. Estão incluídos todos os orifícios como o nariz, a boca, a uretra e ainda pele lesada (tal como feridas). Os tubos colocados nas cavidades (cateter urinário, tubo endotraqueal) ou introduzidos por métodos invasivos (cateteres vasculares para administração de soros) também constituem portas de entrada.

Hospedeiro suscetível - indivíduo que não tem a capacidade de resistir à invasão microbiana. As características dos pacientes que os podem tornar vulnerável à infeção podem ser intrínsecas, inerentes ao próprio paciente (por exemplo, diabetes, tabagismo, obesidade, imunossupressão etc.) ou em consequência de, durante a hospitalização, ser submetido a procedimentos invasivos de diagnósticos ou terapêuticos (cateteres vasculares, sondas vesicais, ventilação mecânica etc.).

O simples contacto entre o paciente e um microrganismo não resulta, obrigatoriamente, no desenvolvimento de sinais e sintomas e, ou, doença clínica - existem outros factores que influenciam a natureza e frequência das IACS. A probabilidade de que a exposição a um microrganismo origine uma infeção depende, então, não só das características do microrganismo, incluindo a resistência aos agentes antimicrobianos, da sua virulência intrínseca e da dose infeciosa a que se está exposto (número de microrganismos), mas também das características dos reservatórios e das vias de transmissão, que abordaremos seguidamente.

Assim, a presença de microrganismos no hospedeiro tem diferentes significados:

* Contaminação: presença de microrganismos sem proliferação.

* Colonização: presença de microrganismos com multiplicação, mas sem efeito clínico adverso (sem reação do hospedeiro).

* Infeção: presença de microrganismos com proliferação e invasão de tecido vivo; há uma resposta inflamatória local e pode haver uma resposta sistêmica - febre e leucocitose.

\section{Para praticar}

Qual a importância da categorização (contaminação, colonização, infeção e toda a descrição da cadeia de transmissão) descrita no texto para as intervenções de prevenção de transmissão?

E para tratamento? 


\section{Reservatórios de infeção e sua transmissão}

As fontes de infeção podem ser:

*ndógenas - do próprio paciente. Bactérias presentes na flora normal ou transitoriamente causam infeção por meio da transmissão a outros locais fora do seu habitat natural.

路Exógenas - de outro paciente, dos profissionais, ou do ambiente (infeção cruzada).

As principais vias de transmissão de microrganismos nos cuidados de saúde são a via do contacto (direto ou indireto), via de gotículas (direto ou indireto), ou por via aérea (Quadro 2):

Quadro 2 - Principais vias de transmissão de microrganismos

\begin{tabular}{|c|c|c|c|}
\hline $\begin{array}{l}\text { Transmissão por } \\
\text { contacto }\end{array}$ & Transmissão por gotícula & Transmissão por via aérea & Outras vias de transmissão \\
\hline $\begin{array}{l}\text { Transmissão por } \\
\text { contacto direto com } \\
\text { o paciente (contacto } \\
\text { pele-pele, com lesões } \\
\text { ou fluidos orgânicos) } \\
\text { ou indiretamente, por } \\
\text { contacto com superfícies } \\
\text { ou equipamento } \\
\text { contaminados (quer pelo } \\
\text { pacientes, quer pelos } \\
\text { profissionais). }\end{array}$ & $\begin{array}{l}\text { Gotículas: > } 5 \text { um } \\
\text { Por deposição direta nas mucosas } \\
\text { (proximidade excessiva) ou } \\
\text { indireta nas superfícies. } \\
\text { Deslocação a distância depende } \\
\text { da velocidade, mecanismo } \\
\text { de propulsão, temperatura e } \\
\text { humidade, densidade das secreções } \\
\text { respiratórias. } \\
\text { Não requer instalações com } \\
\text { ventilação especial. }\end{array}$ & $\begin{array}{l}\text { Gotículas com < } 5 \mu \mathrm{m} \text { ("droplet } \\
\text { nuclei", gotículas evaporadas, } \\
\text { núcleos de gotículas, poeiras) } \\
\text { São produzidas por: } \\
\text { • tosse, espirro, canto, fala } \\
\text { - torneiras/chuveiro } \\
\text { - humidificadores, nebulizadores, } \\
\text { ambus, máscaras de oxigénio } \\
\text { - broncoscopias, traqueostomias } \\
\text { Disseminação a grande } \\
\text { distância requer quarto } \\
\text { com ventilação com pressão } \\
\text { negativa. }\end{array}$ & $\begin{array}{l}\text { Ingestão: gastrenterites } \\
\text { Percutânea: corto-perfurantes, } \\
\text { acessos vasculares } \\
\text { Veículo comum: alimentos, } \\
\text { água, medicamentos, soros } \\
\text { Vetores: moscas, mosquitos, } \\
\text { baratas, ratos }\end{array}$ \\
\hline
\end{tabular}

Fonte: Elaboração dos autores.

Fundamentado no conceito da cadeia de transmissão referido anteriormente, a prevenção e o controlo das IACS passam por quatro pontos, descritos no Quadro 3. 
Quadro 3 - Principais intervenções para romper cada elo da cadeia de transmissão

\begin{tabular}{|c|c|c|c|}
\hline $\begin{array}{l}\text { Identificar, controlar e } \\
\text { eliminar reservatórios }\end{array}$ & $\begin{array}{l}\text { Impedir a transmissão entre } \\
\text { pacientes }\end{array}$ & $\begin{array}{l}\text { Bloquear a passagem de } \\
\text { colonização à infecção }\end{array}$ & $\begin{array}{l}\text { Proteger ou modificar o risco } \\
\text { do hospedeiro }\end{array}$ \\
\hline $\begin{array}{l}\text { Identificar o paciente com } \\
\text { infecção/colonização }\end{array}$ & Precauções básicas & $\begin{array}{l}\text { Tomar medidas relativas à } \\
\text { exposição a dispositivos invasivos } \\
\text { - Duração de exposição }\end{array}$ & $\begin{array}{l}\text { Tomar medidas para } \\
\text { identificação e proteção dos } \\
\text { pacientes mais suscetíveis }\end{array}$ \\
\hline $\begin{array}{l}\text { Tomar medidas relativas aos } \\
\text { pacientes colonizados e/ou } \\
\text { infectados - Isolamento }\end{array}$ & $\begin{array}{l}\text { Precauções especíificas } \\
\text { baseadas nas vias de } \\
\text { transmissão } \\
\text { - Isolamento }\end{array}$ & \multirow[t]{2}{*}{$\begin{array}{l}\text { Promover uso racional } \\
\text { antimicrobianos } \\
\text { - Política de antissépticos e } \\
\text { anitibióticos }\end{array}$} & $\begin{array}{l}\text { Assegurar diagnóstico e } \\
\text { tratamento precoce da infecção }\end{array}$ \\
\hline $\begin{array}{l}\text { Tomar medidas relativas ao } \\
\text { material usado/contaminado } \\
\text { - Limpeza/desinfecção/ } \\
\text { esterilização }\end{array}$ & $\begin{array}{l}\text { Suspender novas admissões, se } \\
\text { necessário }\end{array}$ & & $\begin{array}{l}\text { Controlar/eliminar fatores de } \\
\text { risco extrínseco }\end{array}$ \\
\hline
\end{tabular}

Fonte: Elaboração dos autores.

\section{Avaliação de risco de IACS}

Até recentemente, a avaliação do risco era apenas baseada nos resultados da vigilância epidemiológica, nos surtos ou falhas óbvias nas práticas de prevenção e controlo de infeção (Arias, Soule 2006).

Na atualidade, existe já informação disponível sobre os factores de riscos significativos para a aquisição de IACS e que permitem uma avaliação mais objetiva, podendo contribuir para a melhoria dos programas de prevenção e controlo de infeção.

De acordo com a Joint Commission International a avaliação do risco de IACS deve ser encarada de forma global (JCI 2010).

Essa avaliação deve considerar, em primeiro lugar, a organização em sua totalidade, integrada numa comunidade, devendo incidir sobre os factores de risco extrínsecos, inerentes à localização geográfica do hospital da comunidade que serve, e sobre os factores de risco intrínsecos da organização, tais como as resistências aos antimicrobianos, o tipo de paciente que o hospital atende (condições socioeconômicas, patologias predominantes etc.), os riscos relacionados com os profissionais de saúde (por exemplo, o nível de adesão às boas práticas), entre outras, e os riscos ambientais. Todos eles devem ser considerados para um programa global e efetivo de prevenção e controlo das IACS. 


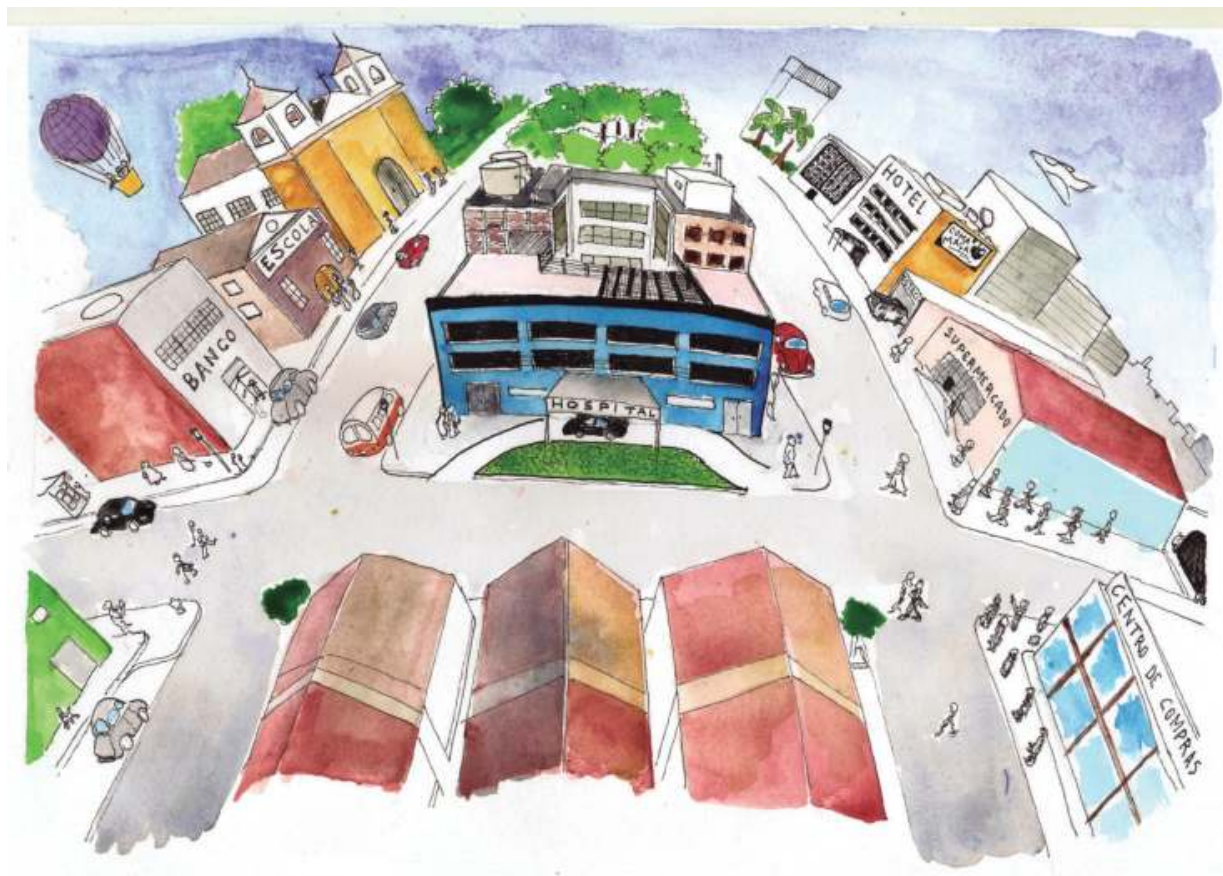

Outro factor fundamental para a implementação de medidas de prevenção e controlo diz respeito ao conhecimento que os profissionais de saúde devem ter sobre os factores de risco, intrínsecos e extrínsecos do paciente, que contribuem para a IACS. Só na posse desse conhecimento é possível planear/planejar e intervir com o objetivo de eliminar ou reduzir a um mínimo aceitável as taxas de infeção ou até mesmo eliminar algumas infeções, como é o caso da infeção associada a alguns dispositivos invasivos (JCIHI 2011).

A avaliação do risco de infeção deve ocorrer no contacto inicial do paciente com a organização de saúde e de forma periódica durante seu internamento/internação e contactos posteriores. Assume-se como uma oportunidade fundamental numa estratégia de prevenção e controlo das IACS, a qual poderá ser materializada na concepção de "instrumentos" de recolha/coleta de informação que possibilitem a associação a planos de cuidados dirigidos. Tal constitui uma indiscutível medida de promoção da segurança do paciente.

\section{Para praticar}

Com base no conhecimento que os profissionais de saúde devem ter sobre os factores de risco intrínsecos e extrínsecos do paciente e que contribuem para a IACS, identifique alguns desses factores na população de pacientes do seu local de trabalho (organização de saúde). 


\section{Prevenção da transmissão: precauções básicas e isolamento}

A circulação de pacientes pelos diferentes níveis dos cuidados de saúde (circulação entre hospitais, cuidados continuados, ambulatório, cuidados domiciliários) criou a necessidade do desenvolvimento de recomendações que possam ser aplicadas em todos os níveis e tipos de cuidados de saúde, usando princípios comuns de controlo de infeção, e que possam ser adaptados a cada local, refletindo suas necessidades específicas.

Surgiu, assim, o conceito de Precauções Básicas Padronizadas (Standard Precautions), medidas que devem ser adotadas na prestação de cuidados em todos os pacientes, onde quer que os cuidados sejam prestados (CDC 2007).

Das Precauções Básicas faz parte o seguinte conjunto de medidas:

colocação (acomodar o paciente de acordo com o risco) dos pacientes;

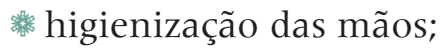

路 higiene respiratória;

utilização de Equipamento de Proteção Individual (EPI);

滕 tratamento do Equipamento Clínico;

蹟 controlo ambiental;

manuseamento seguro da roupa;

蝶 recolha/coleta segura de resíduos;

噄 práticas seguras de injeção;

晋 exposição de risco no local de trabalho.

As mãos contaminadas dos profissionais de saúde são o veículo mais comum de transmissão cruzada de agentes infeciosos relacionados com as IACS, e a higienização das mãos constitui uma ação simples, acessível, rápida e que continua a ser uma das principais medidas para reduzir as IACS em todo o mundo. Contudo, a adesão às práticas de higiene das mãos é baixa em todos os níveis de cuidados de saúde. Médicos e enfermeiros, habitualmente, lavam suas mãos menos da metade das vezes que deveriam, e, quando há maior restrição de tempo e maior carga de trabalho, como em unidades de cuidados intensivos, a adesão às Boas Práticas pode atingir apenas 10\% (WHO 2005).

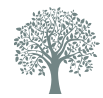

Para mais informações, consulte a Norma n. 029/2012, de 28/12/2012: Precauções Básicas de Controlo de Infeção, no site da Direção-Geral de Saúde: http://www.dgs.pt/ directrizes-da-dgs/normas-ecirculares-normativas/norma-n0292012-de-28122012.aspx

Para conhecer o protocolo que regista a prática de higiene das mãos em serviços de saúde no Brasil, consulte o site: http://www.anvisa.gov.br/ hotsite/segurancadopaciente/ documentos/julho/ PROTOCOLO $\% 20$ HIGIENE $\% 20$ DAS\%20M\%C3\%830S.pdf 


\section{Para refletir}

A partir de sua experiência profissional, a que você credita essa dificuldade em inserir a lavagem das mãos como uma rotina?

O Equipamento de Proteção Individual (EPI) ganhou importância em virtude da necessidade de garantir a segurança não só do profissional de saúde, mas também dos pacientes. Incluem-se na categoria dos EPI: luvas, máscaras, batas, aventais, óculos, viseiras, entre outros. A decisão de usar ou não EPI, e quais os equipamentos a usar em cada momento da prestação de cuidados, deve ser baseada na avaliação de risco de transmissão cruzada de microrganismo, no risco de contaminação do fardamento, pele ou mucosas dos profissionais de saúde com sangue, líquidos orgânicos, secreções e excreções do paciente (Pratt et al. 2001). É importante que se tenha a consciência de que os EPI reduzem, mas não eliminam totalmente, o risco de transmissão cruzada de microrganismos e só são eficazes se usados corretamente e em cada contacto, não substituindo qualquer uma das outras recomendações que integram as Precauções Básicas (Pina 2006, 2007).

Para que contribuam para a prevenção e controlo das IACS, os EPI devem ser usados em complementaridade com as restantes recomendações (higiene das mãos, higiene ambiental, entre outros).

Alguns pacientes podem necessitar de precauções adicionais, específicas, para limitar a transmissão de microrganismos potencialmente infeciosos a outros pacientes. As precauções de isolamento a serem adotadas dependem da via de transmissão implicada.

Quadro 4 - Precauções específicas baseadas nas vias de transmissão

\begin{tabular}{|c|c|}
\hline \multicolumn{2}{|l|}{ Via de transmissão e recomendações } \\
\hline $\begin{array}{l}\text { Transmissão por contacto } \\
\text { Quando a transmissão se faz por contacto direto } \\
\text { ou indireto. }\end{array}$ & Uso de bata/avental e luvas. \\
\hline $\begin{array}{l}\text { Transmissão por gotículas } \\
\text { Quando a transmissão se faz por meio de gotículas. } \\
>5 \mu \mathrm{m} \text { (não permanecem suspensas no ar). }\end{array}$ & $\begin{array}{l}\text { Uso de bata/avental, luvas, máscara. } \\
\text { Quarto individual desejável. }\end{array}$ \\
\hline $\begin{array}{l}\text { Transmissão via aérea } \\
\text { Quando a transmissão se faz por pequenas partículas } \leq 5 \\
\text { um (permanecem no ar durante longos períodos). }\end{array}$ & $\begin{array}{l}\text { Uso de máscara/ respirador. Quarto } \\
\text { individual com pressão negativa. }\end{array}$ \\
\hline
\end{tabular}

Fonte: Elaboração dos autores. 
Todo o equipamento e o material utilizado no paciente devem ser tratados para garantir que não contêm microrganismos que possam ser transmitidos a outros pacientes. Pode ser necessário que sejam esterilizados, desinfetados ou apenas limpos, conforme o local e as circunstâncias em que serão usados. Para categorização, apesar de algumas limitações associadas, utiliza-se habitualmente a classificação de Spaulding (Rutala, Weber 2008), descrita no Quadro 5.

Quadro 5 - Classificação de Spaulding dos níveis de risco de equipamento e material contaminado, definições e recomendações em cada nível de risco

\begin{tabular}{|l|l|l|}
\hline Risco & Definição & Recomendações \\
\hline $\begin{array}{l}\text { Elevado } \\
\text { Material crítico }\end{array}$ & $\begin{array}{l}\text { Todo aquele que penetra nos tecidos } \\
\text { subepiteliais, no sistema vascular } \\
\text { e outros órgãos isentos de flora } \\
\text { microbiana própria (estéreis), bem } \\
\text { como tudo o que esteja diretamente } \\
\text { ligado com eles. }\end{array}$ & $\begin{array}{l}\text { Limpeza seguida de } \\
\text { esterilização (1) }\end{array}$ \\
\hline $\begin{array}{l}\text { Médio } \\
\text { semiterial }\end{array}$ & $\begin{array}{l}\text { Todo aquele que entra em contacto } \\
\text { com as membranas mucosas ou com a } \\
\text { pele não íntegra. }\end{array}$ & $\begin{array}{l}\text { Limpeza seguida de } \\
\text { desinfeção (2;3) } \\
\text { (Exceção: instrumentos usados } \\
\text { na vagina ou colo do útero, por } \\
\text { exemplo, espéculos que devem } \\
\text { ser esterilizados) }\end{array}$ \\
\hline $\begin{array}{l}\text { Risco } \\
\text { Baixo } \\
\text { Materítico }\end{array}$ & $\begin{array}{l}\text { Todo aquele que entra em contacto } \\
\text { apenas com a pele íntegra ou que } \\
\text { não entra em contacto direto com o } \\
\text { paciente. }\end{array}$ & Recomendações \\
\hline \begin{tabular}{l} 
Limpeza \\
\hline
\end{tabular} & \begin{tabular}{l} 
Lefino \\
\hline
\end{tabular} & \\
\hline
\end{tabular}

Fonte: Rutala, Weber 2008.

(1) Até a sua utilização, esse material deve permanecer na embalagem hermeticamente fechada. Logo que a embalagem é aberta ou se, por qualquer motivo, for danificada, o material deixa de ser considerado estéril.

(2) Classificação dos desinfetantes: Nível elevado - destruir todos os microrganismos incluindo esporos; Nível médio - destruir bactérias vegetativas, BK, maioria dos vírus e fungos; Nível baixo destruir as bactérias Gram-positivas, algumas Gram-negativas, vírus lipídicos e alguns fungos.

(3) Na utilização dos desinfetantes, deve-se ter sempre em conta as indicações do fabricante no que se refere às diluições, manuseamento, conservação e prazos de validade. Os desinfetantes devem ser manipulados com luvas de nitrilo ou de tipo doméstico. Relembra-se a importância da lavagem das mãos no fim do procedimento.

Outro elemento essencial das Precauções Básicas é a higiene ambiental nomeadamente das superfícies em que se verifica contacto manual frequente, porque podem originar a recontaminação de mãos higienizadas e das luvas, constituindo um reservatório importante de microrganismos. Muitos estudos demonstram que a limpeza das superfícies é frequentemente inadequada (Pina 2012). 


\section{Antimicrobianos e resistências}

Os fármacos antimicrobianos vieram revolucionar a prática da medicina. Pelos seus efeitos, durante a Segunda Grande Guerra, foram designados como "balas mágicas". Isso levou ao seu uso excessivo e frequentemente inapropriado no que respeita ao antibiótico selecionado, a dose, via de administração e duração de tratamento.

A resistência bacteriana aos antibióticos representa a evolução contínua na luta pela sobrevivência das espécies e se manifesta quer pela capacidade de sofrer mutações, quer pela troca de material genético entre as espécies bacterianas. Está relacionada com a pressão seletiva afetada em especial pelas práticas de prescrição de antimicrobianos, podendo surgir mesmo quando há o cumprimento integral das medidas de prevenção de transmissão cruzada (Joly-Guillou, Regnier 2005).

- Centers for Disease Contro and Prevention: http://www. cdc.gov/getsmart/healthcare/ learn-from-others/factsheets/ antibiotic-use.html

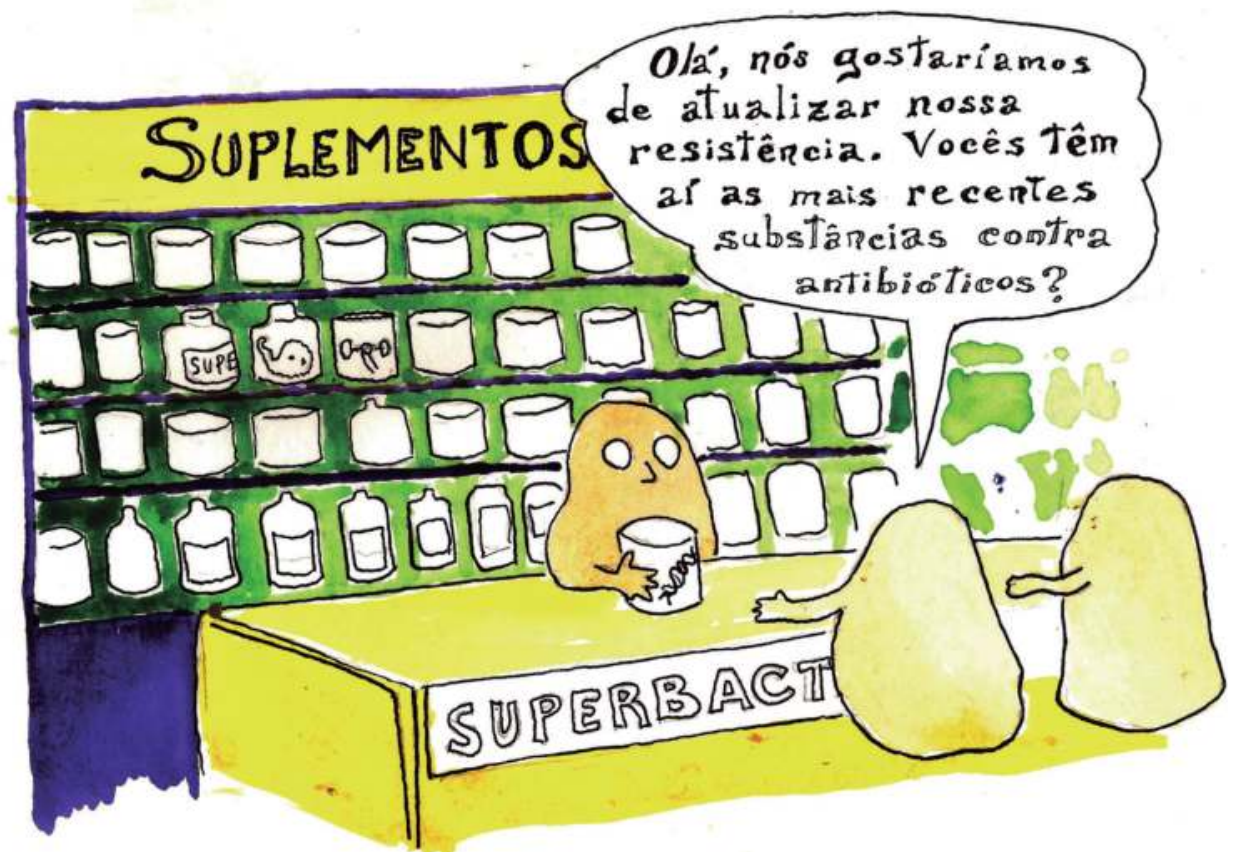

Associa-se a essas questões o cumprimento inadequado das boas práticas de prevenção, o que vem favorecer a transmissão desses microrganismos resistentes entre pacientes. 


\section{Boas práticas no uso de antimicrobianos}

Uma série de estratégias foi desenvolvida e aplicada com sucesso para fomentar as boas práticas no uso de antimicrobianos. Todas elas requerem uma liderança forte e apoio político, já que exigem recursos humanos, financeiros e infraestruturas adequadas. Associado a isso, é essencial priorizar estratégias, ações e recursos nacionais e locais.

Em 2003, o CDC (2003) propôs quatro pilares para a abordagem sistematizada desse problema:

1. prevenção da transmissão;

2. uso criterioso de antimicrobianos;

3. diagnóstico e tratamento efetivo das infeções;

4. prevenção da infeção.

\section{Organização do Programa de Controlo das Infeções (PCI) das IACS}

Para haver eficácia na prevenção e controlo das IACS, é de grande importância a organização de programas de prevenção e controlo das IACS (PCI) tanto a nível local como nacional, tendo como principal objetivo evitar as IACS evitáveis, otimizar a prescrição antimicrobiana, a fim de reduzir as resistências, e fazê-lo de uma forma custo-efetiva. Esses programas são da responsabilidade dos Conselhos de Administração das organizações de saúde e devem ser geridos no dia a dia por uma equipa técnica multidisciplinar, porque requerem contributos/ colaborações da microbiologia, infetologia/infectologia, epidemiologia entre outras.

Um dos elementos essenciais de uma equipa multidisciplinar é o/a enfermeiro/a de controlo de infeção. As competências deste profissionais têm vindo a ser definidas (ECDC 2013) assegurando a sua capacidade para a gestão e monitorização dos PCI. Nalguns países (incluindo Portugal, Brasil e a maioria dos países africanos de língua portuguesa e no Reino Unido), existem também interlocutores em cada serviço para detetar problemas e coordenar a implementação das recomendações do PCI. Esses interlocutores têm papel vital nos centros de saúde e cuidados continuados em que, por conta das suas pequenas dimensões e número de profissionais, não é viável criar equipas multidisciplinares. 
Vigilância epidemiológica "é a observação contínua de todos os aspetos da ocorrência e disseminação de uma doença pertinentes para o seu controlo, com base na obtenção e análise sistemática de informação clínica, demográfica e laboratorial e do envio dessas informações às entidades responsáveis pelo seu controlo" (Beneson 1995).
Os PCI devem refletir as boas práticas baseadas nos princípios da epidemiologia, nas investigações mais recentes e nas Guidelines nacionais e internacionais. Para serem eficazes e efetivos, é muito importante que todos os profissionais da organização contribuam para o planeamento/ planejamento das estratégias a adotar.

As três vertentes do PCI são: a vigilância epidemiológica; o desenvolvimento, disseminação e implementação de recomendações de boas práticas; e a formação dos profissionais de saúde.

As principais dificuldades encontradas na implementação de programas eficazes são:

* o desconhecimento da dimensão e especificidades dos problemas em razão da falta de dados relacionados com as IACS e resistência aos antimicrobianos (daí a necessidade de vigilância epidemiológica);

噒 capacidade laboratorial inadequada, não permitindo conhecer a realidade local, regional e nacional;

* ausência de metodologias uniformes de definições, colheita/ coleta de dados e desconhecimento sobre a eficácia das medidas adotadas. É essencial que existam recursos necessários para uma implementação eficaz e sustentável.

Para conhecer a realidade local, regional e nacional, é essencial que exista um sistema de monitorização com colheita/coleta regular de informação pertinente, sua análise e utilização da informação para a ação. A vigilância eficaz é um ponto-chave para controlo do problema das IACS e resistências aos antimicrobianos. É importante monitorizar as IACS e o aparecimento e disseminação de estirpes resistentes, bem como as práticas de prevenção e controlo de transmissão, assim como as práticas de consumo de antimicrobianos (AM). Essas informações permitem orientar as políticas e avaliar as medidas implementadas a fim de promover a prevenção de transmissão e o uso adequado de AM em todos os níveis de cuidados (internamento/internação e comunidade). É importante que o Plano de Controlo de Infeção seja avaliado com regularidade e ajustado às necessidades que vão surgindo. 


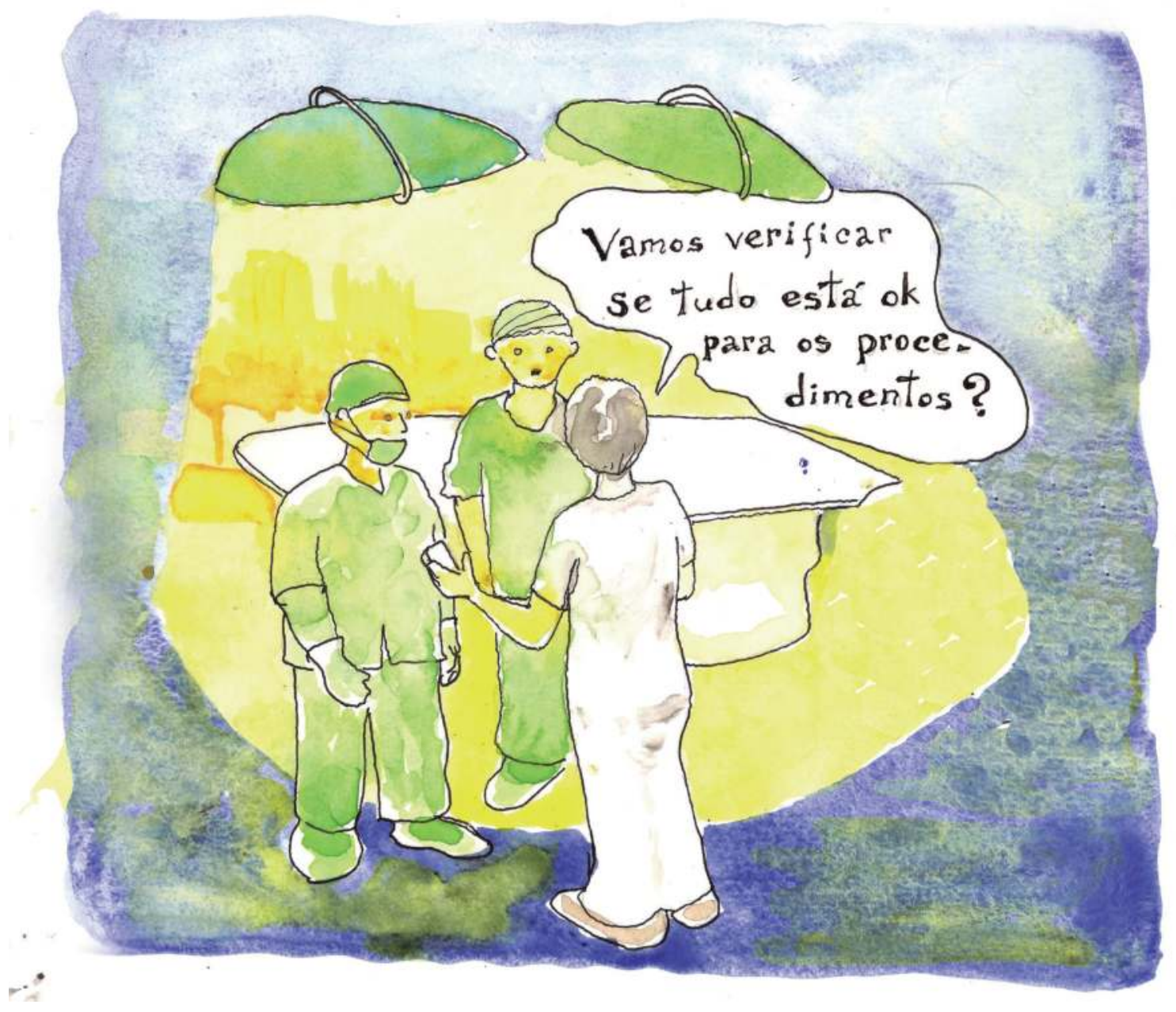

Considerando que muitas IACS são evitáveis, em 2010, um grupo de trabalho nomeado pela OMS, (Seto et al. 2010) definiu as componentes essenciais de um PCI. São elas:

踧 Estrutura formal responsável pelas políticas, metas e estratégias do Programa.

* Guidelines: desenvolvimento, disseminação e implementação.

蔽 Recursos humanos: em número e qualidade necessários.

踏 Vigilância epidemiológica: monitorização das infeções e do cumprimento das práticas recomendadas.

蔽 Capacidade laboratorial para diagnóstico e boa interação com a equipa do controlo de infeção (CI).

踏Um ambiente seguro: água potável, instalações adequadas para higiene das mãos, possibilidades de isolamento de pacientes, armazenamento etc. 
滕 Monitorização e avaliação regular dos programas.

* Coordenação com serviços de saúde pública, de saúde ocupacional e gestão de resíduos.

Em julho de 2015, o Departamento de Saúde do Reino Unido publicou uma actualização das Recomendações para Planeamento e Gestão dos PCI para assegurar cuidados seguros, sendo de salientar os seguintes critérios: um sistema de gestão e monitorização das actividades baseado nas avaliações de risco (global e individual), informação rigorosa aos profissionais, pacientes e visitas, e criação de condições para isolamento de pacientes.

Em resumo, o papel fundamental do Programa de Prevenção e do Controlo da Infeção é apresentado no Quadro 6.

Quadro 6 - O Papel Fundamental dos Programas de Prevenção e Controlo de Infeção

\begin{tabular}{|l|l|}
\hline $\begin{array}{l}\text { Identificar } \\
\text { os riscos }\end{array}$ & $\begin{array}{l}\text { Conhecer o ambiente e os pacientes } \\
\text { Observar o fluxo e a organização do trabalho } \\
\text { Observar os procedimentos }\end{array}$ \\
\hline $\begin{array}{l}\text { Compreender } \\
\text { os riscos }\end{array}$ & $\begin{array}{l}\text { Avaliar e classificar o risco } \\
\text { Avaliar e classificar as possíveis medidas de intervenção }\end{array}$ \\
\hline $\begin{array}{l}\text { Eliminar ou } \\
\text { minimizar } \\
\text { os riscos }\end{array}$ & $\begin{array}{l}\text { Implementação de programas de melhoria } \\
\text { Monitorização das ações }\end{array}$ \\
\hline
\end{tabular}

\section{Para praticar}

Um Programa de Prevenção e Controlo de Infeção de sucesso tem de contemplar algumas vertentes fundamentais.

Recorde, agora, a atividade em que propusemos a leitura do documento sobre segurança do paciente da União Europeia (http://ec.europa. eu/health/patient_safety/docs/council_2009_pt.pdf) e elabore um programa de prevenção e controlo de infeção para seu local de trabalho (organização de saúde ou determinados serviços de saúde), contemplando as prioridades e níveis de intervenção e as vertentes essenciais do programa. 


\section{Considerações finais}

Os cuidados de saúde são dinâmicos e complexos. As vulnerabilidades e o risco estão em constante mudança em consequência das interações complexas entre os profissionais de saúde, os pacientes, a tecnologia e o próprio ambiente em que se prestam cuidados. Para enfrentar o problema das infeções e resistências aos AM, garantindo a segurança do paciente, é imprescindível a contribuição de todos, desde os pacientes, os profissionais e até os decisores políticos, de modo a que sejam parte da solução e não do problema.

Isso é particularmente importante por se reconhecer que as infeções adquiridas em consequência dos cuidados de saúde são em número significativo e na maioria das vezes evitáveis.

\section{Referências}

Arias K, Soule B. The APIC/JCAHO infection control workbook. Washington, DC: Oakbrook Terrace; 2006.

Aldrige S. The discovery and development of penicillin 1928-1945: an international historic chemical landmark. London: The Alexander Fleming Laboratory Museum; 1999.

Allegranzi B et al. Burden of endemic health-care-associated infection in developing countries: systematic review and meta-analysis. Lancet. 2011;377:228-41.

Benenson AS. Control of communicable diseases manual. 16th ed. Washington: American Public Health Association; 1995.

Centers for Disease Control and Prevention. Campaign to prevent antimicrobial resistance. Atlanta (GA): CDC; 2003.

Centers for Disease Control and Prevention. Guidelines for isolation precautions: preventing transmission of infectious agents in healthcare settings. Atlanta (GA): CDC; 2007.

Department of Health (UK), Public and International Health Directorate, Health Protection and Emergency Response Division. The Health and Social Care Act 2008: code of practice on the prevention and control of infections and related guidance. London: Healthcare Associated Infection and Antimicrobial Resistance; July 2015.

European Centre for Disease Prevention and Control. Core competencies for infection control and hospital hygiene professionals in the European Union. Stockholm: ECDC; 2013.

European Comission. Report from Commission to the Council: on the basis of Member States' report on the implementation of Council Recommendation (2009/C 151/01) on the patient safety, including the prevention and control of the health care ssociation infections (text with EEA relevance). Brussels: EC; 2012.

European Comission. Report from Commission to the Council: the Commission's Second Report to the Council on the implementation of Council Recommendation 2009/C151/01 on the patient safety, including the prevention and control of the health care ssociation infections. Brussels: EC; 2014.

Haley RW, Culver DH, White JW, et al. The efficacy of infection surveillance and control programmes in preventing nosocomial infections in US hospitals. Am J Epid. 1985;121:182-205. 
Harbarth S, Sax H, Gastmeier P. The preventable proportion of nosocomail infections: an overview of published reports. J Hosp Infect. 2003;54:258-66.

Institute of Healthcare Improvement. 5 Million Lives Campaign. Boston: IHI; 2018 [citado 2017 out 1]. Disponível em: http://www.ihi.org/Engage/Initiatives/Completed/5MillionLivesCampaign/Pages/ default.aspx.

Joint Commission Institute For Healthcare Improvement [JCIHI]. Implement the IHI Central Line Bundle. Cambridge (MA): Institute for Healthcare Improvement; 2011 [citado 24 Jun 2014]. Disponível em: http://www.ihi.org/knowledge/Pages/Changes/ImplementtheCentralLineBundle.aspx

Joint Commission International [JCI]. Risk assessment for infection prevention and control. Oakbrook Terrace (III): Joint Commission Resources; 2010.

Joly-Guillou ML, Regnier B. L'infection liée aux soins: stratégie de maîtrise des infections nosocomiales. Lyon: Éditions BioMérieux; 2005.

Lister J. Modern history sourcebook: Joseph Lister (1827-1912): antiseptic principles of the practice of surgery, 1867. New York: Fordham University; 2008 [citado 24 Jun 2014]. Disponível em: http:// www.fordham.edu/halsall/mod/1867lister.asp

Ministério da Saúde (BR). Portaria n. 2.616, de 12 de maio de 1998. Diário Oficial da União, 1998 Maio 13;Seção 1:133.

O'Boyle C, Henly S, Larson E. Understanding adherence to hand hygiene reccommendations: the theory of planned behavior. Am J Infect Control. 2001;29(6): 352-60.

Oliveira C. Infecção hospitalar, epidemiologia, prevenção e controle. Rio de Janeiro: Guanabara Koogan; 2005.

Pina E. Equipamento de protecção individual: proteção facial e respiratória. Nursing 2007; 17: 14-22.

Pina E. Métodos de avaliação da limpeza de superfícies. Hotelaria Saúde. 2012 Jan-Jun;1:18-20.

Pina E. O uso de luvas na prestação de cuidados. Nursing. 2006;16:29-33.

Pina E, Ferreira E, Marques A, Matos B. Infecção associada aos cuidados de saúde e segurança do doente. Rev Port Saúde Pública. 2010; Vol Temat (10): 27-39.

Pina E, Paiva JA, Nogueira P, Silva MG. Prevalência de infeção adquirida no hospital e do uso de antimicrobianos nos hospitais portugueses: inquérito 2012. Lisboa: Ministério da Saúde, Direção Geral da Saúde, 2013 [citado 2013 set. 9]. Disponível em: http://www.dgs.pt/upload/membro.id/ ficheiros/i019020.pdf.

Pittet D. Infection control and quality health care in the new millenium. Am J Infect Control. 2005; 33:258-277.

Pittet D, Allegranzi B, Storr J, Bagheri Nejad S, Dziekan G, Leotsakos A, et al. Infection control as a major World Health Organization priority for developing countries. J Hosp Infect. 2008;68(4):285-92.

Pratt R, Pellowe C, Loveday HP, Robinson N, Smith GW, Barrett S. et al. The epic Project: developing national evidence-based guidelines for preventing hospital-acquired infections. J Hosp Infect. 2001 Jan;47(Suppl):S3-82.

Rutala WA, Weber DJ, Healthcare Infection Control Practices Advisory Committee. Guideline for disinfection and sterilization in healthcare facilities, 2008. Atlanta (GA): Centers for Disease Control and Prevention, 2008 [citado 2014 jun 24]. Disponível em: http:/www.cdc.gov/hicpac/Disinfection_ Sterilization/3_OdisinfectEquipment.html. 
Seto WH, Otaíza F, Pessoa-Silva CL. Core Components for Infection Prevention and Control Programs: a World Health Organization network report. Infect Control Hosp Epidemiol. 2010; 31(9):948-50.

Storr J, Wigglesworth N, Kilpatrick C. Integrating human factors with infection prevention and control. London: The Health Foundation; May 2013. (Thought Paper).

Wikipedia. Ficheiro: Nobelpristagare Fleming Midi.jpg 2007 [citado 2014 Jun 24]. Disponível em: http://commons.wikimedia.org/wiki/File:Nobelpristagare_Fleming_Midi.jpg\#mediaviewer/ Ficheiro:Nobelpristagare_Fleming_Midi.jpg

World Health Organization, Department of Communicable Disease, Surveillance and Response Prevention of hospital-acquired infection: a practical guide. Malta: WHO; 2002 [citado 2013 out 5]. Disponível em: http://www.who.int/csr/resources/publications/drugresist/WHO_CDS_CSR_ EPH_2002_12/en/.

World Health Organization, World Alliance for Patient Safety. Who guidelines on hand hygiene in health care: a summary clean hands are safer hands. Geneva: WHO; 2005.

World Health Organization. Ten years of Clean Care is Safer Care - 2005-2015: a global call to action for health workers, ministries of health, leaders and patients. Geneva: WHO; 2015 [citado 2017 set 10]. Disponível em: http://www.who.int/gpsc/ccsc_ten-years/en/. 


\section{Erros relacionados aos medicamentos}

Susana Ramos, Paula Perdigão e Rita Palmeira de Oliveira

A principal finalidade deste capítulo é promover a reflexão sobre os factores contribuintes para o erro de medicação em todo o processo de utilização do medicamento, na perspetiva do desenvolvimento e implementação de medidas para sua prevenção.

A problemática dos erros de medicação e do seu impacte é bem expressa no relatório To Err is human building a safer health care system, que indica a ocorrência de cerca de 7 mil mortes, em cada ano, nos Estados Unidos, como consequência de erros de medicação ocorridos em ambulatório ou nos hospitais (Kohn, Corrigan, Donaldson 2000).

O reconhecimento da necessidade de mobilização global para redução dos danos causados por erros de medicação levou a OMS a lançar, em março de 2017, o Desafio Global de Segurança do Paciente, especificamente direcionado para reduzir em 50\%, no prazo de cinco anos, os danos severos e evitáveis causados a pacientes por erros relacionados a medicamentos. A iniciativa, intitulada Medication Without Harm, inclui recomendações e procedimentos para aplicação em nível global, nacional e local, e corresponde ao Terceiro Desafio Global de Segurança do Paciente lançado pela OMS, depois da temática da redução de infeções associadas a cuidados de saúde (Clean Care is Safer Care) e da cirurgia segura (Safe Surgery Saves Lives).

Você será convidado a refletir sobre cada tema abordado e a realizar pesquisa adicional de acordo com as informações constantes nos destaques ao longo do texto.

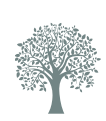

Para aprofundar a discussão sobre a campanha da OMS para redução dos erros de medicamentos, aconselha-se a leitura da brochura sobre o Desafio Global de Segurança do Doente, disponível em:

http://www.who.int/ patientsafety/medicationsafety/campaign/en/ 


\section{Taxonomia na área do medicamento}

O processo de prescrição, dispensa/dispensação e administração de medicamentos a pacientes nas organizações de saúde é complexo e abrange várias etapas que contemplam uma série de decisões e ações inter-relacionadas, envolvendo diferentes profissionais de saúde, tais como o médico, o farmacêutico, o técnico de farmácia, o enfermeiro e o técnico de enfermagem, e o próprio paciente.

O processo em ambiente hospitalar (Figura 1) inicia-se com a prescrição do medicamento realizada pelo médico. A prescrição é enviada à farmácia (fisicamente ou por via informática) e é, depois, validada pelo farmacêutico. Em seguida, o medicamento é preparado para distribuição na farmácia, pelo técnico de farmácia e dispensado ao serviço em que se encontra o paciente. O enfermeiro, após a receção do medicamento, confirma a correspondência entre a prescrição médica e o que foi enviado pela farmácia. Antes de administrar a medicação ao paciente e, sempre que seja necessário, o enfermeiro prepara a medicação (por exemplo, a medição de um volume prescrito ou a diluição de um medicamento injetável). Após a administração da medicação, a monitorização e a vigilância do paciente deverão ser um processo contínuo, sendo da responsabilidade de todos os profissionais envolvidos (médico, enfermeiro e farmacêutico).

Figura 1 - Processo geral de utilização do medicamento em meio hospitalar

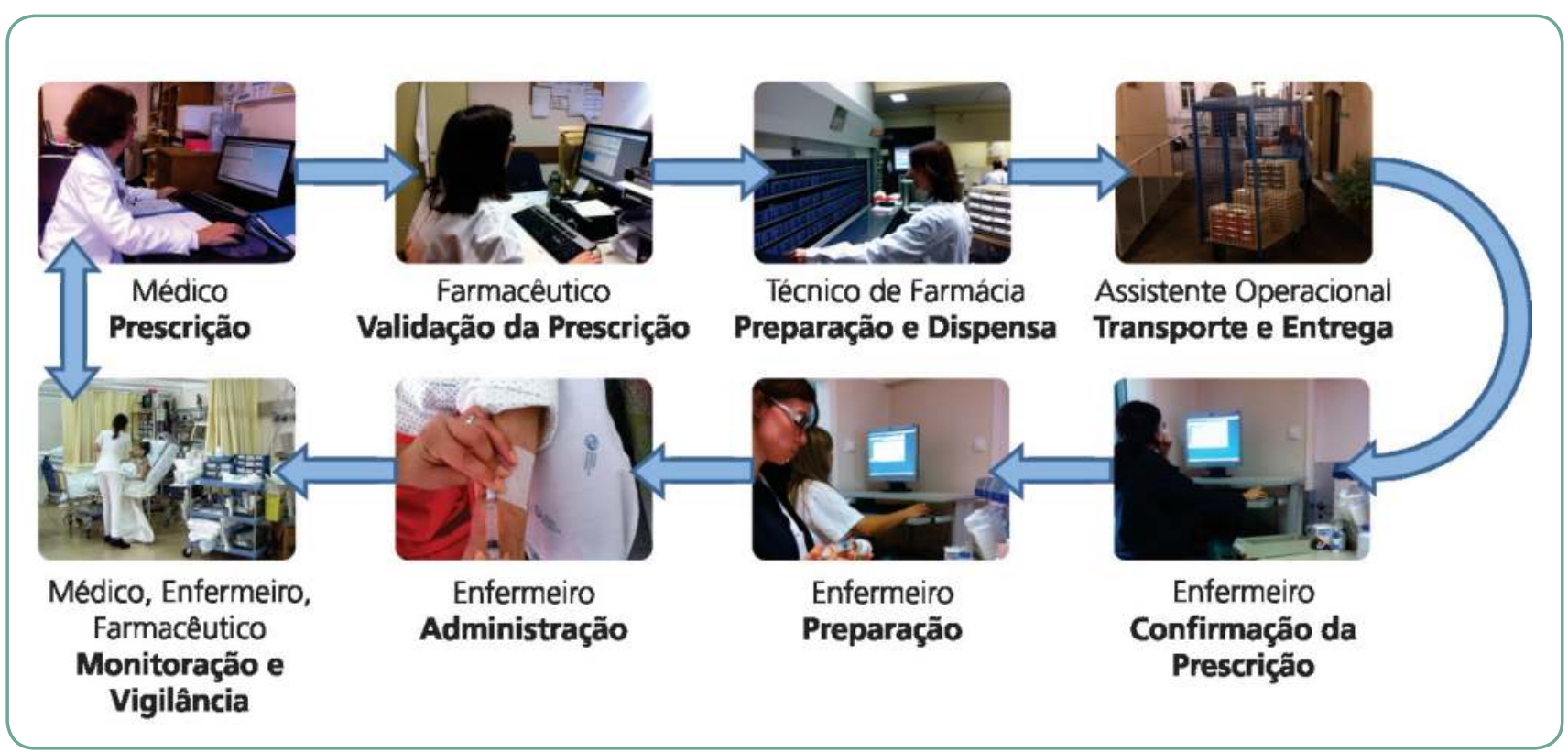

Fonte: Elaboração dos autores. 


\section{Para refletir}

Você se revê no processo de utilização apresentado na Figura 1?

Consegue identificar, dentro da sua prática, onde exatamente você pode intervir para evitar que o erro de medicação ocorra?

Os erros de medicação podem ocorrer em qualquer dos processos que constituem o circuito do medicamento e podem ser de diferentes tipologias, sendo os mais frequentes classificados nas formas descritas no Quadro 1.

Quadro 1- Tipos de erros relacionados com medicação

\begin{tabular}{|l|l|}
\hline $\begin{array}{l}\text { Erros de } \\
\text { prescrição }\end{array}$ & $\begin{array}{l}\text { Seleção incorreta do medicamento (de acordo com contraindicações, } \\
\text { alergias conhecidas ou outros factores). } \\
\text { Monitorização, dose, via de administração, concentração, velocidade de } \\
\text { infusão, instruções de uso inadequadas feitas pelo médico; prescrições } \\
\text { ilegíveis ou que possam induzir a erro. }\end{array}$ \\
\hline $\begin{array}{l}\text { Erro de } \\
\text { transcrição }\end{array}$ & $\begin{array}{l}\text { Equívocos na transcrição da prescrição médica manual para o sistema de } \\
\text { prescrição eletrónica. }\end{array}$ \\
\hline $\begin{array}{l}\text { Erros de } \\
\text { distribuição/ } \\
\text { dispensa/ } \\
\text { dispensação }\end{array}$ & $\begin{array}{l}\text { São os erros que ocorrem no momento da dispensa/dispensação dos } \\
\text { medicamentos pelos serviços farmacêuticos (doses diferentes das prescritas, } \\
\text { diferentes formas farmacêuticas e apresentações dos medicamentos, outro } \\
\text { medicamento diferente do originalmente prescrito). }\end{array}$ \\
\hline $\begin{array}{l}\text { Erro de } \\
\text { preparação }\end{array}$ & $\begin{array}{l}\text { Medicamento incorretamente formulado ou manipulado antes da } \\
\text { administração (reconstituição ou diluição incorreta, associação de } \\
\text { medicamentos física ou quimicamente incompatíveis). }\end{array}$ \\
\hline $\begin{array}{l}\text { Erro de } \\
\text { administração }\end{array}$ & $\begin{array}{l}\text { Estes erros incluem doses administradas pela via incorreta (diferente da } \\
\text { prescrita), ou pela via correta, mas no local errado (troca do olho/ouvido, } \\
\text { esquerdo pelo direito) e os casos em que o padrão de administração não é } \\
\text { respeitado (por exemplo, volume de perfusão). }\end{array}$ \\
\hline
\end{tabular}

Fonte: Cassiani (2005); Belela et al. (2011).

A Organização Mundial da Saúde (OMS) publicou, em 2009, a Estrutura Concetual da Classificação Internacional sobre Segurança do Paciente (OMS 2009), descrevendo a tipologia de incidentes associados à medicação e a fluidos intravenosos (Figura 2).

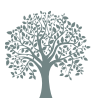

Para aprofundar sobre uma classificação mais completa dos erros associados à medicação, consulte o artigo "A segurança do paciente e o paradoxo no uso de medicamentos", de Sílvia Cassiani, publicado em 2005 na Revista Brasileira de Enfermagem e disponível em: http://www.scielo.br/scielo php?pid=S0034-716720050 00100019\&script= sci_arttext

Para aprofundar a matéria sobre os vários tipos de erros em todo o processo de utilização do medicamento e as estratégias de prevenção a utilizar para cada tipo de erro, consulte o documento "Erros de medicação, definições e estratégias de prevenção", disponível em: http://www. corensp.org.br/sites/default/ files/erros_de_medicacaodefinicoes_e_estrategias_de_ prevencao_0.pdf 
Figura 2 - Classificação dos incidentes relacionados com a medicação e fluídos IV, segundo a classificação da Organização Mundial da Saúde

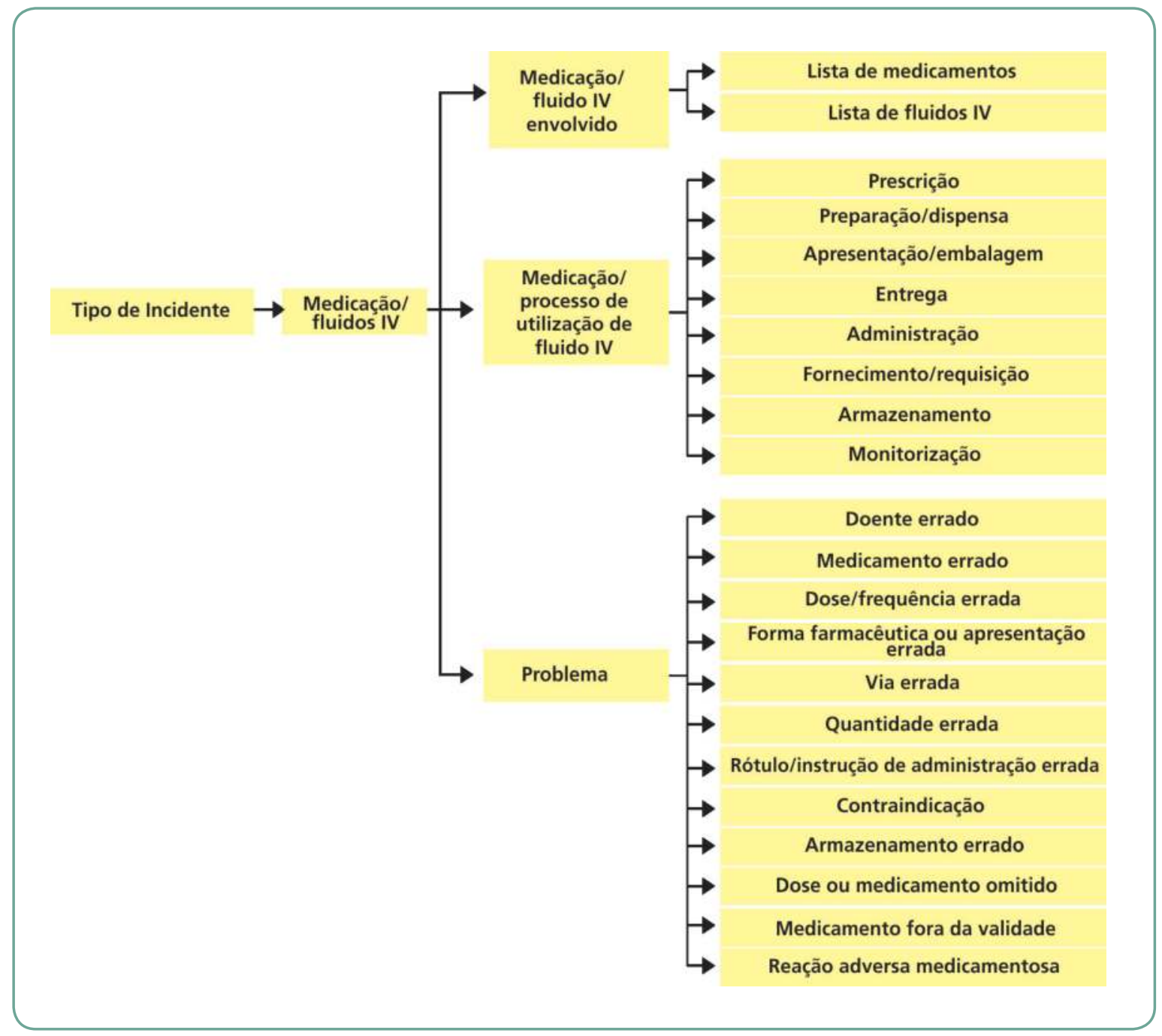

Fonte: OMS (2009).

Apesar de esta temática ser bastante discutida e aprofundada pelos profissionais de saúde, realça-se que o papel do paciente na eficiência do uso do medicamento não pode ser menosprezado. O envolvimento do paciente nos processos de decisão relacionados com medicamentos e a melhoria da informação a que tem acesso é, inclusivamente, um dos objetivos do Desafio Global da OMS referido anteriormente, na perspetiva da redução dos erros relacionados com o uso dos medicamentos, pelo paciente (WHO 2017). Essa valorização do paciente e sua educação para a saúde está, também, bem patente nas recomendações da OMS para a redução de erros relacionados aos medicamentos nos cuidados de saúde primários (WHO 2016). 
A sensibilização dos cidadãos para esta problemática e, mais ainda, a sensibilização para a necessidade de envolvimento de todos os intervenientes no circuito do medicamento é um fator fundamental para a redução dos erros de medicação. Neste sentido, a Ordem dos Farmacêuticos de Portugal desenvolveu uma campanha com o apoio da Federação Internacional Farmacêutica (FIP) para a promoção do uso responsável do medicamento.

\section{Factores contribuintes para o erro de medicação e medidas de segurança}

Como já mencionamos, todo o processo de utilização do medicamento (Figura 1) é passível de ser afetado pelo erro. Tradicionalmente, os métodos que permitem detetar incidentes e, em particular, os eventos adversos concentravam-se no relato voluntário e no rastreamento de erros. No entanto, os investigadores/pesquisadores têm demonstrado que apenas 10 a 20\% dos incidentes são relatados, e, desses, 90 a 95\% não causam qualquer dano aos pacientes (Griffin, Resar 2009).

São vários os métodos que podem ser utilizados para detetar erros de medicação, tendo todos eles vantagens e inconvenientes associados. No entanto, os mais comumente utilizados são: a Revisão Retrospetiva de Processos Clínicos e o Método do Institute of Healthcare Improvement (IHI).

A Revisão Retrospetiva dos Processos Clínicos consiste, tal como o nome indica, numa análise retrospetiva e observacional da informação registada nos processos clínicos de alta clínica dos pacientes. É uma avaliação retrospetiva e observacional da informação registada nos processos dos pacientes, após alta clínica. Permite conhecer a incidência, caracterizar o tipo de evento ocorrido e determinar o seu impacte económico, podendo também fornecer alguma informação sobre as causas que levaram ao seu aparecimento (Vincent 2011). O “Harvard Medical Practice Study" (Baker GR 2004) foi o primeiro estudo a utilizar esse método. Ele serviu de inspiração para a realização de muitos outros estudos efetuados em países tão diversos como o Brasil (Mendes et al. 2009), Inglaterra ou a Nova Zelândia (Vincent 2011).

Esse tipo de análise tem como principal limitação o facto de estar dependente da qualidade do registo clínico e, se não for registada qualquer informação relativamente a eventos que tenham ocorrido durante a hospitalização do paciente, essa informação não poderá ser acedida dessa forma.
O envolvimento do paciente no seu processo de cuidado é abordado no Capítulo 8, "Envolvimento e segurança do paciente: desafios e estratégias", do livro Segurança do Paciente: criando organizações de saúde seguras.

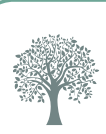

A campanha para promoção do uso responsável de medicamento pode ser consultada em http://www. usoresponsaveldomedicamento.com.

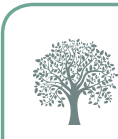

Está disponível, na página do Institute for Healthcare Improvement, o documento "IHI Global Trigger Tool for measuring adverse envents" (Griffin, Resar 2009) que fornece informações sobre a metodologia da "Ferramenta Global IHI", com as instruções passo a passo, de forma a identificar com precisão os eventos adversos (danos) e medir a taxa de eventos adversos ao longo do tempo.

Consulte em http://proqualis.net/ medicamentos/?id=000 001297 o resumo explicativo sobre essa ferramenta e aprofunde a sua aplicação prática com base nas referências disponibilizadas: Rozenfeld et al. (2009) e Giordani et al. (2012). 
Em alternativa, o IHI desenvolveu um método fácil de utilizar para detetar com precisão os eventos adversos (danos) e a medição da taxa de eventos adversos ao longo do tempo, conhecido como Global Trigger Tool. Essa metodologia inclui uma análise retrospetiva de uma amostra aleatória de registos de pacientes que consiste na deteção de triggers ou "gatilhos" (ou pistas) para detetar possíveis eventos adversos. Muitos hospitais têm utilizado essa ferramenta para detetar eventos adversos, para analisar o nível do dano de cada evento adverso e identificar áreas de melhoria nas suas organizações. Importa referir que esse método do IHI não pretende detetar todos os eventos adversos num único processo clínico do paciente. O tempo limite recomendado para a revisão e a seleção aleatória de registos é definido a fim de produzir uma abordagem de amostragem suficiente para o projeto de segurança da prestação de cuidados no hospital.

A definição de estratégias de prevenção quer de caráter transversal, quer dirigidas a cada etapa constitui, por isso, um factor fundamental de promoção da segurança do paciente. Numa perspetiva transversal, a informação sobre medicamentos assume papel preponderante. O acesso a bases de dados nacionais ou internacionais com informação atualizada sobre medicamentos deve ser promovido, estando disponível para consulta pelos profissionais de saúde no decurso das suas funções. No entanto, deve ser promovido o desenvolvimento e compilação de informação objetiva e atualizada respeitante aos medicamentos que pertencem ao guia farmacoterapêutico das organizações de saúde, dando resposta às necessidades identificadas pelos profissionais de saúde nos locais em que é expetável que dela necessitem. Essa pode incluir protocolos terapêuticos, tabelas de ajuste de dose em situações especiais (por exemplo, insuficiência renal ou hepática), instruções de administração de fármacos por via intravenosa, oral, ou por sonda nasogástrica (nomeadamente no que respeita à possibilidade de triturar comprimidos ou abrir cápsulas), cuidados a ter na manipulação de medicamentos etc.

No processo de gestão do risco no processo de utilização do medicamento, o envolvimento de equipas multidisciplinares revela-se particularmente importante para o desenvolvimento e implementação de procedimentos dirigidos à segurança do medicamento, bem como na sua monitorização, numa perspetiva de melhoria contínua.

Em nível hospitalar, o papel da Comissão de Farmácia e Terapêutica, cuja existência tem caráter obrigatório em Portugal e recomendável no Brasil, revela-se de forma especial importante. Essa comissão, habitualmente composta de médicos, enfermeiros e farmacêuticos, é respon- 
sável por definir a política de medicamentos da organização de saúde, promover o uso racional do medicamento e monitorizar seu uso no que respeita à eficácia e segurança.

\section{Segurança na identificação do paciente a fim de prevenir o erro de medicação}

A correta identificação do paciente é essencial para garantir sua segurança em todas as etapas do processo de utilização do medicamento, e sempre que possível, deve ser realizada com recurso da pulseira individual de identificação. Antes da realização de qualquer ato relacionado com a prescrição, dispensa/dispensação, preparação e administração do medicamento, é necessário confirmar a identidade do paciente com, pelo menos, dois dados inequívocos da sua identificação (nome completo e data de nascimento, por exemplo). Antes da administração do medicamento, perguntar qual o nome completo do paciente, para que seja ele a identificar-se, é uma das regras de ouro na prevenção do erro de medicação. Nunca devemos assumir que o paciente que está numa determinada cama/leito é o paciente certo. Quando não é possível o próprio paciente identificar-se, o profissional deve utilizar outros identificadores, como a data de nascimento e o número do processo clínico/prontuário.

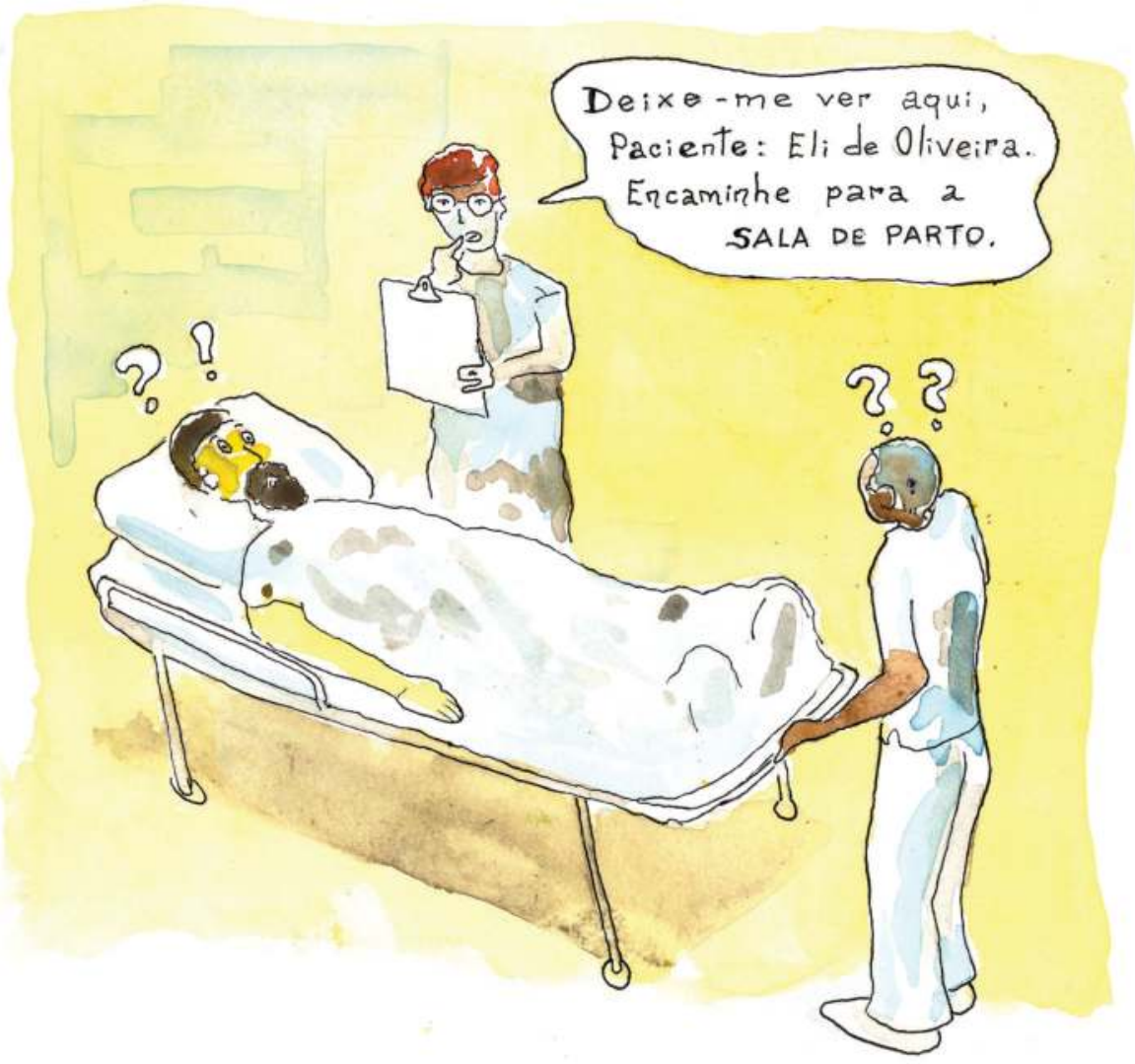




\section{Para refletir}

Na sua organização, existem normas de segurança para a identificação do paciente?

Habitualmente, que mecanismos de segurança utiliza para garantir que se trata do paciente certo?

Identificação do Paciente, disponível em: http://www. who.int/patientsafety/solutions/ patientsafety/PS-Solution2.pdf

A OMS, em 2007, publicou a Solução 2 de Segurança do Paciente, da qual se destacam algumas recomendações (WHO 2007):

路 Enfatizar a responsabilidade dos profissionais de saúde na identificação correta do paciente.

* Usar, pelo menos, dois identificadores (por exemplo, nome completo e data de nascimento) para confirmar a identidade do paciente. Em pediatria, é também indicada a utilização do nome da mãe da criança.

繗 Nunca utilizar a idade, sexo, diagnóstico, número da cama/leito para identificar o paciente.

蛇 Encorajar o paciente e a família a participar de todas as fases do processo de identificação.

路 Verificar de forma contínua a integridade das informações nos locais de identificação do paciente (por exemplo: pulseiras, processo clínico/prontuário, requisições).

静 Promover procedimentos internos (alertas) para distinguir pacientes com o mesmo nome.

\section{Medicamentos potencialmente perigosos}

Conheça a lista dos MPP usados em hospitais e ambulatórios por meio dos links:

- MPP no hospital - http://www. boletimismpbrasil.org/boletins/ pdfs/boletim_ISMP_13.pdf

- MPP no ambulatório - http:// wnw.boletimismpbrasil.org/ boletins/pdfs/boletim_ISMP_16. pdf

- Norma da DGS - https:// www.dgs.pt/directrizes-dadgs/normas-e-circularesnormativas/norma-n-0142015de-06082015.aspx
Os medicamentos potencialmente perigosos (MPP), também conhecidos por medicamentos de alerta máximo, são “aqueles que possuem risco aumentado de provocar danos significativos aos pacientes em decorrência de falha no processo de utilização" (ISMP Brasil 2013). Esses medicamentos podem ser usados em âmbito hospitalar ou ambulatório. As organizações de saúde devem divulgar a lista dos MPP que utilizam e assegurar que os profissionais de saúde conhecem os riscos associados à sua utilização, com vista à implementação de medidas de segurança que controlem os riscos e previnam os erros de medicação. Os profissionais de saúde também devem garantir que os pacientes em ambulatórios sejam informados, de forma clara e inequívoca, sobre o tipo de medicamento e forma de tratamento, validando sempre com o paciente o ensino realizado. 
Os erros que surgem na utilização dos MPP podem não ser os mais frequentes; no entanto, as consequências da sua utilização incorreta poderão causar lesões severas ou mesmo conduzir à morte do paciente. Assim, a implementação de estratégias para a prevenção do erro na utilização dos MPP deve abranger todas as etapas do processo de utilização do medicamento, envolvendo todos os profissionais implicados e o paciente.

\section{Para refletir}

O paciente J.T.R., de 45 anos, internado num hospital, está medicado com um antibiótico endovenoso de 12/12 horas. A farmácia realiza a dispensa/dispensação do medicamento no sistema de dose unitária. $\mathrm{Na}$ enfermaria desse paciente, o enfermeiro procede à preparação e administração dos medicamentos para os vários pacientes, sendo interrompido várias vezes por outros profissionais ou familiares dos pacientes que solicitam apoio ou informações. Entretanto, o enfermeiro prepara o antibiótico do paciente J.T.R. injetando a solução para a sua diluição. Nesse momento, deteta que a solução de diluição dispensada pela farmácia é uma ampola de cloreto de potássio.

Quais os factores que podem ter contribuído para esse erro?

Na sua organização, esse tipo de erro está controlado? Considera que existem barreiras de segurança eficazes na prevenção desse erro?

Que outras estratégias de prevenção do erro com MPP considera importante implementar no seu local de trabalho?

Para a prevenção do erro na utilização dos MPP, existem várias estratégias que devem ser adotadas pelas organizações de saúde. O ISMP refere que essas estratégias podem incluir padronização desde a prescrição até a administração desse tipo de medicamento, melhorias no acesso às informações, restrição ao acesso, uso de rótulos e alertas automatizados e adoção da verificação independente (doublecheck) manual ou automatizada (ISMP Brasil 2013). Outras estratégias passam também pela utilização de seringas próprias para administração de medicamentos orais ou alimentação enteral, cuja conexão é incompatível com os sistemas de administração intravenosa, prevenindo a troca da via de administração.

\section{Controlo de soluções eletrolíticas concentradas injetáveis}

As soluções de eletrólitos concentrados para injeções são em especial perigosas, provocando mortes acidentais e lesões graves relacionadas 
com a administração inadequada desses medicamentos. O cloreto de potássio injetável é o que mais frequentemente está implicado nos erros de administração. Existem diferentes concentrações de cloreto de potássio injetável (por exemplo: 10\%, 15\%, 19,1\% e 20\%), o que poderá representar aumento dos riscos para o paciente em virtude de sua utilização incorreta, como ser administrado ao paciente sem ter sido diluído previamente ou efetuar um cálculo errado por estar disponível numa concentração diferente da usual.

É vital, portanto, a implementação de mecanismos de segurança que passam pela normalização das doses, das unidades de medida e da terminologia, bem como a divulgação de alertas aos profissionais para o risco de confusão entre os nomes das soluções de eletrólitos concentrados específicas (por exemplo, confusão entre o cloreto de sódio e o cloreto de potássio).

Internacionalmente, está descrito que a remoção de soluções de eletrólitos concentrados (em específico o cloreto de potássio injetável) das unidades de cuidados de pacientes tem considerável impacte positivo na redução da mortalidade e de lesões associadas à utilização desses medicamentos. Para além disso, foram implementadas várias medidas de segurança, nomeadamente a dispensa/dispensação desses medicamentos de forma exclusiva após a prescrição, a preparação correta com dupla verificação independente, a utilização de rotulagem adequada e sua administração apenas por profissionais com competência apropriada.

\section{Para refletir}

Como estão armazenadas as soluções de eletrólitos concentrados injetáveis na sua organização?

Que tipos de rótulos são utilizados na sua organização para a identificação das soluções de eletrólitos concentrados injetáveis administrados ao paciente?

De acordo com as recomendações da OMS, destacam-se algumas medidas de segurança na utilização de cloreto de potássio e de outras soluções com eletrólitos concentrados:

Para aprofundar a temática, leia a Solução 5 integrada nas Soluções da Segurança do Paciente da OMS - Control of Concentrated Electrolyte Solutions, disponível em: http:// www.who.int/patientsafety/ solutions/patientsafety/PSSolution5.pdf

*stabelecer normas e circuitos para que o cloreto de potássio injetável seja tratado como uma substância controlada, definindo igualmente normas para sua armazenagem e controlo da sua administração.

* Promover a remoção de soluções de eletrólitos concentrados injetáveis de todas as enfermarias e armazenar em áreas definidas. 
As ampolas de potássio devem ser rotuladas individualmente com rótulo fluorescente, em que esteja bem visível a advertência “Deve ser diluído" (Veja a Figura 3).

滕 Utilizar verificação independente por parte de um segundo profissional treinado e qualificado após a preparação da solução.

滕 Rotular a solução preparada com o alerta "Atenção - Alto risco".

* Utilizar sempre uma seringa de perfusão (bomba de infusão) para a administração das soluções concentradas.

蹸 Contemplar, nos programas de integração, o treino dos profissionais e a disponibilização das normas e dos procedimentos sobre as medidas de segurança relativas ao uso de soluções de eletrólitos concentrados.

Figura 3 - Exemplo de rotulagem de ampolas de cloreto de potássio com alerta colocado na farmácia "Atenção diluir", utilizada no Centro Hospitalar de Lisboa Central, Portugal

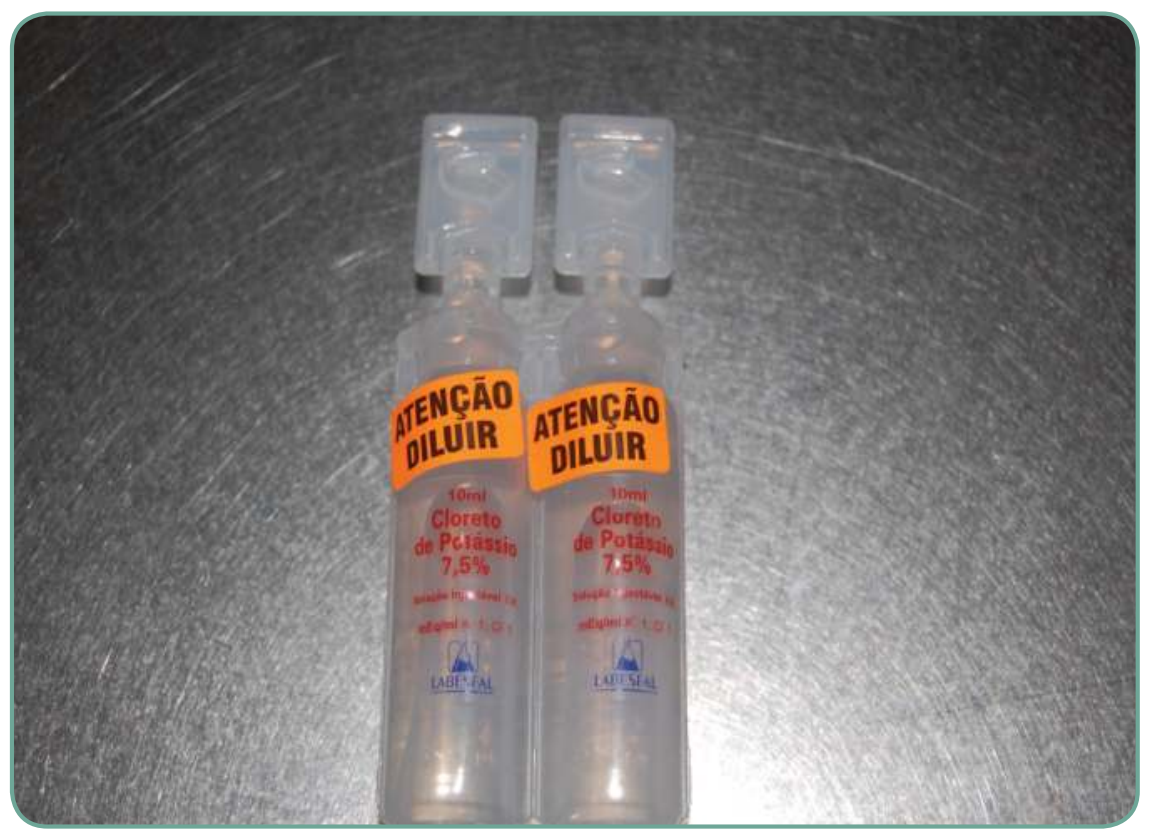

Fonte: Elaboração dos autores.

\section{Medicamentos com nome ortográfico, fonético ou aspecto semelhantes}

A existência de dezenas de milhares de medicamentos atualmente no mercado vem aumentar o potencial de erro em razão da possibilidade de confusão de nomes, tanto os nomes comerciais como a denominação comum internacional, sendo uma das causas de erro de medicação em nível mundial. Com a introdução dos medicamentos genéricos, o risco 


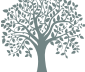

Para aprofundar a temática, leia a Solução 1 integrada nas Soluções da Segurança do Paciente da OMS - LookAlike, Sound-Alike Medication Names, disponível em: http:// www.who.int/patientsafety/ solutions/patientsafety/PSSolution1.pdf aumentou, uma vez que existe maior número de medicamentos com embalagens semelhantes.

As organizações de saúde devem promover atividades na área da identificação e avaliação do risco associado à utilização de medicamentos Look-Alike, Sound-Alike (LASA).

\section{Para refletir}

Que mecanismos de segurança são aplicados na sua organização para a prevenção do erro na utilização dos medicamentos LASA?

Quais mecanismos de segurança utiliza na sua prática diária para a prevenção do erro associado à utilização dos medicamentos LASA?

De acordo com as recomendações da OMS, destacam-se algumas medidas de segurança:

* Garantir a legibilidade da prescrição e incluir a denominação genérica, dose, concentração, orientações para administração e a indicação para utilização do medicamento, como forma de facilitar a diferenciação de nomes com som ou grafismo semelhante.

Rever, anualmente, os medicamentos LASA em uso na organização.

* Proceder à separação dos medicamentos LASA em todas as áreas de armazenamento.

Desenvolver estratégias que evitem a confusão do nome do medicamento, tais como o uso de métodos Tall Man Lettering destacando em maiúsculas a(s) sílaba(s) diferentes de medicamentos com nome semelhante (Veja a Foto 1).

* Utilizar técnicas de destaque do nome do medicamento ou cores diferentes que reduzam a possibilidade de confusão dos nomes dos medicamentos LASA.

䠌 Integrar, na formação contínua dos profissionais, o tema dos medicamentos LASA. 
Foto 1 - Exemplo de aplicação do método de rotulagem com letra Tall Man Lettering para distinguir o nome dos medicamentos

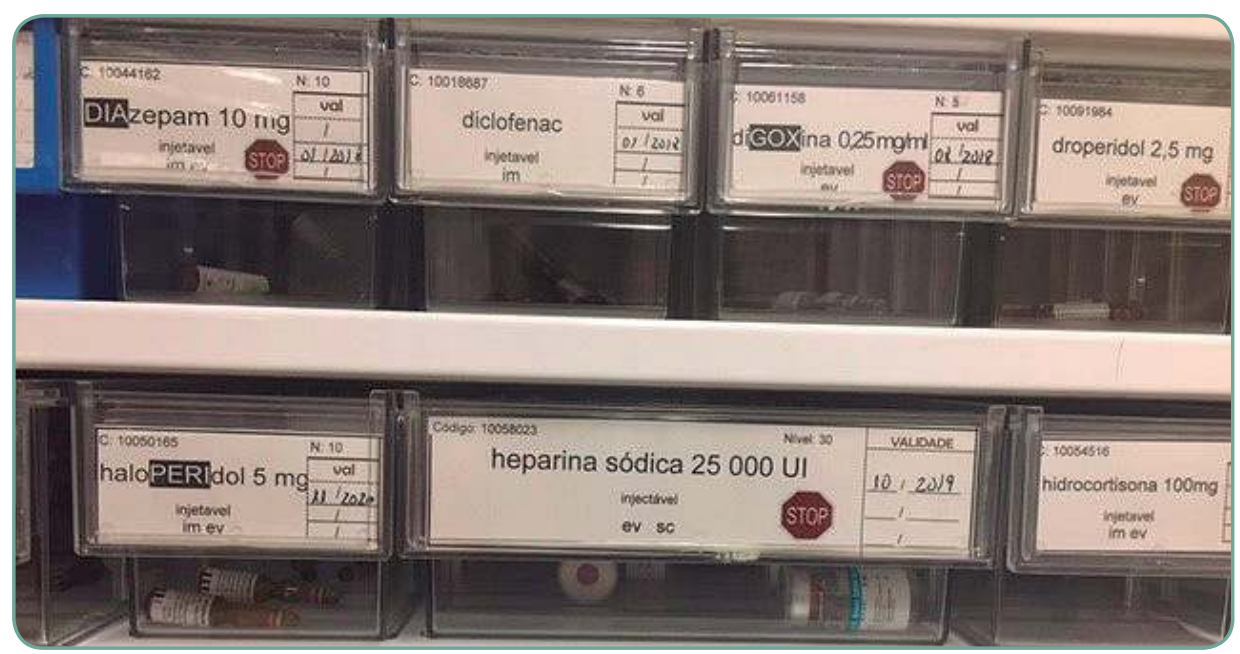

Foto: Centro Hospitalar de Lisboa Central, Portugal.

Apesar de muitos dos erros com medicamentos LASA ocorrerem no internamento/internação, o mesmo grau de rigor na aplicação das estratégias de redução de risco deve ser aplicado, também, em cuidados ambulatórios.

\section{Prescrição de medicamentos}

De acordo com a classificação dos incidentes relacionados com a medicação e fluídos IV (Figura 2), a prescrição de medicamentos pode ser afetada por erros de seleção de medicamento, de doses, instruções de uso, entre outros. A escassez de informação no que respeita à terapêutica habitual do paciente pode ser uma importante causa de erro de medicação. Os programas de conciliação terapêutica, que serão discutidos na seção sobre "Conciliação Medicamentosa", são importantes ferramentas de recolha/coleta e atualização da informação respeitante à terapêutica do paciente, particularmente nos pontos de transição de cuidados de saúde.

Os profissionais autorizados a prescrever medicamentos na organização devem estar claramente identificados e, em todo o processo, deve ser salvaguardada a correta identificação do paciente e garantida a legibilidade da informação (JCI 2013). Essa constitui uma das principais vantagens da prescrição eletrónica quando comparada com a manual, ultrapassando os problemas de legibilidade da prescrição e de omissão de informação na prescrição (por exemplo, no que diz respeito à posologia, quantidade de medicamento ou duração do tratamento), descritos como os erros de medicação mais frequentes. 


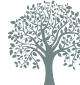

Para aprofundar esse tema, consulte o documento publicado pelo ISMP "List of Error-Prone Abbreviations, Symbols, and Dose Designation", disponível em: http://www.ismp.org/Tools/ errorproneabbreviations.pdf
As vantagens da prescrição eletrónica incluem, ainda, a possibilidade de acoplar sistemas de informação de apoio à decisão (proposta de posologia, informação sobre doses máximas, necessidades de ajustes de dose etc.) e alertas para interações medicamentosas, tempos de tratamento ou monitorização laboratorial. O sucesso de implementação desses sistemas depende, contudo, de adequada monitorização e acompanhamento, visto que a própria transição do sistema manual para o eletrónico tem sido associada à ocorrência de erros de medicação (Lyra Júnior et al. 2010).

A Joint Comission International (2013) sublinha que devem estar claramente definidos os tipos de prescrição considerados aceitáveis e os elementos que constituem uma prescrição completa.

Essas definições incluem alguns dos aspetos anteriormente referidos, tais como a correta identificação do paciente e precauções ou procedimentos específicos para a requisição de medicamentos LASA. Adicionalmente, devem estar bem definidas as ações a serem tomadas sempre que se observem prescrições incompletas, ilegíveis ou pouco claras. Por exemplo, a utilização de abreviaturas, símbolos ou designações das dosagens na prescrição de medicamentos deve ser proibida pelo risco de erro na interpretação da prescrição, conforme exemplificado no Quadro 2.

Quadro 2 - Exemplo de lista do ISMP que trata de abreviaturas, símbolos ou designações das dosagens que não devem ser utilizadas no uso do medicamento

\begin{tabular}{|l|l|l|l|}
\hline $\begin{array}{l}\text { Abreviatura, } \\
\text { símbolos ou } \\
\text { designações de } \\
\text { dosagens }\end{array}$ & Significado real & Erro de interpretação & Uso correto \\
\hline UI & Unidade Internacional & $\begin{array}{l}\text { Confusão com IV } \\
\text { (intravenoso) ou 10 } \\
\text { (dez) }\end{array}$ & Usar "Unidade" \\
\hline $\begin{array}{l}\mu g \\
\text { Colocação do "0" } \\
\text { depois do ponto } \\
\text { decimal } \\
\text { (ex: } 1.0 \text { mg) }\end{array}$ & 1 mg & Confusão com mg & Usar "Mcg" \\
\hline $\begin{array}{l}\text { Não colocação do } \\
\text { "0" antes do ponto } \\
\text { decimal } \\
\text { (ex: .5 mg) }\end{array}$ & 0.5 mg & $\begin{array}{l}\text { Confusão com 10 mg } \\
\text { se não for visualizado } \\
\text { o ponto decimal. }\end{array}$ & $\begin{array}{l}\text { Não utilizar os zeros } \\
\text { depois do ponto } \\
\text { decimal. }\end{array}$ \\
\hline
\end{tabular}


Outra questão que merece particular relevância é a prescrição verbal, visto que, não podendo ser excluída para procedimentos de emergência, deverá ser sujeita a procedimentos específicos que garantam a sua segurança. Nesses casos, é importante tomar precauções, tais como a repetição da ordem recebida (presenciada, de preferência, por outro profissional de saúde) e a obrigatoriedade de regularização da prescrição no processo clínico/prontuário, no menor tempo possível.

\section{Para refletir}

Que procedimentos estão implementados na sua organização para aumentar a segurança de prescrição, incluindo a prescrição verbal?

A elaboração e implementação de protocolos de prescrição é, hoje, também reconhecida como uma importante ferramenta de segurança.

Ainda no que respeita à prescrição, é importante salientar que determinadas populações são, à partida, mais suscetíveis à ocorrência de erros de medicação com consequências graves, nomeadamente a população pediátrica e a população geriátrica, que se caracterizam por diferenças farmacocinéticas e farmacodinâmicas relativamente ao adulto jovem.

No caso da população pediátrica, acresce o facto de serem escassos os medicamentos disponíveis comercialmente e que dão respostas às suas necessidades terapêuticas, e o facto de serem necessários cálculos para adaptação de dose e sistemas de administração apropriados. Visto que nessa população a prescrição de medicamentos se caracteriza, frequentemente, por doses muito reduzidas, torna-se imperativo aplicar as recomendações do Quadro 2 sobre a utilização de "0" (zero) antes do ponto decimal, e a sua eliminação após o ponto decimal (ou último algarismo decimal).

No que respeita à população geriátrica, a sua suscetibilidade a erros de medicação está relacionada, por um lado, com o fenómeno de polimedicação (toma simultânea de vários medicamentos), que aumenta exponencialmente o risco de interações medicamentosas, e, por outro lado, com a diferente resposta à terapêutica medicamentosa quando comparada com o adulto jovem. De facto, foi descrito que a probabilidade teórica de interações medicamentosas atinge 50\% quando um paciente toma cinco medicamentos diferentes e ascende a $100 \%$, para sete medicamentos (Delafuente 2003). Os efeitos adversos decorrentes dessas interações são frequentemente identificados como sintomas de 
novas doenças (devido à multimorbilidade que caracteriza essa população) levando à prescrição de mais medicamentos, no fenómeno conhecido como "cascata de prescrição" (Rochon, Gurwitz 2017).

A perceção de que os pacientes idosos não devem ser tratados do mesmo modo que o adulto jovem conduziu à identificação de Medicamentos Potencialmente Inapropriados (MPI) para essa população. Um conceito expresso em critérios como os Critérios de Beers e os Critérios Stopp (entre outros), que se referem a medicamentos que devem ser evitados nessa população, por reduzida eficácia ou porque os riscos da sua utilização suplantam os benefícios (por exemplo, os medicamentos que aumentam o risco de quedas ou que deprimem o sistema nervoso central) (Corsonello et al. 2009).

\section{Dispensa/dispensação de medicamentos}

Os erros de medicação mais frequentemente associados à etapa de dispensa/dispensação ou distribuição medicamentosa são: a troca do medicamento, troca da dosagem ou forma farmacêutica (apresentação) do medicamento; instruções de utilização erradas; envio do medicamento para o paciente errado; ou medicamento entregue com atraso. No que respeita às causas apuradas para a ocorrência desses erros, vários estudos apontam o elevado volume de trabalho, a ocorrência de medicamentos com nomes semelhantes ou embalagens semelhantes (LASA), interrupções, ilegibilidade das prescrições, bem como as falhas de comunicação com a equipa de enfermagem que administra os fármacos (Lyra Júnior et al. 2010).

Cabe aos serviços farmacêuticos das organizações de saúde desenvolverem e implementarem medidas que promovam a segurança na distribuição de medicamentos, incluindo a verificação no ato da dispensa/ dispensação e a antecipação do risco, nomeadamente no que respeita aos medicamentos LASA ou outros que, dadas as suas características de embalagem ou modo de administração, possam propiciar o erro. Um exemplo dessas medidas é o desenvolvimento de sinalética/sinalização, como a adaptada do código da estrada, destinada a ser aplicada nos locais de armazenamento de medicamentos, chamando a atenção para a periculosidade/perigosidade de determinados medicamentos ou a semelhança das embalagens de medicamentos diferentes (Figura 4). 
Figura 4 - Sinalética/sinalização de segurança no armazenamento de medicação implementada no Centro Hospitalar Cova da Beira, EPE, Portugal

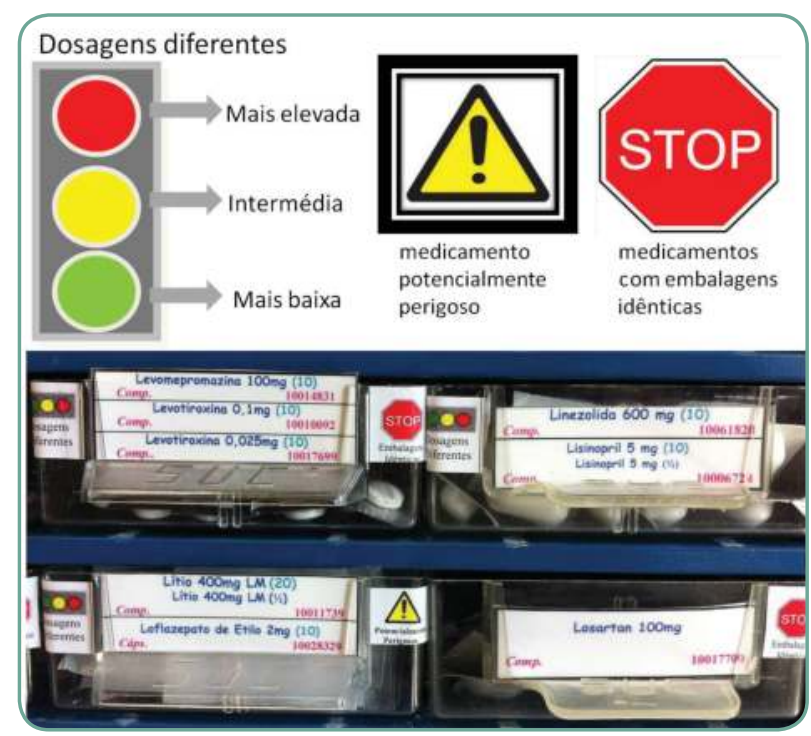

Foto: Serviços Farmacêuticos do Centro Hospitalar Cova da Beira, EPE, Portugal.

Nesse contexto, a utilização de sistemas baseados em cores diferentes para identificar ou distinguir medicamentos tem sido alvo de controvérsia na medida em que, em alguns casos, pode mesmo resultar no aumento do risco de erros de medicação. Outros factores, como o tamanho ou tipo de letra, podem também influenciar a eficácia de diferenciação dos medicamentos semelhantes (Cohen 2006).

A utilização de cores em sectores ou medicamentos específicos, como bloco cirúrgico e anestésicos, pode auxiliar na prevenção de erros (ASA 2009). Contudo, a utilização dessa estratégia para todos os medicamentos dispensados dentro da organização de saúde encontra forte oposição por partes dos estudiosos nessa área (Cohen 2006; Baker DE 2005; ASHSP 1996). Em geral, o excesso de informação gráfica ou visual poderá demonstrar-se contraproducente na implementação de um sistema de gestão de risco do medicamento.

Diferentes sistemas de distribuição de medicamentos podem ser selecionados ou mesmo coexistir na organização de um hospital: o sistema de distribuição clássica, também chamado "tradicional", baseia-se em stocks definidos para as necessidades das enfermarias e são repostos pela farmácia à medida que são utilizados. Esses sistemas não incluem as etapas de validação farmacêutica da prescrição, nem a distribuição individualizada da medicação prescrita, para 24 horas, pelo que a sua implementação exclusiva pode propiciar o erro no processo de utilização do medicamento. Contudo, a coexistência desse tipo de distribuição com a distribuição individual por dose unitária justifica-se uma vez 
que se destina a abranger os medicamentos cuja utilização não permite distribuição exclusiva pelo sistema individualizado (por exemplo, os injetáveis de grande volume, as embalagens multidose como as soluções orais, os medicamentos com grande utilização no serviço clínico em situações de "SOS", como dor e febre ou protocolos, os medicamentos de emergência etc.).

A implementação de sistemas de distribuição em dose unitária é reconhecida como uma estratégia de segurança eficaz. Desde logo, envolve a etapa de validação da prescrição médica, da responsabilidade de um farmacêutico, em que são verificadas as doses, vias de administração, interações relevantes (com medicamentos e alimentos), incompatibilidade com alergias documentadas etc. Todas as dúvidas ou erros detetados devem ser imediatamente esclarecidos com o médico prescritor, de modo a evitar qualquer dano para o paciente.

Finda essa etapa de validação, a medicação é preparada para cada paciente internado (em geral, para um período de 24 horas) e distribuída após confirmação por confrontação com a prescrição inicial. A identificação dessa medicação deve ser inequívoca, seguindo as regras gerais de identificação do paciente previamente expostas. A utilização de equipamentos semiautomáticos para auxiliar a distribuição de medicamentos está associada à diminuição da ocorrência de erro.

Na distribuição, é habitual a separação da medicação em gavetas ou caixas divididas por horários de administração, que desse modo devem auxiliar as equipas de enfermagem nas etapas de verificação da prescrição e medicação que antecedem a administração. Nos serviços clínicos com elevada rotação de pacientes ou alteração de terapêutica (por exemplo, serviços de urgência ou unidades de cuidados intensivos), em que os sistemas de dose unitária não dão resposta adequada, podem ser implementados equipamentos de distribuição que permitem a ligação à prescrição médica, conferindo ao enfermeiro devidamente identificado no sistema acesso ao local de armazenamento da terapêutica prescrita.

Sempre que o processo de distribuição individual requerer que os medicamentos sejam retirados da sua embalagem original, a reembalagem deve ser acompanhada da identificação completa do medicamento perfeitamente legível (DCI, dosagem, lote, validade). Especial atenção deve ser dada à obrigatoriedade de redução da validade atribuída a um medicamento retirado do seu acondicionamento primário original (por exemplo, um comprimido desblisterado), de acordo com a legislação e recomendações aplicáveis ao contexto político-geográfico em causa. Nos casos em que esse processo esteja associado ao risco de troca entre 
medicamentos que passam a apresentar embalagem semelhante (por exemplo, no caso das ampolas reembaladas em papel de alumínio para proteção da degradação provocada pela luz), devem ser adotadas medidas adicionais que evitem o erro.

A gestão do risco no âmbito do medicamento envolve também a dispensa/dispensação ao paciente de ambulatório, incluindo a informação prestada quanto ao modo como deve administrar e manipular os medicamentos. Essa informação deve ser objetiva e clara, e, sempre que possível, a informação oral deve ser acompanhada de informação escrita. A adoção de sistemas de informação gráfica (como o exemplo de pictogramas - Figura 5) é uma estratégia importante para sublinhar as mensagens principais quanto ao modo de administração do medicamento e cuidados a ter na sua manipulação. As imagens são coladas nas embalagens dos medicamentos e folhetos informativos, e, em simultâneo, é fornecida informação verbal.

Figura 5 - Exemplos de pictogramas para transmitir aos pacientes, em ambulatório, mensagens sobre a utilização correta de medicamentos

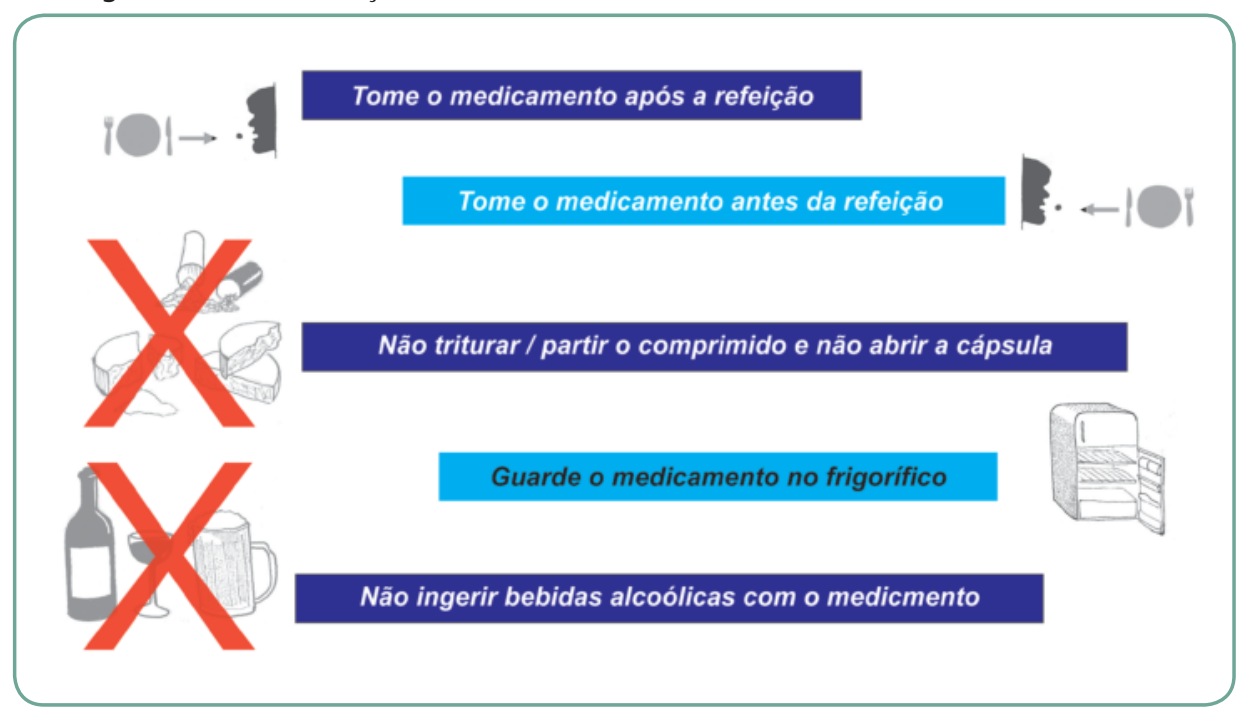

Fonte: Serviços Farmacêuticos, Centro Hospitalar Cova da Beira, EPE, Portugal.

\section{Para praticar}

Para aprofundar o tema, sugere-se a leitura do documento

"Procedimentos seguros para armazenamento e dispensa/dispensação de medicamentos" disponível em: http://www.sbrafh.org.br/site/index/library/ $\mathrm{id} / 53$ (Anacleto 2010).

Confronte essas recomendações do documento com a realidade da sua organização, identificando oportunidades de implementação de procedimentos seguros. 


\section{Preparação e administração de medicamentos}

Em todo o processo do uso do medicamento, é necessário garantir práticas seguras, salientando-se a preparação e a administração de medicamentos como as etapas finais desse processo, sendo crucial o cumprimento sistemático das regras de segurança. A preparação de medicamentos é uma atividade realizada na maioria das vezes por enfermeiros e técnicos de enfermagem, embora também possa ser realizada por outros profissionais de saúde com competências nesse âmbito.

Quanto à administração de medicamentos, Andréia de Brito (2007) reforça: “É uma atividade que exige grande responsabilidade por parte da equipa de enfermagem. Para sua execução, são aplicados princípios científicos, legais e éticos, que fundamentam a ação do enfermeiro e visam promover a segurança necessária a essa prática". Esses princípios são também aplicados por outros profissionais de saúde, pois, essa prática não é exclusiva da enfermagem. Em alguns contextos como, por exemplo, na comunidade, o farmacêutico procede à administração de vacinas ou medicamentos intramusculares; no contexto hospitalar, os técnicos de diagnóstico e terapêutica administram soluções de contraste.

A preparação e administração segura de medicamentos implica a utilização de vários mecanismos de segurança, designados como "certos", e os enfermeiros, de forma habitual, utilizam os "cinco certos". Contudo, na sequência da investigação e desenvolvimento de práticas seguras na preparação e administração de medicamentos, percebeu-se a necessidade de introduzir outros "certos" para aumentar a segurança no uso do medicamento. Por exemplo, o protocolo de segurança no Brasil visa a utilização de "sete certos". Nesse protocolo de segurança, os profissionais devem assegurar que administram ao "paciente certo", o "medicamento certo", na "dose certa", pela "via certa" à "hora certa", sendo incluído mais dois "certos" à prática tradicional, ou seja, "documentação certa (registo certo)" e a "razão certa". Recentemente, alguns artigos publicados nesse âmbito ampliaram o número de certos para "nove certos", e outros artigos já referenciam os "doze certos", de forma a aumentar os mecanismos de segurança nessa etapa final do processo de utilização do medicamento. 


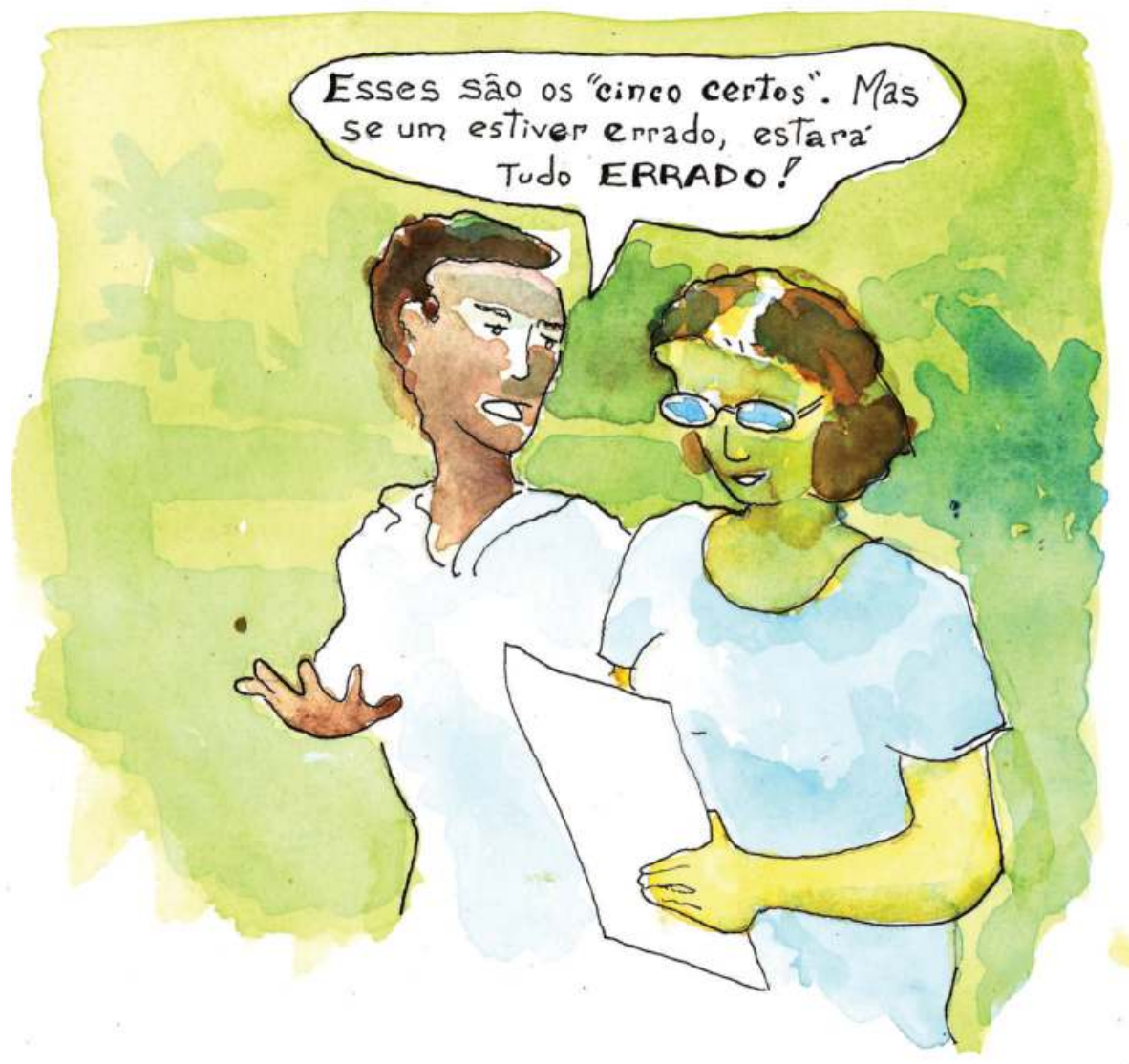

Contudo, apesar da instituição de protocolos e normas sobre essa matéria, vários estudos demonstram que, nessas duas etapas do processo de utilização do medicamento (preparação e administração), ocorrem erros, como referem Tromp e colaboradores (2009) que um ou mais erros ocorrem em $49 \%$ das práticas de preparação e administração de medicamentos endovenosos.

Ramos (2012) verificou que a descontaminação da via de acesso com álcool a $70 \%$ antes da administração de medicamentos injetáveis ocorreu em cerca de metade das práticas observadas $(48,6 \%)$. Paixão e colaboradores (2013) também realizaram um estudo sobre erros de medicação reportados pelos enfermeiros e evidenciaram que os erros mais comuns foram a "inadequada diluição do medicamento" durante a preparação do medicamento $(15,66 \%)$ e a seleção errada do paciente na fase da administração do medicamento (63,01\%). Esses tipos de erros demonstram falhas na utilização de mecanismos de segurança, como a falta de certificação da dose certa, falhas nas práticas para a prevenção da infeção, e erros na confirmação da identidade do paciente. 


\section{Para refletir}

Que tipo de erros de preparação e administração de medicamentos você já vivenciou ou teve conhecimento da sua ocorrência? Que impacte teve na segurança do paciente?

Cassiani (2005) alerta para algumas condições presentes e latentes no processo de preparação e administração de medicamentos e que incluem "instalações incorretas, design empobrecido, falhas na manutenção, decisões administrativas incorretas e organizações mal estruturadas". Paixão e colaboradores (2013) salientam no seu estudo factores relacionados com "lapso de atenção em contextos de sobrecarga de trabalho possivelmente devido ao compromisso de várias tarefas em simultâneo, faltas de rotinas de verificação ou dificuldades de gestão da informação através dos meios informáticos".

Também Mansoa (2010) evidencia no seu estudo que os erros dos enfermeiros, na sua maioria, devem-se a lapsos e falhas na execução e falhas de informação e conhecimento, enquanto Lobo (2008) destaca que os enfermeiros, na prestação de cuidados, consideram os factores ambientais preponderantes para o acontecimento do erro em relação aos factores pessoais.

Como referido, a utilização dos "cincos certos" são os principais mecanismos de segurança que promovem a segurança do paciente no momento da administração de medicamentos; no entanto, existem outros mecanismos de segurança que os profissionais podem utilizar de forma adicional para aumentar a segurança do paciente na administração dos medicamentos.

\section{Para praticar}

Pesquise e responda: Que outros "certos", para além dos "sete certos" já referenciados neste capítulo, o profissional de saúde pode utilizar na atividade de preparação e administração de medicamentos?

A dupla verificação independente é também uma estratégia de prevenção do erro utilizada em algumas organizações de saúde, embora com alguns constrangimentos no seu processo de implementação, muitas vezes associado à escassez de recursos humanos. Essa estratégia implica a um profissional realizar a preparação do medicamento e a 
outro profissional fazer uma verificação independente do medicamento preparado e cálculos efetuados quando aplicável. Nos medicamentos potencialmente perigosos, ela deve ser sempre uma das estratégias utilizadas. Também cada vez mais as tecnologias informáticas vêm ajudar os profissionais a aumentar as barreiras de segurança, como é o exemplo de sistemas informáticos associados a pulseiras de identificação com códigos de barras, que permitem garantir que estamos a administrar o medicamento certo ao paciente certo.

No entanto, os profissionais não podem esquecer que, nessa etapa do processo de utilização do medicamento, o envolvimento do paciente na sua segurança, confirmando sua identificação, assim como conhecendo o medicamento que está a ser administrado e porque razões é necessário para seu tratamento, poderá aumentar as barreiras de segurança, evitando erros de medicação.

\section{Conciliação medicamentosa}

O processo de conciliação medicamentosa é definido como a comparação da terapêutica habitual (ou anterior) do paciente com a tabela terapêutica prescrita em momentos-chave de transição entre cuidados de saúde (admissão, transferência ou alta), com o intuito de evitar discrepâncias que possam resultar em danos para o paciente. O processo resulta, por isso, numa lista de medicação atualizada, que deve ser convenientemente comunicada ao paciente, familiar ou cuidador, ou aos restantes profissionais de saúde, assegurando que o paciente receba a medicação adequada em cada momento.

Segundo dados do IHI, falhas de comunicação entre profissionais de saúde foram associadas a 50\% dos erros de medicação e $20 \%$ dos eventos adversos relacionados com medicamentos em pontos de transição (IHI 2011). A implementação de sistemas de conciliação medicamentosa surge como uma ferramenta de redução de discrepâncias, com implicação na redução de eventos adversos de medicação.

Atualmente, encontram-se disponíveis diversos instrumentos para auxiliar o processo de implementação ou monitorização de eficácia desse tipo de sistemas (Gleason et al. 2011; IHI 2011; NPC 2010; WHO 2007e).

Em termos gerais, o processo envolve equipas multidisciplinares e considera-se dividido em três etapas fundamentais: 
1. Recolha/coleta da melhor história medicamentosa possível deve abranger todos os medicamentos que o paciente toma habitualmente incluindo, para além da terapêutica crónica, os medicamentos não sujeitos à receita médica, vitaminas, suplementos alimentares, produtos de aplicação na pele, colírios, produtos de ervanária e produtos homeopáticos. O paciente deve ser, sempre que possível, a fonte de informação privilegiada. Outras fontes de informação incluem cuidadores ou familiares, médico de família ou outros médicos que seguem o paciente, saco de medicamentos do paciente, que habitualmente se solicita que seja trazido para a organização, receitas médicas anteriores ou registos médicos anteriores do hospital (NPC 2010; Gleason et al. 2011).

2. Comparação com a prescrição atual, identificação e classificação de discrepâncias (intencionais ou não intencionais). Correção das discrepâncias não intencionais por discussão com os profissionais de saúde envolvidos ou realização de alterações terapêuticas devidamente documentadas.

3. Comunicação adequada da lista de medicação reconciliada quer ao paciente e cuidadores, quer a outros profissionais de saúde. Educar o paciente para a necessidade de manter essa lista atualizada.

A informação mínima que deve constar na lista de medicação inclui:

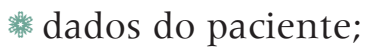

diagnóstico atual e comorbilidades/comorbidades;

滕 lista atualizada de todos os medicamentos prescritos, dose, frequência e via de administração (incluindo informação sobre aumentos ou reduções de dose quando preconizado);

粼 duração do tratamento (quando apropriado);

唜 alergias conhecidas.

Se o documento for gerado no momento da alta hospitalar, poderá incluir informações adicionais sobre as alterações terapêuticas realizadas durante o tratamento e o seu motivo.

Para aprofundar a temática, leia a Solução 6 integrada nas Soluções da Segurança do Paciente da OMS - Assuring Medication Accuracy at Transitions in Care, disponível em: http://www.who.int/ patientsafety/solutions/ patientsafety/PS-Solution6.pdf

O sucesso de um sistema de conciliação medicamentosa depende do envolvimento de equipas multidisciplinares e da sua motivação. Nesse processo, o enfermeiro, farmacêutico e médico assumem papéis fundamentais desde a recolha/coleta de uma boa história medicamentosa, passando pela identificação das discrepâncias até a resolução das discrepâncias não intencionais (Gleason et al. 2011). 
Nos últimos anos, têm aumentado os exemplos de programas de conciliação implementados com sucesso nos hospitais. A sua sustentabilidade a longo prazo depende da disponibilização de sistemas informáticos que suportem o processo de conciliação, e do contributo dos diferentes profissionais de saúde.

\section{Considerações finais}

Admitir a possibilidade de ocorrência de erros de medicação em todas as fases do processo de utilização do medicamento é o primeiro passo a seguir pelos profissionais de saúde no caminho para a melhoria da segurança do paciente. Atualmente, não só estão bem definidos os factores contribuintes para sua ocorrência, como se dispõem de diversas ferramentas de implementação de medidas de segurança que abrangem a prescrição, armazenamento, distribuição e administração de medicamentos. O impacte positivo dessas medidas tem sido posto em evidência, como é o caso da prescrição eletrónica; a correta identificação do paciente; a identificação de medicamentos potencialmente perigosos ou confundíveis entre si; o desenvolvimento de sistemas de alerta e sinalética/sinalização que evitam trocas de medicamentos e asseguram sua correta utilização. Outras estratégias e abordagens surgem naturalmente na prática diária em saúde, baseada na sensibilização e consciencialização/conscientização dos profissionais para a melhoria contínua e gestão do risco no âmbito do medicamento.

\section{Referências}

American Society of Anesthesiologists. Statement on the labeling of pharmaceuticals for use in anesthesiology. Park Ridge (III): ASA; 2009. Approved by the ASA House of delegates on October, and last amended on October 21. Disponível em: https://www.asahq.org/ /media/For\%20 Members/documents/Standards\%20Guidelines\%20Stmts/Labeling\%20Pharmaceuticals\%20for\%20 Use\%20in\%20Anesthesiology.pdf.

American Society of Health System Pharmacists, Council on Professional Afairs [ASHSP]. Use of color to identify drug products. Am J Health Syst Pharm. 1996;53:1805.

Anacleto TA, Rosa MB, Neiva HM, Martins MAP. Erros de medicação: farmácia hospitalar. Brasília: Conselho Federal de Farmácia, Comissão Farmácia Hospitalar, 2010 [citado 2013 out 4]. Encarte de Pharmacia Brasileira, 2010 Jan/Fev. Disponível em: http://www.sbrafh.org.br/site/index/library/id/53

Baker DE. Use of color on pharmaceutical labels on packaging: editorial. Hosp Pharm. 2005;40:296-7.

Baker GR. Harvard medical practice study. BMJ Qual Saf. 2004;(13(2):151-2. 
Belela ASC, Peterlini MA, Pedreira MLG. Erros de medicação: definições e estratégias de prevenção. São Paulo: Conselho Regional de Enfermagem do Estado de São Paulo; 2011 [citado 2013 out 4]. Publicado em parceria com Rede Brasileira de Enfermagem e Segurança do Paciente - Pólo São Paulo. Disponível em: http://www.corensp.org.br/sites/default/files/erros_de_medicacaodefinicoes_e_estrategias_de_prevencao_0.pdf.

Brito FM. Guia eletrónico para administração de medicamentos: fundamentando uma prática de enfermagem [trabalho de conclusão de curso]. Florianópolis: Universidade Federal de Santa Catarina; 2007.

Cassiani S. A segurança do paciente e o paradoxo no uso do medicamento. Rev. Bras. Enferm. 2005;58(3):95-9

Cohen MR. The role of drug packging and labeling in medication errors. In: Cohen MR, editor. Medication errors. Washington: American Pharmaceutical Association; 2006. p. 111-52.

Corsonello A, Pranno L, Garasto S, Fabietti P, Bustacchini S, Lattanzio, F. Potentially inappropriate medication in elderly hospitalized patients. Drugs Aging. 2009;26(1), 31-9.

Delafuente JC. Understanding and preventing drug interactions in elderly patients. Crit Rev Oncol Hematol. 2003;48(2):133-43.

Gleason KM, Brake H, Agramonte V, Perfetti C. Medications at transitions and clinical handoffs (MATCH): toolkit for medication reconciliation. Rockville (MD): Agency for Healthcare Research and Quality, 2011. Prepared by the Island Peer Review Organization, Inc., under Contract No. HHSA2902009000 13C. AHRQ Publication 2011 No. 11(12)-0059.

Giordani F, Rozenfeld S, et al. Vigilância de eventos adversos a medicamentos em hospitais: aplicação e desempenho de rastreadores. Rev Bras Epidemiol. 2012;15(3):455-67.

Griffin FA, Resar, RK. IHI global trigger tool for measuring adverse events. 2nd ed. Cambridge (MA): Institute for Healthcare Improvement; 2009. IHI Innovation Series white paper. Disponível em: http://www.ihi.org/knowledge/Pages/IHIWhitePapers/lHIGlobalTriggerToolWhitePaper.aspx

Institute for Healthcare Improvement [IHI]. How-to guide: prevent adverse drug events by implementing medication reconciliation. Cambridge, MA: Institute for Healthcare Improvement; 2011 [citado 2014 jun 24]. Disponível em: www.ihi.org.

Institute for Safe Medication Pratices. List of error-prone abbreviations, symbols, and dose designation. Horsham (PA): ISMP, 2013 [citado 2014 jun 24]. Disponível em: http://www.ismp.org/ Tools/errorproneabbreviations.pdf.

Instituto para as Práticas Seguras no Uso dos Medicamentos. Medicamentos potencialmente perigosos. Boletim ISMP Brasil 2013 Jan;2(1):1-3.

Instituto para as Práticas Seguras no Uso dos Medicamentos. Nomes de medicamentos com grafias ou som semelhantes. Boletim ISMP Brasil 2014 Abr;3(6):3-8.

Joint Commission International. Gerenciamento e uso de medicamentos (MMU) em padrões de acreditação da Joint Commission International para Hospitais. 4. ed. exp. Oakbrook Terrace (III): JCl; 2013. p. 127-40.

Kohn LT, Corrigan JM, Donaldson MS. To err is human: building a safer health system: a report of the Committee on Quality of Health Care in America, Institute of Medicine. Washington, DC: National Academy Press; 2000.

Lobo ACM. O erro de administração de medicação: causas e fatores contributivos e atitudes dos enfermeiros [dissertação]. [Lisboa]: Universidade Aberta de Lisboa; 2008 [citado 2013 out 4]. Mestre em Comunicação em Saúde sob a orientação do Professor Doutor Jorge Correia Jesuíno. Disponível em: https://repositorioaberto.uab.pt/bitstream/10400.2/714/1/LC444.pdf.

Lyra Júnior DPL, Siqueira JS, Silva DT, Almeida LB, Silva WB, Sousa P, et al. Erro medicamentoso em cuidados de saúde primários e secundários: dimensão, causas e estratégias de prevenção. Rev Port Saúde Pública. 2010;VolTemat(10):40-6. 
Mansoa A. O erro nos cuidados de enfermagem a indivíduos internados numa unidade de cuidados intensivos: estudo de caso sobre a representações dos actores de uma unidade pós cirúrgica de um hospital português [dissertação]. Lisboa: Universidade Nova de Lisboa; 2010 [citado 2013 out 4]. Mestre sob a orientação do Prof. Doutor Paulo Ferrinho. Disponível em: http://pns.dgs.pt/ files/2010/08/erro.pdf.

Mendes W, Martins M, Rozenfeld S, Travassos C. The assessment of adverse events in hospitals in Brazil. Int J Qual Health care. 2009Aug;21(4):279-84

Ministério da Saúde (BR). Portaria n 2.095, de 24 de setembro de 2013. Protocolo de Segurança na prescrição, uso e administração de medicamentos. Diário Oficial da União, 2013 Set 25 [citado 2014 jun 24]. Disponível em: http://www.anvisa.gov.br/hotsite/segurancadopaciente/documentos/ julho/Protocolo\%20Identifica\%C3\%A7\%C3\%A30\%20do\%20Paciente.pdf.

National Prescribing Centre. Medicines reconciliation: a guide to implementation. [London]: NPC; 2010 [citado 2014 jun 24]. Disponível em: http://www.npc.nhs.uk/improving_safety/medicines_ reconciliation/index.php.

Optiz SP. Sistema de medicação: análise dos erros nos processos de administração e preparação de medicamentos em um hospital de ensino [tese]. [Ribeirão Preto]: Escola de Enfermagem de Ribeirão Preto; 2006. Doutor em Enfermagem.

Organização Mundial de Saúde. Estrutura concetual da classificação internacional sobre segurança do paciente: relatório técnico final. Tradução realizada pela Divisão de Segurança do Doente, Departamento da Qualidade na Saúde. Lisboa: Direção Geral de Saúde; 2011.

Organização Mundial de Saúde. Medication Errors: Technical Series on Safer Primary Care. Geneva: World Health Organization; 2016. Licence: CC BY-NC-SA 3.0 IGO.

Organização Mundial de Saúde. Medication Without Harm - Global Patient Safety Challenge on Medication Safety. Geneva: World Health Organization, 2017. Licence: CC BY-NC-SA 3.0 IGO.

Paixão MPBA, Rodrigues MA, Abreu CF. Erros de medicação reportados pelos enfermeiros da prática clínica. Rev Enf Ref. 2013 Jul; Série 3(10):63-8. Acedido em 04-10-2013. Disponível em: https://www.esenfc.pt/v02/pa/conteudos/downloadArtigo.php?id_ficheiro=531\&codigo=.

Ramos S. Prevenção e controlo da infeção na preparação e admnistração de medicamentos endovenosos [dissertação]. Lisboa: Universidade Católica Portuguesa; 2012 [citado 2018 dez 18]. Disponível em: http://repositorio.ucp.pt/bitstream/10400.14/13976/1/Tese_Susana_Ramos_2012-cd.pdf.

Rochon PA, Gurwitz JH. The prescribing cascade revisited. Lancet. 2017;389(10081):1778-1780. doi: 10.1016/S0140-6736(17)31188-1.

Ramos S. Prevenção e Controlo da Infeção na Preparação e Admnistração de Medicamentos Endovenosos. Dissertação apresentada à Universidade Católica Portuguesa para a obtenção de grau de mestre. 2012. Disponível em: http://repositorio.ucp.pt/bitstream/10400.14/13976/1/Tese_ Susana_Ramos_2012-cd.pdf.

Rochon, P. A., \& Gurwitz, J. H.. The prescribing cascade revisited. Lancet. 2017. 389(10081), 17781780. doi: 10.1016/S0140-6736(17)31188-1.

Rozenfeld S, Chaves SMC, Reis LGC, Martins M, Travassos C, Mendes W et al. Efeitos adversos a medicamentos em hospital público: estudo piloto. Rev. Saúde Pública. 2009 Oct;43(5):887-90.

Silva AEBC. Análise de risco do processo de administração de medicamentos por via intravenosa em pacientes de Hospital Universitário de Góias [tese]. Ribeirão Preto: Universidade de São Paulo, Escola de Enfermagem de Ribeirão Preto; 2008 [citado 2013 out 4]. Doutor em Enfermagem. Disponível em: http://pct.capes.gov.br/teses/2008/33002010120P5/TES.pdf.

Tromp M, Natsch S, Van Achterberg T. The preparation and administration of intravenous drugs before and after protocol implementation. Pharm World Sci. 2009; 31:413-20. 
Vincent C. The essentials of patient safety. London: BMJ Books; 2011.

World Health Organization. Medication Errors: Technical Series on Safer Primary Care. Geneva: WHO; 2016.

World Health Organization. Global patient safety challenge: medication without harm. Geneva: WHO; 2017.

World Health Organization, Joint Commission International. Look-alike, sound-alike medication names. Patient Safety Solutions May 2007a [citado 2013 out 4];1(solution 1). Disponível em: http:// www.who.int/patientsafety/solutions/patientsafety/PS-Solution1.pdf.

World Health Organization, Joint Commission International. Patient identification. Patient Safety Solutions May 2007b [citado 2013 out 4]; 1(solution 2). Disponível em: http://www.who.int/ patientsafety/solutions/patientsafety/PS-Solution2.pdf.

World Health Organization, Joint Commission International. Control of concentrated electrolyte solutions. Patient Safety Solutions May 2007d [citado 2013 out 4]; 1(solution 5). Disponível em: http://www.who.int/patientsafety/solutions/patientsafety/PS-Solution5.pdf.

World Health Organization, Joint Commission International. Assuring medication accuracy at transitions in care. Patient Safety Solutions May 2007e [citado 2013 out 4]; 1(solution 6). Disponível em: http://www.who.int/patientsafety/solutions/patientsafety/PS-Solution6.pdf. 


\section{Cirurgia segura}

Maria de Lourdes de Oliveira Moura e Luis Antonio dos Santos Diego

A 55 assembleia Mundial da Saúde, em 2002, preocupada com a segurança do paciente, recomendou à Organização Mundial da Saúde (OMS) atenção especial a essa questão. Reconhecendo o risco maior para o paciente cirúrgico, a OMS divulgou orientações a fim de melhorar a segurança da assistência cirúrgica (OMS 2009). Essas orientações, organizadas na forma de campanha - Cirurgias seguras salvam vidas -, basearam-se nos fundamentos e práticas da segurança cirúrgica, especialmente na prevenção de infecções do sítio cirúrgico, anestesia segura, melhor comunicação no perioperatório e utilização de indicadores da assistência cirúrgica (OMS 2009).

Este capítulo revela ao leitor a magnitude do problema da segurança referente à anestesia e cirurgia. Também aborda alguns dos eventos adversos mais frequentes no ambiente cirúrgico, tais como cirurgias em pacientes e locais errados, cujo risco pode ser reduzido com a adoção de ferramentas de comunicação estruturada, por exemplo, a Lista de Verificação de Segurança Cirúrgica, que também será apresentada e discutida sua aplicação prática, bem como os resultados já observados na segurança cirúrgica.

\section{A magnitude dos problemas de segurança relacionados à cirurgia e anestesia}

As complicações de cirurgia são eventos potencialmente controláveis (Wanzel et al. 2000), que contribuem para os altos custos da assistência à saúde e o aumento da morbidade/morbilidade e mortalidade dos pacientes. As complicações cirúrgicas tornaram-se importante causa de

Em todo o mundo, são realizadas cerca de 234 milhões de cirurgias por ano, com sete milhões de complicações estimadas e um milhão de óbitos, e metade desses considerados evitáveis

(Tang et al. 2014). 
Entre os diversos fatores organizacionais e humanos que contribuem para resultados cirúrgicos desfavoráveis estão: inexperiência do cirurgião, baixo volume hospitalar de cirurgias, carga excessiva de trabalho e fadiga dos profissionais, tecnologia inadequada, deficiência na supervisão de estagiários, falhas na comunicação entre profissionais, horário de realização e falhas administrativas (Gawande et al. 2003). invalidez e morte no mundo, com implicações significativas na saúde pública (OMS 2009). Próximo a 15\% dos pacientes que se submetem à cirurgia apresentam eventos adversos (Anderson et al. 2013). A maioria dos eventos adversos cirúrgicos é de menor gravidade, e os fatais minoria. Problemas com a ferida cirúrgica são os tipos mais frequentes e os mais evitáveis, dentre os eventos adversos cirúrgicos (Anderson et al. 2013).

Em um estudo realizado em hospitais do Rio de Janeiro, a incidência de eventos adversos cirúrgicos foi de 3,5\%, e 68,3\% considerados evitáveis. Cerca de $22 \%$ dos pacientes com evento adverso cirúrgico tiveram incapacidade permanente ou morreram, e mais de $60 \%$ dos casos foram classificados como pouco ou nada complexos (Moura, Mendes 2012). No estudo piloto, realizado em hospitais de Portugal, os eventos adversos relacionados à cirurgia constituíram $27 \%$ do total, e o evento adverso (EA) teve maior expressividade (Sousa et al. 2014). Zeeshan e colaboradores (2014) analisaram os registros de 82.784 pacientes internados para procedimentos cirúrgicos, entre 2006 e 2009. Os autores observaram que 5.368 (6,5\%) sofreram pelo menos um EA. Os tipos de EA mais comuns estavam diretamente relacionados ao cuidado $(20,8 \%)$, seguido de eventos referentes à medicação $(19,2 \%)$ e de eventos pertinentes à realização de procedimentos invasivos $(17,8 \%)$.

O risco de mortalidade por complicações e eventos adversos relacionados à anestesia é de aproximadamente 1 em 100 mil casos na Austrália, Europa e Estados Unidos da América (Mellin-Olsen et al. 2010). Estudos recentes de morbidade/morbilidade, referentes à anestesia, mostram que as complicações permanecem frequentes, embora óbitos sejam incomuns. Em determinado estudo, foi encontrada incidência de 18 a $22 \%$ de eventos perioperatórios de menor gravidade relacionados à anestesia. As taxas de complicações perioperatórias graves foram de 0,45 a $1,4 \%$, e as taxas de complicações com dano permanente de 0,2 a $0,6 \%$. Estudos apontam que as complicações perioperatórias graves relacionadas à anestesia com dano permanente ocorrem em 1 de 170500 pacientes, enquanto os óbitos são bem menos constantes (Mellin-Olsen et al. 2010).

Cirurgiões e anestesiologistas frequentemente trabalham por muitas horas seguidas em atividades de alto risco que exigem extrema atenção, estado de alerta e concentração. A privação do sono e a fadiga podem prejudicar as funções neurocognitivas de maneira significativa, aumentando o risco de erros (Sugden et al. 2010). Depois de nove horas consecutivas de trabalho, o risco de incidente, em razão de um erro não intencional, aumenta exponencialmente a cada hora subsequente (Sinha et al. 2013). 


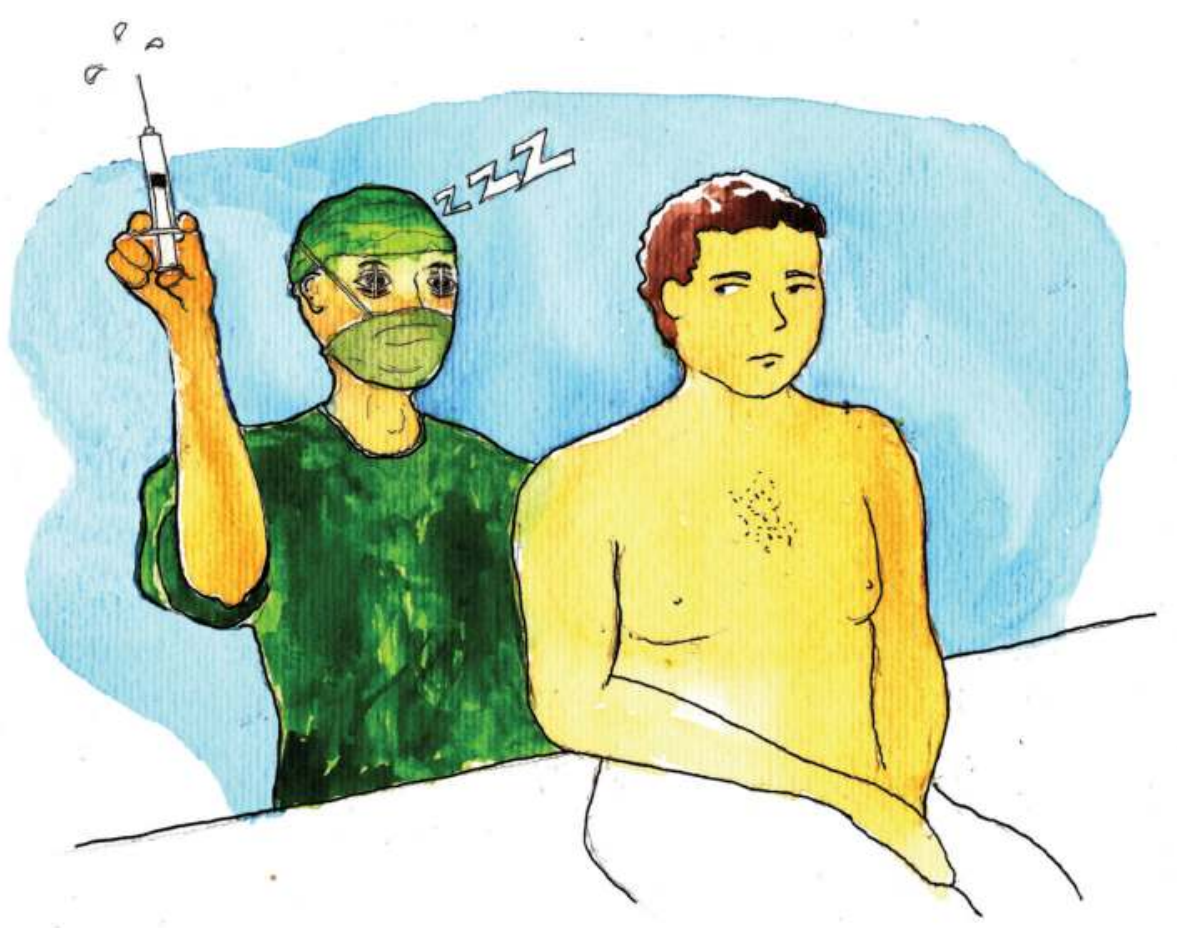

A fadiga leva à diminuição do desempenho, da atenção e do tempo de reação, tornando o julgamento clínico mais lento. Ela também promove a perda de tempo precioso para fazer escolhas críticas e aumenta a vulnerabilidade a erros críticos. Chamadas durante a noite, jornadas de trabalho longas e intensas contribuem para o aparecimento da fadiga, assim como a idade avançada. Vários estudos têm mostrado que a privação do sono diminui a energia e aumenta a ansiedade, depressão, raiva e fadiga. Além disso, o humor é afetado de forma negativa quando a jornada de trabalho é prolongada ou estendida durante a noite (Sinha et al. 2013). Entretanto, apesar dessas situações potencialmente negativas, ainda não se encontra bem estabelecida a correlação com o aumento de EA (Kaderlia et al. 2012; Morrison et al. 2009).

\section{Procedimento cirúrgico errado, em local errado, em paciente errado são eventos que nunca deveriam ocorrer}

Qualquer intervenção cirúrgica realizada em paciente errado, em local errado, ou utilizando procedimento errado representa complicação cirúrgica grave e evitável, classificada como never event, ou seja, evento que nunca deveria ocorrer. Entre os anos de 1990 e 2010, foram identificados nove mil never events cirúrgicos nos EUA (O'Connor et al. 2013).
Esse assunto é abordado no Capítulo 6, "Saúde do trabalhador, ergonomia e segurança do paciente", do livro Segurança do paciente: criando organizações de saúde seguras.

Never events cirúrgicos incluem: realização do procedimento errado, em local errado, no lado incorreto, no paciente errado, retenção não intencional de um corpo estranho dentro de um paciente e morte durante a cirurgia ou no pós-operatório imediato de um paciente classificado como de baixo risco (estado físico 1, de acordo com a classificação da American Society of Anesthesiologists (ASA)) (Lindley et al. 2011). 
No Capítulo 3, "Acreditação e segurança do paciente", do livro Segurança do paciente: criando organizações de saúde seguras, o tema cirurgia segura nos manuais de acreditação hospitalar é abordado mais detalhadamente.
Em 2002, o American College of Surgeons publicou diretrizes para garantir que o procedimento correto fosse efetuado no paciente correto, em local correto. The Joint Commission introduziu um protocolo, em 2004, obrigatório para todas as organizações de saúde certificadas. Ele consiste em:

* verificação a ser realizada antes do procedimento, compreendendo a marcação do local da cirurgia, a constatação de alergia, entre outros quesitos que serão discutidos mais à frente;

* realização de uma pausa cirúrgica (time out), imediatamente antes do início do procedimento cirúrgico.

Apesar de as inúmeras evidências de que os never events podem ser evitados, eles ainda continuam a representar grande desafio para a segurança do paciente. O total de 25 procedimentos em pacientes errados e 107 procedimentos em local errado foram identificados em um estudo realizado por Stahel et al. (2010), que analisou mais de 27 mil notificações de eventos adversos ocorridos em pouco mais de seis anos. Esses eventos resultaram em danos significativos em 35,5\% dos casos e morte do paciente em um caso. A análise de causa raiz desses casos revelou elevada frequência de erros diagnósticos em mais da metade dos casos de procedimento errado e paciente errado. Falhas de comunicação foram identificadas em todos os casos de procedimento errado e paciente errado. Outros estudos também reconheceram a falha de comunicação como uma das principais causas de cirurgia em local errado. O planejamento inadequado de procedimentos e a falta de adesão à pausa cirúrgica são os principais fatores contribuintes desses eventos (Stahel et al. 2010).

Geraghty et al. (2017), mais recentemente, revisaram dados de registro de identificação de erros analisando 29.480 procedimentos, realizados entre maio de 2013 e abril 2015, com apoio de uma lista de verificação cirúrgica. Apesar de não terem ocorrido, foram identificados, durante as reuniões de equipe pré-cirúrgicas, 86 erros que resultariam em cirurgia no local/lado errado, principalmente em procedimentos ortopédicos e oftalmológicos. Já os relatos de eventos adversos ao National Reporting and Learning System (NRLS), do National Heatlh System (NHS), do Reino Unido, totalizaram 188 casos entre abril e setembro de 2017.

\section{Para refletir}

Como é realizada a comunicação em seu ambiente de trabalho? O que você imagina que poderia melhorar para diminuir as falhas que levam a ocorrências de never events? 


\section{A comunicação é a base para a melhoria dos processos}

A comunicação interpessoal é condição ímpar para o sucesso de qualquer atividade humana e, com o objetivo de que seja efetiva, necessita da melhor troca de informações possível. Usualmente, utilizam-se sinais e símbolos para facilitar a tarefa de refletir o que cada um dos comunicantes pensa sobre determinado assunto. Quanto maior a complexidade da informação a ser trocada, maior atenção ao processo comunicativo deve existir, ou seja, deve-se bem observar tanto o envio como a recepção do que se deseja transmitir.

Sem dúvida, a tecnologia aumentou sobremaneira as possibilidades de comunicação mais efetiva entre os cidadãos. No entanto, ferramentas de comunicação, como telefone celular, utilizados indevidamente na sala de cirurgia, podem prejudicar a comunicação efetiva entre membros da equipe cirúrgica, além de promover distração.

Um momento crucial que envolve incidentes, e, também, a comunicação se faz fundamental, é a passagem de caso (handoff/handover) - circunstância específica de transferência de responsabilidade do cuidado do paciente, acompanhada da transferência de informação entre pessoas da mesma ou de outras organizações. Como exemplo, pode-se citar a troca de informações sobre eventos intraoperatórios relevantes e as condições clínicas do paciente após o procedimento cirúrgico. O perioperatório é um período muito rico de troca de informações, desde o diagnóstico e indicação cirúrgica até a alta hospitalar, e a comunicação se tornará mais efetiva quão mais acurado/fiável, claro e sem ambiguidades for o conteúdo a ser transmitido. Infelizmente, isso não ocorre sempre a contento. As falhas de comunicação são a terceira maior causa de eventos sentinela (Joint Commission 2012) e o principal fator contribuinte de eventos adversos.

Existem diversas dificuldades para a comunicação efetiva. Talvez, uma das grandes dificuldades seja a influência da hierarquia funcional, própria da estrutura organizacional tradicional.

Uma liderança legitimada pela equipe, baseada em valores como confiança e respeito mútuo, é crucial para estabelecer a comunicação efetiva. A aviação comercial pode ser um exemplo para a área da saúde como paradigma de trabalho de equipe, pois foi considerando o exemplo da aviação comercial que Gaba e colaboradores (1998) iniciaram, com o apoio da Anesthesia Patient Safety Foundation (APSF), o curso Controle de Recursos da Crise em Anestesia (ACRM) na Universidade de Stanford.
No Capítulo 7 do livro Segurança do paciente: criando organizações de saúde seguras, iremos nos aprofundar mais na questão da comunicação entre os profissionais.
A hierarquia funcional se interpõe em momentos cujas trocas de informações entre os diversos profissionais deve ser a mais franca possível. 
Lyons e Popyoy (2014), em uma metanálise, observaram que listas de verificação cirúrgica melhoram a comunicação durante os procedimentos cirúrgicos, de tal forma a contribuir para menor mortalidade e, principalmente, menor taxa de complicações relacionadas à cirurgia.

\section{A Lista de Verificação de Segurança Cirúrgica e o impacto de sua implementação}

A OMS elaborou uma Lista de Verificação de Segurança Cirúrgica (LVSC), apresentada na Figura 1, já utilizada em diversas organizações de saúde em todo o mundo. A lista foi criada com o objetivo de ser uma ferramenta padronizada para melhorar a segurança do paciente e reduzir a morbidade/morbilidade e a mortalidade associadas a desvios potenciais das melhores práticas, por exemplo, no que diz respeito à profilaxia antibiótica e trombose venosa profunda, bem como erro evitável no cenário cirúrgico (Russ et al. 2015).

Figura 1 - Lista de Verificação de Segurança Cirúrgica da OMS

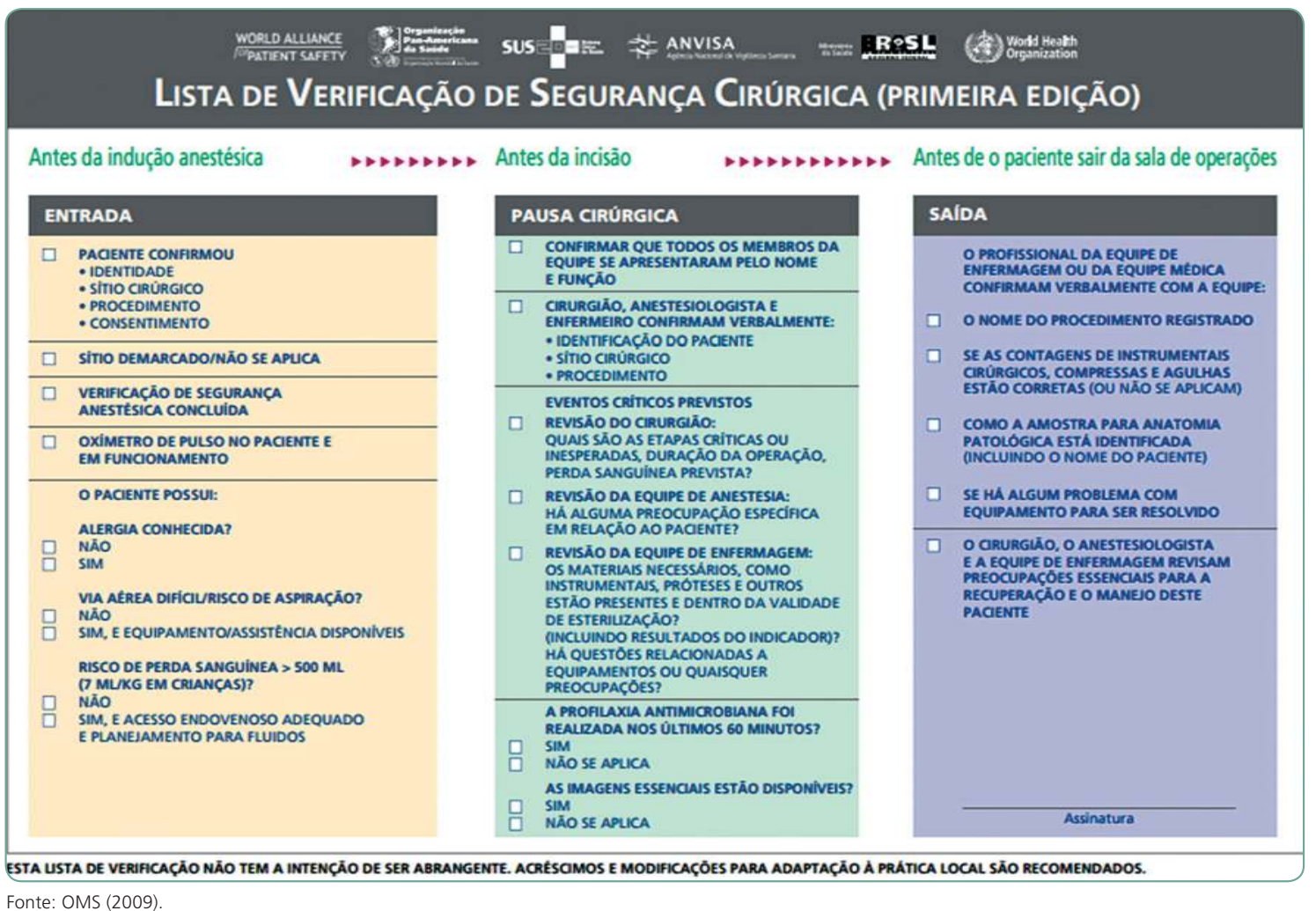


A validação da lista de verificação, como barreira efetiva a eventos adversos decorrentes de atos anestésico-cirúrgicos, veio a ocorrer, inicialmente, com um estudo internacional multicêntrico realizado por Haynes et al. (2009). Efetuado entre outubro de 2007 e setembro de 2008, em oito hospitais de oito cidades, nos cinco continentes (Toronto, no Canadá; Nova Delhi, na Índia; Amã, na Jordânia; Auckland, na Nova Zelândia; Manila, nas Filipinas; Ifakara, na Tanzânia; Londres, na Inglaterra; e Seattle, nos Estados Unidos), tal estudo representou grande variedade de realidades econômicas e culturais. Os resultados foram positivos e estatisticamente significantes em relação à aplicação do instrumento. Observou-se redução da taxa geral de complicações de $11 \%$ para 7\%; decréscimo da mortalidade hospitalar de 1,55 para 0,8\%. Outras taxas, como a de infecção do sítio cirúrgico e reoperação não planejada também experimentaram declínio significativo. Esse estudo foi realizado tão somente em população de pacientes internados.

Haugen et al. (2013) intencionaram considerar o impacto da lista de verificação na cultura de segurança das organizações. O estudo, realizado em hospital universitário de cerca de 1.100 leitos/camas, abordou 641 colaboradores de setores comprometidos com o perioperatório, os quais responderam a um inquérito desenhado para avaliar a percepção da cultura da segurança. A adesão observada à lista de verificação foi de aproximadamente $80 \%$, indicando o sucesso da sua implantação; entretanto, a análise multivariada logrou demonstrar que essa alta adesão, por si só, não proporciona impacto significativo na cultura da segurança, apesar da melhoria nos indicadores de relatos de eventos adversos.

Rydenfält et al. (2013) relacionaram, didaticamente, os principais benefícios da implementação da LVSC:

滕 Diminuição do número de falhas de comunicação na sala de cirurgia;

䗉 Redução do número de complicações decorrentes da cirurgia;

橉 Redução do risco de cirurgia no local errado;

滕 Desenvolvimento de maior preocupação quanto à segurança por parte da equipe operacional;

Melhoria da conformidade ao uso de antibióticos e profilaxia da trombose venosa profunda;

蹸 Facilitação da comunicação e suporte de memória para tarefas críticas.

Outro grupo de especialistas das áreas de qualidade do cuidado e segurança do paciente, com apoio da Agency for Healthcare Research and Quality (AHRQ), realizou abrangente revisão sistemática da literatura objetivando avaliar as evidências científicas de grande número de práticas 
de segurança do paciente. O estudo concluiu que, ao levar em conta as evidências existentes sobre a efetividade, pela recomendação de 22 práticas de segurança do paciente, a lista de verificação pré-cirúrgica e de anestesia para prevenir eventos operatórios e pós-operatórios é fortemente recomendada (Shekelle et al. 2013).

Recente revisão sistemática de Howell et al. (2014), com o propósito primário de definir quais intervenções são eficazes na redução da taxa de eventos adversos em pacientes cirúrgicos e podem ser utilizadas para melhorar a segurança a nível institucional, verificou que a LVSC da OMS reduz significativamente os eventos adversos. Deve ser destacado que a literatura a respeito da lista de verificação da OMS é constituída de estudos de alta qualidade que avaliaram as intervenções de segurança e demonstraram o inequívoco benefício para o paciente.

A análise da literatura apresenta estudos que indicam ser necessária e importante a implementação efetiva da LVSC a fim de garantir resultados favoráveis, e a redução da mortalidade está fortemente associada à conformidade e conclusão da implantação da LVSC (Tang et al. 2014). Entretanto, em decorrência das diferenças entre métodos e desenhos de estudos, ainda permanecem questionamentos sobre o real impacto na mortalidade e prevenção dos EAs. Alguns estudos avaliaram o porcentual de preenchimento da lista de verificação, não sendo possível afirmar que as equipes cirúrgicas executaram a atividade conforme preconizado pela OMS por terem identificado problemas como inconsistência de informações da lista de verificação e omissão de itens. (Kwok et al. 2013; Rodrigo-Rincon et al. 2015; Reed et al. 2016).

Diante das evidências tão eloquentes sobre as vantagens do uso da lista de verificação, não há mais argumentos para não utilizá-la. Baseado nesses bons resultados, já se preconiza o uso de listas desde o momento em que o paciente se interna até o pós-operatório (De Vries et al. 2010).

O Manual Cirurgias Seguras Salvam Vidas, desenvolvido pela OMS (2009), foi traduzido para a língua portuguesa e está disponível em: https:// proqualis.net/sites/proqualis. net/files/seguranca_paciente_ cirurgia_salva_manual.pdf

O Protocolo para Cirurgia Segura está disponível em: https://proqualis. net/sites/proqualis.net/ files/0000024279j862R.pdf.

\section{A aplicação da Lista de Verificação de Segurança Cirúrgica no Brasil e em Portugal}

O Ministério da Saúde do Brasil adaptou a Lista de Verificação de Segurança Cirúrgica LVSC desenvolvida pela OMS (2009) e publicou o Protocolo para Cirurgia Segura como item do Programa Nacional de Segurança do Paciente (PNSP), cuja finalidade é determinar as medidas que devem ser implantadas para reduzir a ocorrência de incidentes e a mortalidade cirúrgica. 
O protocolo deve ser aplicado em todos os locais dos estabelecimentos de saúde nos quais são realizados procedimentos terapêuticos ou diagnósticos, que impliquem incisão no corpo humano ou introdução de equipamentos endoscópios, dentro ou fora de centro cirúrgico, tais como unidades de cirurgia-dia (Hospital Dia), setores ambulatoriais de endoscopia, radiologia intervencionista, clínicas odontológicas, hemodinâmica etc.

Portugal aderiu ao segundo desafio da OMS - utilização da LVSC em 15 de dezembro de 2009. A circular normativa, lançada em junho 2010, determinou, em todos os blocos operatórios de hospitais do setor público, privado e social, o uso da LVSC.

A lista de verificação pode ser aplicada em poucos minutos, em três momentos bem determinados. Todavia, a organização deve estabelecer mecanismos para a correta verificação do que está sendo questionado em cada item. Portanto, a liderança deve prover os recursos necessários para que a verificação de todos os itens seja contemplada. A estrutura é de fundamental importância, e todos os equipamentos, insumos e instalações relacionados com a segurança da cirurgia e da anestesia devem ser verificados. Da mesma forma, a organização deverá adequar seus processos de trabalho para que a lista de verificação seja implementada corretamente, além de desenvolver uma estratégia de divulgação e treinamento de todos os profissionais de saúde envolvidos com a utilização da lista de verificação.

Figura 2 - Preenchimento da Lista de Verificação de Segurança Cirúrgica

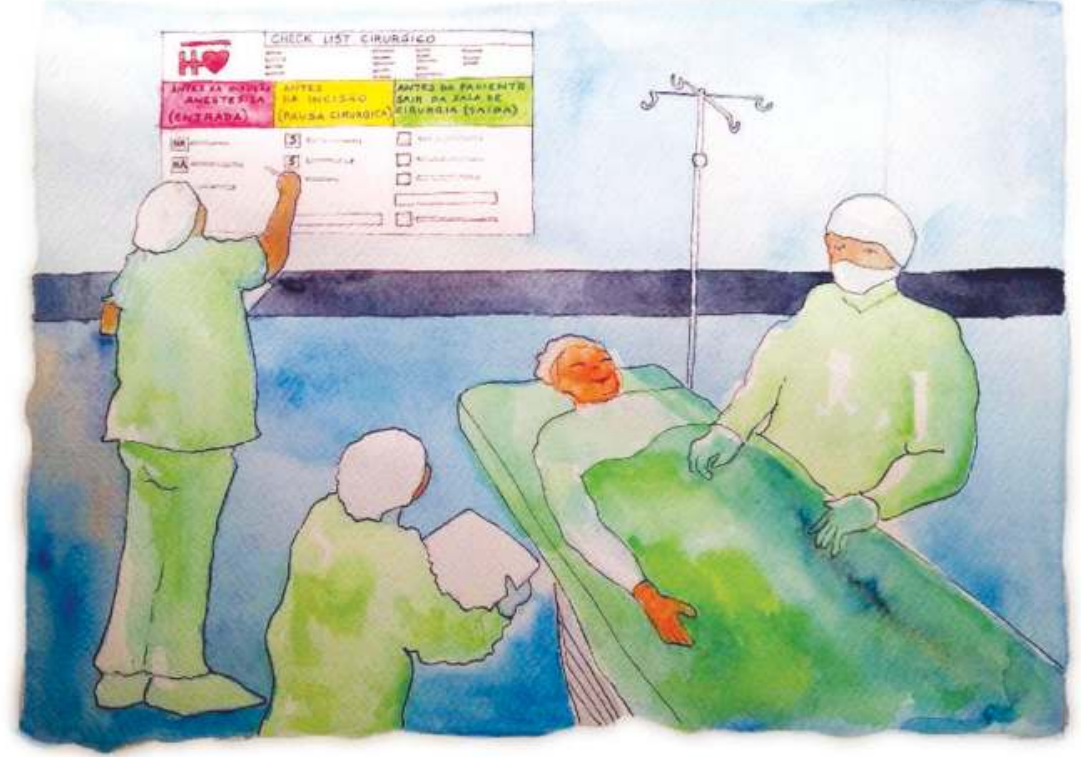

O coordenador deve preencher a Lista de Verificação antes, durante e depois da cirurgia. Neste caso, ele está preenchendo a conferência dos dados da pausa cirúrgica (coluna amarela), que deve acontecer imediatamente antes da incisão da pele.

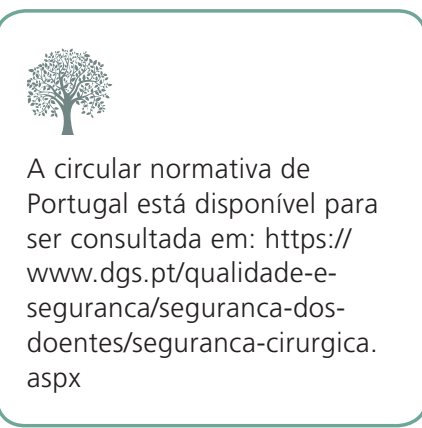

A lista de verificação é aplicada em três etapas do perioperatório: antes da indução anestésica (sign in), antes da incisão cirúrgica (time out ou parada/paragem cirúrgica) e antes de o paciente sair da sala de operações (sign out). Sua aplicação deve ser coordenada por um único profissional em cada etapa. 
A verificação dos itens da lista deverá ser realizada verbalmente e envolver todos os membros da equipe cirúrgica. A existência de um coordenador, podendo ser ele um enfermeiro, anestesista ou cirurgião, é fundamental para a adequação e o bom resultado do processo; portanto, sua escolha deve ser definida no processo de implantação da lista de verificação. A principal qualidade esperada para o coordenador é entender a importância do processo e estar familiarizado com a lista.

\section{Antes da indução da anestesia}

O local de verificação dos itens da primeira etapa (antes da indução da anestesia) da lista pode ser, de maneira ideal, a sala de recepção pré-operatória. Caso ela não exista, poderá ocorrer na entrada do centro cirúrgico ou em outro local previamente acordado. O coordenador deve, então, confirmar verbalmente a identificação do paciente, envolvendo-o no caso de ele estar consciente, e conferir a pulseira de identificação com seus respectivos dados.

É importante que a organização tenha um processo bem definido para identificar o paciente. Todos os que se internam com o objetivo de se submeter a uma cirurgia devem ter dois identificadores em uma pulseira de cor branca. Os identificadores podem ser: nome completo, idade, data de nascimento, número de prontuário/processo clínico ou o nome da mãe, por exemplo. Não é recomendado que o número do leito/cama, quarto ou enfermaria seja utilizado na pulseira de identificação por causa das trocas possíveis de ocorrer. O Protocolo de Identificação do Paciente do Ministério da Saúde tem a finalidade de garantir a correta identificação do paciente, a fim de reduzir a ocorrência de incidentes. O processo de identificação do paciente deve assegurar que o cuidado seja prestado à pessoa para a qual se destina. (Ministério da Saúde 2013)

\section{Para refletir}

Em sua unidade de trabalho, quais tipos de cuidados são considerados na hora da identificação do paciente?

Nessa etapa, deve-se verificar qual o procedimento a ser realizado e em que parte do corpo a intervenção irá ocorrer. A identificação do sítio cirúrgico deve ser efetuada por médico da equipe cirúrgica antes de o paciente ser encaminhado para o local de realização do procedimento. Sempre que possível, ela deve ocorrer com o paciente acordado e cons- 
ciente. No caso de haver lateralidade, como em órgãos duplos (olhos, pulmões, rins etc.), em membros (direito e esquerdo) e em múltiplos níveis (coluna vertebral), confirma-se a demarcação prévia do local. A organização deve padronizar o tipo de marcação a ser utilizada, para evitar a ocorrência de erros. Sinais como " $X$ " não devem ser utilizados, pois podem ser interpretados como negativos, isto é, não é esse o local a ser operado.

Os consentimentos informados necessários à realização do procedimento, como os específicos da cirurgia, da anestesia e da transfusão de sangue e hemocomponentes, são conferidos nessa etapa.

Caberá ao anestesista a confirmação dos itens de verificação relacionados à anestesia. Ele deve ratificar que a conferência de drogas e equipamentos foi criteriosamente realizada e se há disponibilidade de equipamentos para manutenção das vias aéreas, ventiladores, aspirador e outros itens de segurança anestésica (CFM 2018). A segurança da anestesia abrange, também, o período pós-operatório, já que, na etapa antes da indução anestésica, deve ser confirmada a disponibilidade de leitos em unidades adequadas para o pós-operatório, como UTI pós-operatória e Unidade Intermediária.

Em relação ao uso de oxímetro de pulso, previsto na lista de verificação, deve ser ressaltado que seu uso também é obrigatório em procedimentos sob sedação, realizada por médico não anestesista. É importante destacar que o profissional responsável pela monitoração da oximetria não deve estar envolvido com o procedimento. A sedação profunda só pode ser efetuada por médico qualificado e em ambiente que ofereça condições seguras para que ela ocorra, ficando os cuidados do paciente a cargo do médico que não esteja realizando o procedimento que exige sedação (CFM 2003).

O paciente é avaliado se é portador de alergia a algum medicamento. Também fundamental verificar se foi realizada, previamente, a avaliação das vias aéreas do paciente e, se possível, declarar de forma objetiva o que foi constatado (Classificação de Mallampati, distância de incisivos, mobilidade cervical etc.). Deve ser destacada a importância da consulta ambulatorial de anestesia e a visita pré-anestésica na identificação de risco. Caso o paciente seja considerado de alto risco, é necessário verificar a disponibilidade nessa etapa, antes da indução anestésica, de equipamentos e técnicas acessórias, bem como a presença de outro profissional no momento da indução para auxiliar na realização do procedimento. Esse profissional não é, necessariamente, outro anestesista; é possível que seja um cirurgião ou enfermeiro que, 
Uma vez cumprida a primeira etapa da lista de verificação, o paciente deve ser encaminhado à sala de operações para a indução da anestesia e/ou execução do bloqueio, se for o caso. cientes do problema, estejam à cabeceira do paciente com o anestesista no momento da indução. Também é importante observar esse procedimento se houver risco de broncoaspiração (Tang et al. 2014).

Por fim, nessa etapa, é necessário se ter uma estimativa de possível perda sanguínea durante o procedimento, com o objetivo de se prover o acesso venoso compatível com o fluxo de reposição necessário, definir o tipo de fluido necessário (soluções ou hemocomponentes) e constatar se a reserva de hemocomponentes foi realizada previamente. Os limites de $500 \mathrm{ml}$ de perda sanguínea para adultos e $7 \mathrm{ml} / \mathrm{kg}$ para pacientes pediátricos são estabelecidos para o critério de escolha de acesso venoso.

\section{Antes da incisão cirúrgica}

A verificação da segunda etapa da lista é realizada de imediato antes da incisão cirúrgica. Essa etapa, não exatamente uma lista de verificação, é denominada pausa cirúrgica.

Inicia-se com a apresentação formal, pelo nome, de todos os membros da equipe cirúrgica, momento muitas vezes negligenciado, principalmente por equipes que já tenham realizado diversos procedimentos em conjunto. Entretanto, cada vez mais são inseridos novos membros na equipe, os quais participam, mesmo de modo parcial, do procedimento, tais como os técnicos de materiais específicos, órteses e próteses, além de enfermeiros, que são substituídos na última hora. No caso de substituição de algum membro da equipe cirúrgica durante o procedimento, a apresentação deve ser repetida tão logo possível.

Após a apresentação formal, o coordenador deve realizar nova confirmação oral da identidade do paciente, assim como o tipo de procedimento e em que parte dele será realizado. Mais uma vez, a questão da dupla barreira, redundante obviamente, mas necessária quando se pensa em minimizar riscos. Esse momento é a oportunidade de se confirmar a realização da profilaxia antimicrobiana ocorrida há 30-60 minutos, caso seja indicada.

O coordenador deve perguntar ao cirurgião principal se está previsto algum evento crítico em determinado momento mais específico da cirurgia. O anestesista terá oportunidade de apresentar suas considerações, referentes a algum problema na indução da anestesia, ou preocupações, relativas a possíveis doenças coexistentes (hipertensão, diabetes etc.), e se ainda houver dúvida sobre a perda sanguínea. O instrumentador/enfermeira instrumentista deve confirmar se a esterilização do 
material foi conferida por um indicador confiável. Necessário, também, realizar nova verificação de que os exames de imagem indispensáveis à realização da cirurgia, como tomografias, ressonâncias ou radiografias, encontram-se disponíveis na sala de operações. Feito isso, a cirurgia pode ser iniciada.

Foto 1 - Para se chegar ao procedimento cirúrgico em si, muitos passos devem ser pensados e planejados

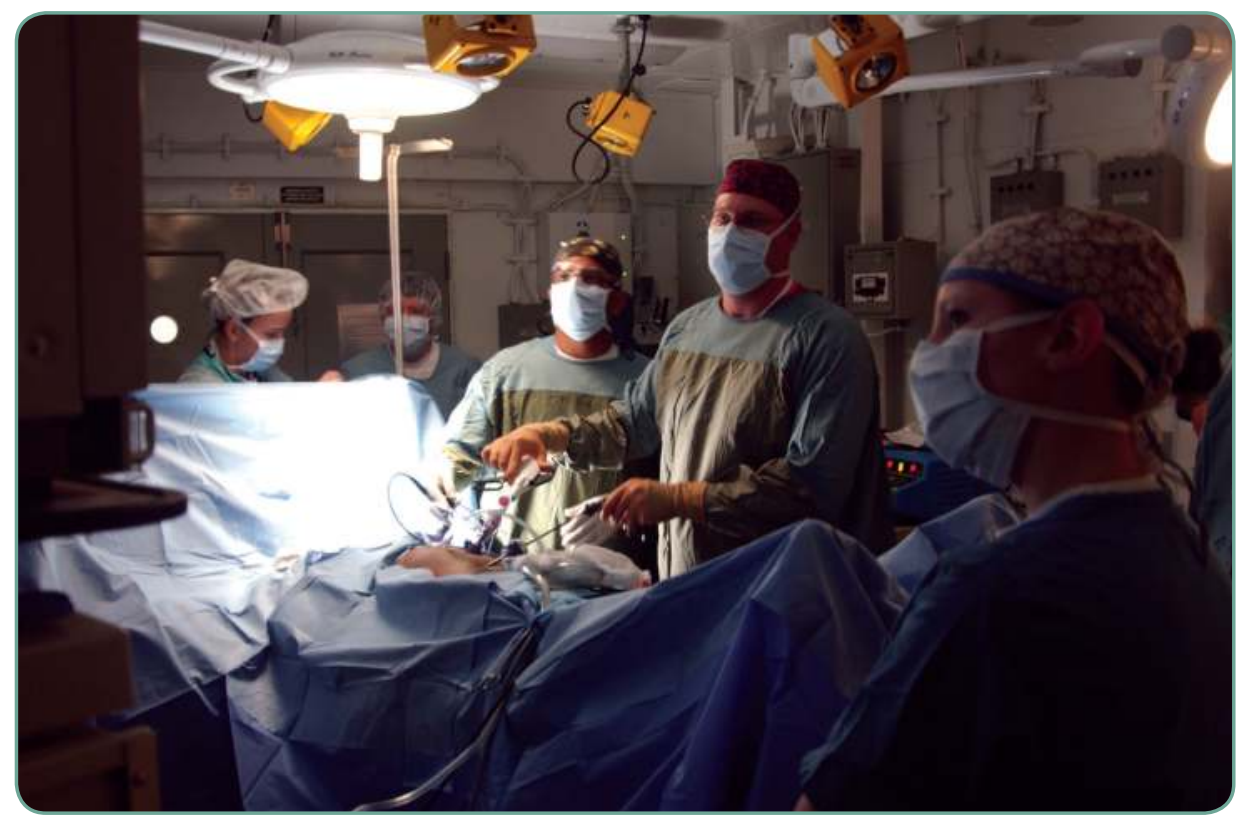

Fonte: Chris Thamann (2005).

\section{Antes da saída do paciente da sala de operações}

A terceira e última etapa da lista de verificação ocorre com o paciente ainda na sala de operações. Esse período antecede a transferência dele para a sala de recuperação pós-anestésica e pode, muitas vezes, coincidir com o fechamento da ferida operatória. O coordenador deve solicitar ao cirurgião a confirmação do nome do procedimento efetivamente realizado, considerando que nem sempre a cirurgia realizada está de acordo com a planejada, e aquele que cuidará do paciente no pós-operatório imediato deve recebê-lo com a informação precisa do procedimento ao qual foi submetido.

Em seguida, o instrumentador/enfermeira instrumentista confirma se a contagem de instrumentos, compressas e agulhas, ao final do procedimento, foi compatível com a contagem inicial. No caso de qualquer inconsistência nesse processo, toda a equipe cirúrgica deve ser alertada para que as medidas cabíveis sejam executadas prontamente. Outro 
item importante, e algumas vezes negligenciado, é a correta rotulagem de eventuais amostras de material biológico. Equívocos nesse procedimento podem determinar erros de conduta clínica no pós-operatório, com repercussões desastrosas em função de um erro diagnóstico.

Caso tenha ocorrido algum problema com equipamentos, esse também é o momento para se fazer o relato. Seu objetivo é evitar que outra cirurgia seja realizada na mesma sala de operações com o equipamento defeituoso.

Todo o procedimento deve ser revisto no contexto do período pós-operatório, isto é, quais são os eventos possíveis em decorrência do que foi realizado na sala de operações. As perdas sanguíneas, o controle da dor aguda e outras preocupações pertinentes devem ser avaliadas, verbalmente discutidas e descritas no prontuário/processo clínico, e, ainda, resumidas nos instrumentos de passagem de caso. O objetivo é uma transferência do cuidado segura, sem problemas nesse processo de passagem de caso.

\section{O processo de implantação da Lista de Verificação de Segurança Cirúrgica}

As evidências sobre processos bem-sucedidos de melhoria da qualidade indicam que o êxito está relacionado ao modo como as mudanças são introduzidas. Dentre os fatores que contribuem para o sucesso estão: a liderança; o envolvimento dos profissionais, especialmente os que lidam diretamente com o paciente; e a participação dos pacientes.

A ruptura das hierarquias tradicionais é essencial para assegurar que as distintas perspectivas multidisciplinares sejam consideradas. O envolvimento dos profissionais da linha de frente do cuidado é fundamental em qualquer programa de melhoria da qualidade, mas não é um processo fácil. Muitos profissionais, embora dispostos a melhorar a qualidade dos serviços que oferecem, talvez não estejam familiarizados com as abordagens de melhoria da qualidade, como as utilizadas para a implementação da LVSC. A capacitação e o apoio são elementos primordiais para o comprometimento dos profissionais com a melhoria (Health Foundation 2014).

A literatura a respeito da melhoria destaca o papel das lideranças, especialmente as lideranças clínicas, que podem ser determinantes para que as iniciativas de melhoria tenham adesão no nível local. Líderes são necessários em todos os níveis, desde a linha de frente até a gestão. $\mathrm{O}$ trabalho de liderança em intervenções de melhoria complexas requer a 
combinação de habilidades técnicas de facilitação e qualidades pessoais. Talvez seja mais adequado caracterizar o líder da melhoria como um facilitador, e não como uma autoridade. O papel do facilitador é permitir que os outros contribuam com seus pontos de vista, conhecimentos e ideias, criando redes, facilitando a cooperação e a colaboração, gerando confiança entre os outros profissionais e promovendo o engajamento (Health Foundation 2013).

Um processo efetivo de implementação é necessário para a real utilidade da LVSC (Conley et al. 2011). Portanto, para que venha a ser amplamente utilizada e efetiva, é indispensável a gestão proativa da alta administração da organização (Fourcade et al. 2012). Apesar das importantes vantagens em sua utilização, a implantação da LVSC, nas organizações, não é tarefa fácil e rápida, porque requer o genuíno comprometimento dos profissionais de saúde envolvidos com os procedimentos cirúrgicos, além da revisão, na organização de todos os processos de cuidado do paciente cirúrgico, de modo a identificar necessidades de ajustes e, até mesmo, alteração da política institucional.

Durante o processo de implantação, a LVSC pode sofrer pontuais adaptações, desde que nenhum item seja excluído. Caso a organização ainda não possua, por exemplo, um processo para obter o consentimento informado, esse item não deve ser omitido, mas, na verdade, será uma excelente oportunidade para sua elaboração colaborativa entre todos os profissionais envolvidos, e assim desenvolver um processo de consentimento informado factível, que venha a cumprir o precípuo objetivo de apresentar aos pacientes e seus familiares as reais condições das intervenções, com suas vantagens e possíveis complicações. Implementar a lista de verificação requer, antes de tudo, a determinação genuína dos gestores da organização, e a hierarquia não deverá vir a ser um obstáculo para sua utilização. A liderança organizacional é, em última análise, a responsável pela qualidade do cuidado e segurança do paciente, condizentes com a missão e valores institucionais, e deve de tudo fazer para que os objetivos sejam alcançados, colocando-os acima, inclusive, de questões financeiras.

Por que será que a implantação da Lista de Verificação de Segurança Cirúrgica tem sido tão lenta?

A implementação da Lista de Verificação de Segurança Cirúrgica depende de diversos fatores (Fourcade et al. 2012; Tang et al. 2014): socioculturais, liderança efetiva, treinamento, retroalimentação em 
tempo real e de seguimento, bem como o envolvimento ativo dos profissionais. A Lista de Verificação de Segurança Cirúrgica deve se tornar parte da cultura cirúrgica.

Por ser extensa, a LVSC exige, inicialmente, quantidade considerável de tempo e esforço. É necessário que a organização tenha decidido mobilizar e sensibilizar seus profissionais, bem como concentrar esforços para identificação e redução dos riscos, a fim de promover a cultura de segurança, e não apenas aplicar uma lista de verificação (De Vries et al. 2010). Trata-se de um processo complexo que deve considerar a adesão dos profissionais, os elementos facilitadores e as dificuldades (Tang et al. 2014).

As dificuldades para a implementação da lista de verificação podem ser de diversas espécies - organizacionais, habilidades humanas, características culturais e crenças (Fourcade et al. 2012, Tang et al. 2014), incluindo:

畨 duplicação de atividades em razão de verificações existentes;

橉 tempo consumido;

粼 timing inadequado;

滕 comunicação ruim entre os profissionais;

镂 falta de familiaridade entre os profissionais;

嗮 vergonha; e

镂 hierarquia na sala de cirurgia.

As dificuldades identificadas com mais frequência são a duplicação de atividades e o tempo gasto na verificação dos itens. Elas devem ser adequadamente tratadas para que a efetiva implementação seja garantida e os resultados favoráveis alcançados (Tang et al. 2014). Importante, ainda, destacar que a marcação dos itens apenas para cumprir com os requisitos previstos na legislação ou em auditorias/revisões não garante segurança, tampouco resultados favoráveis (Fourcade et al. 2012). Grande obstáculo à implementação da lista de verificação é a rotatividade de funcionários, mesmo com a oferta de treinamento (Fourcade et al. 2012), podendo haver dificuldade em se identificar um líder na equipe.

A lista de verificação é uma ferramenta projetada para reduzir o risco, de modo que a compreensão do risco entre os profissionais que a utilizam pode ter papel relevante em sua implementação. Do ponto de vista da segurança, é possível considerar a lista de verificação como barreira 
ou defesa contra uma falha (Rydenfält et al. 2013). Defesas, barreiras e salvaguardas ocupam posição central na abordagem sistêmica da Teoria do Erro Humano (Reason 2000). Sistemas de alta tecnologia têm muitas camadas defensivas, sendo algumas projetadas como alarmes, barreiras físicas, paralisação temporária automática e outras, confiadas a pessoas, tais como cirurgiões e anestesistas, e ainda outras dependentes de procedimentos e controles administrativos. Essas camadas têm como função a proteção de vítimas potenciais e do patrimônio quanto aos riscos locais.

No estudo de Rydenfält et al. (2013), os itens da lista de verificação com maior adesão estão voltados a prevenir danos diretos ao paciente, evitando falhas ativas. Em contraste, os itens que constituem defesas contra condições latentes, como a garantia de que todo o material utilizado é estéril ou a apresentação dos membros da equipe para facilitar a comunicação, tiveram adesão menor, existindo a possibilidade de indicar que a percepção de risco dos profissionais pode estar dirigida para as falhas ativas. A LVSC não deve ser entendida apenas como uma lista com itens a serem preenchidos, seu processo transcende essa prática "mecânica", e todos devem estar cientes de que se trata de uma ferramenta útil ao objetivo maior, ou seja, a segurança do procedimento. Além disso, deve ser ressaltado que tarefas consideradas de rotina podem ser esquecidas por uma falha.

Em estudo mais recente, Russ et al. (2015) identificaram diversas barreiras à implementação da Lista de Verificação de Segurança Cirúrgica, entre elas:

䠣 Ausência de uma abordagem planejada para a implementação ou imposição da lista de verificação.

邹 Falta de educação ou treinamento.

Falta de apoio à implementação.

* Ausência de customização para o contexto local.

路 Resposta da equipe comprometida pelo não envolvimento no planejamento da iniciativa.

*alta de comunicação sobre a relevância da ferramenta.

踖 Resistência geral à introdução de mudanças, particularmente por membros mais importantes da equipe.

滕 Demora excessiva para completar a lista de verificação, criando ineficiência no funcionamento da sala de operação.
No Capítulo 4, "O erro e as violações no cuidado de saúde", do livro Segurança do paciente: conhecendo os riscos nas organizações de saúde, a Teoria do Erro Humano de James Reason é abordada em profundidade. 
蛅 Repetição de práticas de segurança existentes, não contribuindo, em termos de segurança, para o sistema (por exemplo, onde listas de verificação locais já foram desenvolvidas e não removidas antes da introdução da lista de verificação da OMS).

Barreiras específicas referentes à concepção da lista de verificação também foram identificadas no estudo de Russ et al. (2015):

Ser inadequada para alguns procedimentos cirúrgicos ou especialidades cirúrgicas específicas, como cirurgia oftalmológica e obstetrícia, ou para certos contextos, como emergências.

䟕 Questionamentos dos profissionais referentes à robustez das evidências.

Quando não utilizada da maneira pretendida, a lista de verificação pode ter efeitos negativos involuntários sobre os cuidados, tornando-o paradoxalmente menos seguro para o paciente. Como exemplo, pela distração da equipe nos processos rotineiros de segurança, se a lista de verificação for iniciada em momento inadequado ou, ainda, por motivo de animosidade entre os membros da equipe causada por um profissional com resistência à sua aplicação, o que tem impacto negativo no trabalho em conjunto.

\section{Para refletir}

Sua unidade de trabalho enfrenta algumas das barreiras mencionadas à implementação ou à melhoria da eficiência da lista de verificação? Você consegue pensar em mudanças que possam melhorar seu uso?

\section{Considerações finais}

As complicações cirúrgicas são causa importante de morte e incapacidade em todo o mundo: devastadoras para os pacientes, dispendiosas para os sistemas de saúde e, muitas vezes, evitáveis (Haynes et al. 2009). Sua prevenção requer a mudança no processo do cuidado cirúrgico e no comportamento individual dos profissionais envolvidos.

Programas de intervenção baseados na LVSC foram associados à redução significativa na taxa de complicações e morte relacionadas com cirurgia, em um grupo diversificado e significativo de instituições de todo o mundo (Haynes et al. 2009). 
As listas de verificação auxiliam para relembrar itens frequentes, mas facilmente omitidos por evidenciarem as etapas de um processo complexo e estabelecerem um padrão de desempenho elevado. A LVSC é uma ferramenta para ser utilizada por médicos e enfermeiros interessados na melhoria da segurança dos pacientes e na redução de complicações cirúrgicas desnecessárias, inclusive óbitos evitáveis (OMS 2009). Sua ampla implementação e seu uso efetivo têm potencial de evitar grande número de mortes e complicações incapacitantes (Haynes et al. 2009), mas sua implantação continua sendo desafiadora, principalmente em um cenário de cultura de segurança e sistema de aprendizagem em estágios iniciais de desenvolvimento.

\section{Referências}

Anderson O, Davis R, Hanna GB, Vincent CA. Surgical adverse events: a systematic review. Am J Surg. 2013;206:253-262.

Blossom J, Finkelstein J, Guan W, Burns B. Applying GIS Methods to Public Health Research at Harvard University. J Map Geogr Libr 2011 [citado 2014 jun 25];7:349-376. Disponível em: https:// gis.harvard.edu/publications/applying-gis-methods-public-health-research-harvard-university.

Conley DM, Singer SJ, Edmondson L, Berry WR, Gawande AA. Effective surgical safety checklist implementation. J Am Coll Surg. 2011 May;212(5):873-9.

Conselho Federal de Medicina. Resolução CFM 1.670/03. Diário Oficial da União 2003 Jul 14 [citado 2012 ago 26]. Disponível em: http://www.portalmedico.org.br/resolucoes/ CFM/2003/1670_2003.htm.

Conselho Federal de Medicina (BR). Resolução CFM 2.147/2017. Diário Oficial da União: seção 1. 2018 fev 27 [citado 2019 jan. 10]. Disponível em: https://sistemas.cfm.org.br/normas/visualizar/ resolucoes/BR/2017/2174

De Vries EN, Prins HA, Crolla R, Den Outer AJ, Van Andel G, Van Helden SH et al. Effect of a comprehensive surgical safety system on patient outcomes. N Engl J Med. 2010 Nov 11;363(20):1928-37.

Fourcade A, Blache JL, Grenier C, Bourgain JL, Minvielle E. Barriers to staff adoption of a surgical safety checklist. BMJ Qual Saf. 2012;21:191-97.

Gaba DM, Fish KJ, Howard SK. Situações críticas em anestesiologia: condutas e procedimentos. Rio de Janeiro: Revinter; 1998.

Gawande AA, Zinner MJ, Studdert DM, Brennan TA. Analysis of erros reported by surgeons at three teaching hospitals. Surgery 2003;133:614-21.

Geraghty A, Ferguson L, Mclhenny C, Bowie P. Incidence of wrong-site surgey list errors for a 2-year period in a single National Health Service board. J Patient Saf. 2017 Oct 4. (Ahead of print).

Haugen AS, Søfteland E, Eide GE, et al. Impact of the World Health Organization's surgical safety checklist on safety culture in the operating theatre: a controlled intervention study. Br J Anaesth. 2013;110:807-15.

Haynes AB, Weiser TG, Berry WR, et al. A surgical safety checklist to reduce morbidity and mortality in a global population. N Engl J Med. 2009;360:491-99. 
Health Foundation. Superando desafios para melhorar a qualidade: lições extraídas das avaliações dos programas de melhoria da Health Foundation e de literatura relevante. Tradução de Proqualis/ Instituto de Comunicação Científica e Tecnológica em Saúde/Fiocruz. Rio de Janeiro: Fiocruz; 2013 [citado 2019 Jan 5]. Disponível em: https://proqualis.net/sites/proqualis.net/files/Superando\%20 desafios\%20para\%20melhorar\%20a\%20qualidade.pdf

Health Foundation. Simplificando a melhoria da qualidade. Tradução de Proqualis/Instituto de Comunicação Científica e Tecnológica em Saúde/Fiocruz. Rio de Janeiro: Fiocruz; 2014. Disponível em http://proqualis.net/sites/proqualis.net/files/Simplificando\%20a\%20melhoria\%20da\%20 qualidade_0.pdf

Howell AM, Panesar SS, Burns EM, Donaldson LJ, Darzi A. Reducing the burden of surgical harm: a systematic review of the interventions used to reduce adverse events in surgery. Ann Surg. 2014 Apr; 259(4):630-41.

Joint Comission. Sentinel event statistics data: root causes by event type: 2004 - Q1 2012. Oakbrook Terrace (III): The Joint, [2012?] [citado 2012 ago 26]. Disponível em: http://www. jointcommission.org/assets/1/18/Root_Causes_by_Event_Type_2004-1Q2012.pdf.

Kaderlia R, Busingerb A, Oescha A, Stefenellic U, Laffera U. Morbidity in surgery: impact of the 50hour workweek limitation in Switzerland. Swiss Med Wkly. 2012 Jan 24;142:w13506.

Kwok AC, Funk LM, Baltaga R, Lipsitz SR, Merry AF, Dziekan G, et al. Implementation of the World Health Organization surgical safety checklist, including introduction of pulse oximetry, in a resourcelimited setting. Ann Surg. 2013 Apr;257(4):633-9.

Lindley EM, Botolin S, Burger EL, Patel VV. Unusual spine anatomy contributing to wrong level spine surgery: a case report and recommendations for decreasing the risk of preventable 'never events'. Patient Saf Surg. 2011;5:33.

Lyons VE, Popejoy LL. Meta-analysis of surgical safety checklist effects on teamwork, communication, morbidity, mortality, and safety. West J Nurs Res. 2014 Feb;36(2):245-61.

Mellin-Olsen J, Staender S, Whitaker DK, Smith AF. The Helsinki Declaration on patient safety in anaesthesiology. Eur J Anaesthesiol. 2010;27:592-7.

Ministério da Saúde (BR). Portaria n².095, de 24 de setembro de 2013. Protocolo de Segurança na prescrição, uso e administração de medicamentos. Diário Oficial da União, 2013 set 25.

Morrison CA, Wyatt MM, Carrick MM. Impact of the 80-hour work week on mortality and morbidity in trauma patients: an analysis of the National Trauma Data Bank. J Surg Res. 2009 Jun $1 ; 154(1): 157-62$.

Moura MLO, Mendes W. Avaliação de eventos adversos cirúrgicos em hospitais do Rio de Janeiro. Rev Bras Epidemiol. 2012;15(3):523-35.

NHS. Provisional publication of Never Events reported as occurring between 1 April and 31 August 2017. Reeditch: NHS; 2017 [citado 2017 out 21]. Disponível em: https://improvement.nhs.uk/ uploads/documents/Never_Events_1_April_2017_-_31_August_2017_.pdf

O'Connor P, Reddin C, O'Sullivan M, O'Duffy F, Keogh I. Surgical checklists: the human fator. Patient Saf Surg. 2013 [citado 2014 jun 25],7:14. Disponível em: http://www.pssjournal.com/ content/7/1/14.

Organização Mundial da Saúde. Segundo desafio global para a segurança do paciente: cirurgias seguras salvam vidas (orientações para cirurgia segura da OMS). Rio de Janeiro: Organização PanAmericana da Saúde; 2009. Publicado em parceria com Ministério da Saúde e Agência Nacional de Vigilância Sanitária.

Reason J. Human error: models and management. BMJ 2000;320:768-70. 
Reed S, Ganyani R, King R, Pandit M. Does a novel method of delivering the safe surgical checklist improve compliance? A closed loop audit. Int J Surg. 2016 Aug;32:99-108

Rodrigo-Rincon I, Martin-Vizcaino MP, Tirapu-Leon B, Zabalza-Lopez P, Zaballos-Barcala N, Villalgordo-Ortin $\mathrm{P}$, et al. The effects of surgical checklists on morbidity and mortality: a pre- and post-intervention study. Acta Anaesthesiol Scand. 2015 Feb;59(2):205-14.

Russ SJ, Sevdalis N, Moorthy K, Mayer EK, Rout S, Caris J, et al. A qualitative evaluation of the barriers and facilitators toward implementation of the WHO surgical safety checklist across hospitals in England: lessons from the "Surgical Checklist Implementation Project". Ann Surg. 2015 Jan;261(1):81-91.

Rydenfält C, Johansson G, Odenrick P, Åkerman K, Larsson PA. Compliance with the WHO Surgical Safety Checklist: deviations and possible improvements. Int J Qual Health Care. 2013 Apr;25(2):182-7.

Shekelle PG, Wachter RM, Pronovost PJ, Schoelles K, McDonald KM, Dy SM, et al. Making health care safer II: an updated critical analysis of the evidence for patient safety practices.. Rockville, MD: Agency for Healthcare Research and Quality, U.S. Department of Health and Human Services, 2013 Mar. (Comparative Effectiveness Review No. 211. AHRQ Publication No. 13-E001-EF). Disponível em: www.ahrq.gov/research/findings/evidence-based-reports/ptsafetyuptp.html.

Sinha A, Singh A, Tewari A. The fatigued anesthesiologist: A threat to patient safety? J Anaesthesiol Clin Pharmacol. 2013;29(2):151-59.

Sousa P, Uva AS, Serranheira F, Nunes C, Leite ES. Estimating the incidence of adverse events in Portuguese hospitals: a contribution to improving quality and patient safety. BMC Health Serv Res. 2014;14:311. doi:10.1186/1472-6963-14-311.

Stahel PH, Sabel AL, Victoroff M, Varnell J, Lembitz A, Boyle D, et al. Wrong-site and wrongpatient procedures in the universal protocol era: analysis of a prospective database of physician self-reported occurrences. Arch Surg. 2010;145:978-84.

Sugden C, Athanasiou T, Darzi A. What are the effects of sleep deprivation and fatigue in surgical practice?Semin Thoracic Surg. 2012;24:166-75.

Tang R, Ranmuthugala G, Cunningham F. Surgical safety checklist: a review. ANZ J Surg. 2014 Mar;84(3):148-54.

Thamann C. File:US Navy 050118-N-6410T-008 Cmdr. Mary Nadolny, from Newman, Ga., Lt. Cdr. Prashant Reddy, from Dallas, Texas, and Lt. Cdr. James Christopher, from New Roads, La, watch the laparoscopic monitor while performing an appendectomy.jpg. Wikimedia Commons, 2005 [citado 2014 jun 25]. Disponível em: http://commons.wikimedia.org/wiki/File:US_Navy_050118-N6410T-008_Cmdr._Mary_Nadolny,_from_Newman,_Ga.,_Lt._Cdr._Prashant_Reddy,_from_Dallas,_ Texas,_and_Lt._Cdr._James_Christopher,_from_New_Roads,_La,_watch_the_laparoscopic_monitor_ while_performing_an_appendectomy.jpg

Wanzel KR, Jamieson CG, Bohnen JMA. Complications on a general surgery service: incidence and reporting. Can J Surg. 2000; 43:113-17.

Zeeshan MF, Dembe AE, Seiber EE, Lu B. Incidence of adverse events in an integrated US healthcare system: a retrospective observational study of 82,784 surgical hospitalizations. Patient Saf Surg. 2014 May 27;8-23. 


\title{
10. A segurança do paciente e o diagnóstico
}

\author{
Lucas Santos Zambon
}

O contexto de segurança do paciente envolve a diminuição dos riscos de danos desnecessários causados aos pacientes quando eles estão sob cuidados de profissionais e organizações de saúde (WHO 2009). Esses danos desnecessários, conhecidos como eventos adversos, são, em sua maior parte, ocasionados pela ocorrência de erros no processo assistencial.

Há uma parte dos eventos adversos que tem sua origem especificamente em erros de diagnóstico. Conforme demonstrado no importante estudo Harvard Medical Practice Study (Brennan et al. 1991), 14\% dos erros que levam a eventos adversos são exatamente erros de diagnóstico. Apesar da frequência de erros diagnósticos ser menor que a de erros na realização de procedimentos ou cirurgias, conforme o mesmo estudo (cerca de $35 \%$ dos erros que levam a eventos adversos), sua importância se demonstra no fato de que $47 \%$ dos erros de diagnóstico levaram a um dano grave, incluindo dano permanente ou morte do paciente. Ainda nesse estudo, foi constatado que $75 \%$ desses erros foram causados por negligência, ou seja, potencialmente passíveis de serem evitados.

\section{Erro diagnóstico}

É uma falha em (a) estabelecer uma explicação precisa e oportuna para o(s) problema(s) de saúde do paciente ou (b) comunicar essa explicação ao paciente (National Academies of Sciences, Engineering and Medicine 2015). Sendo assim, erros diagnósticos podem ser representados por diagnósticos que ocorrem de forma tardia (levando a perda de oportunidade e impacto prognóstico), por diagnósticos literalmente errados (a explicação encontrada não está correta), ou até mesmo por diagnósticos que não são concluídos (não se encontra uma explicação para o problema do paciente).
O maior volume de eventos adversos identificados em diversos estudos são aqueles relacionados a cirurgias e procedimentos invasivos - sejam eles diagnósticos ou terapêuticos, como a colocação de um cateter venoso central -,e aqueles relacionados a medicamentos.

É importante destacar que o conceito de erro de diagnóstico só ocorre diante de uma queixa de um paciente, para a qual o mesmo deseja uma explicação (diagnóstico). Uma vez que o tempo aparece atrelado ao erro diagnóstico (diagnóstico oportuno), é importante destacarmos que não há erro diagnóstico em situações de rastreamento em que se propõe diagnósticos precoces em fases assintomáticas, ou seja, quando não há queixa do paciente. As situações de rastreamento são propensas à ocorrência de outro tipo de erro que é o overdiagnosis ou sobrediagnóstico, no qual ocorre o diagnóstico de uma condição clínica que nunca teria causado sintomas ou problemas ao paciente. O sobrediagnóstico pode gerar dano ao paciente, seja por levar a estresse psicológico, seja por induzir novos testes mais invasivos ou até mesmo tratamentos, todos desnecessários (IQWIG 2017). 
Como vimos em outros capítulos, o Institute of Medicine (IOM) dos EUA é um importante órgão de referência na área da qualidade e segurança. O IOM era uma unidade da National Academies que foi renomeada como Health and Medicine Division (HMD), dando prosseguimento ao trabalho que vinha sendo desenvolvido com a ampliação do seu foco para a inclusão de outras questões de saúde. Como parte do conjunto de mudanças, os documentos elaborados passaram a ter como autor institucional a National Academies of Sciences, Engineering and Medicine.
Portanto, compreender como erros diagnósticos ocorrem pode auxiliar na definição de estratégias para sua abordagem, potencializando evitar a ocorrência de danos aos pacientes por essa via. Abordaremos, a seguir, um detalhamento do conceito de erro diagnóstico, discutiremos um caso real em que ocorreu um erro diagnóstico, abordaremos outros exemplos de erros diagnósticos, a epidemiologia desses erros, suas origens e potenciais soluções.

\section{Erro diagnóstico}

A National Academies of Sciences, Engineering and Medicine dos Estados Unidos da América (EUA) publicou um relatório, em 2015, chamando atenção da comunidade científica para a importância do Erro Diagnóstico no contexto da segurança do paciente. Esse relatório traz estimativas bastante contundentes:

镂 $5 \%$ dos adultos que procuram atendimento ambulatorial a cada ano sofrem um erro de diagnóstico.

Pesquisas em exames de necropsias demonstram que erros de diagnóstico contribuem por aproximadamente 10\% das mortes de pacientes.

Análises de prontuários sugerem que erros de diagnóstico representam 6 a $17 \%$ dos eventos adversos hospitalares.

路 Erros de diagnóstico são a causa líder de processos judiciais por má prática médica.

瞵 Estima-se que a maioria das pessoas sofrerá ao menos um erro diagnóstico ao longo da vida.

Para lidarmos com os erros de diagnóstico, devemos entender o processo diagnóstico, que é uma atividade complexa e colaborativa (vide figura a seguir). Esse processo se inicia no momento em que o paciente experimenta um problema de saúde e, então, busca o sistema de saúde. Nesse momento ocorre a fase crítica do processo, onde a coleta de informações, sua integração e interpretação (história, exame físico, exames complementares, pareceres de outros profissionais) levam ao fechamento do diagnóstico. Segue-se, então, a fase em que o diagnóstico é comunicado ao paciente, é feito um plano terapêutico para esse diagnóstico, culminando com os desfechos do paciente. 
Figura 1 - O processo diagnóstico

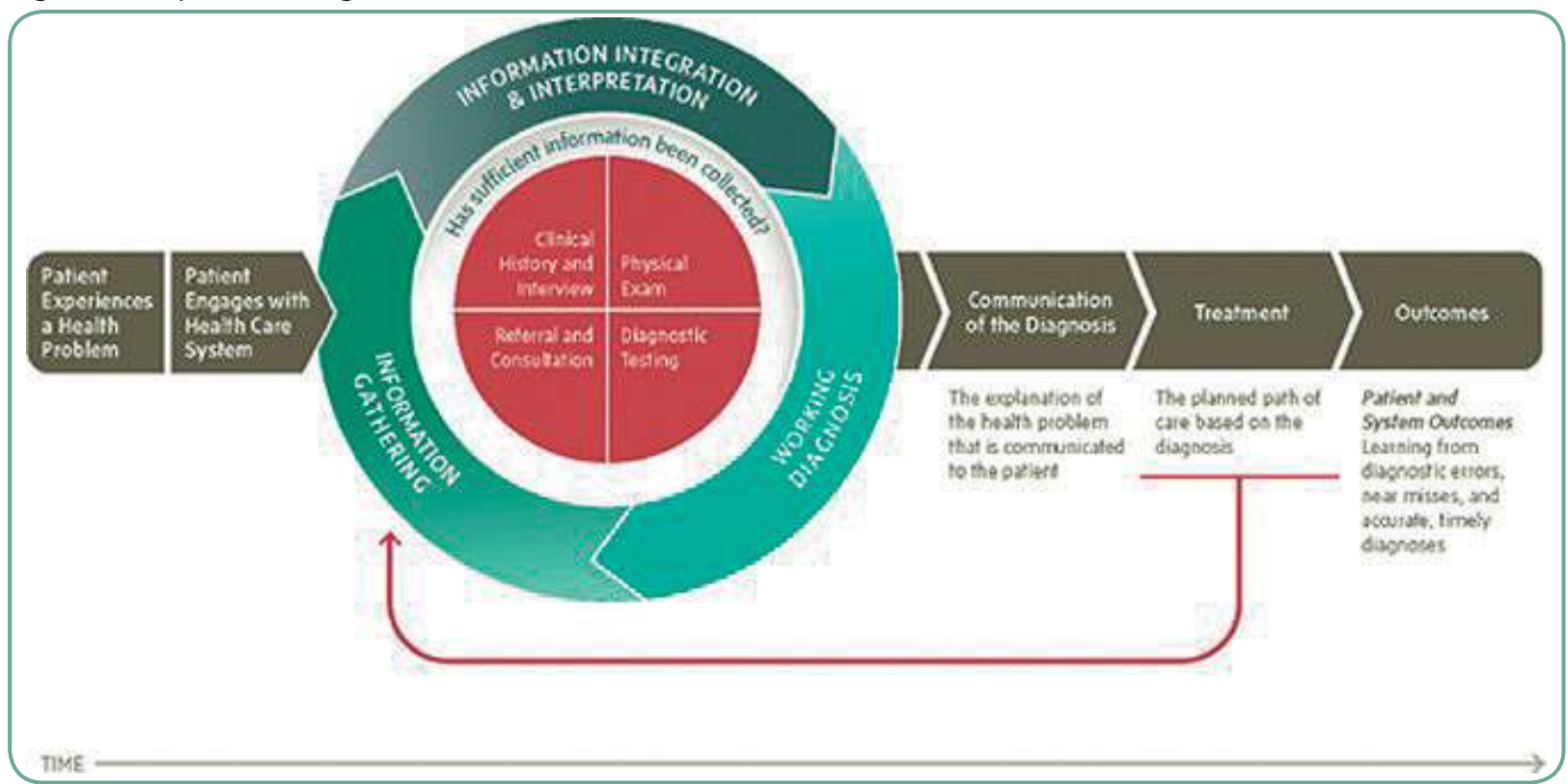

Fonte: Adaptado de National Academies of Sciences, Engineering, and Medicine (2015, p. 33).

- Eixo (cinza) - da esquerda para direita:

Paciente experimenta um problema de saúde

Paciente entra em contato com o sistema de saúde

Comunicação do diagnóstico - Explicação do problema de saúde que é comunicada ao paciente

Tratamento - Plano terapêutico baseado no diagnóstico

Resultados - Resultados do paciente e do sistema aprendizado a partir de erros diagnósticos, near misses e diagnósticos precisos e oportunos

- Centro (vermelho) - início no canto superior esquerdo:

História clínica e entrevista

Exame físico

Exames complementares

Encaminhamento e pareceres

- Círculo (azul) - início no canto inferior esquerdo:

Coleta/recolha de informação

Integração e interpretação da informação

Elaboração do diagnóstico

- Círculo interno (branco):

Informação suficiente foram coletada/recolhida?

- Seta:

Tempo

Com base nessa descrição do processo diagnóstico, podemos identificar claramente alguns pontos que podem levar ao erro diagnóstico:

Falha de engajamento do paciente que tem uma queixa dentro do sistema de saúde.

* Falha em coletar todas as informações necessárias.

* Falha em integrar as informações obtidas. 
蟏 Falha em interpretar as informações obtidas.

蝶 Falha em estabelecer uma explicação para o problema do paciente.

繁 Falha em comunicar a explicação de forma apropriada ao paciente.

A seguir, descreveremos um caso real que exemplifica bem a questão do erro diagnóstico (Dunn et al. 2008).

Uma paciente do sexo feminino, de 66 anos, procurou um Serviço de Emergência Hospitalar (SEH) por causa de dor torácica. Foi realizado um diagnóstico de infarto/enfarte agudo do miocárdio (IAM/EAM) de parede anterior. Ainda no SEH, a paciente começou a apresentar pressão arterial (PA) sistólica de $60 \mathrm{mmHg}$ e evoluiu com parada/paragem cardiorrespiratória (PCR) em fibrilação/fibrilhação ventricular (FV). Ela foi ressuscitada com sucesso e enviada rapidamente para realização de cateterismo cardíaco.

No exame, foi constatado que a artéria descendente anterior (DA) tinha estenose crítica, a coronária direita (CD) uma oclusão completa, e a fração de ejeção do ventrículo esquerdo era de $35 \%$. Durante a tentativa de angioplastia da DA, ocorreu dissecção da artéria, e a paciente evoluiu com choque cardiogênico. Foi instalado, então, um balão intra-aórtico, e a paciente foi rapidamente transferida para a realização de cirurgia de revascularização do miocárdio.

No quarto dia de pós-operatório (PO), a paciente ainda estava sob intubação orotraqueal (IOT) e responsiva apenas a estímulos dolorosos. Foi solicitado um eletroencefalograma (EEG) que mostrou ondas trifásicas, o que foi interpretado como um prognóstico reservado para a paciente. Durante a evolução, a paciente não chegou a recuperar a consciência. Em alguns momentos, apresentava movimentos de agitação, e foi feita restrição física e sedação com lorazepam.

O marido esteve todo o tempo ao lado do leito/cama e relatava que sentia a esposa apertar sua mão e acenar com a cabeça, mas nada disso foi presenciado pela equipe da unidade de terapia intensiva (UTI). Diversos médicos de diferentes especialidades, incluindo neurologistas, avaliaram o caso, e todos concluíram que a paciente estava em encefalopatia anóxica e tinha um prognóstico reservado. O marido insistia que a esposa o reconhecia e apertava sua mão como forma de demonstrar isso; de tanto insistir, ele conseguiu transferir o caso, no $27^{\circ}$ dia de PO, para outro hospital, em busca de uma segunda opinião.

A paciente foi admitida, então, em outro hospital. Durante a avaliação inicial, ela estava hemodinamicamente estável, um pouco febril e rece- 
bendo suporte ventilatório via traqueostomia, arresponsiva e com restrição física nos punhos. O exame físico não tinha maiores alterações, exceto as cicatrizes das feridas operatórias.

Não havia nenhuma alteração focal neurológica, com resposta inespecífica para dor, sem sinais de acometimento de neurônio motor superior. Seus exames laboratoriais mais chamativos eram uma hemoglobina $(\mathrm{Hb})$ de 9,6 g/dL e aumento de fosfatase alcalina e transaminases.

Foi aventada a hipótese diagnóstica de alteração de nível de consciência secundária a medicamentos. Inicialmente, fizeram um teste com duas doses de 0,4 mg de naloxone, que não obteve resultado. Na sequência, foram administradas cinco doses de 0,2 mg de flumazenil. Entre a quarta e a quinta dose, a paciente acordou. O cuff da traqueostomia foi desinflado. Perguntaram à paciente seu nome. Ela respondeu: "Shirley. Meu nome é Shirley Adams." A paciente foi para casa em setembro de 1997, após oito dias de internação hospitalar, no $35^{\circ} \mathrm{PO}$, com um ecocardiograma que mostrou um ventrículo esquerdo de tamanho normal e função preservada.

Vamos tentar discutir rapidamente a origem do erro. Uma paciente, ao ser desmamada de sedação instituída por conta de ventilação mecânica, pode ter mais de uma evolução. A mais simples ocorre nos casos em que a medida que a sedação vai sendo diminuída, a paciente gradativamente desperta e atinge nível de consciência satisfatório sem intercorrências. Mas o que ocorre mais vezes, na prática, com sedação de longa duração é o fenômeno rebote, em que ocorrem manifestações de agitação levando a mais uso de sedativos.

Essa paciente ficou 27 dias em um ciclo de alternância entre o coma e o delirium, ambos induzidos pelo lorazepam. A interrupção diária da sedação não evita esse fenômeno de agitação, e a melhor estratégia é o uso de neurolépticos para controle da agitação. No caso apresentado, o que acabou ocorrendo foi um diagnóstico errado de encefalopatia anóxica - o EEG e a impressão clínica do caso. Os esforços à procura de uma solução para a alteração de nível de consciência foram sustentados pela figura do marido. O simples uso de um antagonista reverteu a situação neurológica da paciente, o que permitiu sua recuperação.

Para refletir

Você já vivenciou algum caso de erro diagnóstico em sua organização?

Como a equipe lidou com esse evento? 
Refletindo sobre o caso

Apesar de estarmos diante de um relato de caso, o que poderia ser mais do que criticado em relação ao nível de evidência que isso gera, alguns fatos tornam essa publicação objeto de profunda reflexão.

Primeiro ponto: a paciente e seu marido são coautores desse relato de caso, escrito dez anos após o ocorrido, em uma publicação sem precedentes de uma sessão da revista CHEST, intitulada "Transparência em Cuidados de Saúde".

Se resumirmos rapidamente esse caso, lembraremos que a paciente foi diagnosticada como portadora de encefalopatia anóxica. Graças a umas poucas doses de antagonista para benzodiazepínicos, ela pôde, dez anos depois, relatar seu caso em uma publicação científica com seu marido, que vivenciou toda a evolução do caso, cuja morbidade/morbilidade era alta, tendo em vista que foi um IAM/EAM que levou a PCR e, depois, evoluiu com choque cardiogênico, precisando de cirurgia de revascularização miocárdica de emergência.

Nesse ponto, por causa de condutas adequadamente seguidas, a paciente pôde receber alta para casa com uma função cardíaca normal. Mas ocorreu um erro fundamental de diagnóstico. Erro que quase "sepultou" uma paciente que recuperou completamente suas atividades de vida após a insistência do marido, que não desistiu de achar que sua impressão sobre a paciente estava correta.

Os erros diagnósticos são difíceis de especificar. Essa categoria de erros, no contexto da segurança do paciente, é muito ampla e difícil de definir (Vincent 2010). Isso porque um erro diagnóstico pode ser algo simples, como não evidenciar uma fratura pequena em uma radiografia, ou algo complexo, como diferenciar uma dissecção de aorta de uma síndrome coronariana em um paciente com dor torácica e fatores de risco para ambas as condições, como hipertensão e tabagismo.

Alguns exemplos de erros diagnósticos são os seguintes (Vincent 2010). 


\section{Exemplos de erros diagnósticos}

Erro no diagnóstico de uma apendicite em um idoso com dor abdominal porque o quadro clínico nāo era típico.

Erro no diagnóstico de uma Doença de Lyme, uma vez que hoje é raro encontrar um caso, e poucos médicos têm experiência no diagnóstico dessa condiçāo.

Erro no diagnóstico de uma gripe quando, na verdade, trata-se de uma Síndrome Monolike, algo que pode ocorrer, já que se trata de quadros clínicos semelhantes

Diagnóstico de um câncer/cancro de cólon que não foi determinado, por ter sido feita retossigmoidoscopia em vez de colonoscopia, por dificuldade para agendar o exame.

Diagnóstico de uma fratura de vértebra que não é feito pelo médico que atendeu o paciente em um SEH, por falta de um radiologista para dar um laudo opiniáo.

Diagnostico de taquicardia ventricular quando, na verdade, era uma taquicardia supraventricular com aberrância, por falta de conhecimento de regras diagnosticas para diferenciar as duas condiçōes no eletrocardiograma.

Diagnóstico de câncer/cancro de mama não realizado por falta de exame físico na avaliaçāo clínica ou de rastreamento adequado.

Diagnóstico de tromboembolismo pulmonar não realizado, por não se pensar nessa hipótese diagnóstica em um paciente que vem transferido de outro serviço, com hipótese erroneamente feita de pnenumonia.

De forma a fornecer mais bases epidemiológicas, alguns estudos tentaram traçar um panorama dos erros diagnósticos. Muito do que sabemos hoje deriva de estudos de autópsias (Goldman et al. 1983; Kirch, Schafii 1996), que mostram de forma consistente taxa de erros diagnósticos de 10 a 15\%. Esses dados têm o viés por serem estudos de autópsia, ou seja, apenas foram analisados pacientes que morreram. Estudos mais detalhados são escassos até pela dificuldade em se traçar uma metodologia que permita aferir erros diagnósticos de forma acurada.

Schiff et al. (2009) tentaram acrescentar dados às questões pertinentes aos erros diagnósticos aplicando um questionário a diversos médicos nos EUA. O questionário pedia aos médicos para relatar três erros de diagnóstico que já cometeram, bem como suas causas e gravidade de repercussão. O total de 669 casos foram relatados por 310 clínicos de 22 instituições. Excluíram-se os casos sem erros de diagnóstico ou faltando detalhes suficientes para a análise e, ao final, a amostra se constituiu de 583 casos. Desses, 162 erros (28\%) foram classificados como importantes, 241 (41\%) como moderados, e 180 (31\%) como menores ou insignificantes. Os erros diagnósticos mais comuns foram: 
Embolia pulmonar

(26 casos; $4,5 \%$ do total)

Reaçōes adversas a

drogas ou overdose

( 26 casos; $4,5 \%$ )

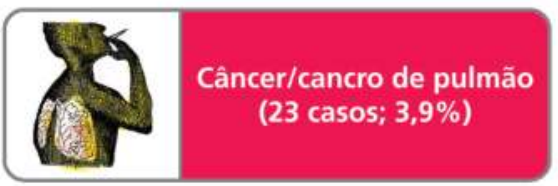

Câncer/cancro colorretal

( 19 casos; $3,3 \%)$

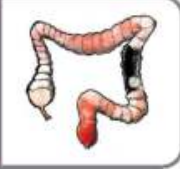

Sindrome

coronariana/coronária

aguda (18 casos, $3,1 \%)$

Câncer/cancro de

mama ( 18 casos; $3,1 \%$ )

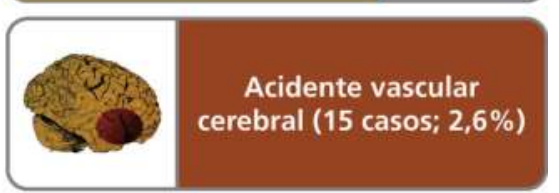

Ocorreram erros mais frequentemente na fase de exames - falhas em pedir, checar e acompanhar resultados laboratoriais - $(44 \%)$, seguido por erros de avaliação clínica - não considerar determinada hipótese diagnóstica - $(32 \%)$, anamnese $(10 \%)$, exame físico $(10 \%)$, e os erros e atrasos de encaminhamento ou realização de consulta em tempo adequado $(3 \%)$.

Tais resultados demonstram que doenças prevalentes e de alta morbidade/morbilidade são de modo interessante as que sofrem mais erros de diagnóstico. Devemos lembrar que IAM/EAM, AVC e os cânceres/ cancros citados normalmente estão entre as dez causas mais frequentes de mortalidade em diversos países, incluindo o Brasil e Portugal.

\section{Para refletir}

Você conhece os dados referentes a erros de diagnósticos de sua região ou organização? Acredita que a prevalência e distribuição dos erros de diagnósticos sejam semelhantes àquelas do estudo apresentado anteriormente?

Outro estudo realizado por Zwaan et al. (2010) procurou evidenciar os eventos adversos por diagnóstico em diversas especialidades médicas para determinar sua incidência. Um estudo de revisão estruturada de 7.926 prontuários/processos clínicos foi para tal realizado. Registros selecionados aleatoriamente foram revisto por médicos treinados em 
21 hospitais, em toda a Holanda. O método utilizado para esse estudo baseou-se no protocolo desenvolvido no Harvard Medical Practice Study (Brennan et al. 1991). Todos os eventos adversos por erro de diagnóstico foram selecionados para análise e comparados com outros tipos de eventos adversos.

Os eventos adversos por erro diagnóstico ocorreram em 0,4\% das admissões hospitalares analisadas e representaram 6,4\% do total dos eventos adversos. Dos eventos por erro diagnóstico, 83,3\% foram considerados evitáveis, uma taxa mais alta que em outros tipos de eventos $(\mathrm{P}<0,001)$. A falha humana foi identificada como a principal causa $(96,3 \%)$, embora os fatores organizacionais e os relacionados ao paciente - comorbidades e aderência ao tratamento - também tenham contribuído (25\% e 30\%, respectivamente). Os eventos adversos por erro diagnóstico tiveram taxa de mortalidade mais elevada que as de outros eventos adversos $(29,1 \%$ vs. $7,4 \%)$.

Outro dado interessante é que eventos por erro diagnóstico foram mais frequentemente descobertos durante uma internação hospitalar/ internamento posterior $(77,4 \%)$ que os outros tipos de evento $(34,5 \%)$ ( $\mathrm{P}<0,001)$, sendo mais frequentes em situação clínica de emergência em comparação com outros eventos adversos (83,9\% vs. 41,9\%, $\mathrm{P}<0,001)$. Eventos por erros diagnóstico ocorreram com mais frequência nos departamentos não cirúrgicos (75,0\%), em oposição aos outros tipos de evento $(33,2 \%, \mathrm{P}<0,001)$, em particular nos departamentos de medicina interna $(28,6 \%)$, cardiologia $(10,7 \%)$ e pneumologia $(10,7 \%)$.

Esse estudo demonstra a importância dos eventos adversos por erro diagnóstico, que causam maior impacto de mortalidade. Além disso, registra como as falhas humanas têm importância em praticamente todos os eventos desse tipo, que são mais facilmente descobertos em internações/internamentos posteriores àquela que gerou o evento, e ocorrem mais frequentemente em pacientes agudos, internados em situação de emergência, mostrando a relação do erro diagnóstico com pacientes mais complexos do ponto de vista de decisão clínica.

Já Gandhi et al. (2006) realizaram estudo no contexto de ambulatório. Os autores efetuaram uma revisão de 307 processos (ocorridos entre 1984 e 2004), em que o paciente alegou negligência médica, seja por diagnóstico errado ou por diagnóstico que demorou a ser feito. Na análise, 181 dos 307 processos foram julgados como envolvendo erros diagnósticos que levaram a resultados adversos. Esse grupo de erros tornou-se o foco de uma análise mais aprofundada. Desses 181 erros, $59 \%$ foi associado a dano grave, $30 \%$ com a morte do paciente, 
e 106 erros envolveram o diagnóstico de câncer/cancro. As falhas mais comuns encontradas foram:

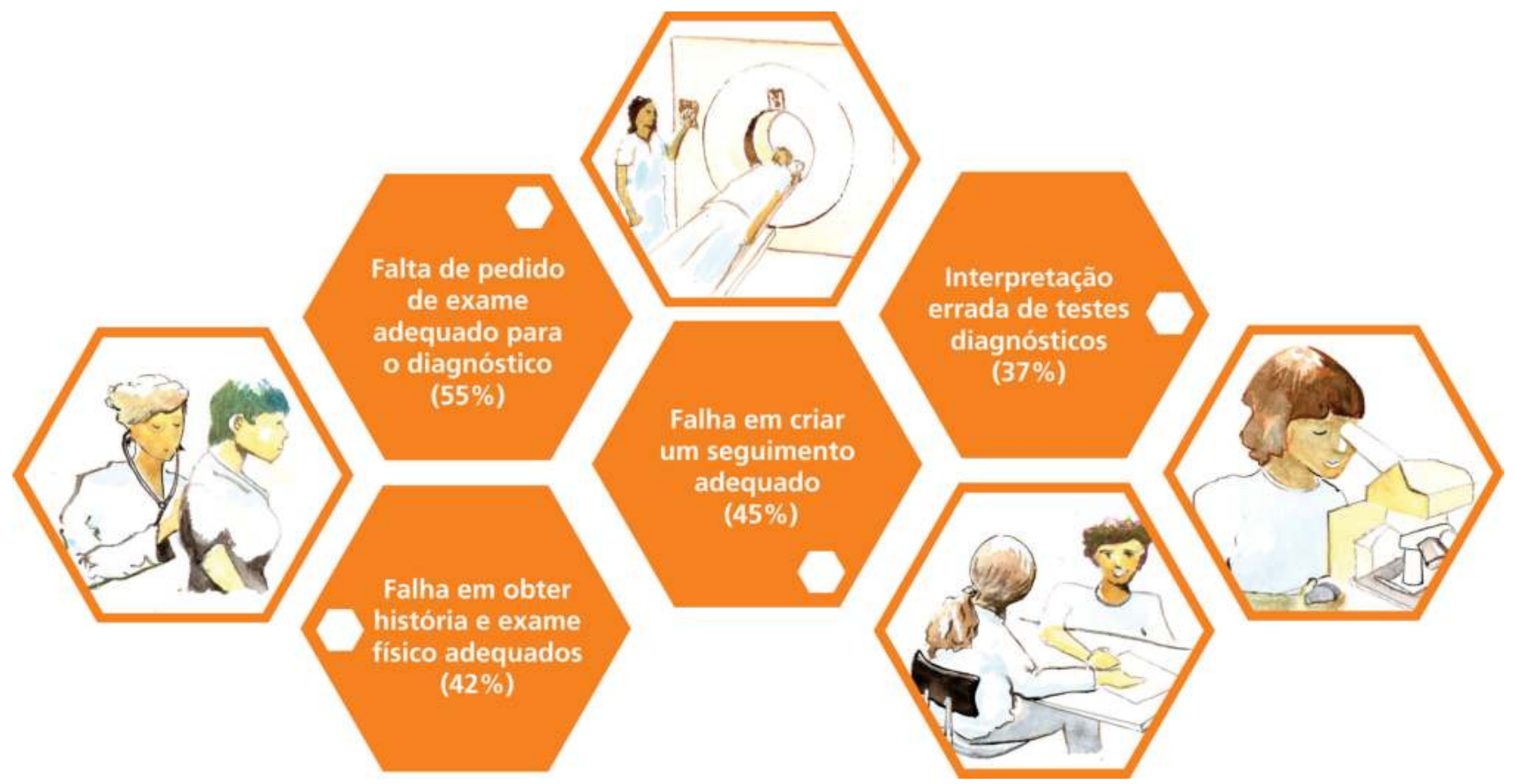

As ideias de James Reason e a discussão sobre o erro são apresentadas no Capítulo 4 deste livro, Segurança do paciente: conhecendo os riscos nas organizações de saúde.
Os fatores mais importantes que contribuíram para a ocorrência de tais erros foram: falha de julgamento $(79 \%)$, falha de vigilância ou memória $(59 \%)$, falha de conhecimento (48\%), fatores associados ao paciente $(46 \%)$ e nas transferências de caso (handoffs) $(20 \%)$.

Por esse estudo, percebe-se que, mesmo no contexto de ambulatório, em que supostamente o médico pode ter mais tempo para avaliar um paciente, examiná-lo e investigá-lo, ainda assim há possibilidade de erros de diagnóstico, e múltiplos fatores contribuem para tal.

\section{Erro humano e diagnóstico médico}

Para James Reason, os erros são as “circunstâncias em que as ações planejadas não conseguem atingir o resultado desejado" (Reason 1990).

Infelizmente, na área da saúde, os erros têm alto potencial para consequências nocivas, isso porque a maior parte dos processos de assistência depende do ser humano, ou seja, são fadados a apresentar erros. Portanto, entender como o ser humano erra, de forma a criar sistemas que evitem ou minimizem a chance dos erros serem cometidos, é a base para uma assistência em saúde segura. E isso é especialmente importante quando pensamos em erros diagnósticos, como veremos mais à frente. 
O erro humano é um reflexo de uma resposta mental a determinada atividade. O modelo de Rasmussen (1983) sugere três níveis de desempenho humano com base no comportamento da resposta mental utilizada em cada um desses níveis. Os três níveis são:

\begin{tabular}{l}
$\begin{array}{l}\text { Desempenho } \\
\text { baseado em } \\
\text { habilidades }\end{array}$ \\
$\begin{array}{l}\text { - Ocorre em situaçōes em que são utilizados padrōes armazenados } \\
\text { de instruçōes já programadas. Aqui são incluidas atividades muito } \\
\text { familiares que sāo feitas em ambientes confortáveis. O ser humano } \\
\text { quando está desempenhando atividades com base em habilidades } \\
\text { funciona muito próximo do que é um piloto automático; }\end{array}$ \\
$\begin{array}{l}\text { Desempenho } \\
\text { baseado em }\end{array}$ \\
$\begin{array}{l}\text { - Ocorre em problemas familiares que são abordados com a utilização } \\
\text { de regras armazenadas. Aqui utiliza-se a lógica, pois em geral, estão } \\
\text { atividades que são familiares ou similares a outras já padronizadas } \\
\text { e que servem de base para a resolução da nova tarefa; }\end{array}$ \\
$\begin{array}{l}\text { Desempenho } \\
\text { baseado em } \\
\text { conhecimento }\end{array}$ \\
$\begin{array}{l}\text { Ocorre em situações novas em que as açōes devem ser } \\
\text { planejadas/planeadas utilizando um processo analitico consciente, } \\
\text { além de utilizar o conhecimento armazenado. O resultado depende } \\
\text { fundamentalmente do conhecimento prévio e da capacidade de } \\
\text { análise, ou seja, aqui funciona muito a 'tentativa e erro'. }\end{array}$ \\
\hline
\end{tabular}

Nota-se que os níveis se apresentam em ordem decrescente de familiaridade com determinada atividade. Importante saber que, à medida que se adquire experiência em uma atividade, progressivamente o comportamento baseado em conhecimento, utilizado no início, migra para o baseado em habilidades. Não é difícil imaginar que isso vá ocorrendo ao longo do tempo com o raciocínio diagnóstico do médico. No início, um médico tece alguns diagnósticos com base no conhecimento adquirido durante sua formação de graduação e pós-graduação (residência médica/internato médico, especialização etc.). Ao longo do tempo e com a experiência adquirida, muitos diagnósticos começam a ocorrer de forma mais automática, ou seja, passam a ser uma questão de habilidades.

Entretanto, podemos imaginar que os três tipos de desempenho ocorrem de forma simultânea no dia a dia do médico ao considerarmos a realização de um diagnóstico. Para doenças comuns, muito prevalentes, as quais o médico pode observar em grande quantidade em sua formação, o diagnóstico é feito com base em habilidades sedimentadas e ocorre de forma rápida e fácil. Doenças um pouco menos comuns, mas ainda prevalentes, acabam sendo diagnosticadas com base em regras, uma vez que basta ter visto outros quadros de diagnósticos semelhantes para chegar àquele em específico. E, por último, há aquelas doenças raras e incomuns, que apenas com base em conhecimento é possível sequer colocá-las como hipóteses diagnósticas para determinado paciente. 
Para saber mais sobre erro humano, leia o Capítulo 4, "O erro e as violações no cuidado de saúde", do livro Segurança do paciente: conhecendo os riscos nas organizações de saúde.
James Reason (1990) classifica os erros com base nos níveis de desempenho humano descritos pelo modelo de Rasmussen. Assim, eles são divididos da seguinte forma:

路 Erros baseados em habilidades: quando a ação realizada não é a que se pretendia.

* Erros baseados em regras: ações que visam à intenção planejada, mas não atingem o resultado pretendido por má aplicação de uma regra ou planejamento inadequado.

镂 Erros baseados em conhecimento: ações não atingem o resultado pretendido por falta de conhecimento.

Para exemplificar como seria isso na prática de diagnóstico, o erro de um diagnóstico de um caso de hipertensão arterial sistêmica - doença muito prevalente e que os médicos entram em contato a todo tempo durante sua formação - seria baseado em habilidades, ou seja, viria a ser causado por um deslize. Já um erro de diagnóstico de uma rara síndrome clínica se dá por falta de conhecimento na maioria das vezes. Sendo assim, teríamos aquilo que está descrito no Quadro 1.

Quadro 1 - Tipos de erro humano

\begin{tabular}{|l|l|l|l|l|}
\hline Tipo de erro & Taxa de erro & $\begin{array}{l}\text { Nível de } \\
\text { Atenção }\end{array}$ & Familiaridade & Causa \\
\hline $\begin{array}{l}\text { Baseado em } \\
\text { conhecimento }\end{array}$ & $1: 2$ & +++ & + & $\begin{array}{l}\text { Modelo mental } \\
\text { sem acurácia }\end{array}$ \\
\hline Baseado em regra & $1: 1000$ & ++ & ++ & $\begin{array}{l}\text { Falha de } \\
\text { interpretação }\end{array}$ \\
\hline $\begin{array}{l}\text { Baseado em } \\
\text { habilidade }\end{array}$ & $1: 10.000$ & + & +++ & Desatenção \\
\hline
\end{tabular}

Fonte: Baseado em Reason (1990).

\section{Erros cognitivos}

O raciocínio clínico, que é a base para a formulação de hipóteses diagnósticas, exige muito do médico do ponto de vista de necessidade cognitiva. Isso significa que realizar um diagnóstico médico requer graus variados de memória, concentração, processamento e resolução de problemas. Agora, imaginemos um médico qualquer que atende diversos pacientes eventualmente em situação de grande volume e stress, como em um SEH. Não é incomum que os médicos estejam responsáveis por diversos pacientes ao longo do tempo, ou ao mesmo 
tempo, e esses pacientes apresentem diversas doenças e comorbidades diferentes, além de terem níveis de gravidade altamente distintos.

Ao levarmos em conta tais fatores, não é difícil imaginar que a realização de diagnósticos médicos se trata de uma atividade humana em que a necessidade cognitiva seja muito acima da média quando comparada com outras atividades. Também não é difícil imaginar que quanto maior a necessidade cognitiva de uma atividade, maior o potencial para ocorrer falhas, tendo em vista a precisão de alta performance de funções cerebrais superiores. Isso é ainda mais complexo se considerarmos um cenário propício ao erro cognitivo, ao qual o médico pode estar sujeito. Nesse cenário, podemos incluir aspectos como a sobrecarga de trabalho por excesso de pacientes, sendo acompanhados simultaneamente pela privação de sono por conta de plantões/turnos, a interrupção do trabalho por causa de intercorrências e chamados, entre outras coisas. Ou seja, se já não bastasse o risco inerente, dentro de um cenário inadequado de trabalho, o erro diagnóstico é potencializado na prática médica como observamos em muitos locais.

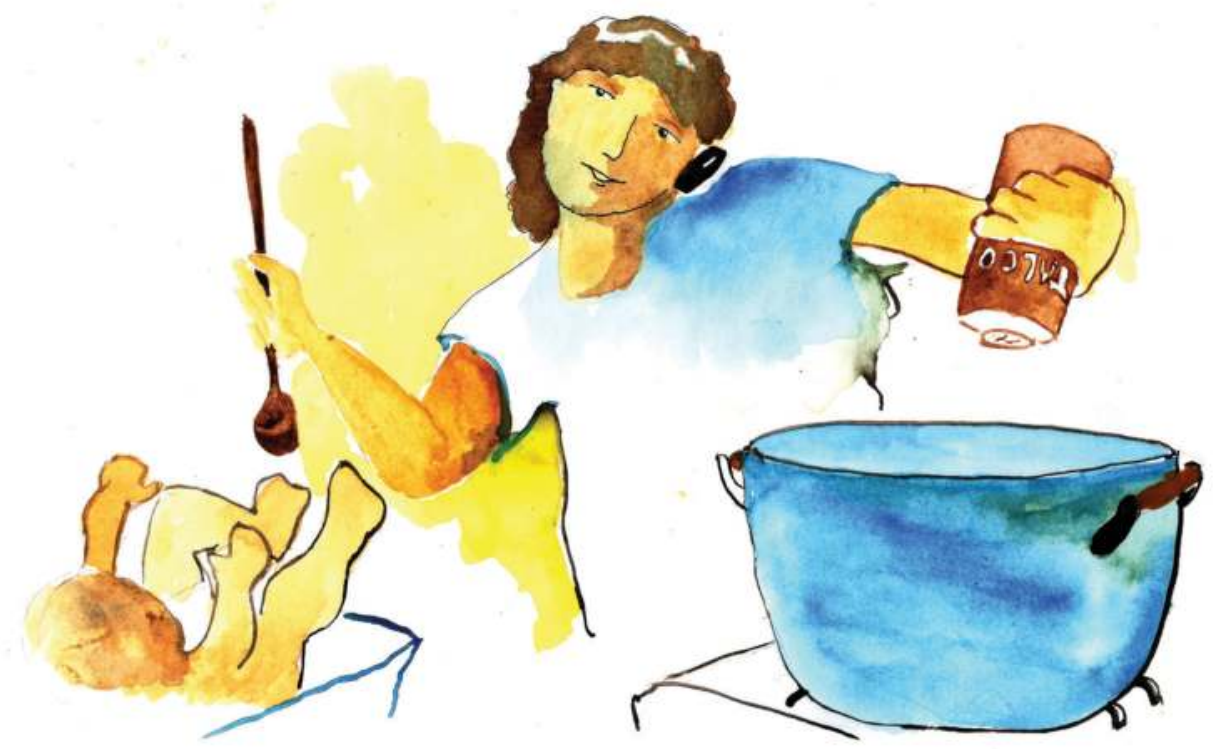

É importante ressaltar que os problemas de cognição estão envolvidos em toda situação de desempenho humano, desde em níveis básicos de habilidades até em desempenhos baseados em regras, e mesmo em um nível mais complexo da cognição - desempenhos baseados em conhecimento. A execução de uma habilidade motora bem treinada, por exemplo, intubação, requer pouco "consumo" cognitivo, pois considera aspectos visuais e de tato, os quais, com o tempo e treinamento, passam a ser realizados de forma automática. Um nível mais elevado de necessidade cognitiva é claramente imprescindível para desempenhos baseados em regras. 
Ainda assim, quando pensamos em algo mais complexo, como uma reanimação cardiopulmonar, que normalmente tem como base alguns algoritmos, a necessidade cognitiva não chega a ser excessiva. Entretanto, desempenhos cognitivos baseados em conhecimentos envolvem interpretação e compreensão de novas situações e problemas dentro de um contexto específico e, muitas vezes, único (Quadro 2). Tal fato é em particular verdade na medicina, em que cada indivíduo se apresenta clinicamente de determinada maneira, mesmo diante da mesma doença, quanto mais em situação de uma doença rara.

Podemos citar, por exemplo, o caso de um paciente com queixa de dispneia, em que o médico precisará integrar e interpretar a queixa atual, os antecedentes clínicos, o exame físico e resultados de exames, para então chegar a uma hipótese diagnóstica. Com o acúmulo/acumular de experiência, mais e mais comportamentos podem ser agrupados em níveis menores de necessidade de cognição. Nesse caso de dispneia, por exemplo, o médico com vasta experiência fará um diagnóstico de forma mais rápida e acurada, uma vez que muito do conhecimento acumulado já se tornou regra ou habilidade. Então, paradoxalmente, médicos mais novos ou recém-formados funcionam com desempenho baseado em conhecimento quase todo o tempo. Já médicos experientes ou experts em determinado assunto funcionam, a maior parte do tempo, com seu desempenho baseado em habilidades.

Falhas cognitivas no raciocínio clínico para formulação de diagnósticos podem ocorrer em qualquer nível de desempenho. Bastante interessante é que essas falhas de diagnóstico podem ser evitadas, mesmo quando ocorrem no mais alto nível de necessidade cognitiva, ou seja, no desempenho que depende de conhecimento. Portanto, os erros diagnósticos ocorrem com médicos considerados experientes ou com os mais novos, e não é difícil imaginar porque um médico mais novo está sujeito a um número maior de erros de diagnóstico. A incidência de falhas cognitivas aumenta sob condições de trabalho que pressionam o profissional, em condições de incerteza, especialmente quando se acelera ou se pressiona o raciocínio (por exemplo, em situação estressante de um paciente muito grave, em que se deve tomar uma conduta de maneira muito rápida), ou quando se usa algum "atalho ruim" no processo cognitivo (Gandhi et al. 2006). Uma vez que condições de trabalho influenciam diversas formas de erro, e não estão no escopo da atual discussão, e a variabilidade clínica dos pacientes não é algo controlável, devemos nos ater e entender os atalhos cognitivos aplicados ao diagnóstico médico. 
Quadro 2 - Necessidade cognitiva conforme atividade médica

\begin{tabular}{|l|l|l|}
\hline Nível & Necessidade cognitiva & Atividade \\
\hline \multirow{2}{*}{ Habilidade } & Baixa & Suturar feridas \\
\cline { 3 - 3 } & & Realizar intubação \\
\hline \multirow{2}{*}{ Regras } & Moderada & Decidir qual exame radiográfico fazer \\
\cline { 3 - 3 } & & Seguir um algoritmo do ACLS* \\
\hline \multirow{2}{*}{ Conhecimento } & Alta & Raciocínio diagnóstico \\
\cline { 3 - 3 } & & Decisões de conduta \\
\hline
\end{tabular}

Fonte: Baseado em Reason (1990) e Rasmussen (1983).

${ }^{*}$ ACLS - Suporte Avançado de Vida

\section{Atalhos cognitivos}

A área da psicologia vem, ao longo do tempo, tentando entender como funciona o raciocínio clínico. Tais estudos demonstram que até mesmo um médico muito bem preparado pode cometer alguma falha em circunstância de utilização de atalhos cognitivos. Portanto, entender como o médico realiza e firma uma hipótese diagnóstica é a base para compreender como erros de diagnóstico ocorrem, e o que fazer para evitá-los.

Em um estudo observacional sobre o raciocínio diagnóstico de um grupo de 12 médicos, Kassirer (1983) descobriu que os melhores faziam seu raciocínio com base no que ele denominou Teste de Hipótese Iterativa.

Vamos imaginar que um médico atenda a um caso de dor torácica, que se iniciou há poucas horas, em um senhor de 70 anos. Ele prontamente estabelece como hipóteses mais graves a serem descartadas um IAM/ EAM, tromboembolismo pulmonar (TEP) ou uma dissecção de aorta. Para chegar à conclusão de uma ou outra hipótese, o médico vai acrescentando peças, como esmiuçar as características da dor, como uma irradiação para membros superiores esquerdos para a hipótese de IAM/ EAM, ou uma dor pleurítica para a hipótese de TEP, ou dor irradiando para as costas no caso de uma dissecção. A seguir, ele pode pegar dados de exame físico como saturação, medidas de pressão arterial nos membros superiores e ausculta cardíaca. É possível que ele acrescente dados de exames complementares, como eletrocardiograma e radiografia de tórax.
Teste de Hipótese Iterativa significa que, para cada situação clínica, com base nos dados obtidos, o médico traça uma série de hipóteses diagnósticas e vai modificando sua opinião em favor de uma ou outra hipótese à medida que novas informações são introduzidas para sua análise. 


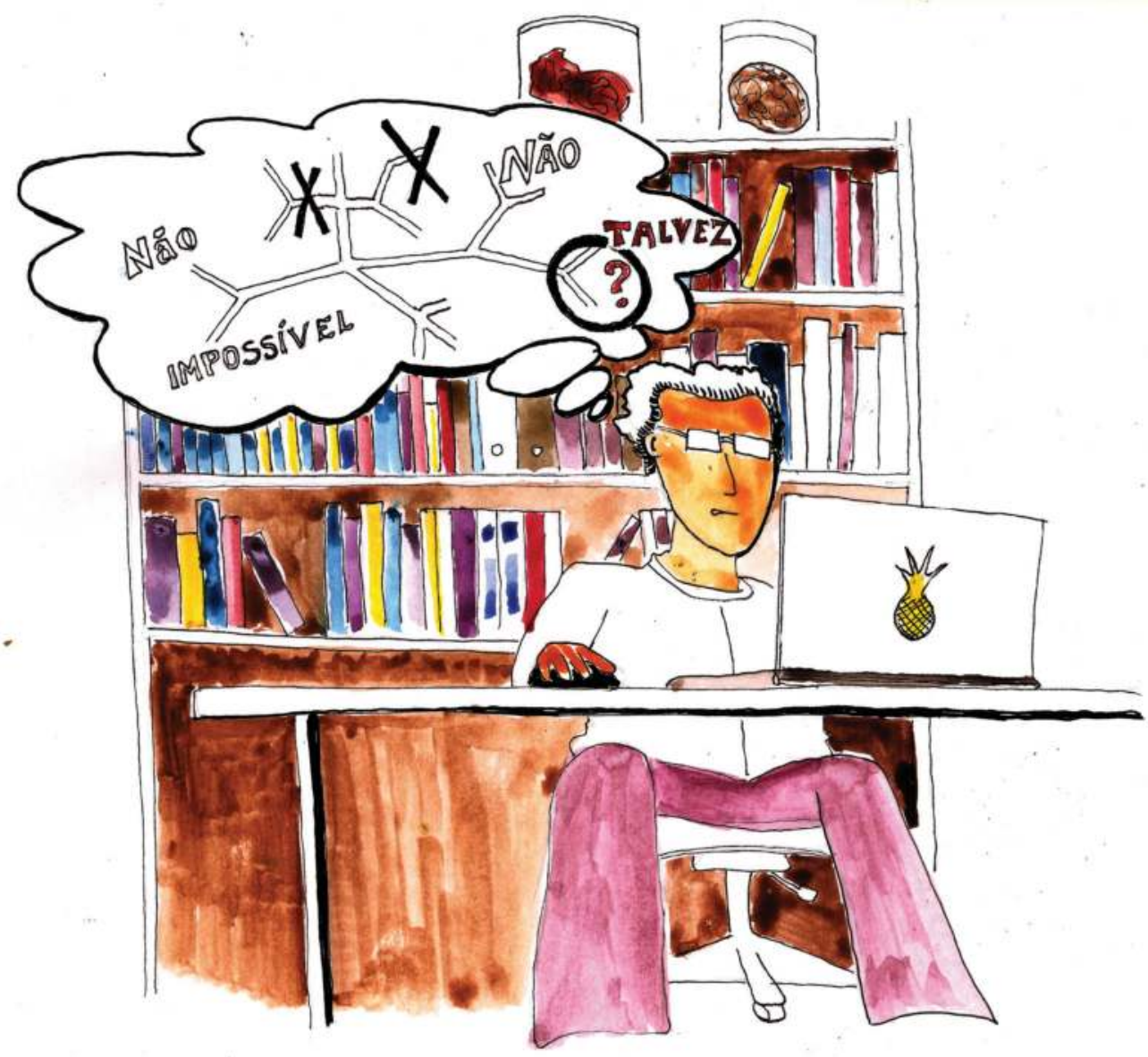

Para cada dado positivo ou negativo que o médico acha para cada uma das hipóteses formuladas, ocorre uma recalibração intuitiva em relação à probabilidade de cada hipótese. Por exemplo, se, nesse caso de dor torácica, ela apresentar característica pleurítica, e, no exame físico, os maiores achados forem hipoxemia e taquicardia, a hipótese que ficará mais forte será a de TEP em detrimento das demais. Quanto mais experiente for o médico, menos dados ele precisará para excluir ou reforçar uma hipótese diagnóstica. Os erros de diagnóstico surgem à medida que as hipóteses são mal formuladas ou se esquece de alguma hipótese diagnóstica, ou são poucos os conhecimentos para embasar a opção por um ou outro diagnóstico diante dos achados.

Essa prática é uma forma inconsciente traçada no processo cognitivo que reproduz, de certa forma, o Raciocínio Bayesiano, desenvolvido no século XVIII por Thomas Bayes (Kassirer 1983). Por esse raciocínio, todo teste médico deve ser interpretado por duas perspectivas: Quão acurado/ fiável é o teste? E qual é a chance de esse paciente ter a doença para a qual está se aplicando o teste? Ou seja, é saber com que frequência um 
teste fornece respostas corretas e se o médico está sabendo realizar a pergunta adequada para chegar ao diagnóstico.

Dentro do Raciocínio Bayesiano, seria algo sem sentido pedir um teste ergométrico para rastreamento de doença coronariana/coronária em paciente jovem sem fatores de risco para doença arterial aterosclerótica, porque, nessa situação, mesmo que o teste seja positivo, ele será um falso-positivo. Por outro lado, em paciente com dispneia aguda de origem não bem estabelecida, ao se realizar uma análise sérica do D-dímero, caso sejam encontrados valores altos, aumentará a probabilidade de que essa dispneia possa ser secundária a um TEP, o que orientará a prosseguir a investigação com um exame mais definitivo, como uma angiotomografia de tórax. Podem ocorrer falhas e erros de diagnóstico ao não se indicar corretamente um exame ou até mesmo uma manobra de exame físico.

Todo teste tem sua sensibilidade, especificidade, valor preditivo positivo e valor preditivo negativo. Conhecer essas relações influencia na escolha correta do exame e consequentemente na interpretação do resultado diante dos casos clínicos. Nas questões relacionadas a erros frente ao Raciocínio Bayesiano, vale muito a conhecida afirmação de Hans Selye, pesquisador/ investigador canadense/canadiano que formulou a seguinte frase: "Quem não sabe o que procura não entende o que encontra" (Selye 2013).

A heurística é outra estratégia de raciocínio que funciona como atalho cognitivo. O termo se refere a qualquer estratégia que economiza e abrevia o processo de pensar, algo que o ser humano faz em diversas situações. Essencialmente, uma heurística bem estabelecida é uma forma de atalho cognitivo para responder a determinada situação. Na maior parte das vezes, ela é muito útil para o médico que precisa ser eficiente, mas, ocasionalmente, ela pode levar ao erro. Dentro dos atalhos cognitivos da heurística é que reside a maior parte das explicações para os erros diagnósticos, como poderemos confirmar a seguir.

São incluídas pela heurística diversas formas de atalhos cognitivos, e podemos citar alguns exemplos como: representatividade, disponibilidade, ancoramento (ou fechamento prematuro), obediência cega, viés de confirmação e procura do mínimo necessário.

A representatividade é uma forma de avaliação de quão similar é determinado caso quando comparada à população em geral com uma doença. Por exemplo, pacientes que estão tendo um IAM/EAM irão classicamente se apresentar com uma dor retroesternal associada a esforços, que pode irradiar para o braço, ombro, pescoço ou mandíbula; e pode estar associada à náusea, diaforese e dispneia. Essa é a
Heurística se refere às estratégias simplificadoras na maneira de pensar, ocasionando economia de tempo e gasto cognitivo. Elas aumentam a eficiência em detrimento de aumentar a chance de erros cognitivos. 
dor chamada típica de angina de peito. Entretanto, alguns grupos de pacientes, em que incluímos mulheres, idosos, diabéticos e pacientes psiquiátricos, são mais propensos a se apresentar com dor torácica atípica. Quanto menos representativo é o quadro clínico do paciente para determinada hipótese diagnóstica, maiores as chances de ocorrer um erro. Pouca experiência ou falta de treinamento aumentam a chance de realizar um erro causado por esse atalho cognitivo. Infelizmente, a maior parte dos textos médicos tende a descrever uma "foto" que seja mais característica da doença, e, depois disso, os estudantes são treinados a procurar por quadros clínicos que se assemelhem a essa descrição, para só assim pensar no diagnóstico.

Já a disponibilidade se refere a outro aspecto. Quando estamos raciocinando e precisamos acessar nossas memórias, algumas delas serão mais disponíveis que outras. Por exemplo, se um médico viu um paciente recentemente com quadro raro de trombose venosa em sistema nervoso central que se apresentou com cefaleia, pode ser que, nos casos seguintes que ele avalie como cefaleia, pense mais vezes em fazer esse diagnóstico diferencial. Portanto, o médico pode ter grande tendência a procurar uma trombose de seio venoso no lugar de outros diagnósticos até mais frequentes, independentemente da apresentação clínica do paciente. A disponibilidade pode ser influenciada também por uma leitura recente ou apresentação de caso ou palestra.

A disponibilidade na memória de uma doença específica vai diminuindo conforme aumenta o intervalo de tempo desde o "encontro". Isso vale mais ainda se o médico nunca viu determinado quadro clínico. Há, também, a influência emocional dos casos. Por exemplo, se um médico teve uma experiência intensa, há dez anos, e errou o diagnóstico de IAM/EAM em um paciente jovem, a partir daí, ele pode ficar excessivamente cauteloso ao manejar casos de dor torácica, o que possibilita resultar em vieses que causarão má utilização de recursos. Então, a disponibilidade influencia o processo de decisão e é possível levar tanto a diagnósticos excessivos como a negligenciar algumas hipóteses por desconhecimento.

O ancoramento ou fechamento prematuro se dá quando um diagnóstico é fechado logo no início da avaliação clínica, e, mesmo que outros dados surjam com o tempo, essa hipótese diagnóstica formulada não é modificada. Isso em geral ocorre porque certos padrões de sinais e sintomas podem sugerir fortemente um diagnóstico em particular, que é assumido sem se levar em conta outras possibilidades diferenciais. Por exemplo, considere um paciente de 60 anos com história de litíase renal que se apresenta com dor lombar, náuseas e hematúria. 
O diagnóstico óbvio é de cólica renal, mas pode se deixar de diagnosticar um câncer/cancro de bexiga, uma glomerulonefrite ou outras doenças mais raras. O ancoramento é difícil de ser reconhecido; talvez, a única forma de se escapar dessa situação é quando novos olhos a enxergam, como ocorre em passagens de plantão/turno ou troca de setor em que o paciente está internado.

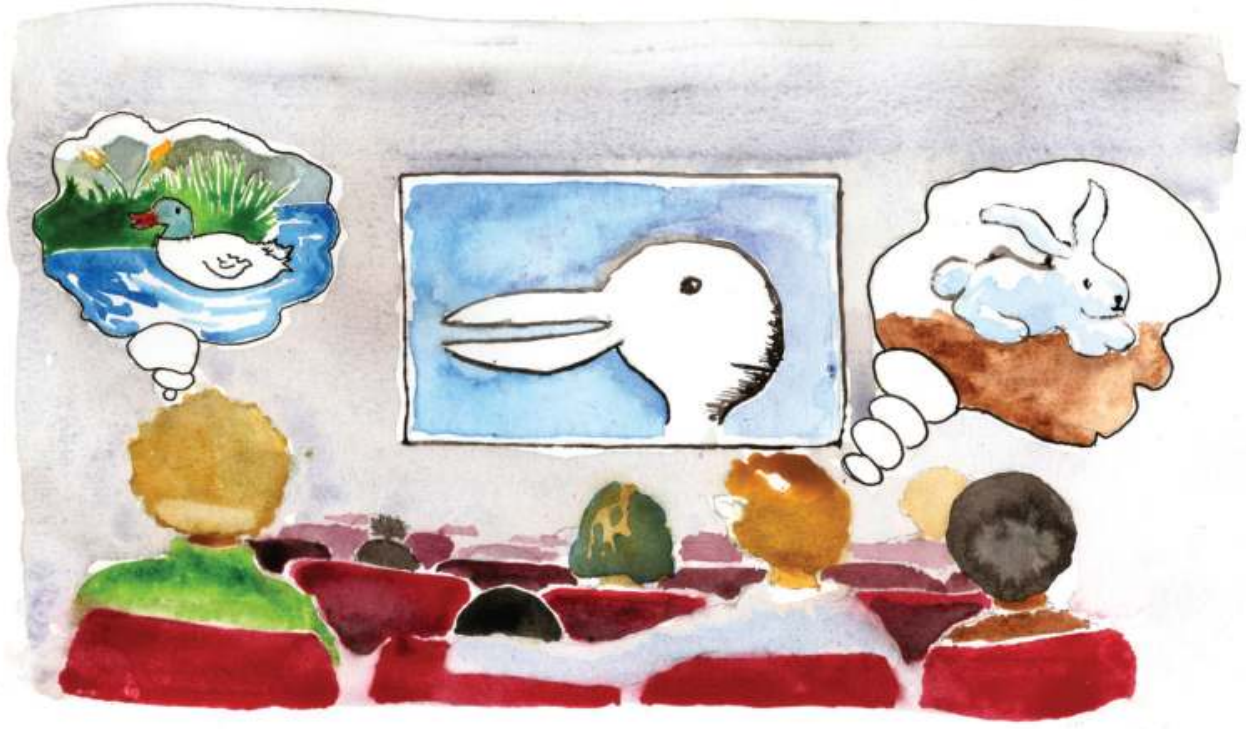

Muito similar ao ancoramento é a obediência cega, quando uma ordem superior ou um resultado de exame não são questionados, apesar de estarem possivelmente errados. Ordens superiores, muitas vezes, originam-se sem conhecimento adequado do caso clínico, por conta de, em diversas ocasiões, virem de pontos distantes da cadeia assistencial. Já os exames podem ter falsos positivos ou falsos negativos, e isso deve ser considerado. Por exemplo, uma hemocultura pode ser negativa e ainda assim o paciente apresentar infecção de corrente sanguínea, já que a sensibilidade da hemocultura não tem valores altos.

\section{Para refletir}

Você acredita que na organização em que trabalha ocorrem casos nos quais a hierarquia interfere ou pode vir a interferir nas análises de exames ou em diagnósticos?

A procura do mínimo necessário tem origem tanto na representatividade como no fechamento prematuro. Refere-se à tendência de se encerrar uma busca ao ser encontrada a primeira resposta, o que pode 
ser ilustrado pelas frequentes falhas em diagnosticar tuberculose em nosso meio. Quando o médico avalia o caso de um paciente com tosse e febre e conclui que se trata de pneumonia, não se aprofundando na história clínica, ele pode estar deixando de pensar e diagnosticar uma tuberculose pulmonar, por exemplo. Ao procurar pelo mínimo necessário, também se deixa de realizar diagnósticos sobrepostos ou hipóteses diagnósticas menos frequentes para determinado quadro clínico. Dessa forma, doenças mais raras são simplesmente subdiagnosticadas.

O viés de confirmação é a tendência de olhar para uma evidência ou informação que pode ser usada para ampliar certa hipótese já levantada, como procurar coisas que se encaixem em um diagnóstico. Isso também inclui a tendência de falhar em perceber evidências que podem contrapor uma visão já estabelecida. Considere um paciente se apresentando com cefaleia e febre, e o médico levanta a hipótese de sinusite aguda. Ao examinar o paciente, o médico encontra sinal de irritação meníngea quando averigua rigidez de nuca, mas atribui o sintoma à mialgia causada pela febre em vez de reconsiderar o diagnóstico e pensar em meningite. Trata-se de um viés de confirmação; o médico encontra um achado significativo, dentro do contexto de cefaleia com febre, em diagnóstico pré-formado de sinusite. Isso tende muito a ocorrer no sentido das doenças mais simples ou de mais fácil condução, porque o cérebro humano prefere respostas mais fáceis ao raciocínio formulado.

\section{Estratégias contra os erros diagnósticos}

É importante destacar que a origem dos erros diagnósticos é multifatorial. O processo diagnóstico, como visto anteriormente, é bastante complexo. Existem milhares de doenças descritas, e há milhares de exames complementares disponíveis. Apesar de podermos identificar uma gama de sintomas e queixas bem menor, o leque de possibilidades e interações entre queixas e exames, bem como sua interpretação, pode levar a conclusões distintas. Além disso, nunca podemos deixar de esquecer que a própria complexidade do sistema de saúde e dos processos de cuidado pode levar a erros diagnósticos. Podemos destacar aqui questões como a perda de informações em pontos de transição de cuidado, falta de coordenação, gargalos de acesso, má utilização de tecnologias ou mesmo indisponibilidade das mesmas, entre outras. E, além dos fatores sistêmicos, temos os vieses cognitivos, ponto crítico em um processo altamente dependente de cognição humana. 
A National Academies of Sciences, Engineering and Medicine dos EUA (2015) propõe que os seguintes pontos sejam abordados de forma a melhorar o processo diagnóstico e, consequentemente, diminuir os erros de diagnóstico:

* Promover trabalho em equipe mais efetivo no processo de diagnóstico, envolvendo profissionais de saúde, pacientes e suas famílias.

Melhorar a educação e o treinamento do profissional de saúde no processo de diagnóstico.

滕 Garantir que as tecnologias da informação em saúde apoiem pacientes e profissionais de saúde no processo de diagnóstico.

滕 Desenvolver e implementar abordagens para identificar, aprender com e reduzir erros diagnósticos e near misses na prática clínica.

Estabelecer um sistema de trabalho e uma cultura que apoie o processo de diagnóstico e melhorias no desempenho do diagnóstico.

繗 Desenvolver um ambiente propício para notificação de incidentes, e um sistema de responsabilidade médica que facilite um diagnóstico melhor, aprendendo com erros diagnósticos e near misses.

綞 Projetar um ambiente de remuneração e prestação de cuidados que apoie o processo de diagnóstico.

滕 Fornecer financiamento dedicado à pesquisa sobre o processo de diagnóstico e os erros diagnósticos.

Ao se pensar que, para que os erros diagnósticos ocorram, existe uma série de pontos relacionados acerca de como se estabelece o erro humano e quais são os erros cognitivos por trás disso, fica difícil imaginar estratégias para minimizar tais ocorrências. Entretanto, diante dessas considerações, qualquer estratégia ou instrumento que reduza o trabalho cognitivo e o tempo gasto no raciocínio irá reduzir a necessidade cognitiva e, portanto, pode impactar positivamente em menor ocorrência de erros diagnósticos.

Quanto às estratégias para minimizar os erros diagnósticos que podem ser aplicadas, de forma prática, em uma organização de saúde, devemos pensar na modificação de processos que podem induzir a erros. Um bom exemplo é quando as tarefas estão bem divididas dentro de uma equipe de saúde e o médico não precisa sobrepor suas atividades com aquelas que devem ser desempenhadas por outros profissionais, como enfermeiros, fisioterapeutas, ou até mesmo assistentes sociais. A criação de protocolos e diretrizes institucionais para determinados tipos de casos também ajuda muito. 

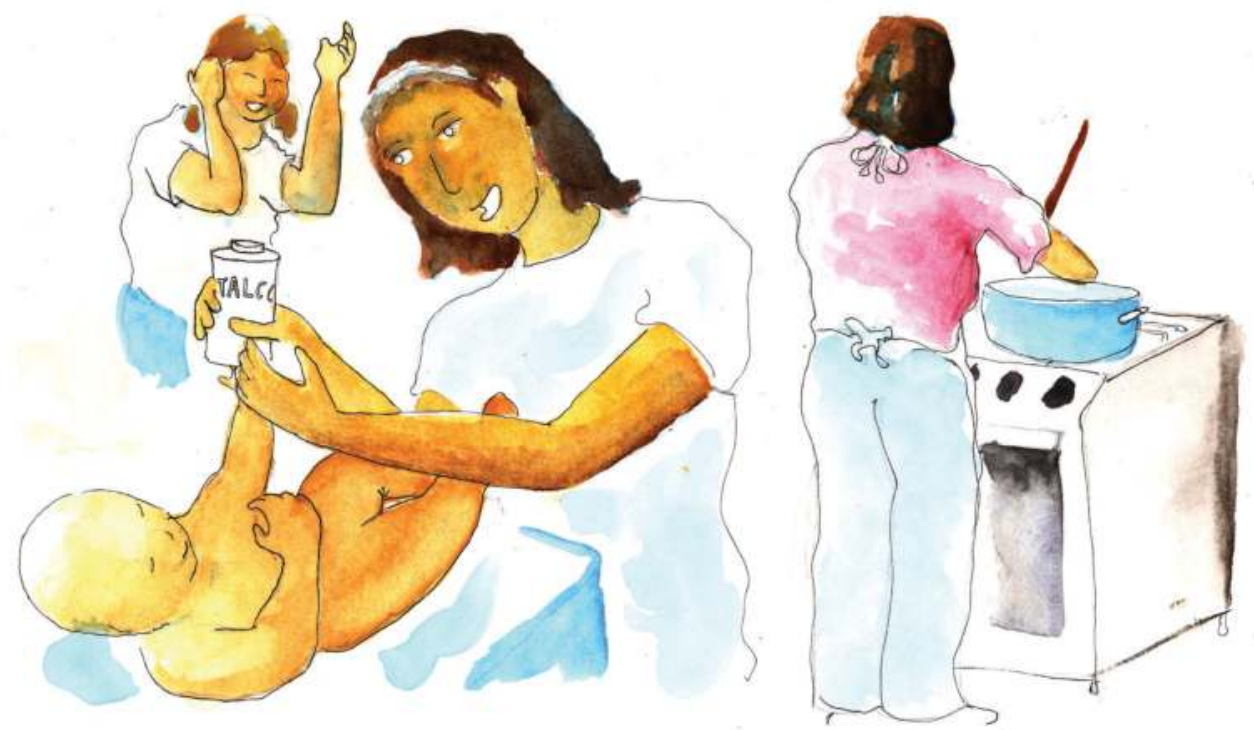

Por exemplo, um hospital pode ter protocolo de dor torácica que obrigue a realização de eletrocardiograma em qualquer paciente que chegue com tal queixa ao SEH, o que potencializa o médico encontrar uma síndrome coronariana aguda mesmo em um quadro de dor atípica. A utilização mais aberta de smartphones, tablets e dispositivos móveis com ferramentas de auxílio diagnóstico, como calculadoras médicas, também pode ser de muita utilidade, uma vez que diversos escores não são simples de serem lembrados, e é possível que a falta de acesso à informação faça com que o médico deixe de aplicar um teste que pode aumentar ou diminuir a probabilidade de um diagnóstico. Devemos lembrar que estamos entrando na era dos grandes bancos de dados e da inteligência artificial; então, cada vez mais estaremos próximos de soluções de altíssima tecnologia no apoio ao processo diagnóstico.

Ferramentas de apoio à decisão clínica já existem na forma de escalas ou algoritmos e precisam ser mais utilizadas pelos médicos (e isso pode estar acessível em prontuários eletrônicos, ou mesmo em ferramentas e aplicações de smartphones ou tablets). Um bom exemplo é a realização de alguma escala preditora para o diagnóstico de trombose venosa profunda (TVP), como Wells ou Geneva (Selye 2013), a fim de direcionar a realização de ultrassonografia com doppler, uma vez que não é possível se basear apenas no exame clínico para confirmar ou descartar o diagnóstico de TVP por sua acurácia ser extremamente baixa (Douma et al. 2011). Um processo de dupla verificação do diagnóstico do paciente periodicamente, seja a cada passagem de plantão/turno, seja a cada transferência de setor (handover), feito de forma sistemática, também pode causar grandes impactos positivos. 


\section{Para refletir}

Na organização em que você atua é comum o uso de protocolos ou escala preditora para diagnósticos? Existe algum tipo de incentivo para que sejam aplicados? Em caso negativo, você saberia dizer por quê?

A Agency for Healthcare Researchand Quality (AHRQ), em 2013, publicou um relatório sobre as evidências de práticas para segurança do paciente (Shekelle et al. 2013) e destaca que há exemplos de possíveis intervenções para reduzir erros diagnósticos:

䇎 Fatores relacionados ao paciente: ter pessoas que possam ser intérpretes de pacientes que falam línguas estrangeiras.

镂Fatores clínicos/humanos: as intervenções podem ser direcionadas de forma separada para erros de planejamento e erros de execução.

* Trabalho de equipe: devem ser feitas intervenções com foco em comunicação, coordenação, resolução de conflitos, carga de trabalho e treinamento.

Além disso, o documento propõe uma classificação para as intervenções focadas em erros diagnósticos em seis tipos:

\section{Técnica:}

Introdução de novas tecnologias para os testes, adptaçôes de equipamentos de testes, ou mudanças nas intervençōes médicas potencialmente afetando o desempenho de diagnóstico;

\section{Métodos Adicionais de Revisão:}

Introdução de passos adicionais desde a interpretação de exames até a disponibilização de relatórios de resultados;

\section{Mudanças de Pessoal:}

Introdução de membros de saúde adicionais e/ou substituição de certos profissionais por outros;

\section{Intervenções Educacionais:}

Implementaçăo de estratégias de ensino;

\section{Mudanças de Processo Estruturadas:}

Implementação de sistemas de feedback ou etapas adicionais no caminho de diagnóstico;

\section{Intervenções nos Sistemas Baseadas em Tecnologia:}

Implementação de ferramentas de base tecnológico em nível sistêmico como algoritmos de suporte à decisão, alertas de texto etc. 


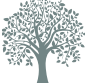

Para consolidar seus conhecimentos, sugerimos a leitura de Como os médicos pensam, de Jerome Groopman (Editora Agir 2008). Nesse livro, o assunto prevalente são os erros diagnósticos, e o autor, que é médico, exemplifica com casos próprios e de outros colegas médicos entrevistados por ele. Abordar casos e analisar raciocínios que levam os médicos a conclusões e diagnósticos brilhantes ou totalmente errados, assim o autor investiga diversos aspectos relacionados aos erros de diagnóstico na prática médica.
Ainda em 2013, foi realizada, por McDonald et al. (2013), uma revisão sistemática sobre estratégias direcionadas a erros diagnósticos. Incluíram-se estudos que avaliaram intervenções para diminuir os erros de diagnóstico em qualquer ambiente clínico, e qualquer desenho de estudo era elegível. No total, foram 109 estudos que abordavam uma ou mais categorias de intervenção contra erros diagnósticos: mudanças de pessoal $(n=6)$, intervenções educativas $(n=11)$, técnica $(n=$ 23), mudanças de processos estruturadas $(n=27)$, intervenções nos sistemas baseadas em tecnologia $(\mathrm{n}=32)$, e os métodos de análise (n = 38). Dos 14 estudos randomizados incluídos - classificados como tendo, em sua maioria, de baixo a moderado risco de viés -, 11 relataram intervenções que reduziram erros de diagnóstico. As evidências foram mais fortes para sistemas baseados em tecnologia (por exemplo, alerta de mensagem de texto) e técnicas específicas (por exemplo, testar as adaptações de equipamentos). Interessante que os estudos não forneceram informações sobre danos, custos ou aplicação contextual das intervenções, ou seja, não analisaram os resultados negativos que podem ser gerados. No geral, essa revisão sistemática demonstrou um campo crescente de pesquisa de erro de diagnóstico, além de identificar intervenções promissoras que merecem avaliações em grandes estudos para serem confirmadas como efetivas.

\section{Considerações finais}

Erros diagnósticos que levam a eventos adversos fazem parte de um grande contexto de segurança do paciente. Apesar de menos frequentes, seu impacto é grande, bem como sua evitabilidade. Sua origem ocorre dentro do contexto do erro humano, em que entram diversos erros cognitivos para os diferentes níveis de desempenho, seja em habilidades, regras ou conhecimento. O raciocínio clínico é um processo extremamente complexo, o que exige conhecimento e também experiência do médico; são utilizados atalhos cognitivos para ser eficiente, e em muitos deles residem os erros de diagnóstico. Traçar estratégias que minimizem o potencial de tais erros, sem, no entanto, tirar a autonomia médica e o julgamento clínico, é o cerne para solucionar essa categoria de erro.

\section{Referências}

Brennan TA, Leape LL, Laird NM, Hebert L, Localio R, Lawthers AG et al. Incidence of adverse events and negligence in hospitalized patients - results of the Harvard Medical Practice Study I. N Engl J Med. 1991;324(6):370-77.

Douma RA, Mos IC, Erkens PM, Nizet TA, Durian MF, Hovens MM, et al. Performance of 4 Clinical Decision Rules in the diagnostic management of acute pulmonary embolism: a prospective cohort study. Ann Intern Med. 2011 Jun 7;154(11):709-18. 
Dunn WF, Adams SC, Adams RW. Iatrogenic delirium and coma: a near miss. Chest 2008; 133:1217-20.

Gandhi TK, Kachalia A, Thomas EJ, et al. Missed and delayed diagnoses in the ambulatory setting: a study of closed malpractice claims. Ann Intern Med. 2006;145(7):488-96.

Goldman L, Sayson R, Robbins S, Cohn LH, Bettmann M, Weisberg M. The value of the autopsy in three medical eras. N Engl J Med. 1983; 308(17):1000-5.

Grant BJB. Diagnosis of suspected deep vein thrombosis of the lower extremity. [S.I.]: Uptodate; 2014 May [citado 2014 mar 17]. Disponível em: http://www.uptodate.com.

Institute for Quality and Efficiency in Health Care. Informed health online. Cologne, Germany: IQWiG; 2017 Apr 20 [citado 2017 abr 20]. What is overdiagnosis? Disponível em: https://www. ncbi.nlm.nih.gov/books/NBK430655/.

Kassirer JP. Teaching clinical medicine by iterative hypothesis testinglets preach what we practice. N Engl J Med. 1983;309:921-3.

Kirch W, Schafii C. Misdiagnosis at a university hospital in 4 medical eras. Medicine (Baltimore). 1996;75(1):29-40.

McDonald KM, Matesic B, Contopoulos-loannidis DG, et al. Patient safety strategies targeted at diagnostic errors: a systematic review. Ann Intern Med. 2013;158(5_Part_2):381-9.

National Academies of Sciences, Engineering, and Medicine. Improving diagnosis in health care. Washington, DC: National Academies Press; 2015.

Rasmussen J. Skills, rules, and knowledge: signals, signs, and symbols, and other distinctions in human performance models. IEEE Trans Syst Man Cybern. 1983 May/June;SMC-13(3):257-66.

Reason J. Human error. New York: Cambridge University Press; 1990.

Schiff GD, Hasan O, Kim S, et al. Diagnostic error in medicine: analysis of 583 physician-reported errors. Arch Intern Med. 2009;169(20):1881-87.

Selye H. Wikipedia; 2013 [citado 2013 nov 10]. Disponível em: http://pt.wikipedia.org/wiki/Hans_Selye.

Shekelle PG, Wachter RM, Pronovost PJ, Schoelles K, McDonald KM, Dy SM, et al. Making health care safer II: an updated critical analysis of the evidence for patient safety practices.. Rockville, MD: Agency for Healthcare Research and Quality, U.S. Department of Health and Human Services, 2013 Mar. (Comparative Effectiveness Review No. 211. AHRQ Publication No. 13-E001-EF). Disponível em: www.ahrq.gov/research/findings/evidence-based-reports/ptsafetyuptp.html.

Shojania KG, Burton EC, McDonald KM, Goldman L. Changes in rates of autopsy detected diagnostic errors over time. JAMA. 2003;289(21):2849-56.

Sonderegger-Iseli K, Burger S, Muntwyler J, Salomon F. Diagnostic erros in three medical eras: a necropsy study. Lancet. 2000; 355(9220):2027-31.

Vincent C. Patient safety. 2nd ed. London: Wiley Blackwell; 2010.

Wachter RM. Understanding patient safety. 2nd ed. New York: McGraw-Hill; 2012.

World Health Organization. The conceptual framework for the international classification for patient safety: technical report. Version 1.1. Geneva: WHO; 2009 Jan. [citado 2013 maio 3]. Disponível em: http://www.who.int/patientsafety/implementation/taxonomy/icps_technical_report_en.pdf.

Zwaan L, Bruijne M, Wagner C, et al. Patient record review of the incidence, consequences, and causes of diagnostic adverse events. Arch Intern Med. 2010;170(12):1015-21. 


\section{Erros relacionados ao laboratório}

Wilson Shcolnik

Neste capítulo, serão abordados: o processo laboratorial e a qualidade em laboratórios clínicos; os erros laboratoriais e a segurança do paciente; testes laboratoriais remotos; e os indicadores de segurança do paciente aplicados ao laboratório clínico. Não serão aqui consideradas especificidades de laboratórios de anatomia patológica.

\section{O papel do laboratório clínico na assistência à saúde}

A medicina laboratorial ou patologia clínica é a especialidade médica voltada para o uso racional do laboratório clínico no apoio ao cuidado integral à saúde. Em alguns países, além de médicos, os farmacêuticos-bioquímicos e os biomédicos podem dirigir laboratórios clínicos.

Os laboratórios clínicos desempenham papel essencial para o oferecimento de assistência à saúde de qualidade e baseada em evidências. Muitas decisões clínicas que ocorrem durante o processo de assistência à saúde são tomadas com base em informações contidas em resultados de exames laboratoriais. De forma tradicional, os principais objetivos de suas atividades são confirmar, estabelecer ou complementar o diagnóstico clínico. Secundariamente, os resultados laboratoriais podem fornecer elementos para o prognóstico de determinadas doenças, além de estabelecer critérios de normalidade e delinear fatores de risco evolutivos (Carraza, Andriolo 2000; Misbah et. al. 2013). Entretanto, é preciso considerar que os progressos obtidos com o sequenciamento do genoma humano abriram novas possibilidades para a medicina preditiva, o que tornou ainda mais promissor e relevante o papel dos laboratórios clínicos na prática médica no que tange a diagnósticos precoces e
Os aspectos relacionados aos serviços de hemoterapia e os aspectos transfusionais serão tratados no Capítulo 12, "Gestão do risco de quedas, úlceras por pressão e de incidentes relacionados com transfusão de sangue e hemoderivados", deste livro, Segurança do paciente: conhecendo os riscos nas organizações de saúde. 
identificação de pacientes que podem se beneficiar de novos fármacos, possibilitando a personalização da terapia, a atuação preventiva e individualizada (Kirsztajn 2010).

\section{Você sabia?}

Além dos riscos à saúde, mais de $30 \%$ dos erros laboratoriais estão associados a desconforto adicional ao paciente, realização de procedimentos invasivos desnecessários e aumento dos custos do cuidado de saúde (Plebani et al. 2006).

Pelo exposto, o sistema de saúde está crescentemente dependente de serviços laboratoriais confiáveis. No presente, estima-se que o laboratório clínico contribua com cerca de $70 \%$ dos dados utilizados pelos médicos para suas decisões, representando próximo a 5\% dos gastos do sistema de saúde (Forsman 1996; Lippi, Mattiuzzi 2013; Rohr et al. 2016).

A missão do laboratório clínico, sob uma ótica tradicional, é "fornecer resultados de exames precisos, em tempo hábil a baixo custo". Porém, segundo Epner (2013), isso hoje é insuficiente e deveria se considerar a missão de "propiciar um diagnóstico rápido e eficiente, a seleção de tratamentos apropriados e o monitoramento efetivo das condições de saúde."

O laboratório clínico, instalado de forma centralizada, ainda é o local em que a maioria dos exames é realizada, embora seja possível observar forte tendência de crescimento na utilização de testes laboratoriais remotos, também denominados "exames de beira de leito/cama" ou point-of-care tests (Poct). Tais exames merecem especial atenção, pois, dependendo das condições de utilização, podem colocar em risco a segurança do paciente.

\section{Para refletir}

Como são feitos os testes laboratoriais em sua organização:

centralizados ou de forma remota?

Você identifica riscos à segurança dos pacientes em relação (ou em função) aos (dos) locais em que os exames são realizados?

\section{O processo laboratorial e a qualidade em laboratórios clínicos}

Em consequência da grande evolução científica e tecnológica observada nas últimas décadas, aumentou também a complexidade da prática 
laboratorial que ocorre em um ambiente em que coexistem procedimentos, equipamentos, tecnologia e conhecimento humano, tornando possível a ocorrência de erros laboratoriais. Os poucos estudos existentes sobre as consequências dos erros laboratoriais revelam que, felizmente, há baixa frequência de eventos adversos ocasionados por falhas no processo laboratorial. Entretanto, informações laboratoriais erradas, além de eventos adversos, podem afetar de forma direta os resultados da assistência à saúde (Shcolnik 2012).

\section{O processo laboratorial}

O processo laboratorial pode ser apresentado de forma didática como constituído em três fases, demonstradas na Figura 1:

1. pré-analítica;

2. analítica; e

3. pós-analítica.

Figura 1 - O processo laboratorial

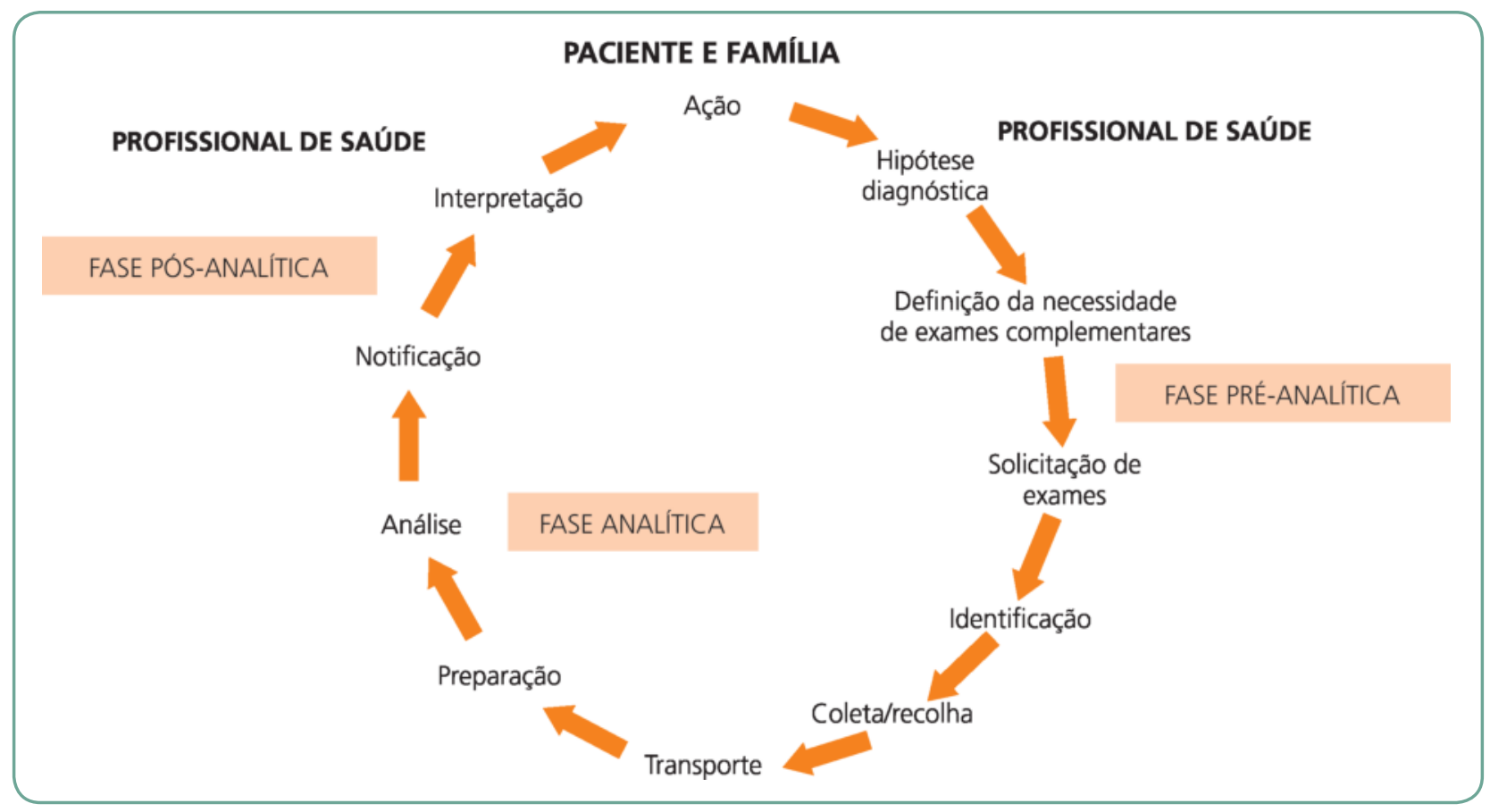

Fonte: Adaptado de ISO/TR 22869:2005 (ISO 2005).

A fase pré-analítica se inicia na solicitação do exame, sucedida pelo preparo adequado para o exame e identificação do paciente, coleta/ recolha, transporte e preparação da amostra a ser analisada. A fase analítica propriamente dita é realizada por meio de instrumentos e reagentes no interior do laboratório. 
A fase pós-analítica é constituída da emissão e transmissão/comunicação do resultado do exame e interpretação do responsável pela assistência.

A seguir, veremos que, atualmente, a maior frequência de erros ocorre nas fases pré e pós-analíticas.

\section{A qualidade no laboratório clínico}

A preocupação dos laboratórios clínicos com a qualidade, sempre associada à padronização e monitoramento de desempenho dos seus processos, vem de longa data. Inicialmente, a maior atenção foi com a qualidade analítica, que deu margem à organização de programas de controle interno e externo da qualidade, hoje denominados "ensaios de proficiência".

O controle interno da qualidade permite aos laboratórios avaliar a precisão das suas análises e detectar erros analíticos antes de liberar os resultados dos exames. Isso ocorre graças à utilização e análise de amostras-controle (soros/sangues/urinas-controle), cujos resultados são conhecidos previamente e devem ser comparados aos encontrados pelos laboratórios clínicos. Caso isso não ocorra, o laboratório clínico terá de necessariamente reavaliar seu sistema analítico antes de proceder às análises de amostras de seus clientes. Já os ensaios de proficiência são realizados por meio da análise de materiais de controle desconhecidos e servem para os laboratórios avaliarem a exatidão dos resultados obtidos pela comparabilidade laboratorial, garantindo a confiabilidade/ fiabilidade analítica.

Para refletir

O laboratório que atende à sua organização de saúde realiza diariamente o controle interno da qualidade e participa de forma ativa de programa de Controle Externo da Qualidade (ensaio de proficiência) para garantir a precisão e exatidão das análises? Se não o faz, qual a justificativa? Você acredita ser viável implementar essas ações?

Em muitos países, a utilização de programas de controle da qualidade é obrigatória, e as legislações não se restringem a reduzir o risco sanitário, incluindo também a realização de atividades relacionadas à gestão da qualidade.

Além de normas para funcionamento, os laboratórios dispõem de sistemas de qualidade e programas de acreditação que, com seus requisi- 
tos ou padrões específicos, podem garantir a boa prática laboratorial e permitir que a qualidade dos serviços seja mantida, o que agrega valor ao resultado final da assistência. No Brasil, existem normas específicas para acreditação laboratorial. No âmbito da ISO, a norma 15189:2012 apresenta requisitos para qualidade e competência em laboratórios clínicos que têm sido incorporados a normas de acreditação. A norma 15189:2012 vem sendo utilizada de forma crescente em alguns países da Europa e outros continentes. Segundo o Instituto Português de Acreditação (Ipac), a norma ISO 15189:2012 é aplicada exclusivamente aos laboratórios clínicos; no entanto, eles podem também optar pela norma ISO/IEC 17025, também aplicada a outros tipos de laboratórios.

A utilização de indicadores de desempenho para avaliar a qualidade do processo laboratorial tem sido crescente. Alguns desses indicadores são relacionados à segurança do paciente e serão tratados adiante.

\section{Erros laboratoriais}

Segundo a ISO 22367:2008, um erro laboratorial pode ser definido como

falha na realização de ação, de acordo com o planejado ou a intenção, ou uso de um plano errado para atingir um objetivo, podendo ocorrer em qualquer etapa do processo laboratorial, desde a requisição do exame até o reporte do resultado, incluindo a sua interpretação ou reação diante do seu recebimento.

A maioria dos erros durante a assistencia à saude, sobretudo em hospitais, referem-se aos relacionados à medicação e a eventos cirúrgicos. Recentemente, pesquisas têm demonstrado que os erros diagnósticos são frequentes. A inadequada solicitação de exames (sub ou superutilização), assim como erros ocorridos no decorrer das fases do processo laboratorial podem levar a incidentes, inclusive com lesão - os eventos adversos. A comunicação de valores críticos, encontrados em resultados de análises laboratoriais, em tempo hábil pode salvar vidas e evitar eventos adversos (Plebani 2009).

\section{Você sabia?}

Resultados críticos "são resultados de exames que geram a necessidade de intervenção ou tomada de decisão imediata pelo médico assistente, por poderem representar risco para a vida do paciente. Por isso, devem ser comunicados pelo laboratório o mais rápido possível" (Lundberg 1990, p. 709).
Essa definição de erro tem conformidade com a definição explicitada no Capítulo 4 deste livro. 
Os erros laboratoriais e suas características estão bem estudados, e dados colhidos entre 1990 e 1997 demonstram que as taxas de erros analíticos decresceram de 162.116 para 447 por milhão de testes realizados. Isso se deve à ampla difusão de automação, tecnologia da informação, padronização de técnicas e utilização de regras de controle de qualidade bem definidas, além de investimentos em capacitação de profissionais de laboratório. Mas, mesmo com os avanços conseguidos e, apesar da evolução tecnológica, assim como em outras áreas da medicina, sempre é preciso considerar que as "maravilhas tecnológicas" têm criado uma expectativa de perfeição no setor laboratorial, não se pode esquecer, porém, que elas, inevitavelmente, introduzirão consigo novas formas de erros (Leappe, Berwick 2000; Wu, 2000).

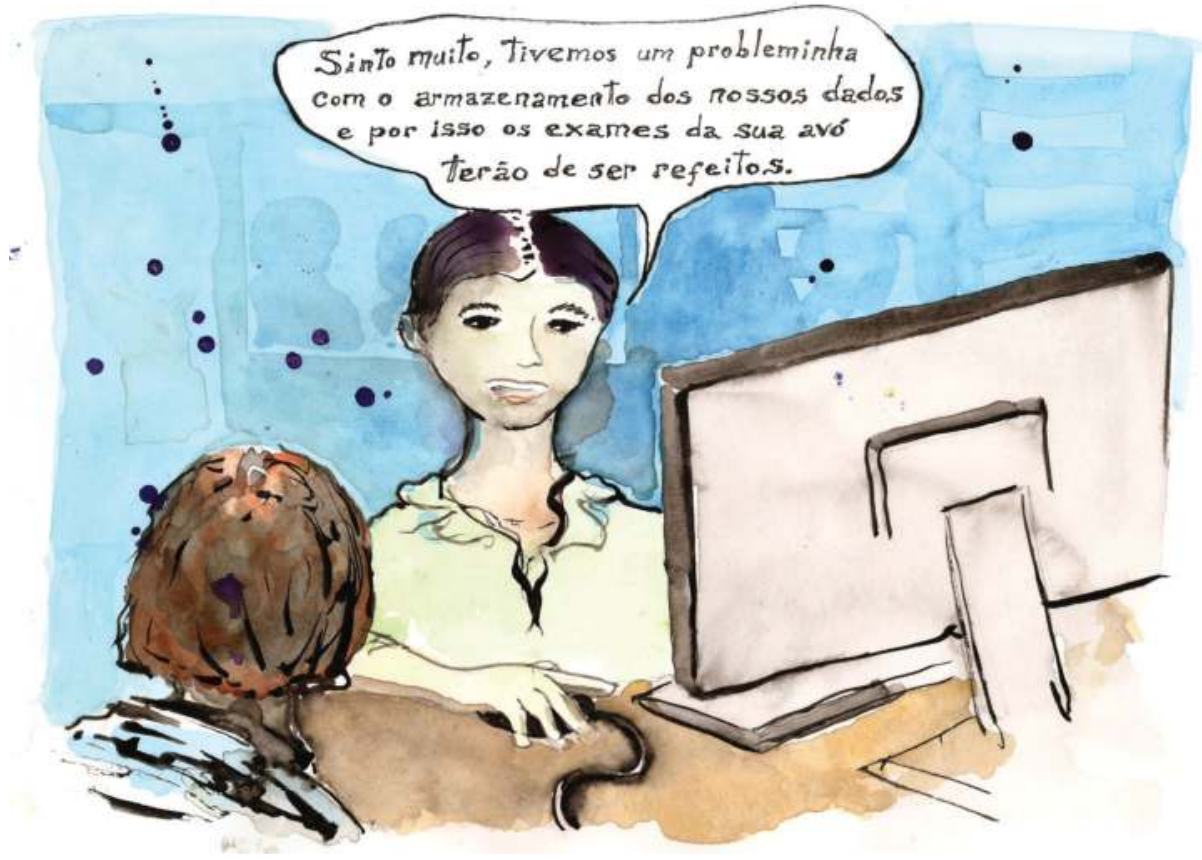

Admiráveis avanços obtidos na tecnologia de instrumentos analíticos, automação e ciência da computação simplificaram muitas tarefas laboratoriais consideradas repetitivas e enfadonhas (Lippi et al 2006). Por meio de tais avanços e com o desenvolvimento e implementação exitosa de elevados padrões de qualidade, os erros na fase analítica não representam mais o principal fator de preocupação. Atualmente, os principais problemas laboratoriais derivam da indisponibilidade de especificações da qualidade para a fase extra-analítica (pré e pós-analíticas) e são consensualmente aceitos (Plebani 2011, 2013; Wallin et al. 2008). 
Você sabia?

Cerca de $75 \%$ de erros laboratoriais produzem resultados de exames dentro dos intervalos de referência; $12,5 \%$ produzem resultados errados tão absurdos que levam à desconsideração clínica; e 12,5\% restantes podem gerar algum efeito sobre a saúde do paciente (Goldschmidt 1995).

Estudos realizados em laboratório de emergência demonstraram que, no intervalo de dez anos, as distribuições de erros em relação às fases do processo laboratorial não se modificaram, sendo $62-68 \%$ na fase pré-analítica; 13-15\% na fase analítica; e 18-23\% na fase pós-analítica (Carraro, Plebani 2007; Plebani, Carraro 1997).

Por muitos anos, melhorias na segurança da fase pós-analítica foram obtidas por meio da ampla utilização de automação e transferência eletrônica de resultados (Walz, Darcy 2013). Mas, com o advindo dos registros eletrônicos em saúde e considerando o enorme número de dados fornecidos pelos laboratórios clínicos, muitos deles críticos para a segurança do paciente, o novo desafio que se apresenta é a transformação desses dados em informações úteis, assegurando que resultados confiáveis e de fácil interpretação sejam enviados, recebidos e bem interpretados pelos que são responsáveis pela assistência do paciente.

O laboratório clínico, tal como outros ambientes de trabalho existentes no setor de saúde, é um sistema complexo, no qual interagem dinamicamente pessoas, tecnologia e rotinas organizacionais, e, como todas as outras partes do sistema, suscetível a erros (Carraro, Plebani 2007).

Quadro 1 - Tipos de erros encontrados durante as fases do processo laboratorial

\begin{tabular}{|c|c|}
\hline $\begin{array}{l}\text { Fases do processo } \\
\text { laboratorial }\end{array}$ & Tipos de erros encontrados \\
\hline Pré-analíticos & $\begin{array}{l}\text { Erro no preenchimento do tubo de coleta/recolha } \\
\text { Tubo de coleta/recolha com material insuficiente } \\
\text { Tubo de coleta/recolha ou recipiente impróprios } \\
\text { Amostra não preservada durante o transporte ou pré-análise } \\
\text { Extravio de tubo contendo amostra } \\
\text { Erro na identificação do paciente } \\
\text { Erro no procedimento de solicitação de exames }\end{array}$ \\
\hline
\end{tabular}


Quadro 1 - Tipos de erros encontrados durante as fases do processo laboratorial (cont.)

\begin{tabular}{|l|l|}
\hline $\begin{array}{l}\text { Fases do processo } \\
\text { laboratorial }\end{array}$ & Tipos de erros encontrados \\
\hline Pré-analíticos & $\begin{array}{l}\text { Conflitos na comunicação de dados } \\
\text { Falta de requisição médica ou incorreção da informação diagnóstica } \\
\text { Incompreensão ou má interpretação da requisição médica } \\
\text { Incorreção do cadastramento do paciente/exame no sistema de } \\
\text { informática laboratorial } \\
\text { Preparo inadequado do paciente } \\
\text { Horário de coleta/recolha incorreto }\end{array}$ \\
\hline Analíticos & $\begin{array}{l}\text { Erros aleatórios inerentes aos sistemas analíticos ou causados por } \\
\text { problemas nos instrumentos analíticos } \\
\text { Inexatidão do sistema analítico }\end{array}$ \\
\hline Pós-analíticos & $\begin{array}{l}\text { Liberação de resultados apesar de desaconselhado pelo controle da } \\
\text { qualidade } \\
\text { Atraso na liberação de resultados (TAT) } \\
\text { Erros de digitação, de transcrição e outros semelhantes } \\
\text { Erros nos laudos e na comunicação de resultados ao solicitante } \\
\text { Laudos ambíguos, indefinidos ou de difícil compreensão } \\
\text { Demora/atrasos na liberação de resultados }\end{array}$ \\
\hline
\end{tabular}

Fonte: Elaboração do autor.

\section{Eventos adversos}

Existem dois obstáculos para o estudo dos eventos adversos relacionados a erros laboratoriais: o primeiro é que a maioria dos laboratórios clínicos não coleta/recolhe dados sobre o resultado da assistência consequente aos erros laboratoriais, e o segundo é o desafio prático de detectar o número relativamente baixo de eventos adversos relacionados a erros laboratoriais entre o enorme número de exames realizados (Yuan et al. 2004).

Ao considerar as definições de evento adverso pela Organização Mundial da Saúde (OMS), nota-se que é baixa a frequência de incidentes com danos aos pacientes (Shcolnik, Mendes 2013). Os diversos autores que estudaram a relação dos erros laboratoriais e o dano ao paciente empregaram vários termos, mas é possível observar a preocupação com incidentes que não atingiram o paciente ou não produziram dano.

Astion considerou "evento adverso real" o "dano ao paciente, causado durante a assistência e não pelo processo de doença, que resultou em incapacidade ou prolongamento da internação/internamento hospitalar" (Astion 2003). "Evento adverso potencial" foi definido por esse autor como 
erro ou incidente que não produziu dano, mas que tem claro potencial para produzir. Podem ter sido interceptados antes de produzir dano ou alcançado o paciente, sem causar dano. Estas definições permitiram diferenciar o incidente com lesão do incidente sem lesão ou o incidente que não atinge o paciente (near miss) (Astion 2003; Weingart et al. 2001).

Outro autor, O'Kane (2008), considerou importante e desejável que os sistemas de análise de notificações de incidentes nas organizações de saúde não meçam apenas eventos adversos reais, mas, também, eventos adversos potenciais, graduando sua gravidade, pois eles podem auxiliar na priorização de ações corretivas e na monitorização do desempenho geral do laboratório clínico. Um incidente pode nem sempre afetar o paciente e ocasionar um evento adverso real, mas o incidente que não atinge o paciente (near miss) pode representar um evento adverso potencial que contribui para identificar a fragilidade de sistemas, os quais podem, no futuro, levar a um evento adverso evitável (O'Kane et al. 2008).

Uma revisão sistemática, realizada em 2012, revelou que as proporções dos eventos adversos e os impactos clínicos evidenciados nos estudos variaram conforme a (Shcolnik 2012):

繗 definição utilizada por diferentes autores;

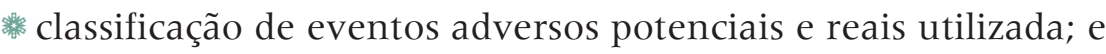

䠌 graduação de eventos adversos, em função de sua gravidade.

Os resultados dessa revisão podem ser encontrados na Tabela 1 .

Tabela 1 - Eventos adversos, impactos clínicos e evitabilidade descritos nos estudos, por autor e ano de publicação

\begin{tabular}{l|l} 
Autor/ Ano & Resultados dos estudos \\
\hline Nutting 1996 & $\begin{array}{l}27 \% \text { incidentes com impacto na assistência à saúde. } \\
\text { Impacto na assistência à saúde: coleta/recolha; erro no resultado do exame citológico preventivo para câncer/ } \\
\text { cancro de colo de útero; erro na determinação do tempo de protrombina; resultado falso-negativo de } \\
\text { sorologia para HIV; falso-positivo para gravidez; atraso na liberação de resultado de potássio; falso-negativo de } \\
\text { cultura de urina; atraso na liberação de resultado de cultura de fezes; internação/internamento desnecessária. }\end{array}$ \\
\hline Plebani1997 & $\begin{array}{l}26 \% \text { incidentes com efeitos no desfecho do paciente. Em 19\%, houve necessidade de investigação adicional; } \\
6,4 \% \text { levaram à assistência inapropriada ou modificação da terapêutica. } \\
\text { Efeitos no desfecho do paciente: necessidade de investigação adicional ou assistência inapropriada ou } \\
\text { modificação terapêutica, que resultaram em aumento injustificável de custos; transfusão inapropriada; } \\
\text { modificação na infusão de heparina; infusão de solução de eletrólitos inapropriada; modificação inapropriada } \\
\text { de terapia com digoxina. }\end{array}$ \\
\hline CDC 2001 & $\begin{array}{l}\text { A partir da investigação dos dois óbitos, verificou-se que todos os 2.146 exames revistos continham erros de } \\
\text { cálculo. }\end{array}$ \\
\hline
\end{tabular}


Tabela 1 - Eventos adversos, impactos clínicos e evitabilidade descritos nos estudos, por autor e ano de publicação (cont.)

\begin{tabular}{l|l} 
Autorl Ano & Resultados dos estudos \\
Weingart 2001 & $\begin{array}{l}\text { Não foram observados eventos adversos (EAs) associados a erro laboratorial. } \\
48 \text { Eventos Adversos Potenciais (EPA) }(54,5 \% \text { do total de incidentes e } 4,9 \% \text { das internações/internamentos). } \\
\text { Erro laboratorial foi origem de oito EPAs (16,7\% do total de EPAs, ou } 9 \% \text { do total de incidentes). } \\
\text { Evento Adverso Potencial: atrasos na liberação do resultado do exame, dificuldades na alta hospitalar. }\end{array}$
\end{tabular}

Astion 2003

EAs - 6 casos (5,4\%); EPA - 122 casos (95\%); EPA + EA 1 caso (1\%): atraso nos resultados dos exames (110 casos - 85\%). Recoleta/recolha (51 casos - 40\%); dano relacionado à flebotomia (7 casos - 5\%).

EA: atraso de resultados, recoleta/recolha, liberação de resultados incorretos a médicos; dano relacionado à flebotomia.

EPAs: atraso em dosagem de tireoglobulina; reidentificação de amostra hospitalar depois de perda de identificação; questionamentos por médicos de baixos valores de hemoglobina e hematócrito com recoleta/ recolha e obtenção de resultados dentro de valores de referência; entrega de resultados de exames urgentes de coagulação em duas horas em uma unidade de tratamento intensivo; demora de três dias para recebimento de resultado de hemocultura positiva (Klebsiellapneumoniae) em paciente submetido à diálise, ocasionando falta de tratamento durante dois dias e tratamento errado durante um dia.

94 incidentes evitáveis.

Yuan 2005

$301(62,7 \%)$ dos resultados corrigidos não foram considerados com impacto clínico significativo.

154 casos (32,1\%) indicados para entrevista com médicos: 32 (6,7\%) casos de resultados corrigidos foram associados a impacto clínico adverso; 19 (54\%) casos de atraso terapêutico; 8 (25\%) casos de terapêutica medicamentosa imprópria; 1 (3,1\%) procedimento ou exame invasivo desnecessário; $5(15,6 \%)$ casos de morbidade/morbilidade transitória (menos de uma semana); 1 (3,1\%) morbidade/morbilidade (mais de uma semana); 4 (12,5\%) aumentos no nível da assistência.

EAs: atraso na terapia medicamentosa; terapia medicamentosa imprópria ou desnecessária; procedimento ou exame invasivo desnecessário; morbidade/morbilidade transitória; elevação no nível da assistência.

Evitabilidade em 28 casos (87,5\%).

Carraro 2007

121 erros $(75,6 \%)$ não tiveram efeito nos pacientes, enquanto $39(24,4 \%)$ tiveram impacto negativo na assistência.

Desfecho no paciente: admissão na UTI 1 caso (0,6\% do total de incidentes); transfusão desnecessária 2 casos (1,3\%); investigação adicional 9 casos (5,6\%); repetição de exames 27 casos $(16,9 \%)$.

Evitabilidade em $73,1 \%$ dos casos.

Natividad 2007

614 resultados corrigidos, 97 (15,8\%) foram considerados positivos (atenderam um ou mais critérios de rastreamento), e 517 (84,2\%) foram negativos quanto ao rastreamento. Dos 97 resultados corrigidos, $8(8,2 \%)$ foram associados a impactos clínicos adversos.

Impacto clínico adverso: 5 casos envolvendo elevação do nível de assistência; 2 casos com tratamentos desnecessários; 1 caso com tratamento não ministrado; e 1 caso com atraso no tratamento

Evitabilidade - 59 (60,8\%) evitáveis; 27 (27,8\%) inevitáveis e 11 (11,3\%) indeterminados. 
Tabela 1 - Eventos adversos, impactos clínicos e evitabilidade descritos nos estudos, por autor e ano de publicação (cont.)

\begin{tabular}{l|l} 
Autor/ Ano & $\begin{array}{l}\text { Resultados dos estudos } \\
\text { O'Kane } 2008\end{array}$ \\
$\begin{array}{l}\text { Correlação entre grau de gravidade e falhas da qualidade reais e potenciais: } \\
\text { Grau de gravidade } 1 \text { (menor) } \rightarrow \text { Falhas Reais } 72,7 \% \text { e Falhas Potenciais } 0,3 \% ; \\
\text { Grau de gravidade } 2 \rightarrow \text { Falhas Reais } 6,9 \% \text { e Falhas potenciais 11,6\%; } \\
\text { Grau gravidade } 3 \rightarrow \text { Falhas Reais } 20,8 \% \text { e Falhas Potenciais 15,9\%; } \\
\text { Grau gravidade } 4 \rightarrow \text { Falhas Reais } 0 \% \text { e Falhas Potenciais } 6,2 \% ; \\
\text { Grau gravidade } 5 \text { (maior) } \rightarrow \text { Falhas Reais } 0 \% \text { e Falhas Potenciais } 66 \% .\end{array}$ \\
\hline
\end{tabular}

Fonte: Shcolnik (2012).

Os autores dos estudos selecionados na revisão de literatura, relacionados na Tabela 1, empregaram conceitos diversos para as consequências no cuidado ao paciente em razão do erro de laboratório. Essas consequências foram: desde nenhuma influência na assistência, até a recoleta/recolha de amostras, repetições de exames, atrasos na liberação de resultados de exames, influência no diagnóstico e/ou tratamento, tratamentos impróprios e/ou desnecessários, realização de investigação adicional desnecessária, internação/internamento em unidade de terapia intensiva, danos decorrentes da flebotomia e óbitos.

Excetuando-se os óbitos e a morbidade/morbilidade transitória ou elevação no nível da assistência que, segundo a taxonomia da OMS (WHO 2009), devem ser classificados como eventos adversos, os demais eventos descritos mereceriam investigação mais detalhada, o que permitiria considerá-los "incidente sem dano" ou mesmo um incidente que não atinge o paciente (near miss) (Shcolnik, Mendes 2013).

Cabe destacar que a ocorrência de duas mortes em 2001, em um hospital da Pensilvânia, ocorreu em consequência de erro laboratorial durante o cálculo errado do índice internacional normalizado (INR), executados em 2.146 exames de avaliação do tempo de protrombina. Esse exame é relacionado ao monitoramento do uso de medicamento anticoagulante oral, e os resultados errados notificados ocasionaram modificação nas doses e sangramentos em dois pacientes que faleceram.

Os estudos selecionados confirmam a baixa frequência de eventos adversos decorrentes de erros laboratoriais, o que, é possível, ocorre em virtude de barreiras existentes ao longo e externamente ao processo laboratorial (Lippi et al. 2010; Plebani 2009, 2010). Mas, mesmo considerando a baixa frequência dos eventos adversos, a investigação de incidentes associados aos erros laboratoriais deve continuar a ser estimulada, visto que, além dos danos aos pacientes, podem trazer outros impactos e prejuízos ao sistema de saúde. 

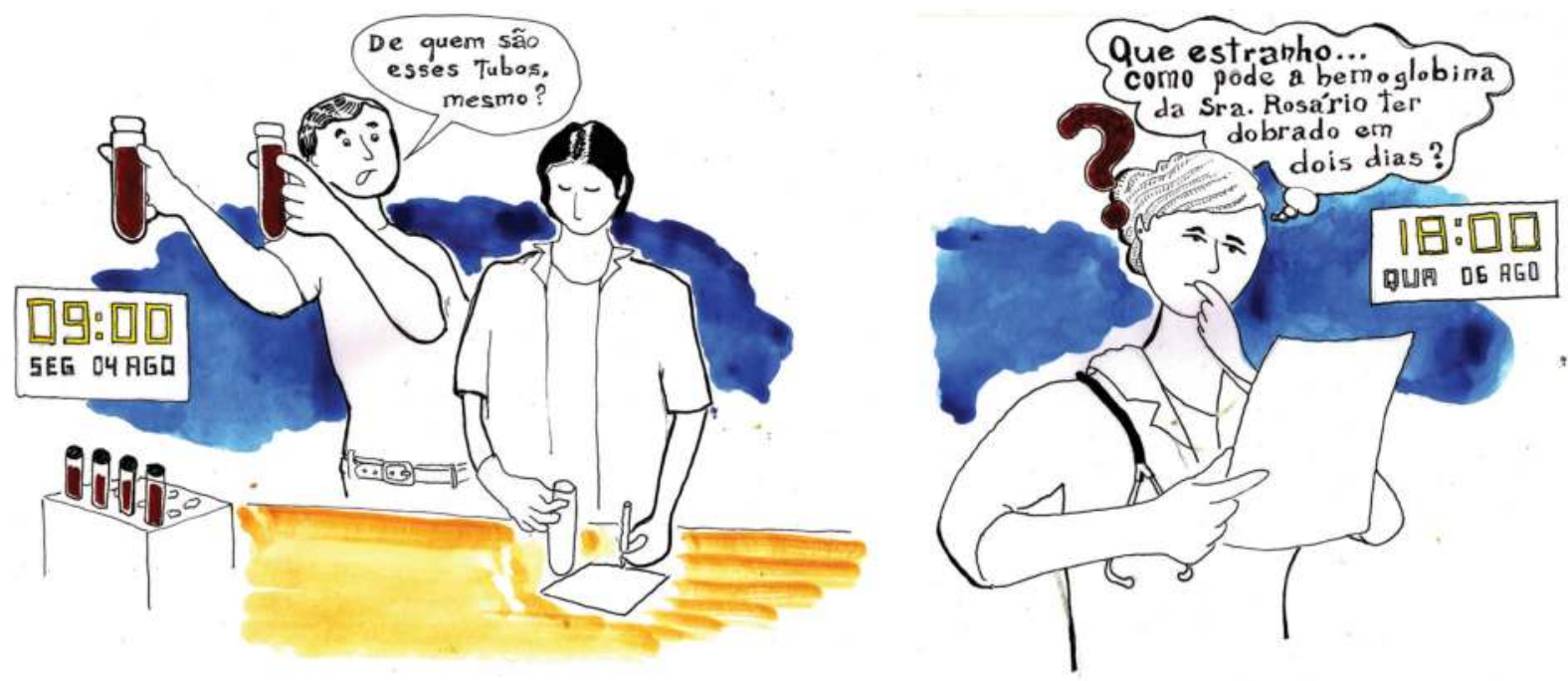

Novas investigações com o objetivo de aumentar o conhecimento acerca dos impactos dos erros laboratoriais na segurança do paciente devem adequar os conceitos sobre eventos adversos reais e potenciais, assim como sua gravidade, à classificação internacional sobre segurança dos pacientes da OMS (Shcolnik, Mendes 2013).

Os vários participantes da cadeia de assistência à saúde, a fim de tornar a assistência mais segura, devem trabalhar conjunta e coordenadamente para identificar e corrigir as condições inseguras existentes, e todo incidente deve ser reportado e investigado independentemente da sua frequência. Com base nessas afirmações, o Fórum Nacional da Qualidade, nos Estados Unidos, em 2011, incluiu em sua lista dois eventos relacionados a laboratório clínico que devem ser comunicados e investigados:

* morte ou dano resultante de perda ou substituição irreparável de amostra biológica;

dano resultante de falha no follow up ou comunicação de resultados de exames laboratoriais e radiológicos (National Quality Forum 2011).

Para refletir

Como são identificados e geridos os erros no laboratório da sua organização de saúde? 


\section{Como prevenir erros laboratoriais e eventos adversos?}

Conforme demonstrado na Tabela 1, vários autores apontam para o alto grau de evitabilidade de ocorrência de erros laboratoriais, o que justifica investimentos em gerenciamento de riscos com o objetivo de identificar e reduzir erros laboratoriais, bem como a ocorrência de eventos adversos deles originados.

As ferramentas da qualidade disponíveis para a avaliação de risco, redução das não conformidades, erros e eventos adversos que podem ser aplicadas ao ambiente laboratorial, são:

蹸 padronização e treinamento;

晋 análises de causa raiz;

諩 análise de Pareto;

跻 brainstorming;

踏 diagrama de Ishikawa;

橉 cinco porquês;

*ailure Mode and Effect Analysis;

路 outras, como acreditação e benchmarking.

Laboratórios que voluntariamente submetem-se a processos de acreditação laboratorial já são estimulados a identificar, registrar e buscar as origens de quaisquer falhas continuamente, o que possibilita definir ações corretivas eficazes. Da mesma forma, também são estimulados a agir de forma proativa, implementando ações preventivas para falhas possíveis, mas que ainda não tenham se manifestado (Mendes 2006).

Quando se procede à análise de causa raiz dos erros laboratoriais, grande quantidade desses erros pode ser atribuída a fatores humanos. Entretanto, algumas vezes, os erros laboratoriais são causados por deficiências ou falhas nos sistemas analíticos usados na realização dos exames, aí incluídos reagentes, equipamentos ou instrumentos utilizados na determinação de estado de saúde (Stankovic, Romeu 2007).

Recomenda-se que a abordagem da equipe do laboratório para a discussão de erros laboratoriais e eventos adversos deles decorrentes seja feita de modo a lembrar a inevitabilidade do erro humano. É importante considerar que os problemas certamente já existem, antes mesmo de se falar de forma aberta sobre eles, e devem ser buscados problemas "latentes" (sistêmicos), e não apenas erros "ativos", mais facilmente identificados.
Benchmarking: padrão de comparação; padrão de excelência (http://proqualis.net/glossario). 


\section{Do erro laboratorial ao gerenciamento de riscos}

Gerenciamento de riscos pode ser definido como

a aplicação sistemática de políticas, procedimentos e práticas relacionadas à análise, avaliação, controle e monitoramento de riscos. Sistemas de monitoramento e notificação de erros atuam como sistemas de vigilância úteis para preservar a segurança do paciente, pois identificam erros que podem se traduzir em eventos adversos (Plebani 2007).

Estratégias de gerenciamento de riscos, integradas à rotina diária já têm sido propostas, reduzindo o foco na identificação do erro laboratorial e movendo-o para a predição de incidentes, aumento e diversificação das defesas (barreiras), acarretando a redução da vulnerabilidade dos processos.

Segundo a norma ISO 22367:2008, Laboratórios Clínicos: redução dos erros através do gerenciamento de riscos e melhoria contínua, a identificação de erros ou incidentes deve ser realizada por meio de:

revisōes de auditorias internas;

relatórios de notificaçōes de incidentes;

oportunidades de melhoria; $\mathrm{e}$

de processos prospectivos de análise de riscos.

As informações sobre a ocorrência de eventos adversos ocasionados por erros laboratoriais também podem ser obtidas principalmente pelos registros de:

\section{resultados atrasados;}

resultados retificados;

resultados críticos (pânico) não comunicados; e

queixas ou reclamações. 
A norma recomenda que todos os erros laboratoriais devem ser classificados e investigados, pois isso determinará as intervenções mais indicadas. A classificação deve abranger, mas não se restringir a (Astion 2003):

\section{responsavilidade do erro;}

fase do processo laboratorial em que o erro ocorreu;

tipo de erro - cognitivo ou não cognitivo, sistêmico

ou ativo;

evitabilidade; e

impactos na assistência e nos pacientes.

A avaliação dos impactos no desfecho clínico e a existência de eventos adversos é essencial, pois, com base nessas informações, será possível:

conectar a equipe do laboratório aos pacientes;

determinar a ordem de prioridades das intervenções;

criar sentimento de urgência na organização; e

obter dados valiosos para auxiliar na obtenção de recursos.

A participação de médicos e equipes extralaboratoriais na investigação de eventos adversos decorrentes de erros laboratoriais é de fundamental importância, pois eles detêm informações nem sempre disponíveis às equipes laboratoriais, o que lhes permite obter dados sobre o impacto dos incidentes, os quais, dificilmente, seriam conhecidos pela equipe do laboratório (Yuan et al. 2005).

Para refletir

Em seu serviço, diante da ocorrência de incidentes provenientes de erros laboratoriais, os médicos são consultados para obtenção de impactos na assistência? 
Segundo o Colégio Americano de Patologistas, para assegurar a segurança do paciente, o laboratório clínico deve se preocupar com a redução de erros ao longo de todo o processo laboratorial, com foco nas fases pré e pós-analítica, considerando que a fase analítica está sendo amparada pelos programas de controle de qualidade.

\section{Testes laboratoriais remotos Point-of-care tests (Poct)}

Podemos definir os testes laboratoriais remotos como

amostras analisadas próximo ao paciente, assumindo-se que os resultados são liberados instantaneamente ou num curto intervalo de tempo, de modo a prover dados aos responsáveis pela assistência, que lhes permitirão imediato diagnóstico ou intervenção clínica (Ehrmeyer, Laessig, Ronald 2007, p. 766).

Esses testes são empregados frequentemente por membros da equipe de saúde, em especial nos serviços de emergência. São exemplos desses testes: detecção de nível de glicose sanguínea por glicosímetros, detecção de antígenos ou anticorpos relacionados a agentes infecciosos, analisadores de gases sanguíneos e eletrólitos, marcadores de doenças cardíacas, dosagem de fatores da coagulação, urinálise, entre outros.

Os testes laboratoriais remotos representam ferramenta valiosa para redução do tempo de entrega de resultados (TAT), particularmente no monitoramento de variáveis metabólicas com rápida cinética, tornando a informação disponível em minutos após a coleta/recolha do material biológico, evitando desperdício de tempo e risco de anormalidades nas condições de transporte das amostras a serem analisadas (Plebani 2007). Entretanto, é necessária a validação dos benefícios clínicos e operacionais dessa ferramenta considerando que as especificações analíticas para os Poct devem ser as mesmas que as usadas para as análises em laboratório. A liberação instantânea dos resultados, quando não são seguidas as recomendações ou boas práticas de execução desses exames, somada à possibilidade de uma rápida intervenção ou decisão médica, podem representar riscos à segurança dos pacientes (Plebani 2007).

Quanto mais testes laboratoriais remotos são realizados por médicos, enfermeiras e outros membros da equipe de saúde, mais salvaguardas são necessárias a fim de prevenir erros e reduzir riscos de eventos adversos (Kost 2001). Entre as iniciativas para garantir a segurança desse procedimento está a conectividade bidirecional entre o local em que esses exames são realizados, com sistemas de informação laboratorial, utilizados pelo laboratório central, a quem deve caber o gerenciamento desses procedimentos, e também com o prontuário 
médico/processo clínico do paciente. Devem ser assegurados ainda a validação dos dispositivos utilizados, a capacitação periódica de operadores e o controle de qualidade das análises realizadas.

No Brasil, a RDC 302/2005, da Anvisa, dispõe que a execução dos Poct e de testes rápidos deve estar vinculada a um laboratório clínico, posto de coleta/recolha ou serviço de saúde pública ambulatorial ou hospitalar, sendo o responsável técnico pelo laboratório clínico responsável por todos os Poct realizados dentro da organização, ou em qualquer local, incluindo, entre outros, atendimentos em hospital-dia, domicílios e coleta/recolha laboratorial em unidade móvel.

A Sociedade Brasileira de Patologia Clínica/Medicina Laboratorial (SBPC/ML) publicou, em 2013, a Diretriz para a Gestão e Garantia da Qualidade de Testes Laboratoriais Remotos e a norma do Programa de Acreditação de Laboratórios Clínicos da SBPC/ML. Tais documentos abordam o assunto. Em Portugal, os Poct designam-se de Dispositivos médicos para diagnóstico in vitro (DMDIV). O Decreto-Lei n. 189, de 12 de agosto de 2000, que transpõe a diretiva 98/79/CE define o que são DMDIV. A autoridade competente que assegura a implementação das diretivas comunitárias em Portugal é o Infarmed. Também é essa entidade que tem o dever de certificar que os DMDIV cumprem os requisitos legais para segurança do paciente.

Figura 2 - Testes rápidos

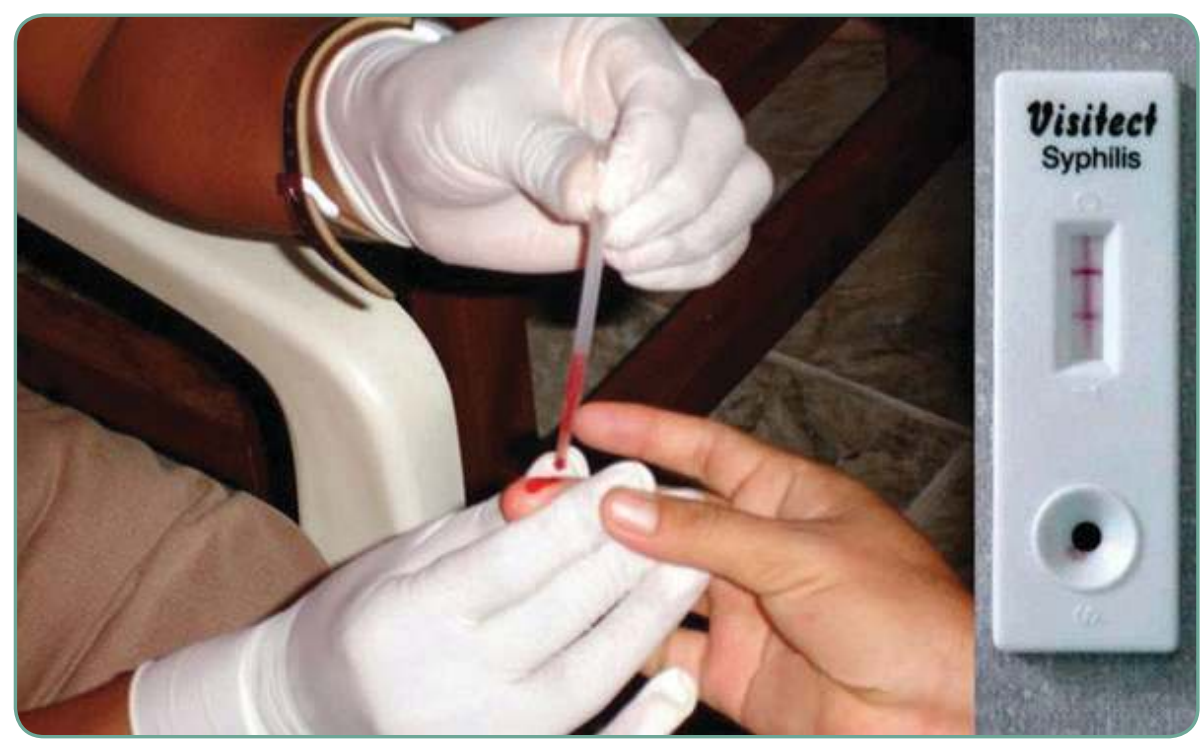

Fonte: Wikimedia Commons (2013).

Existem testes rápidos qualitativos e semiquantitativos úteis na detecção de antígenos ou de anticorpos ligados a vários agentes infecciosos (por exemplo, para diagnóstico de infecção por HIV), ou ligados a marcadores laboratoriais relacionados à doenças (por exemplo, marcadores de doença coronariana/coronária aguda). 
Não se pode desconsiderar o risco de erros decorrentes do aumento na disponibilização de resultados sob a forma de smartphones, tablets e portais. Surge, então, a necessidade de assegurar que os resultados de exames postados em registros eletrônicos de saúde sejam corretamente recebidos e interpretados por responsáveis pela assistência à saúde (Walz, Darcy 2013). Outra preocupação que merece a atenção de laboratórios está relacionada às transições de alto risco durante a assistência, como a alta hospitalar com pendência de resultados de exames, que precisam ser monitoradas e incorporadas em processos e monitoramento da qualidade.

\section{Indicadores de segurança do paciente aplicados ao laboratório clínico}

Indicadores de qualidade representam ferramenta essencial, pois permite aos gestores e à equipe laboratorial avaliar sua qualidade, possibilitando comparações com base em critérios pré-definidos. Um indicador de qualidade pode ser definido como "medida objetiva que avalia domínios críticos da assistência, baseado em evidências associadas a esses domínios, que podem ser implementados de forma consistente e comparável entre diferentes cenários, e ao longo do tempo" (IOM 2000).

O uso de indicadores, no decorrer de um período, permite identificar, corrigir e monitorar defeitos continuamente em busca de melhor desempenho, bem como assegurar a segurança do paciente por meio de intervenções efetivas. Para avaliar os serviços laboratoriais, é preciso utilizar um conjunto de indicadores relacionados a todas as fases do processo laboratorial, com foco em áreas com impacto direto no paciente e nos desfechos da assistência à saúde (Plebani et al 2013).

Entre os indicadores de qualidade propostos para serem usados em laboratórios clínicos, podemos encontrar alguns relacionados à segurança do paciente.

No Brasil, por iniciativa da Sociedade Brasileira de Patologia Clínica, em 2005, foi criado o Programa Indicadores Laboratoriais para possibilitar o benchmarking de aspectos analíticos, gerenciais e mercadológicos. Com essas iniciativas, a comunidade laboratorial brasileira passou a contar com mais uma ferramenta de gestão da qualidade de nível mundial. No programa brasileiro, entre os indicadores relacionados à segurança do paciente, é possível encontrar as taxas de: 
繙 atraso na entrega de resultados;

路 insucesso na comunicação de resultados considerados críticos;

赫 laudos retificados;

* contaminação de hemoculturas;

滕 contaminação de uroculturas e

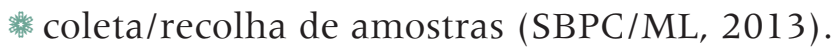

Para refletir

O laboratório que atua em seu local de trabalho investiga as consequências dos erros laboratoriais detectados e sua relação com os desfechos clínicos? De que maneira essa investigação é feita? Qual tem sido a aplicabilidade dos dados coletados, caso existam?

Outra experiência interessante está em curso na Austrália e na Nova Zelândia por meio do projeto Sistemas de Monitoramento e Gerenciamento de Incidentes Chave (Key Incident Monitoring $\theta$ Management Systems - KIMMS), que permite aos laboratórios o registro do conjunto de incidentes-chave e erros que podem ocorrer durante o ciclo de processos laboratoriais, o que permite benchmarking entre pares. O estímulo para intensificar a atenção, com vistas à redução de erros e ao aumento da segurança do paciente, está entre os objetivos desse projeto.

Algumas tentativas de padronização de indicadores têm sido propostas para avaliar a qualidade dos serviços laboratoriais (Signori et al. 2007; Sciacovelli et al. 2011). Resultados de estudo realizado pelo grupo de trabalho vinculado à International Federation of Clinical Chemistry demonstraram que um sistema de indicadores da qualidade, gerenciado da mesma maneira que um programa de controle externo da qualidade, usualmente utilizado em laboratórios clínicos, pode servir como ferramenta para monitorar e controlar os processos laboratoriais e permitir a identificação de riscos que levam a erros e danos aos pacientes (Sciacovelli et al. 2011).

Em uma revisão de literatura realizada sobre indicadores laboratoriais, consideraram que alguns deles são relacionados à qualidade e à segurança do paciente. Exemplos desses indicadores estão apresentados no Quadro 2. É interessante notar que, nesse estudo, não se considerou o indicador de atraso no reporte de resultados de exames como um indicador relacionado à segurança (Shahangian, Snyder 2009). 
Quadro 2 - Indicadores laboratoriais relacionados à segurança do paciente

Erros na identificação de pacientes (pulseira de código de barras)

Taxa de rejeição de amostras inadequadas para exames

Taxa de contaminação de hemoculturas

Taxa de informações erradas na identificação do recipiente de amostras

Taxa de desempenho em ensaios de proficiência

Taxa de resultados de exames corrigidos (retificados)

Taxa de sucesso na comunicação de valores críticos

Taxa de disponibilidade de resultados de exames laboratoriais de pacientes hospitalizados em horários de visitas e discussões matinais (rounds)

Tempo médio para comunicação de resultados críticos

Tempo de liberação de resultados (TAT) - turn around time

Taxa de exatidão de transmissão de resultados por meio de interfaces e em reportes em papel

\section{Exames laboratoriais e erros diagnósticos}

Uma pesquisa realizada em 2017, nos Estados Unidos da América (EUA), revelou que $21 \%$ dos adultos entrevistados relataram experiência pessoal com erro no cuidado de saúde, culminando frequentemente com impactos emocionais, físicos, financeiros e nas relações familiares dos pacientes. O atendimento ambulatorial foi apontado como o ambiente mais frequente de ocorrência, e os erros relacionados ao diagnóstico e à comunicação entre provedores e pacientes foram os mais comuns entre os entrevistados que relataram tal experiência. Problemas não diagnosticados, diagnósticos incorretos ou atrasados foram relatados por 59\% dos entrevistados que apontaram erros no cuidado de saúde (NORC at the University of Chicago, IHI/NPSF Lucian Leape Institute 2017).

O Capítulo 10, "A segurança do paciente e o diagnóstico", deste livro, Segurança do paciente: conhecendo os riscos nas organizações de saúde, aborda de maneira aprofundada o processo diagnóstico e seus impactos na segurança do paciente.
O relatório "Melhorando o Diagnóstico no Cuidado de Saúde" (Improving Diagnosis in Health Care), publicado pela National Academies of Sciences, Engineering and Medicine, em 2015, representou uma sequência da série sobre o "Abismo da Qualidade" (Crossing the Quality Chasm) e abordou um tema que havia recebido pouca atenção até então, mas que representa um aspecto crítico do cuidado de saúde, o processo diagnóstico.

O paciente foi colocado no centro da solução do erro diagnóstico, que foi definido como "falha em (a) estabelecer uma explicação precisa e oportuna para o(s) problema(s) de saúde do paciente ou (b) comunicar 
essa explicação ao paciente" (National Academies of Sciences, Engineering and Medicine 2015).

Segundo o relatório, os adultos norte-americanos experimentarão, ao menos, um (1) erro diagnóstico ao longo de sua vida, algumas vezes com consequências devastadoras. Estimativas conservadoras apontam que $5 \%$ de adultos que buscam assistência ambulatorial experimentarão um erro diagnóstico, a metade com possibilidade de danos. Estudos post-mortem, realizados ao longo de décadas, revelaram que os erros diagnósticos contribuíram para aproximadamente 10\% das mortes. A revisão de prontuários médicos sugere que os erros diagnósticos contribuem para 6-17\%) dos eventos adversos ocorridos em pacientes hospitalizados, sendo a principal causa de indenização em ações judiciais por má prática. Singh et al. (2017), entretanto, questionaram se esses números poderiam ser replicados para outros países, já que nos EUA, ao contrário de muitos países, o sistema de saúde é mais integrado, há acesso a prontuários eletrônicos, o que contribui para a definição de diagnósticos.

Considerou-se, nas conclusões do referido relatório, que o sistema de trabalho e a cultura existentes no cuidado de saúde não favorecem o processo de diagnóstico, que é tido como resultante de um esforço colaborativo e envolve cooperação entre membros de uma mesma equipe e entre diferentes profissionais, podendo ocorrer em consequência a erro humano ou a erro sistêmico.

Segundo Epner et al. (2013), erros diagnósticos relacionados a exames laboratoriais podem ocorrer quando:

\section{um exame inapropriado é solicitado;}

um exame inapropriado não é solicitado;

um resultado de exame apropriado é mal utilizado;

um exame apropriado é solicitado, mas uma demora ocorre no processo laboratorial;

um resultado de exame apropriadamente solicitado está errado (é inexato). 
Para relembrar as recomendações do referido relatório para a melhoria do processo diagnóstico e consequente diminuição dos erros de diagnóstico, leia o Capítulo 10, "A segurança do paciente e o diagnóstico", deste livro, Segurança do paciente: conhecendo os riscos nas organizações de saúde.
O papel importante e crescente de radiologistas e patologistas como membros da equipe diagnóstica foi enfatizado no relatório, e repercutida a recomendação, já registrada em relatórios anteriores, de desenvolvimento de uma cultura organizacional que valorize a discussão e o feedback do desempenho diagnóstico.

Existe grande oportunidade de cooperação de patologistas clínicos e profissionais de laboratório na fase do processo laboratorial denominada "pré-analítica", a qual envolve a seleção e a solicitação dos exames pelos médicos assistentes. Essa fase é considerada como ponto de fragilidade no processo de trabalho, por conta do grande número e variabilidade dos exames disponíveis, tornando difícil a escolha apropriada dos exames por um médico generalista, o que acaba colocando em risco a definição de um diagnóstico.

Já na fase pós-analítica, deve haver possibilidade de diálogo entre o médico solicitante e o patologista clínico, a quem cabe sugerir a realização de novos exames, na dependência do contexto clínico; realizar considerações sobre possibilidades diagnósticas, considerando resultados de exames obtidos; e avaliar benefícios e danos relacionados à realização de novos exames e tratamentos, com base nas informações obtidas nos resultados. Fatores que contribuem para falhas nessa fase incluem: interpretação incorreta de exames e falha na orientação dos médicos assistentes para agirem sobre resultados de exames, por exemplo, solicitação de exames de follow-up ou ação terapêutica consistente com os resultados obtidos (National Academies of Sciences, Engineering, and Medicine 2015).

\section{Considerações finais}

Em consequência da grande evolução científica e tecnológica observada nas últimas décadas, a exemplo do que ocorre em outras áreas da assistência, aumentou também a complexidade da prática laboratorial, que ocorre em um ambiente no qual coexistem procedimentos, equipamentos, tecnologia e conhecimento humano, tornando possível a ocorrência de erros laboratoriais.

Apesar da falta de padronização da taxonomia e metodologias diversas empregadas em vários estudos que objetivaram a identificação e classificação dos incidentes decorrentes de erros laboratoriais, os relatos confirmam a baixa frequência de eventos adversos em consequência desse tipo de erros, e são eles associados a altos índices de evitabilidade. Isso é possível ocorrer em razão das barreiras existentes ao longo e externamente ao processo laboratorial. Tais achados justificam o estímulo a 
medidas que visam identificar, monitorar e prevenir esses incidentes. A utilização de indicadores de qualidade relacionados à segurança do paciente, que devem cobrir todas as fases do processo laboratorial, precisa ser estimulada para tal fim.

Em algumas organizações de saúde, em que se realizam testes laboratoriais remotos pela rápida disponibilização de resultados, o risco de eventos adversos decorrentes de erros laboratoriais deve ser mitigado pela utilização de boas práticas e capacitação periódica dos profissionais de saúde que os utilizam.

"As maravilhas tecnológicas têm realmente criado para os pacientes uma expectativa de perfeição, mas não podemos esquecer que trarão consigo novas formas de erros!" (Leape, Berwick 2000).

\section{Referências}

Agência Nacional de Vigilância Sanitária [Anvisa]. Nota técnica n. 039/2014-Grecs/GGTES/

Anvisa. 2014 [citado 2015 mar. 23]. Disponível em: http://portal.anvisa.gov.br/wps/ wcm/connect/b1a8b200456cc5f1a2a6ffa667b641b5/Nota+T\%C3\%A9cnica++039++vers\%C3\%A3o+para+o+site.pdf?MOD=AJPERES.

Agência Nacional de Vigilância Sanitária [Anvisa]. Resolução-RDC n. 302, 13 de outubro de 2005. Diário Oficial da União, 2005 out 14 [citado 2014 jun 26]. Disponível em: http://www.in.gov.br / imprensa/visualiza/index.jsp?.jornal= 1\&pagina=33\&data=14/10/2005.

Astion ML et al. Classifying laboratory incident to identify problems that jeopardize patient safety. Am J Clin Pathol. 2003 Jul;120(1):18-26.

Carraro P, Plebani M. Errors in a stat laboratory: types and frequencies 10 years later. Clin Chem. 2007;53:1338-42.

Carraza FR, Andriolo A. Diagnóstico laboratorial em pediatria. São Paulo: Sarvier; 2000. p. 3.

Ehrmeyer SS, Laessig RH, Ronald H. Point-of-care testing, medical error, and patient safety: a 2007 assessment. Clin Chem Lab Med. 2007;45(6):766-73.

Epner PL. Driving improved patient outcomes from the clinical laboratory; seeding knowledge for tomorrow's labs. 2013 [citado 2019 jan. 8]. Disponível em: http://seeding-knowledge.com/2013/ images/lectures/7-KSA-Improving_patient_Outcomes_PE.pdf

Epner PL, Gans JE, Graber ML.When diagnostic testing leads to harm: a new outcomes-based approach for laboratory medicine. BMJ Qual Saf 2013;22:ii6-ii10. doi:10.1136/bmjqs-2012-001621

Forsman RW. Why is the laboratory an afterthought for managed care organization? Clin Chem. 1996;42:813-6.

Goldschmidt HMJ. Gross errors and work flow analysis in the clinical laboratory. Klin Biochem Metab. 1995;3:131-40.

Institute of Medicine [IOM]. To err is human: building a safer heath system. Washington, DC: National Academic Press; 2000. 
International Standard Organization. ISO 15189:2003: medical laboratories: particular requirements for quality and competence. Geneva: ISO; 2003 [citado 2011 nov 12]. Disponível em: www.iso. org/.

International Standard Organization. ISO/TR 22869:2005: medical laboratories: guidance on laboratory implementation of ISO 15189: 2003. Geneva: ISO; 2005.

International Standard Organization. ISO/TS 22367:2008: medical laboratories: reducing error through risk management and continual improvement: complementary element. Geneva: ISO; 2008.

Key Incident Monitoring \& Management Systems [Project] (KIMMS). New South Wales: Australian Government's Quality Use of Pathology Program, 2013 [citado 2013 jul 21]. Disponível em: http:// www.rcpaqap.com.au/kimms/.

Kirsztajn GM. Diagnóstico laboratorial em nefrologia. São Paulo: Sarvier; 2010.

Kost GJ. Preventing medical errors in point-of-care testing. Arch Pathol Lab Med. 2001 Oct;125(10):1307-15.

Leape LL, Berwick DM. Safe health care: are we up to it? BMJ. 2000;320:725-6. Editorial.

Lippi G, Mattiuzzi C. Testing volume is not synonymous of cost, value and efficacy in laboratory diagnostics. Clin Chem Lab Med. 2013;51:243-5.

Lippi G, Simundic A, Mattiuzzi C. Overview on patient safety in healthcare and laboratory diagnostics. Biochem Med. 2010:20(Spec Issue 2);131-43.

Lippi GC, Mattiuzzi C, Plebani M. Preanalytical variability: the dark side of the moon in laboratory testing. Clin Chem Lab Med. 2006;44(4):358-65.

Lundberg GD. Critical (panic) value notification established laboratory practice policy (paameter). J Am Med Assoc. 1990;263:709.

Mendes ME, Gartner MT, Sumita NM, Sanchez PB. Gestão por processos no laboratório clínico: uma abordagem prática. Rio de Janeiro: EPR Editora; 2006.

Misbah SA et al. The role of the Physician in Laboratory Medicine. J Clin Pathol. 2013;66(5):432-7.

National Academies of Sciences, Engineering, and Medicine. Improving diagnosis in health care. Washington, DC: National Academies Press; 2015.

National Quality Forum. Serious reportable events in healthcare 2011 update: a consensus report. Washington, DC: NQF; 2011 [citado 2013 jul 17]. Disponível em: http://www.qualityforum.org/ Publications/2011/12/Serious_Reportable_Events_in_Healthcare_2011.aspx.

NORC at the University of Chicago, IHI/NPSF Lucian Leape Institute. Americans' experiences with medical errors and views on patient safety. Cambridge, MA: Institute for Healthcare Improvement and NORC at the University of Chicago; 2017.

O'Kane M, Lynch PLM, McGowan N. Development of a system for the reporting, classification and grading of quality failures in the clinical biochemistry laboratory. Ann Clin Biochem. 2008;45;12934.

Plebani M. The CCLM contribution to improvements in quality and patient safety. Clin Chem Lab Med. 2013;51(1):39-46.

Plebani M. Closing the brain-to-brain loop in laboratory testing. Clin Chem Lab Med. 2011;49(7):1131-33.

Plebani M. The detection and prevention of errors in laboratory medicine. Ann Clin Biochem. 2010;47:101-10. 
Plebani M. Errors in laboratory medicine and patient safety: the road ahead. Clin Chem Lab Med. 2007;45(6):700-7.

Plebani M. Exploring the iceberg of errors in laboratory medicine. Clin Chim Acta. 2009;404:16-23.

Plebani M, Carraro P. Mistakes in a stat laboratory: types and frequency. Clin Chem. 1997 Aug;43(8Pt1):1348-51.

Plebani M, Lippi G. To err is human: to misdiagnose might be deadly. Clin Biochim. 2010;43:1-3.

Plebani M, Ceriotti F, Messeri G, Ottomano C, Pansini N, Bonini IP. Laboratory network of excellence:enhancing patient safety and service effectiveness. Clin Chem Lab Med. 2006;44(2):150-160.

Plebani M, Sciacovelli L, Marinova M, Marcuccitti J, Chiozza ML. Quality indicators in laboratory medicine: a fundamental tool for quality and patient safety. Clin Biochem. 2013 Sep [citado 2013 jul 6];46(13-14):1170-4. Disponível em: http://dx.doi.org/10.1016/j.clinbiochem.2012.11.028.

Programa de Acreditação de Laboratórios Clínicos (PALC), Sociedade Brasileira de Patologia Clínica/ Medicina Laboratorial (SBPC/ML). PALC acreditação laboratorial: norma 2013. Brasília: SBPC/ ML; 2013 [citado 2013 jul 20]. Disponível em: http://www.sbpc.org.br/ upload/conteudo/Norma_ palc2013_web.pdf.

Rohr UP, Binder C, Dieterle T, Giusti F, Messina CG, Toerien E, et al. The value of in vitro diagnostic testing in medical practice: a status report. PLoS One. 2016;11:e0149856.

Sciacovelli $\mathrm{L}$ et al. Monitoring quality indicators in laboratory medicine does not automatically result in quality improvement. Clin Chem Lab Med. 2011;50(3):463-9.

Shahangian S, Snyder SR. Laboratory medicine quality indicators: a review of the literature. Am J Clin Pathol. 2009 Mar;131(3):418-31.

Shcolnik W. Erros laboratoriais e segurança do paciente: revisão sistemática [dissertação]. Rio de Janeiro: Escola Nacional de Saúde Pública Sergio Arouca, Fundação Oswaldo Cruz, 2012.

Shcolnik W, Mendes W. Erros laboratoriais e eventos adversos, metodologias de estudo: uma revisão sistemática. J Bras Patol Med Lab. 2013;49(5):332-40.

Signori C, Cerriotti F, Sanna A, Plebani M, Messeri G, Ottomano C et al. Process and risk analysis for reduce errors in clinical laboratories. Clin Chem Lab Med. 2007;45(6):742-8.

Singh H, Schiff GD, Graber ML, Onakpoya I, Thompson MJ. The global burden of diagnostic errors in primary care. BMJ Qual Saf 2017;26:484-94. doi:10.1136

Sociedade Brasileira de Patologia Clínica/Medicina Laboratorial (SBPC/ML). Diretriz para a gestão e garantia da qualidade de testes laboratoriais remotos. São Paulo: Manole; 2013.

Stankovi AK, Romeu P. The role of in vitro diagnostic companies in reducing laboratory error Clin Chem Lab Med. 2007;45(6):781-8.

Tate JR, Johnson R, Barth J, Panteghini M. Harmonization of laboratory testing - Current achievements and future strategies. Clin. Chim. Acta 2014;432:4-7.

Wallin O, Soderberg J, Van Guelpen B, Stenlund H, Grankvist K, Brulin C. Preanalytical venous blood sampling practices demand improvement: a survey of test-request management, test tube labeling and information search procedures, Clin Chim Acta. 2008;391:91-7.

Walz SE, Darcy TP. Patient safety \& post-analytical error. Clin Lab Med. 2013;33:183-94.

Weingart $S$ et al. A physician-based voluntary reporting system for adverse events and medical errors. J Gen Intern Med. 2001;12(16):809-14. 
Wikimedia Commons. File:Rapid point-of-care syphilis test-CDC.jpg. 2013 maio 13 [citado 2014 jun 25]. Disponível em: http://commons.wikimedia.org/wiki/File:Rapid_point-of-care_syphilis_test-CDC. jpg? uselang=pt-br.

World Health Organization. The conceptual framework for the international classification for patient safety: technical report. Version 1.1. Geneva: WHO; 2009 [citado 2011 fev 20]. Disponível em: http://www.who.int/patientsafety/implementation/taxonomy/icps_technical_report_en.pdf.

Wu AW. Medical error: the second victim. BMJ. 2000;320:725-7.

Yuan $S$ et al. Clinical impact associated with corrected results in clinical microbiology testing. J Clin Microbiol. 2005;43(5):2188-93. 


\section{Gestão do risco de quedas, úlceras por pressão e de incidentes relacionados com transfusão de sangue e hemoderivados}

Paulo Sousa, Silvia Oliveira, Ana Alves e Ana Teles

Neste capítulo, aprofundaremos a temática das quedas e das úlceras por pressão (também denominada de lesão por pressão) abordando, numa fase inicial, seus conceitos, suas causas, consequências, custos e medidas preventivas. Será, igualmente, referido alguns dos principais instrumentos de avaliação e ações a adotar após sua ocorrência. Ainda, neste capítulo, serão abordados os incidentes relacionados com a transfusão de sangue e hemoderivados, suas consequências, factores contribuintes e formas de diminuir ou evitar sua ocorrência.

Outras situações que colocam em risco a segurança dos pacientes, tais como tromboembolismo venoso; delirium, acidente vascular cerebral e enfarte/infarto agudo do miocárdio, como complicações pós-operatórias; a gestão/gerenciamento da dor, uso único para dispositivos de injeção, falhas de conexões, fadiga de alarmes e interrupção da enfermagem serão apresentadas de forma mais sucinta nos anexos ao final deste livro Segurança do paciente: conhecendo os riscos nas organizações de saúde.

\section{Quedas}

Uma queda, de acordo com a OMS (WHO 2012), é definida como um evento caracterizado pela descida abrupta do corpo para um nível inferior ao que se encontra, como solo ou pavimento. Para Almeida, Abreu e Mendes (2010), as quedas são um evento traumático, multifactorial e habitualmente involuntário e inesperado, acarretando consequências para o individuo, familiares, profissionais, instituições de saúde, assim como para a sociedade. Torna-se, portanto, fundamental sua correta caracterização, evidenciando suas especificidades. 
Sabia que...

A queda é a segunda causa de morte acidental ou não intencional no mundo?

Por ano, estima-se que 424 mil indivíduos falecem na sequência de uma queda?

Os adultos com idade superior aos 65 anos são os que mais sofrem quedas fatais (WHO 2012)?

A queda no paciente é o evento adverso mais reportado/notificado ao National Patient Safety Agency (NPSA) na Inglaterra e País de Gales?

Durante um ano, foram reportadas/notificadas ao NPSA mais de 200 mil quedas ocorridas em ambiente hospitalar?

Dessas 200 mil quedas reportadas/notificadas, 26 resultaram em morte, e, posteriormente, algumas fraturas da anca/fraturas de quadril tenham culminado da mesma forma em morte (NPSA 2007)?

\section{Como são classificadas as quedas?}

Os pacientes caiem por diversas razões, e, para que se implemente um efetivo plano preventivo, torna-se importante compreender sua etiologia. De acordo com Morse (2009), as quedas podem ser classificadas em:

\section{Quedas acidentais ou fisiológicas:}

associadas a perigos ambientais, como urina ou água derramada no chão, constituindo cerca de $14 \%$ do total de quedas;

\section{Quedas fisiologicamente previsíveis:}

correspondem aos indivíduos com elevada predisposiçăo para queda (alto risco), devido as suas inúmeras alteraçōes fisiológicas. Esse tipo de queda é responsável por $78 \%$ do total de quedas;

\section{Quedas fisiologicamente imprevisíveis:}

podem ser atribuídas a causas fisiológicas, no entanto, ocorrem sob condiçöes que năo permitem a sua previabilidade, até a primeira ocorrência. Da totalidade de quedas ocorridas, $8 \%$ dizem respeito a esse tipo.

Essa classificação, como referido por Almeida, Abreu e Mendes (2010), remete-nos para a existência de factores que predispõem à ocorrência de queda, quer sejam factores intrínsecos, quer extrínseco. É sobre as causas de risco que nos debruçaremos de seguida. 
Para refletir

Você tem conhecimento da incidência de quedas no serviço, unidade ou na organização em que atualmente exerce funções? Você acredita que esses incidentes têm sido considerados (e valorizados), pela organização, um problema a que urge dar respostas? Por que você acredita ser dessa maneira?

\section{Quais as principais factores responsáveis pela ocorrência de queda?}

De forma a maximizar a efetividade da prevenção de quedas nos pacientes com elevado risco, torna-se premente identificar as causas que contribuem para esse incidente. Sabe-se que, na origem das quedas, estão múltiplos factores (causa multifactorial) e, por uma questão de sistematizar e agrupar esses factores, vários autores os classificam em dois grandes grupos: intrínsecos e extrínsecos (Ganz et al. 2013; Morse 2009; Nice 2013; NPSA 2007; Saraiva et al. 2008).

\section{Factores intrínsecos}

Os factores intrínsecos, também conhecidos por factores individuais, incluem alterações fisiológicas relacionadas com o avançar da idade, patologias e efeitos causados pelo uso de fármacos.

As alterações fisiológicas relacionadas com o próprio envelhecimento incluem alterações da visão e audição, distúrbios vestibulares, transformações ao nível dos reflexos posturais, flexibilidade, diminuição da capacidade funcional, deformidades ósseas, deformidades nos pés, distúrbios propriocetivos, diminuição da sensibilidade dos barorrecetores à hipotensão postural, sedentarismo, distúrbios musculoesqueléticos, marcha enfraquecida, aumento da incidência de condições patológicas.

No que se refere às patologias mais frequentes, predisponentes de quedas, é possível enumerar as doenças do foro cardíaco/doenças cardíacas, osteoarticulares, respiratórias, psiquiátricas, geniturinárias, endocrinometabólicas, neurológicas, demência, déficit cognitivo, e estado de saúde atual, como desidratação, hipoglicemia, déficit nutricional.

Ainda referente aos factores intrínsecos, o uso de fármacos é também apontado/indicado como um factor relevante para a ocorrência de queda. Dessa forma, múltiplos grupos de medicamentos são mencionados como responsáveis pelo aumento do risco de queda, como os 
diuréticos, hipotensores, vasodilatadores, nitratos, digitálicos, laxantes, opioides, hipoglicemiantes, hipnóticos, sedativos, ansiolíticos, analgésicos. A medicação múltipla, superior a quatro medicamentos por indivíduo, é igualmente referida como um factor importante no aumento do risco de queda.

\section{Factores extrínsecos}

Os factores externos referem-se aos perigos ambientais existentes nas unidades, em particular, e ao hospital, em geral. Infelizmente, as unidades hospitalares têm sido projetadas em função da necessidade dos funcionários, em detrimento da segurança do paciente.

Assim, as múltiplas áreas que contribuem para o aumento do risco incluem:

淟 corrimão: inexistência desses no quarto e casa de banho/banheiro e no percurso para eles;

pavimento: superfícies escorregadias, escadas, presença de cabos;

踏 cama, cadeiras e dispositivos de apoio à marcha: inadequados, desajustados aos pacientes, sem grades, destravadas;

踏 campainha de chamada: fora do alcance do paciente;

suporte de soros: inapropriado em altura e mobilidade;

滕 iluminação: pouca luminosidade;

滕 vestuário: pouco apropriado;

滕 calçado: escorregadio;

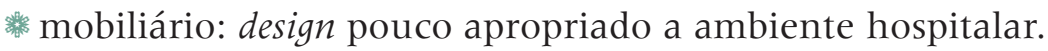

\section{Para refletir}

Na organização em que você trabalha, em que condições estão as áreas que foram listadas anteriormente? Você já viu ou teve notícias de alguma queda em consequência de condições inapropriadas?

Para saber mais sobre as condições em que ocorrem as quedas, consulte o terceiro relatório do Observatório de Segurança do Paciente, da National Patient Safety Agency. Disponível em: http://www.nrls.npsa.nhs.uk/ resources/?entryid $45=59821$

Como já referido, os factores intrínsecos são os que mais contribuem para a ocorrência de queda; no entanto, a maioria das quedas é resultado de uma combinação de diferentes factores. Assim, é possível afirmar que as quedas são resultado da sinergia entre múltiplos factores, intrínsecos e extrínsecos. 
Sabia que...

Os pacientes sofrem mais quedas durante os dias úteis da semana, quando há mais pacientes no hospital.

É a meio da manhã que os pacientes sofrem mais quedas, por ser o momento em que se encontram mais ativos.

Apenas uma pequena porcentagem de quedas é testemunhada pelos profissionais de saúde.

Os pacientes idosos que já tenham sofrido um episódio de queda constituem um grupo vulnerável e de elevado risco para que o episódio se repita (NPSA 2007).

Paralelamente, o NPSA (2007) refere que os pacientes internados apresentam um risco acrescido de queda em comparação com os residentes na comunidade, e isso ocorre por causa de sua condição de saúde no momento, à medicação, que pode condicionar sua mobilidade, e/ou à memória, assim como pela presença de um ambiente que lhe é estranho.

\section{Quais as principais consequências quando ocorre uma queda?}

As consequências decorrentes de uma queda podem ser divididas em três grandes grupos: físicas, psicológicas e sociais (Oliver et al. 2004; NPSA 2007; NHS 2009), como demonstra o quadro a seguir.

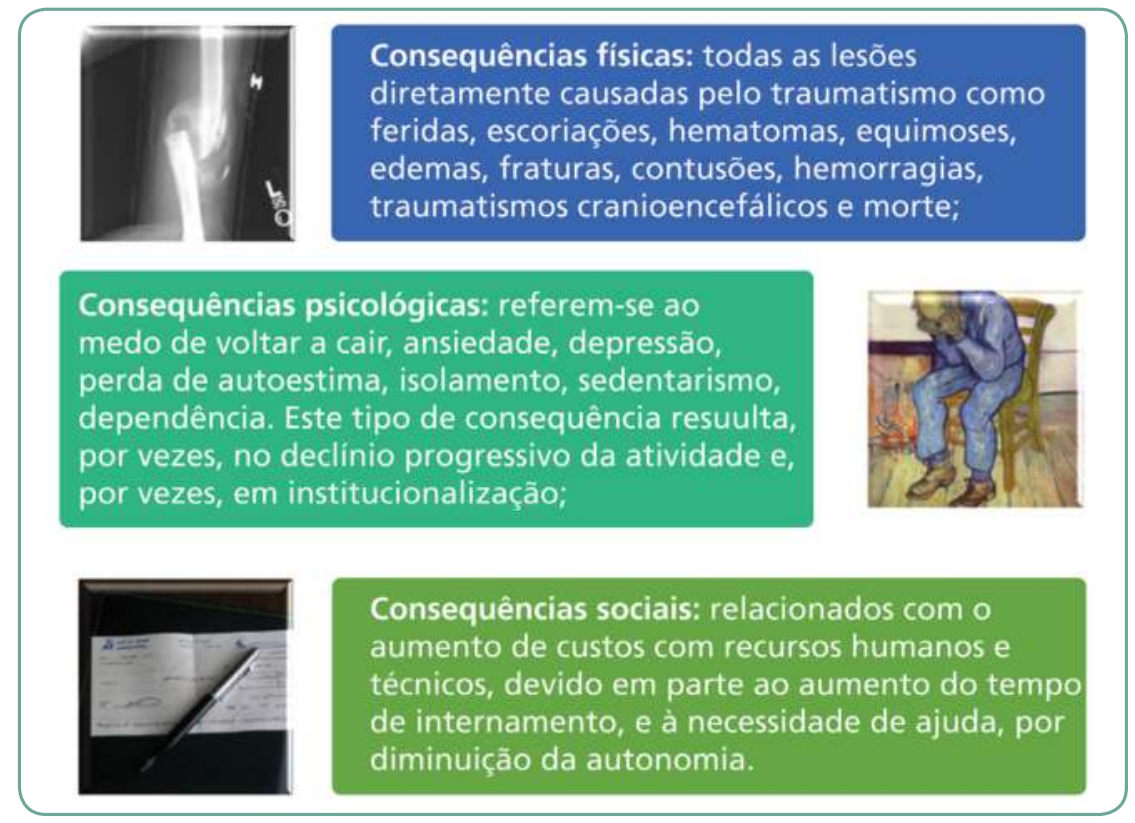

Fonte: Rhodes (2004), The Yorck Project (2005), Pshegubj (2010). 
Sabia que...

Num estudo realizado por Schwendimann et al. (2006), 66.4\% das quedas ocorridas num hospital público de Zurich não resultaram em danos físicos, $29.7 \%$ resultaram em danos físicos reduzidos, e $3.9 \%$ das quedas ocorridas provocaram lesões físicas severas.

Por fim, de acordo com NPSA (2007), é possível referir que, para além dos custos humanos, existem ainda outros custos relacionados com aumento de recursos materiais e profissionais, demora média de internamento/internação estimados em 15 milhões de libras a cada ano. Todavia, existem custos adicionais difíceis de quantificar, por exemplo, um paciente que sofra uma queda e, após alta hospitalar, necessite de cuidados continuados, como se verifica a título exemplificativo, com pequenas feridas que degeneram para úlceras e necessitam de tratamento prolongado, e esses custos não estão incluídos nesse valor. O mesmo se constata com custos envolvidos com as reclamações e indenizações. Mais recentemente, um estudo da OCDE (Slawomirski et al. 2017) veio destacar o impacto económico dos eventos adversos em geral e, das quedas em particular.

As consequências de uma queda não são apenas vividas pelo paciente, mas também pelos seus familiares, cuidadores e pelos profissionais de saúde, causando, por vezes, neles sentimento de culpabilidade e ansiedade (Oliver et al. 2004).

A gravidade do incidente pode ser ainda classificada em diferentes graus, que, segundo o NPSA (2007), é possível classificar da seguinte forma:

Sem lesão ou prejuízo: quando não ocorreu qualquer dano físico para o paciente.

* Lesão leve: quando resulta em dano ou ferimento que requer primeiros socorros, tratamento minor, observação ou medicação extra.

橉 Lesão moderada: quando resulta em tratamento em ambulatório, algum tipo de cirurgia, ou internamento/internação prolongado no hospital.

蝶 Lesão severa: quando causa lesão permanente, como dano cerebral, resultando em diferentes incapacidades.

橉 Morte: quando a morte é causa direta da queda. 
Sabia que...

Intervenções multidimensionais (alinhadas) podem reduzir o risco de queda em até 30\% (Miake-Lye et al. 2013).

\section{É possível prevenir quedas?}

A intervenção no sentido de prevenir a ocorrência de quedas deve envolver os diferentes profissionais de saúde, familiares e o próprio paciente. E porque cada paciente é único, seu plano preventivo deve ser individualizado, de acordo com suas necessidades, traduzindo um equilíbrio entre as ações preventivas e sua independência, privacidade, dignidade e reabilitação (NPSA 2007; Ganz et al. 2013).

A prevenção deve iniciar-se com a avaliação do paciente e dos seus factores de risco, e existem diversos instrumentos possíveis para avaliar o risco de queda. No entanto, a Escala de Morse, como é referida por McFarlane-Kolb (2004), é facilmente adaptável a diferentes contextos. Talvez, por esse facto, seja mais comumente utilizada um pouco por todo o mundo.

De acordo com Ganz et al. (2013), a aplicação dessa escala (Morse) deve ser efetuada quando da admissão do paciente ao serviço de internamento/internação; na sua transferência para outra unidade ou serviço; quando ocorre alguma alteração na condição do paciente; ou após um episódio de queda.

A Escala de Morse é composta de seis parâmetros de avaliação listados a seguir:

1. história de queda;

2. diagnóstico secundário;

3. apoio para se deslocar/caminhar;

4. medicação endovenosa/cateter heparinizado;

5. marcha, e

6. estado mental.

Cada um dos parâmetros corresponde a um valor numérico, que somado entre todos confere um score, perante o qual é atribuído o risco (veja na Tabela 1). Quando o valor é inferior a 25, o paciente apresenta baixo risco de queda. Quando o valor se encontra entre o 25 e 45, o paciente apresenta risco moderado de queda. Por fim, se o valor obtido na avaliação for superior a 45, o paciente apresentará alto risco 
de queda, devendo assim a intervenção incidir num plano preventivo personalizado que engloba diferentes ações, de acordo com os diferentes factores de risco do paciente (Quadro 1).

Tabela 1 - Itens de avaliação da Escala de Morse

\begin{tabular}{|c|c|c|}
\hline Item & $\begin{array}{l}\text { Pontuação } \\
\text { da escala }\end{array}$ & $\begin{array}{l}\text { Pontuação } \\
\text { do paciente }\end{array}$ \\
\hline História de queda (imediata ou anterior) & $\begin{array}{ll}\text { Não } & 0 \\
\text { Sim } & 25\end{array}$ & \\
\hline Diagnóstico secundário & $\begin{array}{l}\text { Não } \\
\text { Sim }\end{array}$ & \\
\hline $\begin{array}{l}\text { Apoio para se deslocar/caminhar } \\
\text { - Nenhuma/acamado/apoio do enfermeiro } \\
\text { - Muletas/canadianas/andarilho } \\
\text { - Apoia-se no mobiliário }\end{array}$ & $\begin{array}{c}0 \\
15 \\
30\end{array}$ & \\
\hline - Medicação endovenosa/cateter heparinizado & $\begin{array}{l}\text { Não } \\
\text { Sim }\end{array}$ & \\
\hline $\begin{array}{l}\text { Marcha } \\
\text { - Normal/acamado/cadeira de rodas } \\
\text { - Enfraquecida } \\
\text { - Necessita de apoio }\end{array}$ & $\begin{array}{c}0 \\
10 \\
20\end{array}$ & \\
\hline $\begin{array}{l}\text { Estado mental } \\
\text { - Consciente das suas capacidades } \\
\text { - Superestima/esquece-se das suas limitações }\end{array}$ & $\begin{array}{c}0 \\
15\end{array}$ & \\
\hline $\begin{array}{l}\text { Total da pontuação } \\
<25 \text { Baixo Risco } \\
\text { 25-45 Risco Moderado } \\
>45 \text { Alto Risco }\end{array}$ & & TOTAL \\
\hline
\end{tabular}

Fonte: Adaptado de Morse (2009).

Quadro 1 - Intervenções que devem ser realizadas em pacientes que apresentam alto risco de queda

\section{Intervenções ao nível dos factores intrínsecos}

- Envolver os pacientes e os familiares na prevenção das quedas, alertando para os factores de risco.

- Detetar e tratar doença cardiovascular.

- Detetar e tratar as causas de delírio.

- Detetar e tratar problemas de visão. 
Quadro 1 - Intervenções que devem ser realizadas em pacientes que apresentam alto risco de queda (cont.)

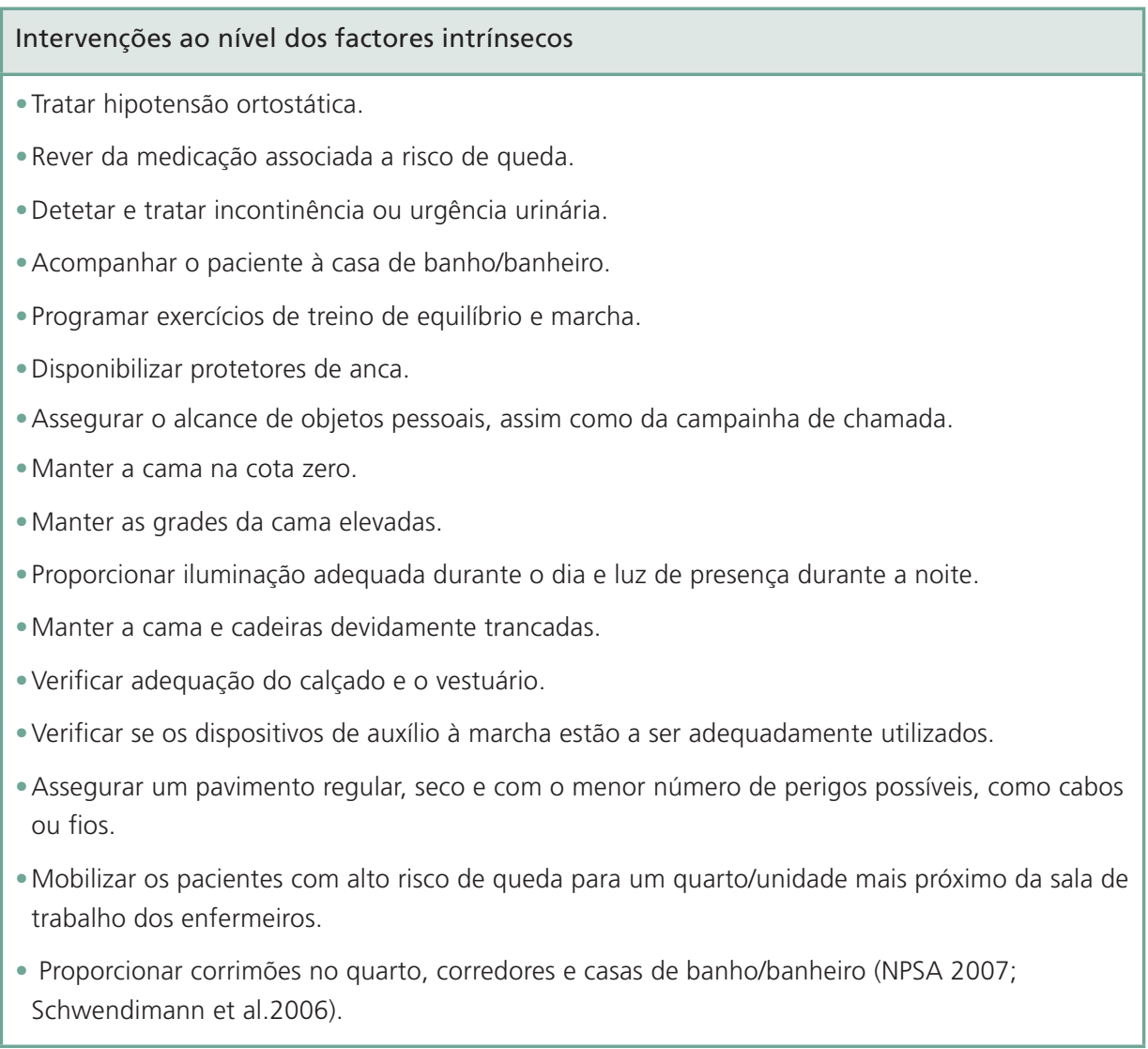

Fonte: Ganz et al. 2013; NPSA 2007; Schwendimann et al. 2006.

Contudo, a prevenção de quedas pode não se restringir unicamente à avaliação do risco de queda (aplicação de uma escala) e à intervenção nos factores de risco. As estratégias de prevenção podem ser complementadas com uma cultura de constante investigação das situações de quedas; criação de um grupo de "quedas"; eleição de um profissional (enfermeiro, médico) dinamizador; treino dos profissionais de saúde para implementar as medidas preventivas; realização de auditorias e; aprendizagem por meio da análise das circunstâncias em que ocorreram as quedas, conforme esquematizado na Figura 1 (Almeida, Abreu, Mendes 2010; NHS 2009).

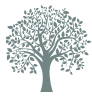

Para saber mais sobre as medidas preventivas, recomendamos a consulta dos seguintes sites:

- http://www.npsa.nhs.uk/

- http://www.patientsafetyfirst. nhs.uk/

- http://www.nice.org.uk/ No Brasil, existe um protocolo de prevenção de quedas:

- http://www.anvisa.gov.br/ hotsite/segurancadopaciente/ documentos/julho/

Protocolo\%20-\%20

Preven \%C3\%A7\%

C3\%A30\%20de

$\% 20 Q u e d a s . p d f$ 
Figura 1 - Estratégias de prevenção de quedas baseadas na evidência científica

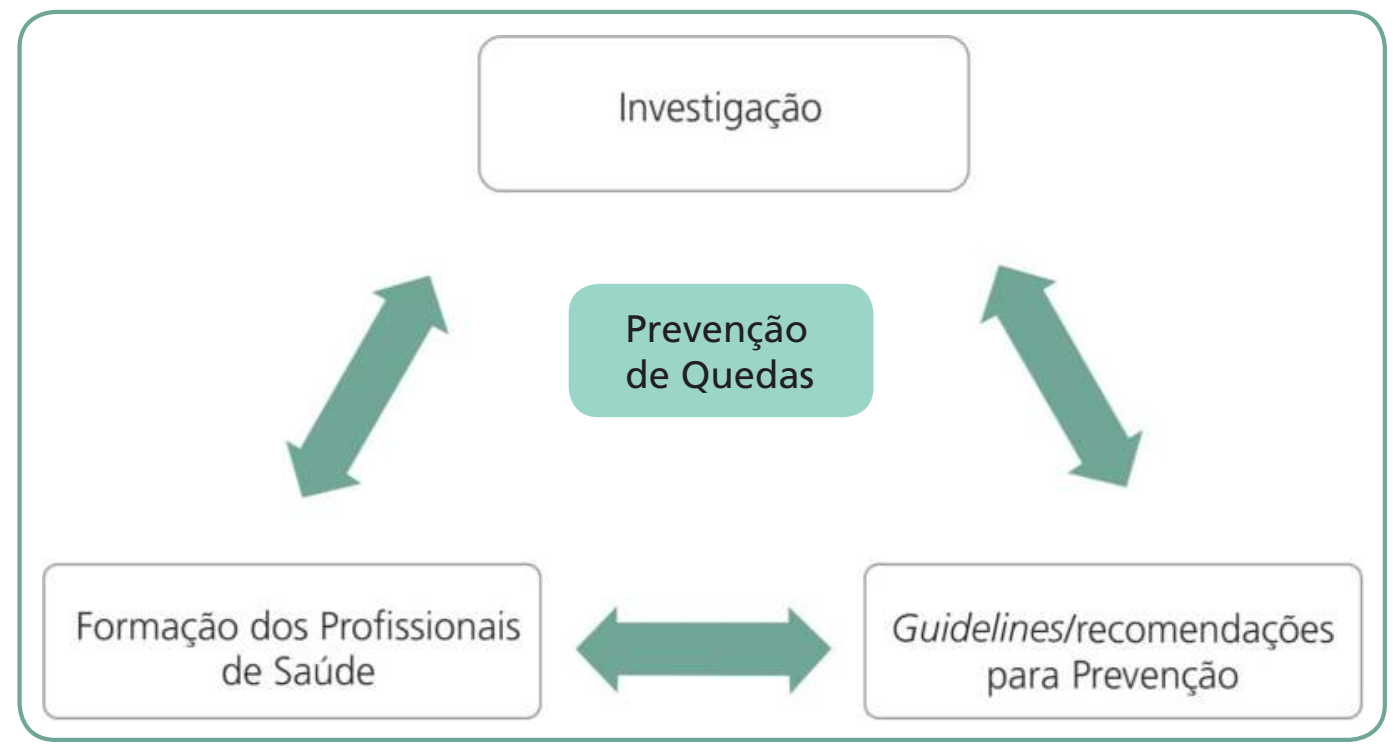

Fonte: Adaptado de Almeida, Abreu, Mendes (2010).

\section{Para refletir}

Na sua organização, é prática atual a avaliação do risco de quedas para todos os pacientes? Considera isso importante? Por quê?

Ainda na sua organização, existem estratégias de prevenção para quedas das que foram discutidas até aqui? (procedimentos normalizados, instrumentos de avaliação do risco, grupo de trabalho, elemento dinamizador).

\section{O que fazer quando ocorre uma queda?}

Quando ocorre uma queda, deve-se de imediato avaliar o paciente, identificar e caracterizar as lesões e tratá-las com a maior brevidade possível. Adicionalmente, devem ser identificadas as causas intrínsecas e extrínsecas que levaram à queda. Em paralelo, os profissionais devem eliminar, tanto quanto possível, os riscos que contribuíram para que a queda ocorresse. Por fim, mas não menos importante, os profissionais de saúde devem relatar o incidente mencionando a informação-chave (tão clara e descritiva quanto possível), promovendo assim o conhecimento da presença dos factores de risco e a aprendizagem por meio dessas ocorrências (NHS 2009; NPSA 2007; Oliver et al. 2004). 


\section{Úlceras por pressão}

O National Pressure Ulcer Advisory Panel e o European Pressure Ulcer Advisory Panel definem úlcera por pressão (UP) como uma “lesão causada na pele ou no tecido subjacente, geralmente sob uma proeminência óssea, como resultado da pressão ou da combinação entre a pressão e as forças de torção" (EPUAP 2009, p.7).

Uma úlcera por pressão pode apresentar quatro categorias que variam de acordo com os tipos de tecidos atingidos:

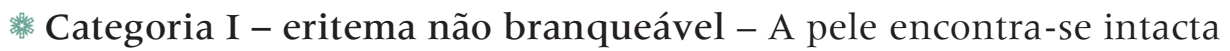
e ruborizada; ao toque, não branqueia. A área pode encontrar-se dolorosa, firme, suave, mais quente ou mais fria comparativamente com o tecido adjacente. Segundo O National Pressure Ulcer Advisory Panel e o European Pressure Ulcer Advisory Panel, essa categoria pode ser difícil de detetar em indivíduos que apresentem tons de pele mais escuros.

Figura 2 - Úlcera por pressão: categoria I

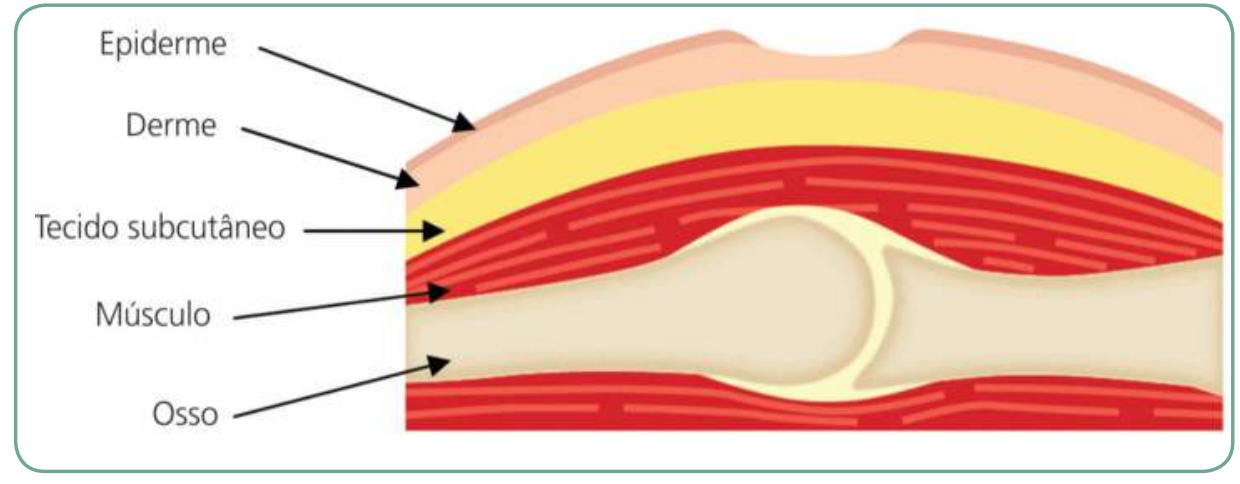

Ilustração de Armando Lopes.

Categoria II - perda parcial da espessura da pele -

Observa-se uma lesão aberta pouco profunda. Também se pode apresentar como uma flictena (empolamento da epiderme, tipo "bolha"); é uma úlcera superficial brilhante ou seca sem esfacelo ou hematomas. 
Figura 3 - Úlcera por pressão: categoria II

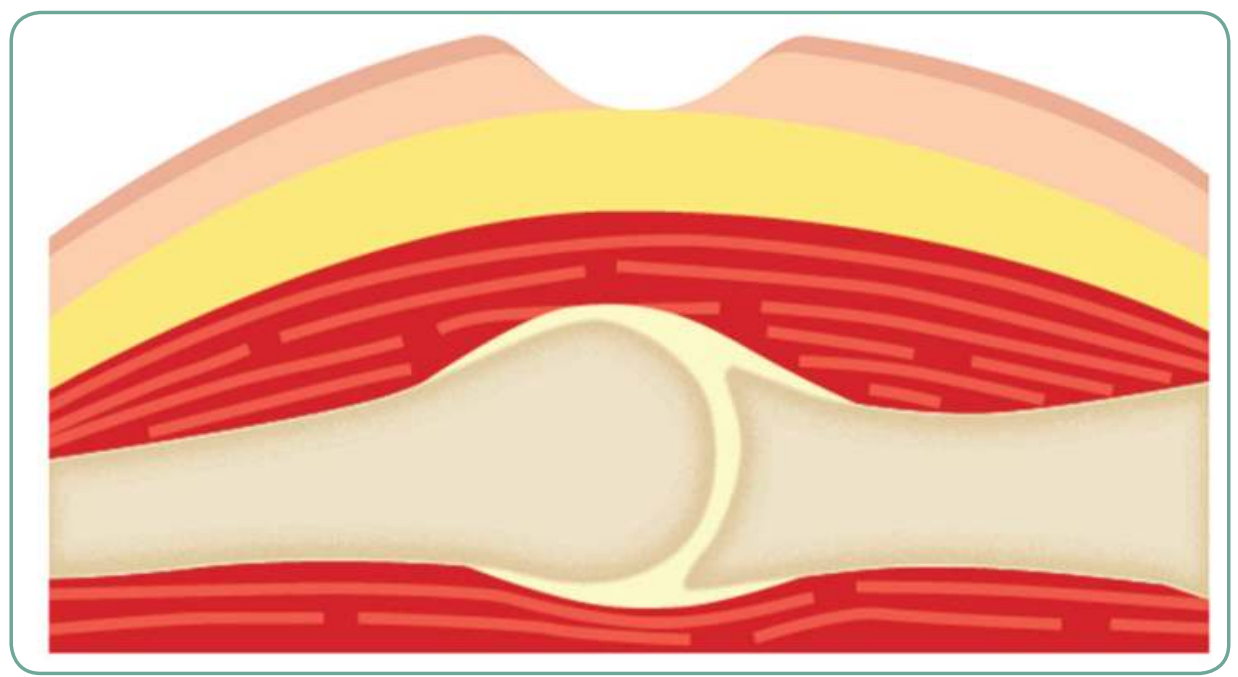

Ilustração de Armando Lopes.

* Categoria III - perda total da espessura da pele - O tecido subcutâneo encontra-se visível; os ossos, tendões ou músculos não se encontram expostos. Nessa categoria, incluem-se as úlceras tunelizadas. A profundidade de uma úlcera por pressão III varia consoante a localização anatómica. Uma vez que a asa do nariz, os pavilhões auriculares, a região occipital e maleolar não apresentam tecido adiposo subcutâneo, as úlceras II, nessas localizações, podem ser pouco profundas. No entanto, as regiões anatómicas com adiposidade significativa podem desenvolver úlceras por pressão extremamente profundas.

Figura 4 - Úlcera por pressão: categoria III

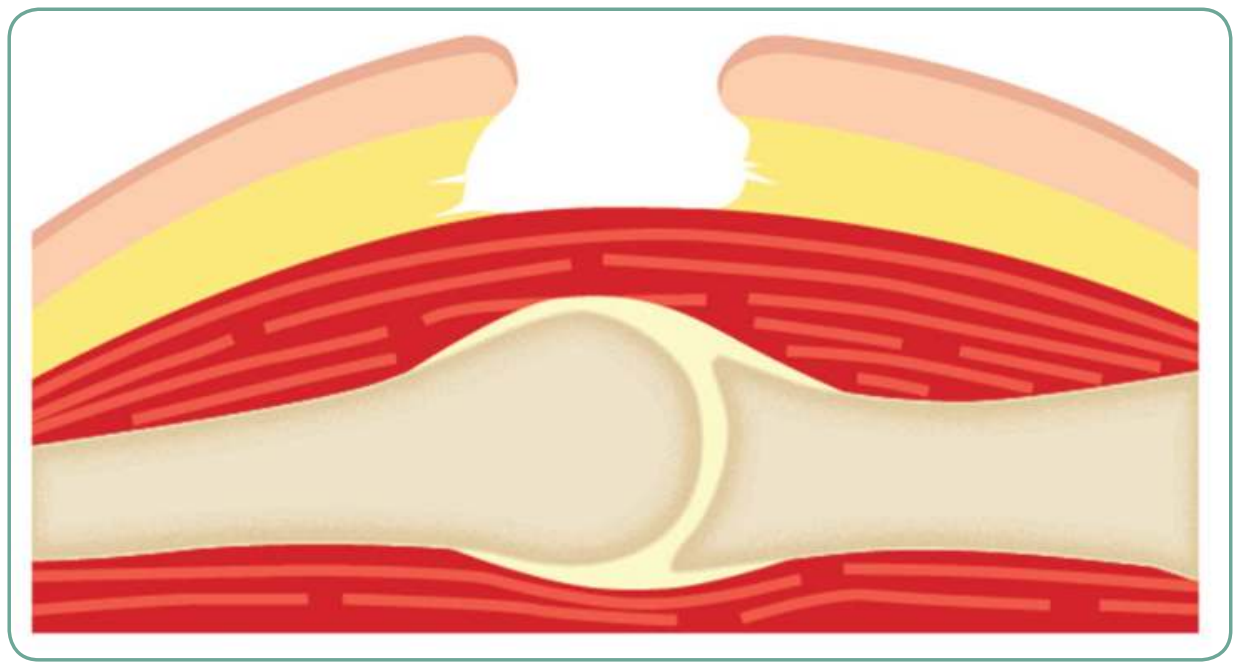

Ilustração de Armando Lopes. 
*ategoria IV - perda total da espessura tecidular - Verifica-se exposição do osso, tendão ou músculo; podem estar presentes tunelizações. À semelhança da categoria III, também na IV, a profundidade varia de acordo com a localização anatómica. A asa do nariz, os pavilhões auriculares e as regiões occipital e maleolar não têm tecido adiposo subcutâneo, e as úlceras, nessas localizações, podem ser pouco profundas. As úlceras dessa categoria podem ser causa de osteomielite ou osteíte; o músculo e/ou osso encontram-se visíveis ou diretamente palpáveis.

Figura 5 - Úlcera por pressão: categoria IV

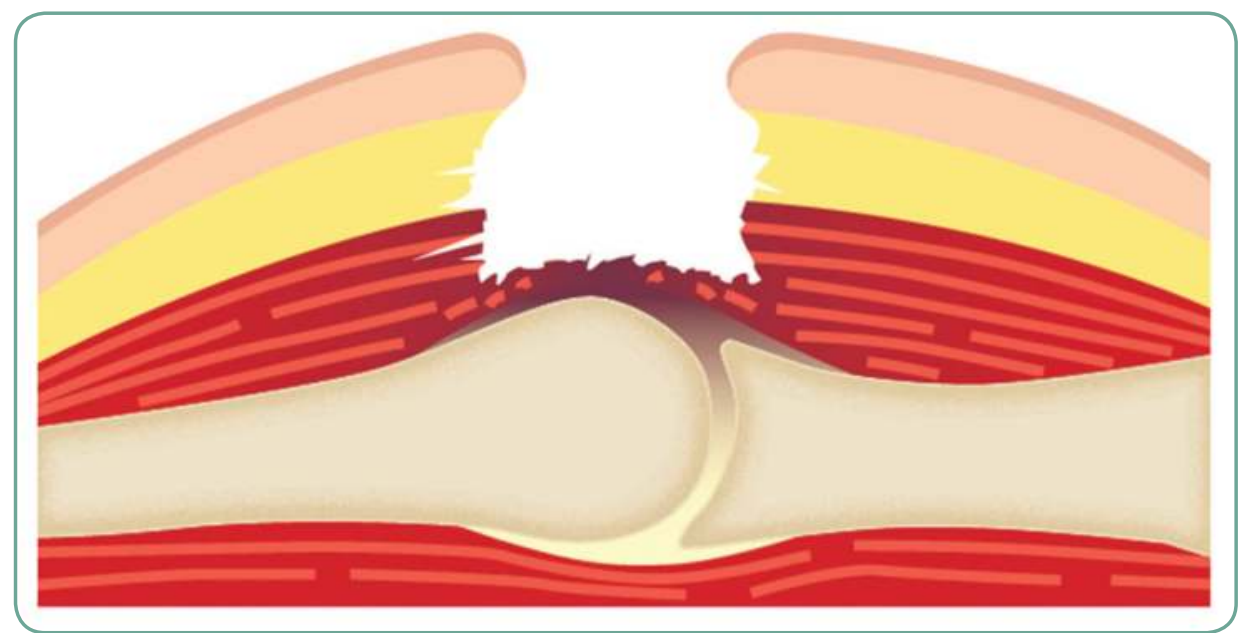

Ilustração de Armando Lopes.

Nos Estados Unidos da América, ainda são definidas duas outras categorias adicionais (EPUAP 2009):

* perda total da espessura da pele e tecidos com profundidade desconhecida;

踏 suspeita de lesão dos tecidos profundos com profundidade desconhecida.

\section{Importância da avaliação do risco de UP}

Existem diversas escalas de avaliação do risco de úlceras por pressão, tais como Braden, Norton, Waterloo, que diferem, entre outros, nos parâmetros a avaliar.

Em Portugal, a escala adotada e validada é, desde 2001, a de Braden (veja a escala a seguir) na qual são avaliados seis parâmetros: perceção sensorial, humidade, atividade, mobilidade, nutrição e fricção de deslizamento.

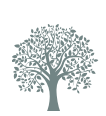

No Brasil, existe um protocolo que tem por objetivo a prevenção de úlcera por pressão, desenvolvido em parceria entre o Ministério da Saúde, a Anvisa e a Fiocruz. Disponível em: http://www.anvisa.gov.br/ hotsite/segurancadopaciente/ documentos/julho/ PROTOCOLO $\% 20$ ULCERA $\% 20$ POR\%2OPRESS\%C3\%830.pdf 
Em cada parâmetro da Escala de Braden, o enfermeiro deve, perante o paciente a avaliar, selecionar uma situação entre as três ou quatro enunciadas (para cada parâmetro). A cada situação selecionada corresponde uma determinada ponderação numérica, e, posteriormente, soma-se o conjunto dos valores obtidos em cada parâmetro avaliado.

Quanto mais baixa for a pontuação obtida, maior será o risco de o paciente vir a desenvolver úlceras por pressão. Quando a soma dos seis parâmetros avaliados resulta em um valor igual ou inferior a 16, o resultado sugere que o paciente apresenta risco elevado para o desenvolvimento de úlceras por pressão. Caso o resultado obtido seja superior ou igual a 17, constata-se que existe baixo risco de desenvolvimento de úlceras por pressão.

Mediante os resultados obtidos com a utilização da Escala de Braden (ou outra validada), existe a possibilidade de elaborar planos de cuidados adequados às necessidades dos pacientes.

\section{Para refletir}

Em sua organização, usa-se algum tipo de escala ou protocolo para prevenção de úlcera por pressão? Qual? Você acredita que essa prática tem trazido bons resultados? 


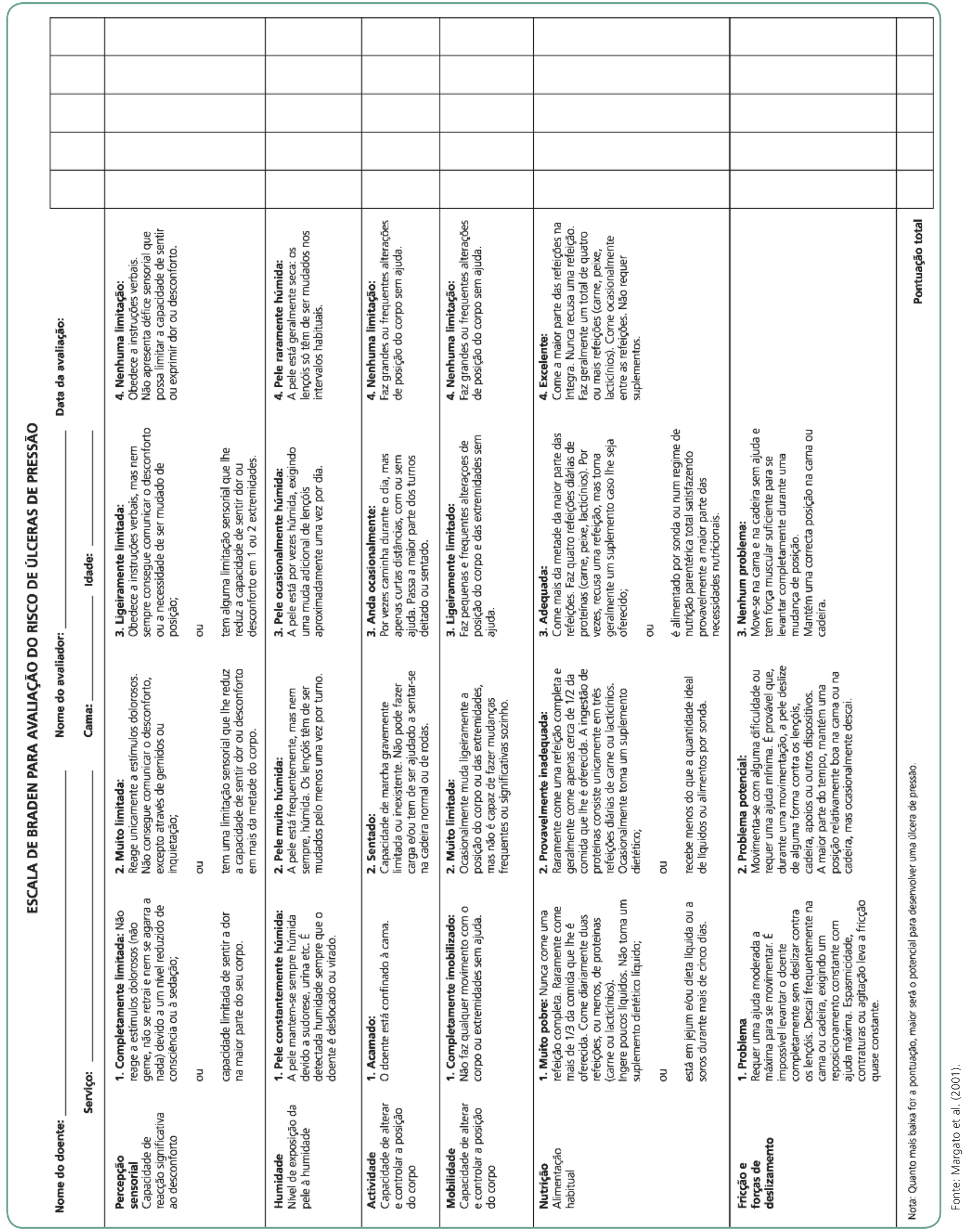


O suporte fotográfico pode funcionar como adjuvante/ colaborador na prática da avaliação do risco de úlceras por pressão. É prática frequente dos profissionais de enfermagem e pessoal médico procederem ao registo fotográfico das úlceras por pressão e posterior inclusão no processo clínico/prontuário, para que se consiga comparar, visualmente, a evolução obtida.
A avaliação do risco deve ser efetuada no dia da admissão, possibilitando assim a comparabilidade e a contínua atenção por parte dos profissionais acerca da evolução observada e da necessidade de manter o plano de cuidados elaborado para o paciente, ou de o alterar consoante a sua evolução.

Em Portugal, a Direção-Geral da Saúde elaborou uma orientação (Ministério da Saúde 2011) na qual se defende a periodicidade de reavaliação, por parte dos enfermeiros, do risco de desenvolvimento de úlceras por pressão. Assim:

- Internamentos/internações hospitalares - de 48/48 horas a todos os pacientes internados.

- Serviços de urgência e unidades de cuidados intensivos - de 24/24 horas.

- Unidades de cuidados continuados e paliativos - de 48/48 horas.

- Cuidados domiciliários - semanalmente.

- Pacientes que não permaneçam mais de $\mathbf{4 8}$ horas num serviço de internamento/internação - efetuar avaliação caso ocorra alguma intercorrência.

Para saber mais sobre essas orientações consulte, a página da DGS em: http://www.dgs.pt/upload/membro.id/ficheiros/i015800.pdf

A monitorização contínua da incidência e da prevalência das úlceras por pressão é fundamental, pois é preciso

testar se as ferramentas reduzem a ocorrência de eventos adversos, e não assumir que uma ferramenta validada será benéfica para os pacientes. Apesar das evidências de que preveem o risco, não há evidência de que as ferramentas de avaliação do risco reduzam a incidência de úlceras por pressão (Anthony et al. 2010, p.135).

\section{A dor no paciente com UP}

Quando se aborda o tema das úlceras por pressão, outro tópico surge, imediatamente, lado a lado com ele - a dor; dor pela existência da úlcera, pelos apósitos/curativos utilizados, pela manipulação da ferida, entre outros factores. Para Pieper, Langemo e Cuddigan (2009), a dor é encarada como uma experiência sensorial e emocional desagradável, associada a um dano tecidual real ou potencial.

Independentemente da idade do paciente ou de seu estado de saúde, a existência de dor não pode ser subvalorizada, pois sua presença contém 
implicações psicossociais quer para o paciente, quer para a família ou, ainda, para os profissionais de saúde.

De acordo com os autores supracitados, a World Union Of Wound Healing Societies elaborou um documento que define os princípios de boas práticas associadas à manipulação das úlceras por pressão, nas quais se considera importante:

繗 estar ciente da dor provocada pela existência de ferida;

轔 evitar manipulações desnecessárias;

繗 explorar técnicas para minimizar a dor;

繗avaliar a pele e o tecido circundante em termos de presença de infeção ou necrose;

atender à temperatura dos apósitos/curativos utilizados;

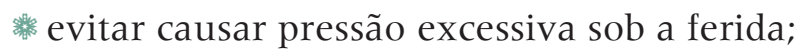

繙 fornecer avaliação e monitorização contínua.

\section{As úlceras por pressão são evitáveis?}

Cerca de 95\% das úlceras por pressão podem ser evitadas se existir a identificação precoce do grau do risco (Ministério da Saúde 2011; Posnett, Franks 2008).

No Reino Unido, Posnett e Franks (2008) concluíram que cerca de 400 mil pessoas desenvolviam, anualmente, uma nova úlcera por pressão. Isso podia ser, em certos casos, evitado com consequente redução não só das complicações e comorbilidades/comorbidades associadas, como também das despesas em saúde.

Em Portugal, a prevalência das úlceras por pressão em meio hospitalar varia entre 11,5\% para a prevalência média e 17,5\% quando estratificado para serviços específicos, tais como os serviços de medicina (Ministério da Saúde 2011).

\section{Será que a ocorrência de úlceras por pressão é evitável em todas as situações?}

Essa foi uma das questões em análise numa conferência efetuada em 2010 pelo National Pressure Ulcer Advisory Panel, na qual, entre outros aspetos, os peritos de diversas organizações prestigiadas concluíram que "nem todas as úlceras por pressão são evitáveis, porque existem 
Courtney et al., citados por Sullivan e Schoelles (2013), verificaram que uma redução de $50 \%$ para $5 \%$ de úlceras por pressão adquiridas em meio intra-hospitalar representou diminuição das despesas em $\$ 2.438 .000$ US dólares, e, em 2008, num hospital da Flórida com 548 camas/leitos a redução, estatisticamente significativa, da prevalência de UP acarretou a poupança de $\$ 11.5$ milhões de US dólares.

situações em que a pressão do paciente não pode ser aliviada, e a perfusão não pode ser melhorada" (Black et al. 2011, p.30). Entre outras conclusões, os autores consideraram que:

\section{Situaçōes limitantes à evitabilidade do surgimento das UP}

A mobilidade e as limitações de atividade săo fortes e independentes fatores contribuem para a incidência das úlceras por pressão.

Embora não se tenha concluído até a data acerca do correto intervalo que determine a alternância de posicionamentos, 0 intervalo de duas em duas horas continua a ser utilizado como guia orientador.

Não importa o quão adequado e correto é o plano de cuidados desenhado para um paciente e o quão sofisticado é a cama/leito e colchão que este utiliza, se nao existirem profissionais disponiveis, com boa formaçăo e competentes para colocar em prática.

\section{Os custos das UP... Prevenir ou tratar?}

A estratégia de abordagem nas úlceras por pressão deverá ser multifactorial, pois sua existência e complicações acarretam custos elevados. Segundo Sullivan e Schoelles (2013), nos Estados Unidos da América, as complicações associadas às UP adquiridas em meio intra-hospitalar causam, por ano, cerca de 60 mil mortes e morbilidades/morbidades em um número significativo de pacientes. Embora se tenha anteriormente mencionado que nem todas as úlceras por pressão são evitáveis, a aposta na sua prevenção é essencial não só para proteger os pacientes, como também para reduzir os custos económicos e sociais associados.

Um estudo desenvolvido por Bennett, Dealey e Posnett (2004) no Reino Unido concluiu que:

- O custo esperado de cura de uma úlcera por pressão varia de acordo com a sua categoria - 1.064 Libras (UPP categoria I) a 10.551 (UPP categoria IV).

- "O custo aumenta com a categoria da úlcera, porque o tempo necessário para a cura é mais longo para uma úlcera mais grave, assim como a possibilidade de incidência de complicações" (Bennett et al. 2004, p.233).

- Os cuidados aos pacientes com úlceras por pressão foi estimado em cerca de $4 \%$ do total das despesas do Serviço Nacional de Saúde inglês (NHS) - O custo total dos cuidados relacionados com úlceras por pressão no Reino Unido varia entre 1.4 a 2.1 mil milhões/bilhões de libras. 
Dealey, Posnett e Walker (2012) concluíram, mediante um estudo realizado no Reino Unido, que os custos relativos ao tratamento diário de pacientes com UP categorias I e II variam entre 43 e 347 libras. Os autores concluem que uma UP categoria I pode custar mais de mil libras por episódio de internamento/internação. Por isso, é fundamental ter consciência da possibilidade de ocorrência de complicações (tais como infeção, celulite ou osteomielite) com consequente aumento do tempo de internamento/ internação, atraso da cura e aumento dos custos - daí a contínua importância do investimento na prevenção e no tratamento precoce.

Os custos elevados que a existência de úlceras por pressão origina servem também de alavanca para otimizar os cuidados e modernizar as práticas. Um estudo desenvolvido por McGuinness et al. (2012) num serviço de neurociência (neurologia e neurocirurgia) de um hospital nos Estados Unidos da América implementou, desde 2008, uma estratégia de cuidados que envolvia, entre outras ações:

a aquisição de camas específicas;

路 uma cultura de alternância de decúbitos dos pacientes de uma em uma hora ou de duas em duas horas;

橉 a criação de uma equipa especializada denominada Skin and Wound Assessment Team (SWAT), constituída de enfermeiros especializados na área que monitorizavam a existência de úlceras por pressão.

\section{Para refletir}

Na organização em que você desempenha funções, existe um grupo de profissionais (tipo grupo de avaliação ou prevenção de úlceras por pressão) que se dedica às questões das úlceras por pressão?

Caso exista, ele tem obtido sucesso? Caso não exista, a que se deve essa ausência? 
Implementar medidas de avaliação, gestão e prevenção das úlceras por pressão permite obter ganhos ao nível da qualidade dos cuidados e da segurança do paciente.
Os autores mencionam que, mediante as estratégias adotadas, assistiram a uma importante redução da incidência de úlceras por pressão adquiridas em meio hospitalar, no referido serviço, de $48 \%$ em 2009, de $57 \%$ em 2010 e de $61 \%$ em 2011 , e consequente redução dos custos por internamento/internação (um paciente com úlcera de pressão categoria IV custa em média, segundo os autores, 129.248 dólares americanos, por um único internamento/internação/admissão) (McGuinness et al. 2012).

Num outro estudo, Brem et al. (2010) referem que cerca de 50\% de úlceras por pressão categoria II e $95 \%$ de úlceras por pressão categorias III e IV não cicatrizaram em oito semanas. Os autores mencionam que a presença ou o desenvolvimento de uma úlcera por pressão pode aumentar o tempo de internamento/internação, em média, em 10,8 dias.

\section{Para praticar}

- Qual a importância do contínuo investimento em práticas de avaliação e gestão do risco de UP?

- A existência de equipas especializadas e multidisciplinares, nas Organizações de Saúde, trará benefícios em termos de diminuição da frequência e/ou gravidade das úlceras por pressão?

\section{Incidentes relacionados com a transfusão de sangue e hemoderivados}

A medicina transfusional é a área médica que se refere à utilização terapêutica do sangue e componentes sanguíneos, incluindo a transfusão sanguínea. A transfusão de sangue consiste na perfusão de um determinado volume de sangue ou componente sanguíneo, proveniente de um dador/doador saudável, a um paciente.

A transfusão sanguínea é uma parte essencial da moderna assistência à saúde, podendo ter desde funções profilácticas a terapêuticas. O uso clínico dos diferentes componentes sanguíneos são variáveis, e vão desde o tratamento de anemias até à prevenção de hemorragias (Quadro 2). 
Quadro 2 - Uso clínico dos componentes sanguíneos

\begin{tabular}{|c|c|c|}
\hline Eritrócitos & Plaquetas & Plasma \\
\hline $\begin{array}{l}\text { - Traumas } \\
\text { - Cirurgias } \\
\text { - Anemias severas }\end{array}$ & $\begin{array}{l}\text { - Prevenção de hemorragias } \\
\text { - Correção de problemas de } \\
\text { funcionalidade das plaquetas }\end{array}$ & $\begin{array}{l}\text { - Correção de deficiências de } \\
\text { fatores de coagulação } \\
\text { - Hemorragias massivas }\end{array}$ \\
\hline
\end{tabular}

Fonte: Fonte: Adaptado de Chaudhary (2011)

Por exemplo, a transfusão de eritrócitos é utilizada em diversas áreas clínicas, quer para prevenção quer para tratamento (Figura 6).

Figura 6 - Estimativa da transfusão de eritrócitos nos países desenvolvidos

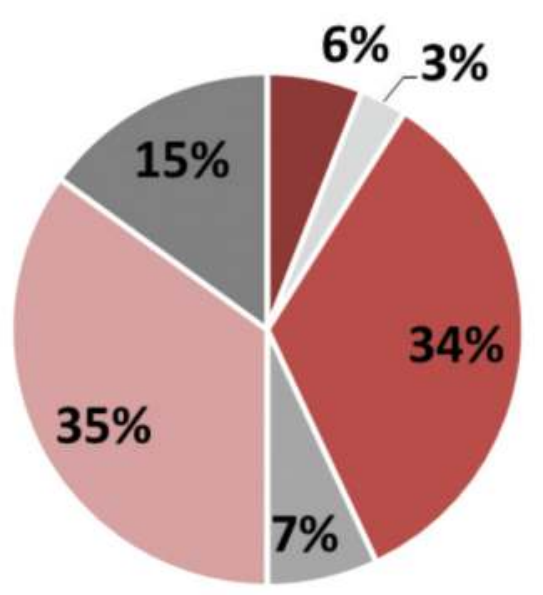

- Relacionado com a gravidez

Pediátricas

- Cirúrgicas

Traumas

Médicas

Hematológicas

Fonte: Adaptado de WHO (2006).

A transfusão de componentes sanguíneos e seus derivados, se usada corretamente, pode salvar vidas e melhorar a saúde dos pacientes. No entanto, à semelhança das demais práticas médicas, não é isenta de riscos. E embora seja uma prática conhecida desde tempos remotos, sempre foi acompanhada por barreiras à sua aplicação em virtude das questões essenciais de segurança que se iam colocando.

Em tempos passados, os riscos associados à transfusão estavam relacionados com a transmissão de agentes infecciosos (Figura 7) e incompatibilidades sanguíneas por desconhecimento dos diferentes sistemas de grupos sanguíneos. No entanto, com os constantes avanços científicos, essas preocupações foram sendo colmatadas/atenuadas, e, atualmente, o risco de uma ocorrência desse gênero é apenas residual. 
Figura 7 - Risco de transmissão de infeção através da transfusão nos EUA, por unidade transfundida

\begin{tabular}{|l|c|c|}
\cline { 2 - 3 } \multicolumn{1}{c|}{} & $\mathbf{1 9 8 5}$ & $\mathbf{2 0 0 7}$ \\
\hline HIV & $1 / 100000$ & $1 / 1000000$ \\
\hline HBV & $1 / 1000$ & $1 / 80000$ \\
\hline HCV & $1 / 100$ & $1 / 800000$ \\
\hline Bactérias & $1 / 3000$ & $1 / 80000$ \\
\hline $\begin{array}{l}\text { Agentes } \\
\text { Emergentes }\end{array}$ & & $1 / 30000$ \\
\hline
\end{tabular}

Fonte: Adapatdo de Klein et al (2007).

$\mathrm{O}$ risco de transmissão de Hepatite $\mathrm{B}$ e $\mathrm{C}$ e HIV tem vindo a diminuir significativamente ao longo dos anos. Também o risco de transmissão de infeções bacterianas, associado à transfusão de plaquetas, diminuiu na última década. Os constantes avanços tecnológicos permitiram não só obter testes de rastreio cada vez mais sensíveis e específicos, detetando os agentes infeciosos mais precocemente, mas também criar tecnologias que reduzem a transmissão de um vasto leque de agentes infeciosos. A implementação de critérios mais apertados na seleção de dadores de sangue também foi uma medida tomada nesse sentido.

Apesar das melhorias significativas da segurança dos componentes sanguíneos, os erros de transfusão e as reações adversas daí decorrentes ainda ocorrem um pouco por todo o mundo. Embora algumas complicações relacionadas com a transfusão sejam inevitáveis, a maioria das reações transfusionais fatais é atribuída ao erro ou falha humano. Esses erros ou falhas podem conduzir a diferentes impactes nos pacientes (podendo mesmo levar à morte) e, consequentemente, a maior necessidade de alocação de recursos.

Os riscos transfusionais (Quadro 3) podem resultar em complicações fisiológicas que podem colocar em risco a vida dos pacientes. É possível que as complicações tenham origem em erros decorrentes de procedimentos inadequados e incorretos ao longo do processo transfusional, ou podem ter por base outras situações alheias a esse processo.

Os riscos transfusionais (Quadro 3) podem resultar em complicações fisiológicas que podem colocar em risco a vida dos pacientes. É possível que as complicações tenham origem em erros decorrentes de procedimentos inadequados e incorretos ao longo do processo transfusional, ou podem ter por base outras situações alheias a esse processo. 
Quadro 3 - Riscos e benefícios associados à transfusão de sangue e componentes sanguíneos

\begin{tabular}{|l|l|}
\hline Benefícios & Riscos \\
\hline - Transfusão de eritrócitos indicada em & - Erro que conduz à transfusão incorreta, que \\
paciente com diminuição da capacidade de & pode resultar numa reação transfusional grave \\
transporte de oxigénio. & em razão de incompatibilidade ABO. \\
- Transfusão de plaquetas para tratamento ou & - Transmissão de agentes infecciosos por \\
prevenção de hemorragias em pacientes com & transfusão. \\
déficits quantitativos e qualitativos & - Lesão pulmonar aguda relacionada com a \\
de plaquetas. & transfusão. \\
- Transfusão de plasma e crioprecipitado & - Outras reações transfusionais. \\
para profilaxia ou tratamento de déficits & - Infeção bacteriana por conta de componentes \\
congénitos de factores da coagulação. & sanguíneos contaminados. \\
& - Sobrecarga volémica. \\
\hline
\end{tabular}

Fonte: Adaptado de Australian Red Cross Blood Service (2012).

O erro humano tem sido identificado como uma das principais fontes das fatalidades relacionadas com transfusões de incompatibilidade $\mathrm{ABO}$. A incompatibilidade $\mathrm{ABO}$ corresponde a uma reação grave do sistema imunitário do paciente em razão da transfusão de componente sanguíneo cujo grupo é diferente e incompatível com o dele.

Nos EUA, a frequência de mortes evitáveis por transfusão, atribuídas à identificação errada da amostra de sangue pré-transfusional da unidade de sangue ou do destinatário, varia de 1:600.000 transfusões a 1:800.000 (Krombach et al. 2002).

Num estudo realizado entre 1996 e 1999 pelo SHOT (Serious Hazards Of Transfusion - Sistema de Hemovigilância do Reino Unido), verificou-se uma incidência de erro de 1:16.000 (335 erros por 5,5 milhões de unidades de concentrado de eritrócitos transfundidas entre 1996 e 1999). Concluiu, também, que os erros referentes à transfusão ABO incompatíveis eram responsáveis por $54 \%$ de todas as complicações relacionadas com a transfusão e, ainda, colocaram a condição de vida do paciente em risco 97 vezes, conduzindo a 4 mortes (1:1.400.000 transfusões) e a 29 casos de morbilidade major/morbidade imediata (1:200.000 transfusões) (Krombach et al. 2002).

No relatório do SHOT de 2012, os eventos adversos causados por erros continuam a ser os mais frequentes, sendo a transfusão do componente sanguíneo incorreto o erro mais notificado (SHOT 2013).

Em 2015, o relatório do SHOT refere a existência de 26 mortes, das quais oito eram preveníveis. Revela que o risco de morte associada à 
transfusão causada por erro é de 1:320 000. Refere, também, que 166 pacientes sofreram danos graves, sendo que um em cada três eram preveníveis.

Verifica-se, portanto, que, atualmente, o risco transfusional prioritário é o relacionado com erros transfusionais que podem ocorrer ao longo de todo o processo.

O processo transfusional é um complexo e envolve muitos intervenientes/atores e procedimentos, englobando um conjunto de pontos críticos em que há a efetiva possibilidade de ocorrência de erro. E embora haja reações que derivam de complicações inevitáveis, na sua grande maioria, essas devem-se a erros humanos, e como tal evitáveis.

A cadeia transfusional corresponde ao conjunto de etapas que envolvem o processo transfusional (Figura 8), estendendo-se desde o recrutamento e seleção do dador/doador até a administração e monitorização da transfusão no paciente.

Podemos considerar duas abordagens do processo transfusional: a primeira na perspetiva do dador/doador; e a segunda na perspetiva do paciente.

Figura 8 - Etapas do processo transfusional

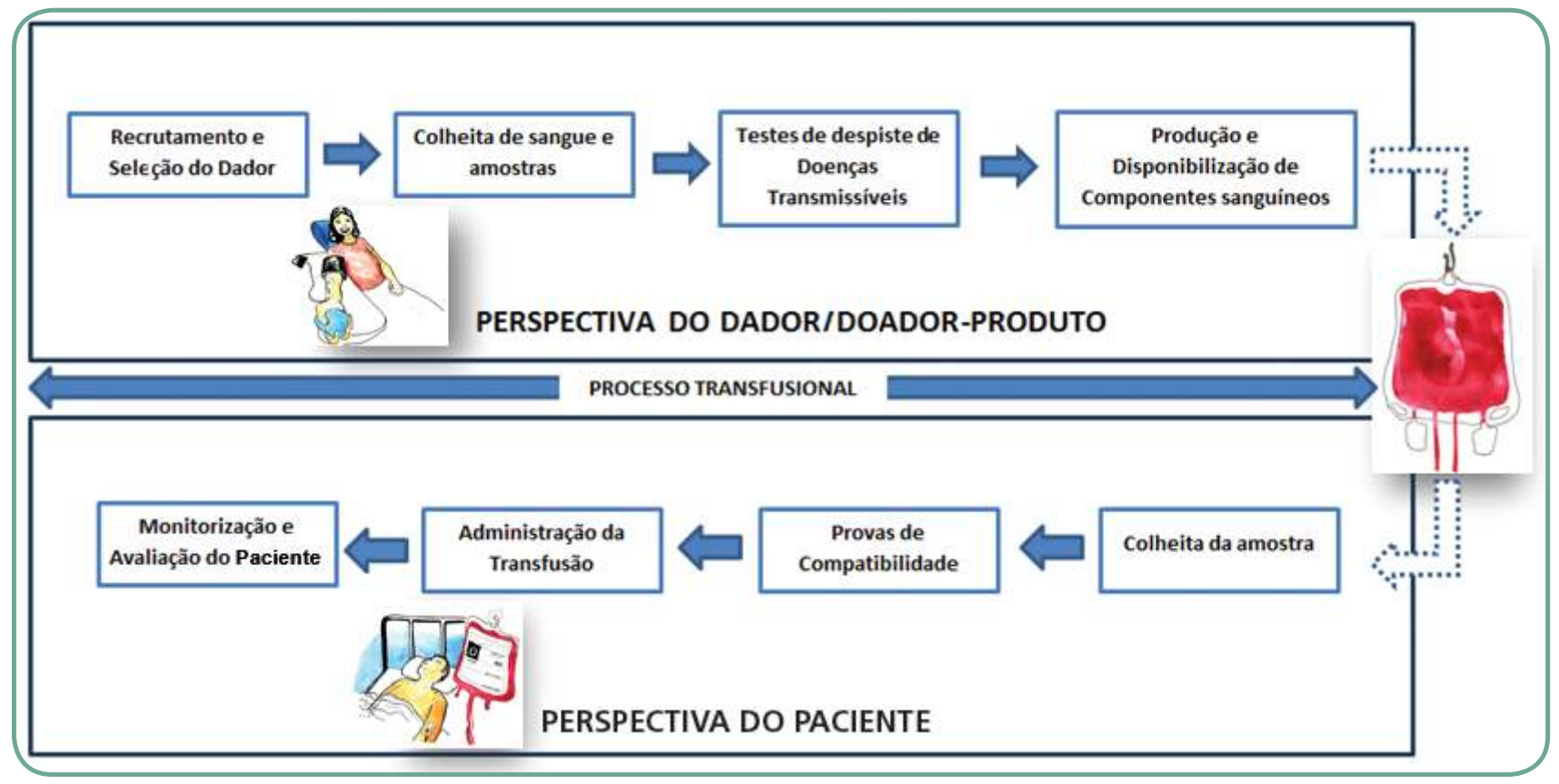

Fonte: Adaptado de Klein (2010). 
Na transfusão de sangue, a segurança do paciente depende da segurança do produto sanguíneo e da segurança do processo clínico de transfusão. A OMS classifica os incidentes transfusionais em dois grupos:

1. Aqueles que estão diretamente relacionados com o sangue e componentes sanguíneos, e

2. Aqueles que estão relacionados com o processo transfusional (OMS 2010).

Há três áreas no processo de transfusão (excetuando a segurança do sangue - produto), que são propícias a erros (Figura 9). A primeira área onde há possibilidade de ocorrência de erro é referente à decisão de transfundir, seguida da colheita/coleta de amostras para testes pré-transfusionais, e finalmente à administração da transfusão ao paciente (Dzik 2006).

Figura 9 - Potenciais áreas de erro do processo transfusional na perspetiva do paciente

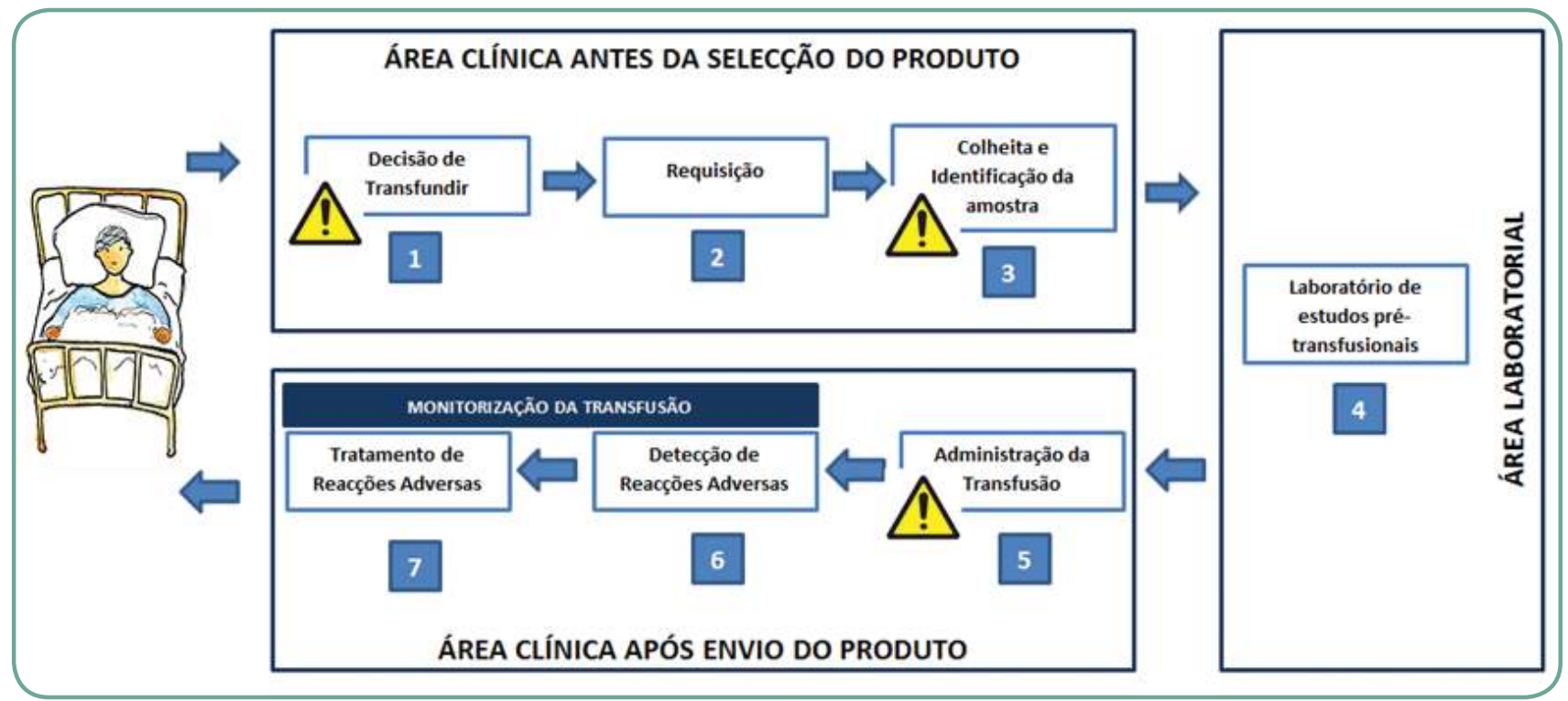

Fonte: Adaptado de Dzik (2006).

Na figura acima indicada, os momentos críticos do processo transfusional, em que erros podem ocorrer, estão marcados com a sinalética/ sinalização de atenção (triângulo amarelo). É fundamental que esses passos sejam efetivamente controlados para garantir a segurança dos pacientes e prevenir incidentes e eventos adversos evitáveis. O objetivo é promover a melhoria da qualidade do processo transfusional, isto é, a transfusão da unidade certa para o paciente certo no momento certo e nas condições certas e, ainda, de acordo com as diretrizes (guidelines) apropriadas. O que se pretende é uma utilização segura do sangue, clinicamente eficaz e eficiente (OMS 2010). 


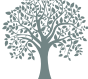

A nomenclatura dos eventos adversos em transfusão tem características particulares. Daí que se recomenda a leitura das definições propostas pelo ISBT em 2011 e 2015. http://www.isbtweb. org/fileadmin/user_upload/ WP_on_Haemovigilance/ISBT_ definitions_final_2011_4_. pdf

http://www.isbtweb.org/ fileadmin/user_upload/ISBT_ definitions_sentinel_events_adopted2015.pdf

É recomendada a leitura das definições propostas para os eventos adversos em transfusão pelo SHOT em 2017.
Vários são os incidentes decorrentes de transfusão. Segundo o SHOT, são considerados incidentes os decorrentes de vários tipos de erros que ocorrem ao longo do processo transfusional (SHOT 2013). Assim são considerados incidentes em transfusão:

㫫 a transfusão do componente sanguíneo incorreto;

路 transfusão de componente sanguíneo incorreto por requisitos especiais não conhecidos;

橉 transfusão evitável, atrasada ou subtransfusão;

檞 erros de manipulação e armazenamento;

橉 sangue certo no paciente correto, mas com falhas de identificação.

Alguns desses incidentes podem resultar numa reação transfusional adversa para o paciente, nomeadamente numa reação hemolítica por incompatibilidade $\mathrm{ABO}$. A incompatibilidade $\mathrm{ABO}$ representa uma das ameaças mais temíveis em medicina transfusional, uma vez que pode causar a morte do paciente. Em geral, é o resultado de várias falhas que ocorreram ao longo da cadeia transfusional e não foram identificadas atempadamente (antes da transfusão se iniciar). Está, geralmente, associada à incorreta identificação da amostra e/ou do paciente.

A Joint Commission on the Accreditation of Healthcare Organizations (JCAHO) realizou um estudo em que, ao longo de três anos, avaliou os near misses, tendo identificado 12 casos relacionados com reações transfusionais, e 10 desses resultaram em morte. Onze dos casos descritos foram reações hemolíticas, das quais oito resultaram de verificações incompletas do paciente e do sangue, e os restantes três casos foram originados pela manipulação e processamento de amostras, ou unidades de sangue, em mais de um paciente ao mesmo tempo e no mesmo local (JCAHO 2003).

A análise de incidentes (Incorrect Blood Component Transfusion - IBCT) relatados pelo SHOT em 2003 revelou que aproximadamente 50\% dos incidentes ocorreram por vários erros ou falhas no processo transfusional. Em segundo lugar, cerca de 70\% dos erros ocorreram nas áreas clínicas, e o erro mais frequente $(27 \%)$ ocorreu por uma falha pré-transfusional à cabeceira do paciente, onde se deve assegurar que o sangue certo deve ser administrado ao paciente certo (Stainsby et al. 2005).

De acordo com um estudo SHOT, realizado entre 1996 e 2008, que reflete os perigos reais da transfusão, verificou-se que, em 5.374 casos revistos, 2.355 das reações adversas ocorreram por transfusão do componente errado, e as restantes 3.019 foram diluídas por 13 categorias de incidentes e reações adversas (European Union 2010). 
A identificação incorreta do paciente é uma causa importante de eventos adversos evitáveis em todas as áreas da prática clínica, não só em medicina transfusional. Num período de 12 meses, entre fevereiro de 2006 e janeiro de 2007, a National Patient Safety Agent (NPSA) do Reino Unido recebeu 24.382 relatórios de pacientes com erros ou falhas na identificação. Um exemplo de evento adverso causado por erros de identificação durante a cadeia transfusional é a administração do componente sanguíneo ao paciente errado ou na quantidade errada. Em tais situações, foram identificados como principais factores que podem causar ou criar predisposição a erros os seguintes aspetos:

滕 intervenções realizadas em diversos locais;

踏 por membros diferentes da equipa;

蝶 em turnos/plantões diferentes;

距 falhas de comunicação (European Union 2010).

\section{Para refletir}

Você tem conhecimento de casos de incidentes envolvendo a cadeia transfusional em seu serviço ou organização de saúde? Como é que sua organização tem lidado com essas questões e o que tem sido feito para evitá-las?

Várias têm sido as medidas preventivas sugeridas para a redução desses erros. São disso exemplos, a utilização de pulseira com código de barras de identificação do paciente e a realização de testes de compatibilidade à cabeceira do paciente, antes da administração da transfusão. Outra das sugestões refere-se à utilização de barreiras físicas, como a colocação do componente num saco que só pode ser aberto após a leitura do código de barras da pulseira do paciente. A formação dos profissionais e sua consciencialização/conscientização são essenciais, bem como a implementação de procedimentos adequados de verificação durante todo o processo e, em especial, à cabeceira do paciente. O uso das tecnologias de informação como sistema de apoio a detetar erros e a emitir alertas é também uma mais-valia para melhorar a segurança transfusional. Não obstante, entende-se que nenhuma dessas medidas pode ser considerada a ideal para todos os casos, pois é necessário avaliar qual a mais adequada para cada organização (e situação). Parece, no entanto, ser consensual que são necessárias mais evidências para comprovar a efetividade e a eficiência das várias medidas e seu real impacte na eliminação ou diminuição dos erros na transfusão (Murphy et al. 2007). 


\section{Considerações finais}

Em síntese, as questões das quedas, das úlceras por pressão e dos erros transfusionais têm assumido, por parte dos responsáveis da saúde, crescente preocupação, quer por apresentarem elevada frequência (por exemplo, as quedas são o incidente mais relatado pelos profissionais de saúde), quer pelo impacte que têm. São múltiplos os factores que estão na sua origem (causas multifactoriais), e as estratégias que visam mitigar ou eliminar tais ocorrências também têm de ser adaptadas a essa diversidade. As consequências das quedas, das UP e dos erros transfusionais podem ter impacte clínico, económico e social muito significativo não só para os pacientes e familiares, mas também para os profissionais e organizações de saúde. De acordo com alguns autores, por exemplo, as quedas podem ser prevenidas até $30 \%$ se for realizada uma correta avaliação e gestão do risco.

Por último, o relato dessas ocorrências é fundamental para analisar as condições em que ocorreram os incidentes, permitindo quantificar sua frequência e tipologia (magnitude do problema e definir prioridades de intervenção) e, acima de tudo, possibilitar a aprendizagem e o conhecimento. Dessa forma, será possível diminuir ou evitar que situações idênticas ocorram no futuro.

\section{Referências}

Almeida R, Abreu C, Mendes A. Quedas em doentes hospitalizados: contributos para uma prática baseada na prevenção. Rev Enferm Referência. 2010 dez [citado 2013 out. 17]; Série 3(2):163-72. Disponível em http://www.scielo.oces.mctes.pt/pdf/ref/v3n2/v3n2a17.pdf

Anthony D. et al. Do risk assessment scales for pressure ulcers work. J Tissue Viability. 2010 [citado 2013 set 10]:132-5. Disponível em: http://www.sciencedirect.com/science/article/pii/ S0965206X09000588

Australian Red Cross Blood Service. Annual report 2011-2012. Sidney: The Service; 2012.

Bennett G, Dealey, C, Posnett J. The cost of pressure ulcers in the UK. Age Ageing. 2004 [citado 2013 set 27];33(3):230-5. Disponível em: http://ageing.oxfordjournals.org/content/33/3/230.long

Black J, Edsberg LE, Baharestani MM, Langemo D, Goldberg M, McNichol L, et al. Pressure ulcers: avoidable or unavoidable? Results of the National Pressure Ulcer Advisory Panel Consensus Conference. Ostomy Wound Manage. 2011 [citado 2013 set 10];57(2):24-37. Disponível em: http://www.npuap.org/wp-content/uploads/2012/01/A-UA-pr-ul1.pdf

Brem H, Maggi J, Nierman D, Rolnitzky L, Bell D, Rennert R, et al. High cost of stage IV pressure ulcers. Am J Surg. 2010 Oct [citado 2013 set 27];200(4):473-477. Disponível em: http://www.ncbi. nlm.nih.gov/pmc/articles/PMC2950802/pdf/nihms199415.pdf

Calman K. Cancer: science and society and the communication of risk. Br Med J. 1996;313:801.

Chaudhary R. Rationale use of blood components. Indian J Transf Med. 2011. Disponível em: http:// ijtm.in/view_article.php?id=16 
Dealey C, Posnett J, Walker A. The cost of pressure ulcers in the United Kingdom. J Wound Care. 2012;21(6):261-66.

Delgado M. A melhoria contínua da qualidade. In: Campos L, Borges M, Portugal R. Governação dos hospitais. Alfragide: Casa das Letras, 2009. p. 45-55.

Demarré L, Van Lancker A, Van Hecke A, Verhaeghe S, Grypdonck M, Lemey J, Annemans L, Beeckman D. The cost of prevention and treatment of pressure ulcers: a systematic review. Int J Nurs Stud. 2015 Nov;52(11): 1754-74.

Dzik S. Non-infectious serious hazards of transfusion. Blood Develop. 2002; 17:1-4.

Dzik WH. New technology for transfusion safety. Br J Haematol. 2006: 181-90.

European Pressure Ulcer Advisory Panel. International guideline: prevention of pressure ulcers: quick reference guide. Washington DC: EPUAP/NPUAP; 2009 [citado 2013 set 9]. Disponível em: http:// www.epuap.org/guidelines/Final_QuickTreatment.pdf.

European Network for Safety among Elderly. Fact sheet: prevention of falls among elderly. Athens: EUNESE, 2006 [citado 2013 out 18]. Disponível em: http://www.injuryobservatory.net/wp-content/ uploads/2012/08/Older-Guide-Prevention-of-Falls.pdf.

European Union. Project optimal blood use. Bruxelles: EU; 2010.

France D, Slayton J, Moore S, Domenico H, Matthews J, Steaban RL, et al. A multicomponent fall prevention strategy reduces falls at an Academic Medical Center. Jt Comm J Qual Patient Saf. 2017 Sept;43(9):460-70

Ganz D, et al. Preventing falls in hospitals: a toolkit for improving quality of care. Rockville: Agency for Healthcare Research and Quality, 2013 [citado 2013 out 20]. Disponível em: http://www.ahrq. gov/professionals/systems/long-term-care/resources/injuries/fallpxtoolkit/index.html.

Joint Commission on Accreditation Healthcare Organization. Blood transfusion errors: preventing future occurrences. Oakbrook Terrace (III): JCAHO; 2003. Retrieved from Pratice Alert:29.

Kiely P, Gambhir M, Cheng AC, McQuilten ZK, Seed CR, Wood EM. Emerging infectious diseases and blood safety: modeling the transfusion-transmission risk. Transfus Med Rev. 2017 July;31(3):154-64.

Klein H. How safe is blood, really? Biologicals. 2010;38:100-4.

Klein $\mathrm{H}$, et al. Pathogen inactivation: making decisions about new techonologies - report of a consensus conference. Transfusion. 2007: 47:2338-47.

Krombach J, et al. Human error: the persisting risk of blood transfusion: a report of five cases. Anesth Analg. 2002.

Makai P, Koopmanschap M, Bal R, Nieboer AP. Cost-effectiveness of a pressure ulcer quality collaborative. Cost Eff Resour Alloc. 2010 [citado 2013 set 11];8:11-24. Disponível em: http:// www.resource-allocation.com/content/pdf/1478-7547-8-11.pdf

Margato C, Miguéns C, Ferreira P, Gouveia J, Furtado K. Escala de Braden para avaliação de risco de úlceras por pressão. Versão validada para Portugal. [local desconhecido: editora desconhecida]; 2001.

McFarlane-Kolb H. Falls risk assessment, multitargeted interventions and the impact on hospital falls. Int J Nurs Pract. 2004 May [citado 2013 out 19];10:199-206. Disponível em http:// onlinelibrary.wiley.com/doi/10.1111/j.1440-172X.2004.00482.x/pdf.

McGuinness J, Persaud-Roberts S, Marra S, Ramos J, Toscano D, Policastro L, et al. How to reduce hospital-acquired pressure ulcers on a neuroscience unit with a skin and wound assessment team. Surg Neurol Int. 2012 [citado 2013 set. 17]; 3(1):138. Disponível em: http://www. surgicalneurologyint.com/temp/SurgNeurollnt31138-3771742_102837.pdf 
Miake-Lye IM, Hempel S, Ganz DA, Shekelle PG. Inpatient fall prevention programs as a patient safety strategy: a systematic review. Ann Intern Med. 2013 Mar 5 [citado 2013 out 20]. Disponível em: http://annals.org/article. aspx?articleid $=1656443$.

Ministério da Saúde (PT), Direção Geral da Saúde. Úlceras por pressão. Lisboa: MS, DGS, 2011 [citado 2013 set 9]. Disponível em http://www.dgs.pt/ms/8/pagina. aspx? codigoms=5521\&back=1\& codigono=001100150176AAAAAAAAAAAA.

Morse J. Preventing patient falls: establishing a fall intervention program. 2nd ed. New York: Springer Publ.; 2009.

Murphy MF, et al. Prevention of bedside errors in transfusion medicine (PROBE-TM) study: a cluster-randomized, matched-paired clinical areas trial a simple intervention to reduce errors in the pretransfusion bedside check. Transfusion 2007 May; 47:771-80.

National Blood Authority. 2013 [citado 2013 fev 12]. Disponível em: http://www.blood.gov.au

National Health Service, Patient Safety First (UK). The "How to guide" for reducing harm from falls. London: NHS, PSF; 2009 [citado 2013 out 17]. Disponível em: http://www.patientsafetyfirst.nhs.uk/ ashx/Asset.ashx?path=/Intervention-support/FALLSHow-to\%20Guide\%20v4.pdf.

National Institute for Health and Care Excellence. Falls: assessment and prevention of falls in older people. London: NICE; 2013 [citado 2013 out 20]. (NICE clinical guideline, 161). Disponível em: http://www.nice.org.uk/nicemedia/ live/14181/64088/64088.pdf.

National Patient Safety Agency, National Health Service (UK). Slips, trips and falls in hospital: the third report from the patient safety observatory. London: NPSA, NHS, 2007 [citado 2013 out 17]. Disponível em: http://www.nrls.npsa.nhs.uk/resources/?entryid45=59821.

Oliver D, et al. Risk facts and risk assessment tools for falls in hospital in-patients: a systematic review. Age Ageing. 2004 [citado 2013 out 17];33:122-33. Disponível em: http://ageing. oxfordjournals.org/content/33/2/122.long.

Organização Mundial da Saúde. Processo de Transfusão médica e segurança de pacientes. Genebra: OMS, 2010 [citado 2014 jun 25]. Disponível em: http://www.who.int/bloodsafety/clinical_use/who_ eht_10_05_pt.pdf

Peña J, Dzik W. Utilization management in the blood transfusion service. Clin Chim Acta. 2014:427:178-82. Dora

Pieper B, Langemo DE, Cuddigan J. Pressure ulcer pain: a systematic literature review and national pressure ulcer advisory panel white paper. Ostomy Wound Manage. 2009 Feb [citado 2013 set 9];55(2):16-31. Disponível em: http://www.npuap.org/wp-content/uploads/2012/01/Pieper_2009_ Feb1.pdf.

Posnett J, Franks P. The burden of chronic wounds in the UK. Nurs Times. 2008 [citado 2013 set 27]:44-5. Disponível em http://www.nursingtimes. net/the-burden-of-chronic-wounds-in-theuk/573423.article.

Potter P, Allen K, Costantinou E, Klinkenberg WD, Malen J, Norris T, et al. Evaluation of sensor technology to detect fall risk and prevent falls in acute care. Jt Comm J Qual Patient Saf. 2017 Aug;43(8):414-21

Pshegubj. My first earnings cheque. Flick, 2010 [citado 2014 jul 21]. Disponível em: http://www. flickr.com/photos/pshegubj/5161075477/.

Rhodes B. Ficheiro:Communitive midshaft humeral fracture callus.jpg. Wikipedia, 2004 [citado 2014 jul 21]. Disponível em: http://pt.wikipedia.org/wiki/Ficheiro:Communitive_midshaft_humeral_ fracture_callus.jpg.

Saraiva D, et al. Quedas: indicador da qualidade assistencial. Nursing. 2008 Jul;235:28-35. 
Sardo PMG, Guedes JAD, Alvarelhão JJM, Machado PAP, Melo EMOP. Pressure ulcer incidence and Braden subscales: Retrospective cohort analysis in general wards of a Portuguese hospital. J Tissue Viability. 2018 May [citado 2019 jan 20];27(2):95-100. Disponível em: https://www.sciencedirect. com/science/article/pii/S0965206X17300499?via\%3Dihub

Schwendimann R, et al. Falls and consequent injuries in hospitalized patients: effects of an interdisciplinary falls prevention program. Bio Med Central. 2006 Jun [citado 2013 out 18];6(69):1-7. Disponível em: http://www.ncbi.nlm.nih.gov/pmc/articles/PMC1534028/pdf/1472-6963-6-69.pdf.

Serious Hazards of Transfusion SHOT. Annual SHOT Report 2012. London: SHOT; 2013.

Serious Hazards of Transfusion SHOT. Annual SHOT report 2015. London: SHOT; 2015. Dora

Serious Hazards of Transfusion SHOT. SHOT Definitions of current categories \& what to report. Revised 2017. Manchester: SHOT; 2017 [citado 2019 jan 20]. Disponível em: https://www.shotuk. org/wp-content/uploads/SHOT-Definitions-Update-2017-FINAL-2.pdf

Skelton D, Todd C. What are the main risk factors for falls amongst older people and what are the most effective interventions to prevent these falls? Copenhagen: Health Evidence Network, WHO Regional Office for Europe, 2004 Mar [citado 2013 out 20]. Disponível em: http://www.euro.who. int/_data/assets/pdf_file/0018/74700/E82552.pdf.

Slawomirski L, Auraaen A, Klazinga N. The economics of patient safety: strengthening a valuebased approach to reducing patient harm at national level. [place unknown]: OECD; 2017.

Stainsby D, et al. Reducing adverse events in blood transfusion. Br J Haematol. 2005:131.

Sullivan N, Schoelles K. Preventing in facility pressure ulcers as a patient safety strategy. Ann Intern Med. 2013 [citado 2013 set 10]: 410-6. Disponível em: http://annals.org/article. aspx? articleid=1657885.

World Health Organization, Department of Essencial Health Tecnologies. Blood transfusion safety. Geneve: WHO; 2006.

World Health Organization, Department of Essencial Health Tecnologies. Blood transfusion safety. Geneva: WHO; 2006.

World Health Organization. Falls. Genéve: WHO; 2012 Oct [citado 2013 out 21]. (Fact sheet; n. 344). Disponível em: http://www.who.int/mediacentre/factsheets/fs344/en/.

The Yorck Project. Ficheiro:Vincent Willem van Gogh 002.jpg. Wkipedia, 2005 [citado 2014 jul 21]. Disponível em: http://pt.wikipedia.org/wiki/Ficheiro:Vincent_Willem_van_Gogh_002.jpg. 


\section{Segurança do paciente na Atenção Primária à Saúde}

Simone Grativol Marchon e Walter Mendes

Este capítulo apresenta os incidentes, os erros mais frequentes, métodos específicos para avaliá-los e possíveis soluções para mitigar os eventos adversos na Atenção Primária à Saúde (APS).

\section{Atenção Primária à Saúde}

Os sistemas de saúde, em todo o mundo, vêm apontando necessidades de estabelecer estratégias mais ativas e intensivas de melhoria da qualidade nos diferentes níveis de atenção. Destaca-se a APS, em virtude de ser um modelo de atenção que funciona como eixo organizador dos sistemas de saúde.

Desde a Conferência Internacional da Organização Mundial de Saúde (OMS), em Alma-Ata (Figura 1), cidade do Cazaquistão, na antiga União Soviética, em 1978, considera-se a APS a chave do equilíbrio de um sistema de saúde moderno, pois proporcionava enfoque mais equânime, abordagem mais centrada no paciente, gestão da doença baseada na comunidade e medicina mais preventiva (WHO 1978). 
Figura 1 - Cartaz da conferência de Alma-Ata

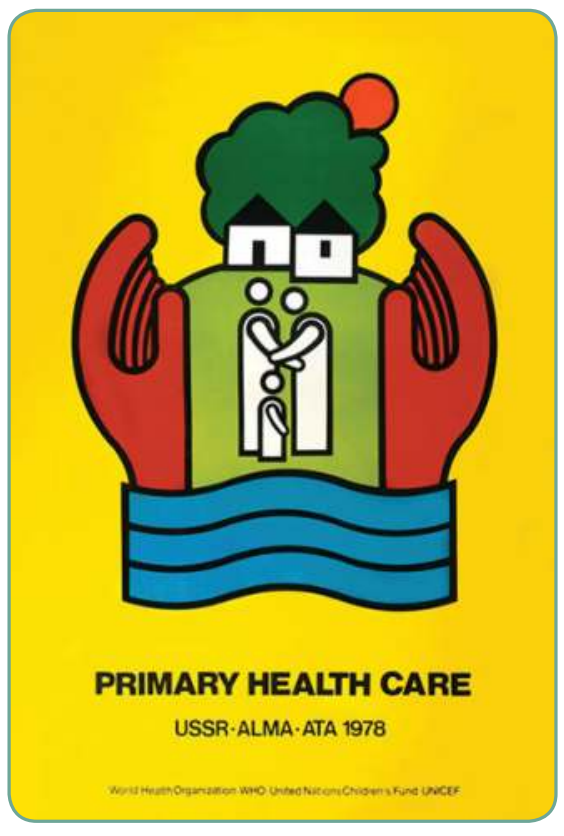

Fonte: WHO (2008b).

A transição para modelos de sistema de saúde baseados na APS, no entanto, não ocorreu de forma retilínea nos diversos países. Houve progresso considerável em algumas partes do mundo, mas, em certos países, principalmente os de renda média e baixa, persiste a oferta baseada em cuidados especializados (WHO 2012a). Há, porém, crescente percepção de que, em virtude do aumento das demandas sobre os sistemas de saúde, modelos mais eficientes precisam ser desenvolvidos. Tal aumento decorre do crescimento da mobilidade social proveniente da globalização e do envelhecimento da população, o que fortalece a opção por sistemas de saúde baseados na APS (WHO 2012a).

O cuidado realizado no primeiro nível de atenção está mais próximo das pessoas, e é possível identificar melhor os resultados dos indicadores de saúde, que mostram menor custo e maior satisfação dos usuários/ utentes (Starfield 2002). A APS é geralmente realizada por médicos clínicos gerais, embora existam variações, dependendo da organização do sistema de saúde de cada país (Starfield 2002). A APS é o nível da atenção mais utilizado pela população, como porta de entrada preferencial, e apresenta, como um dos seus atributos, a coordenação de uma rede de atenção à saúde.

World Health Organization Declaration of Alma-Ata (1978). Disponível em: http:// cmdss2011.org/site/wpcontent/uploads/2011/07/ Declara\%C3\%A7\%C3\%A3oAlma-Ata.pdf

Nas últimas décadas, a APS tem se tornado mais complexa (Mendes 2012). A concepção de que a APS não é sinônimo de baixa densidade tecnológica vem se fortalecendo. Com o aumento da complexidade tecnológica do cuidado à saúde, houve ampliação das funções clínicas da APS. 
Cuidados que eram prestados em outros níveis de complexidade da atenção passaram a ser realizados na APS (Mendes 2012), havendo maior preocupação com a identificação das necessidades de saúde dos usuários/utentes se comparado com outros serviços.

A OMS, recentemente, identificou cinco elementos-chave a fim de que a APS atinja o objetivo de melhorar a saúde para todos (http://www. who.int/topics/primary_health_care/en/):

滕 reduzir a exclusão e as disparidades sociais na saúde (reformas na cobertura universal);

* organizar serviços de saúde em torno das necessidades e expectativas das pessoas (reformas na prestação de serviços);

噄integrar a saúde em todos os setores (reformas nas políticas públicas);

路 buscar modelos colaborativos/adjuvantes de diálogo político (reformas na liderança);

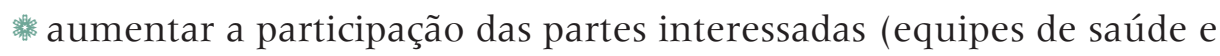
usuários/utentes).

A luta pela segurança dos pacientes na APS se insere nas reformas propostas pela OMS, sendo importante implementar mudanças para promover uma cultura de segurança positiva.

\section{Atenção Primária à Saúde e a segurança do paciente}

Embora a maioria dos cuidados seja prestada por serviços de APS, as pesquisas/investigações sobre a segurança dos pacientes têm sido centradas na assistência hospitalar, com muito mais publicações quando comparadas às realizadas na APS. Os cuidados hospitalares são de maior complexidade e de maior risco, por isso é natural que esse ambiente seja o foco principal das investigações.

No Capítulo 2 deste livro, foram apresentados os momentos históricos relevantes para a segurança do paciente. Entretanto, no contexto da APS, o relatório elaborado em 2006 pelo Comitê Europeu de Segurança do Paciente foi o marco mais importante. Esse comitê indicou a necessidade de incrementar os estudos de segurança do paciente na APS (Sousa 2006). Logo após, em 2008, a OMS constatou que, da forma como está organizada a prestação de cuidados na APS, não existe a possibilidade de mitigar os efeitos dos incidentes nos pacientes, conforme descrito no relatório Cuidados de Saúde Primários - Agora Mais Que Nunca (WHO 2008a): 
Um sistema mal pensado que é incapaz de garantir níveis de segurança e higiene, levando a elevadas taxas de infecções, juntamente com erros de medicação e outros eventos adversos que são evitáveis e que constituem causas de morte e de falta de saúde, muitas vezes subestimadas (WHO 2008a).

Quando o relatório da OMS de 2008 foi elaborado, havia poucas pesquisas/investigações a respeito dos riscos para os pacientes submetidos ao atendimento primário e ambulatorial, bem como do impacto à sua saúde. Entretanto, vários estudos sobre incidência de eventos adversos (EAs) em hospitais, baseados em revisão retrospectiva de prontuários/ processos clínicos - descritos no Capítulo 5 deste livro -, já mostravam que uma fração dos EAs identificados durante a internação/internamento tinham ocorrido antes da admissão do paciente no hospital, sendo possível terem sucedido na APS. No estudo canadense/canadiano, para citar um exemplo, $31 \%$ dos EAs ocorreram antes da admissão e foram detectados durante a internação/internamento (Baker et al. 2004).

A OMS, em fevereiro de 2012, constituiu um grupo - Safer Primary Care Expert Working Group - para estudar os riscos em pacientes sob cuidados primários, a magnitude e a natureza do dano evitável, em razão das práticas inseguras nesses ambientes, e os mecanismos de proteção e segurança ao paciente na APS (WHO 2012b).

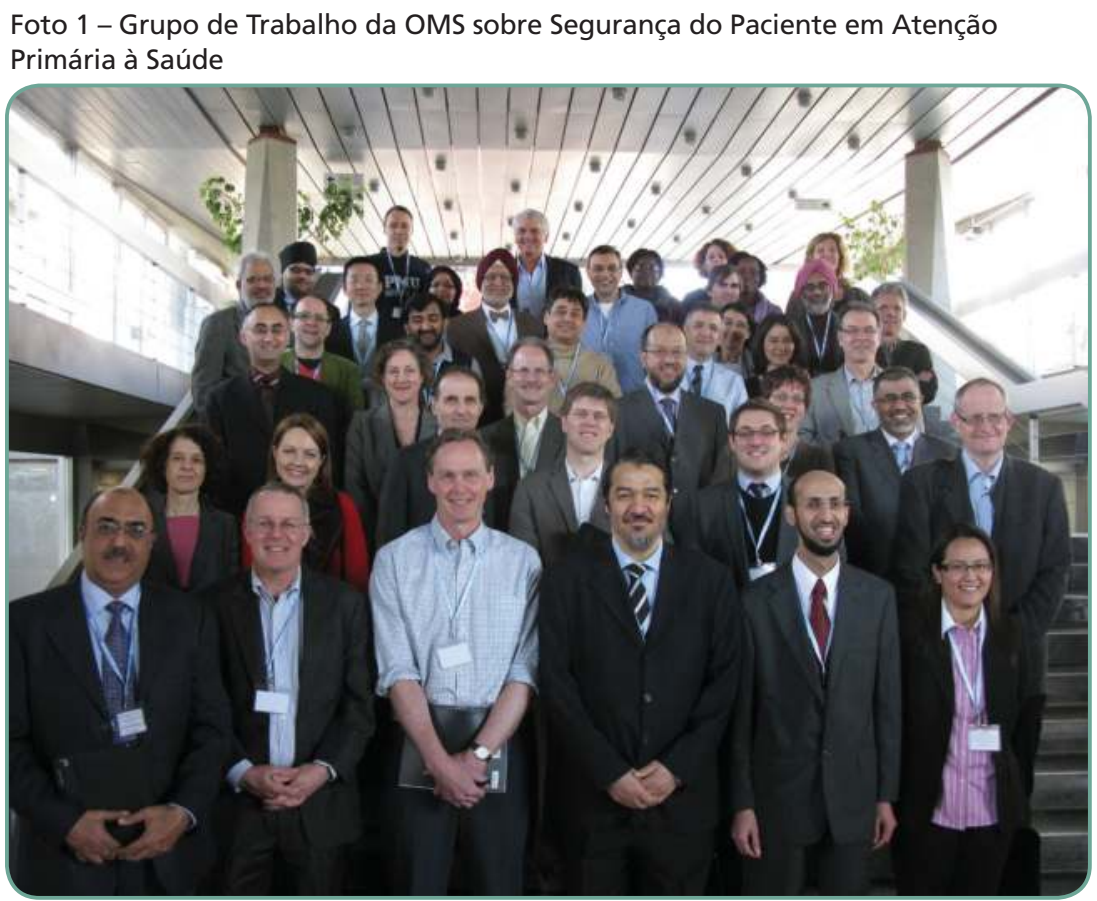

Fonte: http://www.who.int/patientsafety/safer_primary_care/en/ 
Pesquisadores/investigadores que participam desse grupo da OMS, sob a liderança da professora Meredith Makeham, publicaram um artigo de revisão sistemática denominado Methods and Measures used in Primary Care Patient Safety Research" (Makeham et al. 2008), cujo objetivo foi conhecer as metodologias disponíveis para a realização de pesquisas/ investigações sobre segurança do paciente em APS e os tipos de EAs mais frequentes.

Nesse estudo (Makeham et al. 2008), ficou demonstrado que incidentes decorrentes da APS também são frequentes. Existem riscos específicos na APS tanto por causa do ambiente como pelo tipo de cuidado de saúde prestado. Essa revisão sistemática mostrou, entretanto, que os estudos sobre segurança do paciente na APS ainda estão na fase de infância (Makeham et al. 2008). Uma revisão, realizada pelos autores deste capítulo, reforçou tal afirmativa (Marchon, Mendes 2014).

\section{Os métodos e os resultados dos estudos sobre a Atenção Primária à Saúde e a segurança do paciente}

Vários métodos têm sido adotados para avaliar incidentes em saúde. Discutem-se os pontos fortes e fracos de cada um deles a fim de selecionar o mais adequado em função do que se quer medir (Thomas, Petersen 2003). Contudo, existem diferenças sobre o tipo de incidente, em especial o incidente com lesão, ou seja, o EA. Enquanto a maioria dos EAs dos pacientes hospitalizados está associada à cirurgia e ao tratamento medicamentoso (De Vries et al. 2008), na APS, os EAs mais frequentes relacionam-se ao tratamento medicamentoso e ao diagnóstico (Makeham et al. 2008).

Há diferenças, também, sobre as metodologias usadas no hospital e na APS para medir os EAs e compreender suas causas. A maior parte dos estudos hospitalares tem utilizado a revisão retrospectiva de prontuários/processos clínicos (De Vries et al. 2008) como método. Já nos estudos sobre APS, o método mais empregado é a análise de incidentes (Makeham et al. 2008) informados por sistemas de notificação/reporte. Nos hospitais, considerando apenas os estudos de revisão retrospectiva de prontuários/processos clínicos, a incidência média de EAs é 9,2\%, e a proporção média de EAs evitáveis (média da proporção de EAs evitáveis entre todos os EAs) é de 43,5\% (De Vries et al. 2008). Na APS, a frequência de incidentes variou muito, de 0,004 a 240 por mil consultas, e a proporção de incidentes evitáveis variou de $45 \%$ a $76 \%$, dependendo do método empregado na pesquisa/investigação (Makeham et al. 2008).

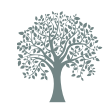

Importante que você leia a literatura de apoio, para dar continuidade ao conteúdo do capítulo. Os artigos sugeridos a seguir the ajudarão a avançar nos estudos:

Makeham M, Dovey S, Runciman W, Larizgoitia I. Methods and measures used in primary care patient safety research. Geneva: World Health Organization; 2008. Disponível em: http:// www.who.int/patientsafety/ research/methods_measures/ makeham_dovey_full.pdf

Sequeira AM, Martins L, Pereira VH. Natureza e frequência dos erros na actividade de medicina geral e familiar geral num ACES: estudo descritivo. Rev Port Clin Geral. 2010;26:572-84. Disponível em: rpmgf.pt/ ojs/index.php/rpmgf/article/ download/10800/10536 
Ressalvamos que, na área de pesquisa/investigação sobre a segurança do paciente, por ser relativamente recente, questões sobre a validade e identificação de métodos aplicados na mensuração de incidentes na APS são levantadas, contudo precisam ser mais estudadas.

Numa revisão sistemática (Marchon, Mendes 2014), foram descritas diversas fontes de coleta/recolha de dados para identificar incidentes, sendo o sistema de notificação/reporte de incidentes o mais encontrado na literatura. Dados também foram obtidos por meio de grupos focais, entrevistas e questionários respondidos por médicos e outros profissionais de saúde, pacientes e familiares (Marchon, Mendes 2014).

Ainda nessa revisão de literatura (Marchon, Mendes 2014), os autores identificaram como fatores contribuintes de incidentes:

1. (i) falhas na comunicação interprofissional e com o paciente;

2. (ii) falhas na gestão, tais como: falta de insumos e de medicamentos, profissionais pressionados para serem mais produtivos em menos tempo, falhas em prontuários/ processos clínicos, falhas na recepção dos pacientes, planta física da unidade de saúde inadequada, descarte inadequado de resíduos da unidade de saúde, tarefas excessivas e falhas no cuidado.

Segundo The Health Foundation - instituição acadêmica que trabalha em parceria com o sistema de saúde do Reino Unido -, cerca de 1 a 2\% das consultas de APS podem causar incidentes, e o tipo de EA mais comum é o relacionado ao tratamento medicamentoso (Estudio APEAS 2008). O fator contribuinte para os incidentes mais encontrado foi a falha na comunicação. Na revisão de literatura de Makeham e colaboradores/ adjuvantes (2008), os incidentes mais comumente encontrados nos estudos selecionados foram por causa de:

橉 erros de diagnóstico (26\% a $57 \%)$;

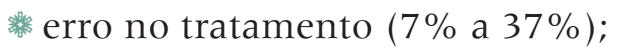

tratamento medicamentoso (13\% a 53\%);

路 decorrente da forma da organização do serviço (9\% a 56\%).

Nessa revisão, a comunicação interprofissionais e entre os profissionais e os pacientes ( $5 \%$ a $72 \%$ ) também foi o maior/major fator contribuinte para os incidentes. 
O estudo espanhol (Estudio APEAS 2008), liderado pelo pesquisador/ investigador Jesus Aranaz, em 48 centros de APS de 16 Comunidades Autônomas da Espanha, revelou que, em um universo de 96.047 pacientes e 452 profissionais, foram identificados 18,63\% de EAs. A distribuição por tipo de EAs foi:

腆 48,2\%, relacionados com o tratamento medicamentoso;

25,7\% com os cuidados em geral; e

膦 $13,1 \%$ com o diagnóstico.

A falha na comunicação entre os profissionais ou entre os profissionais e o paciente foi o fator contribuinte mais frequente. Os EAs mais encontrados foram: agravamento na evolução da doença; náuseas, vômitos ou diarreia secundários à medicação; prurido, rashes ou lesões dermatológicas secundárias à medicação; infecção de ferida cirúrgica e/ou traumática e alterações neurológicas secundárias à medicação. É importante destacar que, nesse estudo, 70,2\% dos EAs foram considerados evitáveis.

De acordo com Aranaz e colaboradores/adjuvantes (2008), a revisão retrospectiva de prontuários/processos clínicos em hospitais é o padrão-ouro em estudos de mensuração de EAs, mas, na APS, não existe tal padrão. A pesquisa/investigação quantitativa na APS é considerada imatura, e as medidas de ocorrência de incidentes não têm se mostrado robustas (Makeham et al. 2008).

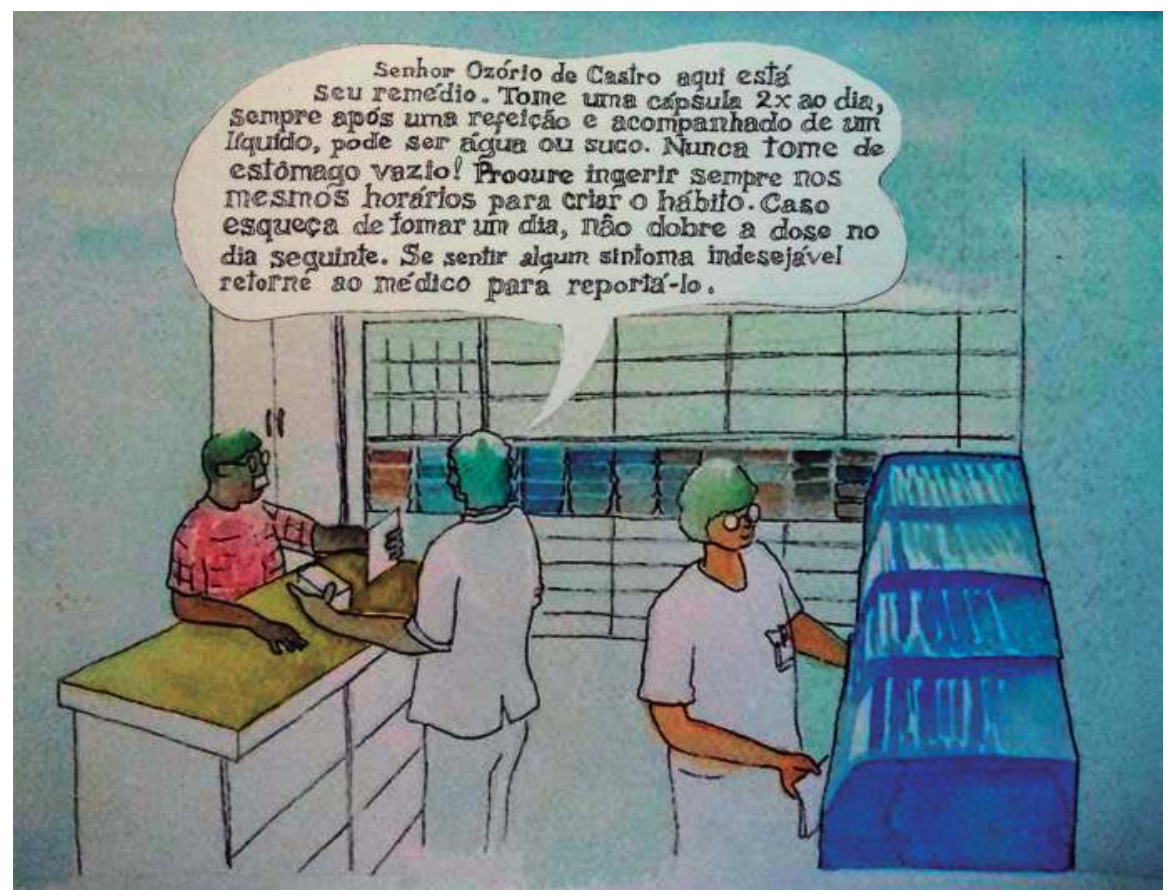

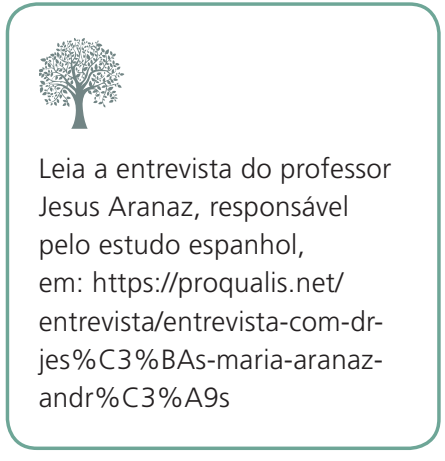


O método mais utilizado para avaliar erros no cuidado ou EAs é a análise dos incidentes registrados nos sistemas de notificação/reporte de incidentes e auditorias/revisões. Os estudos (Hickner et al. 2008; Wallis, Dovey 2011 ) que utilizaram esse método apontaram, como causas mais frequentes de incidentes na APS, aquelas relacionadas aos medicamentos $(32,5 \%)$ e ao erro de diagnóstico $(30,9 \%)$.

Outro método muito usado para avaliar os fatores contribuintes dos incidentes (Makeham et al. 2008) é a entrevista com profissionais de saúde da APS. Estudos (Balla et al. 2012; Gaal et al. 2010) indicaram a ocorrência de erros frequentes: relacionados a medicamentos; ao diagnóstico, causados por falhas nos registros dos pacientes; e originados pela pressão, a fim de que os profissionais diminuíssem o tempo do cuidado.

Alguns estudos utilizaram como método o emprego de questionários para avaliar os incidentes. Em um estudo (Mira et al. 2010) que analisou os EAs, relatados pelos pacientes, e os aspectos organizacionais do serviço de saúde, concluiu-se que os fatores contribuintes preponderantes são as falhas na comunicação entre médicos e pacientes. Outro estudo (O'Beirne et al. 2011) mostrou que os médicos e enfermeiros relatam mais incidentes ocorridos com os pacientes do que os profissionais administrativos. Nesse estudo, os principais incidentes relatados fizeram referência à documentação, tratamento medicamentoso, gestão dos serviços e registro clínico.

Alguns estudos (Buetow et al. 2010; Manwell et al. 2009) empregam o método de grupo focal para analisar a ocorrência de incidentes na APS. Neles, existe considerável variação nas respostas sobre a importância dos erros, em função da diversidade da composição dos grupos focais. Entretanto, a falha na comunicação, a pressão para diminuir o tempo do atendimento e o sistema de informação inadequado foram os fatores contribuintes mais relevantes.

Vários pesquisadores/investigadores recorrem a uma combinação de métodos para analisar melhor os incidentes em APS. Em estudos (Cañada Dourado et al. 2011; Harmsen et al. 2010) nos quais foram empregadas a análise de incidentes em sistemas de notificações/reportes e auditorias, análise observacional e grupo focal, observou-se que cerca de 1 a $5 \%$ das consultas de cuidados primários originaram EAs. Nesses estudos, os principais fatores contribuintes foram relacionados à organização do trabalho, tais como tarefas excessivas e baixa capacidade de integração dos profissionais com os pacientes. Outro estudo (Wetzels et al. 2009) com combinação de métodos, que utilizou a aná- 
lise de incidentes em sistemas de notificações/reportes e auditorias, revisão de prontuários/processos clínicos e entrevistas, evidenciou que cerca de $50 \%$ dos incidentes não atingiram o paciente. Em 33\%, houve internação/internamento hospitalar não planejada em razão da piora dos sintomas, e, em $75 \%$ dos incidentes avaliados, havia potencial para causar dano à saúde.

Os incidentes relacionados ao cuidado ocorrem em países de todos os níveis de evolução, e as evidências sugerem que o impacto é proporcionalmente maior em países em desenvolvimento (WHO 2010). Alguns autores (Sousa et al. 2010) defendem que a investigação em segurança do paciente deve, de forma primordial, centrar-se nos fatores contribuintes, na dimensão, na natureza e no impacto dos incidentes decorrentes da APS, sobretudo em países nos quais esse conhecimento não existe ou é escasso.

Austrália, EUA, Reino Unido, Espanha e outros têm realizado estudos sobre a segurança do paciente na APS, mas, na maioria dos países, ainda não são desenvolvidas pesquisas/investigações sobre a segurança do paciente na APS. Estabelece-se, assim, um desafio para equipes que estudam e tentam melhorar a segurança dos cuidados de saúde primários em vários contextos e configurações socioeconômicas.

Os primeiros estudos estão sendo publicados na América Latina, confirmando a alta frequência de incidentes medicamentosos e uma associação com as condições socioeconômicas dos pacientes (Montserrat-Capella 2015).

No Brasil, um trabalho pioneiro (Marchon 2015) utilizou um questionário para profissionais de saúde no conexto da estratégia da saúde da família, baseado no estudo australiano Primary Care International Study of Medical Errors (Pcisme), na intenção de avaliar a segurança do paciente na APS. Método esse aplicado também em outros países, tais como Austrália, Portugal, França e Alemanha. Trata-se de um questionário para avaliar se houve algum incidente durante o cuidado, e, se tiver ocorrido, caracterizar e conhecer sua gravidade e os fatores que contribuíram para sua ocorrência (Makeham et al. 2008). O questionário, adaptado para a realidade brasileira, está demonstrado no Quadro 1.

Quadro 1 - Questionário Pcisme adaptado para a realidade brasileira

\begin{tabular}{|l|l|}
\hline Profissional $n^{\circ}$ & Incidente relatado no \\
\hline Questões & Alternativas de respostas \\
\hline $\begin{array}{l}\text { O incidente está relacionado com um } \\
\text { paciente em particular? }\end{array}$ & Sim ou Não \\
\hline
\end{tabular}


Quadro 1 - Questionário Pcisme adaptado para a realidade brasileira (cont.)

\begin{tabular}{|c|c|}
\hline Profissional $n^{\circ}$ & Incidente relatado no \\
\hline Questões & Alternativas de respostas \\
\hline Se sim, até que ponto conhece o paciente? & $\begin{array}{l}\text { - Não conheço } \\
\text { - Conheço, mas não é meu paciente } \\
\text { • Conheço pouco (é a } 1^{\text {a }} \text { vez do paciente na consulta) } \\
\text { - Conheço bem (é meu paciente) }\end{array}$ \\
\hline $\begin{array}{l}\text { Idade do paciente (em anos). } \\
\text { Para crianças menores de } 1 \text { ano, usar } \\
\text { meses }\end{array}$ & Texto livre \\
\hline Sexo do paciente & Masculino ou Feminino \\
\hline $\begin{array}{l}\text { O paciente pertence a um grupo com } \\
\text { vulnerabilidade social? } \\
\text { Se SIM, qual? }\end{array}$ & $\begin{array}{l}\text { Sim ou Não } \\
\text { Texto livre }\end{array}$ \\
\hline $\begin{array}{l}\text { O paciente tem um problema de doença } \\
\text { crônica? }\end{array}$ & Sim ou Não \\
\hline $\begin{array}{l}\text { O paciente tem um problema de saúde } \\
\text { complexo? (condição de difícil manejo } \\
\text { clínico, presença de comorbidades/ } \\
\text { comorbilidades, dependência de álcool } \\
\text { e/ou drogas, distúrbios neurológico ou } \\
\text { psiquiátrico) }\end{array}$ & Sim ou Não \\
\hline $\begin{array}{l}\text { O que aconteceu? Por favor, considere o } \\
\text { que, quem esteve envolvido: } \\
\text { Quem? (não colocar nomes, apenas a } \\
\text { categoria profissional: médico, enfermeiro, } \\
\text { técnico de laboratório, recepcionista etc.) }\end{array}$ & $\begin{array}{l}\text { - Houve um incidente, mas não chegou a atingir o } \\
\text { paciente } \\
\text { - Houve um incidente, que atingiu o paciente, mas não } \\
\text { causou dano ao paciente } \\
\text { - Houve um incidente, que atingiu o paciente e causou } \\
\text { dano ao paciente }\end{array}$ \\
\hline $\begin{array}{l}\text { Qual foi o resultado? Identifique as } \\
\text { consequências reais e potenciais, ou algum } \\
\text { outro tipo consequência. }\end{array}$ & Texto livre \\
\hline $\begin{array}{l}\text { O que pode ter contribuído para esse } \\
\text { erro? Por favor, considere quaisquer } \\
\text { circunstâncias especiais. }\end{array}$ & Texto livre \\
\hline $\begin{array}{l}\text { O que poderia ter prevenido o erro? Por } \\
\text { favor, considere o que deve mudar para } \\
\text { evitar repetição desse tipo de erro. }\end{array}$ & Texto livre \\
\hline
\end{tabular}


Quadro 1 - Questionário Pcisme adaptado para a realidade brasileira (cont.)

\begin{tabular}{|c|c|}
\hline Profissional $n^{\circ}$ & Incidente relatado no \\
\hline Questões & Alternativas de respostas \\
\hline $\begin{array}{l}\text { Onde aconteceu o erro? (escolha todas as } \\
\text { opções que se aplicam) }\end{array}$ & $\begin{array}{l}\text { - Consultório } \\
\text { - Hospital/serviços de urgência } \\
\text { - Na farmácia } \\
\text { - No laboratório } \\
\text { - No RX onde realizou exames } \\
\text { - Consultório de enfermagem } \\
\text { - Domicílio do paciente } \\
\text { - No contato telefônico } \\
\text { - Atendimento administrativo } \\
\text { - Outros locais: }\end{array}$ \\
\hline $\begin{array}{l}\text { Teve conhecimento de que outro paciente } \\
\text { tenha sofrido este tipo de erro? }\end{array}$ & Sim ou Não \\
\hline $\begin{array}{l}\text { Se sim, como classificaria a gravidade desse } \\
\text { dano? }\end{array}$ & $\begin{array}{l}\text { - Dano mínimo (com recuperação de até um mês) } \\
\text { - Dano moderado (recuperação entre um mês e um } \\
\text { ano) } \\
\text { - Dano permanente } \\
\text { - Óbito } \\
\text { - Não tenho como classificar }\end{array}$ \\
\hline $\begin{array}{l}\text { Com que frequência ocorre esse erro na } \\
\text { sua prática? }\end{array}$ & $\begin{array}{l}\text { - Primeira vez } \\
\text { - Raramente (1 a } 2 \text { vezes por ano) } \\
\text { - Às vezes (3 a } 11 \text { vezes por ano) } \\
\text { - Frequentemente (mais de } 1 \text { vez por mês) }\end{array}$ \\
\hline
\end{tabular}

Fonte: Marchon (2015).

Os tipos de erros que contribuíram com os incidentes e sua distribuição podem ser conferidos no Gráfico 1 (Marchon 2015). 
Gráfico 1 - Erros que contribuíram para incidentes

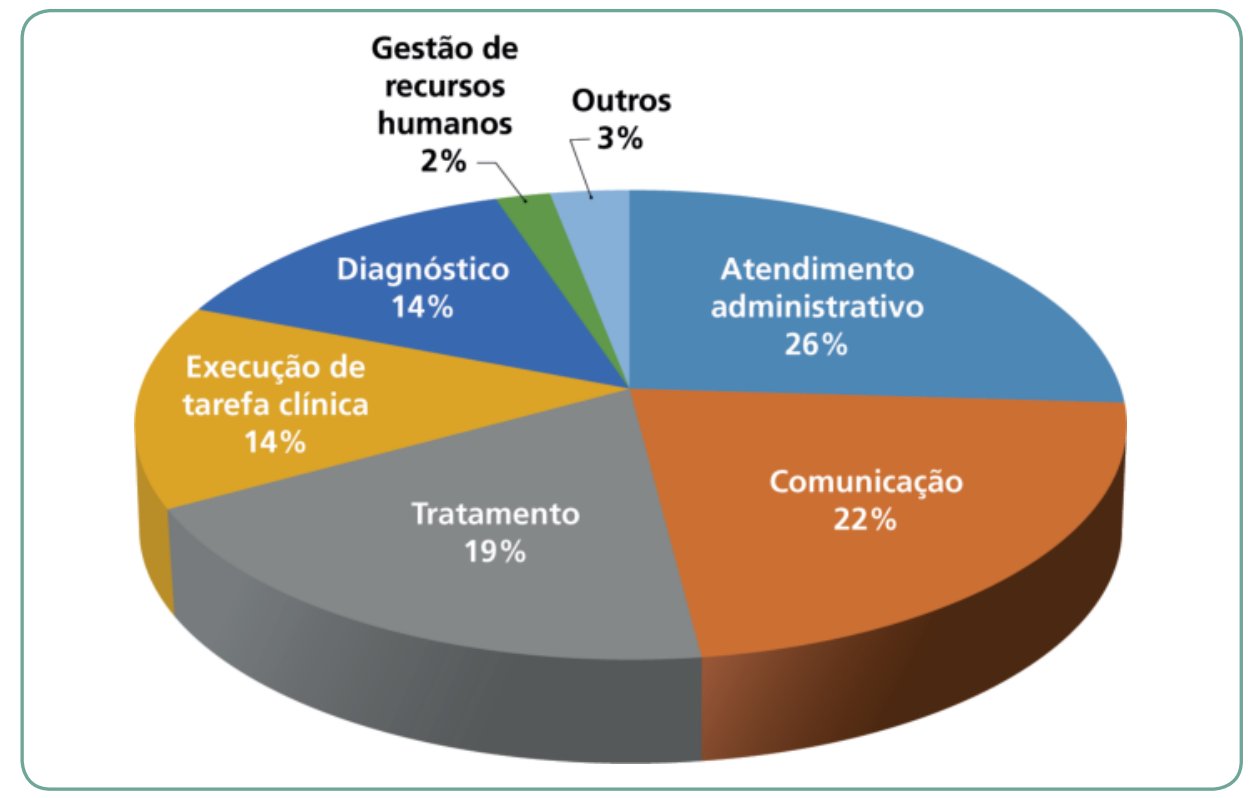

Fonte: Marchon (2015).

Os fatores que contribuíram com os incidentes estão distribuídos como mostrado no Gráfico 2 (Marchon 2015).

Gráfico 2 - Fatores contribuintes dos incidentes

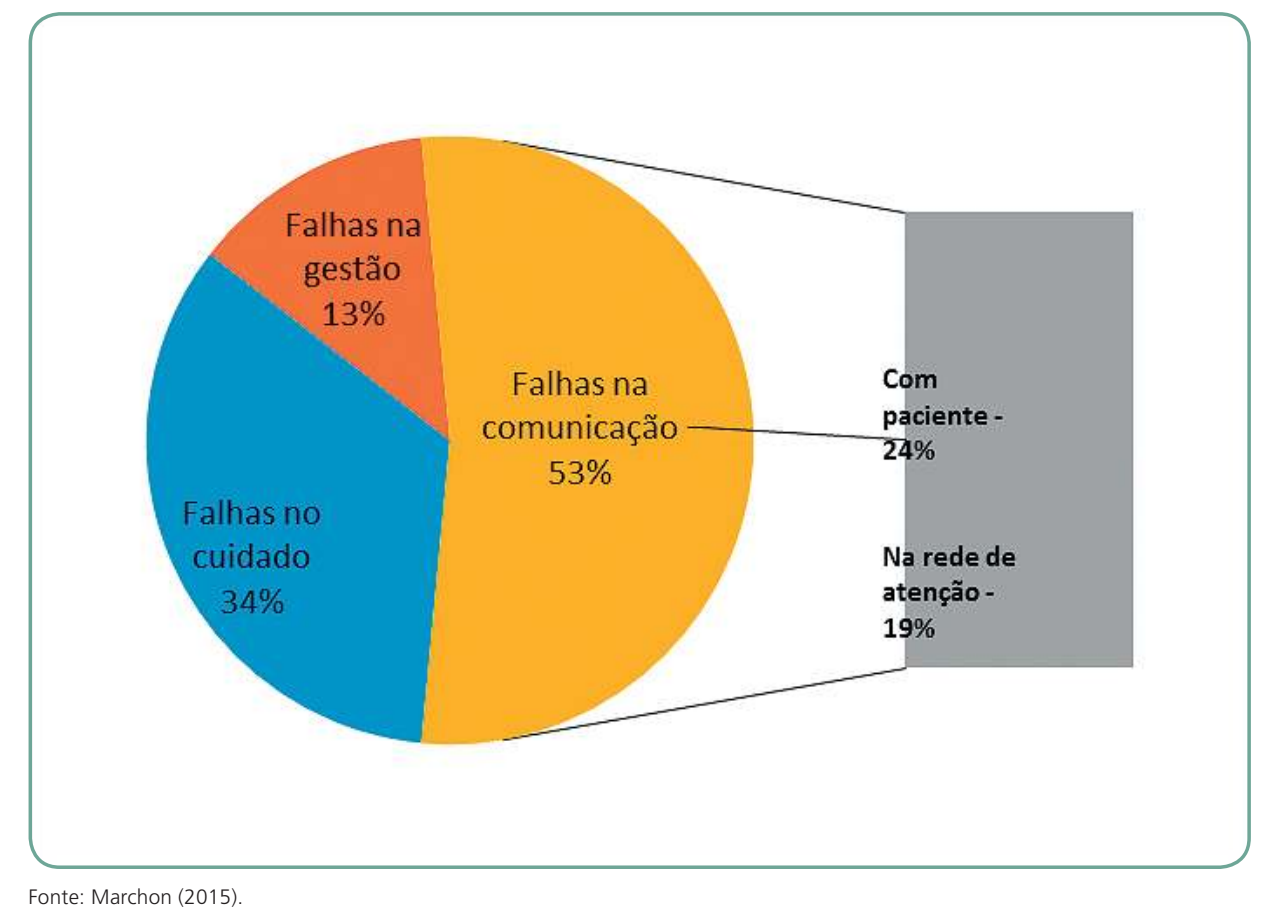


Os profissionais que colaboraram na pesquisa/investigação apresentaram como dificuldades para o bom relacionamento da equipe as diferenças de opinião, de visão profissional, de formação acadêmica, de cultura de segurança do paciente, de comportamento, de escolaridade, de hierarquização profissional e de responsabilização com o paciente (Marchon 2015).

\section{Para refletir}

Avaliando o que acontece em sua organização, quais os tipos de erro que mais contribuem para ocorrência de incidentes? Quais fatores você acredita serem os principais responsáveis por esses erros? Que medidas mais imediatas poderiam ser tomadas para melhorar esse quadro?

A OMS recomenda que pesquisas/investigações e intervenções sobre o tema entrem nas agendas de todos os países por causa das oportunidades de melhoria da segurança do paciente (Sousa 2006). Para orientar a pesquisa/investigação em países com dificuldades de obter informações mais concisas, a OMS lançou, em 2010, Assessing and tackling patient harm: a methodological guide for data poor hospitals [Avaliando e evitando a ocorrência de danos ao paciente: um guia metodológico para hospitais com escassez de dados] (WHO 2010, tradução nossa), em que descreve metodologias que podem ser utilizadas para estimar a extensão dos danos causados durante os cuidados de saúde ou implementar ações prioritárias relativas a questões de segurança do paciente.

\section{Soluções para prevenir ou mesmo mitigar as causas mais frequentes dos erros na Atenção Primária à Saúde}

Apesar da insuficiência de pesquisas/investigações sobre incidentes na APS, existem soluções amplamente reconhecidas para prevenir ou mesmo mitigar as causas mais frequentes dos erros. É de suma importância adotar medidas individuais e organizacionais, de forma a reduzir e até prevenir incidentes nos cuidados primários, apontando soluções (Quadro 2) (Ribas 2010). 
Quadro 2 - Os principais incidentes e fatores contribuintes na APS e as soluções

\begin{tabular}{|c|c|}
\hline Tipo de incidentes & Soluções \\
\hline $\begin{array}{l}\text { Falha no tratamento medicamentoso: } \\
\text { Troca de medicação } \\
\text { Interação medicamentosa } \\
\text { Prescrição duplicada de princípios ativos iguais } \\
\text { ou sobrepostos em sua ação } \\
\text { Atraso no início de tratamento } \\
\text { Troca de pacientes }\end{array}$ & $\begin{array}{l}\text { Normalizar apresentação da informação sobre } \\
\text { o medicamento. } \\
\text { Gerenciar medicamentos de aspecto e nome } \\
\text { parecidos. } \\
\text { Promover medidas de segurança na aplicação } \\
\text { de injetáveis. } \\
\text { Conciliar os tratamentos entre níveis de } \\
\text { cuidados. } \\
\text { Introduzir alertas de segurança nas prescrições. } \\
\text { Explicar a prescrição ao paciente. }\end{array}$ \\
\hline $\begin{array}{l}\text { Erro no diagnóstico: } \\
\text { Atraso ou ausência de diagnóstico } \\
\text { Atraso ou ausência de avaliação de resultados } \\
\text { de exames } \\
\text { Interpretação incorreta de resultados } \\
\text { Vieses de decisão } \\
\text { Troca de identificação de pacientes }\end{array}$ & $\begin{array}{l}\text { Introduzir alertas e follow-ups de resultados } \\
\text { anormais. } \\
\text { Normalizar a nomenclatura e interpretação dos } \\
\text { exames. } \\
\text { Disponibilizar sistemas de apoio à decisão. }\end{array}$ \\
\hline $\begin{array}{l}\text { Inadequada comunicação interprofissional: } \\
\text { Troca de pacientes }\end{array}$ & $\begin{array}{l}\text { Minimizar o uso de instruções verbais ou } \\
\text { telefônicas, preferindo, sempre que possível, o } \\
\text { contato pessoal. }\end{array}$ \\
\hline $\begin{array}{l}\text { Inadequada comunicação com o paciente: } \\
\text { Atraso ou falha na comunicação com o } \\
\text { paciente } \\
\text { Comunicação ineficaz entre médico e paciente } \\
\text { sobre o diagnóstico ou medicação }\end{array}$ & $\begin{array}{l}\text { Educar permanentemente em anamnese. } \\
\text { Verificar sistematicamente a identidade dos } \\
\text { pacientes, cruzando mais que um dado de } \\
\text { identificação (por exemplo: nome e data de } \\
\text { nascimento). } \\
\text { Encorajar o paciente a participar de forma ativa } \\
\text { do processo. } \\
\text { Partilhar experiências de near miss, EAs e } \\
\text { eventos- } \\
\text {-sentinela com os pacientes. } \\
\text { Fornecer informação clara e escrita sempre que } \\
\text { possível. } \\
\text { Implementar registro clínico único. }\end{array}$ \\
\hline $\begin{array}{l}\text { Falhas na organização do serviço de saúde: } \\
\text { Conciliar os tratamentos entre os diferentes } \\
\text { níveis de complexidade dos cuidados } \\
\text { Falta de protocolos para todas as intervenções, } \\
\text { desde a entrada até a saída do paciente }\end{array}$ & $\begin{array}{l}\text { Estabelecer procedimentos de avaliação e } \\
\text { prevenção de incidente em todo o circuito do } \\
\text { paciente dentro do sistema de saúde. } \\
\text { Utilizar simulação de casos. } \\
\text { Atualizar os procedimentos periodicamente, } \\
\text { de forma a incorporar as técnicas mais seguras } \\
\text { com o conhecimento científico mais atual. }\end{array}$ \\
\hline
\end{tabular}


Quadro 2 - Os principais incidentes e fatores contribuintes na APS e as soluções (cont.)

\begin{tabular}{|l|l|}
\hline Tipo de incidentes & Soluções \\
\hline $\begin{array}{l}\text { Inadequados registros clínicos: } \\
\text { Tusência de registros (dados do paciente) }\end{array}$ & $\begin{array}{l}\text { Introduzir sistemas de apoio à decisão, alertas } \\
\text { ou passos limitantes nos programas de } \\
\text { prontuário/processo clínico. }\end{array}$ \\
\hline $\begin{array}{l}\text { Falta de capacitação do profissional: } \\
\text { Não valorização do risco de erro por parte de } \\
\text { profissionais e pacientes }\end{array}$ & $\begin{array}{l}\text { Desenvolver redes de comunicação entre } \\
\text { profissionais e entre estes e os pacientes. } \\
\text { Capacitar os pacientes e o público em geral } \\
\text { nas medidas que contribuem para sua própria } \\
\text { segurança. }\end{array}$ \\
\hline $\begin{array}{l}\text { Falta de notificação/reporte de incidentes: } \\
\text { Desconhecimento da existência de incidentes e } \\
\text { respectivas soluções }\end{array}$ & $\begin{array}{l}\text { Implementar sistemas de notificação/ } \\
\text { reporte de EAs, voluntário e obrigatório, não } \\
\text { culpabilizante. } \\
\text { Implementar rotinas de discussão de EAs nas } \\
\text { equipes. } \\
\text { Implementar sistemas de registro de incidentes } \\
\text { nas equipes (por exemplo, Diário de Bordo). } \\
\text { Premiar as organizações que incluem em sua } \\
\text { prática a notificação/reporte e implementação } \\
\text { de medidas de correção de incidentes. }\end{array}$ \\
\hline
\end{tabular}

O Quadro 2 mostra que, para incidentes e fatores contribuintes conhecidos, existem soluções estruturadas que deveriam ser de ciência dos gestores das organizações de saúde. Muitas dessas soluções já são desenvolvidas em hospitais, mas necessitam ser adaptadas para a APS.

\section{Considerações finais}

Neste capítulo, foi possível perceber que o tema da qualidade e segurança do paciente surge na agenda internacional e nacional, apesar de ainda representar um desafio a ser alcançado. Com o objetivo de alinhar as políticas no campo da Segurança do Paciente na APS, a OMS publicou, em dezembro de 2016, uma série de nove monografias - The Technical Series on Safer Primary Care (Figura 3), que aborda as questões relacionadas e apresenta as possíveis diretrizes para melhoria da segurança do paciente na APS. As monografias são: (i) O engajamento do paciente no cuidado; (ii) A educação e a capacitação dos profissionais do cuidado; (iii) Os fatores humanos; (iv) Os erros administrativos; (v) Os erros diagnósticos; (vi) Os erros medicamentosos; (vii) A multimorbidade/multimorbilidade; (viii) As transições do cuidado; (ix) As ferramentas eletrônicas. 
Essa iniciativa demonstra que os incidentes ocorrem na APS, contudo vem sinalizando que melhorias são possíveis para o cuidado seguro. Sugerimos uma aproximação mais amiúde na leitura deste material.

Figura 2 - Capa de uma das nove monografias da OMS sobre segurança na APS
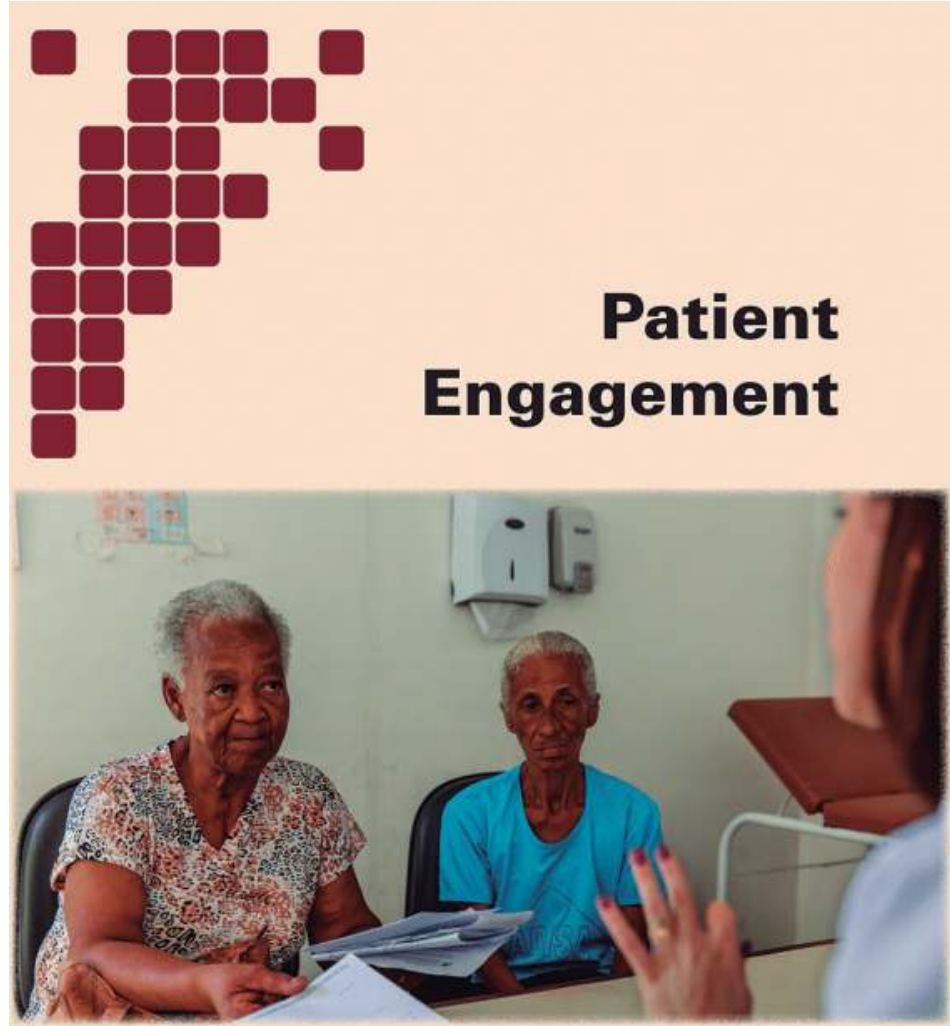

Technical Series on Safer Primary Care

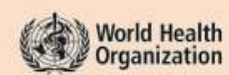

Fonte: http://apps.who.int/iris/bitstream/handle/10665/252269/9789241511629-eng.pdf;jsessionid=B3851D55E5FC1B315EE795161 CF38EF1? sequence $=1$

\section{Referências}

Aranaz JM, Ivorra F, Compañ AF, Miralles JJ et al. Adverse events in ambulatory surgical procedures. Cir Esp. 2008;84(5):273-8.

Baker GR, Norton PG, Flintoft V, Blais R, Brown A, Cox J, et al. et al. The Canadian adverse events study: the incidence of adverse events among hospital patients in Canada. CMAJ. 2004;170(11):1678-86. 
Balla J, Heneghan C, Thompson M, Balla M. Clinical decision making in a high-risk primary care environment: a qualitative study in the UK. BMJ Open. 2012 [citado 2014 jun 25];2(1). Disponível em: http://bmjopen.bmj.com/content/2/1/e000414.full

Buetow S, Kiata L, Liew T,Kenealy T, Dovey S, Elwyn G. Approaches to reducing the most important patient errors in primary health-care: patient and professional perspectives. Health Soc Care Community. 2010 May [citado 2014 jun 25]; 18(3):296-303. Disponível em: http://www.ncbi.nlm. nih.gov/pubmed/20141539

Cañada Dourado A, García Cubero C, García Ferradal I, Alonso Safont T, Sánchez Márquez MA, Serrablo Requejo $S$ et al. Identificación de las prácticas seguras simples en un área de atención primaria. Rev Calid Asist. 2011 [citado 2014 jun 25];26(5):292-98. Disponível em: http://www. biomedsearch.com/nih/Identification-simple-safe-practices-in/21783398.html

De Vries EN, Ramrattan MA, Smorenburg SM, Gouma DJ, Boermeester MA. The incidence and nature or in-hospital adverse events: a systematic review. Qual Saf Health Care. 2008;17:216-23. Disponível em: http://www.ncbi.nlm.nih.gov/pubmed/18519629

Estudio APEAS: estudiosobre la seguridad de los pacientes en atención primaria de salud. Madrid: Ministerio de Sanidad y Consumo; 2008.

Gaal S, Van den Hombergh P, Verstappen W, Wensing M. Patient safety features are more present in larger primary care practices. Health Policy. 2010 Sep; 97(1):87-91.

Graham DG, Harris DM, Elder NC, Emsermann CB, Brandt E, Staton EW et al. Mitigation of patient harm from testing errors in family medicine offices: a report from the American Academy of Family Physicians National Research Network. Qual Saf Health Care. 2008 Jun [citado 2014 jun 25];17(3):201-8. Disponível em: http://www.ncbi.nlm.nih.gov/pubmed/18519627

Harmsen M, Gaal S, Van Dulmen S, et al. Patient safety in Dutch primary care: a study protocol. Implement Sci 2010 [citado 2014 jun 25]; 5(1):50. Disponível em: http://www.ncbi.nlm.nih.gov/ pmc/articles/PMC2914083/

Hickner J, Graham DG, Elder NC, Brandt E, Emsermann CB, Dovey S,et al. Testing process errors and their harms and consequences reported from family medicine practices: a study of the American Academy of Family Physicians National Research Network. Qual Saf Health Care. 2008 Jun [citado 2014 jun 25];17(3):194-200. Disponível em: http://www.ncbi.nlm.nih.gov/ pubmed/18519626

Kostopoulou O, Delaney B. Confidential reporting of patient safety events in primary care: results from a multilevel classification of cognitive and system factors.Qual Saf Health Care. 2007 Apr [citado 2014 jun 25];16 (2):95-100. Disponível em: http://www.ncbi.nlm.nih.gov/ pubmed/17403753

Kuo GM, Phillips RL, Graham D, Hickner JM. Medication errors reported by US family physicians and their office staff.Qual Saf Health Care. 2008 Aug [citado 2014 jun 25];17(4):286-90. Disponível em: http://www.ncbi.nlm.nih.gov/pubmed/18678727

Makeham M, Dovey S, Runciman W, Larizgoitia I. Methods and measures used in primary care patient safety research. Genéve: World Health Organization; 2008 [citado 2014 jun 25]. Disponível em: www. who.int/patientsafety/research/methods_measures/primary_care_ps_research/en/index.html.

Manwell LB, Williams ES, Babbott S, Rabatin JS, Linzer M. Physician perspectives on quality and error in the outpatient setting. WMJ. 2009 May [citado 2014 jun 25];108(3):139-44. Disponível em: http://www.ncbi.nlm.nih.gov/pubmed/19552351.

Marchon SG, Mendes Junior WV. Segurança do paciente na atenção primária à saúde: revisão sistemática. Cad. Saúde Pública, 2014 Sept;30(9):1-21. Disponível em: http://www.scielo.br/pdf/ csp/v30n9/pt_0102-311X-csp-30-9-1815.pdf 
Marchon SG, Mendes Junior WV, Pavao ALB. Características dos eventos adversos na atenção primária à saúde no Brasil. Cad. Saúde Pública. 2015 Nov [citado 2019 jan 20];31(11):2313-30. Disponível em: http://dx.doi.org/10.1590/0102-311X00194214.

Mendes EV. O cuidado das condições crônicas na atenção primária à saúde: o imperativo da consolidação da estratégia da saúde da família. Brasília: Organização Pan-Americana da Saúde; 2012. p. 512. Disponível em: http://bvsms.saude.gov.br/bvs/publicacoes/cuidado_condicoes_ atencao_primaria_saude.pdf

Mira JJ, Nebot C, Lorenzo S, Pérez-Jover V. Patient report on information given, consultation time and safety in primary care. Qual Saf Health Care. 2010 Oct [citado 2014 jun 25];19(5):e33. Disponível em: http://www.ncbi.nlm.nih.gov/pubmed/20511244.

Montserrat-Capella D, Suárez M, Ortiz L, Mira JJ, Duarte HG, Reveiz L, et al. Frequency of ambulatory care adverse events in Latin American countries: the AMBEAS/PAHO cohort study. Int J Qual Health Care. 2015 Feb [citado 2019 jan 20];27(1):52-9. Disponível em: http://intqhc. oxfordjournals.org/content/intghc/27/1/52.full.pdf

O'Beirne M, Sterling PD, Zwicker K, Hebert P, Norton PG. Safety incidents in family medicine.BMJ Qual Saf. 2011 Dec [citado 2014 jun 25]; 20(12):1005-10. Disponível em: http://www.ncbi.nlm.nih. gov/pubmed/21893612

Ribas MJ. Eventos adversos em cuidados de saúde primários: promover uma cultura de segurança. Rev Port Clin Geral 2010; 26:585-9.

Sousa P. Patient safety: a necessidade de uma estratégia nacional. Acta Med Port. 2006;19:309-18.

Sousa P, Uva AS, Serranheira F. Investigação e inovação em segurança do doente. Rev Port Saúde Pública. 2010; vol. temat. (10):89-95.

Starfield B. Atenção primária: equilíbrio entre necessidades de saúde, serviços e tecnologia. Brasília: Organização das Nações Unidas para a Educação, a Ciência e a Cultura, Ministério da Saúde; 2002. p. 207-45.

Thomas EJ, Petersen LA. Measuring errors and adverse events in healthcare. J Gen Intern Med. 2003 [citado 2019 jan 20];18:61-7. Disponível em: http://psnet.ahrq.gov/resource. aspx? resourcelD $=1319$

Wallis K, Dovey S. No-fault compensation for treatment injury in New Zealand: identifying threats to patient safety in primary care. BMJ Qual Saf. 2011 [citado 2014 jun 25];20(7):587-91. Disponível em: http://www.ncbi.nlm.nih.gov/pubmed/21228439

Weiner SJ, Schwartz A, Weaver F, Goldberg J, Yudkowsky R, Sharma G, et al. Contextual errors and failures in individualizing patient care: a multicenter study.Ann Intern Med. 2010 Jul 20 [citado 2014 jun 25]; 153(2):69-75. Disponível em: http://www.ncbi.nlm.nih.gov/pubmed/20643988

Wetzels R, Wolters R, Van Weel C, Wensing M. Harm caused by adverse events in primary care: a clinical observational study.J Eval Clin Pract. 2009 Apr [citado 2014 jun 25]; 15(2):323-7. Disponível em: http://www.ncbi.nlm.nih.gov/pubmed/19335492

World Health Organization. Cuidados de saúde primários: agora mais que nunca: relatório mundial de saúde 2008. Geneva: WHO; 2008a [citado 2014 jun. 25]. Disponível em: http://www.who.int/ whr/2008/08_overview_pr.pdf

World Health Organization. Declaration of Alma-Ata. In: International Conference on Primary Health Care; 1978 Sept. 6-12; Alma-Ata. Geneva: WHO; 1978 [citado 2014 jun. 25]. Disponível em: http://www.who.int/publications/almaata_declaration_en.pdf

World Health Organization. Documents of month: February 2008. Geneva: WHO; 2008b [citado 2014 jun 25]. Disponível em: http://www.who.int/archives/exhibits/month_documents_2008/en/ index $1 . \mathrm{html}$ 
World Health Organization. Safer Primary Care: a global challenge. Summary of inaugural meeting Safer Primary Care Expert Working Group; 2012a Feb 27-28; Geneva. Disponível em: http://www. who.int/patientsafety/safer_primary_care/en/index.html

World Health Organization. Safer Primary Care Expert Working Group. Geneve: WHO; 2012b [citado 2012 set 6]. Disponível em: http://www.who.int/patientsafety/safer_primary_care/en/index. html

World Health Organization. Assessing and tackling patient harm: a methodological guide for datapoor hospitals. Geneva: WHO; 2010 [citado 2014 jun 25]. Disponível em: http://www.who.int/ patientsafety/research/methodological_guide/PSP_MethGuid.pdf. 


\section{Superlotação dos serviços de emergência}

Victor Grabois e Roberto José Bittencourt

Neste capítulo, abordaremos uma situação que afeta a segurança dos pacientes - a superlotação dos Serviços de Emergência Hospitalar (SEH). Veremos as estratégias que podem ser utilizadas para organizar melhor o cuidado nesses serviços que apresentam grande demanda e mitigar os incidentes, mesmo em SEH superlotados.

\section{Introdução}

A superlotação nos SEH é reflexo do desequilíbrio entre a demanda de pacientes com condições agudas por serviços de saúde e a baixa oferta de serviços assistenciais. Possivelmente, é a expressão mais visível das dificuldades do sistema de saúde no atendimento das necessidades da população. Indica o baixo desempenho do sistema em sua totalidade, e do hospital em particular, induz à baixa qualidade assistencial (Bittencourt, Hortale 2009).

A superlotação nos SEH é um fenômeno mundial, caracterizado por:

- todos os seus leitos/camas ocupados, com pacientes em macas nos corredores;

- tempo de espera para o primeiro atendimento médico acima de uma hora;

- tempo de espera para internação/internamento em mais de duas horas após a decisão clínica;

- alta tensão na equipe assistencial, expondo-os à síndrome de Burnout;

- pressão para novos atendimentos. 
Uma revisão da literatura (Bradley 2005) mostrou que o aumento do tempo de permanência no SEH é o principal marcador da superlotação. A falta de leitos/camas para internação/internamento é a mais importante causa. O atraso no diagnóstico e no tratamento é a principal consequência, aumentando a taxa de mortalidade hospitalar, com óbitos evitáveis. Estudos (Graff et al. 2002; Schull et al. 2004; Magid et al. 2004) realizados em SEH superlotados mostraram que o tratamento da pneumonia, meningite, sépsis, infarto/enfarte agudo do miocárdio, apendicite, acidente vascular cerebral, trauma cervical, trauma craneano, fraturas expostas, fraturas de fêmur tiveram resultados desfavoráveis por causa do atraso no atendimento médico.

\section{Para refletir}

A quantidade de leitos/camas na organização em que você trabalha é adequada à demanda? Em caso negativo, existe um projeto para aumentar a quantidade ou outra medida para lidar com essa questão? O que você sugere para resolver o problema?

A superlotação se expressa por meio de dois componentes, que podem ou não interagir. O primeiro pode existir sem o segundo e vice-versa, todavia prevalece a ocorrência simultânea (Hortale 2009).

O primeiro componente está relacionado com a pressão exercida nos SEH - "pressão de porta" - pelo grande número de atendimentos em razão das baixas ofertas e resolubilidade das organizações de saúde não hospitalares. Essa "pressão de porta" aumentou nos últimos dez anos em função do aumento dos atendimentos aos idosos.

Vecina Neto e Malik (2007) revelam serem os brasileiros acima de 65 anos os que demandam quatro vezes mais internações/internamentos que a média da população. Segundo o Observatório Europeu dos Sistemas e Políticas de Saúde (Rechel et al. 2009), o aumento da expectativa de vida na população americana será ampliado em $46 \%$ até 2027. O novo perfil da população poderá ter impacto direto na assistência hospitalar, especialmente nos SEH, com o aumento da morbimortalidade e comorbidades/comorbilidades, ocasionadas pelas doenças crônico-degenerativas, assim como por causas externas, reaparecimento de antigas doenças e aparecimento de novas doenças infecciosas, muitas imprevisíveis. 
O segundo componente está relacionado com a presença excessiva de pacientes nos ambientes internos dos SEH acima da capacidade instalada de leitos/camas aguardando internação/internamento ou a definição clínica do seu caso. Não há como deixar de mencionar a importância da integração dos SEH com os demais serviços hospitalares em busca de uma efetividade organizacional, que é a relação entre os serviços assistenciais oferecidos pelo hospital e a obtenção de resultados esperados. Segundo Asplin \& Magid (2007): “hospitais que tiveram maior sucesso em diminuir a superlotação nos SEH foram aqueles que reconheceram o problema do fluxo do paciente em todo o hospital e definiram iniciativas para tirá-lo do SEH".

\section{O desempenho dos SEH avaliados sob a lógica de um modelo integrador}

Como avaliar o desempenho dos SEH? Eles fazem parte de um sistema de saúde considerado complexo, que inclui o hospital e sua rede de apoio, cujo desempenho pode ser avaliado pelo modelo integrador de Sicotte e colaboradores (1998). Esse modelo, após ter sido aperfeiçoado pelo Groupe de Recherche Interdisciplinaire em Santé (Gris) - Secteur Santé Publique - Faculté de Medeciné - Université de Montréal, passou a se chamar Évaluation Globale et Intégrée de la Performance dans les Systèmes de Santé (Egipss).

O modelo Egipss considera as várias teorias de desempenho das organizações de saúde, reconhece suas peculariedades e busca integrá-las. O modelo pretende responder a duas perguntas (Champagne et al. 2005):

* Como medir adequadamente o desempenho dos serviços de saúde com várias missões, via de regra contraditórias?

跣 Como melhorar o desempenho de uma organização em que o desempenho de um serviço pode causar diminuição de desempenho em outro?

A Figura 1 apresenta o diagrama do Egipss (Contandriopoulos et al. 2010), com as quatro dimensões para análise de desempenho das organizações de saúde: adaptação; alcance de metas; produção de serviços; manutenção dos valores. As dimensões são relacionadas entre si, em seis tipos de equilíbrios: estratégico, tático, operacional, contextual, alocativo e legitimado.
Évaluation Globale et Intégrée de la Performance dans les Systèmes de Santé pode ser livremente traduzido por Avaliação Global e Integral da Performance nos Sistemas de Saúde. 
Figura 1 - Modelo integrador Egipss

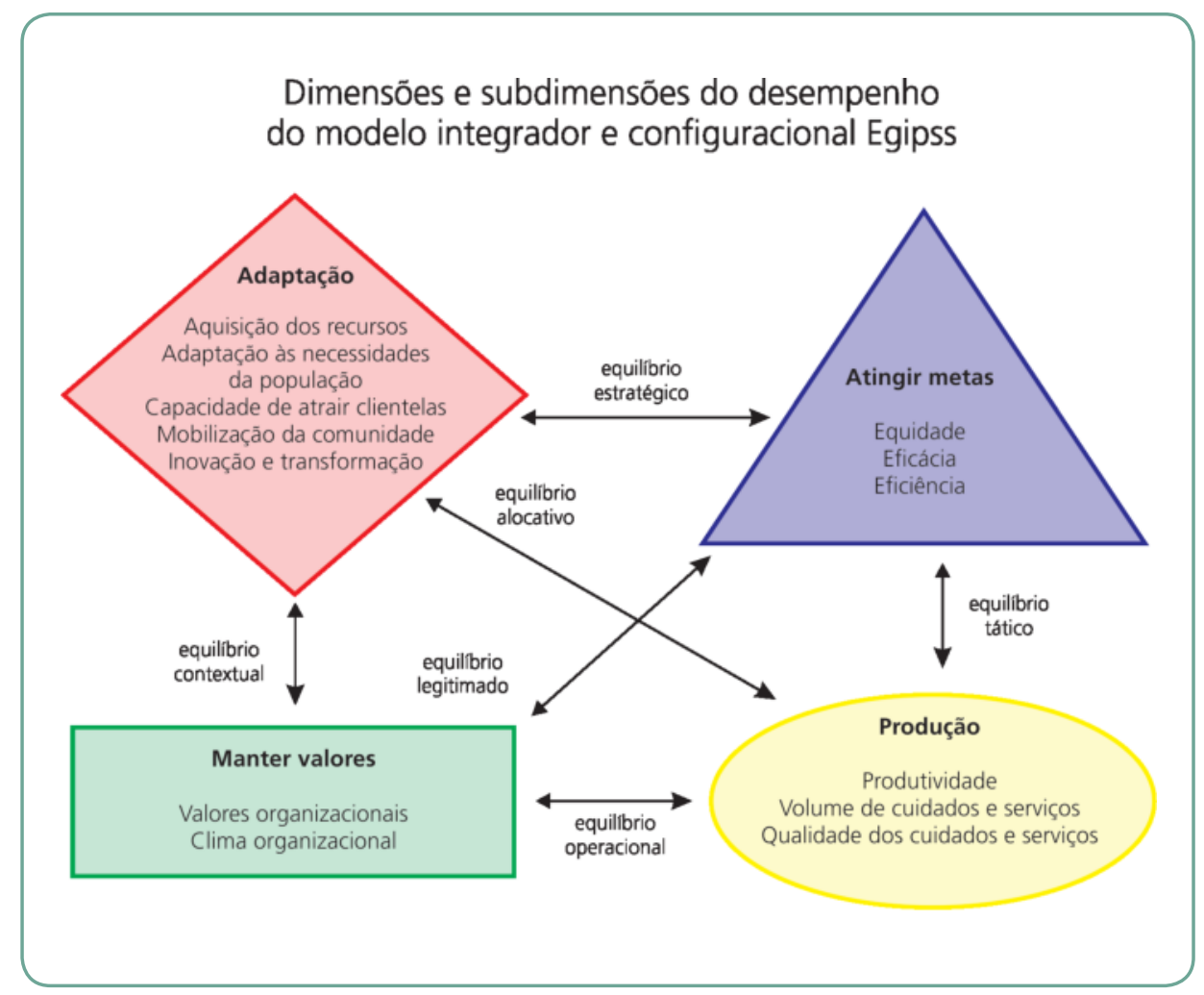

Fonte: Contandriopoulos et al. (2010, p. 297-324)

\section{Os fatores que determinam o desempenho dos SEH}

Ao utilizarmos como padrão de análise o modelo Egipss, o desempenho dos SEH pode ser avaliado à luz da definição dos quatro fatores que determinam a produção dos serviços de saúde (Contandriopoulos et al. 2010):

1. Em relação ao volume e ao tipo de cuidados de saúde: os serviços de saúde estão submetidos à grande pressão de porta com grande volume de atendimento de casos não emergenciais em virtude da pouca articulação e resolubilidade das demais organizações de saúde.

2. Em relação à coordenação, entre os fatores que impactam a produção: existem vários "hospitais" em disputa, especialmente no que diz respeito à ocupação dos leitos/camas hospitalares. O SEH, a Unidade de Tratamento Intensivo (UTI), o Centro Cirúrgico (CC) e o ambulatório do hospital disputam os serviços de laboratório, de imagem, de internação/internamento e outros, sem a devida coordenação. 
3. Em relação à produtividade dos serviços de saúde: a capacidade dos SEH está aquém das necessidades dos pacientes, incluindo os recursos estruturais (por exemplo, recursos humanos e tecnologia), e processos adequados de trabalho. O resultado é a baixa produtividade.

4. Em relação à qualidade dos cuidados de saúde: nos SEH superlotados, as abordagens clínicas são inadequadas, aumentando a insegurança do paciente e da taxa de mortalidade.

\section{Os tipos de equilíbrio e o desempenho do SEH}

Destacam-se três tipos de equilíbrio na relação entre a produção de serviços e as outras dimensões do desempenho do SEH (Contandriopoulos et al. 2010):

O equilíbrio tático:

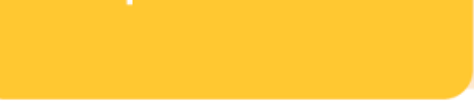

O equilíbrio tático alocativo:
- Os SEH são parte de um ambiente complexo com disputas de todo tipo de interesse e, em especial, pela ocupação do leitoo/cama hospitalar, onde prevalece a escassez.
A falta de integração dos SEH com o restante dos serviços do hospital dificulta a alocação de recursos. É um serviço que não atrai altos investimentos institucionais, tanto ambientais como tecnológicos.
0 equilíbrio tático operacional:
O estresse abrevia a longevidadae dos profissionais que atuam nos SEH. Profissionais mais experientes - vitais para melhor abordagem clínica nesses ambientes - tendem a ficar por pouco tempo, provocando alta rotatividade no setor, diminuindo a qualidade assistencial.

Em relação aos demais tipos de equilíbrio:

䠰 incapacidade de se integrar à missão do hospital - equilíbrio estratégico;

o clima organizacional em dissonância com as necessidades sociais e sanitárias - equilíbrio contextual; e

跣as distorções das metas interferem negativamente na cultura organizacional - equilíbrio legitimador. 


\section{Repercussões dos SEH superlotados na segurança do paciente}

Um SEH superlotado tem todos os leitos/camas ocupados, inclusive os leitos/camas extras. Existe demora na avaliação dos pacientes, recebam os medicamentos prescritos, realizem os exames solicitados e, por fim, internados (Twanmah 2009).

A superlotação dos SEH está associada à ocorrência de eventos adversos, ainda que não seja fácil a obtenção de evidências. Alguns incidentes citados na literatura são: o retardo no início da antibioticoterapia, retardo no início e inadequação da analgesia, insatisfação do paciente, maiores taxas de mortalidade nas UTIs e maiores taxas de complicações cardiovasculares nas síndromes de dor torácica.

As transferências de pacientes para corredores do hospital e não para leitos/camas de internação/internamento em quartos ou enfermaria geram enorme insatisfação dos pacientes e seus familiares.

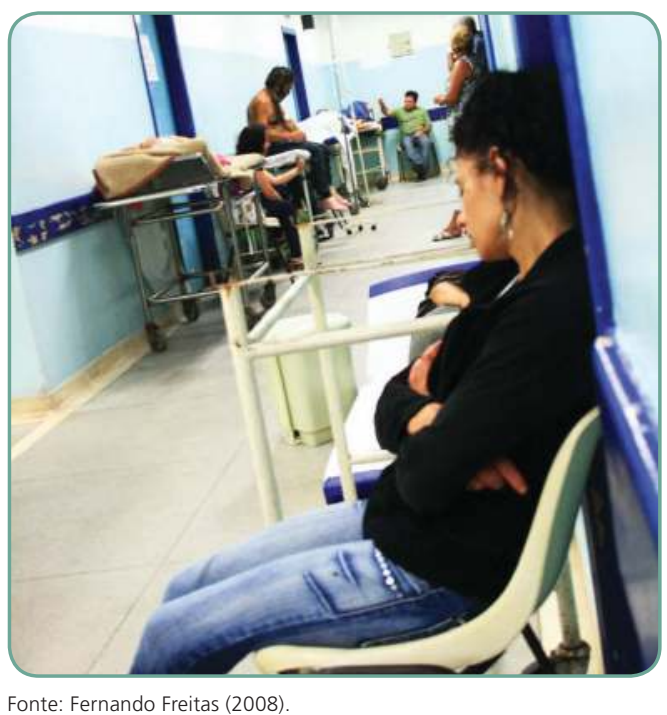

Cerca de 70\% dos pacientes com pneumonia em emergências sem superlotação tiveram a antibioticoterapia iniciada nas primeiras quatro horas, enquanto apenas $28 \%$ de pacientes com pneumonia em emergências superlotadas iniciaram a antibioticoterapia nas primeiras quatro horas (Waterer et al. 2006). A mortalidade dos pacientes que permaneceram mais de seis horas aguardando sua internação/interna- 
mento é de $17,4 \%$, enquanto para os pacientes que aguardaram menos de seis horas, a mortalidade foi de 12, 9\% (Trzeciak, Rivers 2003).

Os idosos são os pacientes mais vulneráveis à ocorrência de eventos adversos, por que demonstram situações clínicas mais sutis e atípicas. A maioria apresenta comorbidades/comorbilidades, usam muitos medicamentos simultaneamente, tem margens terapêuticas mais estreitas e deficiência cognitiva e funcional (Samaras et al. 2010). Os SEH sofrem grande impacto com a presença dos idosos. Como têm maior potencial de gravidade, demandam leitos/camas de UTI mais rapidamente. As altas hospitalares de idosos têm especial significação para as emergências, pois dentre essas, $27 \%$ voltam a procurar os serviços de emergência.

Os ambientes de cuidado, os aspectos relacionados aos profissionais e organizacionais, as dificuldades de comunicação nos SEH podem ser apontados/indicados como fatores contribuintes de incidentes. Os ambientes de cuidado são, muitas vezes, ruidosos, sem janelas, com controle de temperatura ineficiente, com macas sem grades dispostas muito próximas, aumentando, assim, os riscos de contaminação cruzada. Os profissionais têm, em geral, sobrecarga de trabalho em ambientes desorganizados ou mesmo caóticos, o que intensifica o stress. Esses elementos facilitam a desatenção, desconcentração, ocorrência de lapsos e levam a erros de medicação (pacientes trocados, doses e vias inadequadas), cirurgias e procedimentos nos pacientes errados ou em membros errados.

\section{Para refletir}

Em sua unidade de trabalho, você identifica alguns dos problemas listados no parágrafo anterior? O que você imagina que pode ser feito a fim de resolver esses fatores que contribuem para a ocorrência de incidentes?

Medicações de alto risco são muito utilizadas em emergências. Os eletrólitos são considerados os mais perigosos, particularmente o cloreto de potássio e o cloreto de sódio. Outros medicamentos requerem muita atenção, como os anticoagulantes (Peth 2009).

A passagem de plantões/turno é uma atividade de rotina nos SEH e considerada um momento de alto risco. Segundo Kelly (apud Cheung et al. 2009), 24\% das queixas sobre a ocorrência de más práticas foram relacionadas à passagem de plantão/turno inadequada. A troca de plan-

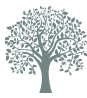

Para saber mais sobre medicamentos que podem ser perigosos, visite o endereço:

http://www.ismp-brasil.org/ $\mathrm{faq} /$ medicamentosp otencialmenteperigosos.php

Você também poderá encontrar outras informações sobre o tema no Capítulo 8, "Erros relacionados aos medicamentos", do livro Segurança do paciente: conhecendo os riscos nas organizações de saúde. 
A passagem de plantões/turno será mais bem abordada adiante, neste capítulo e no 7, "Comunicação entre os profissionais de saúde e a segurança do paciente", do livro Segurança do paciente: criando organizações de saúde seguras. tão/turno é um momento de transferência de responsabilidade sobre o paciente e de informações a respeito do cuidado.

Fatores relacionados aos profissionais podem contribuir para a ocorrência de incidentes, por exemplo, a baixa consciência da situação de superlotação da emergência, tais como: posturas inconvenientes, como interromper de forma abrupta a prestação de cuidados para iniciar a passagem do plantão/turno; compreensão inadequada, desatenção ao que está sendo falado; decisões apressadas por parte de quem está assumindo o plantão/turno. Mesmo após a passagem de plantão/turno, o profissional que chega ao SEH se esquece de informações ou de tarefas essenciais, ou inicia o cuidado sem uma reflexão mais aprofundada a respeito do paciente sob sua responsabilidade (Cheung et al. 2009).

A realização de procedimentos nos SEH também é desafio à segurança do paciente. Um dos focos de prevenção para a ocorrência de eventos adversos é reduzir o risco da realização da cirurgia no lugar errado, na pessoa errada e do procedimento errado.

Segundo o modelo de Asplin e colaboradores (2003), existem intervenções prévias no momento da chegada do paciente no SEH que são essenciais para reduzir a demanda e avaliar adequadamente o risco e o grau de prioridade para o atendimento. O médico hospitalista pode atuar como elemento de ligação entre os diferentes serviços, responsável pelo gerenciamento integrado dos leitos/camas, introduzindo grau de dinamismo na avaliação do progresso dos pacientes hospitalizados. O suporte de leitos/camas de menor complexidade permite a continuidade do cuidado e a possibilidade de oferta de atenção multiprofissional de acordo com as necessidades de cada paciente.

\section{Estratégias com foco na segurança do paciente para enfrentar a superlotação}

Estratégias e técnicas voltadas à segurança do paciente podem ajudar às equipes dos SEH a manter o cuidado mais seguro, mesmo em condições de superlotação. Vejamos as principais:

Adoção de protocolos que permitam avaliar risco de incidente.

Suporte de farmacêuticos para aperfeiçoar o manejo de medicamentos.

璘 Utilização da lista de verificação da cirurgia segura.

蝶 Definição de quais procedimentos devem ser realizados nos SEH ou nos Centros Cirúrgicos. 
Utilização de sistemas de prescrição computadorizada, de forma a reduzir erros de medicação relacionados a alergias, incompatibilidade entre medicamentos, doses excessivas ou por vias erradas ou em horários equivocados.

滕 Estabelecimento de metas diárias para o cuidado que permitam definir pacientes prioritários, facilitar a comunicação entre as equipes.

* Realização de discussões coletivas matinais para organizar as atividades (briefings) utilizando três questões simples:

1. O que ocorreu durante a noite que todos os profissionais necessitam saber (problemas com equipamentos, modificações no quadro clínico de pacientes, ocorrência de incidente)?

2. Por onde começamos os "rounds": (Por qual paciente? Quem pode ser transferido? Quem está de alta?).

3. Podemos antecipar algum problema durante o dia (insuficiência de pessoal, problemas com os equipamentos)?

繗 Utilização de pacotes de intervenções (bundles) relativos à Prevenção de Infecção Associada à Ventilação Mecânica (PAVM), de Infecção Associada ao Uso de Cateter Venoso Central, e de lembretes etc.

Utilização de tabuletas ou smartphones com informações sobre o paciente, com protocolos clínicos, sistemas de apoio à decisão etc.

滕 Uso de ferramentas para aprendizagem com incidentes que já ocorreram (O que ocorreu? Por que ocorreu? Priorizar fatores contribuintes. Quais estratégias podem reduzir novas ocorrências?).

镂 Utilização de pulseiras brancas para dupla identificação de pacientes.

锩 Definição de políticas de manejo de medicamentos nos SEH (segregação de medicamentos perigosos; identificação por escrito dos medicamentos look alike, sound alike, dose unitária etc.).

Existem outras estratégias fundamentais para tornar o cuidado mais seguro nos SEH, em particular naqueles que estão superlotados:

滕 Visitas das lideranças ao SEH com foco na segurança do paciente.

蔽 Capacitação sobre segurança do paciente.

滕 Criação de equipes de saúde responsáveis por um programa de segurança do paciente21 (CUSP - Comprehensive Unit Based Safety Program) (Armstrong Institute for Patient Safety and Quality, 2013).

滕 Emprego de técnicas de simulação para fortalecer as equipes em torno de sistemas seguros de cuidado. 
Para refletir

Em sua organização, são utilizadas algumas dessas estratégias? Quais?

Se elas não são empregadas, a que você credita essa lacuna de cuidados? O que pode ser feito para reverter esse quadro?

No ambiente de cuidados, os aspectos de luminosidade, ruído, amplitude dos espaços, privacidade, entre outros, devem ser revistos, de forma a oferecer aos profissionais maiores possibilidades de concentração e de conforto no trabalho, assim como para os pacientes e seus familiares.

\section{Estratégias sistêmicas para enfrentar a superlotação dos serviços de emergência hospitalar}

O modelo "Ciclo Resolutivo da Superlotação dos Prontos-Socorros" estabelece as dimensões necessárias ao enfrentamento da superlotação dos SEH (Bittencourt 2010).

Trata-se de um ciclo, pois todas as estações devem ser implementadas de forma simultânea, em uma espiral crescente de medidas gerenciais. Para a viabilização dessas medidas, é necessário contar com a alta governabilidade institucional e boa capacidade técnica de governo. As intervenções, em cada etapa do ciclo resolutivo, podem e devem ser aperfeiçoadas ou traduzidas localmente.

Figura 2 - Ciclo resolutivo da superlotação dos SEH

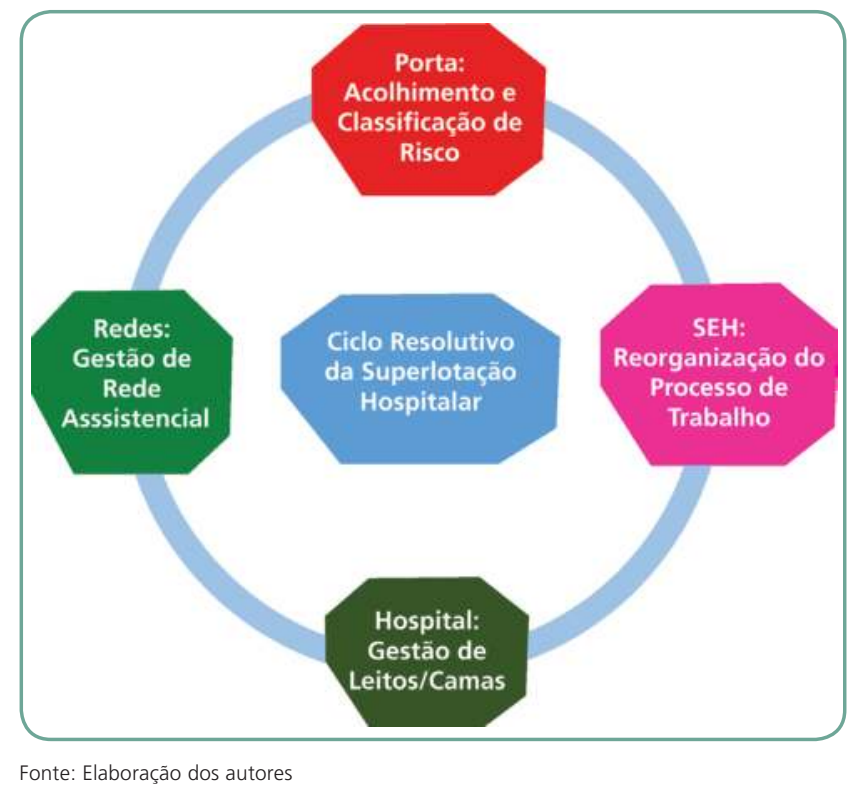




\section{Acolhimento e classificação de risco}

O acolhimento do paciente em situações agudas nos SEH representa um momento especial, que não é adequado em grande parte das organizações. É comum o acolhimento ser realizado por profissionais de segurança patrimonial ou agentes de portaria, em vez de um profissional de saúde, para abordar imediatamente os problemas que levaram o paciente ao SEH.

Logo após ser acolhido, o paciente deve ser encaminhado a um ambiente reservado em que é realizada a Classificação de Risco (CR) por enfermeiros treinados, utilizando um protocolo (Mackway-Jones et al. 2010). A CR não é uma triagem, pois todos os pacientes deverão ser atendidos; seu objetivo central é estabelecer a prioridade do atendimento em função da gravidade clínica e não por ordem de chegada. Além do uso dos protocolos, os sistemas informatizados reduzem o risco e diminuem o tempo da CR.

Para refletir

A Classificação de Risco é utilizada em sua unidade?

Em caso positivo, que problemas você observa serem resolvidos com esse protocolo?

Em caso negativo, por que essa medida não é implementada?

A CR cria uma nova ordem para o atendimento, com prioridade por gravidade, e não em função da ordem de chegada. Ela pode gerar insatisfação dos pacientes classificados como de menor gravidade, cujo tempo para o atendimento, na maioria das vezes, supera o preconizado nos protocolos. Não raro, encontramos situações de grande tensão nos SEH por essa razão. Por menor que seja o problema clínico, o tempo para o atendimento é importante. O Fast Track é uma ferramenta utilizada para diminuir a pressão de porta dos SEH (Committee on the Future of Emergency Care in the United States Health System 2007), pois auxilia nos fluxos dos pacientes classificados como de menor risco clínico nesses serviços para outras unidades assistenciais. No Brasil, um exemplo seria a transferência de pacientes dos SEH para as Unidades de Pronto Atendimento (Upas), para a atenção básica por meio do atendimento em agendas abertas, resguardando o transporte sanitário seguro, e até mesmo para ambulatórios no próprio hospital. Dessa forma, os atendimentos nos SEH seriam focados nos pacientes mais graves. 
Percebe-se que a era do médico autônomo, que heroicamente resolvia todos os problemas do paciente, já se encerrou (Fried, Carpenter 2006). Outrossim, o médico hospitalista vem assumindo o papel de coordenador clínico.
Protocolo de Manchester de Classificação de Risco (Committee on the Future of Emergency Care in the United States Health System 2007)

Vermelho (emergência): tempo-resposta máximo $=0$ minuto

Laranja (muito urgente): tempo-resposta máximo $=10$ minutos

Amarelo (urgente): tempo-resposta $=60$ minutos

Verde (pouco urgente): tempo-resposta $=120$ minutos

Azul (não urgente): tempo-resposta $=240$ minutos

\section{Reorganização do processo de trabalho nos SEH e nos setores de internação/ internamento hospitalar}

À medida que pacientes com quadro clínico cada vez mais grave e instável procuram os SEH, surge a necessidade de um nível superior de coordenação da assistência - a gestão da clínica. Trata-se da gestão com foco na efetividade clínica e na segurança do paciente, apoiada em equipes de alto desempenho (Fried, Carpenter 2006).

O antigo médico visitador, que apenas examinava o paciente, prescrevia a medicação do dia, solicitava exames e pareceres, relacionava-se pouco com os demais profissionais e, em seguida, ia para outra atividade no mesmo ou em outro hospital tornou-se ultrapassado. Também ultrapassado seja o processo de trabalho baseado no regime de plantão/ turno hospitalar, que não garante a responsabilização e vínculo com o paciente. Modernamente, é dada ênfase à constituição de equipes que exercem sua atividade de forma horizontal.

O novo padrão instituído pelo médico hospitalista, com atuação originalmente desenvolvida nos Estados Unidos, Canadá e Inglaterra, tem sido utilizado como responsável por gerenciar os recursos hospitalares e coordenar as ações assistenciais, tornando-as menos fragmentadas, mais holísticas, efetivas e eficientes. O médico hospitalista deve prestar assistência mais intensiva, baseada na experiência e expertise - itens extremamente valorizados (Wachter, Goldman 1996). Em um estudo no qual um médico hospitalista assumiu a responsabilidade central nos SEH como diretor de leitos/camas do hospital e passou a coordenar dois "rounds" por dia na UTI e no SEH, houve diminuição do tempo de permanência no hospital, no tempo de saída do paciente do SEH e na taxa de mortalidade (Howell et al. 2008). 
Todavia, o principal fator de sucesso do trabalho de coordenação clínica do médico hospitalista está na constituição de equipes de alto desempenho, que deverão ser implementadas nos SEH e nas unidades de internação/internamento a partir de alguns princípios (Fried, Carpenter 2006).

\section{As equipes são multiprofissionais}

A maioria dos hospitais funciona com profissionais atuando de forma isolada, muitas vezes em antagonismo. A formação de equipes năo se dá espontaneamente e demanda persistência por parte da direção do hospital, organizando-se por unidades de produção assistencial.

\section{Objetivos claros}

Em cada serviço de saúde existem problemas específicos, com nuances pouco perceptíveis à direção da organizaçăo hospitalar, e que devem gerar soluçōes adequadas. As equipes devem atuar com metas, indicadores e objetivos bem definidos, evitando perda de energia, diante dos inúmeros problemas do cotidinao.

\section{Autoridade}

A direçăo do hospital deve delegar autoridade para as equipes resolverem os problemas da sua esfera de atuaçăo.

\section{Metodologia de trabalho}

As equipes devem ser capacitadas para utilizar ferramentas de gestão a fim de se manterem motivadas, resolver suas contradiçőes internas, tendo uma liderança capacitada para moderar os conflitos e estimular a participaçăo de todos seus membros.

\section{Tomada de decisões}

Planejar, agir, avaliar e qualificar (PDCA). Essa ferramenta permitirá a atuaçăo das equipes baseada em evidências, melhorando continuamente as soluções, aumentando a capacidade de aprendizado da equipe.

\section{Premiação/incentivos financeiros}

A organizaçăo deve introduzir uma remuneração flexível pela produçăo dos serviços de saúde, premiando a atuaçăo coletiva das equipes, não só do indivíduo.

\section{Para refletir}

Existe a figura do médico hospitalista em sua organização? Você acha possível, frente à forma de organização da sua unidade, ter um médico hospitalista e a constituição de equipes de alto desempenho? Por quê? 


\section{Gestão de leitos/camas}

A principal estratégia para melhorar o fluxo de saída dos pacientes do SEH é aprimorar a gestão do principal recurso do hospital: o leito/cama. Trata-se de um recurso finito, escasso, geralmente em déficit crônico.

Quando se analisa a situação geral dos leitos/camas hospitalares no Brasil, percebe-se um paradoxo, pois, com base nas disposições legais sobre oferta de internações/internamentos (Portaria n. 1.101/2002), há leitos/camas hospitalares além do preconizado, revelando um descompasso. Ao considerarmos $10 \%$ da população de 180 milhões internadas anualmente, com média de permanência de cinco dias e taxa de ocupação de $80 \%$, seriam necessários 310 mil leitos/camas. Hoje em dia, existem cadastrados $440 \mathrm{mil}$ leitos/camas, todavia, registra-se a falta de leitos/camas de UTI, já que seriam necessários 31 mil leitos/camas $(10 \%)$, e existem cadastrados apenas 12 mil leitos/camas (Vecina Neto, Malik 2007). Apesar desse déficit, dados recentes confirmam importante tendência à diminuição de leitos/camas hospitalares e o discreto aumento de leitos/camas de terapia intensiva (Coelho 2006).

\section{Para refletir}

Em sua região, existe relação entre superlotação de SEH e déficit de leitos/ camas? Qual fonte de informação você usa para ter esse conhecimento?

A realidade demográfica que, agora, se apresenta mudou o perfil nosológico da população, com implicações em novas necessidades de leitos/ camas hospitalares tanto em quantidade como na precisão de leitos/ camas de retaguarda, e a separação de leitos/camas para pacientes crônicos e agudos. Essa oportunidade favorece a introdução de novos padrões para atenção hospitalar, em que a gestão da clínica é o centro da atividade da gestão hospitalar (Portela 2007) e a capacidade de assumir os desafios da gravidade e complexidade dos pacientes que cada vez mais "habitam" os hospitais. A tendência mundial é que os hospitais absorvam, principalmente, pacientes graves e instáveis para a realização de procedimentos complexos (McKee, Healy 2002).

Nesse contexto, as enfermarias com um a dois leitos/camas realizarão cuidados mais intensivos, possibilitando assistência mais individualizada, facilitando maior controle da infecção hospitalar, mais conforto ao paciente e ao acompanhante. A gradação do risco clínico deverá ser avaliada com objetivo de prestar melhor assistência aos pacientes 
internados. Esse modelo ampliará as taxas de utilizações do leito/cama hospitalar, possibilitará o aumento da rotatividade e a diminuição do tempo de permanência, otimizando os recursos hospitalares. A permanência no hospital será mais intensa e mais curta. Os dispositivos organizacionais utilizados para dar conta desse desafio são: "gestão de leitos/camas" e "gestão de vagas".

A gestão de leitos/camas objetiva agilizar o desempenho clínico - procedimentos diagnósticos e terapêuticos - nos serviços em que os pacientes permanecem em observação ou internados. Consideram-se como parâmetros de maior efetividade a redução da média de permanência e a otimização da capacidade instalada.

A gestão de vagas objetiva compatibilizar a oferta e a demanda por leitos/camas, geralmente escassos, estabelecendo as prioridades para ocupar as unidades de internação/internamento baseadas nos acordos firmados entre os serviços do hospital, assim como proporcionar mais agilidade à internação/internamento e à transferência dos pacientes com maior risco clínico. Busca-se garantir uma taxa de ocupação hospitalar entre 85 e $90 \%$.

As diretrizes para a gestão de leitos/camas e vagas são (Bittencourt et al. 2009):

Centralizar a oferta de vagas de leitos internos e externos e realizar a interface com os serviços demandantes de leitos (recuperação pós-anestésica, pacientes provenientes das UTIs e outras). A centralização da liberação de vaga nos serviços de internaçăo locais ou dos demais hospitais inscritos na rede assistencial é um dos elementos fundamentais nesse processo de gestão, na medida em que a relaçăo de poder sobre a unidade funcional básica e estratégica do hospital - o leito - configura o padrāo de acesso ao mesmo. A gestão descentralizada de leitos vagos pode estimular o uso dos micropoderes, possibilitando a utilizaçăo privada da oferta mediante critérios inadequados. Simultaneamente, ocorre a identificação das demandas por leitos, sendo que a pressāo das unidades demandantes precisa ser canalizada de forma sistemática e ágil, de tal maneira que seu foco permaneça na atenção ao paciente, geralmente grave.
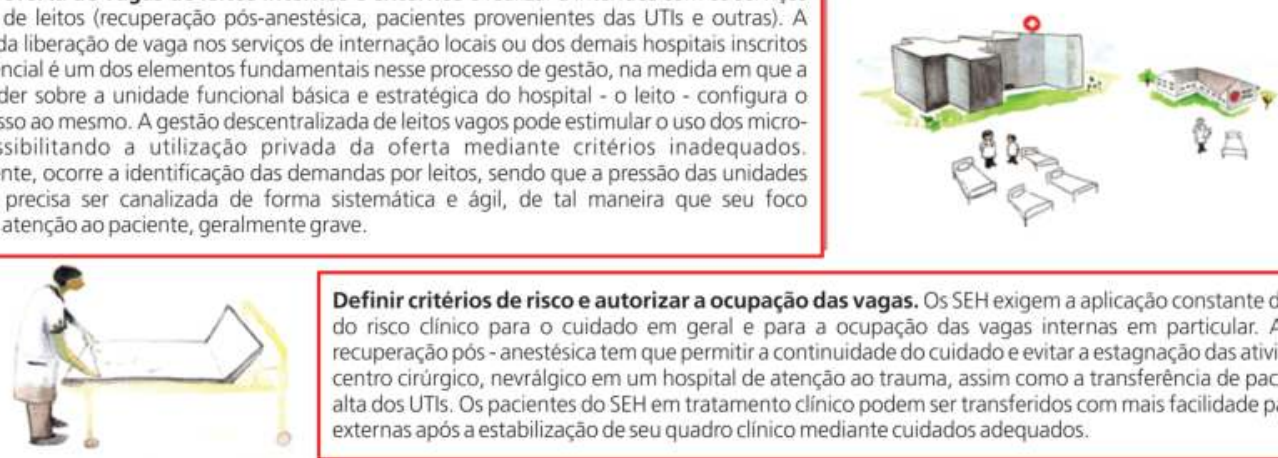

Definir critérios de risco e autorizar a ocupação das vagas. Os SEH exigem a aplicação constante do critério do risco clínico para o cuidado em geral e para a ocupaçâo das vagas internas em particular. A sala de recuperaçāo pós - anestésica tem que permitir a continuidade do cuidado e evitar a estagnação das atividades no centro cirúrgico, nevrálgico em um hospital de atenção ao trauma, assim como a transferência de pacientes de alta dos UTIs. Os pacientes do SEH em tratamento clínico podem ser transferidos com mais facilidade para vagas externas após a estabilização de seu quadro clínico mediante cuidados adequados.

Organizar a transferência inter-hospitalar. E um momento extremamente delicado, pois se trata de transferir pacientes graves, ou potencialmente graves, cuja comunicaçăo deve ser entre as autoridades clínicas de ambos os hospitais envolvidos, de maneira clara e formal, com base em protocolos. Mecanismos de acompanhamento da evolução dos pacientes pós-alta/pós-transferência auxilia no controle de qualidade das decisōes tomadas para a alta ou transferência.
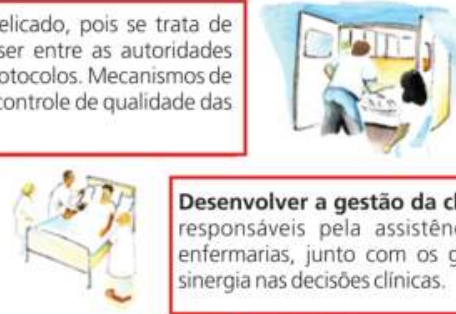

Desenvolver a gestão da clínica. Consiste na visita das equipes responsáveis pela assistência aos pacientes no SEH e nas enfermarias, junto com os gerentes destas unidades, buscando sinergia nas decisōes clínicas.

Monitorar com o censo hospitalar (oferta x demandas de vagas por enfermaria) e com o tempo médio de permanência (TMP) nos leitos internos. O censo hospitalar permite que se avalie, por meio do gráfico de tendências, antecipadamente, a saturaçāo operacional do SEH. OTMP medido nas diversas unidades identifica o consumo dos recursos hospitalares, contribuindo para a análise do desempenho clínico.

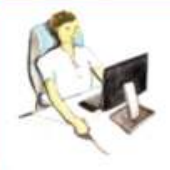


Adscrição significa responsabilização. Um serviço de saúde com uma clientela adscrita tem responsabilidade por um grupo de cidadãos em um território definido.
A gestão de leitos/camas e vagas deve estar vinculada diretamente à diretoria técnica, permitindo monitoramento diário e ações corretivas imediatas. É um trabalho contínuo.

\section{Gestão da rede assistencial de apoio}

O hospital enfrenta o grande desafio da integração com as demais organizações de saúde para obter a integralidade da assistência (Rechel et al. 2009). A constituição de redes de atenção em saúde é o novo paradigma, aprofundando o princípio da ação solidária, cooperativa e com foco na melhoria da efetividade assistencial e organizacional. Atuar em rede de atenção à saúde é necessário, mas é de execução difícil e pressupõe (Brasil 2011):

contratualização de metas e resultados;

滕 definição da carteira de serviços em cada ponto da atenção;

* planejamento ascendente a partir das necessidades da população;

橉 sistemas logísticos e de informação;

* superar a abordagem isolada (hospitais ou centros de atenção primária) para a contratualização no âmbito da região de saúde, seguindo critérios de adscrição da população estratificada por grau de risco.

Em uma rede de atenção à saúde organizada é possível desenvolver e implementar o conceito de "Linha de Cuidado" (Cecílo, Merhy 2007), que representa uma forma de transversalização e articulação das práticas de produção de saúde entre os vários serviços de saúde, visando à garantia da integralidade do cuidado. As linhas de cuidado devem ser frutos da articulação de saberes da clínica, da epidemiologia, do planejamento, para aprimorar a efetividade da atenção a partir da definição das responsabilidades assistenciais de cada serviço de saúde, de todos os níveis da atenção, dos mecanismos de integração e corresponsabilização clínico-sanitária e das formas de garantir os recursos materiais e humanos necessários à sua operacionalização.

O hospital e o SEH fazem parte da rede de assistência como um "ponto sistêmico" integrado às demais organizações de saúde, com sua vocação assistencial bem definida por meio de linhas assistenciais estruturadas que ultrapassam os muros do hospital, dialogando com as demais organizações do sistema via complexo regulador. O sistema sem muros (Hartz, Contandriopoulos 2004). Esse novo papel do hospital é inadiável, é o fim do "hospital que faz tudo", fechado em si mesmo, sob pena de continuar a representar o ponto de estrangulamento do sistema de saúde, pois, diante do simbolismo da população e da até 
então baixa resolubilidade dos demais componentes da rede, ainda se constitui importante porta de entrada do sistema.

No entanto, espera-se, também, o caminho inverso, a desospitalização por meio dos serviços de atenção domiciliar e da integração com as equipes de atenção básica. Ambas permitirão ampliar os cuidados fora do ambiente hospitalar, com o aumento da participação dos serviços comunitários em procedimentos antes tipicamente hospitalares, otimizando a utilização do "cobiçado" leito/cama hospitalar (Bittencourt 2003).

O desenvolvimento da tecnologia da informação e das comunicações terá grande impacto nos serviços de saúde, pois a integração de toda a informação pelas redes aumentará a utilização de prontuários/processos clínicos únicos e eletrônicos e o uso da telemedicina. A consulta em tempo real, proporcionada pela telemedicina, permitirá a ligação de pequenas unidades de saúde com os grandes centros de especialistas, levando condutas complexas para mais perto do paciente (Rechel et al. 2009).

Cabe ressaltar a Portaria do Ministério da Saúde do Brasil, 2.809, de 07 de dezembro de 2012, que cria as Unidades de Internação/Internamento em Cuidados Prolongados (UCP), assim como os Hospitais Especializados em Cuidados Prolongados (HCP), como mais uma opção para transferir pacientes que ocupam leitos/camas de agudos, nos hospitais com SEH. Trata-se de uma grande evolução, pois, no Brasil, ainda não existe a classificação de leitos/camas de agudos e crônicos, como ocorre na Europa.

\section{Considerações finais}

Não há dúvidas de que a superlotação dos SEH é fator contribuinte para incidentes relacionados ao cuidado. O ideal é que os SEH não tenham superlotação e sejam dimensionados para atuar nos momentos de acidentes com múltiplas vítimas. Entretanto, essa não é a realidade em muitos países, com insuficiência orçamentária e dificuldades de gestão. O capítulo apresentou alternativas que podem mitigar essa situação. Em síntese, percebe-se, por meio do modelo “Ciclo Resolutivo da Superlotação dos Prontos-Socorros", que a ampliação do acesso a novos e necessários serviços de saúde, assim como a integração entre eles, com base na gestão clínica-operacional, permite consolidar uma abordagem consistente para esse grave e complexo problema sanitário. Os recursos financeiros envolvidos a fim de viabilizar tal modelo são imediatos, crescentes e enfrentam resistências, fruto das constantes crises financeiras de caráter mundial (Contandriopoulos et al. 2010). Todavia, esse é o dilema permanente, que envolve novos investimentos no setor saúde, e sempre o pautamos por atender às necessidades inadiáveis da população. 


\section{Referências}

Armstrong Institute for Patient Safety and Quality. CUSP Implementation Workshop; 2013 Sep 26-27. Baltimore: Johns Hopkins Medicine; 2013.

Asplin BR, Magid DJ. If you want to fix crowding, start by fix your hospital. Ann Emerg Med. 2007; 49(3):273-4.

Asplin BR, Magid DJ, Rhodes KV, Solberg LI, Lurie N, Camargo CA Jr. A conceptual model of emergency department crowding. Ann Emerg Med. 2003;42:173-80.

Bittencourt RJ. Ciclo resolutivo da superlotação dos prontos-socorros: texto de apoio. Brasília, DF: Universidade Católica de Brasília; 2013. Disciplina de Planejamento e Gestão em Saúde do Curso de Medicina.

Bittencourt RJ. Programa de Atenção ao Paciente Crônico-Grave (PAPCG). In: Estruturação de Núcleo Interdisciplinar de Pesquisa e Desenvolvimento em Sistemas de Atenção à Saúde (Relatório final). Belo Horizonte: CNPq; 2003. Projeto CNPq N480098/01-8.

Bittencourt RJ. A superlotação dos serviços de emergência hospitalar como evidência de baixa efetividade organizacional [tese]. Rio de Janeiro: ENSP, Fiocruz; 2010.

Bittencourt RJ, Amaral MA, Prudente L, Scarazatti GL, Massaro A, Pinto ACG. Gestão de leitos e vagas hospitalares: relato de experiência no Hospital de Urgência de Sergipe. QualiHosp 2009.

Bittencourt RJ, Hortale VA. Intervenções para solucionar a superlotação nos serviços de emergência hospitalar: uma revisão sistemática. Cad Saúde Pública. 2009;25(7):1439-54.

Bradley VM. Placing Emergency Department crowding on the decision agenda. J Emerg Nurs. 2005;31(3):247-58.

Brasil. Decreto n. 7.508, de 28 de junho de 2011. Regulamentação da Lei 8.080/90. Diário Oficial da União 2011 jun 29.

Cecílo LCO, Merhy EE. A integralidade do cuidado como eixo da gestão hospitalar. In: Pinheiro R, Mattos RA. Construção da integralidade: cotidiano, saberes, e práticas em saúde. Rio de Janeiro: Ed. UERJ; 2007. p. 199-212.

Champagne F, Contandriopoulos A-P, Picot-Touché J, Béland F, Nguyen H. Un cadre d'évaluation de la performance des systems de services de santé: le modèle EGIPSS: rapport technique. Montreal: Université de Montréal; 2005.

Cheung DS et al. Improving Handoffs in Emergency Department. Ann Emerg Med. Forthcoming 2009 [citado 2013 set 28]. Disponível em: https://mef.sites.medinfo.ufl.edu/files/2009/11/Wears2009-Improving-handoffs-in-the-ED.pdf

Coelho IB. Gestão hospitalar. Campinas: Faculdade de Ciências Médicas, UNICAMP; 2006. Curso de Gestão da Clínica Ampliada em Hospitais.

Committee on the Future of Emergency Care in the United States Health System. Hospital-based emergency care: at the breaking point. Washington, DC: National Academy of Sciences; 2007. p. $18,130,424$.

Contandriopoulos A-P, Hartz Z, Gerbier M, Nguyen A. Elementos de arquitetura dos sistemas de avaliação do desempenho dos serviços de saúde. In: Contandriopoulos A-P, Hartz Z, Gerbier M, Nguyen A. Saúde e cidadania. Campinas: Saberes; 2010. cap. 8; p. 297-324. 
Freitas F. Corredor da morte. Flick 2010 fev 9 [citado 2014 jun 29]. Disponível em: http://www. flickr.com/photos/30530989@N05/5307121034/in/photolist-95YobN-9EjJGe-9EjJJa-9EjJKn9EnDWw-9EjJCz-9Sf1oF-8fKhnV-8zNp6P-kARff4-8PXSBy-8qZD4g-afts8g-8k2YVr-8XMati-8CYhvn8Xd1Yw-adHVbX-akn59N-8WLSBz-am7JT2-8yFzdm-bFUuvT-bFUtwZ-bFUxb8-bFUs2B-bsZFGbbFUBER-bFUPsp-bsZEVh-bsZSLG-8PXwgp-fre4er-9EnDZA-9EjJN4-bsZLrU-9xLNH5-9xHNGn-9xLMQybsZAyo-a4MEWw-9AbqK5-9A8sMB-9A8skV-8Xa1se

Fried B, Carpenter WR. Understanding and improving team effectiveness in quality improvement. In: McLaughlin CP, Kaluzny AD. Continuous quality improvement in health care. Ontario: Jones and Barlett Publ.; 2006. p. 154-88.

Graff L, Stevens C, Spaite D, Foody J. Measuring and improving quality in emergency medicine. Acad Emerg Med. 2002;9(11):1091-107.

Hartz ZMA, Contandriopoulos A-P. Integralidade da atenção e integração de serviços de saúde: desafios para avaliar a implantação de um "sistema sem muros". Cad Saude Publica 2004;20 (Suppl 2); S332-S336.

Howell E, Bessman E, Kravet S, Kolodner K, Marshall R, Wright S. Active bed management by emergency department throughput. Ann Intern Med. 2008;149:804-10.

Mackway-Jones K, Marsden J, Windle J. Sistema Manchester de classificação de risco. Belo Horizonte: Grupo Brasileiro de Classificação de Risco; 2010.

Magid DJ, Asplin BR, Wears RL. The quality gap: Searching for the consequences of Emergency Department crowing. Ann Emerg Med. 2004;44(6):586-8.

McKee M, Healy J. Chapter one: The significance of hospitals: na introduction. In: McKee M, Healy J., editors. Hospitals in changing Europe. Buckingham: Open University; 2002. p. 3-13. (European observatory on health care systems series).

Ministério da Saúde (BR). Portaria n. 1.101, de 12 de junho de 2002. Estabelece parâmetros de cobertura assistencial no âmbito do Sistema Único de Saúde. Diário Oficial da União 2002 jun $13: 36$.

Peth HA Jr. Medication safety in emergency department. In: Croskerry P, Cosby KS, Schenkel SM, Wears RL. Patient safety in emergency medicine. Philadelphia: Wolter Kuuwer Health, Lippincott Williams \& Wilkins; 2009. p. 144-8.

Portela MC. Accountability e qualidade. Cien Saude Colet. 2007;12(3):840-1.

Rechel B, Wright S, Edwards N, Dowdeswell B, Mckee M. The changing context of capital investment. Introduction: hospitals within a changing context. In: Investing in hospitals of the future. Copenhagen: European Observatory on Health Systems and Policies; 2009. Chapter 1, p. 3-25. (Observatory studies series; 16).

Samaras N, Chevalley T, Samaras D, Gold G. Older patients in the emergency department. Ann Emerg Med.2010 Sep [citado 2013 set 26];56(3): 261-9. Disponível em: http://nuhem.com/emlinks/ LLSA\%20Articles\%202013/Older\%20patients\%20in\%20the\%20ED.pdf.

Schull M, Vermeulen M, Slaughter G, Morrison L, Daly P. Emergency department crowding and thrombolysis delays in acute myocardial infarction. Ann Emerg Med. 2004;44(6):577-85.

Sicotte C, Champagne F, Contandriopoulos A-P, Béland F, Denis J-L, Bilodeau H. A conceptual framework for the analysis of health care organizations' performance. Health Serv Manage Res 1998;11(1):24-48. 
Trzeciak S, Rivers EP. Emergency department overcrowding in the United States: an emerging threat to patient safety and public health. Emerg Med J 2003 [citado 2013 set 28];20:402-5. Disponível em: http://www.ncbi.nlm.nih.gov/pmc/articles/PMC1726173/pdf/v020p00402.pdf

Twanmah JR. Emergency department overcrowding, patient flow and safety. In: Croskerry P, Cosby KS, Schenkel SM, Wears RL. Patient safety in emergency medicine. Philadelphia: Wolter Kuuwer Health, Lippincott Williams \& Wilkins; 2009.Cap. 22, p.149-157.

Vecina Neto G, Malik AM. Tendências na assistência hospitalar. Cien Saude Colet. 2007; 12(4):825-39.

Wachter R, Goldman L. The emergening hole of "hospitalist" in American Health Care Systems. N Engl J Med. 1996;335(7):51-517.

Waterer GW, Kessler LA, Wunderink RG. Delayed administration of antibiotics and atypical presentation in community acquired pneumonia. Chest. 2006;130(1):11-5. 


\section{Gestão do risco não clínico}

António Tavares, Elsa Soares, Sílvia Carla da Silva André, Carla Barreiros, Cândida Pité-Madeira, Ricardo Alcoforado Maranhão Sá e Irene Rêgo Haddad

As organizações de saúde devem garantir uma estrutura segura para os pacientes e trabalhadores. O primeiro passo é reconhecer que existem riscos não clínicos que devem ser prevenidos e/ou mitigados. Neste capítulo, serão apresentados quatro (4) subtemas abordando o risco não clínico, ou seja, relacionados com a infraestrutura e as práticas não clínicas. O primeiro, mais geral, abordando o conceito de risco não clínico. O segundo sobre os riscos relacionados à estrutura predial e incêndios; o terceiro sobre os riscos com os equipamentos médico-hospitalares. Por último, o quarto subtema aborda a gestão dos resíduos.

\section{Gestão do risco}

Conforme já mencionado no capítulo a respeito de taxonomia (Capítulo 3 deste livro), a Classificação Internacional sobre Segurança do Paciente conceitua segurança do paciente como a redução do risco de danos desnecessários, relacionados com os cuidados de saúde, para um mínimo aceitável. Falhas na infraestrutura também podem contribuir para os danos desnecessários. O perigo, nessa classificação, é uma circunstância, agente ou ação com potencial para provocar danos, e o risco é a probabilidade de ocorrência de um incidente. Ou seja, o risco é a probabilidade de uma pessoa sofrer algum dano na sua saúde em razão da exposição a um perigo.

A gestão de riscos tem sido destacada nas políticas públicas de saúde e na elaboração de protocolos nos hospitais. Nos EUA, o conceito de gestão de riscos tem sido utilizado no sector de saúde desde a década de 1920 (Silva 2010). As atividades de gestão de riscos iniciaram-se nos 
O Capítulo deste livro, "Direito em segurança do paciente", trata, entre outras coisas, da gestão de riscos sob o viés das questões jurídicas por trás da segurança do paciente. hospitais americanos como uma forma de minimizar os custos originados por negligências ocorridas na área da saúde (Taublib 1998; Silva 2010).

Nesse contexto, a gestão do risco pode ser definida como o processo sistemático de identificar, avaliar e tratar o risco potencial e o risco real. Precisa expressar também as medidas que devem ser utilizadas para a redução da frequência e gravidade dos incidentes inesperados, refletindo na redução das ações judiciais, além de promover a fiabilidade/ confiabilidade dos pacientes (WHO 2010).

Os estabelecimentos de saúde, em especial os hospitais, envolvem uma diversidade de riscos, implicando uma necessidade de implantação de normas fixas que determinem as atividades de análise e avaliação dos riscos. Assim, deve-se entender que os hospitais necessitam de se aproximar de um nível de risco aceitável, de forma a oferecer maior segurança aos pacientes, profissionais de saúde e público em geral.

De acordo com a Figura 1, os riscos nos hospitais podem ser inseridos em três zonas, conforme a frequência ou a gravidade dos efeitos para a saúde. A fim de manter os riscos numa zona de aceitabilidade, os hospitais, por meio da gestão de riscos, devem ter como objetivos a identificação, análise, avaliação e monitorização contínua dos riscos, visando criar mecanismos para minimizar os efeitos para a saúde e implementar a capacidade de resposta por parte da organização.

Figura 1 - Níveis de risco existentes em estabelecimentos hospitalares

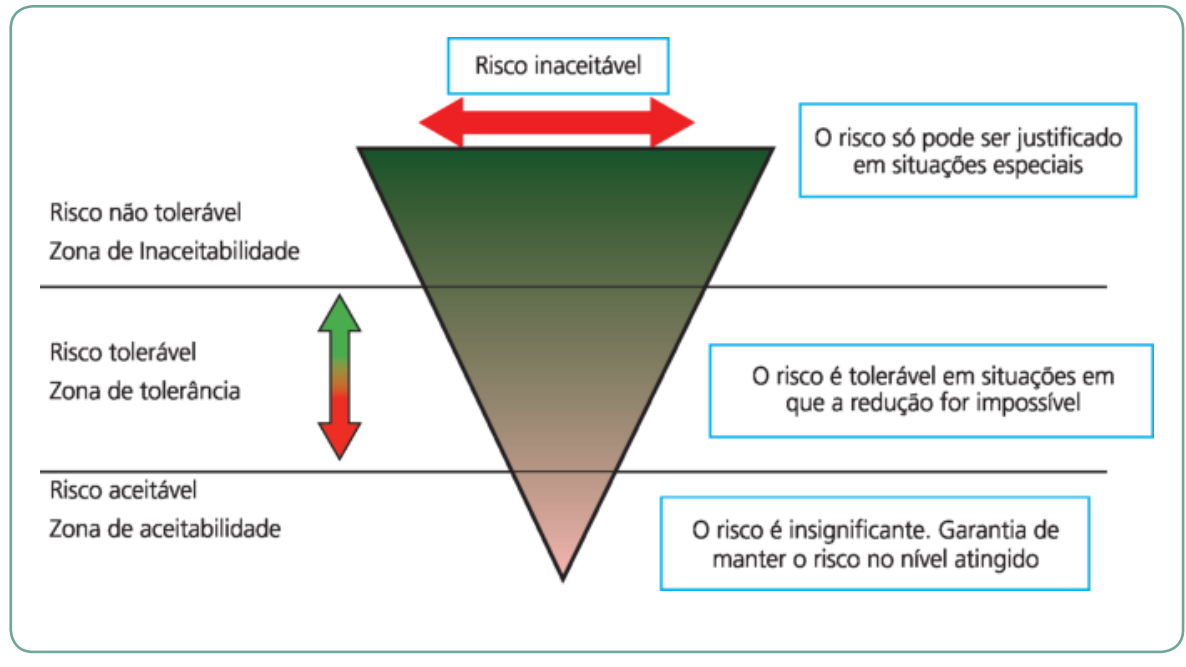

Fonte: Adaptado de Desroches (2005). 
O passo inicial para a gestão de riscos consiste na definição e identificação dos riscos aceitáveis num estabelecimento de saúde (Figura 2). Após terem inventariado todos os riscos, os técnicos devem proceder à análise e avaliação dos riscos para conhecer os cenários dos eventos indesejáveis e as possíveis consequências.

Na fase de avaliação dos riscos, são determinados os riscos prioritários a fim de elaborar as ações para minimizar a possibilidade da ocorrência de um evento indesejado, além de estabelecer objetivos para a manutenção de um nível aceitável de riscos. É de referir que esse processo deve ser cíclico e permanente.

Figura 2 - Fases da gestão de riscos

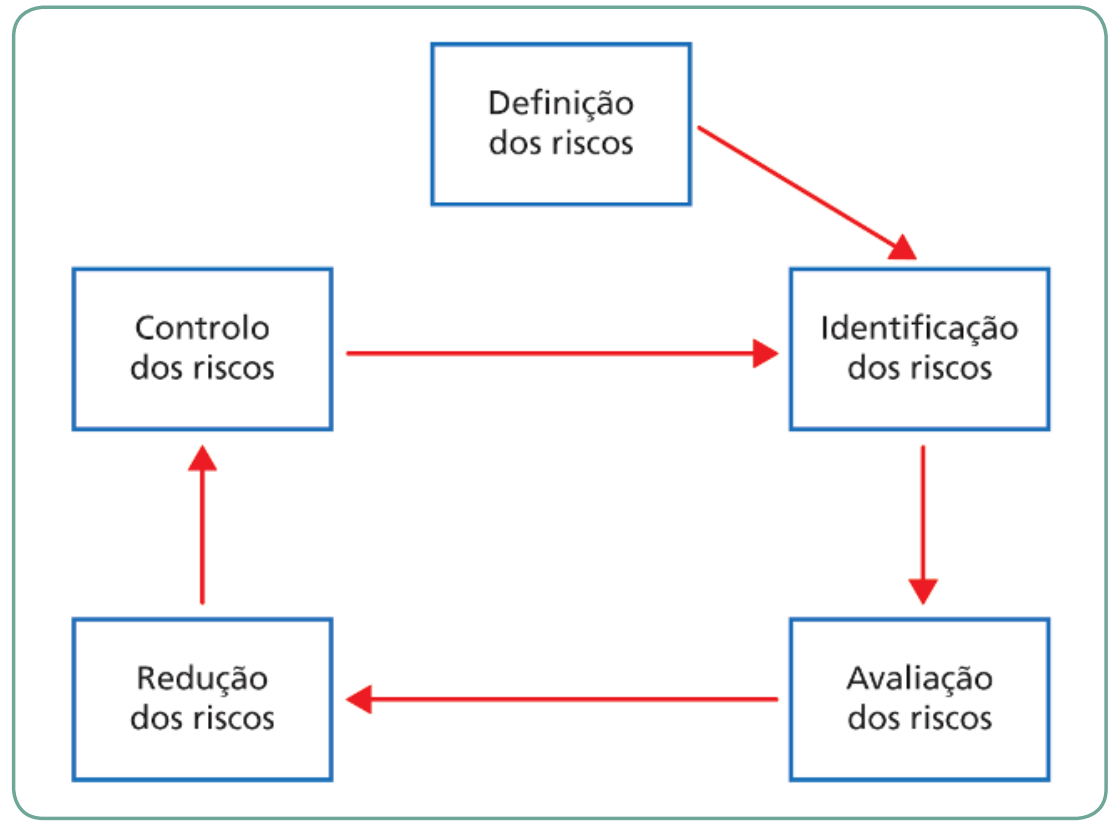

Fonte: Elaboração dos autores.

Atualmente, nos países desenvolvidos, a gestão de riscos integra as prioridades da administração dos hospitais. Recomenda-se que os hospitais implementem e robusteçam os programas de gestão de riscos a fim de proteger os pacientes, profissionais de saúde e o público, contribuindo assim para a proteção da saúde e a minimização de custos (WHO 2010).

Nos hospitais, a estrutura física, as atividades desenvolvidas, os equipamentos médico-hospitalares e as substâncias e materiais utilizados podem originar riscos aos pacientes, profissionais de saúde e público em geral, além do meio ambiente. Os riscos podem ser de natureza física, química, biológica e psicossocial, o que exige um controlo sistemático para a minimização dos efeitos para a saúde. 
Assim, os hospitais devem organizar-se no desenvolvimento de atividades para minimizar ou mesmo suprimir a ocorrência de riscos, clínicos ou não clínicos, uma vez que podem ter como consequências danos para a saúde das pessoas envolvidas, além do aumento de custos.

Tal fato é válido para todas as unidades prestadoras de cuidados de saúde, nas quais se deve ter atenção a todos os requisitos estruturais fundamentais para cada local onde são prestados cuidados de saúde, desde uma sala de tratamento (Tavares et al. 2017) até o local de maior complexidade.

Quadro 1 - Classificação dos riscos em ambiente hospitalar e os possíveis eventos associados

\begin{tabular}{|c|c|}
\hline Natureza dos riscos & Eventos \\
\hline Riscos clínicos & $\begin{array}{l}\text { - Erro de diagnóstico } \\
\text { - Erro de análise } \\
\text { - Erro terapêutico }\end{array}$ \\
\hline Riscos biológicos & $\begin{array}{l}\text { - Contaminação } \\
\text { - Intoxicação }\end{array}$ \\
\hline Riscos humanos & $\begin{array}{l}\text { - Falta de qualificação } \\
\text { - Falta de prudência } \\
\text { - Negligência }\end{array}$ \\
\hline Riscos físicos & $\begin{array}{l}\text { - Eletrocussão } \\
\text { - Radiação, explosão } \\
\text { - Queimadura, incêndio }\end{array}$ \\
\hline Riscos tecnológicos & $\begin{array}{l}\text { - Aparelhos a pressão } \\
\text { - Instrumentos médicos }\end{array}$ \\
\hline Riscos ambientais & $\begin{array}{l}\text { - Fenómenos naturais } \\
\text { - Qualidade da água } \\
\text { - Alimentação } \\
\text { - Sistema de águas residuais } \\
\text { - Resíduos } \\
\text { - Qualidade do ar }\end{array}$ \\
\hline Riscos psicológicos & - Stress, burnout \\
\hline Outros & $\begin{array}{l}\text { - Falta de recursos financeiros } \\
\text { - Falta de recursos humanos } \\
\text { - Influência política }\end{array}$ \\
\hline
\end{tabular}

Fonte: Adaptado de Desroches (2005). 


\section{Riscos relacionados à estrutura predial e o risco de incêndios}

No contexto hospitalar, existem riscos clínicos e riscos não clínicos. Os riscos clínicos são riscos relacionados direta ou indiretamente à assistência prestada pelos profissionais de saúde aos utentes/usuários, que podem ocasionar danos físicos ou psicológicos aos pacientes. Os riscos não clínicos são riscos originados por procedimentos e práticas de atividades relacionadas com a manutenção da estrutura física e dos suportes assistenciais (Desroches 2005).

\section{Incêndios}

Os incêndios nos estabelecimentos hospitalares têm significado social e económico mais amplo que a simples constatação do facto. A remoção e transferência de pacientes, a suspensão de serviços essenciais à população e até a promoção do pânico são prejuízos de alto custo social.

Nos EUA, no período de 2006 a 2010, notificou-se uma média de 6.240 incêndios em estabelecimentos de saúde por ano. Os lares para idosos foram responsáveis por $46 \%$ dos casos, $23 \%$ dos casos em hospitais, e $21 \%$ em serviços de saúde mental. Esses incêndios causaram 6 mortes, 171 bombeiros feridos e uma perda de 52,1 biliões de dólares em danos materiais (NFPA 2012).

Constatou-se que $61 \%$ dos incêndios foram originados em equipamentos da cozinha, $7 \%$ em equipamentos de lavandaria, como máquinas de lavar e secar, 6\% em aquecedores, $4 \%$ foram associados à distribuição de energia elétrica e 14\% a outros factores (NFPA 2012).

Os hospitais são instituições com características especiais, concebidas quase exclusivamente em função dos seus clientes (utentes/usuários especiais pela sua doença e sofrimento, alguns deles com limitações físicas e mentais), com sistemas técnicos e organizacionais muito próprios, proporcionando aos seus trabalhadores condições de trabalho muito específicas, que, em certas circunstâncias, constituem um risco acrescido quando comparadas com as mesmas atividades realizadas noutro sector.

Todos esses condicionantes podem originar redução da capacidade de resposta a acidentes, em especial, no caso de incêndios.

As condições desfavoráveis apresentadas pelos pacientes internados num hospital tornam-se uma dificuldade no momento de evacuação. Nesse contexto, há o consenso internacional sobre a impossibilidade 
de evacuação total em alguns hospitais; assim, há a necessidade de enfatizar as ações de prevenção, por meio da adoção de medidas, para impedir a ocorrência de incêndio, bem como ações para controlar o seu desenvolvimento.

Figura 1 - Tela a óleo exposta no Museo Nacional de Bellas Artes em Buenos Aires, chamada "Incendio de un hospital (1808)", de Francisco Goya (1746-1828)

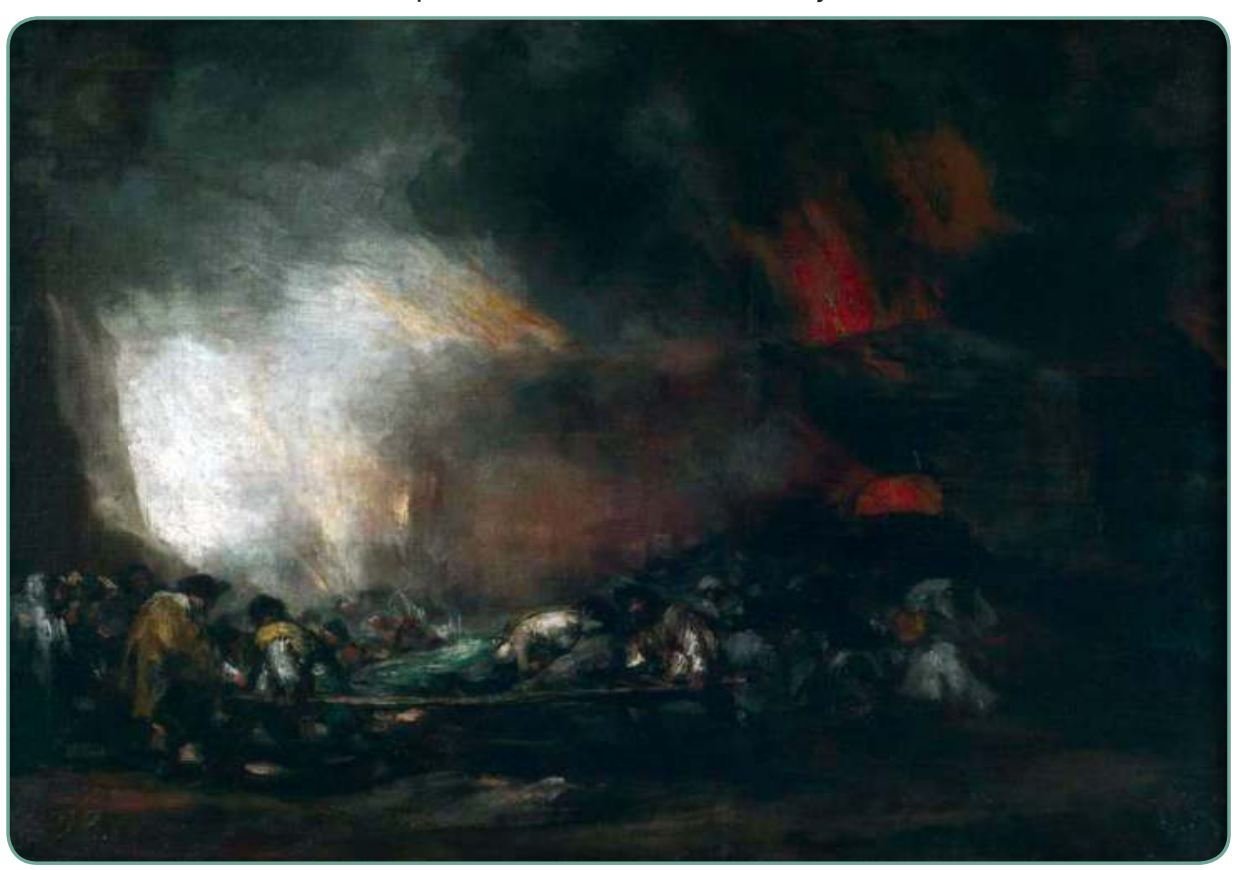

Fonte: Wikimedia Commons (2014).

A prevenção de incêndios inicia-se com a construção do edifício que deverá atender às normas de segurança existentes em cada país (Silva, 2010). Porém, salienta-se que numerosos hospitais, em diversas cidades, estão instalados em edifícios antigos, os quais foram sofrendo adaptações ao longo do tempo e construídos em épocas em que não existiam os requisitos e meios técnicos para a proteção contra incêndios.

Nesse contexto, esses estabelecimentos precisaram de se adaptar por meio de reformas para alcançar um nível definido por leis e de forma a garantir a segurança dos trabalhadores, dos pacientes e dos visitantes.

Embora, frequentemente, os incêndios tenham origem na lavandaria, armazém, central de esterilização, cozinha, farmácia, laboratório, depósitos de gases medicinais e oficinas, as enfermarias, as salas de ambulatório e as salas de espera merecem especial atenção em virtude 
da permanência de grande número de pessoas, algumas delas com restrições de mobilidade (MS 1995; Silva 2010).

Uma organização hospitalar deve estabelecer medidas de autoproteção, implementando uma organização de segurança, de modo a prevenir a ocorrência de um incêndio e estabelecer a atuação em caso de emergência. Essas medidas, listadas a seguir, devem atender aos riscos inerentes à sua atividade, bem como refletir sua organização:

\section{Medidas de autoprotecção}

Recolha/coleta de informação sobre os processos associados à atividade, produtos manuseados e armazenados, equipamentos e sistemas utilizados, arquitetura dos espaços e caracterização da ocupação humana.

Análise e avaliação dos riscos de incêndio, bem como das medidas adoptadas para lhes fazer face.

Elaboração de um programa de prevenção e combate a incêndios, incluindo exercícios periódicos de simulacro dirigidos aos profissionais.

Criação de um grupo capacitado (no Brasil tem o nome de Brigadas de Incêndio) para atuar no momento do sinistro.

Capacitação de todos os profisisonais para lidar no momento do incêndio (por exemplo, conhecer um número para alertar os responsáveis de combate ao incêndio).

A minimização da probabilidade de ocorrência de incêndios depende da adoção de uma atitude preventiva por todos os ocupantes da organização, por meio do conhecimento dos riscos envolvidos no seu trabalho e do cumprimento de procedimentos elementares de prevenção. A garantia de que as condições de segurança são adequadas ao risco de incêndio depende do cumprimento de procedimentos de segurança relativos à utilização dos espaços, dos sistemas e dos equipamentos.

As medidas preventivas são compostas de planos de prevenção conforme a categoria de risco correspondente. Devem ser definidas regras de laboração e de comportamentos que constituem o conjunto de procedimentos de prevenção a adotar pelos ocupantes dos diversos espaços, de acordo com sua tipologia - laboratórios, farmácia, lavandaria etc. -, destinados a garantir a manutenção das condições de segurança, nomeadamente: 
* acessibilidade dos meios de alarme e intervenção em caso de emergência;

曗acessibilidade dos meios de socorro aos espaços;

蝶 acessibilidade dos veículos de socorro dos bombeiros aos meios de abastecimento de água e de outros meios;

facilidade de acesso aos percursos de evacuação dos espaços, os quais devem manter-se desimpedidos de quaisquer obstáculos;

* eficácia da estabilidade ao fogo e dos meios de compartimentação, isolamento e proteção;

橉 vigilância dos espaços, em especial dos de maior risco de incêndio;

滕 conservação dos espaços em condições de limpeza e arrumação adequadas;

segurança na manipulação e no armazenamento de matérias e substâncias perigosas;

能 segurança em todos os trabalhos de manutenção, recuperação, beneficiação, remodelação de sistemas e de instalações, que impliquem aumento do risco de incêndio,

zonas limítrofes ou interiores de áreas florestadas, qualquer edifício ou zona urbanizada devem permanecer livres de mato suscetível de facilitar a propagação do fogo a uma distância de $50 \mathrm{~m}$ do edificado.

O sistema de segurança contra incêndio num hospital considera o espaço envolvente urbano e não urbano e não somente o edifício, sendo influenciado pela sua localização e configuração. Para tanto, ao elaborar um plano de segurança contra incêndio, devem ser considerados os seguintes aspetos (Silva 2010): 


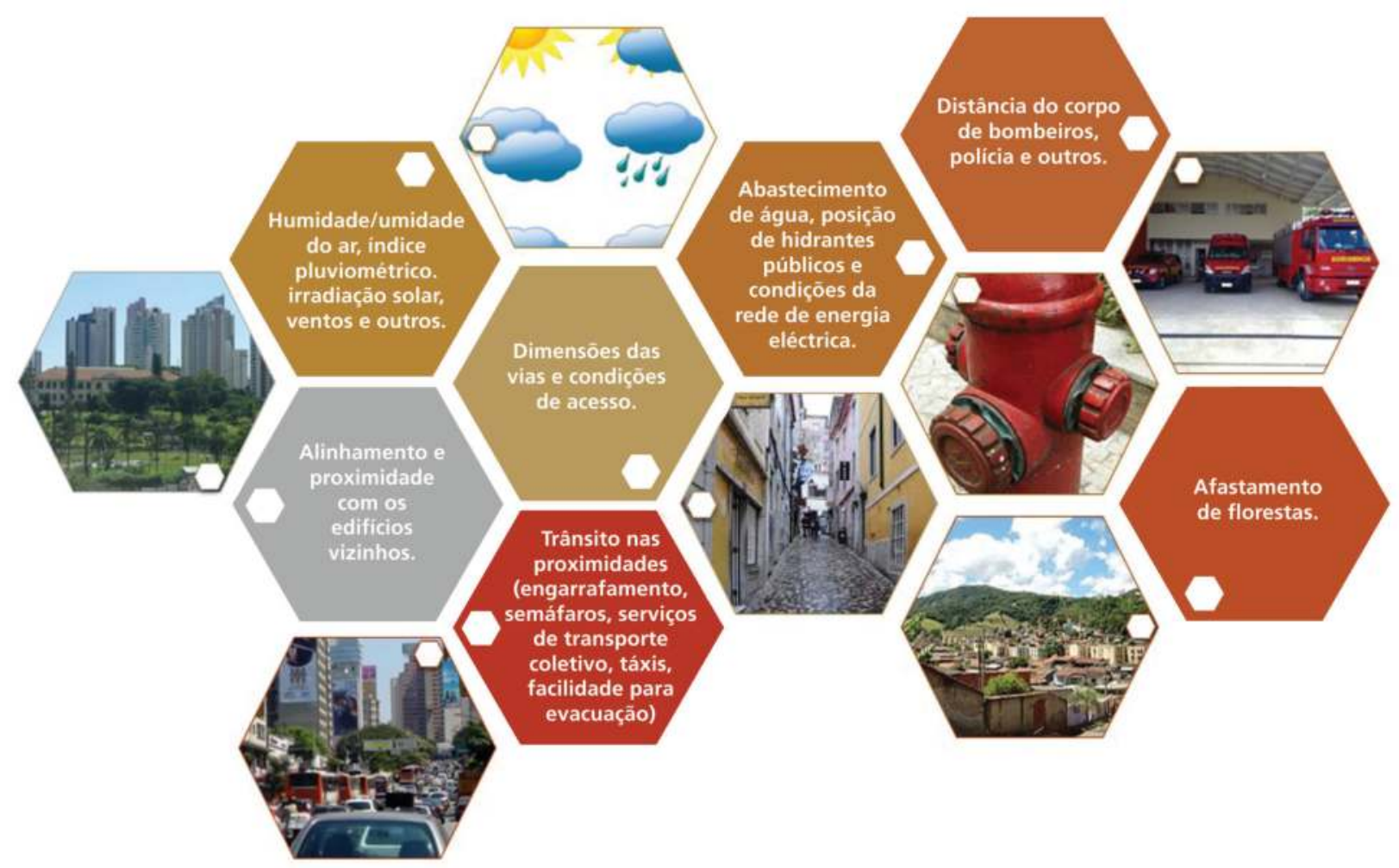

Fonte: Previsión... (2013), Lukaaz (2010), Rebel (2011), Prata (2011), AlexSP (2011), Floresta (2014), Ortiz (2006).

A análise sociourbanística ajuda a garantir o acesso de ajuda externa em situações de emergência, bem como a determinação de facilidades de evacuação da área.

As medidas preventivas contra incêndios iniciam-se na fase de elaboração do projeto do edifício hospitalar. Nesse contexto, as medidas de segurança podem ser agrupadas da seguinte forma:

滕 Construção: limitação de altura, vias de evacuação.

跕 Condições urbanísticas do meio envolvente: acesso a viaturas de bombeiros.

膦 Instalações técnicas: pontos de água (hidrantes), energia elétrica, gases medicinais.

Equipa de prevenção de acidentes: formação e treino de um grupo de profissionais para implementar as medidas de redução dos riscos de incêndios (Gill, Ono 2006).

As fontes mais comuns de incêndios são as de origem térmica, elétrica, mecânica e química. Entre as causas citadas, pode também referir-se à falta de atenção e descuido dos profissionais, em especial pela falta de adesão a medidas de segurança. 
Em relação às características internas dos edifícios hospitalares, são de destacar os seguintes aspetos que, a não serem observados, podem contribuir para o aumento das consequências funestas de um incêndio:

蛅 andares com compartimentos corta-fogos diferentes;

* isolamento e proteção de locais de risco, como bloco cirúrgico, bloco obstétrico, neonatologia e unidades de cuidados intensivos;

滕 isolamento e proteção das vias de evacuação, bem como as características das portas, escadas e uso de elevadores;

* sinalização/sinalética, iluminação e deteção, uma vez que os edifícios devem ter equipamentos que forneçam informações em situações de perigo e possibilitem a evacuação em caso de incêndio;

滕 controlo do fumo;

潾 equipamentos e sistema de extintores, meios que propiciem a intervenção imediata sobre os focos de incêndio;

路 sistema de alarme;

* posto de segurança para monitorizar e controlar os riscos, centralizando as informações de segurança e os meios de difusão de alarmes e de transmissão de alerta (Silva 2010).

As medidas de segurança contra incêndios em hospitais devem ser revistas e adaptadas de forma periódica; designadamente, os planos de formação e treino não somente dirigidos aos profissionais envolvidos nas atividades de prevenção e de emergência para controlar as possíveis causas de incêndio, mas também para a manutenção de uma equipa treinada e orientada para situações de emergência.

\section{Para praticar}

Analise as questões a seguir sobre avaliação dos riscos de incêndios:

Considere a organização de saúde em que trabalha.
a) Quais os factores que poderão estar implicados no aparecimento de um incêndio?
b) O que pode levar a que sejam despoletados/desencadeados?
c) Quais serão as consequências, caso tal se verifique?
d) Qual a probabilidade de ocorrer? 


\section{Água potável e abastecimento}

A água é essencial ao funcionamento de um hospital. É requerida para consumo humano, higiene dos pacientes, confeção de alimentos, limpeza, lavandaria, atividades médicas, como hemodiálise, medicina física e reabilitação etc.

A água, assim como a energia, deve ser garantida durante as 24 horas do dia, todos os dias da semana.

Dada a vulnerabilidade dos pacientes de um hospital, devem ser acautelados os riscos inerentes à água, os quais podem ser microbiológicos ou químicos.

Deve ser assegurado o fornecimento de água adequado (em quantidade, pressão e qualidade) a todo o hospital, devendo ser avaliada, em conjunto com a entidade gestora do sistema de abastecimento público, a necessidade de instalação de reservatório de reserva e de regularização de consumo. Caso seja prevista a instalação de reservatório, ele deve ser concebido de forma a salvaguardar a qualidade da água armazenada, devendo ser alvo de manutenção adequada e avaliação periódica da sua potabilidade.

No hospital, em função das características da água do sistema de abastecimento público, da dimensão e características do sistema de distribuição predial e também dos cuidados aí prestados, deve ser equacionada a necessidade de instalação de um tratamento complementar, com o objetivo de garantir os requisitos de qualidade em todos os pontos de consumo.

O tratamento poderá passar por filtração e reforço de desinfeção. Poderão também ser requeridos tratamentos adicionais à água, uma vez que os requisitos de qualidade de uma água destinada ao consumo humano não são os mesmos dos requeridos a uma água destinada a determinado tratamento ou procedimento ou, ainda, a um equipamento, como é o caso da hemodiálise, tanques terapêuticos etc.

Para além da proteção dos riscos relacionados à água fria, em função da sua utilização, devem ser salvaguardados os riscos associados à água quente sanitária, uma vez que a temperatura poderá favorecer o desenvolvimento microbiano, como é o caso da bactéria Legionella.

Em função das características da rede predial da água quente sanitária (dimensão, tipo de material da rede predial e equipamentos de aquecimento e armazenamento), deve ser equacionada a instalação de tratamentos 
como o reforço de desinfeção e, também, garantido que, em todos os pontos de consumo, a temperatura da água se encontra acima de $50^{\circ} \mathrm{C}$ (preferencialmente $55^{\circ} \mathrm{C}$ ).

Para a garantia do bom funcionamento do sistema de distribuição predial e dos requisitos de qualidade da água em todos os pontos de consumo, deve existir o projeto do sistema de distribuição predial (rede predial de água fria e de água quente sanitária) e ser definido um plano de segurança da água, os quais devem ser atualizados sempre que seja realizada qualquer alteração ao sistema.

No plano de segurança da água, deve constar uma caracterização detalhada do sistema de distribuição predial (identificação de todos os equipamentos, tubagens e os materiais que o compõem), identificando e avaliando os riscos existentes quer na rede predial de água fria, quer na rede predial de água quente sanitária, e devem ser definidos procedimentos de operação manutenção e monitorização, de forma a evitar os eventuais riscos existentes.

Um dos aspetos que merece algum destaque refere-se à lavagem das mãos, procedimento que não pode em nenhuma circunstância ser comprometido pela escassez de água.

Os pontos de água devem ser em número suficiente e colocados em locais de fácil acesso para promover a higienização das mãos. As torneiras devem ser de acionamento não manual, especialmente as que se destinam aos profissionais de saúde ou a manipuladores de alimentos, devendo esses dispositivos ser dotados de sistema de secagem individual de mãos.

\section{Para refletir}

Na organização em que você trabalha, quais os cuidados necessários ao bom funcionamento do sistema de distribuição de água que são observados?

Analise o plano de segurança da água da sua organização e, a partir do descrito nessa seção, sistematize os tipos de riscos em que ela incorre.

\section{Sistema de águas residuais hospitalares}

Os hospitais consomem um volume significativo de água por dia. O consumo médio de água em hospitais varia entre 400 a 1.200 L/cama/ leito/dia (Deloffre-Bonnamour 1995; CCLIN 1999). Esse elevado con- 
sumo de água em hospitais repercute-se numa elevada produção de águas residuais (Emmanuel et al. 2002; Gautam et al. 2007).

As águas residuais produzidas nos hospitais são resultantes das atividades médicas e não médicas, dos laboratórios, dos centros de imagiologia e diagnóstico, cozinha e lavandaria, entre outros.

Num estabelecimento hospitalar, para além das águas pluviais e de outras águas exteriores ao edifício, consideram-se quatro tipos de águas residuais:

\section{Águas residuais sujas ou de tipo doméstico.}

Aguas residuais especiais (medicamentos, reagentes químicos, antissépticos etc.).

Águas residuais contaminadas, infetadas ou com tratamento

bacteriológico ou biológico provenientes de blocos operatórios,

laboratórios, de serviços de infetocontagiosas.

Aguas residuais radioativas.

Todas elas devem ser drenadas por redes independentes e sujeitas a tratamento prévio.

As águas residuais de estabelecimentos hospitalares têm características semelhantes a efluentes não industriais; contudo, para alguns poluentes, as concentrações encontradas podem ser superiores às esperadas para esse tipo de efluentes.

As águas residuais provenientes de hospitais caracterizam-se por terem uma carga orgânica importante, carga microbiana e ainda, na sua composição, disruptores endócrinos, metais pesados, detergentes e desinfetantes, solventes e ainda substâncias radioativas.

A eliminação na rede de águas residuais, mesmo sujeita ao efeito de diluição pode, em certas circunstâncias, gerar efeito cumulativo de algumas substâncias com repercussões nos ecossistemas, dado o volume de águas residuais produzidas em unidades hospitalares. 
Em atenção ao já exposto, é da máxima importância implementar medidas preventivas que possam limitar o impacte ambiental resultante dessa atividade.

Figura 3 - Fluxo dos efluentes líquidos

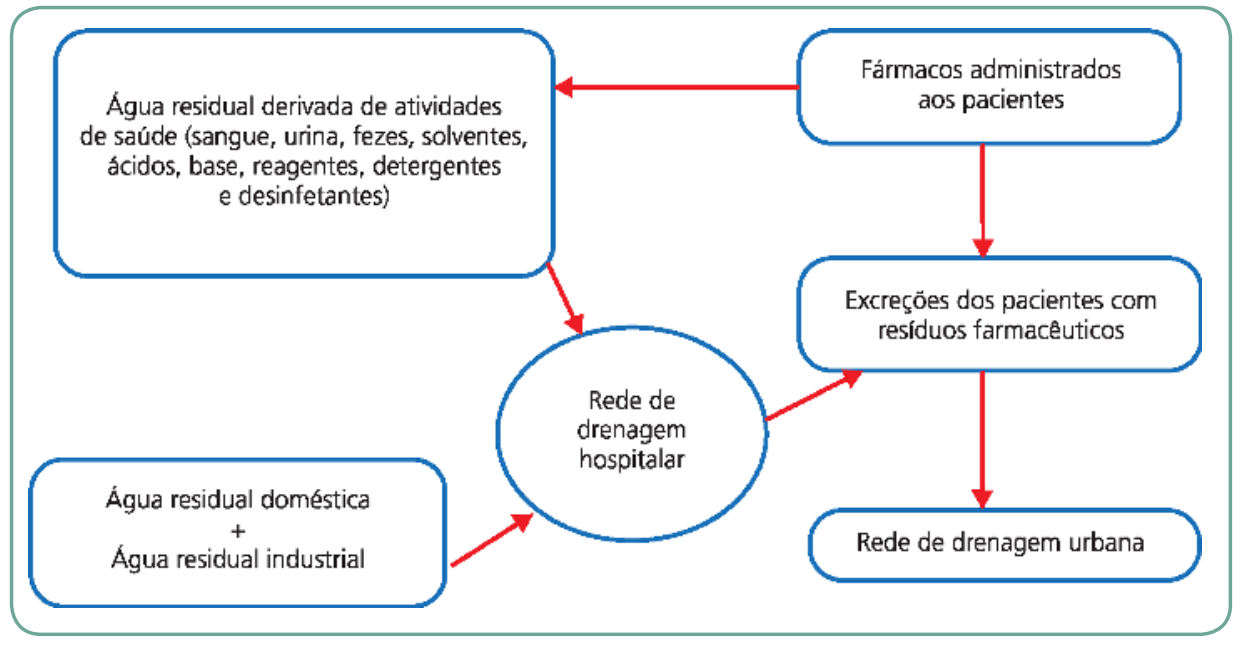

Fonte: Elaboração dos autores.

\section{Alimentação}

A alimentação em meio hospitalar tem-se revelado, nos últimos anos, uma ferramenta de melhoria no processo de cura dos pacientes internados, sendo um factor importante no controlo de comorbilidades/ comorbidades e de redução da duração do internamento/internação.

Têm surgido, nas últimas décadas, novas patologias relacionadas com o consumo de alimentos. O papel dos serviços de alimentação hospitalar na prevenção dessas ocorrências, durante o internamento/internação, é da máxima importância.

As cozinhas hospitalares deverão fornecer um serviço em que a qualidade é sinónimo de segurança alimentar, e, nesse contexto, devem ser considerados dois aspetos essenciais:

Qualidade nutricional

Segurança alimentar

Dentro do conjunto de riscos no ambiente hospitalar, deve-se ter em conta a possibilidade de as refeições dos pacientes poderem ser um veículo de transmissão de microrganismos ou de contaminantes, que podem causar deterioração do estado de saúde ou mesmo aparecimento de um problema de saúde diferente do que o paciente apresentava aquando do seu internamento/internação. 


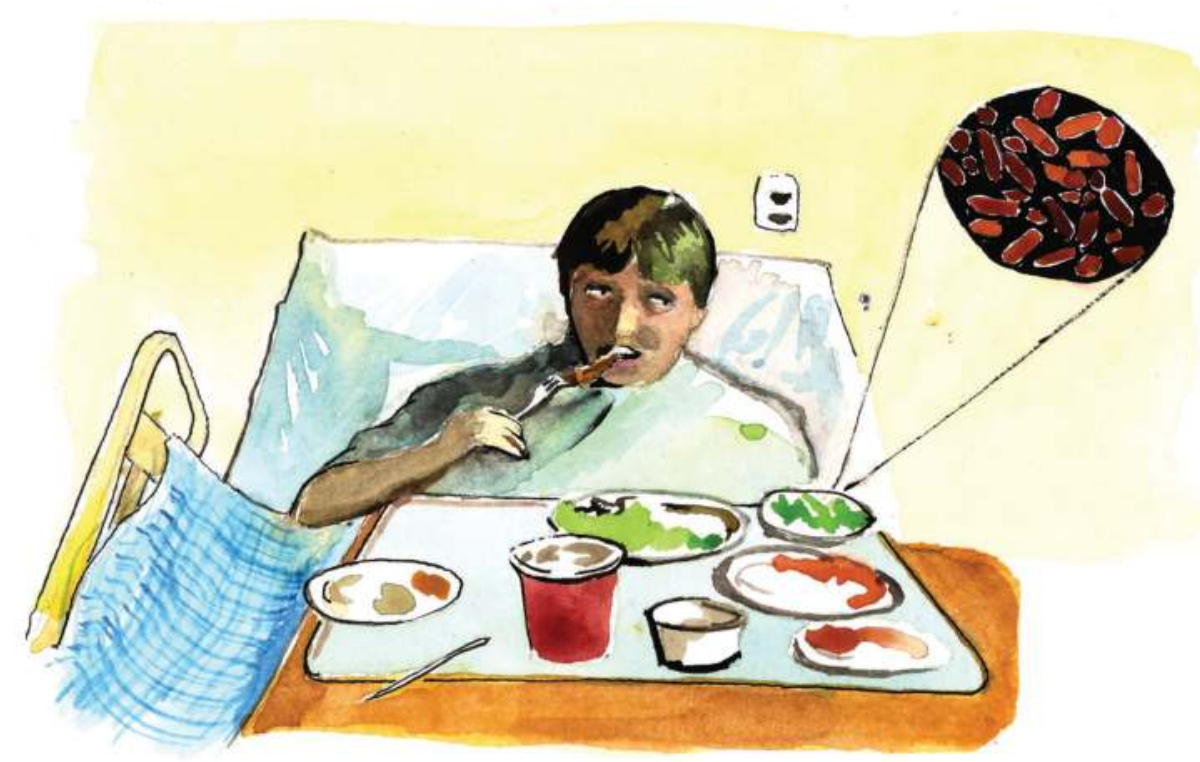

Tal qual os medicamentos administrados, há de se ter os mesmos cuidados para identificar o paciente que está recebendo a alimentação, a fim de evitar que os alimentos veiculem agentes que possam ser causadores de doença ou agravem situações patológicas previamente existentes.

O atual quadro regulamentar obriga os hospitais a serem responsáveis pela segurança dos alimentos disponibilizados aos pacientes. Esses devem ter sistemas de confeção e distribuição de alimentos baseados nos princípios da análise de perigos e pontos de controlo críticos (HACCP - Hazard Analysis and Critical Control Points), além do uso voluntário de diretrizes ou normas que promovam Boas Práticas de Higiene e Boas Práticas de Manipulação.

O sistema de HACCP está especialmente concebido para a segurança dos alimentos. É um sistema preventivo que identifica perigos associados e as medidas preventivas para controlo. Esse instrumento avalia os riscos dos perigos associados aos alimentos e prevê medidas preventivas para seu controlo em todas as etapas de produção, em vez do controlo apenas do produto final.

O novo enfoque no controlo dos alimentos, no entanto, determina que os hospitais ou as empresas de alimentação fornecedoras formem seus manipuladores em higiene dos alimentos, devendo ser sempre respeitado o sistema de HACCP. Essa formação deve estar de acordo com as tarefas que realizem e com os riscos associados às suas atividades, de modo a garantir a segurança dos alimentos preparados e distribuídos nos hospitais. 


\section{Energia}

Os hospitais consomem grande quantidade de energia, especialmente em razão das suas características específicas, de acordo com as valências médicas que oferecem, os procedimentos técnicos executados e o número de pessoas que servem.

Nos hospitais, há, diariamente, grande circulação de profissionais, pacientes e visitantes, o que exige o uso de energia por 24 horas durante todos os dias da semana. Destacam-se, ainda, equipamentos de laboratórios, esterilização, sistemas de ar-condicionado e iluminação, lavandaria, serviços de alimentação e refrigeração e equipamentos informáticos (Energy Information Administration 2012).

Nos EUA, em 2012, os hospitais e estabelecimentos de saúde gastaram mais de 8 biliões de dólares com o consumo de energia elétrica, o que conduziu ao desenvolvimento de ações e atividades educativas para reduzir os custos com a energia e, ao mesmo tempo, manter a qualidade de cuidados prestados.

Para garantir a segurança dos pacientes, a disponibilidade de energia elétrica é essencial, dado que assegura o funcionamento adequado dos equipamentos hospitalares, conforto e continuidade do cuidado em saúde.

Salienta-se que a dependência cada vez maior da energia elétrica, também exige maior atenção para as normas de segurança dessas mesmas instalações.

Normas internacionais e específicas de cada país incluem os requisitos de segurança das instalações elétricas em estabelecimentos de saúde, em especial nos Centros Cirúrgicos (CC) e Unidades de Terapia Intensiva (UTI). Tais normas visam garantir o fornecimento seguro de energia aos equipamentos médicos, proporcionando segurança aos pacientes, profissionais da saúde e visitantes (Barbosa et al. 2009).

A gestão de energia em hospitais visa à conservação e manutenção dos equipamentos elétricos, como forma de otimizar o uso de energia e reduzir o risco de acidentes para as pessoas envolvidas. Os incêndios, choques e queimaduras constituem os principais acidentes com equipamentos e instalações elétricas (Schneider Eletric 2008). 
A conservação e manutenção das instalações elétricas, sistemas de iluminação e ar-condicionado e a adoção de sistemas de aquecimento por meio de painéis solares podem ser considerados importantes formas de otimização de energia sem interferência na qualidade do cuidado oferecido aos pacientes.

Ao considerar a importância da energia elétrica para o funcionamento de um hospital, é importante existirem geradores de emergência, de forma a garantir a continuidade do cuidado e reduzir os riscos para os pacientes que estão dependentes de equipamentos ligados à energia elétrica. Os geradores devem ter acionamento automático a fim de evitar a descontinuidade da energia.

Num ambiente hospitalar, entende-se que qualquer pessoa pode estar exposta a algum tipo de risco resultante das instalações elétricas. Assim, a maioria dos acidentes com equipamentos elétricos ocorre com indivíduos que trabalham com ou próximo de equipamentos e com pessoas sem formação adequada, ou pelo uso inadequado de equipamento, mau estado de conservação de equipamentos e/ou instalação elétrica (Schneider Eletric 2008).

O desenvolvimento de um plano de segurança das instalações e equipamentos elétricos de um hospital deve ter em consideração:

䗉 a manutenção das instalações elétricas;

* evitar a sobrecarga de tomadas;

* garantir que o equipamento elétrico é seguro e adequado para a realização das atividades;

a existência de sistemas de corte de energia de emergência.

A manutenção dos equipamentos e instalações elétricas, assim como a formação adequada dos profissionais que manuseiam esses equipamentos nos hospitais são aspetos importantes para a segurança.

\section{Para praticar}

Para prevenção de riscos não clínicos, considera-se a existência de água potável e energia durante 24 horas e um sistema adequado de coleta de águas residuais.

Faça uma análise crítica dessa afirmação, expondo a relação desses factores com a reabilitação dos pacientes, processo de trabalho e gestão de riscos.

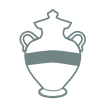

Em locais em que existam matérias inflamáveis e/ou com possibilidade de explosão, deve ser dada especial atenção à instalação de equipamentos, de modo a prevenir situações de risco. 


\section{Sistema de ventilação e climatização}

A qualidade do ar no interior dos hospitais, em especial em áreas de elevado risco de contaminação, como são as salas de cirurgia, serviços farmacêuticos e a maioria das áreas de internamento/internação ou de tratamento, impõe um conjunto de condicionalismos técnicos de instalações e de equipamentos que deverão ser levados em conta pelos profissionais e gestores na área da saúde.

Assim, se as instalações não estiverem concebidas para ter uma ventilação adequada, deve ser previsto um sistema de ventilação forçada, de modo a garantir a eficaz renovação do ar interior.

Os sistemas de condicionamento de ar devem basear-se no recurso a unidades de tratamento de ar, ligadas a um sistema de gestão técnica centralizada, utilizando equipamentos e materiais adequados que previnam a acumulação de poeiras e microrganismos, devendo possibilitar a sua fácil limpeza e manutenção.

Os procedimentos médicos e a recuperação dos pacientes precisam de um ambiente com condições adequadas. Nesse contexto, o sistema de climatização composto de aquecimento, ventilação e humidade do ar, além ser um requisito básico para o conforto, é também um instrumento importante para a garantia da qualidade do ar interior.

O sistema de climatização pode ser definido como o processo de tratamento do ar em recintos fechados, de modo a controlar, simultaneamente, a temperatura, humidade e qualidade do ar.

Considera-se que as normas de instalação, procedimentos de limpeza e manutenção do sistema de climatização hospitalar necessitam de fiscalização e rigidez no cumprimento, como forma de garantir um ambiente seguro para a reabilitação da saúde dos pacientes e para os profissionais de saúde.
Em ambientes hospitalares, o sistema de climatização deve obedecer a normas específicas determinadas pela legislação de cada país. Assim, tal sistema deve ter em consideração alguns princípios como a necessidade de restringir a circulação do ar dentro e entre diversas áreas ou compartimentos, diferenças de pressões em algumas áreas específicas e instalação de filtros adequados para impedir a disseminação de microorganismos a partir de zonas infetadas. Alguns pacientes, em função das suas patologias, necessitam de cuidados em ambientes com pressão negativa ou positiva.

\section{Gases medicinais}

O sistema de distribuição de gases medicinais tem por finalidade o transporte dos gases desde as centrais até as tomadas, assim como a remoção de gases anestésicos e do vácuo medicinal utilizado para a aspiração de fluidos corporais. 
Os gases medicinais a considerar são o oxigénio medicinal (medicamento), protóxido de azoto medicinal (medicamento), ar comprimido medicinal (medicamento), dióxido de azoto (gás medicinal).

O armazenamento deve ser dimensionado conforme as necessidades de consumo, de acordo com as normas em vigor.

Devem ser observadas condições para assegurar aspetos de segurança, nomeadamente:

A localização do reservatório no exterior deve estar de acordo com as normas e legislação vigente.

* A localização da central deve ser em área técnica própria, dotada de sistemas de alarmes adequados.

Todas as instalações e equipamentos devem ser projetados atendendo a alguns aspetos:

segurança;

䠝 impacte ambiental;

* utilização racional de energia.

O sistema de extração de gases anestésicos deve ser totalmente independente da instalação de ar-condicionado ou da ventilação e da rede de gases medicinais, com tomadas em todos os pontos de utilização de N2O.

O manuseamento e utilização inadequada dos gases ou a utilização de forma errónea pode colocar em risco a vida de todos os que circulam no ambiente hospitalar (University Teaching Trust 2012).

A alteração das concentrações de qualquer gás no ambiente ou em áreas de armazenamento, mesmo que mínima, pode ter efeito negativo sobre as pessoas e o ambiente. Esses efeitos incluem envenenamento, intoxicação, anestesia, asfixia, incêndio ou explosão (University Teaching Trust 2012).

Os gases medicinais são armazenados em altas pressões. Salienta-se que a pressão em si não é perigosa, mas as situações de risco ocorrem aquando de um manuseamento inadequado.

Considerando as características especiais desses gases, os profissionais que os manuseiam devem receber formação e treino adequados, devendo utilizar equipamentos de proteção individual específicos para tal situação. Uma simples bala de oxigénio sem uma corrente a prendê-la pode tombar em cima de uma paciente causando dano. 


\section{Os riscos com equipamentos médico- hospitalares}

Nesta seção, pretende-se abordar a importância da gerência dos equipamentos médico-hospitalares sob a responsabilidade do engenheiro clínico para a garantia da segurança dos pacientes. Dois casos verídicos serão apresentados a fim de mostrar como os problemas, nessa área, são corriqueiros, e existe risco para o paciente quando não há uma gestão adequada desses equipamentos.

\section{Caso 1}

Uma paciente de 26 anos foi submetida à cirurgia plástica para correção de hipertrofia mamária. Para realizar a hemostasia, o cirurgião empregou o bisturi elétrico, cuja placa de dispersão foi colocada na panturrilha direita. Após três horas de cirurgia, a equipa médica percebeu odor de queimado na sala de operação. Notou-se, então, que, ao usar o bisturi elétrico, um ruído provinha da mão direita da paciente. Removeram o sensor do oxímetro, e o anestesiologista constatou uma queimadura no polegar da paciente. Depois disso, o sensor foi retirado, e o bisturi elétrico e a placa trocados.

A queimadura foi avaliada como de terceiro grau, com lesão do aparelho extensor do dedo, atingindo a parte óssea da articulação entre as falanges proximal e distal. A análise do bisturi elétrico revelou descontinuidade do fio de retorno, próximo à inserção na placa de dispersão. Para recuperação da área lesada, a paciente se submeteu a novas internações a fim de realizar desbridamentos da lesão, além de enxerto de retalho cutâneo. Como sequelas, uma contratura em extensão da articulação interfalangeana do polegar direito, a destruição do leito ungueal e o desvio radial do dedo lesado (Bisinotto et al. 1996).

\section{Caso 2}

Outro caso foi de uma recém-nascida de 12 dias que morreu em uma incubadora na maternidade. Ela nasceu com icterícia e se submetia a um banho de luz, sendo exposta a uma temperatura muito alta. A família relatou que o corpo da criança ficou todo queimado. A certidão de óbito expressou como causa da morte um distúrbio metabólico. A pediatra que atendeu a criança informou que a menina tinha outras complicações, por ser um bebê prematuro e de baixo peso, mas admitiu a falta de cuidado da equipa com o controlo de temperatura da incubadora. Na época, a direção da maternidade afirmou que iria apurar as responsabilidades sobre o caso (Bebê... 2012). 
O uso dos equipamentos médico-hospitalares é uma atividade que causa incidentes frequentes. Cada vez mais componentes variados dos sistemas de atenção à saúde causam eventos adversos, independentemente do grau de desenvolvimento do país (WHO 2006).

\section{A gestão por meio de um plano pode evitar incidentes decorrentes do uso dos equipamentos médico-hospitalares?}

Não pode existir uma organização de saúde segura sem um plano ou programa específico que oriente o manejo dos equipamentos médico-hospitalares, sob a responsabilidade de um profissional capacitado. O Plano de Gerenciamento de Equipamentos Médico-Hospitalares (PGEMH) pode ser definido como:

o conjunto de procedimentos de gestão, planejados e implementados a partir de bases científicas e técnicas, normativas e legais, com o objetivo de garantir a rastreabilidade, qualidade, eficácia, efetividade, segurança e em alguns casos o desempenho das tecnologias de saúde utilizadas na prestação de serviços de saúde (Brasil 2010).

Um PGEMH contempla desde o processo de seleção do equipamento para aquisição até o destino final de cada equipamento, incluindo o planeamento dos recursos físicos, materiais e humanos, bem como da capacitação dos profissionais envolvidos no processo. Para cada uma dessas atividades do ciclo, existe um procedimento operacional padrão (POP), que orienta a execução.

O engenheiro clínico é o profissional responsável por gerenciar as tecnologias de saúde durante todo o seu ciclo de vida. Segundo o American College of Clinical Engineering, “o engenheiro clínico é o profissional que aplica e desenvolve os conhecimentos de engenharia e práticas gerenciais às tecnologias de saúde, para proporcionar uma melhoria nos cuidados dispensados ao paciente" (ACCE 2013). Além do engenheiro clínico, técnicos em equipamentos médico-hospitalares e auxiliares administrativos compõem a equipa responsável pelo gerenciamento dos equipamentos médico-hospitalares.

A OMS recomenda, no mínimo, um engenheiro clínico para cada 300 leitos e um técnico em equipamentos médico-hospitalares para cada 150 leitos. O "Down State Medical Center" (EUA) recomenda que a equipa mínima seja formada por um engenheiro clínico, quatro técnicos em equipamentos médico-hospitalares e uma secretária para hospitais de 200 a 300 leitos. 


\section{A gestão dos equipamentos médico-hospitalares}

O ciclo de gestão dos equipamentos médico-hospitalares envolve:

\section{Ciclo de gestão}

\begin{tabular}{l} 
a seleção e aquisição; \\
\hline o recebimento; \\
\hline a instalação; \\
\hline o treinamento do usuário; \\
\hline o inventário técnico; \\
\hline intervenção técnica - manutenção preventiva e corretiva; \\
\hline a transferência; \\
\hline
\end{tabular}

o armazenamento; a desativação e o descarte.

\section{Aquisição dos equipamentos médico-hospitalares}

O processo de aquisição de equipamentos médico-hospitalares exige qualificação e conhecimento, envolvendo várias etapas e estudos prévios. Esses procedimentos, muitas vezes, não são realizados - seja por desconhecimento ou mesmo por despreparo da equipa responsável pelo processo, sobretudo em organizações de saúde de países em desenvolvimento (Lucatelli et al. 2003).

No processo de aquisição de um novo equipamento, as ações devem ser realizadas com a estreita colaboração entre o corpo clínico, membros da administração, os engenheiros e os técnicos em equipamentos médico-hospitalares. Esse procedimento permite considerar os contextos: técnicos (obras, instalações, eletricidade, gás e fluidos, abastecimento de água), humanos (número, composição e capacitação dos profissionais), a demanda, a infraestrutura física, o tempo necessário para sua adequação e os recursos materiais necessários à utilização do equipamento médico-hospitalar.

A falta de acompanhamento por profissional especializado na etapa de aquisição do equipamento médico-hospitalar, segundo a OMS, pode acarretar um aumento que varia de $10 \%$ a $30 \%$ em gastos adicionais, com acessórios, serviços, peças e modificações nas instalações físicas. 
A sistematização de uma metodologia para a aquisição de equipamentos médico-hospitalares otimiza a tomada de decisões de renovação de equipamentos, contribui para a melhor qualidade no atendimento ao usuário e reduz a ocorrência de eventos adversos.

No processo de planeamento, seleção e aquisição de equipamentos médico-hospitalares, devemos considerar o fluxo para incorporação de novas tecnologias, levando em conta os critérios de seleção, sua regularização e de seus fornecedores com a autoridade sanitária competente.

\section{Recebimento dos equipamentos médico-hospitalares}

Receber um equipamento adquirido é uma atividade técnica de extrema importância e deve ser realizada por um técnico com competência para tal. Entre outras questões, existe uma farta documentação, que deve ser verificada nesse momento: a especificação técnica do equipamento; a comprovação da regularização do equipamento no órgão sanitário competente; o documento fiscal descriminando marca, modelo e número de série e acessórios do equipamento; os documentos complementares (como manual de instalação, manual de operação, desenhos, circuitos, entre outros) e a comprovação de que os equipamentos tenham sido ensaiados e aprovados no recebimento.

Recomendamos que os registos a respeito do recebimento devem ser devidamente armazenados pela unidade de saúde. No processo de recebimento, é necessário prevenir quanto ao uso de equipamentos médico-hospitalares que não tenham sido ensaiados e aprovados no recebimento. Os registos de não conformidades identificadas durante o recebimento, verificação e aceitação do equipamento de saúde devem também ser armazenados na organização, além de serem notificados à autoridade sanitária competente.

\section{Instalação dos equipamentos médico-hospitalares}

A instalação correta é primordial para o funcionamento seguro dos equipamentos médico-hospitalares, o que garante seu funcionamento dentro dos parâmetros para os quais foram projetados e, acima de tudo, evitando uma situação de risco aos pacientes e operadores.

No processo de instalação de equipamentos médico-hospitalares, é recomendável prever o registo formal das atividades de instalação dos equipamentos; que a instalação seja realizada por profissional comprovadamente treinado; e atenda aos requisitos estabelecidos pelo fabricante.
Ensaio de aceitação do equipamento é o conjunto de verificações de segurança e desempenho realizado para demonstrar que o equipamento atende aos requisitos estabelecidos pelo fabricante e pelo usuário ou seu representante. 


\section{Treinamento dos usuários/utentes dos equipamentos médico-hospitalares}

O treinamento do usuário de equipamentos médico-hospitalares deve incluir a capacitação em normas de segurança previstas em atos legais e normativos; novos equipamentos e ferramentas; e novos processos de trabalho. A organização de saúde deve escolher e aplicar os treinamentos exaustivos de acordo com as necessidades operacionais e as necessidades dos profissionais. Recomendamos que o equipamento somente deve ser utilizado por profissional comprovadamente treinado e estar em condições adequadas de segurança.

Danos e mortes de pacientes estão relacionados diretamente ao mau uso ou operação incorreta dos equipamentos médico-hospitalares, e, de acordo com a OMS, cerca de $60 \%$ a $80 \%$ dessas falhas ocorrem em razão de erros de operação dos equipamentos.

O uso inadequado dos equipamentos médico-hospitalares, de acordo com a OMS, reduz a vida útil do equipamento entre $30 \%$ e $80 \%$, além de levar a subutilização ou até a não utilização de $20 \%$ a $40 \%$ desses equipamentos.

\section{Para refletir}

Em sua organização, já ocorreram incidentes com os equipamentos por despreparo dos usuários/utentes ou por falta de segurança adequada na sua instalação? Como é realizado o treinamento dos usuários/utentes dos equipamentos existentes?

\section{Inventário técnico dos equipamentos médico-hospitalares}

O inventário de equipamentos médico-hospitalares é o conjunto de informações concernentes aos equipamentos, partes e acessórios existentes no serviço de saúde. O inventário deverá conter todos os equipamentos médico-hospitalares de propriedade da organização de saúde, inclusive os adquiridos por meio de contratos e convênios, sublocados, em consignação, temporários ou permanentes. 
O inventário deve conter as seguintes informações de cada equipamento:

- nome técnico do equipamento;

- nome e o modelo comercial do equipamento;

- fabricante do equipamento;

- fornecedor do equipamento;

- lista de partes e acessórios do equipamento;

- lista de insumos e reagentes do equipamento (se houver);

- data de aceitação do equipamento;

- data de instalação do equipamento;

- data de funcionamento do equipamento e da desativação do equipamento;

- responsável pela assistência técnica (quando terceirizado) e dados de regularização do equipamento no órgão sanitário competente;

- número de série do equipamento;

- código de identificação individual do equipamento ou de patrimônio (esses últimos, criados pela organização).

O inventário deverá ser atualizado a cada nova aquisição ou desativação do equipamento pela organização de saúde. A unidade de saúde deverá prever a periodicidade das auditorias internas do inventário e o método para determinar a amostragem para realização da auditoria.

\section{Registo histórico de cada equipamento médico-hospitalar}

O registo histórico de cada equipamento médico-hospitalar deve conter as informações que permitam a rastreabilidade, inclusive a metrológica, de toda a vida útil de um equipamento médico-hospitalar.

O registo histórico deve conter, além dos dados do inventário, as seguintes informações:

- identificação do departamento ao qual pertence o equipamento, incluindo informações de transferência, quando houver;

- manual de operação e de manutenção;

- relatórios de manutenção preventiva e corretiva;

- nome do profissional designado como responsável pelo equipamento em cada departamento; 
Os eventos adversos dos dois casos apresentados no início desta seção, muito provavelmente, foram decorrentes da falta de manutenção dos equipamentos - o bisturi elétrico e a incubadora
- histórico de falhas do equipamento;

- histórico documentado dos problemas e incidentes relacionados a incidentes causados em pacientes por falhas do equipamento (com as ações tomadas pela organização e a notificação ao órgão sanitário competente, quando pertinente);

- histórico documentado dos problemas e incidentes relacionados ao equipamento, com as ações tomadas pela organização e a notificação ao órgão sanitário competente, quando pertinente;

- documentação de intervenções técnicas no equipamento.

O registo histórico de equipamentos médico-hospitalares deve ser arquivado pelo tempo que o equipamento estiver em utilização na organização, acrescido de, pelo menos, dois anos.

\section{Intervenção técnica nos equipamentos médico- hospitalares}

Intervenção técnica é a ação destinada a manter ou relocar um item do equipamento em um estado no qual possa desempenhar uma função requerida, como inspeção, ensaio, manutenção, ajuste e calibração. As manutenções podem ser corretivas, preventivas ou preditivas.

A organização de saúde deve criar, documentar e implementar procedimentos para todas as intervenções técnicas nos equipamentos médico-hospitalares, que devem assegurar a sua rastreabilidade metrológica. Essas intervenções devem ser documentadas no registo histórico do equipamento, indicando o nome do executor, e efetuadas somente por profissional comprovadamente treinado.

Em caso de terceirização de qualquer intervenção técnica, deve haver um acordo formal entre as partes. A organização de saúde deve dispor de todas as informações sobre essas intervenções realizadas pelo serviço terceirizado para alimentar o registo histórico do equipamento. É preciso, ainda, criar, documentar e implementar os procedimentos de manutenção corretiva (MC) e de manutenção preventiva (MP) para cada equipamento médico-hospitalar, que devem fazer parte do registo histórico do equipamento.

Dados da OMS dão conta que o excesso de paradas do equipamento, em razão da ausência de manutenção preventiva, incapacidade de realizar o reparo ou falta de partes e peças, resulta em 25\% a 35\% dos equipamentos inoperantes ou funcionando de maneira precária. 


\section{Para refletir}

Os equipamentos de sua organização passam por manutenções periódicas?

Quem realiza esse tipo de trabalho: a própria organização, ou existe uma empresa que presta esse serviço?

Que tipos de incidentes já ocorreram por falta de manutenção adequada?

\section{Transferência dos equipamentos médico-hospitalares}

A transferência é um processo delicado, pois a quebra de um equipamento médico-hospitalar de alto custo representa grande prejuízo para a organização de saúde. A transferência deve ser planejada e realizada de forma a manter a integridade, a segurança, a rastreabilidade, o desempenho e a adequada utilização do equipamento. O registo da transferência é essencial para que se mantenha a rastreabilidade do equipamento médico-hospitalar.

\section{Armazenamento dos equipamentos médico- hospitalares}

Muito frequentemente, não é dada a devida importância ao correto armazenamento dos equipamentos médico-hospitalares, cuidado que garante aumento de sua vida útil e redução dos custos de manutenção. Portanto, a estocagem deve ser feita sem contacto direto com o solo e luz solar, em áreas livres de pó, animais e lixo, com a manutenção da temperatura ambiente indicada pelos fabricantes. Os equipamentos devem ser armazenados isoladamente de produtos e substâncias que possam afetar sua identidade, integridade, segurança e desempenho, como mostra a figura da página seguinte.

O armazenamento dos equipamentos médico-hospitalares deve ser feito em local específico, não podendo ocorrer em área de circulação, mesmo que temporariamente. No caso de fontes radioativas ou de equipamentos que possuam fontes radioativas incorporadas, devem estar de acordo com o plano de proteção radiológica aprovado para a

O plano de proteção radiológica é o documento exigido para fins de licenciamento de instalações radioativas, que estabelece 0 sistema de proteção radiológica a ser implantado pela organização. organização de saúde, conforme legislação vigente. 

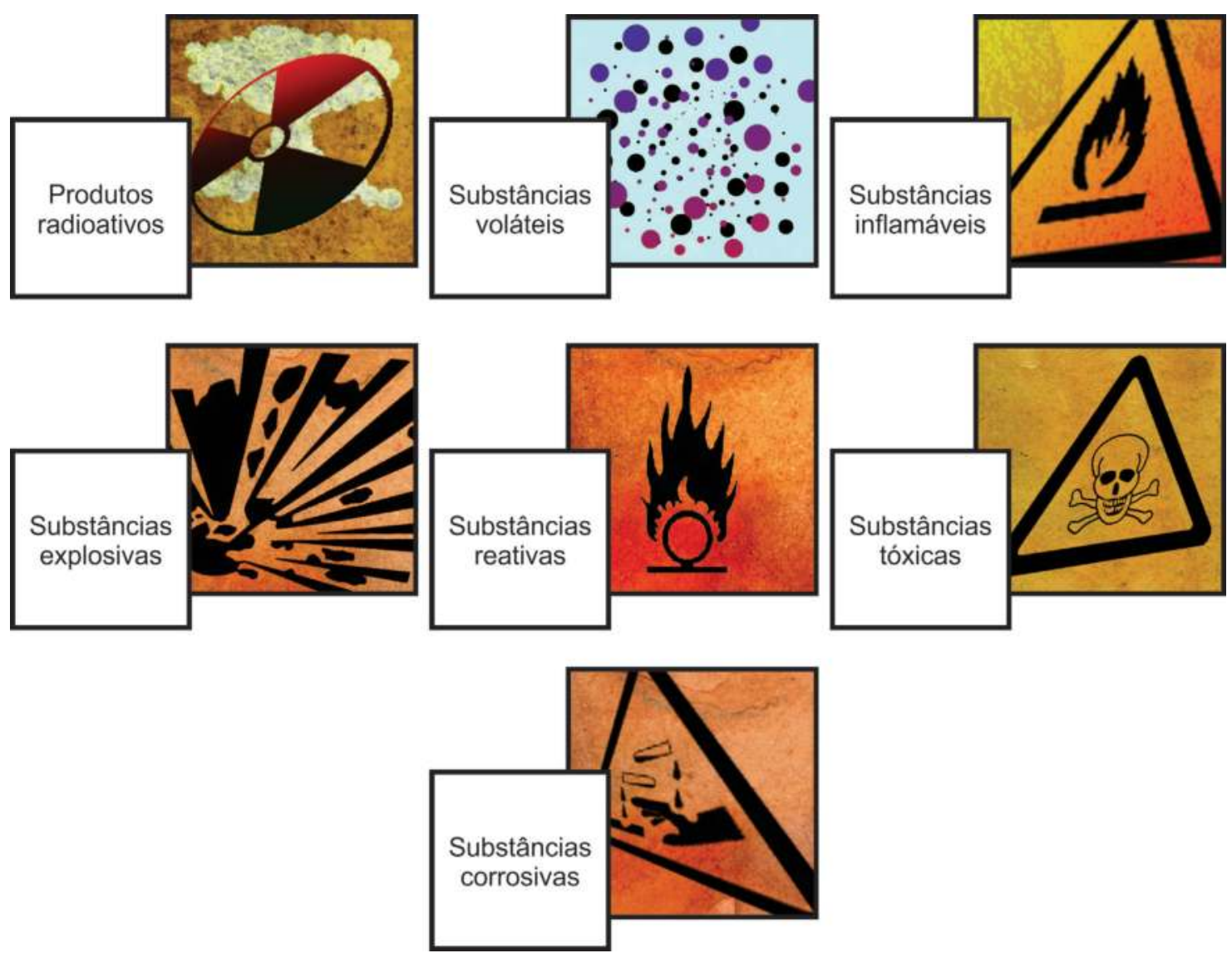

\section{Desativação e descarte dos equipamentos médico-hospitalares}

Todo equipamento médico-hospitalar, ao final da sua vida útil, deve ser considerado inservível e desativado. No ato da desativação, o responsável pelo gerenciamento de equipamentos deve gerar um laudo de desativação que contemple: os dados do equipamento; a data da desativação; o motivo da desativação e o responsável pela desativação. Além de desativados, devem ser também segregados e devidamente identificados e documentados quanto à sua condição e destino.

Veja, mais adiante neste capítulo, a seção Gerenciamento de resíduos.
Os equipamentos médico-hospitalares devem ser descartados de acordo com programa de gerenciamento de resíduos de saúde. Não raro os resíduos hospitalares são descartados em locais não adequados e contaminam o meio ambiente. O programa de gerenciamento de resíduos de saúde deve estabelecer e documentar critérios para o descarte levando em conta os custos e precauções para esse processo. 


\section{Notificação de incidente com equipamentos médico-hospitalares}

Um item importante na gestão dos equipamentos médico-hospitalares é a notificação de incidentes tanto para sistemas locais (hospitalares) como sistemas nacionais, com as informações necessárias para uma investigação minuciosa. Equipamentos podem ser retirados do mercado a tempo de não provocar mais incidentes. Num estudo que levantou as notificações de eventos adversos com aparelhos de tomografia, identificou-se o problema causado por erro de software na formação ou apresentação de imagens, o que resultou em vários exames falsos positivos e negativos (Sá 2009).

\section{Monitoramento}

A organização deve criar indicadores que lhe permitam avaliar a conformidade com os objetivos do PGEMH. Os indicadores podem medir o desempenho do PGEMH (estágio de andamento do projeto ou de uma atividade durante a fase de execução) ou o impacte do PGEMH (efeitos que o plano gerou na população-alvo ou no meio socioeconómico). Os indicadores devem ser revistos durante as revisões periódicas do PGEMH. Os indicadores mais comumente utilizados são:

\section{Temporal:}

tempo médio de atendimento; tempo médio de resposta; tempo médio de reparo; tempo médio de parada; horas de manutenção corretiva por equipamento.

\section{Qualidade:}

manutenção preventiva realizada versus manutenção corretiva; número de solicitação de serviços - chamadas de Ordem de Serviço (OS) por equipamento; número de OS abertas por mês, número de OS fechadas por número de OS abertas; número de OS por técnico; número de OS de manutenção corretiva; número de OS de manutenção preventiva; número de OS por setor de instituição de saúde; horas produtivas por horas disponíveis; reparos repetidos; número de horas de capacitação de usuários.

\section{Custo:}

custo de manutenção corretiva por equipamento; custo de manutenção geral versus valor de aquisição do equipamento; custo do equipamento parado; custo diário de um leito parado.

Os indicadores podem ser adotados tanto para avaliar a equipa interna da organização como o desempenho dos serviços prestados por empresas especializadas em manutenção de equipamentos médico-hospitalares (terceirizados). 


\section{Gerenciamento de resíduos}

Abordaremos, nesta seção, a gestão dos resíduos produzidos no hospital. Esses resíduos representam um risco não só para os pacientes e trabalhadores nas organizações de saúde, mas também para o meio ambiente e, em consequência, para o cidadão. Vocês verão que existem diferenças na legislação do Brasil e de Portugal, onde se destacam a incineração dos resíduos e o uso do mercúrio. Esperamos que as convergências e as divergências da abordagem contribuam para a ampliação da discussão do tema, ainda pouco valorizado.

A partir da segunda metade do século XX, com os novos padrões de consumo da sociedade industrial, a geração de resíduos cresceu em ritmo superior à capacidade de absorção da natureza. O descarte inadequado de resíduos produz passivos ambientais capazes de colocar em risco e comprometer os recursos naturais e a qualidade de vida das atuais e futuras gerações.

A poluição do ar e a escassez de água se tornaram problemas crônicos nas metrópoles. Faltam locais adequados para colocar o lixo gerado ou tratar os esgotos sem incomodar a população do entorno.

Seis gerações de pessoas foram expostas ou contaminadas por hexaclorociclohexano - inseticida usado no início do século passado no combate ao mosquito que transmite a malária -, cuja fábrica ficava numa localidade denominada "Cidade dos meninos", no Estado do Rio de Janeiro, Brasil. A produção diária de lixo em Portugal mais que duplicou na última geração. Em 2011, viviam em Luanda 5 milhões de pessoas, cada uma a produzir, em média, 1 quilo de lixo por dia.

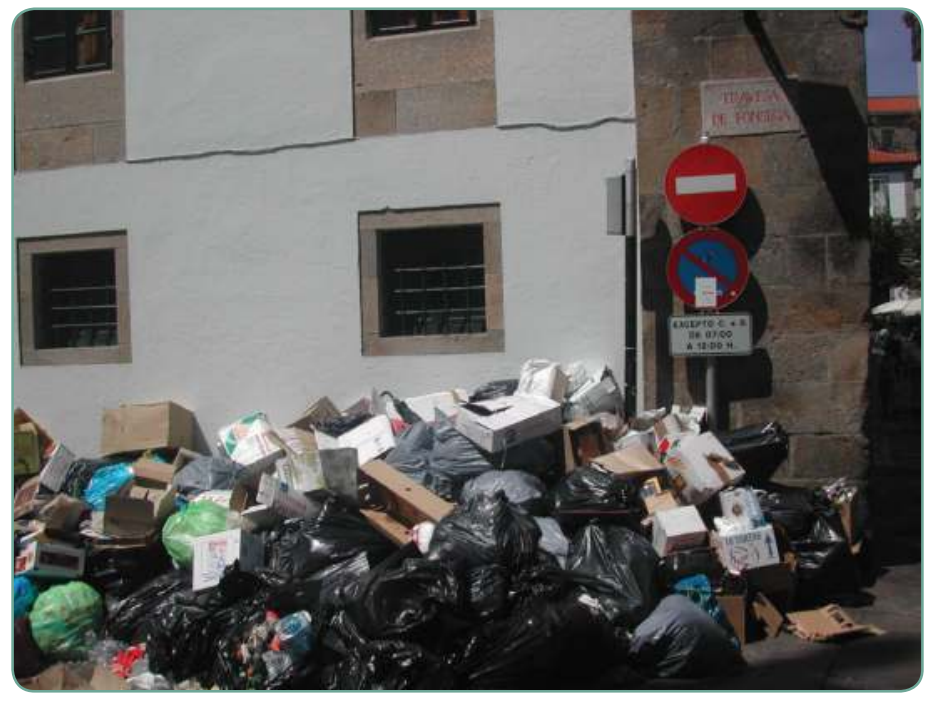

Foto: Jmerelo (2005). 
O caso mais emblemático de contaminação foi na Baía de Minamata, Japão, contaminada com dejetos de uma indústria que produzia policloreto de vinil (PVC) e acetaldeído. O material era jogado na baia pelo esgoto, apesar de conter mercúrio. Inicialmente, apenas os peixes morriam; depois, foram os moluscos e aves. O mercúrio foi se acumulando nos peixes, que serviam de alimento à população do entorno. A "síndrome de Minamata" demorou 20 anos para se manifestar na população local após o início da contaminação, causando danos neurológicos irreversíveis em cerca de 2.955 pessoas.

A população mundial já atingiu a marca dos 7 biliões de pessoas. As bactérias se tornaram resistentes ao arsenal terapêutico disponível, doenças antes consideradas de fácil tratamento, agora, requerem cuidados especiais, internação, isolamento etc.

Apesar do conforto e tecnologias conquistados, as pequenas e grandes cidades já sofrem os efeitos decorrentes da mudança climática global, com necessidade de adaptação, migração de populações ou mitigação urgente dos problemas.

A vida no planeta está realmente correndo perigo. As consequências da soma dos problemas ambientais - extremos de temperatura e terremotos -, acrescidos pela poluição, tensão social, racial e geopolítica, violência urbana, fome, guerras, epidemias, são imprevisíveis e, certamente, vão interferir no nosso futuro, se nada for feito de facto.

As soluções para alguns desses problemas já são discutidas e negociadas mundialmente pelos governos e pela sociedade organizada, mas também é possível e necessária a contribuição individual e sectorial na difícil tarefa de preservar a vida no planeta.

\section{Histórico brasileiro quanto ao gerenciamento de resíduos}

No final da década de 1970, o governo brasileiro lançou uma norma (Portaria n. 53/1979) com vistas a orientar o controlo de resíduos sóli-

dos de natureza industrial, domiciliar, de serviços de saúde e demais resíduos gerados pelas diversas atividades humanas. Posteriormente, algumas políticas nacionais e legislações ambientais contemplaram a questão de resíduos sólidos. Mas foi por volta do ano 2000 que o movimento se ampliou. Em 2001, foi criado o Estatuto das Cidades (Lei n. 10.257); em 2005, a Política Nacional de Saneamento Básico; em 2010 , o Congresso Nacional aprovou a Política Nacional de Resíduos Sólidos, 
Cadeia da logística reversa é o conjunto de ações que garante que o resíduo do insumo adquirido seja devolvido ao seu fabricante. dando ênfase à coleta seletiva, reciclagem, descarte correto de produtos e equipamentos com potencial de contaminação ambiental e a cadeia da logística reversa.

Os resíduos dos serviços de saúde ganharam destaque legal no início da década de 1990, quando foi aprovada a Resolução do Conselho Nacional de Meio Ambiente (Conama) n. 6, de 19 de setembro de 1991. Essa resolução desobrigou a incineração ou qualquer outro tratamento de queima dos resíduos sólidos provenientes dos estabelecimentos de saúde e de terminais de transporte e deu competência aos órgãos estaduais de meio ambiente para estabelecer normas e procedimentos ao licenciamento ambiental do sistema de coleta, transporte, acondicionamento e disposição final dos resíduos, nos estados e municípios que optaram pela não incineração.

Posteriormente, a Resolução Conama n. 5, de 5 de agosto de 1993, fundamentada nas diretrizes da resolução já citada, estipulou que as organizações de saúde e terminais de transporte deviam elaborar o plano de gerenciamento de seus resíduos contemplando a geração, segregação, acondicionamento, coleta, armazenamento, transporte, tratamento e disposição final dos resíduos. Essa resolução foi atualizada em 2001 (Resolução n. 283) abordando especificamente o tratamento e a destinação final dos resíduos de serviços de saúde, não englobando mais os resíduos de terminais de transporte.

A Agência Nacional de Vigilância Sanitária (Anvisa), cumprindo sua missão de "regulamentar, controlar e fiscalizar os produtos e serviços que envolvam riscos à saúde pública", chamou para si essa responsabilidade e promoveu um grande debate público para orientar a publicação de uma resolução específica: a Resolução da Diretoria Colegiada (RDC) n. 33, de 25 de fevereiro de 2003, que passou a considerar os riscos aos trabalhadores, à saúde e ao meio ambiente. Em dezembro de 2004, a Anvisa publicou a RDC n. 306, após alinhamento com o Conama, que, em maio de 2005, publicou a Resolução n. 358, revogando a Resolução n. 283. O progresso alcançado com as resoluções relacionou-se, principalmente, aos seguintes aspetos:

definição de procedimentos seguros;

滕 consideração das realidades e peculiaridades regionais;

* classificação e procedimentos recomendados de segregação e manejo dos Resíduos de Serviços de Saúde (RSS).

As resoluções brasileiras em vigor são a RDC Anvisa n. 306/04 e a Resolução Conama n. 358/05, que têm como eixos: 
滕 orientar o gerenciamento dos RSS em todas as suas etapas;

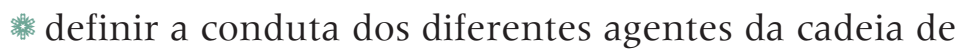
responsabilidades;

晋 refletir um processo de mudança de paradigma no trato dos RSS, fundamentada na análise dos riscos envolvidos, em que a prevenção passa a ser eixo principal, e o tratamento é visto como uma alternativa para dar destinação adequada aos resíduos com potencial de contaminação. Com isso, exigem que os resíduos recebam manejo específico, desde a sua geração até a disposição final, definindo competências e responsabilidades para tal.

\section{Enquadramento legislativo português dos resíduos hospitalares}

O quadro legislativo português relativamente à gestão dos resíduos, em geral, segue a matriz de gestão de resíduos a nível europeu, sendo complementado por normas específicas de cada Estado-Membro.

Nas décadas de 1970 e 1980, a União Europeia (UE) considerava os resíduos hospitalares como especiais, mas não estavam inseridos no grupo de resíduos perigosos, o que veio a ocorrer no início da década de 1990.

Em Portugal, a legislação sobre resíduos sofreu alterações significativas, desde a década de 1980. A ex-direção-geral dos hospitais definiu algumas normas gerais sobre a gestão dos resíduos hospitalares (Circular Normativa n. 23/87, de 2 de maio). Em 1990, o Ministério da Saúde publicou o Despacho n. 16/90, de 21 de agosto, definindo a gestão dos resíduos nos hospitais públicos e classificando-os em dois grupos - resíduos contaminados e não contaminados. O tratamento dos resíduos limitava-se à incineração.

No que a gestão dos resíduos hospitalares, no entanto, diz respeito, o primeiro diploma que a refere é o Decreto-Lei n. 310/95, de 20 de novembro. Esse foi revogado pelo Decreto-Lei n. 239/97, de 9 de setembro, que visou melhorar as normas para a gestão dos resíduos, reafirmando o princípio da responsabilidade do produtor.

Posteriormente, o Decreto-Lei n. 239/97 foi revogado pelo Decreto-Lei n. 178/2006, de 5 de setembro, que já teve em conta as operações de descontaminação de solos e a monitorização dos locais de deposição após o seu encerramento. Esse diploma foi alterado pelo Decreto-Lei 
n. 73/2011, de 17 de junho, reforçando a prevenção da produção de resíduos e fomentando a sua reutilização e reciclagem, com o objetivo de prolongar o seu uso na economia e, posteriormente, oferecer um destino final adequado.

Os resíduos hospitalares são definidos como: “Resíduos resultantes de atividades de prestação de cuidados de saúde a seres humanos ou a animais, nas áreas da prevenção, diagnóstico, tratamento, reabilitação ou investigação e ensino, bem como de outras atividades envolvendo procedimentos invasivos, tais como acupuntura, piercings e tatuagens" (Decreto-Lei n. 73/2011, de 17 de junho).

De acordo com a lei geral dos resíduos, o produtor é responsável pela gestão dos resíduos até a entrega a um operador autorizado. É de referir que, se a produção de resíduos equiparados a urbanos não ultrapassar a produção diária de 1.100 L/dia, a entidade gestora dos resíduos urbanos tem de os receber.

Em 1996, foi aprovado o Despacho n. 242/96, de 5 de julho, que divide os resíduos hospitalares em quatro grupos:

Não perigosos:

Grupo I: resíduos equiparados a urbanos, não apresentam exigências especiais no seu tratamento;

Grupo II: resíduos hospitalares não perigosos, não estão sujeitos a ratamento específico, podendo ser equiparados a urbano;

\section{Perigosos:}

Grupo III: resíduos hospitalares de risco biológico, que estão contaminados ou suspeitos de contaminação, suscetíveis de incineração ou de outro pré-tratamento eficaz, permitindo posterior eliminação com os resíduos urbanos; Grupo IV: resíduos hospitalares específicos de incineração obrigatória.

Esse despacho definiu a gestão dos resíduos hospitalares no que diz respeito às operações de recolha/coleta, transporte, armazenagem, tratamento, valorização e eliminação dos resíduos. Também, determinou que o tratamento dos resíduos deve ser em função da sua perigosidade/ periculosidade, permitindo tratamentos alternativos à incineração para os resíduos de risco biológico. O despacho também refere "[...] cada unidade de prestação de cuidados de saúde deve ter um plano de gestão de resíduos hospitalares (PGRH), adequado à sua dimensão, estrutura e quantidade de resíduos produzidos, tendo em conta critérios de operacionalidade e de menor risco para os doentes trabalhadores e público em geral" (MS, 2007) pelo que deve nomear um gestor de resíduos hospitalares, responsável pela elaboração do PGRH, bem como pelo 
controlo do processo de gestão desses resíduos. O PGRH deve abordar as fases de recolha/coleta, transporte, armazenagem, tratamento, valorização e eliminação de resíduos e dispor de mecanismos de controlo, incluindo controlo financeiro e de acidentes (Tavares, Barreiros 2004).

Em 2004, a Portaria n. 209/2004, de 3 de março, publicou a Lista Europeia de Resíduos, em que são definidas as características de perigo atribuíveis aos resíduos e as operações de valorização e eliminação dos resíduos.

Relativamente ao transporte de resíduos hospitalares, a Portaria n. 335/97, de 16 de maio, define as regras de transporte (quem pode transportar e como o deve fazer - criando guias de transporte). O transporte de resíduos hospitalares perigosos segue o regulamento de transporte de mercadorias perigosas, e, atualmente, é o Decreto-Lei n. 41-A/2010, de 29 de abril, que regula o transporte terrestre, rodoviário e ferroviário, de mercadorias perigosas, alterado pelo Decreto-Lei n. 206A/2012, de 31 de agosto (dá cumprimento aos códigos internacionais de transporte de mercadorias perigosas). As empresas que transportam esse tipo de mercadorias têm que ter, entre outros, um conselheiro de segurança com formação reconhecida nessa matéria, e todos os motoristas têm que ter uma carta de condução especial que os habilita a saber como transportar esse tipo de mercadoria e como atuar em caso de acidente.

Anualmente, todos os produtores, operadores e transportadores de resíduos têm a obrigatoriedade de informar o quantitativo de resíduos produzidos ou geridos. Para tal, foi criado um sistema integrado de registo eletrônico de resíduos (Sirer), pela Portaria n. 1408/2006, de 18 de dezembro, abordando informações sobre os produtores, operadores e operações da gestão de resíduos. Essa portaria foi alterada pela Portaria n. 320/2007, de 23 de março, e pela Portaria n. 249-B/2008, 31 de março.

Portugal dispõe de um segundo Plano Estratégico de Resíduos Hospitalares (Perh). Em 2010, o Perh (1999-2005) foi revisto, e publicado o novo Perh (2011-2016) pela Portaria n. 43/2011, de 20 de janeiro. Esse plano assenta numa lógica de ciclo de vida dos materiais e na sua valorização, estimulando as melhores técnicas disponíveis, de modo a salvaguardar o ambiente e a saúde humana.

A evolução das legislações sobre os resíduos demonstra a preocupação para o desenvolvimento de uma gestão adequada, considerando o contexto económico, além da minimização dos riscos para a saúde e para o ambiente (Tavares 2004). 


\section{Para refletir}

Você sabe se é efetuada a correta triagem e separação dos resíduos hospitalares $(\mathrm{RH})$ na sua organização?

E como são feitos a recolha/coleta e o transporte interno dos RH na sua organização?

A legislação que versa sobre o tema em seu país é seguida na sua organização? Que aspetos não são cumpridos?

Há um Plano de Gestão de RH na sua organização? Se sim, você sabe quem é o profissional que está designado como gestor desse plano?

\section{Classificação dos resíduos sólidos}

Os resíduos sólidos podem ser classificados em função dos riscos potenciais ao meio ambiente e à saúde e, também, em função da natureza e da origem.

Risco ao meio ambiente é a probabilidade da ocorrência de efeitos adversos ao meio ambiente, decorrentes da ação de agentes físicos, químicos ou biológicos, causadores de condições ambientais potencialmente perigosas que favoreçam a persistência, disseminação e modificação desses agentes no ambiente.

Com relação aos riscos potenciais ao meio ambiente e à saúde pública, existem normas que classificam os resíduos sólidos em duas classes: classe I e classe II (no caso brasileiro a NBR 10.004/2004).

Os resíduos classe I, denominados perigosos, são aqueles que, em função de suas propriedades físicas, químicas ou biológicas, podem apresentar riscos à saúde e ao meio ambiente por possuírem uma ou mais das seguintes propriedades: inflamabilidade, corrosividade, reatividade, toxicidade e patogenecidade.

Os resíduos classe II, denominados não perigosos, são subdivididos em duas classes:

Classe II-A (não inertes) podem ser biodegradáveis, combustíveis ou solúveis em água.

踏 Classe II-B (inertes) não apresentam nenhum de seus constituintes solubilizados a concentrações superiores aos padrões de potabilidade de água, com exceção dos aspetos cor, turbidez, dureza e sabor. 
Com relação à origem e natureza, os resíduos sólidos são classificados em: domiciliar, comercial, varrição e feiras livres, organizações de saúde, portos, aeroportos e terminais rodoviários e ferroviários, industriais, agrícolas e resíduos de construção civil.

Com relação à responsabilidade pelo gerenciamento, pode-se agrupá-los em dois grandes grupos:

Resíduos sólidos urbanos (RSU), compreendido pelos resíduos domiciliares ou residenciais; resíduos comerciais; resíduos públicos, cuja responsabilidade é de nível municipal.

Resíduos de fontes especiais, compreendido por resíduos industriais; resíduos da construção civil; resíduos de portos, aeroportos e terminais rodoferroviários; resíduos agrícolas; rejeitos radioativos; resíduos de serviços de saúde, cuja responsabilidade é do gerador do resíduo.

O Quadro 1 ilustra a classificação do RSU em função de sua origem e seus principais componentes, chamando a atenção para a comparação com a classificação dos RSS, definida pelas normas atuais e que vamos apresentar mais à frente.

Quadro 1 - Classificação dos resíduos sólidos urbanos em função de sua origem e seus principais componentes

\begin{tabular}{|c|c|c|}
\hline \multicolumn{3}{|l|}{ Resíduos sólidos urbanos } \\
\hline Doméstico ou residencial & Residências & $\begin{array}{l}\text { Orgânicos: restos de alimentos, } \\
\text { jornais, revistas, embalagens } \\
\text { vazias, frascos de vidros, papel } \\
\text { e absorventes higiênicos, fraldas } \\
\text { descartáveis, preservativos, } \\
\text { curativos/apósitos, embalagens } \\
\text { contendo tintas, solventes, } \\
\text { pigmentos, vernizes, pesticidas, } \\
\text { óleos lubrificantes, fluido de freio, } \\
\text { medicamentos, pilhas, baterias, } \\
\text { lâmpadas incandescentes e } \\
\text { fluorescentes. }\end{array}$ \\
\hline Comercial & $\begin{array}{l}\text { Supermercados, bancos, lojas, } \\
\text { bares, restaurantes etc. }\end{array}$ & $\begin{array}{l}\text { Os componentes variam } \\
\text { de acordo com a atividade } \\
\text { desenvolvida, mas, de } \\
\text { modo geral, se assemelham } \\
\text { qualitativamente aos resíduos } \\
\text { domésticos. }\end{array}$ \\
\hline
\end{tabular}


Quadro 1 - Classificação dos resíduos sólidos urbanos em função de sua origem e seus principais componentes (cont.)

\begin{tabular}{|c|c|c|}
\hline \multicolumn{3}{|c|}{ Resíduos sólidos urbanos } \\
\hline Público & $\begin{array}{l}\text { Limpeza de vias públicas (inclui } \\
\text { varrição e capina), praças, } \\
\text { praias, galerias, córregos, } \\
\text { terrenos baldios, feiras livres e } \\
\text { animais }\end{array}$ & $\begin{array}{l}\text { Podas } \\
\text { Resíduos difusos (descartados } \\
\text { pela população): entulho, papéis, } \\
\text { embalagens gerais, alimentos, } \\
\text { cadáveres, fraldas etc. }\end{array}$ \\
\hline
\end{tabular}

Fonte: Extraído do Manual de Gerenciamento de Resíduos (Anvisa 2006a).

\section{Resíduos do Serviço de Saúde (RSS)}

São considerados geradores de RSS todos os serviços relacionados com o atendimento à saúde humana ou animal, inclusive os serviços de assistência domiciliar; laboratórios analíticos de produtos para a saúde; necrotérios, funerárias e serviços em que se realizem atividades de embalsamamento, serviços de medicina legal, drogarias e farmácias, inclusive as de manipulação; estabelecimentos de ensino e pesquisa na área da saúde, centro de controlo de zoonoses; distribuidores de produtos farmacêuticos, importadores, distribuidores produtores de materiais e controlos para diagnóstico in vitro, unidades móveis de atendimento à saúde; serviços de acupuntura, serviços de tatuagem, dentre outros similares.

Importante lembrar que, para que a infeção, ocorra é necessária a inter-relação entre os seguintes factores: presença do agente; dose de infetividade; resistência do hospedeiro; porta de entrada; e via de transmissão.
Os RSS merecem atenção em todas as fases do manejo em decorrência dos riscos que podem oferecer. A maior parte dos resíduos hospitalares não é perigosa, pois se assemelham aos resíduos urbanos. A natureza perigosa do lixo hospitalar está relacionada a um ou mais componentes biológicos potencialmente infetantes, químicos perigosos, elementos radioativos e materiais perfuro cortantes. Qualquer pessoa (profissional, paciente, visitante, transeunte, catador de lixo de rua) pode estar em risco se os resíduos não estiverem devidamente contidos ou descartados, em duas situações:

1. Em caso de acidentes ocupacionais, por causa de falhas no acondicionamento e principalmente na segregação dos materiais perfurocortantes. A proteção mecânica é frequentemente negligenciada, e a presença de catadores nos lixões ou aterros controlados representa uma grande exposição;

2. Em caso de destinação inadequada de qualquer tipo de resíduo, alterando as características do meio. Podemos citar a contaminação do solo, das águas superficiais e subterrâneas e do ar pela incineração de produtos à base de PVC, que geram dioxinas e furanos. 
Para refletir

Como é feito o descarte de resíduos sólidos onde você trabalha?

Você se preocupa com a forma de descarte dos resíduos considerados

perigosos? Você faz orientações quando observa algum erro? Que

precauções toma?

\section{Classificação dos Resíduos de Serviços de Saúde (RSS)}

A gestão de RSS no mundo tem como base a proteção dos indivíduos, do ambiente e, agora, muito fortemente, a sustentabilidade. É estabelecida principalmente por meio de acordos e convenções, como a Basel Convention de Bamako. Os RSS são classificados em cinco grupos: A, B, C, D e E (no Brasil, é normatizado pela RDC n. 306 da Anvisa e a Resolução Conama n. 358).

Grupo A - engloba os componentes com possível presença de agentes biológicos que, por suas características de maior virulência ou concentração, podem apresentar risco de infeção. Não podem ser reciclados, reutilizados ou reaproveitados. Ex: peças anatômicas, bolsas transfusionais contendo sangue.

Grupo B - são aqueles que contêm substâncias químicas com características de inflamabilidade, corrosividade, reatividade e toxicidade. Ex: reagentes de laboratório, pesticidas, solventes, ácidos; produtos hormonais, quimioterápicos e antimicrobianos; substâncias para revelação de radiografias, óleos e lubrificantes usados e resíduos contendo metais pesados, como mercúrio de termômetros, tensiômetros e baterias.

Grupo C - materiais resultantes de atividades humanas que contenham radionuclídeos em quantidades superiores aos limites de eliminação especificados nas normas de organismos que disciplinam a gestão da energia nuclear em cada país (no caso do Brasil, a Comissão Nacional de Energia Nuclear - Cnen).

Grupo D - são resíduos que não apresentam risco biológico, químico ou radiológico à saúde ou ao meio ambiente, podendo ser equiparados aos resíduos domiciliares. Ex: sobras de alimentos, fraldas e absorventes.

Grupo E - materiais perfurocortantes ou escarificantes. Ex: lâminas de barbear, agulhas, ampolas de vidro, lâminas de bisturi, lancetas, espátulas e outros similares. 
A atual classificação de resíduos de saúde, simbologia por grupo e tipo de embalagens é representada na Figura 4.

Figura 4 - Simbologia por grupo e tipo de embalagens para a classificação dos resíduos de serviços de saúde

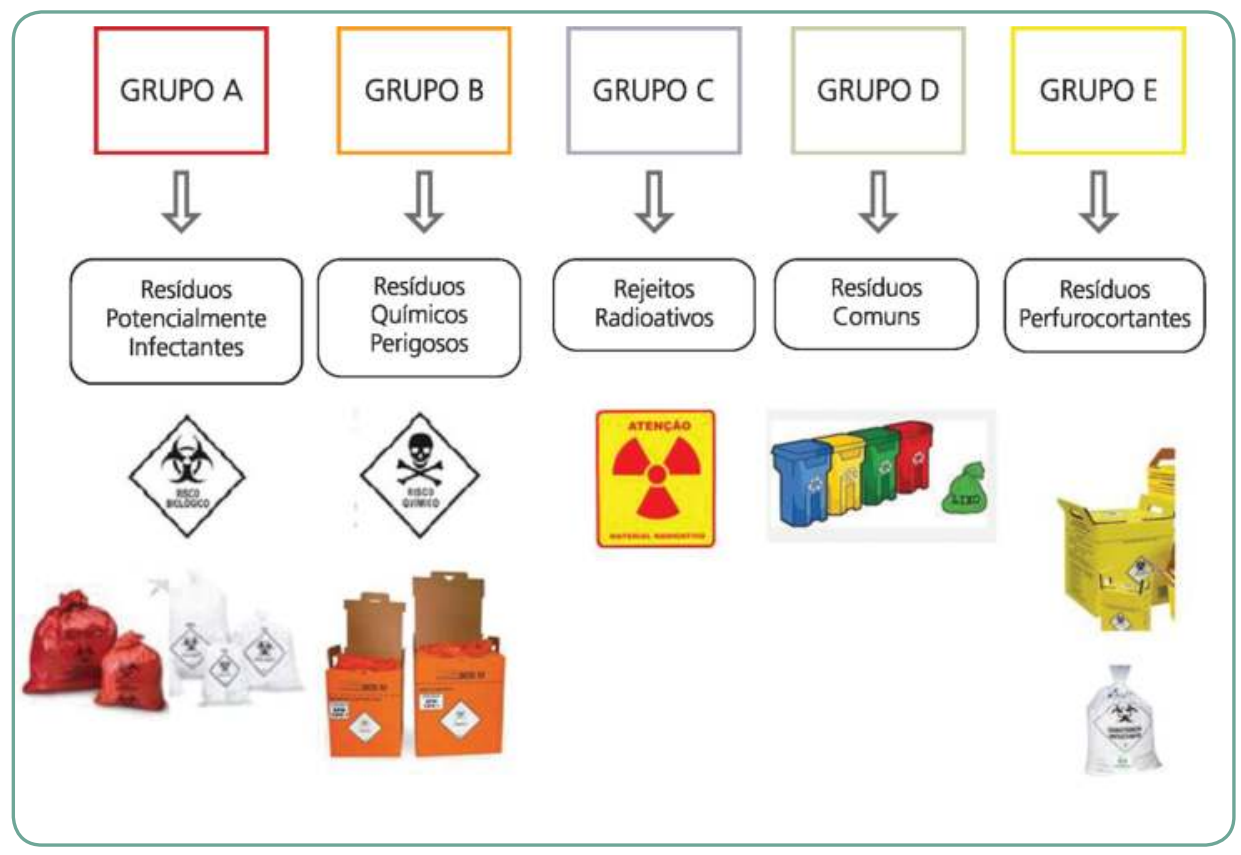

Fonte: Elaboração da autora, adaptado de Leme (2013).

\section{Manejo dos Resíduos de Serviços de Saúde (RSS)}

Consiste em gerenciar os resíduos em seus aspetos intra e extra-hospitalar, cumprindo todas as etapas, desde a segregação até a disposição final. Para melhor compreensão, vamos descrever as etapas desse manejo.

\section{Segregação}

É o momento mais importante da decisão do caminho que o resíduo irá seguir. De acordo com suas características, será classificado e acondicionado, garantindo a proteção da saúde humana e do meio ambiente. Se essa etapa for bem cumprida, boa parte dos resíduos será destinada como resíduo comum, reservando os manejos especiais para aqueles que realmente oferecem riscos.

Para facilitar essa decisão, podemos sinalizar os recipientes em que serão depositados os resíduos. A Figura 5 mostra um modelo de comu- 
nicação num hospital brasileiro - Hospital dos Servidores do Estado (Rio de Janeiro). Dentro da norma de cada país, o hospital deve adotar seu modelo de comunicação.

Figura 5 - Modelos de comunicação para segregação de Resíduos de Serviços de Saúde

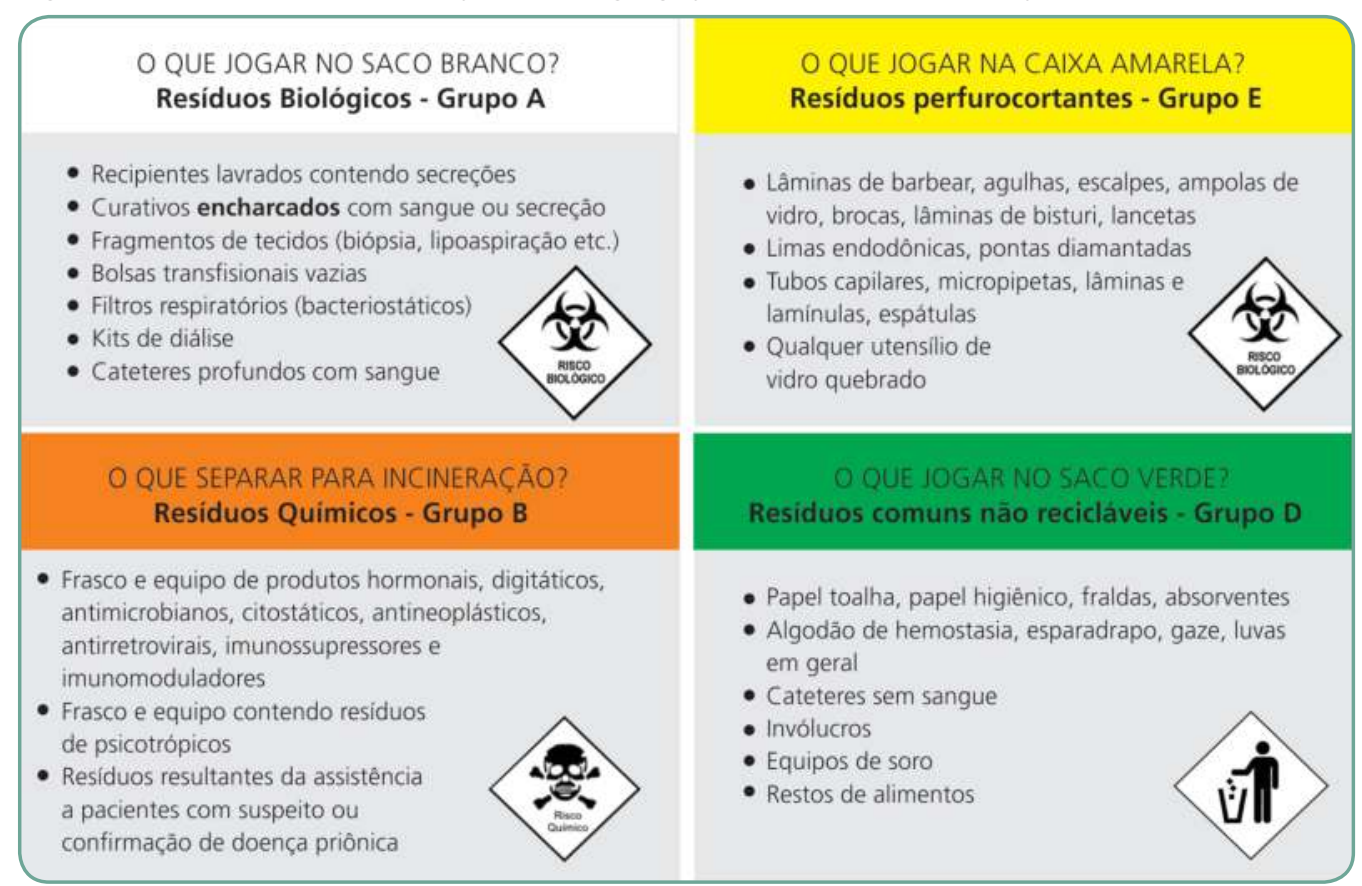

Fonte: Hospital dos Servidores do Estado (Rio de Janeiro) - Irene Haddad.

\section{Acondicionamento}

Consiste na disposição dos resíduos segregados em recipientes (sacos, lixeiras ou contenedores) compatíveis com a geração de cada resíduo. No Brasil, a NBR 9.191/2000 da ABNT definiu critérios para os sacos plásticos. Esses recipientes devem ser preenchidos até $80 \%$ de sua capacidade e devem ser resistentes à punctura, ruptura e vazamento. A Figura 6 apresenta exemplo de acondicionamento correto de perfurocortantes. 
Figura 6 - Exemplo de acondicionamento seguro de agulha

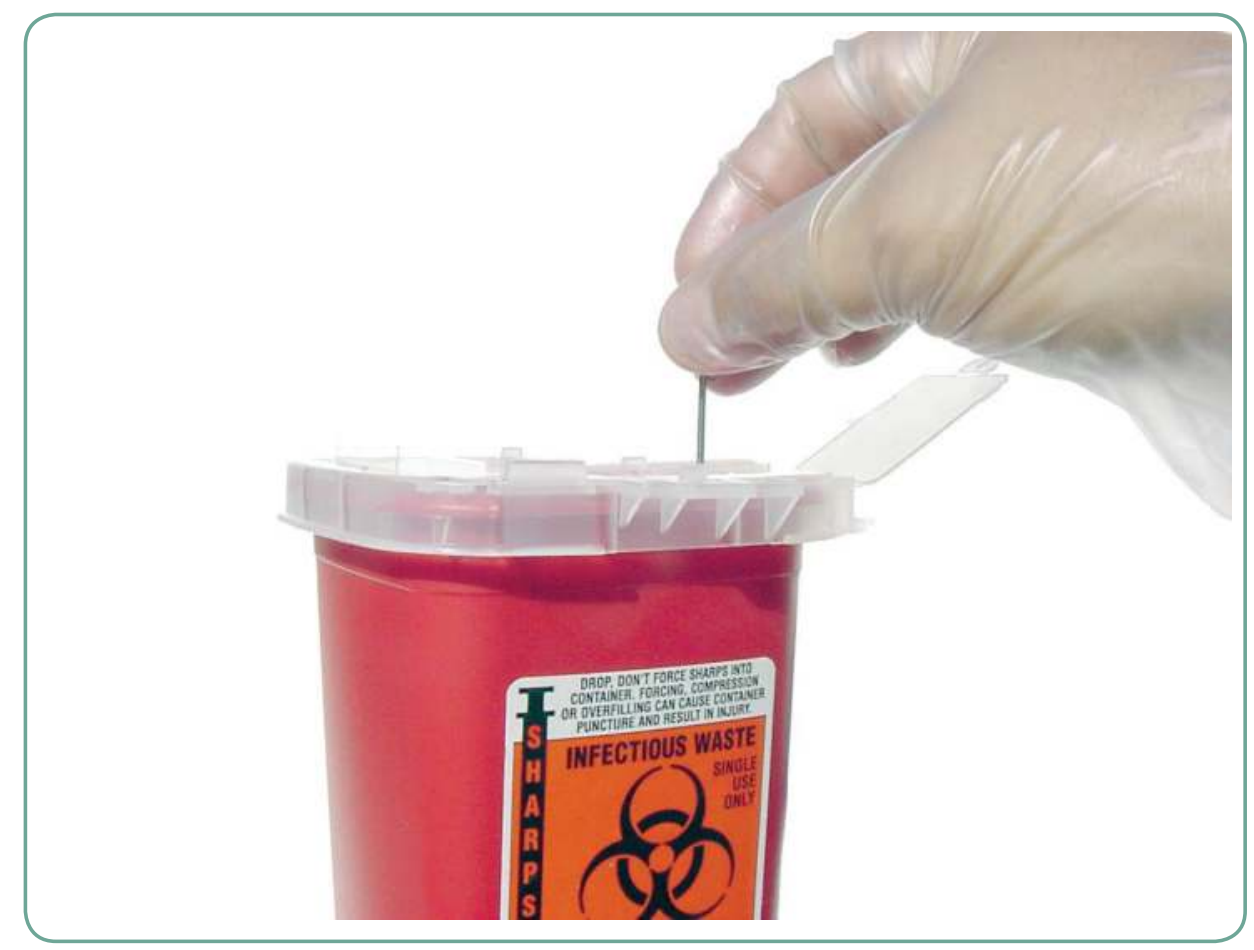

Foto: Rafti (2003).

\section{Identificação}

É um conjunto de medidas que permite o reconhecimento dos resíduos contidos nos sacos e recipientes. Deve estar visível nos sacos de acondicionamento, nos recipientes de coleta interna e externa, nos recipientes de transporte interno e externo e nos locais de armazenamento. No Brasil, os símbolos, cores e frases estão referenciados na NBR 7.500/2003 da $\mathrm{ABNT}$, além de outras exigências relacionadas à identificação de conteúdo e ao risco específico de cada grupo de resíduos.

\section{Coleta e transporte internos}

Consiste no recolhimento dos resíduos nos pontos de geração, sem compactação manual, e o seu encaminhamento em contenedores diferenciados e exclusivos para locais seguros. A Figura 7 apresenta uma situação ilustrativa de coleta e transporte de RSS. 
Figura 7 - Coleta e transporte de Resíduos de Serviços de Saúde

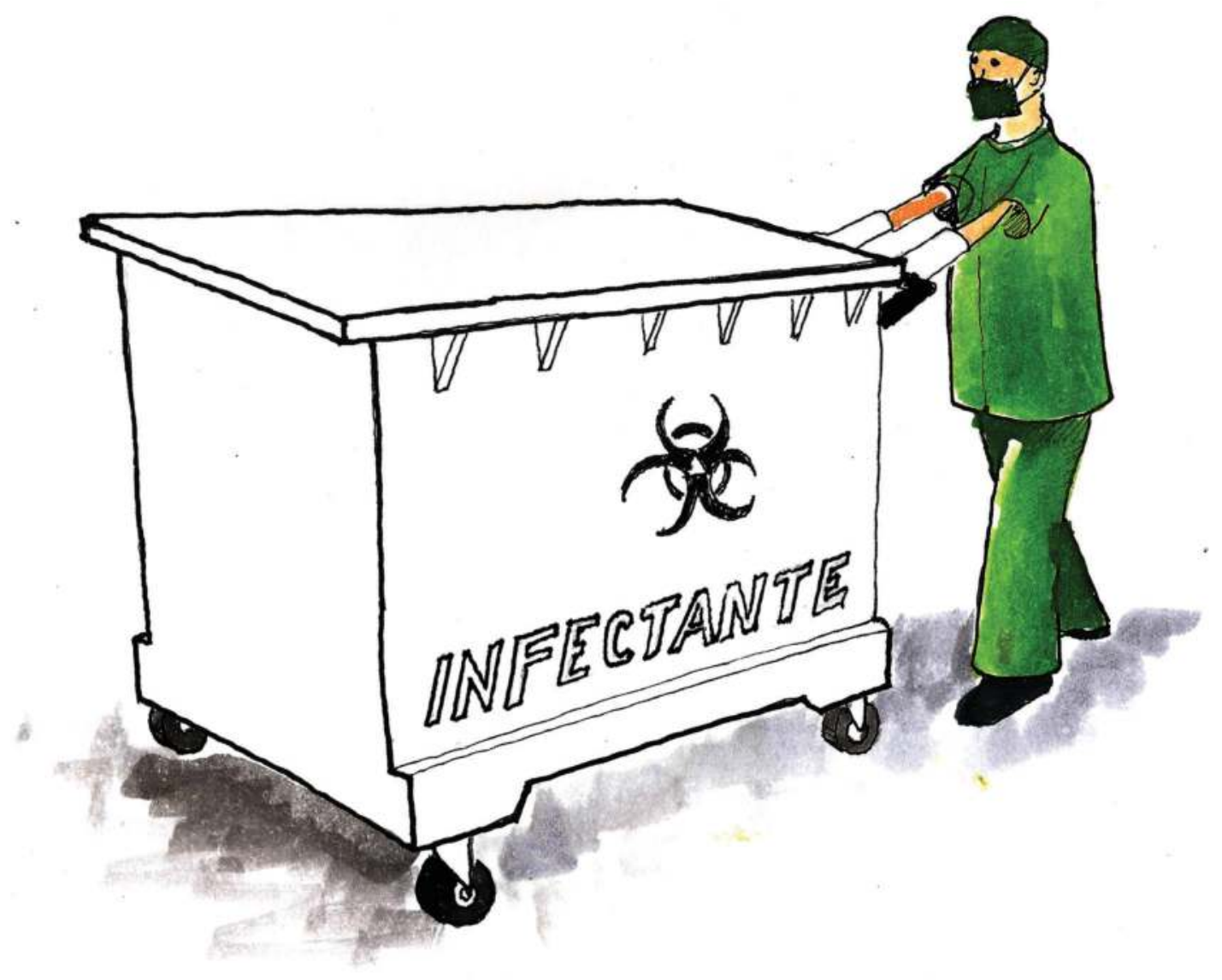

\section{Armazenamento temporário}

Consiste na guarda temporária dos recipientes contendo resíduos já acondicionados e identificados em local próximo aos pontos de geração, visando agilizar a coleta interna e otimizar o deslocamento entre os pontos geradores e o ponto da coleta externa. Estão incluídos nessas condições os materiais recicláveis (papelão, por exemplo) e as lâmpadas contendo mercúrio. O abrigo de resíduos do Grupo B deve estar identificado em local de fácil visualização, com sinalização/sinalética de segurança - resíduos químicos, com símbolo baseado na norma (no Brasil - NBR 7.500 da ABNT; e o armazenamento de resíduos perigosos deve contemplar ainda as orientações contidas na NBR 12.235 da ABNT).

\section{Tratamento}

Consiste na aplicação de método, técnica ou processo que modifique as características dos riscos inerentes aos resíduos, reduzindo ou eliminando o risco de contaminação, de acidentes ocupacionais ou de dano 
ao meio ambiente. O tratamento pode ser aplicado no próprio estabelecimento gerador ou em outro estabelecimento, observadas, nesses casos, as condições de segurança para o transporte.

O processo de autoclavação, aplicado em laboratórios para redução de carga microbiana de culturas e estoques de microrganismos, está dispensado de licenciamento ambiental, ficando sob a responsabilidade dos serviços que as possuírem a garantia da eficácia dos equipamentos, mediante controlos químicos e biológicos periódicos devidamente registados. A Figura 8 mostra o equipamento autoclave.

Figura 8 - Autoclave de laboratório

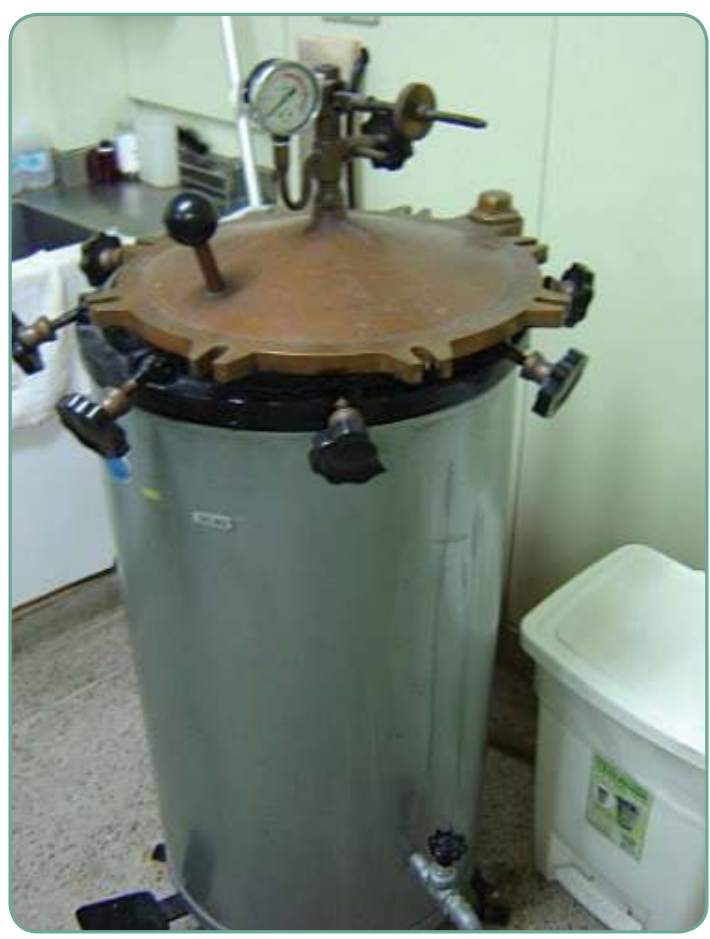

Foto: Irene Haddad (2009).

O processo de destilação simples e fracionada e a recuperação de solventes orgânicos é outro método de tratamento simples e seguro. A Figura 9 apresenta um destilador e a descrição do processo. 
Figura 9 - Descrição do processo de destilação simples do Xilol (a direita)

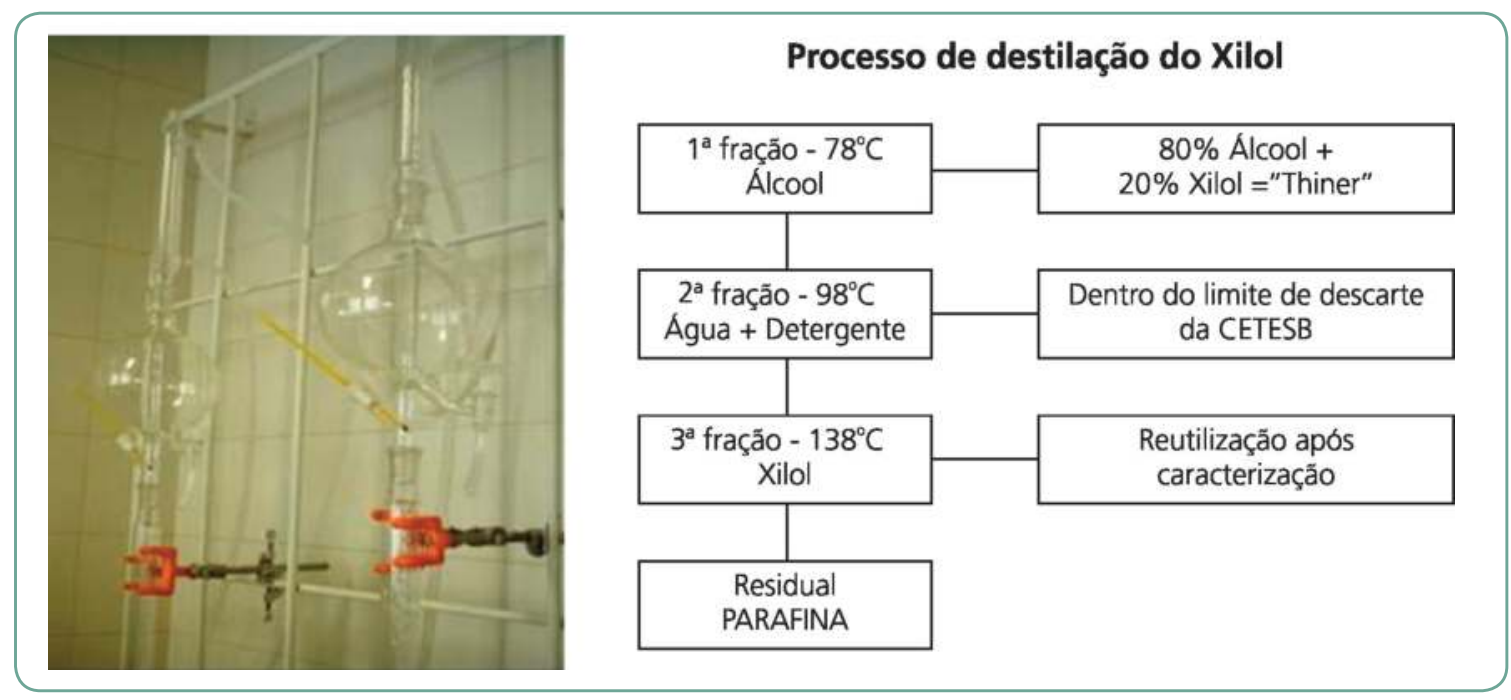

Fonte: Borghesan (2010).

\section{Armazenamento externo}

Consiste na guarda dos recipientes de resíduos até a realização da coleta externa em ambiente exclusivo, com acesso facilitado para os veículos coletores. Não é permitida a manutenção dos sacos de resíduos fora dos recipientes ali estacionados. Não é permitido transbordo de sacos de um recipiente para outro ou de um recipiente para o veículo coletor pelo alto risco de acidentes.

\section{Coleta e transporte externos}

Consistem na remoção dos RSS do abrigo de resíduos até a unidade de tratamento ou disposição final utilizando técnicas que garantam a preservação das condições de acondicionamento e a integridade dos trabalhadores, da população e do meio ambiente. As embalagens devem ser mantidas íntegras até a disposição final. Os resíduos comuns seguem as mesmas recomendações aplicáveis ao resíduo domiciliar. No Brasil, as normas NBR 12.810 e NBR 14.652 da ABNT norteiam essas etapas.

\section{Disposição final}

Consiste na disposição de resíduos no solo, previamente preparado com a finalidade de recebê-los, obedecendo a critérios técnicos de construção e operação, com licenciamento ambiental. No Brasil, esses critérios estão descritos na Resolução Conama n. 237/97. 


\section{Um tom sobre reciclagem}

Os RSS classificados como Grupo D podem ter seu volume diminuído com a implantação de projetos e ações socioambientais, focando as embalagens secundárias, terciárias e até quaternárias de alguns produtos (papel, papelão, espuma de polietileno expandido, paletes, cintas de contenção etc.) e outros materiais definidos como recicláveis ou reaproveitáveis (vidro, plástico, papel, papelão, metal).

Como alerta, é importante que as pessoas envolvidas ou interessadas em participar da segregação de materiais e reciclagem sejam identificadas e cadastradas, e suas ações sejam do conhecimento e autorização dos responsáveis pelo gerenciamento dos RSS - tanto os colaboradores internos como os externos, participantes de organizações não governamentais, catadores, voluntários etc.

A reciclagem ainda é uma ação socioambiental de grande valor e impacte, apesar das advertências em relação ao destino final real desses materiais. A reciclagem de papel e papelão, além do não uso de copos de plásticos são ações de fácil introdução nas organizações de saúde e podem incluir a participação de membros da sociedade menos favorecidos, gerando recursos e empregos, protegendo o meio ambiente, à medida que poupa recursos naturais e espaço nos aterros sanitários.

Além da adequação às legislações vigentes, caberá ao gestor da organização de saúde encontrar soluções de gestão integrada e ambientalmente corretas em sua região, implantando e dando continuidade a processos de trabalho referentes a todos os grupos de resíduos em sua organização, além das iniciativas de reciclagem e reuso.

\section{Para refletir}

Sua organização está envolvida com algum projeto de reciclagem?

De que tipo? Como é realizada a separação e de quem é a responsabilidade pela coleta?

\section{Segurança ocupacional}

Os profissionais envolvidos diretamente com os processos de higienização e limpeza, coleta, transporte, tratamento e armazenamento de resíduos devem ser submetidos a exames médicos periódicos (admissional e demissional, no mínimo), conforme estabelecido nos programas nacionais de saúde ocupacional ou de saúde do trabalhador 
de cada país. No caso do Brasil, o Programa de Controlo Médico de Saúde Ocupacional (PCMSO) da Portaria n. 3.214 do Ministério do Trabalho e Emprego (MTE) ou em legislação específica para o serviço público. Os profissionais devem ser imunizados conforme os programas nacionais de imunização e realizar posterior controlo laboratorial sorológico para avaliação da resposta imunológica.

\section{O mercúrio, a saúde e o meio ambiente}

O mercúrio é um metal pesado, altamente tóxico, persistente no meio ambiente, capaz de se disseminar pelo ar (vapor de mercúrio) e pela água (metil mercúrio). A exposição ao mercúrio pode afetar o cérebro, a medula, os rins, o fígado e atravessar facilmente a placenta, colocando em risco o desenvolvimento neurológico do bebê.

O uso de dispositivos contendo mercúrio implica risco para a saúde dos profissionais e dos pacientes em caso de quebras, derramamentos etc., como potenciais riscos ao meio ambiente. Os vapores de mercúrio não são observados a olho nu, mas podem ser vistos com o auxílio de uma luz fluorescente.

Em 2013, numa pequena cidade do interior do estado brasileiro de São Paulo, cerca de 140 pessoas (muitas delas crianças) foram seriamente contaminadas e várias precisaram ser hospitalizadas por conta da destinação inadequada de alguns poucos frascos (50 gramas cada) de mercúrio odontológico. Um evento extremamente sério, que teve pouquíssima repercussão na mídia.

O amálgama é um problema tanto de contaminação ambiental como de exposição ocupacional. O consumo mundial de mercúrio na odontologia vem caindo, mas ainda existe grande polêmica sobre quando será possível eliminá-lo totalmente. É importante reduzir seu uso e, enquanto não for possível eliminar totalmente, cuidar com rigor da segurança dos dentistas e do controlo ambiental, especialmente dos resíduos. O que se pode fazer para minimizar os danos aos dentistas é usar o sistema pré-dosado, em cápsulas, com amalgamadores agitadores (não os misturadores, mais caros e totalmente contraindicados).

Estudos apontam que, nos EUA, o consumo de mercúrio para odontologia caiu de 31 toneladas em 2001 para 16,5 toneladas em 2007. De qualquer forma, trata-se de quantidades incrivelmente altas para uma substância tão perigosa. 


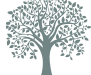

Para saber mais sobre os vapores de mercúrio, assista: http://www.youtube.com/ watch?v=9-mFk7tzKCU

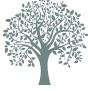

Sobre a questão do mercúrio na área da saúde, leia em http://www.noharm.org/saude_sem_dano/temas/toxicos/ mercurio/
No aspeto ambiental, temos o problema do descarte inadequado, agravado pelo interesse económico na prata e nos outros metais presentes no amálgama. O mercúrio é queimado nas piores condições possíveis, contaminando o trabalhador da metalúrgica e o posterior descarte desse mercúrio no meio ambiente. Os restos de mercúrio e amálgama devem ser acondicionados em embalagens plásticas, com tampa à prova de vazamento e sob selo d'água. A recuperação do mercúrio e da prata somente deve ser encaminhada a empresas com licença de operação.

Evitar a geração de resíduos e gerenciá-los adequadamente também ajuda enquanto não se consegue acabar com os amálgamas por completo. Já os termômetros e esfigmomanômetros com mercúrio podem ser $100 \%$ substituídos com a mesma precisão e qualidade de medição (Anvisa 2006b).

Há uma tendência mundial em substituir dispositivos de mercúrio por alternativas seguras, certificadas e disponíveis no mercado. Vários países da Europa já proibiram seu uso, incluindo Portugal. Também na América Latina as instituições caminham para a substituição. A Secretaria da Saúde do Estado de São Paulo proibiu a compra de qualquer dispositivo contendo mercúrio. O Estado de Santa Catarina também baniu o mercúrio da saúde. Nos Estados Unidos, mais de 5 mil estabelecimentos de saúde adotaram compromissos de eliminação do mercúrio; as principais cadeias farmacêuticas suspenderam a venda de termômetros de mercúrio e 29 estados dos EUA aprovaram leis que restringem o uso de produtos com mercúrio.

Com os objetivos de informar os profissionais de saúde sobre os perigos vivenciados por eles pela exposição ao mercúrio decorrente das quebras e promover o papel de liderança do sector saúde na redução das emissões de mercúrio no meio ambiente, torna-se importante encorajar a criação de grupos de trabalho que promovam a substituição desses dispositivos. O primeiro passo é fazer um diagnóstico:

橉 Quantos termômetros e tensiômetros contendo mercúrio existem na organização?

*uantos dispositivos são substituídos por período?

Em caso de quebra de termômetro, qual o procedimento utilizado?

Para refletir

Procure responder às questões do diagnóstico anterior avaliando sua organização. 
A partir dessas respostas, que normalmente surpreendem o entrevistador, é necessário estabelecer um programa a fim de proceder a substituição e garantir que as próximas compras sejam livres de mercúrio.

As vacinas e medicamentos têm quantidades mínimas de mercúrio, não nocivas à saúde. As principais fontes de contaminação por mercúrio na saúde são:

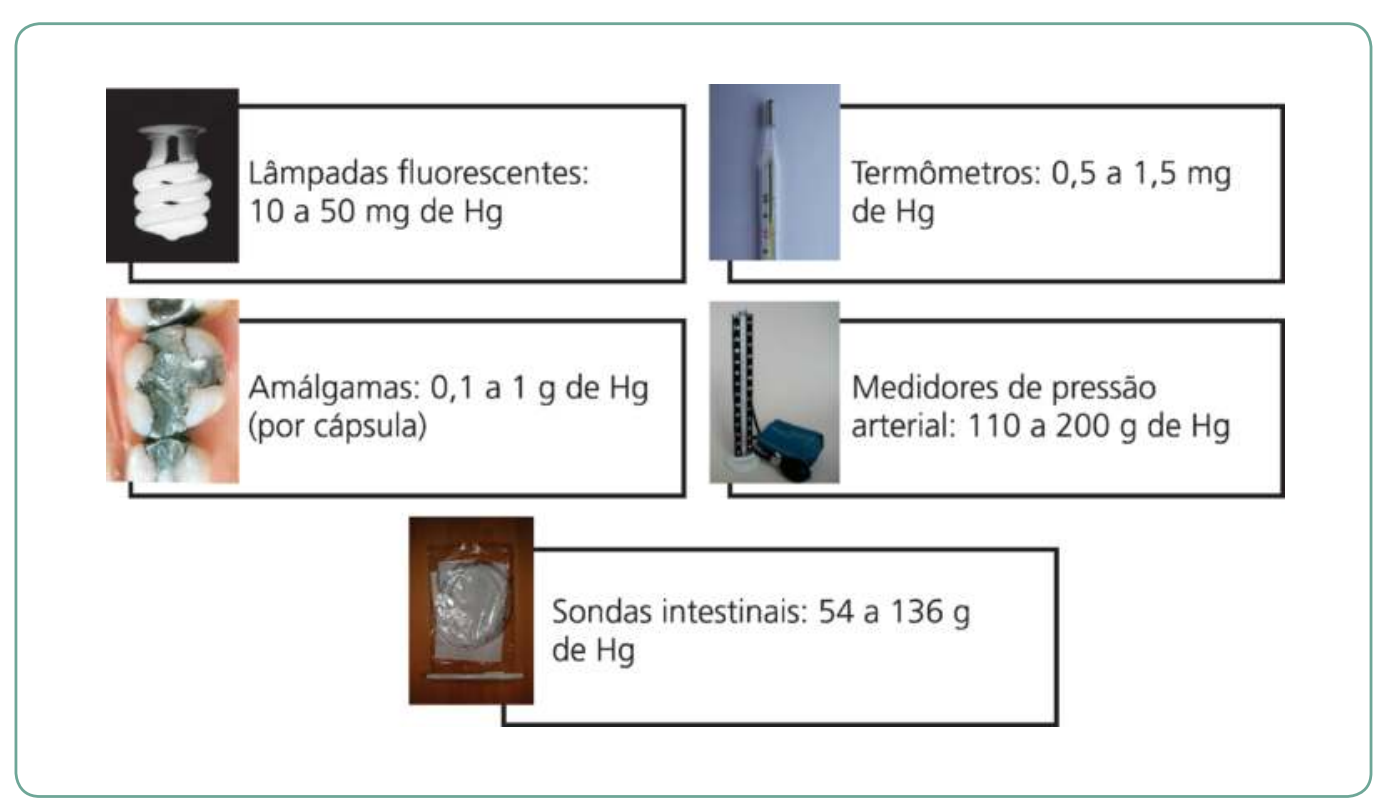

Fonte: Giligone (2008), Carretta (2009), Hayes (2006), Thermometer (2013), Hayes (2006), AlexNB (2009).

\section{Manejo em caso de quebra de termômetro de mercúrio}

No caso de quebra de termômetro de mercúrio, alguns cuidados são necessários para evitar a contaminação de pessoas e do ambiente. É preciso ter em mãos:

镂 quatro ou cinco bolsas herméticas, tipo ziplock;

滕 rótulos de identificação de "resíduos contendo mercúrio";

saco de lixo (2 mm ou mais de espessura);

䠝 recipiente plástico com tampa que feche bem (por exemplo, frasco de filme fotográfico);

滕 luvas de látex (ou nitrílicas, quando disponível);

悽 máscara para vapores;

滕 toalhas de papel;

影 tira de papelão; 
Esse item foi adaptado do Guia para a Eliminação do Mercúrio em Estabelecimentos de Saúde, produzido pela ONG Saúde Sem Dano http://www.noharm.org/ salud_sin_danio/, traduzido para a língua portuguesa com o apoio da ONG Projeto Hospitais Saudáveis e disponível para download no site http://www.hospitaissaudaveis.org/ biblioteca.asp.

A Agenda Global para Hospitais Verdes e Saudáveis, disponível em http://www.hospitaissaudaveis.org/ noticias_ler.asp?na_codigo=12, é um excelente instrumento de apoio a iniciativas que visam promover a sustentabilidade e a saúde ambiental no sector saúde. São dez objetivos interligados contendo uma série de ações que podem ser implementadas tanto por hospitais como por sistemas de saúde. seringa (sem agulha) ou conta-gotas;

噄 fita adesiva (de $30 \mathrm{~cm}$ );

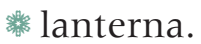

Os procedimentos para lidar com esse tipo de incidente devem começar com a retirada dos adornos das mãos para que o mercúrio não se combine com os metais. É preciso atentar para não pisar na região onde supostamente estão as bolinhas de mercúrio. Em seguida, solicite que todos se retirem das proximidades do local onde houve o derramamento, feche a porta e desligue o sistema de refrigeração ou ventilação, evitando a dispersão dos vapores de mercúrio.

É imprescindível vestir as luvas para recolher os restos de vidro ou qualquer outro material cortante, colocando-os sobre uma toalha de papel, que, posteriormente, irá para dentro da bolsa hermética, tipo ziplock. Esse procedimento inicia-se localizando as bolinhas de mercúrio e, com o auxílio de uma tira de papelão, em movimentos lentos para controlar o recolhimento e evitar a dispersão, juntam-se as bolinhas em uma toalha de papel. Quando o recolhimento parecer completado, desligue a iluminação e, com o auxílio de uma lanterna, segure em um ângulo baixo perto do chão, procurando pelo brilho das gotas de mercúrio, que podem estar aderidas à superfície ou em pequenas fissuras. O mercúrio pode percorrer longas distâncias sobre superfícies duras e lisas, por isso não se pode deixar de inspecionar o ambiente inteiro.

Com o auxílio de um conta-gotas ou seringa, aspira-se as gotas de mercúrio, devagar e com cuidado, transferindo o mercúrio para um recipiente plástico com tampa. O recipiente deve ser colocado dentro de uma bolsa hermética, tipo ziplock, que será fechada e rotulada.

Depois de ter recolhido as maiores gotas, usa-se uma fita adesiva para recolher gotas menores, difíceis de ver. A fita também deve ser colocada em uma bolsa hermética, tipo ziplock, fechada e rotulada.

Todos os materiais recolhidos e mais aqueles utilizados na limpeza, inclusive as luvas, deverão ser colocados em um saco de lixo, que será fechado e rotulado como resíduo químico perigoso. O próximo passo será contactar o responsável pela limpeza, para que esses materiais sejam encaminhados a um local seguro (recipiente tipo tambor, lacrado e identificado como resíduo químico perigoso), aguardando a coleta, transporte e destinação final conforme a legislação vigente. E não esqueça de que a área do derramamento deve receber boa ventilação externa (janela aberta) ou artificial por cerca de 24 horas. 


\section{Considerações finais}

Os riscos não clínicos estão presentes na rotina de um hospital. Assim, é imprescindível o cumprimento das legislações, normas e protocolos para garantir a segurança e minimizar a possibilidade de ocorrência de acidentes e complicações. A interferência dos riscos não clínicos no cuidado demonstra a complexidade do sector da saúde, ou seja, um sector multifacetado que exige e necessita do envolvimento de múltiplas variáveis para desempenhar com eficiência e segurança suas funções.

\section{Referências}

Agência Nacional de Vigilância Sanitária. Cartilha de notificações em tecnovigilância. Brasília, DF: Anvisa; 2003.

Agência Nacional de Vigilância Sanitária. Manual de gerenciamento de resíduos de serviços de saúde. Brasília, DF: Anvisa; 2006a.

Agência Nacional de Vigilância Sanitária. Resolução RDC n. 2, de 25 de janeiro de 2010. Dispõe sobre o gerenciamento de tecnologias em saúde em estabelecimentos de saúde. Brasília, DF: Anvisa; 2010.

Agência Nacional de Vigilância Sanitária. Resolução RDC n. 306, de 15 de julho de 2004. Dispõe sobre o Regulamento Técnico para o gerenciamento de resíduos de serviços de saúde. Brasília, DF: Anvisa; 2004 [citado 2004 ago 26]. Disponível em: http://www.anvisa.org.br.

Agência Nacional de Vigilância Sanitária. Serviços odontológicos: prevenção e controle de riscos. Brasília, DF: Anvisa; 2006b.

Agência Portuguesa do Ambiente, Direcção-Geral da Saúde, Direcção-Geral de Veterinária. Plano estratégico dos resíduos hospitalares 2011-2016: PERH. [Lisboa]: APV; 2011 [citado 2013 dez 17]. 166 p. Disponível em: http://www.apambiente.pt/_zdata/Politicas/Residuos/Planeamento/ PERH/ PERH_2011_2016.pdf.

AlexNB. File: Kendall stomach tube Fr18.jpg. Wikimedia Commons, 2009. Disponível em: http:// commons.wikimedia.org/wiki/File:Kendall_stomach_tube_Fr18.jpg.

AlexSP. Ficheiro: viatura bombeiros varias.jpg. Wikipédia, 2011 [citado 2014 jul 20]. Disponível em: http://pt.wikipedia.org/wiki/Ficheiro:Viatura_bombeiros_varias.jpg.

American College of Clinical Engineering. Plymouth: ACCE; 2013 [citado 2009 jan. 28]. Disponível em: http://accenet.org/.

Associação Brasileira de Empresas de Limpeza Pública e Resíduos Especiais. Panorama dos resíduos sólidos no Brasil. São Paulo: Abrelpe; 2012.

Associação Brasileira de Normas Técnicas. NBR 7500: símbolos de riscos e manuseio para o transporte e armazenagem de materiais: simbologia. São Paulo: ABNT; 1987.

Associação Brasileira de Normas Técnicas. NBR 9190: sacos plásticos para acondicionamento de lixo: classificação. São Paulo: ABNT; 1985.

Associação Brasileira de Normas Técnicas. NBR 12810: coleta de resíduos de serviços de saúde: procedimentos. São Paulo: ABNT; 1993.

Associação Brasileira de Normas Técnicas. NBR 13853: coletores para resíduos de serviços de saúde perfurantes ou cortantes: requisitos e métodos de ensaio. São Paulo: ABNT; 1997. 
Associação Brasileira de Normas Técnicas. NBR 15943: diretrizes para um programa de gerenciamento de equipamentos de infraestrutura de serviços de saúde e de equipamentos para a saúde. Rio de Janeiro: ABNT; 2011.

Barbosa ATR, laione F, Wendling RF. Um sistema de segurança elétrico hospitalar interligado por rede sem fio. In: 27. Simpósio Brasileiro de Telecomunicações. Blumenau: Sociedade Brasileira de Telecomunicações; 2009.

Bebê morre em incubadora de maternidade em Ilhéus, sul da Bahia. G1 Bahia. 2012 out 25 [citado 2013 ago 25]. Disponível em: http://g1.globo.com/bahia/noticia/2012/10/bebe-morre-emincubadora-de-maternidade-em-ilheus-sul-da-bahia.html.

Bisinotto FMB, Abud TMV, Alves J Neto, Sousa MCQ. Queimadura provocada por bisturi elétrico associado ao oxímetro de pulso: relato de caso. Rev Bras Anestesiol. 1996;46:2:133-5.

Borghesan L. [Aula no] Seminário Hospitais Livres de Mercúrio Rio de Janeiro; 2010.

Brasil. Lei n 12.305, de 2 de agosto de 2010. Institui a Política Nacional de Resíduos Sólidos; altera a Lei n. 9.605, de 12 de fevereiro de 1998; e dá outras providências. Diário Oficial da União. 2010 ago 3.

Chartier $Y$, et al., editor. Safe management of wastes from health-care activities. 2nd ed. Geneva: WHO; 2013.

Conselho Nacional do Meio Ambiente (BR), Resolução n 358, de 29 de abril de 2005. Dispõe sobre o tratamento e a disposição final dos resíduos dos serviços de saúde e dá outras providências. Brasília, DF: CONAMA; 2005.

Ministério da Saúde (BR). Saúde ambiental e gestão de resíduos de serviços de saúde: Projeto Reforsus. Brasília, DF: MS; 2003.

Ministério da Saúde (BR). Secretaria de Assistência à Saúde. Condições de segurança contra incêndio. Brasília, DF: MS; 1995.

Ministério do Meio Ambiente (BR). ICLEl-Brasil. Planos de gestão de resíduos sólidos: manual de orientação. Brasília, DF: MMA; 2012.

Carretta E. File:filling amaggam.jpg. Ekimedia Commons, 2009 [citado 2014 jul 20]. Disponível em: http://commons.wikimedia.org/wiki/File:Filling_amalgam.jpg.

Castro CF, Abrantes JB. Manual de segurança contra incêndio em edifícios. Sintra: Escola Nacional de Bombeiros; 2009.

Centre de Coordination de la Lutte contre les Infections Nosocomiales de I'Interrégion Paris - Nord. Élimination des effluents liquides des établissements hospitaliers : recommandations.. Paris : CCLIN Paris-Nord, Institut Biomédical des Cordeliers; 1999 [citado 2014 jun 28]. 74p. Disponível em: http://web.ccr.jussieu.fr/guide_effluents_liquides.pdf

Chartier $Y$, et al., editor. Safe management of wastes from health-care activities. 2nd ed. Geneva: WHO; 2013.

Conselho Nacional do Meio Ambiente (BR). Resolução n 358, de 29 de abril de 2005. Dispõe sobre o tratamento e a disposição final dos resíduos dos serviços de saúde e dá outras providências. Brasília, DF: CONAMA; 2005.

Constanzo SD, Murby J, Bates J. Ecosystem response to antibiotics entering the aquatic environmental. Mar Pollut Bull. 2005;51:218-23.

Le Corre K, Katouli M, Stratton H, Ort C, Keller J. Hospital wastewater. Ago. 2012. Urban Water Security Research Alliance Technical Report 2012 Ago;76. 
Deloffre-Bonnamour N. Les rejets des établissements de santé: des effluents liquides aux déchets solides. Mémoire de Maîtrise. Lyon: Université Claude Bernard-Lyon1, Institut Universitaire Professionnalisé, Génie de l’Environnement-Ecodéveloppement; 1995.

Department of Energy (US). Energy efficiency and renewable energy: annual report. Washington, DC: U.S. Dept. of Energy; 2012.

Desroches, A. Introdução à gestão do risco. [Local desconhecido]: Centrale Paris; 2005.

ECRI Institute. Risk management, quality improvement and patient safety. Healthcare risk control. 2009 Jul;2(4):25p.

Emmanuel E, et al. Effects of hospital wastewater on aquatic ecosystem. In: Asociación Interamericana de Ingeniería Sanitaria y Ambiental. 28th Congreso Interamericano de Ingenieria Sanitaria y Ambiental; 2002 Oct 27 - Nov 1; Cancun. [Anais]. México: AllSA; 2002.

Energy Information Administration (US). Comercial buildings energy consumption survey (CBECS). Washington, DC: EIA; 2012 [citado 2019 Jan 20]. Disponível em: http://www.eia.gov/consumption/ commercial/ reports/2012/large-hospital.cfm

Environmental Protection Agency. Saving water in hospitals. Washington, DC: EPA; 2012. 2p.

Falcão F. Contributo para o estudo da problemática das águas residuais hospitalares [dissertação]. Lisboa: Faculdade de Ciências e Tecnologia da Universidade Nova de Lisboa; 2009. 150 f.

Falvey DG, Streifel AJ. Ten-year air sample analysis of Aspergillus prevalence in a university hospital. J Hosp Infect. 2007 Sep;67(1):35-41.

Floresta (Coronel Favbriciano). Wiokipedia, 2014 [citado 2014 jul 20]. Disponível em: http:// pt.wikipedia.org/wiki/Floresta_(Coronel_Fabriciano)

Gadelle F. Le monde manquera-t-il bientôt d'eau? Sécheresse 1995;6(1):11-15.

Gautam AK, Kumar S, Sabumon PC. Preliminary study of physico-chemical treatment options for hospital wastewater. J Environ Manage. 2007 May;83(3):298-306.

Giligone. Ficheiro:compact fluorescent-bw.jpg. Wikipedia, 2008 [citado 2014 jul 20]. Disponível em: http://pt.wikipedia.org/wiki/Ficheiro:Compact_Fluorescent-bw.jpg.

Gill A, Ono R. Segurança contra incêndios em hospitais. [S.I.]: NUTAU; 2006. 9p.

Hayes MV. File: Mercury manometer.jpg. Wikimedia Commons, 2006 [citado 2014 jul 20].

Disponível em: http://commons.wikimedia.org/wiki/File:Mercury_manometer.jpg.

Health Care Access Annual Reporting. Guide to hospital performance. [Local desconhecido]: HCAR, 1999.

Jmerelo. File:Lixo na rua.jpg. Wikimedia Commons, 2007 [citado 2014 jun 28]. Disponível em: http://commons.wikimedia.org/wiki/File:Lixo_na_rua.jpg.

Jochimsen EM, Carmichael WW, An JS, Cardo DM, Cookson ST, Holmes CE, et al. Liver failure and death following exposure to microcystin toxins at a hemodialysis center in Brazil. N Engl J Med. 1998 Mar 26;338(13):873-8.

Khalil E. Air-conditioning systems developments in hospitals: comfort, air quality, and energy utilization. [Local desconhecido]: [editor desconhecido]; [200?].

Kim KY, Kim CN. Airborne microbiological characteristics in public buildings of Korea. Build Environ. 2007;5(42):8.

Kümmerer K. Antibios in the aquatic environment: a review, part 1. Chemosphere. 2009:417-434.

Le Corre K, Katouli M, Stratton H, Ort C, Keller J. Hospital wastewater. Ago. 2012. (Urban Water Security Research Alliance Technical Report 2012 Ago; 76). 
Leme IL. Iniciativas socioambientais em serviços de saúde: gerenciamento de resíduos. São Paulo: [editora desconhecida]; 2013.

Lopez M, Abreu F. Central de gases medicinais: coração de uma instituição hospitalar. Cad Est Tecnol. 2013;1(1):158-71.

Lucatelli MV, et al. Gestão da confiabilidade tecnológica no ambiente hospitalar. Florianópolis: Universidade Federal de Santa Catarina; 2003 [citado 2014 jun 25]. Disponível em: www. mantenimientomundial.com/sites/mmnew/bib/notas/12hospita.asp

Lukaaz. Ficheiro: casa do regente Feijó-by Lucas,jpg. Wikipedia, 2010 [citado 2014 jul 20]. Disponível em: http://pt.wikipedia.org/wiki/Ficheiro:Casa_do_Regente_Feij\%C3\%B3_-_by_Lucas.JPG.

Madeira C, et al. Plano de gestão de resíduos hospitalares em centros de saúde. Lisboa: DirecçãoGeral da Saúde; 2007.

Meirelles-Pereira F, et al. Ecological aspects of the antimicrobial resistance in bacteria of importance to human infections. Braz J Microbiol. 2002;33:287-93.

Ministério da Saúde (BR). Saúde ambiental e gestão de resíduos de serviços de saúde: Projeto Reforsus. Brasília, DF: MS; 2003.

Ministério da Saúde (BR), Secretaria de Assistência à Saúde. Condições de segurança contra incêndio. Brasília, DF: MS; 1995.

Ministério da Saúde (PT). A gestão do risco no centro. Lisboa: MS; 2011.

Ministério da Saúde (PT). A organização interna e a governança dos hospitais. Lisboa: MS; 2010.

Ministério da Saúde (PT). Direcção-Geral da Saúde. Divisão de Saúde Ambiental.

Plano de gestão de resíduos hospitalares em centros de saúde. Lisboa: DGS; 2007.

Ministério do Meio Ambiente (BR), ICLEl-Brasil. Planos de gestão de resíduos sólidos: manual de orientação. Brasília, DF: MMA; 2012.

National Fire Protection Association, Fire Analysis and Research Division. Fires in healthcare facilities. Quincy (MA): NFPA; 2012.

Operating room. Chapter 3: Operating room and Central Processing Divison. [2011]. 19p.

Ortiz MRD. Ficheiro:traffic jan São Paulo 09200630.jpg. Wikipedia, 2006 [citado 2014 jul 20]. Disponível em: http://pt.wikipedia.org/wiki/Ficheiro:Traffic_jam_Sao_Paulo_09_2006_30.JPG

Pouria S, et al. Fatal microcystin intoxication in haemodialysis unit in Caruaru, Brazil. Lancet 1998;352:21-6.

Prado T. Avaliação da eficiência de um sistema de tratamento de efluente hospitalar por processo anaeróbico na remoção de coliformes, Pseudomas aeruginosas, Klebsiella pneumoniae resistentes a antibióticos e vírus da hepatite A. 2007 [tese]. Rio de Janeiro: Escola Nacional de Saúde Pública, Fiocruz; 2007. 125f. Tese. Doutorado em Saneamento e de Saúde Ambiental.

Prata I. [Hidrante]. Flick, 2011 [citado 2014 jun 20]. Disponível em: http://www.flickr.com/photos/ igorprata/84763722/sizes/m/in/photostream/

Prayitno, Kusuma Z, Yanuwiadi B, Laksmono RW. Study of hospital wastewater characteristic in Malang City. Res Inventy: Int J Eng Sci. 2013 Jan;2(2):13-6.

Previsión del tiempo. Pixabay, 2013 [citado 2014 jul 20]. Disponível em: http://pixabay.com/es/ previsi\%C3\%B3n-del-tiempo-clima-sol-nube-146472/.

Rafti, W. File: sharps container.jpg. Wikipedia, 2003 [citado 2014 jul 20]. Disponível em: http:// en.wikipedia.org/wiki/File:Sharps_Container.jpg. 
Rebel W. File: ruas de Sintra 0559.jpg. Wikimedia, 2011 [citado 2014 jul 20]. Disponível em : http:// commons.wikimedia.org/wiki/File:Ruas_de_Sintra_0590.jpg.

Reinthaler FF, et al. Antibiotic resistance of E.coli in sewage and sludge. Water Res. 2003;37:1685-90.

Ribeiro P, et al. Plano nacional de gestão de resíduos 2011-2020. Lisboa: Agência Portuguesa do Ambiente; 2011.

Sá RA. Levantamento e análise de eventos adversos com aparelhos de tomografia computadorizada. Rio de Janeiro: [editora desconhecida]; 2009.

Santa Casa de Misericórdia de Goiânia, Serviço de Controle de Infecção Hospital, Comissão de Controle de Infecção Hospitalar. Rotina de controle da qualidade da água. Goiania: A Comissão; 2006.

Saúde sem Dano. Agenda Global Hospitais Verdes e Saudáveis. 2011 [citado 2014 jun 28].

Disponível em: http://www.hospitaissaudaveis.org/noticias_ler.asp?na_codigo=12.

Schneider Electric. Hospital isolated power systems. Nashville: SE ; 2008.

Schwartz T, et al. Detection of antibiotic-resistant bacteria and their resistance genes in wastewater, surface water, and drinking water biofilms. FEMS Microbiol Ecol. 2003;43:325-35.

Silva T. Segurança contra incêndios em hospitais [dissertação]. Porto: Departamento de Engenharia Civil, Faculdade de Engenharia do Porto, Universidade do Porto; 2010.

Taublib D. Controle de qualidade total, da teoria à prática em um grande hospital: abordagem histórica da qualidade. Rio de Janeiro: Qualitymark; 1998. p. 13.

Tavares A. A gestão dos resíduos hospitalares e o papel da autoridade de saúde: caso do Concelho da Amadora [tese]. Lisboa: Escola Superior de Saúde Pública; Universidade Nova de Lisboa; 2004 [citado 2013 dez 17]. Disponível em: http://run.unl.pt/bitstream /10362/3317/1/RUN\%20-\%20 Tese\%20de\%20Doutoramento\%20-\%20Ant\%C3\%B3nio\%20Tavares.pdf.

Tavares A, Barreiros, C. Gestão de resíduos hospitalares nos centros de saúde e extensões do Distrito de Lisboa. Rev Portug Clínica Geral. 2004; 20:20-31.

Tavares A, Coelho M, Dias, C, Lourenço C, Lopes F, Pereira, F. Requisitos estruturais das salas de tratamento. Tecnohospital. 2017; 79:30-5.

Thermometer. Pixabay, 2013 [citado 2014 jul 20]. Disponível em: http://pixabay.com/en/ thermometer-temperature-instrument-106378/.

University Teaching Trust. Basic medical gas safety. [Local desconhecido]: The University; 2012.

Watts J, et al. Introduction to fire risk analysis. In: The SFPE handbook of fire protection engineering. 3rd ed. Quincy: SFPE; 2002. Chapter 5-1, Society of Fire Protection Engineers.

Wikimedia Commons. File:Francisco de Goya - Incendio de un hospital.jpg. 2014 [citado 2014 jun 28]. Disponível em: http://commons.wikimedia.org/wiki/File:Francisco_de_Goya_-_Incendio_de_un_ hospital.jpg

Wikipedia. File:Sharps Container.jpg. 2003 [citado 2014 jun 28]. Disponível em: http://en.wikipedia. org/wiki/File:Sharps_Container.jpg.

World Health Organization. Fact sheets on environmental sanitation: epidemic diarrhoeal diseases control. Geneva: WHO; 1996.

World Health Organization. Financiamento dos sistemas de saúde: o caminho para a cobertura universal: relatório mundial da saúde. Genebra: WHO; 2010.

World Health Organization. Seguridad del paciente. In: World Health Organization. 59th Asamblea Mundial de la Salud, 2006 May 4. A59/22. Punto 11.16; Informe de la Secretaría. 


\title{
16. Maternidade segura
}

\author{
Lenice Gnocchi da Costa Reis
}

As maternidades são organizações de saúde singulares, pois cuidam, ao mesmo tempo, de duas pessoas que não apresentam necessariamente doença. A gestação e o parto são processos fisiológicos, e as intervenções devem ser de forma cuidadosa avaliadas em termos de risco e benefício, tanto para mãe como para o filho.

Os eventos adversos em uma maternidade variam bastante. Ocorrem aqueles comuns a todas as organizações de saúde, alguns com menor repercussão para a saúde dos pacientes, mas também são observados eventos graves, como a morte materna e os casos de near miss materno (ou morbidade/morbilidade materna grave). Importante destacar que a maioria pode ser evitada. Assim, iniciativas voltadas para promover melhoria da qualidade do cuidado e da segurança do paciente em serviços obstétricos são capazes de contribuir muito para redução desses casos.

Conforme mencionado ao longo deste livro, conhecer o perfil dos eventos adversos das organizações e os fatores relacionados à prestação do cuidado que influenciam sua qualidade e segurança é um bom começo para pensar na melhoria do cuidado em saúde. Além disso, identificar iniciativas comprovadamente efetivas e analisar sua adequação ao contexto de nossas organizações é um caminho que pode ser útil para alcançar as mudanças necessárias. Isso não é diferente para a área obstétrica, e vale lembrar seu pioneirismo em avaliar a efetividade do cuidado (Chalmers 1989).

Neste capítulo, serão abordadas algumas questões específicas dos serviços obstétricos, na intenção de aproximar conceitos e ampliar as pos- 
Morte materna é definida, segundo a Organização Mundial da Saúde (OMS), como a morte de uma mulher durante a gestação ou dentro do período de 42 dias após o término da gestação, independentemente da duração ou da localização da gravidez, em razão de qualquer causa relacionada com ou agravada pela gravidez ou por medidas que se referem a ela, porém não em virtude de causas acidentais ou incidentais (OMS 1995, p. 143)
No Capítulo 3, "Taxonomia em segurança do paciente" deste livro, é possível a você recordar a definição de evento sentinela.
Razão de Mortalidade Materna (RMM) é o número de óbitos maternos, por cem mil nascidos vivos de mães residentes em determinado espaço geográfico, no ano em questão (RIPSA 2010). sibilidades de desenvolvimento e adaptação de iniciativas voltadas à melhoria da qualidade do cuidado e da segurança do paciente.

\section{A morte materna como problema a ser enfrentado em todo o mundo}

A preocupação com a qualidade e a segurança da atenção ao parto não é nova. A morte materna já foi tema de romances, pois se tratava de uma situação bastante comum e aceita como vontade divina até o final do século XIX e início do século XX (Chamberlain 2006).

Muitos avanços já foram alcançados na área da Saúde; no entanto, ainda hoje, deparamo-nos com a tragédia da morte materna que traz graves repercussões às famílias e ativa o ciclo da pobreza na sociedade. Nas organizações de saúde, gera angústia, conflitos e tensão entre os membros das equipes e pacientes. Pelo simples fato de engravidar, processo natural da reprodução humana, a mulher assume uma carga de risco que vem sendo negligenciada, pois a maior parte dessas mortes poderia ser evitada (Cecatti et al. 1999).

A morte materna constitui-se em grave violação dos direitos humanos e traz à tona o fato de que o Estado não cumpre seu dever de proteção à vida e à saúde da mulher; além disso, expõe a desigualdade entre gêneros na sociedade (Reis et al. 2011).

A ocorrência de uma morte materna alerta que houve alguma falha no cuidado prestado e deve deflagrar um conjunto de medidas a fim de que suas causas sejam esclarecidas e corrigidas. Por isso, a morte materna é considerada um evento sentinela, e pode ser tomado como indicador da qualidade do sistema de saúde, em especial relacionado ao acesso aos serviços de saúde, à adequação e à oportunidade do cuidado (Benagiano, Thomas 2003).

A mortalidade materna global se mantém em patamares extremamente elevados - cerca de 830 mulheres morreram, a cada dia, no ano de 2015 por complicações na gestação e no parto. Entre os anos 1990 e 2015, houve redução de $44 \%$ das mortes maternas em todo o mundo; no entanto, essa queda foi bastante aquém da prevista pelos Objetivos de Desenvolvimento do Milênio (ODM), e o progresso diferiu entre as diferentes regiões do mundo (Liu et al. 2016).

Nos países com economias mais avançadas, a Razão de Mortalidade Materna (RMM) está em torno de 12/100 mil nascidos vivos, enquanto, nos países com menor índice de desenvolvimento, alcança a cifra 
absurda de 239/100 mil nascidos vivos. As diferenças também estão presentes em um mesmo país. As regiões com maior grau de urbanização e famílias com maiores rendimentos, em geral, apresentam menores valores para esse indicador. As mulheres mais pobres e que vivem em países com menos recursos são as mais afetadas, o que revela a persistência da iniquidade no acesso às organizações de saúde, bem como o contraste entre os países ricos e pobres. (WHO 2016).

No Brasil, houve avanços importantes e redução de 58\% das mortes maternas nesse período. No entanto, de acordo com os dados do Portal ODS, existe variação considerável entre os estados, e alguns mantêm cifras muito altas, acima de 80 óbitos maternos a cada 100 mil nascidos vivos (http://portalods.com.br/noticias/mortalidade-materna-cresce-no-brasil/)

Quanto às causas das mortes maternas, cada país apresenta um quadro particular. Em países mais desenvolvidos, as doenças cardiovasculares e a tromboembolia venosa, por exemplo, ganham maior destaque. De certa forma, a composição desse quadro reflete o grau de avanço na qualidade do cuidado prestado à mulher durante todo o ciclo gravídico puerperal. Assim, causas que podem ser facilmente evitadas, cujas medidas de prevenção, controle e tratamento são sobejamente conhecidas, não figuram entre as mais prevalentes nesses países.

No Brasil, as quatro causas principais de morte materna são: transtornos da pressão arterial (eclampsia e pré-eclampsia), hemorragia pós-parto, infecções e o aborto inseguro. Elas respondem por $80 \%$ das mortes. É importante destacar que, para essas causas, já se dispõe há muito de conhecimento e de tecnologias para seu enfrentamento (Ronsmans, Graham 2006).

A partir da avaliação das metas dos ODM e da constatação de que apenas parte do objetivo de redução da mortalidade materna foi alcançada, uma nova estratégia foi desenvolvida objetivando acelerar seu declínio. Em 2016, a Organização das Nações Unidas (ONU) lançou a Agenda 2030, com 17 Objetivos de Desenvolvimento Sustentável (ODS) a serem alcançados até 2030. O terceiro objetivo está voltado para garantir vidas saudáveis e promover o bem-estar de todos em todas as idades e, entre suas metas, estão: reduzir a mortalidade materna global para menos de 70/100 mil nascidos vivos, e a mortalidade neonatal para menos de 12/100 mil nascidos vivos. 
Para praticar

O que significa usar a RMM como indicador do ODS?

Tomando seu município como referência, verifique qual foi a redução da mortalidade materna alcançada entre 1990 e 2015. Explique o quadro encontrado.

O que esse quadro mostra sobre a posição da mulher na sociedade?
A pesquisa/investigação Nascer no Brasil (2009) estimou que a incidência de near miss materno, no período de fevereiro de 2011 a outubro de 2012, foi 10,21 por mil nascidos vivos e destacou a importância de qualificar os serviços de assistência ao parto para a redução da morte materna.

\section{Outros eventos relacionados à gravidez e ao parto}

Alguns autores têm alertado para o fato de a morte materna ser apenas a ponta de um iceberg (Laurenti 1988). Segundo Geller e colegas (2004), entre a gestação saudável e a morte materna, há um continuum de resultados não fatais também muito importantes.

De acordo com o estudo de Callaghan e colegas (2008), a morbidade/ morbilidade materna grave (near miss materno) é 50 vezes mais comum que a morte materna e pode causar danos importantes, muitas vezes de caráter permanente. No Capítulo 3, “Taxonomia em segurança do paciente", deste livro, soubemos que near miss, segundo a classificação da OMS, significa o incidente que não atingiu o paciente. Mas o near miss materno é um conceito diverso. Diz respeito às situações em que mulheres apresentam complicações potencialmente letais durante a gravidez, parto ou puerpério, e só sobrevivem em razão do acaso ou do cuidado de saúde prestado. Embora tenha sido cunhado por Stones et al., em 1991, até hoje, no entanto, discute-se quais os critérios mais adequados para classificar os quadros como ameaçadores da vida (Stones et al. 1991).

A atenção é fator essencial, pois nem todo caso de near miss materno pode ser considerado um evento adverso. Nem sempre é possível ser identificado um evento ou circunstância (incidente) que tenha levado ao quadro grave apresentado pela mulher. No entanto, outras vezes, verifica-se que algumas medidas de proteção e prevenção (por exemplo, avaliação do risco da gestante para eclampsia, hemorragia, infecção ou queda) não foram adotadas ou os protocolos não acionados. Nesses casos, a não identificação do risco e a não adoção de medidas em tempo hábil estão claramente relacionadas à evolução e à gravidade dos casos, podendo, portanto, ser considerados eventos adversos. 
Berg e colegas (2009), valendo-se de uma base de dados americana, estimaram as taxas de morbidade/morbilidade intraparto ocorridas durante os anos de 2001 a 2005, comparando-as com aquelas obtidas em estudo anterior, para o período de 1993 a 1997. Observaram que, em ambos os períodos, quase $29 \%$ das internações/internamentos para o parto apresentaram algum tipo de complicação.

Além dos incidentes comuns a outros serviços de saúde, como quedas, e aqueles relacionados a medicamentos e transfusões de sangue e hemocomponentes, há um conjunto de incidentes com lesão - eventos adversos - típicos, embora nem sempre exclusivos, dos serviços obstétricos. Podem ser eventos adversos graves, como morte materna, hemorragia pós-parto, eclampsia, ruptura uterina e infecções puerperais, mas, também, eventos adversos de menor gravidade, como lacerações de períneo, cefaleia pós-raquianestesia e fistulas vaginais, que podem surgir em períodos posteriores (Cunningham et al., 2012).

Ainda que esses eventos adversos não signifiquem risco de morte para as mães, não devem ser desconsiderados, já que trazem desconforto à vida social, sexual e reprodutiva, além de apresentarem a possibilidade de permanecer por longo tempo.

\section{Papel das organizações de saúde}

As mudanças no cuidado obstétrico foram muitas ao longo do tempo. O emprego de manobras obstétricas e dos vários tipos de fórceps está descrito desde antes do século XVII. O ato de lavar as mãos para atender a parturiente, proposto por Semmelweiss, e o uso do estetoscópio de Pinard foram introduzidos no século XIX. Data do século XX, a incorporação do clorofórmio e da ocitocina na prática obstétrica (Drife 2002). Atualmente, fazem parte do arsenal da obstetrícia muitas outras tecnologias, tais como: exames de imagem, monitoramento cardíaco fetal com o cardiotocógrafo, vários tipos de medicamentos e de técnicas cirúrgicas entre outros.

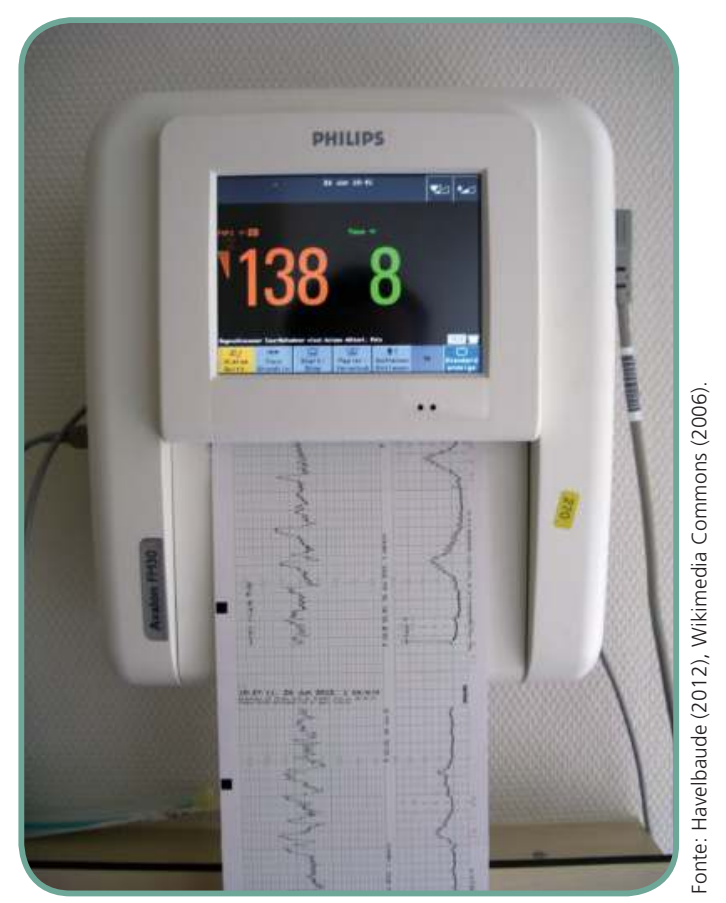


Os conceitos de uso excessivo (overuse), uso insuficiente (underuse) e uso inadequado (misuse) já foram apresentados no Capítulo 1, "Qualidade do cuidado em saúde", deste livro.
Essas tecnologias trouxeram benefícios inquestionáveis, mas podem gerar uma série de problemas. Quando seu uso é abusivo, com aplicação fora das indicações para as quais foram previstas, é possível que afetem os resultados de modo desfavorável. Para tanto, é necessário que a utilização das tecnologias seja pautada no conhecimento científico estabelecido e precedida de um balanço entre riscos e benefícios; no caso da atenção ao parto, tal cálculo envolve dois pacientes, o que torna a tarefa bastante complexa. Exemplo clássico dessa situação é a cesariana. Existem indicações precisas sobre sua utilização e, se corretamente indicada e realizada, produz benefícios tanto para mãe como para o filho. É sabido, no entanto, que a cesariana tem sido utilizada de forma abusiva em muitos países, o que possibilita resultar em eventos adversos graves e gerar custos adicionais aos sistemas de saúde (Villar et al. 2006).

\section{Para praticar}

Pense numa situação de uso insuficiente (underuse) de uma tecnologia/ procedimento na área obstétrica e procure identificar os fatores que podem influenciar essa subutilização.

Os serviços obstétricos guardam especificidades e, ainda que a gravidez e o parto sejam processos fisiológicos, podem ocorrer emergências que necessitem de respostas rápidas.

Os serviços de saúde e seus profissionais precisam estar preparados para assistir tanto à mãe como ao bebê e, com esse objetivo, devem ter capacidade de coordenação de pessoas, equipamentos e processos de trabalho bem estabelecidos. O acesso a serviços obstétricos bem estruturados e em tempo hábil é essencial para garantir um parto e nascimento seguros.

Thaddeus e Maine (1994) apontaram a relação entre a morte materna e a demora na decisão de buscar assistência médica, a demora em ter acesso ao serviço de saúde e, ainda, a demora em receber o tratamento adequado no momento oportuno ("modelo dos três atrasos"). Amorim e colegas (2008) sustentam que esse modelo também se aplica para explicar parte dos casos de near miss materno.

A relação dos fatores sociodemográficos e clínico-obstétricos com os resultados da atenção ao parto tem sido bastante estudada. É necessário aprofundar os estudos e a compreensão sobre os fatores assistenciais relacionados às organizações de saúde e aos arranjos que estrutu- 
ram o sistema de saúde. Geller e colegas (2004) afirmam que esses fatores exercem importante papel à rapidez da progressão da mulher no continuum da saúde materna (Figura 1). É possível, por meio de intervenções no sistema de saúde, nas organizações de saúde e em seus procedimentos, protocolos e rotinas, modificar o comportamento desses fatores e produzir melhorias na qualidade dos serviços, tornando-os mais efetivos, seguros e eficientes.

Figura 1 - Fatores de risco relacionados ao continuum da saúde materna

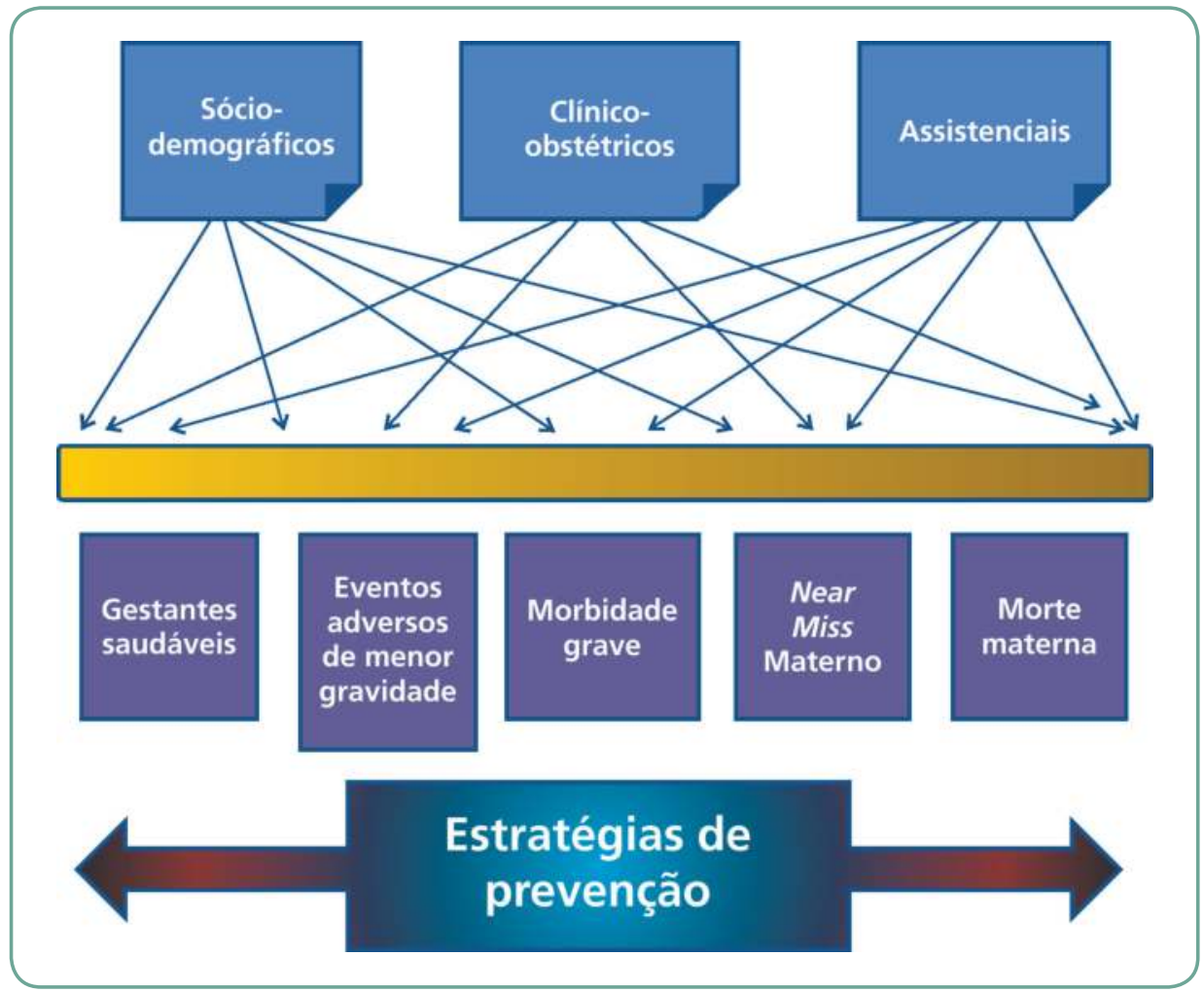

Fonte: Reis (2011)

Como já mencionado em outros capítulos, todas as organizações de saúde devem conhecer seu perfil de incidentes e, em particular, dos eventos adversos, além de estudar as causas e os fatores que contribuem para sua ocorrência. Uma abordagem sistêmica com o objetivo de identificar, analisar e classificar os incidentes é fundamental, pois ajuda a direcionar o foco das intervenções para a redução e prevenção desses eventos.

No que diz respeito aos serviços obstétricos, podem ser destacados, no caso da atenção ao parto, vários fatores que contribuem para a ocorrência de eventos adversos e devem ser controlados. No Quadro 1, estão alguns deles, relacionados tanto à estrutura como ao processo de trabalho dos serviços obstétricos.
Revisite o Capítulo 1, "Qualidade do cuidado de saúde", deste livro para relembrar a avaliação da qualidade com base na estrutura, processo e resultado. 
Quadro 1 - Fatores contribuintes relacionados à estrutura e ao processo na área obstétrica

\begin{tabular}{|l|l|}
\hline Estrutura & Processo \\
\hline $\begin{array}{l}\text { Recursos humanos (nº de profissionais, formação dos } \\
\text { profissionais, composição da equipe, escalas de trabalho) }\end{array}$ & Treinamentos específicos e periódicos \\
\hline $\begin{array}{l}\text { Equipamentos/instrumental compatível com o perfil } \\
\text { assistencial e o número de partos e intervenções obstétricas } \\
\text { realizadas }\end{array}$ & $\begin{array}{l}\text { Trocas de plantão/turno estruturadas com incorporação de técnicas de } \\
\text { comunicação e transmissão de informações relevantes } \\
\text { Adesão e implementação dos protocolos clínicos }\end{array}$ \\
\hline Transporte disponível para mãe e o recém-nato. & Implementação de rotinas e adesão aos procedimentos operacionais \\
\hline Serviços de apoio (hemoterapia, laboratório) & $\begin{array}{l}\text { Fornecimento de serviços de apoio em tempo hábil - exames, } \\
\text { hemocomponentes e medicamentos }\end{array}$ \\
\hline Instalaçães físicas e sua conservação. & Organização e completude dos prontuários/processos clínicos \\
\hline Relação de medicamentos, com protocolos de uso. & $\begin{array}{l}\text { Incentivo e orientação para o uso de técnicas não farmacológicas de } \\
\text { controle da dor }\end{array}$ \\
\hline Modelo de atenção ao parto* - diretrizes e protocolos. & Presença de acompanhante em todas as fases do trabalho de parto e parto \\
\hline
\end{tabular}

Fonte: Elaborado pela autora.

* Para Robbie Davis-Floyd (1998), a assistência ao parto poderia ser classificada em três modelos distintos: tecnológico, humanista e holístico. Variam em relação à composição da equipe assistente, à intensidade do uso de tecnologia, local do parto, o papel que a mulher desempenha em todo o processo, entre outros elementos.

A forma como o sistema de saúde está estruturado também pode afetar os resultados. Suas características quanto à universalidade, descentralização, distribuição, cobertura da rede de serviços e financiamento são alguns dos fatores que interferem na qualidade da atenção ofertada. Outros fatores contribuintes estão relacionados ao modelo de atenção ao parto, tais como:

紫 local do parto;

影 tipo de profissional assistente;

瞵 tipo de parto;

滕 técnicas de indução/aceleração do parto;

粰 uso de episiotomia, analgesia e de outras tecnologias.

\section{Para praticar}

Qual é o modelo de atenção ao parto em sua região? Informe-se a respeito da composição das equipes, o local preferencial de parto, os métodos utilizados para o alívio da dor, sobre a presença de acompanhantes e outras características que julgar relevantes.

Procure saber a taxa de cesariana de sua região. Que fatores contribuem para o valor observado referente a essa taxa? 


\section{Qualidade nos serviços obstétricos}

Como já mencionado, Donabedian (1990) é considerado o autor clássico da área da qualidade do cuidado de saúde. Sua definição de qualidade está assentada sobre os sete pilares, e sua proposta de avaliação baseia-se na tríade estrutura, processo e resultado.

O conceito de qualidade foi discutido anteriormente, seu caráter multidimensional ressaltado, assim como foram apontadas as modificações que vem sofrendo a partir das contribuições de diversos autores. O Institute of Medicine (IOM), no relatório Crossing the quality chasm: a new health system for the 21st Century (IOM 2001), que sugeriu mudanças para o sistema de saúde americano voltadas à melhoria de sua qualidade, apontou as seguintes dimensões desse conceito: segurança, efetividade, centralidade do paciente, oportunidade, eficiência e equidade.

Alguns autores propõem que essas dimensões sejam transpostas para a área de atenção obstétrica (Carter et al. 2010), e pode-se afirmar ser o cuidado ótimo, nesse caso, aquele considerado:
No Capítulo 1, "Qualidade do cuidado de saúde", deste livro, já tratamos desse assunto. Volte a ele para relembrar o relatório que incluiu a segurança do paciente como uma dimensão da qualidade.

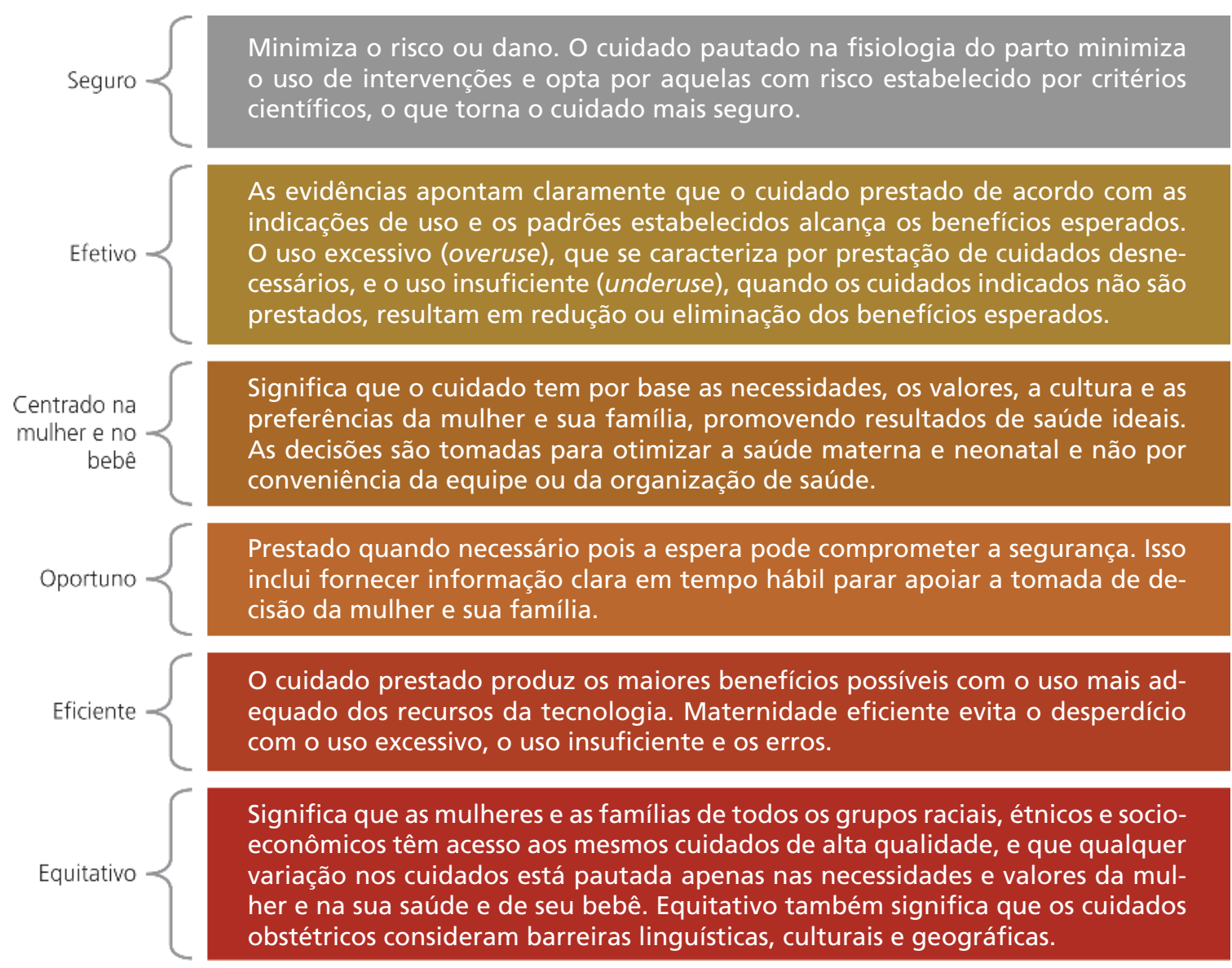


Sobre direitos reprodutivos, indicamos a leitura do documento Direitos sexuais e direitos reprodutivos: uma prioridade do governo, disponível em: http://bvsms.saude.gov.br/bvs/ publicacoes/cartilha_direitos_ sexuais_reprodutivos.pdf
Os dois campos são igualmente relevantes, mas o segundo merece ênfase para a área obstétrica, pois o trabalho de parto é um processo que pode gerar angústia e insegurança; estabelecer uma relação respeitosa de apoio e encorajamento, com base numa comunicação aberta e transparente, permite construir uma relação de confiança, entendida como elemento-chave para a qualidade do cuidado e a segurança do paciente.
Também foi proposta uma adaptação do conceito de qualidade para o contexto dos serviços obstétricos. Hulton e colegas (2000) enfatizaram duas dimensões relevantes - oportunidade e adequação - ao definirem qualidade como:

“[...] grau em que os serviços maternos aumentam a probabilidade de que o tratamento oportuno e adequado, consistente com o conhecimento científico corrente, alcance os resultados esperados e respeite os direitos reprodutivos" (Hulton et al. 2000, p. 9, tradução nossa).

\section{Para refletir}

O que você conhece acerca dos direitos reprodutivos? Como esses direitos vêm sendo garantidos pelo Estado brasileiro?

Essa ênfase direcionada à adequação e oportunidade do tratamento se justifica pelas características especiais envolvidas no trabalho de parto. De acordo com o modelo dos três atrasos, citado anteriormente, essas duas dimensões influenciam sobremaneira nos resultados obtidos. A gestante que não obtém o cuidado adequado na hora em que precisa pode sofrer danos irreparáveis, assim como seu bebê. Do mesmo modo, a adoção de práticas que não estejam fundamentadas no conhecimento científico, com eficácia, efetividade e segurança estabelecidas, pode trazer riscos desnecessários.

Outro ponto merece ser lembrado. Donabedian dividiu a qualidade em dois campos distintos do cuidado de saúde:

O primeiro deles diz respeito à qualidade técnica do cuidado, sendo considerado cuidado de alta qualidade técnica quando os pacientes são submetidos somente a procedimentos, testes ou serviços cujos benefícios excedem, por uma margem suficientemente ampla, os riscos e quando são executados com alto grau de excelência técnica.

O $\mathrm{O}$ segundo campo refere-se à relação estabelecida entre equipe de saúde e paciente, a forma como são tratados os pacientes, obedecendo a valores, normas e expectativas dos pacientes e dentro dos princípios éticos (Donabedian 1980). 


\section{Problemas relacionados aos serviços obstétricos - conhecer, medir e monitorar}

As organizações de saúde que procuram melhorar a qualidade dos cuidados prestados precisam conhecer bem sua realidade. Fazer uma autoavaliação, tendo como orientação padrões de qualidade estabelecidos pela autoridade sanitária ou por organismos de acreditação, é considerada uma iniciativa proveitosa. Importante, ainda, os aspectos relacionados à estrutura e ao processo, alguns apontados no Quadro 1, serem avaliados, e suas falhas e deficiências identificadas para orientar intervenções e investimentos.

Saber como cada etapa do processo de trabalho é realizada e a forma como elas se interligam, que profissionais estão envolvidos e quais as suas atribuições, como também examinar protocolos e procedimentos operacionais padrão ajuda a conhecer a organização dos serviços de saúde. Além do uso de padrões pré-estabelecidos, entrevistas com profissionais e pacientes possibilitam contribuir para compreender, de forma mais abrangente, aspectos relacionados ao processo de trabalho, às expectativas e às vivências experimentadas nos serviços de saúde.

Resta, ainda, conhecer os resultados que as organizações apresentam. Alguns indicadores podem ser bastante úteis, como as taxas de infecção hospitalar, de cesariana, de reinternação/reinternamento, o número de transfusões/100 partos, o tempo médio de permanência, entre outros. Os indicadores selecionados podem compor um painel que permita ao grupo gestor e aos profissionais tomar consciência acerca de seu trabalho e monitorar mudanças e variações, considerando sua complexidade e a posição que ocupam dentro da rede de serviços oferecida à população.

As análises da tríade estrutura, processo e resultado e do contexto organizacional permitem elaborar estratégias e intervenções para a melhoria do cuidado e da segurança do paciente, e seu impacto pode ser medido e monitorado por um conjunto de indicadores.

\section{Para praticar}

Selecione cinco indicadores de resultados que julga serem relevantes objetivando monitorar um serviço obstétrico. Justifique sua seleção e comente as limitações de seu uso, a dificuldade/necessidade de dados para sua construção. 


\section{Alguns fatores da estrutura que contribuem para o cuidado seguro}

Uma das questões mais discutidas, quando se estuda os serviços obstétricos, é o acesso. A identificação de barreiras de acesso, que podem ser de diferentes naturezas (geográfica, econômica, cultural, por exemplo), é fundamental, já que a demora em fornecer o cuidado adequado pode gerar danos às mulheres e aos bebês (Dartnall et al. 2005). Mapear como a rede de serviços está geograficamente localizada e as alternativas de transporte disponíveis é primordial a fim de se obter um plano de referência que minimize o tempo para se chegar a esses serviços quando deles se precisa.

A composição e o número de integrantes das equipes é um item da estrutura que, muitas vezes, está comprometido. A área da obstetrícia tem enfrentado, ao longo dos últimos anos, uma avalanche de queixas judiciais, fazendo com que diminuísse o número de especialistas em vários países (WHO 2008). A figura da parteira licenciada ou da enfermeira obstetriz ainda não é consolidada em alguns sistemas de saúde. Assim, sem profissionais com formação e perfil adequados para atuar nessa área, compor equipes de forma satisfatória não é tarefa fácil. Essa dificuldade pode gerar sobrecarga de trabalho, cansaço e ser responsável por erros no processo de trabalho. Além disso, não são incomuns relatos de mulheres que se sentem abandonadas e sem orientação durante o período do pré-parto (Dias, Deslandes 2006).

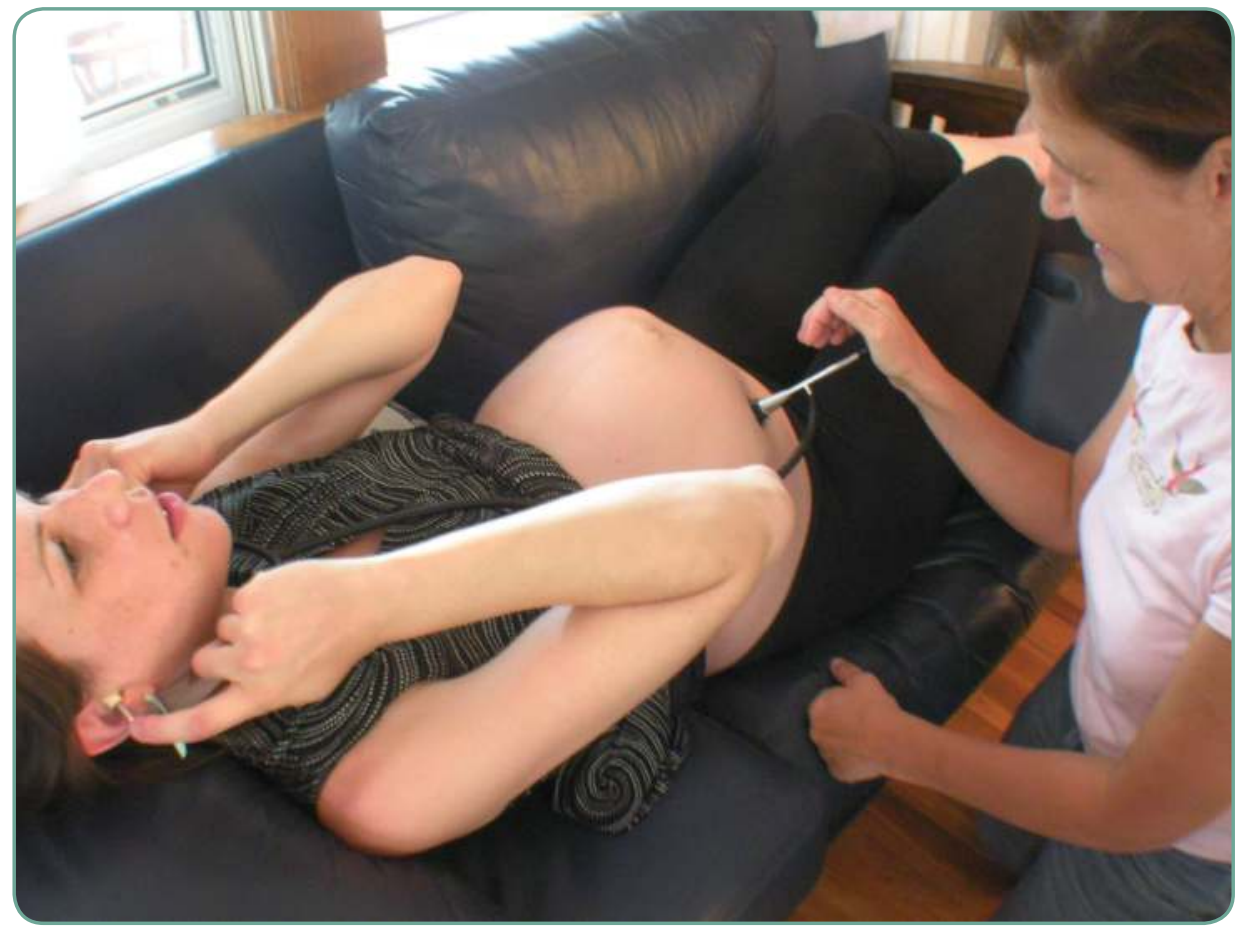

Fonte: Wikipedia (2010) 
Programas de treinamento são escassos, em especial aqueles voltados para preparar a equipe multiprofissional (Magluta et al. 2009). Equipes de saúde precisam conhecer e aplicar técnicas de comunicação no trabalho e desenvolver capacidade de cooperação. Saber relatar um caso de forma objetiva, clara e completa, atuar em equipe, assumir a liderança em determinadas situações podem ser objeto de treinamento, como em outras áreas em que é preciso boa coordenação do processo de trabalho para respostas rápidas e precisas. Na área obstétrica, há relatos de uso de manequins para treinamentos e simulações desde o século XVIII (Rosen 2008). Hoje, algumas iniciativas começam a ser mais disseminadas.

Instalações físicas têm sido frequentemente apontadas como inadequadas, pois não permitem privacidade nem uso de técnicas não farmacológicas para o alívio da dor, tampouco a presença de acompanhante, considerado bastante relevante para a segurança da paciente (Carman et al. 2013).

A disponibilidade de equipamentos é mais um dos elementos da estrutura que conta na repercussão dos desfechos clínicos. Para cada perfil de complexidade de serviço obstétrico, é preciso o acesso a um conjunto de tecnologias que garanta o cuidado às mães e aos bebês em tempo oportuno.

Outros elementos relativos à estrutura dos sistemas e serviços de saúde, tais como a definição prévia de mecanismos de referência, existência de transporte de pacientes, acesso garantido às tecnologias essenciais (hemocomponentes, exames laboratoriais e medicamentos), frequentemente são apontados como questões problemáticas (Magluta et al. 2009).

\section{Alguns fatores do processo que contribuem para o cuidado seguro}

O uso de tecnologias sem considerar as evidências científicas pode resultar em eventos adversos e desperdício de recursos. O uso indiscriminado de tecnologias é objeto de relato de diversos autores, em vários países (Bosch 1998; Johanson et al. 2002; D’Orsi et al. 2005). O exemplo mais citado é a cesariana, mas existem outras intervenções, por exemplo, enemas, tricotomia, ocitocina venosa, ainda usadas de forma incontrolada. No entanto, não executar alguns procedimentos também possibilita a ocorrência de eventos adversos. A adoção de práticas efetivas para o manejo do parto, como presença de acompanhante, controle não farmacológico da dor, são pouco incorporadas (Parada, Carvalhaes 2007). 
Em função da falta de cursos para preparação das equipes de saúde, as falhas na comunicação entre os membros das equipes são queixas frequentes e apontadas como fatores que contribuem para a ocorrência de eventos adversos também na área obstétrica (White et al. 2005).

A não realização de atividades coletivas com o objetivo de discutir o processo de trabalho impede que: o trabalho de cada membro da equipe seja reconhecido, haja compartilhamento de objetivos e se estabeleça uma relação cooperativa.

O cumprimento de rotinas e protocolos é crucial, bem como sua revisão. Seu descumprimento, sua modificação e a criação de atalhos necessitam ser discutidos abertamente. O uso de algumas tecnologias ou procedimentos sabidamente ineficazes ou prejudiciais precisa ser abandonado. Esse conjunto de tecnologias é bastante amplo e fazem parte dele: o uso rotineiro de enema, tricotomia, infusão venosa de ocitocina durante o trabalho de parto, episiotomia, cateterização vesical, restrição de alimentos e fluidos durante o trabalho de parto e a manobra de Valsalva durante o segundo estágio do trabalho de parto (WHO 1996).

No entanto, procedimentos sabidamente benéficos precisam ser incentivados no cotidiano. Higienizar as mãos e usar luvas, avaliar o risco da gestante, medir a pressão arterial repetidamente durante toda a internação/internamento com registro da medida, avaliar e registrar a evolução do trabalho de parto a intervalos adequados, verificando dilatação e apagamento do colo uterino, descida do feto pelo canal do parto, batimentos cardíacos do feto, observar sangramento no período pós-parto. Essas são medidas simples, efetivas e seguras. Além disso, compartilhar com a mulher e a família as informações sobre a evolução do trabalho de parto traz tranquilidade e confiança. Discutir as condutas, tornando claros os benefícios e riscos, favorece a confiança e a segurança, permite que a mulher faça suas escolhas de modo responsável, sem colocar em risco sua vida ou a do bebê.

\section{Iniciativas para promover a melhoria do cuidado e a segurança do paciente em maternidades}

Existem, hoje, diversas iniciativas em curso. São propostas tanto de âmbito local como nacional, voltadas para melhorar a qualidade do cuidado, isto é, torná-lo mais seguro, efetivo, centrado na paciente, oportuno, eficiente e equitativo. 


\section{Evidência científica como base para definição de diretrizes e protocolos clínicos}

Para orientar a tomada de decisão sobre mudanças necessárias à melhoria da qualidade do cuidado e da segurança do paciente em maternidades, já existe disponível um alentado conjunto de evidências acerca da eficácia e segurança das intervenções no trabalho de parto. Atualmente, Cochrane Collaboration, organização independente dedicada à produção de informação confiável sobre cuidados de saúde, dispõe de diversas revisões sistemáticas (RS) a respeito das intervenções na área obstétrica que devem servir de base para a definição de protocolos clínicos e rotinas de cuidado.

A OMS publicou, na década de 1990, o relatório sobre o cuidado ao parto normal, Care in normal birth: a practical guide (WHO 1996), e, com base em revisões sistemáticas sobre as intervenções utilizadas na obstetrícia, propôs que essas fossem classificadas em quatro categorias:
Vale a pena lembrar que há uma gradação dos estudos quanto à força da evidência científica. Procure saber que gradação é essa.

a) Práticas que são comprovadamente úteis e devem ser incentivadas.

b) Práticas que são claramente danosas ou ineficazes e devem ser

abandonadas.

c) Práticas para as quais não existem evidências suficientes para permitir

sua recomendação clara e que devem ser utilizadas com reserva, enquanto pesquisas adicionais não esclarecem a questão.

d) Práticas que são frequentemente usadas de forma inadequada.

O escopo de cada grupo pode e deve ser periodicamente atualizado e discutido por toda a equipe para que sejam feitas as revisões de protocolos de atenção obstétrica.

Com a intenção de que o cuidado seja efetivo, isto é, realize o maior benefício possível em condições normais de trabalho, as indicações de uso das tecnologias devem ser respeitadas, as boas práticas adotadas

Boas práticas são as técnicas identificadas como as melhores em termos de eficácia, eficiência e segurança e, por isso, embora não se tratem de uma norma obrigatória, são altamente recomendáveis. 
No Capítulo 9, "Investigação/ pesquisa em segurança do paciente", do livro Segurança do paciente: criando organizações de saúde seguras, veremos em mais detalhes os métodos de detecção de incidentes.

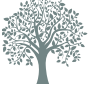

A fim de conhecer melhor os instrumentos para avaliação do cuidado materno e identificação de eventos adversos, acesse: Immpact Toolkit: a guide and tools for maternal mortality programme assessment. Disponível em: https://www. gov.uk/dfid-research-outputs/ immpact-toolkit-a-guide-andtools-for-maternal-mortalityprogramme-assessmentversion-2 e as habilidades e competências profissionais reforçadas por meio de treinamentos periódicos e específicos.

\section{Para praticar}

Identifique pelo menos três exemplos de intervenções para cada uma das categorias propostas pela OMS no relatório Care in normal birth: a practical guide (WHO 1996).

Reflita sobre os possíveis eventos adversos que podem ser evitados com a adoção ou abandono de algumas delas.

\section{Conhecer a organização de saúde}

Conhecer a organização de saúde, suas fragilidades e potencialidades, os recursos de que dispõe, seus processos de trabalho, seus resultados e o papel que desempenha na rede de atenção e no sistema de saúde é essencial para a melhoria da qualidade. Além disso, a existência de um diagnóstico inicial orienta as estratégias de intervenção.

Entre as metas de qualquer programa voltado à segurança do paciente está a de reduzir a ocorrência de incidentes. Por essa razão, é preciso conhecer o perfil dos incidentes, as causas e fatores que contribuem para sua ocorrência. A adoção de um método de detecção de incidentes e, em especial, dos eventos adversos tem sido apontada como um dos elementos da intervenção para a melhoria do cuidado e da segurança do paciente. Em geral, são métodos retrospectivos, baseados na análise estruturada de prontuários/processos clínicos, mas podem também ser técnicas prospectivas, como a observação direta e as rondas clínicas. A notificação/reporte voluntária e anônima da ocorrência de incidentes é outra possibilidade de conhecer o que ocorre na organização. A opção por qualquer uma das técnicas disponíveis deve ser orientada pela natureza e características das organizações.

Cada um desses métodos apresenta vantagens e desvantagens. Isoladamente, nenhum deles é capaz de identificar toda gama de incidentes que ocorrem em uma organização de saúde. A combinação de métodos potencializa a capacidade de detecção dos incidentes, permitindo uma visão mais próxima da realidade da organização de saúde analisada (Jeffs et al. 2007).

O Quadro 2 apresenta a síntese de alguns instrumentos voltados para conhecer a realidade dos serviços obstétricos, não apenas para a identificação de eventos adversos e morte materna, mas também na intenção de identificar outras consequências do cuidado e a percepção sobre sua qualidade. 
Quadro 2 - Instrumentos para avaliação do cuidado materno e identificação de eventos adversos

\begin{tabular}{|c|c|c|}
\hline Nome da Técnica & Uso & Descrição \\
\hline Sampling at Service Sites (SSS) & Medir a mortalidade materna & $\begin{array}{l}\text { Estratégia para captar dados sobre mortes } \\
\text { maternas em que os pesquisadores/investigadores } \\
\text { visitam os locais onde se encontra grande número } \\
\text { de mulheres potencialmente expostas, tais como } \\
\text { serviços de saúde. }\end{array}$ \\
\hline $\begin{array}{l}\text { Tracing adverse and favourable } \\
\text { events in pregnancy care } \\
\text { (Trace) }\end{array}$ & $\begin{array}{l}\text { Medir e descrever a mortalidade materna, } \\
\text { morbidade/morbilidade e a qualidade dos } \\
\text { serviços de cuidado obstétrico }\end{array}$ & $\begin{array}{l}\text { Inquéritos para rastrear eventos adversos ou } \\
\text { desfavoráveis no cuidado obstétrico. Obtenção de } \\
\text { informação qualitativa sobre os casos de morte } \\
\text { materna; morbidade/morbilidade materna grave } \\
\text { (near miss) e, se necessário, casos normais e outras } \\
\text { complicações. }\end{array}$ \\
\hline $\begin{array}{l}\text { Perceptions of Quality of Care } \\
\text { (PQOC) }\end{array}$ & $\begin{array}{l}\text { Medir e descrever a qualidade dos serviços de } \\
\text { cuidado obstétrico }\end{array}$ & $\begin{array}{l}\text { Métodos qualitativos para estudo das percepções } \\
\text { dos membros da comunidade e provedores em } \\
\text { relação a barreiras e facilitadores do cuidado de } \\
\text { boa qualidade. Fornece informação sobre fatores } \\
\text { que podem afetar os cuidados especializados ao } \\
\text { parto. }\end{array}$ \\
\hline $\begin{array}{l}\text { Health Worker Incentives } \\
\text { Survey (HWIS) }\end{array}$ & Avaliar fatores ligados aos sistemas de saúde & $\begin{array}{l}\text { Questões para investigar fatores motivacionais } \\
\text { em profissionais de saúde e outros aspectos do } \\
\text { contexto ligados aos recursos humanos com vistas } \\
\text { a obter medidas de funcionalidade dos serviços. }\end{array}$ \\
\hline $\begin{array}{l}\text { Maternal Death from } \\
\text { Informants (Made-in) and } \\
\text { Maternal Death Follow-on } \\
\text { Review (Made-for) }\end{array}$ & Medir a mortalidade materna & $\begin{array}{l}\text { Técnica de pesquisa que usa informantes para } \\
\text { identificar mortes relacionadas à gravidez, } \\
\text { objetivando estimar a razão de mortalidade } \\
\text { materna e fornecer informações sobre as possíveis } \\
\text { causas de mortalidade. Entrevistas de seguimentos } \\
\text { com familiares das pacientes que foram ao óbito, } \\
\text { confirmando se as mortes são maternas ou não e } \\
\text { explorando as causas e circunstâncias da morte. }\end{array}$ \\
\hline
\end{tabular}

Fonte: Adaptado de Immpact Toolkit: a guide and tools for maternal mortality programme assessment (2010).

A análise de eventos sentinela tem sido apontada como uma iniciativa promissora para conhecer, de forma mais aprofundada, uma organização, na medida em que representam eventos graves, e, geralmente, as autoridades regulatórias exigem que sejam notificados. Na área obstétrica, são considerados eventos sentinela que merecem ser analisados: morte intraparto, morbidade/morbilidade materna grave que tenha 


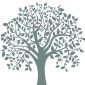

O IHI disponibiliza, em seu site, um instrumento específico com essa técnica (Trigger Tool) para a área perinatal (http://www. ihi.org/knowledge/Pages/Tools/ PerinatalTriggerTool.aspx).

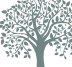

Para conhecer esse instrumento, veja a página da OMS. http://www.who.int/ patientsafety/implementation/ checklists/scc_portuguese/en/ produzido dano permanente ou dano grave temporário, troca de bebês, reação hemolítica transfusional e hiperbilirrubinemia neonatal grave (Pettker 2017).

Existem outros métodos bem conhecidos, como é o caso do modelo proposto pela Agency for Healthcare Research \& Quality (AHRQ), que definiu um conjunto de indicadores (Patient Safety Indicators) e as bases de dados de notificação/reporte voluntária dos serviços de saúde. Há, ainda, um método que gera grande interesse, formulado pelo Institute for Healthcare Improvement (IHI), denominado Trigger Tool, baseado na identificação de elementos (rastreadores) que podem dar pistas de que tenha ocorrido um EA.

A OMS lançou uma lista de verificação (checklist) para melhorar a segurança no parto e nascimento. Esse instrumento sintetiza as recomendações baseadas em sólidas evidências científicas para a atenção ao parto e pretende auxiliar na adesão às boas práticas. Seus itens de verificação estão divididos em quatro partes: na admissão; antes da expulsão (ou antes da cesariana); logo após o parto (no espaço de 1 hora); e antes da alta. Os itens de verificação estimulam o uso do partograma, a atenção com a pressão arterial, a adoção de boas práticas, a comunicação clara com a mãe e o acompanhante, a prontidão para resposta rápida em caso de hemorragia e eclampsia, cuidados com bebê, a estimulação da amamentação precoce, entre outros. Logo, é considerado um bom orientador para o desenho de processos de trabalho e definição de protocolos.

\section{Para refletir}

Em sua região, estão disponíveis os recursos e tecnologias necessários para garantir o parto seguro?

Que outras iniciativas você identifica como efetivas a fim de aumentar a adesão às boas práticas na atenção ao parto?

\section{Coordenação e tarefas bem definidas e desenhadas}

Para que o cuidado seja prestado de modo seguro, deve ser bem organizado, com coordenação e tarefas bem definidas e desenhadas de acordo com os preceitos das boas práticas, sob o princípio da responsabilidade e do trabalho em equipe, com regras de comunicação claras. Desse modo, espera-se que a fragmentação do cuidado, a duplicação de atividades ou a omissão sejam evitadas, uma vez que podem contribuir para a ocorrência de eventos adversos. Entre os princípios que devem 
ser observados está a centralidade do cuidado na paciente, ainda que a coordenação do cuidado mereça ser apreciada por ângulos diversos.

Os serviços obstétricos guardam algumas especificidades. Em certas instituições, há equipes e áreas separadas para as diversas etapas da atenção ao parto. Assim, a admissão da mulher pode ser realizada em um ambiente e por equipe que não vai acompanhá-la por todo o trabalho de parto. Mecanismos de coordenação e estratégias de comunicação entre as equipes devem estar bem definidos, com um plano terapêutico claro e responsabilidades identificadas. Desse modo, espera-se que seja garantida a continuidade do cuidado.

Os treinamentos de equipes na área obstétrica têm se mostrado como iniciativa efetiva, fortalecem a comunicação, a liderança e o compromisso (Merién et al. 2010). Existem disponíveis diversos tipos de treinamentos para as equipes, como pode ser observado no Quadro 3.

Quadro 3 - Treinamentos para equipes multidisciplinares na área obstétrica

\begin{tabular}{|c|c|}
\hline Nome do curso & Descrição \\
\hline $\begin{array}{l}\text { Advances in Labor and Risk } \\
\text { Management (ALARM) }\end{array}$ & $\begin{array}{l}\text { Programa de educação continuada para os prestadores } \\
\text { de cuidados intraparto da Sociedade de Obstetras e } \\
\text { Ginecologistas do Canadá (SOGC). }\end{array}$ \\
\hline $\begin{array}{l}\text { Advanced Life Support in Obstetrics } \\
\text { (ALSO) }\end{array}$ & $\begin{array}{l}\text { Curso multidisciplinar para o gerenciamento de } \\
\text { emergências obstétricas. }\end{array}$ \\
\hline Care Team $O B$ & $\begin{array}{l}\text { Curso institucional para o aprimoramento de habilidades, } \\
\text { preparação para emergências, trabalho em equipe e } \\
\text { melhorias de comunicação. }\end{array}$ \\
\hline $\begin{array}{l}\text { Managing Obstetrical Risks Efficiently } \\
\text { (MORE OB) }\end{array}$ & $\begin{array}{l}\text { Programa abrangente, com três anos de duração, inclui } \\
\text { segurança do paciente e desenvolvimento profissional } \\
\text { para a melhoria de unidades de obstetrícia do hospital. }\end{array}$ \\
\hline $\begin{array}{l}\text { Practical Obstetric Multiprofessional } \\
\text { Training (PROMPT) }\end{array}$ & $\begin{array}{l}\text { Programa de formação multiprofissional inclui parteiras, } \\
\text { obstetras e anestesistas aprovados pelo Royal College } \\
\text { of Midwives e pelo Royal College of Obstetricians and } \\
\text { Gynaecologists (UK). }\end{array}$ \\
\hline STABLE Program & $\begin{array}{l}\text { Curso de pós-ressuscitação / cuidado de estabilização } \\
\text { pré-transporte de crianças doentes. Acrônimo composto } \\
\text { por: S (sugar and safe care) - nível estável de glicemia } \\
\text { e cuidados seguros; T - temperatura; A (airway) vias } \\
\text { aéreas; B (blood pressure) pressão arterial; L (lab work) } \\
\text { exames laboratoriais; E (emotional support) apoio } \\
\text { emocional. }\end{array}$ \\
\hline $\begin{array}{l}\text { Team Strategies and Tools to Enhance } \\
\text { Performance and Patient Safety (Team } \\
\text { STEPPS) }\end{array}$ & $\begin{array}{l}\text { Sistema de trabalho em equipe desenvolvido para os } \\
\text { profissionais de saúde com } \\
\text { foco na melhoria da segurança do paciente, que tem sido } \\
\text { aplicado aos cuidados } \\
\text { de maternidade. }\end{array}$ \\
\hline
\end{tabular}

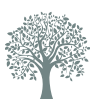

Para conhecer melhor alguns desses cursos, busque:http:// transform. childbirthconnection. org/resources/safetycourses/ 
Quadro 3 - Treinamentos para equipes multidisciplinares na área obstétrica (cont).

\begin{tabular}{|l|l|}
\hline Nome do curso & Descrição \\
\hline CRM - Crew Resource Management & $\begin{array}{l}\text { Programa de treinamento para equipes, especialmente } \\
\text { desenhado para aprimorar a comunicação. }\end{array}$ \\
\hline
\end{tabular}

Fonte: Elaborado pela autora.

A comunicação dos profissionais de saúde será abordada no Capítulo 7, "Comunicação entre os profissionais de saúde e a segurança do paciente", do livro Segurança do paciente: criando organizações de saúde seguras.
As iniciativas para melhorar a coordenação das atividades devem contemplar questões já identificadas como situações de perigo. Do mesmo modo que em outros serviços de saúde, as trocas de plantão/turno são os períodos propensos a ocorrência de eventos adversos (Randell et al. 2011). Organizar a forma como a passagem das informações será realizada, com protocolos de comunicação, é elemento-chave para garantir o cuidado certo. Atualmente, tem se recomendado o uso de ferramentas de comunicação, como o SBAR (Situação, Background, Avaliação, Recomendação), para transferências e mesmo para trocas de plantão/ turno, de modo a garantir que sejam repassadas informações críticas sobre as pacientes (Thomas, Dixon 2012).

Outras ações de caráter organizativo, como a correta identificação dos pacientes, a completude de seus prontuários/processos clínicos, o registro de ocorrências, a rotina de conferências de prescrições, a definição de padrões de comunicação, são algumas das práticas que podem minimizar erros.

\section{Comprometimento das lideranças das organizações de saúde}

Além da base científica, as iniciativas para promover a segurança do paciente devem ter como diretriz o comprometimento das lideranças das organizações de saúde, das famílias e dos pacientes com o cuidado de qualidade, pois é a partir de uma visão ampliada e integradora que podem ser identificadas as lacunas na atenção ao parto que imprimam às iniciativas significado e viabilidade.

O estabelecimento de compromissos e responsabilidades faz parte do arcabouço organizacional para promover a cultura de segurança, que traz a possibilidade de influenciar a ocorrência de eventos adversos. Para alguns autores, a melhoria do clima de segurança é o primeiro passo direcionado a reduzir o risco de o paciente sofrer um evento adverso (Pettker et al. 2009). 
Adotar como dimensão da qualidade do cuidado a centralidade na paciente pressupõe considerar seus valores, sua cultura, respeitar e compreender seus temores e insegurança, oferecer o cuidado digno e respeitoso, bem como estabelecer uma relação de confiança. Se, para os profissionais de saúde, os partos fazem parte da rotina, é preciso considerar que significa uma experiência única para cada mulher e sua família, envolvendo incertezas e diversas situações emocionais, as quais podem necessitar de abordagens individualizadas e cuidados especiais. É papel dos profissionais compartilhar com a mulher e sua família as informações sobre a evolução do trabalho de parto, além de esclarecer os benefícios e riscos das opções de intervenção, encorajando-os a fazer escolhas de modo responsável, sem colocar em risco a vida da mulher ou do bebê (Walsh 2004; Main, Bingham 2008).

A equidade deve ser um princípio básico do cuidado ao parto, assim como de todo o sistema de saúde. As mulheres, sem exceção, têm o direito de receber o cuidado ao parto com o mais alto grau de qualidade disponível, sem haver diferenças que não sejam aquelas determinadas pela necessidade de saúde, valores e escolhas individuais. Nível de escolaridade, etnia e raça, por exemplo, não se constituem em fatores que possam influenciar no tipo de cuidado a ser oferecido às mulheres e seus bebês.

\section{Considerações finais}

O propósito deste capítulo foi apresentar os eventos adversos relacionados à gestação e ao parto - desde a morte materna até as condições menos graves que não ameaçam a vida, mas podem ser compreendidas, inclusive, como violações dos direitos humanos das mulheres. Esses eventos adversos, os incidentes e os fatores contribuintes são bastante conhecidos.

Os gestores das organizações e serviços obstétricos precisam se apropriar do arcabouço teórico conceitual da qualidade em saúde e da segurança do paciente, incorporar métodos para conhecer e monitorar sua realidade, implementar práticas a fim de prevenir incidentes, capacitar as equipes de saúde, envolver os pacientes e criar um ambiente voltado à melhoria da qualidade do cuidado e da segurança do paciente.

Algumas das ferramentas aqui apresentadas podem ser adaptadas e auxiliar na correção de problemas, bem como promover a melhoria da saúde materna e infantil. 


\section{Referências}

Alkema L, Chou D, Hogan D, Zhang S, Moller AB, Gemmill A, et al. Global, regional, and national levels and trends in maternal mortality between 1990 and 2015, with scenario-based projections to 2030: a systematic analysis by the UN Maternal Mortality Estimation Inter-Agency Group. Lancet. 2016 Jan 30;387(10017):462-74.

Amorim MMR, Katz L, Valença M, Araujo DE. Morbidade materna grave em UTI obstétrica noRecife, região nordeste do Brasil. Rev. Assoc. Med. Bras. 2008; 54(3):261-6.

Benagiano G, Thomas B. Safe motherhood: the FIGO initiative. Int J Gynaecol Obstet 2003Sep;82(3):263-74.

Berg CJ, MacKay AP, Qin C, Callaghan WM. Overview of maternal morbidity during hospitalizationfor labor and delivery in The United States: 1993-1997 and 2001-2005. Obstet Gynecol. 2009May;113(5):1075-81.

Bosch X. Spanish doctors criticised for high tech births. BMJ 1998;317:1406.

Callaghan WM, Mackay AP, Berg CJ. Identification of severe maternal morbidity during deliveryhospitalizations, United States, 1991-2003. Am J Obstet Gynecol. 2008 Aug;199(2):133. e1-8.

Carman KL, Dardess P, Maurer M, Sofaer S, Adams K, Bechtel C et al. Patient and familyengagement: a framework for understanding the elements and developing interventions andpolicies. Health Aff. 2013 Feb [citado 2014 jun 28];32:223-1. Disponível em: http://content. healthaffairs.org/content/32/2/223.short - aff-3

Carter MC, Corry M, Delbanco S, Foster TCS, Friedland R, Gabel R et al. 2020 vision for a highquality, high-value maternity care system. Womens Health Issues. 2010 Jan-Fev;20(1 Suppl):S7-17.

Cecatti JG, Faúndes A, Surita FGC. Maternal mortality in Campinas: evolution, under-registration and avoidance. São Paulo Med J. 1999 Jan;117(1):5-12.

Chalmers I, Enkin M, Keirse MJ (editor). Effective care in pregnancy and childbirth. New York: Oxford University Press; 1989. 1516 p

Chamberlain G. British maternal mortality in the 19th and early 20th centuries. J R Soc Med. 2006 [citado 2014 jun 29];99:559-63. Disponível em: http://www.ncbi.nlm.nih.gov/pmc/articles/ PMC 1633559/pdf/0559.pdf.

Cunningham FG, Leveno KJ, Bloom SL, Hauth JC, Rouse DJ, Spong CY. Obstetrícia de Williams. $23^{\mathrm{a} e d}$. Fonseca AV, et al., tradutor. Porto Alegre: AMGH; 2012.

Dartnall L, Ganguly N, Baatterham J. Access to maternity services: research report. Washington,DC: Department of Health; 2005.

Davis-Floyd R, St John G. From doctor to healer: the transformative journey. New Jersey: RutgersUniversity Press; 1998.

Dias MAB, Deslandes SF. Expectativas sobre a assistência ao parto de mulheres usuárias de uma maternidade pública do Rio de Janeiro, Brasil: os desafios de uma política pública de humanização da assistência. Cad. Saúde Pública. 2006 Dec [citado 2019 jan 20];22(12):2647-55. Disponível em: http:// www.scielo.br/scielo.php?script=sci_arttext\&pid=S0102-311X2006001200014\&lng=en\&nrm=iso

Donabedian A. Explorations in quality assessment and monitoring, vol 1: the definition of qualityand approaches to its assessment. Ann Arbor (MI): Health Administration Press; 1980.

Donabedian A. The seven pillars of quality. Arch. Pathol. Lab. Med. 1990;114(11):1115-18. 
D'Orsi E, Chor D, Giffin K, Angulo-Tuesta A, Barbosa GP, Gama AS, et al. Qualidade da atenção aoparto em maternidades do Rio de Janeiro. Rev Saúde Públ. 2005;39(4):645-654.

Drife J. The start of life: a history of obstetrics. Postgrad Med J. 2002;78:311-15.

Geller SE, Rosenberg D, Cox SM, Brown ML, Simonson L, Driscoll CA, et al. The continuumof maternal morbidity and mortality: factors associated with severity. Am J Obstet Gynecol.2004;191(3):939-44.

Hulton AL, Mathews Z, Stones RW. A framework for the evaluation of quality of care in maternityservices. Southampton (UK): University of Southampton, 2000 [citado 2014 jun]. Disponível em:www.scocstats.soton.ac.uk/choices.

Immpact Toolkit: a guide and tools for maternal mortality programme assessment. Aberdeen(Scotland): University of Aberdeen, 2010.

Institute of Medicine [IOM]. Crossing the quality chasm: a new health system for the 21st Century. Washington, DC: National Academy Press, 2001.

Jeffs L, Law MP, Baker GR. Patient measures in acute care settings: report to World Allience forPatient Safety. Geneva: WHO; apr 2007.

Johanson R, Newburn M, Macfarlane A. Has the medicalisation of childbirth gone too far? BMJ2002; 324:892-5.

Laurenti R. Marcos referenciais para estudos e investigações em mortalidade materna. Rev SaúdePúbl. 1988;22(6):507-12.

Leme IL. Iniciativas socioambientais em serviços de saúde: gerenciamento de resíduos. São Paulo: [editora desconhecida]; 2013.

Liu L, Oza S, Hogan D, Chu Y, Perin J, Zhu J et al. Global, regional, and national causes of under-5 mortality in 2000-15: an updated systematic analysis with implications for the Sustainable Development Goals. Lancet. 2016 Dec 17;388(10063):3027-35.

Leme IL. Iniciativas socioambientais em serviços de saúde: gerenciamento de resíduos. São Paulo:[editora desconhecido]; 2013.

Magluta C, et al. Estrutura de maternidades do Sistema Único de Saúde do Rio de Janeiro: desafioà qualidade do cuidado à saúde. Rev Bras Saúde Mater Infant. 2009;9(3):319-29.

Main EK, Bingham D. Quality improvement in maternity care: promising approaches from themedical and public health perspectives. Curr Opin Obstet Gynecol. 2008; 20(6):574-80.

Merién AER, van Ven J, Mol BW, Houterman S, Oei SG. Multidisciplinary team training in asimulation setting for acute obstetric emergencies: a systematic review. Obstet \& Gynecol. 2010May;115(5):1021-31.

Mhyre JM. Maternal mortality. Curr Opin Anaesthesiol. 2012 Jun;25(3):277-85.

Nascer no Brasil. Principais resultados. Rio de Janeiro: ENSP, Fiocruz; 2009 [citado 2019 jan 20]. Disponível em: http://www6.ensp.fiocruz.br/nascerbrasil/principais-resultados2/

Organização Mundial da Saúde [OMS]. Classificação estatística internacional de doenças eproblemas relacionados à saúde. 2. ed. São Paulo: Ed. Universidade de São Paulo; 1995.

Parada CMGL, Carvalhaes MABL. Avaliação da estrutura e processo da atenção ao parto:contribuição ao debate sobre desenvolvimento humano. Rev Lat Am Enfermagem. 2007;15(n.spec.):792-8.

Pettker CM. Systematic approaches to adverse events in obstetrics, part I: event identification and classification. Semin Perinatol. 2017 Apr;41(3): 151-5. 
Pettker CM, Thung SF, Norwitz ER, Buhimschi CS, Raab CA, Copel JA, et al. Impact of acomprehensive patient safety strategy on obstetric adverse events. Am J Obstet Gynecol. 2009May;200(5):492.e1-8.

Randell R, Wilson S, Woodward P. The importance of the verbal shift handover report: a multisitecase study. Int J Med Inform. 2011;80(11):803-12.

Reis LGC. Eventos adversos no trabalho de parto e parto em serviços obstétricos: desenvolvimentoe aplicação de método de detecção [tese]. Rio de Janeiro: Escola Nacional de Saúde Pública, Fundação Oswaldo Cruz; 2011.

Reis LGC, Pepe VLE, Caetano R. Maternidade segura no Brasil: o longo percurso para a efetivaçãode um direito. Physis. 2011;21(3):1139-60.

RIPSA. Razão de mortalidade materna (Taxa de mortalidade materna, coeficiente de mortalidade materna) - C.3 - 2010 [citado 2019 mar 20]. Brasília, DF; 2010. Disponível em: http://fichas.ripsa. org.br/2010/c-3/.

Rosen KR. The history of medical simulation. J Crit Care. 2008 Jun;23(2):157-66.

Ronsmans C, Graham WJ. Maternal mortality: who, when, where, and why. Lancet. 2006 Sep 30;368(9542):1189-200.

Ronsmans C, Graham WJ. Maternal mortality: who, when, where, and why. Lancet.2006;368(9542):1189-200.

Rutstein DD, Mullan RJ, Frazier TM, Halperin WE, et al. Sentinel health events (occupational): abasis for Physician recognition and public health surveillance. Am J Public Health. 1983;73(9):1954-62.

Seguy B. File:Forceps a tracteur. Tarnier (1877 France) et Dewey (1900 GB et USA).JPG. Wikipedia,2009 [citado 2014 jul 20]. Disponível em: http://en.wikipedia.org/wiki/File:Forceps_a_ tracteur._Tarnier_(1877_France)_et_Dewey_(1900_GB_et_USA).JPG.

Stones W, Lim W, Al-Azzawi F, Kelly M. An investigation of maternal morbidity with identificationof life-threatening 'near miss' episodes. Health Trends 1991;23:13-5.

Thaddeus S, Maine D. Too far to walk: maternal mortality in context. Soc Sci Med. 1994Apr;38(8):1091-110.

Thomas V., Dixon A. Improving safety in maternity services: a toolkit for teams.: London: The King's Fund; 2012 [citado 2016 jun 16]. Disponível em: http://www.kingsfund.org.uk/publications/ maternity_safety.html.

United Nations. The Millennium development goals report 2013. New York: UN Department ofPublic Information; 2013 [citado 2014 jun 28]. Disponível em: http://www.un.org/ millenniumgoals/pdf/Goal_5_fs.pdf.

Villar J, et al. Caesarean delivery rates and pregnancy outcomes: the 2005 WHO global survey onmaternal and perinatal health in Latin America. Lancet 2006;367:1819-29.

Walsh D. Birth centre care: a review of the literature. Birth Issues, 2004; 13(4):129-34.

White AA, Pichert JW, Bledsoe SH, Irwin C, Entman SS. Cause and effect analysis of closed claims inobstetrics and gynecology. Obstet Gynecol. 2005 May;105(5 part 1):1031-38.

Wikimedia Commons. File: Kardiotokograf.jog. 2006 [citado 2014 jul 20]. Disponível em: http:// commons.wikimedia.org/wiki/File:Kardiotokograf.jpeg.

World Health Organization. Care in normal birth: a practical guide: maternal and newborn health/ safe motherhood unit. Geneva: WHO; 1996. 
World Health Organization. Improving maternal and perinatal health: European strategic approachfor making pregnancy safer. Copenghagen: WHO; 2008 [citado 2014 jun 29]. Disponível em: http://www.euro.who.int/_data/assets/pdf_file/0012/98796/E90771.pdf

World Health Organization, UNICEF, UNFPA, World Bank. Trends in maternal mortality: 1990to 2010. Geneva: WHO; 2012 [citado 2013 out]. Disponível em: http://whqlibdoc.who.int/ publications/2012/9789241503631_eng.pdf

World Health Organization. Maternal mortality. Geneva: WHO; 2016 Nov [citado 2019 jan 20]. Disponível em: http://www.who.int/mediacentre/factsheets/fs348/en/.

World Health Organization, UNICEF, UNFPA, World Bank. Trends in maternal mortality: 1990 to 2010. Geneva: WHO; 2012 [citado 2013 out]. Disponível em: http://whqlibdoc.who.int/ publications/2012/9789241503631_eng.pdf 


\section{Segurança do paciente e imagiologia}

Joana Barata Tavares e Ricardo Alcoforado Maranhão Sá

Neste capítulo, abordaremos a segurança do paciente em avaliações diagnósticas em serviços de imagiologia. Falaremos dos seguintes temas:

距 eventos adversos resultantes da ultrassonografia;

跣eventos adversos resultantes da tomografia computorizada;

* eventos adversos resultantes da ressonância magnética;

路 eventos adversos resultantes dos agentes de contraste.

Nos últimos anos, a imagiologia tem sofrido grande evolução por conta de cada vez mais técnicas que permitem não só uma acuidade diagnóstica crescente, mas também a realização de procedimentos terapêuticos guiados por imagem.

A medicina passa, assim, por uma revolução em que os pacientes são, sem dúvida, os principais beneficiados. Contudo, com o advento dessa plétora tecnológica, cada vez mais questões se suscitam sobre quão seguras são essas técnicas para o paciente, sendo o objetivo deste capítulo responder a algumas delas. 


\section{Eventos adversos da ultrassonografia}

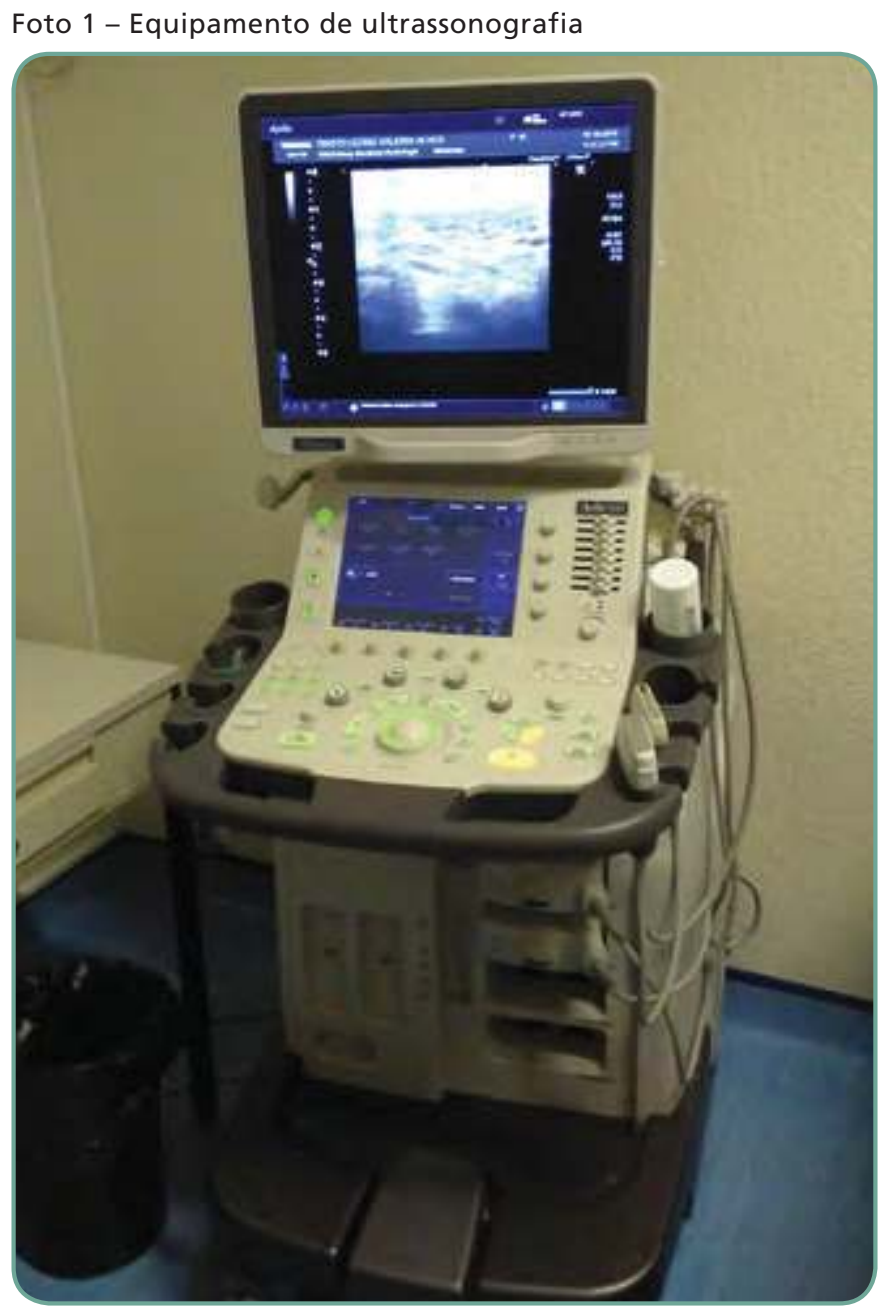

Foto: Joana Barata Tavares (2016)

As ondas ultrassónicas podem afetar os tecidos do paciente, condicionando dois tipos de eventos adversos: térmicos e não térmicos.

No que diz respeito aos eventos adversos térmicos, o aquecimento tecidual decorre da absorção da energia fornecida pelas ondas emi- tidas pela sonda do aparelho (Wells 1998), e a quantidade de energia fornecida (intensidade do ultrassom) depende, essencialmente, da necessidade de se obter boas imagens.

O aquecimento tecidual também depende do tempo de exposição e das características de absorção específicas do tecido. Tecidos com maior conteúdo em colagénio, como o osso, têm maior coeficiente de absorção e vice-versa. 
No entanto, com a utilização, cada vez mais frequente e abrangente, dos estudos de ultrassonografia, o avanço das tecnologias permitiu à World Federation for Ultrasound in Medicine and Biology (1992) emitir uma declaração (WFUMB 1992) em que é confirmado o fato de que, para avaliações diagnósticas standard (modo B), os equipamentos utilizados hoje em dia não aumentam a temperatura de forma eventualmente perigosa, não sendo capazes de provocar queimaduras. Tal é válido não só para a aplicação transcutânea da sonda (a mais usual), mas também para sua aplicação endoscópica e endovaginal (World Federation for Ultrasound in Medicine and Biology 1992).

No que se refere aos eventos adversos não térmicos, o principal é a cavitação acústica. A interação do ultrassom com bolhas de gás, usualmente existentes em tecidos como os de pulmões e intestinos, pode aumentar a temperatura e a pressão dentro da bolha, com consequente estresse mecânico nos tecidos circundantes. No entanto, os exames com frequência realizados nos serviços de imagiologia avaliam os tecidos moles e o sangue, sendo muito pouco provável a cavitação acústica nesses tipos de tecidos. Foi definido um preditor/preditivo de cavitação, sabido ser o índex mecânico (sigla MI, em inglês), que aparece, atualmente, no monitor dos scanners mais modernos, na intenção de que o operador possa minimizar a exposição do paciente, cumprindo o princípio ALARA, acrónimo inglês para as low as resonable achievable (o mais baixo possível).

Foi definido um preditor/preditivo de cavitação, sabido ser o índex mecânico (sigla MI, em inglês), que aparece, atualmente, no monitor dos scanners mais modernos, na intenção de que o operador possa minimizar a exposição do paciente, cumprindo o princípio ALARA, acrónimo inglês para as low as resonable achievable (o mais baixo possível).

\section{Eventos adversos da ultrassonografia}

Térmicos: o aquecimento dos tecidos depende:

- da quantidade de energia emitida pelo aparelho;

- do tempo de exposição;

- das características de absorção de cada tecido;

- da modalidade de emissão dos ultrassons - e, como o ultrassom portátil standard usa o modo $B$, é extremamente improvável que os tecidos aqueçam de forma significativa.

Não térmicos:

- cavitação acústica.
Cavitação acústica corresponde à formação de bolhas intrateciduais com grande temperatura e pressão. Tal deve-se à interação do ultrassom com pequenas bolhas de gás usualmente existentes em tecidos humanos, como os pulmões ou o trato digestivo. 


\section{Eventos adversos da tomografia computorizada}

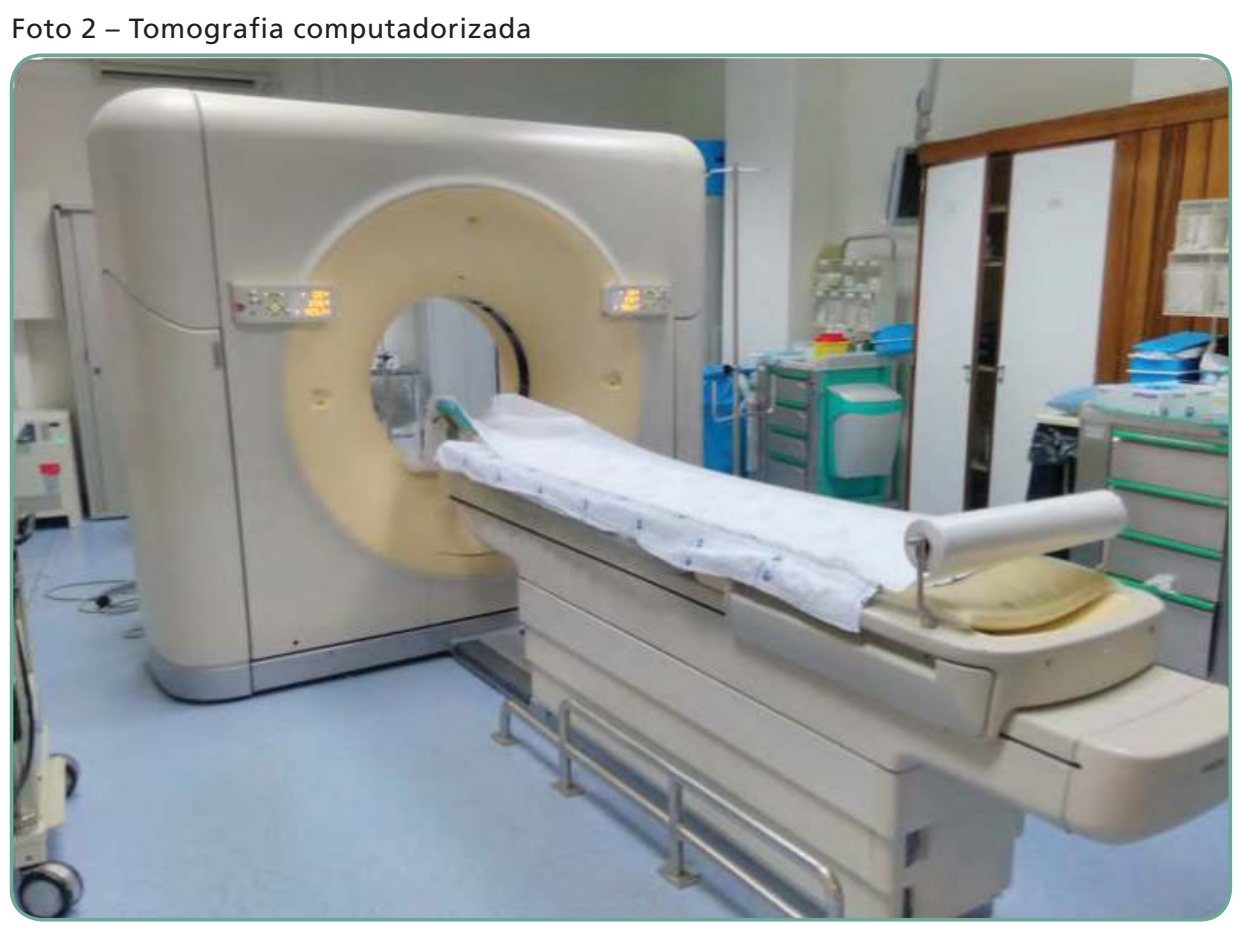

Foto: Joana Barata Tavares (2016).

Os tecidos têm diferentes suscetibilidades para os efeitos da radiação ionizante, sendo os de maior radiossensibilidade as gónadas, a mucosa intestinal, o cristalino e as camadas basais da pele.
O principal problema à segurança do paciente na tomografia computorizada é a radiação ionizante, pois ela possui energia suficiente para arrancar um elétron a/de uma molécula de água. Ao induzir instabilidade elétrica nos componentes moleculares celulares (ionização), condiciona a produção de radicais livres, que podem provocar danos em diversos tecidos ou órgãos.

A radiação ionizante pode ter efeitos estocásticos e determinísticos. Nos efeitos determinísticos, existe um limiar, estando a gravidade dependente da dose. Para os efeitos estocásticos, embora também dose-dependentes, não é possível estabelecer limite abaixo do qual possamos assegurar que o efeito não se manifeste. Pode-se, então, inferir que, nos efeitos estocásticos, nem todos os indivíduos expostos sofrem alterações, conquanto nos efeitos determinísticos, passado o limiar da dose, todos os expostos apresentam alterações.

Os efeitos determinísticos decorrem de lesões no ADN em que há morte celular, sem reparação; são efeitos somáticos, nomeadamente com alterações da pele (alopecia transitória, eritema e necrose cutânea), do cris- 
talino e das gónadas (esterilidade). Podem ser considerados precoces (menos de seis meses), usualmente reversíveis, como trombocitopenia e hemorragias, ou tardios (mais de seis meses), usualmente irreversíveis, como esclerose ou fibrose.

Para controlo da taxa de exposição à radiação ionizante, é necessário monitorar os indicadores de exposição, que podem ser:

噒 externos, quando medem a concentração do agente no ponto de contacto com o organismo humano. No caso da radiação ionizante, assumem-se como indicadores externos os níveis de radiação ambiental e a dose de radiação absorvida.

蝶 internos, quando são medidos no meio biológico dos expostos.

Como indicador interno, assume-se a dose efetiva: a medida usada em proteção radiológica para estimar o risco resultante de exposição à radiação ionizante, ou seja, utiliza-se para refletir o conjunto dos efeitos estocásticos sobre o corpo inteiro.

O grande objetivo da proteção radiológica é preservar as pessoas dos riscos provenientes das atividades humanas que utilizam equipamentos e materiais emissores de radiações. De acordo com o International Commission on Radiological Protection (1990), o sistema de proteção radiológica deve ser baseado tanto na prevenção de efeitos biológicos determinísticos, mantendo a dose inferior a um limiar determinado, como na exigência, a fim de que sejam aplicadas todas as medidas razoáveis para reduzir a incidência de efeitos biológicos estocásticos.

Em um estudo sobre incidentes relacionados com aparelhos de tomografia computadorizada, na base de dados dos bancos de notificações Medical Device Reporting (MDR) e Manufacturer and User Facility Device Experience (Maude), ambos da U.S. Food and Drug Administration (FDA), no período de $1^{\circ}$ de janeiro de 1984 a 31 de dezembro de 2007, foram encontrados 519 incidentes referentes ao equipamento, sendo 233 relatos do MDR e 286 relatos do Maude. Conforme mostrou o estudo, $64,5 \%$ dos incidentes analisados foram classificados como mau funcionamento. Os incidentes foram classificados por tipo de falha, sendo o erro de software a maior ocorrência $(20,7 \%)$.

Os erros de softwares podem ser listados como os dados perdidos de pacientes, além de problemas na formação ou reconstrução da imagem, imagens fora de sequência, inicialização ou parada indevida do equipamento ou, ainda, nova varredura. Erros inerentes aos operadores dos aparelhos, como troca de dados entre pacientes ou inserção de dados
Dose de radiação absorvida é a quantidade de energia absorvida nos tecidos por unidade de massa, $(1 \mathrm{~Gy}=1 \mathrm{~J} / \mathrm{kg})$, sendo as fontes naturais 2-4 mGy/ano e as fontes de diagnóstico 1-50 mGy/hora.

Dose efetiva é uma medida que representa a soma das doses equivalentes (dose absorvida no órgão ou tecido ponderado, segundo o tipo e a qualidade da radiação), depois de ponderadas por um fator que tem a radiossensibilidade própria do tecido em estudo - a sua unidade é o sievert (Sv). 
em outro paciente, são também frequentes. Esses problemas podem levar ao atraso ou repetição do exame, diagnósticos incorretos e dano ao paciente (Sá, Mendes 2015).

\section{Eventos adversos da tomografia computorizada}

\section{Radiação ionizante}

- Efeitos determinísticos: existe um limiar para o aparecimento do efeito, estando a gravidade dependente das doses.

- Efeitos estocásticos: embora a gravidade do efeito também se amplie com o aumento da dose de exposição, não é possível estabelecer limite abaixo do qual possamos assegurar que o efeito não se manifeste.

\section{Problemas de software}

- Podem levar ao atraso ou repetição do exame, a erro de diagnóstico e dano ao paciente.

\section{Eventos adversos da ressonância magnética}

Em linhas gerais, existem quatro grandes áreas nas quais podem ser divididos os riscos potenciais das explorações dos exames de ressonância magnética (RM):

橉 exposição ao campo magnético;

粼 exposição às ondas de radiofrequência;

滕 efeito do íman (ímã) sobre metais ferromagnéticos;

䗉 exposição ao ruído do funcionamento do aparelho e claustrofobia. 
Foto 3 - Ressonância magnética

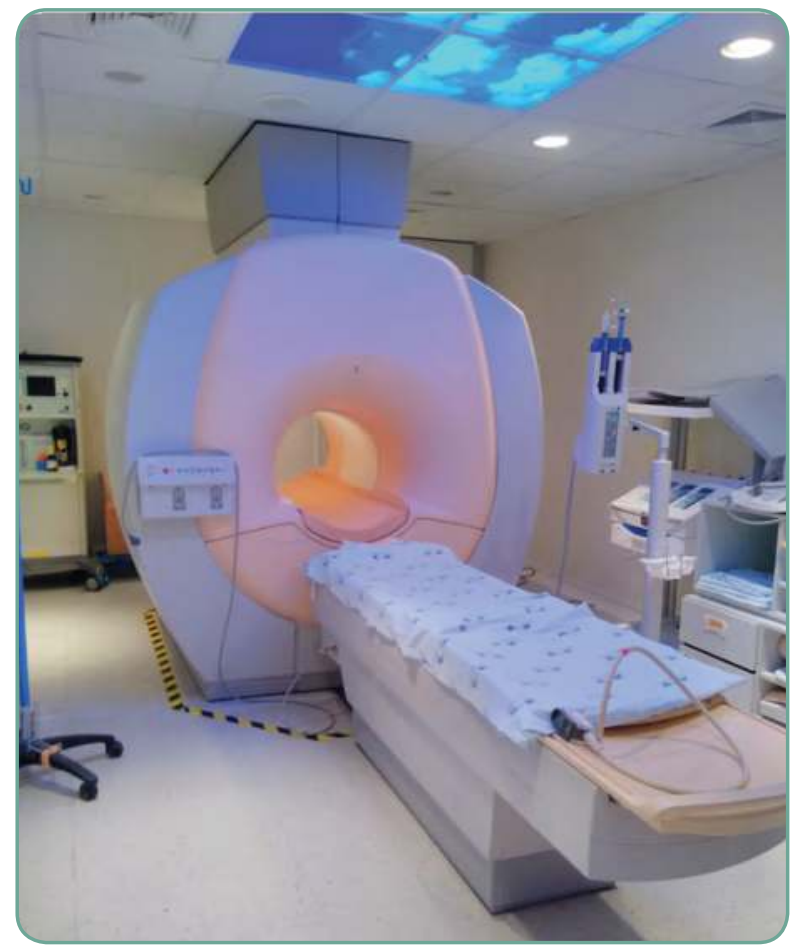

Foto: Joana Barata Tavares (2016).

A seguir, cada um desses itens serão abordados.

\section{Exposição ao campo magnético}

O Tesla (T) é a unidade de medida do Sistema Internacional para a força de um campo magnético. Atualmente, a maioria dos equipamentos de RM usados na prática clínica varia entre 1 e 3T. Para comparação, o campo magnético terrestre varia entre 30 microtesla $(\mu \mathrm{T})$ nos meridianos e $60 \mu \mathrm{T}$ nos polos terrestres.

Existem dois tipos de campo magnético a ter em consideração na sala da RM: o campo magnético estático do íman (imã) e os campos magnéticos variáveis - são os gradientes que se aplicam sobre o campo magnético estático para se obter informação espacial da imagem. Ambos os campos podem produzir alterações sobre diversos órgãos e sistemas, e, em geral, essas alterações são proporcionais à intensidade do campo magnético. No entanto, para a intensidade de campo dos equipamentos aprovados para uso clínico em serviços de imagiologia (a maioria não ultrapassa os 3T), não se demonstraram eventos adversos (Lafuente 2004). 
Atualmente, ainda em contexto experimental, estão sendo desenvolvidos e já usados aparelhos de 9,4T.
Esse assunto assume, contudo, importância em razão do desenvolvimento de aparelhos de RM, com cada vez maior intensidade de campo. Com o aumento da intensidade de campo, os danos possíveis de ocorrer são:

䗲 aumento da temperatura corporal;

* alterações sobre o sistema nervoso central (a 24T há 10\% de redução temporária da velocidade de condução dos impulsos nervosos) (Lafuente 2004);

magnetofosfenos (alterações visuais temporárias decorrentes dos movimentos dos olhos quando submetidos a campo magnético acima de 4T (Lafuente 2004));

綞 alterações hematológicas reversíveis, que ocorrem mesmo em campos de baixa intensidade, mas dependem de longos períodos de exposição (> uma hora por dia, durante seis semanas (Lafuente 2004)), os quais não ocorrem na prática clínica;

* efeito magnetohidrodinâmico (aumento temporário da onda T do ECG em todos os pacientes expostos a campos magnéticos superiores a 0,1T (International Commission on NonIonizingRadiation Protection 2009) e aumento temporário ligeiro da tensão arterial, $10 \%$ de elevação em campos de $6 \mathrm{~T}$ e $28 \%$ em camposde 10T (International Commission on Non-Ionizing Radiation Protection 2009).

No caso específico dos campos magnéticos variáveis, por serem ativados e desativados frequentemente durante as aquisições de imagem, a Food and Drug Administration (FDA), dos Estados Unidos da América, considera a possibilidade de os efeitos acima de 6T serem tão graves que limitou sua utilização. O nível de segurança definido é três vezes inferior ao valor de excitabilidade dos nervos periféricos (Zaremba 2005). Acima desse limite, podem ocorrer convulsões, contracturas musculares involuntárias, arritmias cardíacas e magnetofosfenos. Esse nível de segurança é configurado pelo operador do aparelho de RM, contudo, sendo todos os estudos atualmente realizados em 6T experimentais, tal ainda não é um risco na prática clínica diária.

\section{Exposição a ondas de radiofrequência}

A radiação de radiofrequência é definida pela radiação electromagnética não ionizante estabelecida nas frequências entre 0 e 3000 GHz. A exposição à radiofrequência pode produzir dois efeitos: 
não térmicos, muito controversos, com possibilidade de estarem associados ao desenvolvimento de instabilidade dos microssatélites e à génese de cancro/câncer; atualmente, em investigação (World Federation for Ultrasound in Medicine and Biology 1992);

* térmicos, os mais importantes, já que, durante o exame de RM, a maioria da energia transmitida com a radiofrequência se transforma em calor dentro do paciente.

A energia depositada pelos pulsos de radiofrequência quantifica-se pelo índice de absorção específico, Specific Absortion Rate (SAR), que se expressa em $\mathrm{W} / \mathrm{kg}$ (watts por quilo). O SAR permite fazer uma estimativa dos efeitos térmicos da radiofrequência e representa o índice de absorção de energia electromagnética. Depende da duração e intensidade do pulso de radiofrequência (tipo de sequência), temperatura ambiente (não deve ultrapassar os $24^{\circ} \mathrm{C}$ ), grau de humidade (nunca ultrapassar a $60 \%$ de humidade relativa), peso, configuração anatômica e estado do sistema de termorregulação do paciente. Os aparelhos RM oferecem sempre os valores do SAR calculados para cada sequência, baseados em uma função complexa que depende de muitas variáveis, como a antena utilizada, repetição do pulso, duração do estudo, peso do paciente, entre outras.

Os níveis de segurança recomendados para uma exploração por RM, sem lesões para o paciente por aumento da temperatura corporal, foram estabelecidos pela FDA a um nível de SAR menor de $4 \mathrm{~W} / \mathrm{kg}$ de média sobre o total do corpo (American Institute of Ultrasound in Medicine 1992). Esses valores foram definidos porque pacientes expostos a tais níveis de SAR não sofrem de aumento da temperatura corporal, desde que seu sistema de termorregulação esteja adequado. Contudo, existem casos em que o sistema de termorregulação pode estar desregulado, sugerindo-se avaliação individualizada da relação risco/benefício da realização do estudo de RM. Exemplos desses casos são pacientes febris ou com cardiopatia descompensada, com isolamentos térmicos (por exemplo, engessados), com pensos transdérmicos, em que podem ocorrer queimaduras da pele, entre outros.

\section{Efeito do íman (imã) sobre metais ferromagnéticos}

Um objeto metálico que se situe no interior do campo magnético experimentará um movimento de rotação em função da sua liberdade de movimento.
Instabilidade dos microssatélites diz respeito a alterações no ADN celular em razão do mau funcionamento de proteínas (enzimas) de reparação. Quanto maior a frequência de instabilidades, maior a possibilidade de desenvolver cancro/câncer.

Pensos transdérmicos são pensos para administração percutânea de terapêutica, muito usados em pacientes com dores musculares. Geralmente, o paciente põe um penso novo a cada $12 \mathrm{~h}$, durante 5 dias, para alívio da dor. É sempre importante perguntar se o paciente que vem fazer o estudo de RM possui um penso; em caso de resposta afirmativa, solicita-se que o retire. 
Gaiola de Faraday equivale à construção de um campo elétrico exterior à sala, que faz com que as cargas elétricas se rearranjem. Tal permite, por um lado, cancelar o campo interno protegendo-o do exterior ou, por outro, cancelar o campo externo, protegendo-o do campo magnético no interior. Isso é conseguido por meio de isolantes nas paredes da sala onde está colocado o aparelho de RM - o campo magnético fica contido no interior da sala.

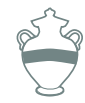

Caso a RM seja realizada em pacientes que apresentem dispositivos como os mencionados, danos importantes podem ocorrer Por exemplo:

- paciente com prótese incompatível no osso da coluna vertebral pode ficar paraplégico caso a prótese se mova e se aloje na medula espinhal.

- paciente com limalha de metal perto do olho pode ficar cego se a limalha se mover e condicionar disrupção do globo ocular.
O efeito projétil ou de míssil consiste na capacidade de o campo magnético estático atrair, centralmente, objetos ferromagnéticos desde o bordo do campo, com movimento de translação e rotação. Essa força de atração tem efeito numa área elipsoidal, que depende da intensidade do campo: os sistemas de baixo campo têm um raio de ação elipsoidal menor de $1 \mathrm{~m}$, mas os sistemas de alto campo magnético podem ter um raio de ação de até $20 \mathrm{~m}$, sendo, por isso, essencial proteger o raio de ação - esse é o motivo de as salas de RM serem feitas de forma a constituírem Gaiolas de Faraday.

Esse efeito supõe importante risco para o paciente e qualquer pessoa que possa se interpor na possível trajetória do objeto. Exemplos de objetos tradicionalmente descritos como terem sofrido efeito projétil são cadeiras de rodas, tesouras, pinças, ganchos metálicos das bolsas de urina, máquinas polidoras para limpeza, entre muitos outros. A melhor proteção é permitir a entrada, na sala do aparelho, somente ao paciente e aos profissionais da saúde que ali trabalham.

Além do risco de ser atingido por um objeto que sofra o efeito projétil, outros riscos estão presentes por causa do efeito imã. Existem materiais com grande quantidade de partículas metálicas em sua composição, por exemplo, alguns tipos de maquilhagem/maquiagem que podem produzir artefactos na imagem de RM cranioencefálica, ou até irritação ocular; dessa forma, todos os pacientes submetidos a uma exploração por RM devem retirar a maquilhagem/maquiagem. As tatuagens também apresentam possibilidade de condicionar sensação de irritação por aquecimento.

Os metais ferromagnéticos são o ferro, cobre, níquel e o aço inoxidável em suas formas ferrítica e martensítica. Infelizmente, numerosos dispositivos médicos incluem, em sua composição, esses tipos de aço, sendo, por isso, essencial fazer o inquérito inicial ao paciente, em que se avalia a existência de dispositivos médicos que possam conter esses materiais, constituindo contraindicação para realizar o RM.

Assim, é fundamental descartar próteses ou implantes mecânicos como próteses ortopédicas, válvulas cardíacas mecânicas, clipes hemostáticos em aneurismas ou dispositivos intravasculares. Os implantes ativados de forma elétrica, mecânica ou magnética, como marcapassos, implantes cocleares, próteses oculares ou esfíncteres/estomas magnéticos devem também ser descartados.

Perante a presença dessas próteses ou implantes, é necessário ser avaliada sua composição, localização e força do campo magnético estático e gradientes a que se irá submeter o paciente. 
Outro caso paradigmático de limitação para os estudos de RM são os trabalhadores de metal, como aqueles de chapas de automóveis ou escultores em metais, entre outros, já que é possível terem limalhas que saltaram durante sua atividade profissional. Sempre que existam dúvidas, devem ser realizadas radiografias (ou até tomografias computorizadas) para exclusão da sua presença.

Todas as salas de RM são, atualmente, construídas com mecanismos de paragem/parada de emergência, para o caso de algum objeto ser atraído para o íman. Ressalva-se, contudo, que tais mecanismos só devem ser acionados em casos críticos, já que reativar o campo magnético é um processo demasiadamente perigoso, longo e com custos muito elevados. Ao parar de forma brusca o campo magnético, há evaporação de grande quantidade de hélio líquido, sendo necessária sua reposição, o que pode levar à formação de nuvens de hélio, que, apesar de não serem tóxicas, podem condicionar deslocamento de massas de ar com hipoxia e morte, em poucos minutos. Atualmente, as salas de RM também estão equipadas com sistemas de ventilação do hélio para prevenir tais incidentes.

Em um estudo sobre incidentes relacionados com aparelho de ressonância magnética na base do banco de notificações Maude, da FDA, no período de $1^{\circ}$ de janeiro de 2014 a 31 de dezembro de 2014, encontram-se 91 incidentes, cujo desfecho foram lesões. Ao analisá-los, 3 incidentes foram excluídos, pois não se referiam aos aparelhos de ressonância magnética ou estavam duplicados. Dos 88 incidentes restantes, o estudo mostrou: 71 relacionados a danos em pacientes $(80,7 \%)$; 11 a danos em técnicos de radiologia (12,5\%); 5 a danos à equipe de manutenção $(5,7 \%)$; e 1 a danos no equipamento $(1,1 \%)$.

Os tipos de danos em pacientes foram: queimaduras na pele, o mais frequente (61 casos, 69,3\%); por colisão com material ferromagnético ( 4 casos, $4,6 \%$ ); por choque mecânico entre o paciente e o magneto ( 3 casos, 3,4\%); e outros danos (3 casos, 3,4\%) (Sá, Mendes 2015).

\section{Exposição ao ruído do funcionamento do aparelho e claustrofobia}

O aparelho de RM emite ondas sonoras muito elevadas, mas, como na prática clínica diária os pacientes estão pouco tempo expostos a esse ruído, não estão descritas alterações da acuidade auditiva. No entanto, como prevenção, abafadores de som devem ser fornecidos aos pacientes na intenção de minimizar esses efeitos. 
No que diz respeito a pacientes com claustrofobia, caso o exame RM seja essencial, deve-lhes ser oferecida a hipótese de realizar o exame sob anestesia, informando, contudo, ao paciente dos riscos inerentes à indução anestésica, nomeadamente parada respiratória por má reação fisiológica à anestesia e/ou desconexão do aparelho de anestesia (Sá, Mendes 2014).

\section{Eventos adversos dos agentes de contraste}

Os dois principais agentes de contraste utilizados em serviços de imagiologia são os iodados e os baseados em gadolínio.

\section{Contrastes iodados}

Os contrastes iodados são usados nos estudos de tomografia computorizada e de angiografia.

\section{Reações ao contraste}

Perante a administração de um agente de contraste iodado, existem dois tipos de eventos adversos agudos que se podem obter: fisiológicos e do tipo alérgico. Sua distinção é muito importante, já que ter um evento do tipo alérgico a um agente de contraste implica a pré-medicação num exame futuro, enquanto, no caso dos eventos fisiológicos, ela não é necessária.

Os incidentes do tipo fisiológico decorrem da quimiotoxicidade e/ou osmotoxicidade direta das moléculas constituintes dos agentes de contraste. São, geralmente, doses dependentes, e as mais exemplificativas são as alterações cardiovasculares (arritmias, depressão da contractilidade miocárdica ou até edema pulmonar cardiogénico) e as reações vasovagais (hipotensão com bradicardia). Enquanto as primeiras são muito raras, usualmente associadas a procedimentos angiográficos como os cateterismos cardíacos, as segundas são muito frequentes e, em geral, associam-se a estados de ansiedade, ocorrendo, muitas vezes, antes do contraste ser administrado: por exemplo, quando se está a pedir o consentimento informado ou a puncionar um vaso para administração intravascular.

Os incidentes do tipo alérgico são, por sua vez, independentes da dose de contraste. Pensa-se que o mecanismo seja a libertação de histamina pelos basófilos e eosinófilos, e a maioria das reações não são IgE mediadas, por isso não são verdadeiras reações alérgicas. 
Por infelicidade, a distinção entre esses dois tipos de incidentes nem sempre foi feita, e, historicamente, a incidência de eventos adversos aos meios de contraste iodado sempre incluiu os dois tipos. No caso de contraste iodado de elevada osmolalidade, a porcentagem de efeitos adversos está descrita entre 5\% a 15\% (American College of Radiology 2013), enquanto para contrastes iodados de baixa osmolalidade, esse número varia entre 0,2\% e 0,7\% (Gilgen-Anner et al. 2007; Mortele et al. 2005). Percebe-se, assim, que, atualmente, em quase todos os serviços de imagiologia, são usados contrastes iodados de baixa osmolalidade.

Até agora, tratou-se de eventos adversos agudos logo após a administração do agente de contraste, mas também existem eventos adversos tardios, os quais não devem ser ignorados. Aparecem de uma hora até uma semana depois da administração do contraste (a maioria entre as três horas e os dois dias após) e são maioritariamente do tipo alérgico. São, sobretudo, cutâneos (urticária, rash persistente ou apenas prurido), mas também estão descritos em náuseas e vómitos. Muito raramente foram relatados casos de sialodenopatia ou poliartropatia aguda; essas reações, porém, ocorrem acima de tudo em pacientes com disfunção renal (Coakley, Panicek 1997; Donnelly, Williams, Watkin 1993).

Os principais fatores contribuintes para o desenvolvimento de reações alérgicas são a história de uma reação prévia do tipo alérgico ao contraste, asma, doença renal e cardíaca graves e estados de ansiedade.

Não existe nenhum estudo que suporte que alergias à comida, como marisco e produtos lácteos, acarretem risco acrescido para o desenvolvimento de reações alérgicas após administração de agentes de contraste (Lasser 1988; Lieberman, Seigle 1999).

Apesar de tradicionalmente se descrever maior predisposição para falência renal irreversível em pacientes com mieloma múltiplo e maior risco para aqueles com drepanocitose, não existem estudos que validem esse aumento de risco com o uso de contrastes iodados de baixa osmolalidade.

\section{Pré-medicação}

Para casos de reação alérgica ao contraste, a pré-medicação é indicada. O uso de metilprednisolona endovenosa reduz a histamina sanguínea, com diminuição do número de basófilos e eosinófilos circulantes no fim da primeira hora após a injeção, com efeito máximo de supressão
Osmolalidade é o número de partículas osmoticamente ativas de soluto presentes em um quilograma do solvente. É diferente de osmolaridade, que se refere ao número de partículas osmoticamente ativas de soluto presentes em um litro de solução.
A administração de bloqueadores H1, anti-histamínicos, como a difenidramina, reduz a frequência de urticária, angioedema e sintomas respiratórios (American College of Radiology 2013). 
oito horas após a injeção de metilprednisolona. Assim, percebe-se que a pré-medicação deve ser feita pelo menos quatro a seis horas antes da administração de contraste e, se tal não for possível, não vale a pena injetar prednisolona, dando-se apenas bloqueadores $\mathrm{Hl}$ antes da administração de contraste (Hazirolam et al. 2009).

\section{Aquecimento do contraste}

A viscosidade do agente de contraste, tal como em muitos outros agentes líquidos, depende da temperatura a que ele se encontra. Vários estudos (Mehta et al. 2007; Schwab, Kuefner, Anders 2009; Vergara, Seguel 1996) avaliaram os efeitos do aquecimento do agente de contraste iodado previamente à sua injeção; e a maioria concluiu que o aquecimento do agente até a temperatura corporal $\left(37^{\circ}\right)$ diminui sua viscosidade, sendo necessária a menor pressão de injeção na administração do contraste. Nenhum estudo reportou aumento da incidência de eventos adversos relacionados ao agente de contraste quando ele é aquecido, tendo, inclusive, sido reportada menor incidência de eventos adversos ligeiros (Mehta et al. 2007).

Atualmente, a maioria dos serviços de imagiologia aquece os agentes de contraste iodado previamente à sua administração, sobretudo quando é necessária maior velocidade de injeção: acima dos 5mL/segundo.

\section{Nefrotoxicidade}

A nefrotoxidade induzida pelo contraste consiste numa deterioração súbita da função renal após a administração recente de contraste iodado, e na falta de outro evento nefrotóxico. A fisiopatologia dessa toxicidade é ainda controversa, mas pensa-se que duas causas concorrem para seu aparecimento: vasoconstrição renal e toxicidade tubular direta.

Não existe nenhum critério exato para o diagnóstico de nefrotoxicidade, porém o mais utilizado é o aumento de $0,5 \mathrm{mg} / \mathrm{dL}$ no valor absoluto de creatinina sérica (American College of Radiology 2013). No entanto, salienta-se o fato de que, segundo a Acute Injury Network (Akin) (Bruce et al. 2009), o diagnóstico de lesão aguda é realizado nas primeiras quarenta e oito horas após um evento nefrotóxico, com o aumento de apenas $0,3 \mathrm{mg} / \mathrm{dL}$ no valor absoluto de creatinina sérica.

Infelizmente, existem poucos estudos randomizados que avaliam a nefrotoxicidade dos agentes de contraste iodado comparando o grupo que recebeu com outro que não recebeu contraste. Bruce et al. (2009) 
demonstrou que apenas pacientes com creatinina sérica acima de $1,8 \mathrm{mg} / \mathrm{dL}$ tinham maior risco para disfunção renal após exposição a contrastes iodados de baixa osmolalidade.

Deve-se, contudo, ter especial atenção a pacientes com insuficiência renal aguda, já que, nesses casos, o valor de creatinina sérica não é confiável, e o contraste só deve ser aplicado se o benefício for claramente superior ao risco.

Pacientes anúricos com doença renal terminal não estão em risco de nefrotoxicidade pelo contraste, sendo possível administrá-lo sem risco de maior lesão. Deve-se, contudo, limitar a dose de contraste ministrada a fim de reduzir o excesso de volume intravascular.

Segundo o American College of Radiology (2013), deve ser realizada a medição dos níveis séricos de creatinina previamente à administração de contraste iodado nos seguintes casos:

蝶 paciente com mais de 60 anos;

橉 história de doença renal (diálise, transplante renal, rim único, neoplasia ou cirurgia renal prévia);

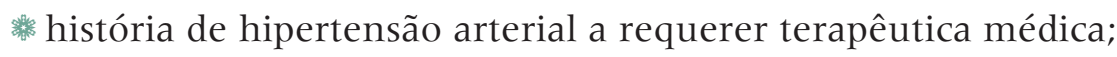

絜 história de diabetes mellitus;

uso de metformina.

Salienta-se a questão de que o uso de metformina não confere maior risco para nefrotoxidade. Esse agente anti-hiperglicémico pode, contudo, em casos raros, promover o desenvolvimento de acidose láctica em pacientes com doença renal: 0 a 0,084 casos por cada mil (Collidge et al. 2007).

Apesar da incidência ser muito baixa, essa condição é bastante grave, com mortalidade de $50 \%$. Assim, a restrição na administração de contraste em pacientes com insuficiência renal a fazerem metformina não é para prevenção de nefrotoxicidade, mas sim prevenção do desenvolvimento de acidose láctica.

Existem várias medidas que devem ser tomadas a fim de prevenir a nefrotoxicidade dos agentes de contraste iodado. A principal é a hidratação, e o ACR (American College of Radiology 2013) sugere uma solução salina a $0,9 \%$ a $100 \mathrm{~mL} / \mathrm{h}$, começando seis horas a doze horas antes da administração de contraste e terminando quatro horas a doze horas depois. 
A administração de $\mathrm{N}$-acetilcisteína é controversa, já que ela baixa a creatinina sérica sem alterar a cistatina-C (melhor marcador de função renal), ou seja, pode baixar o valor de creatinina sérica sem, na verdade, prevenir lesão renal. Contudo, a maioria dos protocolos inclui sua administração. Enquanto o uso de bicarbonato de sódio é controverso, o de diuréticos, como o manitol e a furosemida, não está recomendado (American College of Radiology 2013).

\section{Contrastes baseados em gadolínio}

Os contrastes baseados em gadolínio são utilizados em exames de RM.

Os quelatos de gadolínio são bem tolerados, sendo os incidentes agudos menos frequentes do que com contraste iodado. A frequência de eventos adversos agudos, após injeção de dose standard de gadolínio $(0,1$ a $0,2 \mathrm{mmol} / \mathrm{kg})$, varia entre $0,07 \%$ e $2,4 \%$ (American College of Radiology 2013), sendo a maioria ligeiros, como náuseas, cefaleias ou tonturas. Eventos do tipo alérgico são muito raros: 0,004\% a 0,7\% (American College of Radiology 2013).

Deve-se ter especial atenção a pacientes que já tiveram uma reação alérgica ao gadolínio, já que a probabilidade de ter uma nova reação, usualmente mais grave do que a primeira, é oito vezes superior à de um paciente sem esses antecedentes. Pessoas com asma e alergias a outros fármacos também têm maior risco para desenvolver eventos adversos quando submetidas a esse tipo de contraste.

Os contrastes baseados em gadolínio não condicionam nefrotoxidade nas doses recomendadas, e, muitas vezes, os clínicos pedem exames de RM com contraste, em vez de exames de TC com contraste, porque pensam que assim poupam o sistema renal residual de pacientes com insuficiência renal. No entanto, existe o risco de desenvolver fibrose sistémica nefrogénica com a administração de gadolínio pelo que a substituição de um agente de contraste iodado por um baseado em gadolínio não está recomendada em pacientes com insuficiência renal.

\section{Fibrose sistémica nefrogénica (FSN)}

A FSN é uma doença fibrosante que envolve, primariamente, a pele e o tecido subcutâneo, além de também poder envolver outros órgãos, como pulmões e sistema musculoesquelético. Os sintomas iniciais envolvem o espessamento da pele e prurido, mas existe a possibilidade de progredir rapidamente, com contraturas e imobilização articular. Em alguns casos, essa doença pode ser fatal. 
A doença ocorre quando da administração de agentes de contraste baseados em gadolínio a pacientes com doença renal terminal. A fisiopatologia ainda é controversa, mas pensa-se que se deva à dissociação do gadolínio dos quelatos, com formação de ligações entre o gadolínio e aniões/ânions como o fosfato, com consequente formação de precipitados insolúveis que se depositam em vários tecidos, condicionando uma reação fibrótica sistémica (Collidge et al. 2007).

Segundo a ACR (American College of Radiology 2013), os seguintes pacientes devem fazer avaliação da sua taxa de filtração glomerular previamente ao recebimento da administração de contrastes baseados em gadolínio:

噒 paciente com mais de 60 anos;

慕 história de doença renal (diálise, transplante renal, rim único, neoplasia ou cirurgia renal prévia);

* história de hipertensão arterial a requerer terapêutica médica;

紫 história de diabetes mellitus.

Os pacientes com maior risco de desenvolver FSN são os que estão a fazer diálise, os com taxa de filtração glomerular abaixo de $40 \mathrm{~mL} /$ min/1,73m (Mortele et al. 2005) e aqueles com insuficiência renal aguda. Especial atenção deve ser dada a pacientes com doença renal terminal (taxa de filtração glomerular $<30 \mathrm{ml} / \mathrm{min} / 1,73 \mathrm{~m}$ (Mortele et al. 2005)), pois nunca devem realizar estudos com administração de gadolínio. Se um exame de imagem com contraste for indispensável, dever-se-á optar por uma TC com contraste iodado, cumprindo o protocolo de hidratação previamente descrito.

\section{Considerações finais}

As diferentes técnicas de avaliação diagnóstica, hoje em dia disponíveis em serviços de imagiologia, associam-se a diferentes tipos de incidentes e, em especial, a eventos adversos. Apesar de tradicionalmente se associar esses eventos à radiação ionizante da TC, com a emergência de novas técnicas, como a RM, os eventos associados à exposição a campos eletromagnéticos começam a assumir cada vez mais importância, sendo fundamental seu conhecimento pelo profissional da saúde.

Por fim, saber distinguir os principais eventos adversos associados a cada tipo de contraste, sejam os baseados em iodo, sejam os baseados em gadolínio, é importante na definição de protocolos de pré-medicação adequados a cada paciente. 


\section{Referências}

American College of Radiology. Manual in contrast media. Version 9. Allergic-like Physiol Reactions. 2013: 21-27.

American Institute of Ultrasound in Medicine. National Electronics Manufacturers' Association. Standard for the display of thermal and acoustic output indices on diagnostic ultrasound equipment. Rockville: American Institute of Ultrasound in Medicine; 1992.

Bailey CJ, Turner RC. Metformin. N Engl J Med. 1996; 334: 574-579.

BRUCE RJ et al. Background fluctuation of kidney function versus contrast induced nephrotoxicity. AJR Am J Roentgenol. 2009; 192: 711-718.

Coakley FV, Panicek DM. lodine allergy: an oyster without a pearl? AJR Am J Roentgenol. 1997; 169: 951-952.

Cochran ST, Bomyea K, Sabre JW. Trends in adverse events after IV administration of contrast media. AJR Am J Roentgenol. 2001; 176: 1385-1388.

Collidge TA et al. Gadolinium-enhanced MR imaging and nephrogenic systemic fibrosis: retrospective study of a renal replacement therapy cohort. Radiology. 2007; 245: 168-175, 2007.

Donnelly PK, Williams B, Watkin EM. Polyarthropathy-adelayed reaction to low osmolality angiographic contrast medium in patients with end stage renal disease. Eur J Radiol. 1993; 17: 137-132.

Gilgen-Anner $Y$ et al. lodine mumps after contrast media imaging: arare adverse effect to iodine. Ann Allergy Asthma Immunol. 2007; 99: 93-98.

Hazirolam T et al. The impact of warmed intravenous contrast media on the bolus geometry of coronary CT angiography applications. Korean J Radiol. 2009; 10: 150-155.

International Commission on Non-Ionizing Radiation Protection. Guidelines on limits of exposure to static magnetic fields. Health Phys. 2009; 96(4): 504-514.

International Commission on Radiological Protection. 1990 Recommendations of the International Commission on Radiological Protection. Ann ICRP. 1991; 21(1-3).

Lafuente J. Atlas de resonancia magnética. 2nd. ed. Madrid: Mallinckrodt; 2004.

Lasser EC. Pretreatment with corticosteroids to prevent reactions to i.v. contrast material: overview and implications. AJR Am J Roentgenol. 1988; 150: 257-259.

Lieberman PL, Seigle RL. Reactions to radiocontrast material. Anaphylactoideventsin radiology. Clin Rev Allergy Immunol. 1999; 17: 469-496.

Mehta RL et al. Acute kidney injury network: report of an initiative to improve outcomes in acute kidney injury. Crit Care. 2007; 11: R31.

Mortele KJ et al. Universal use of nonionic iodinated contrast mediumforCT: evaluation of safety in a large urban teaching hospital. AJR Am J Roentgenol. 2005; 184: 31-34.

Sá RAM, Mendes W. Adverse events and death related to the use of the magnetic resonance equipment. In: ISQua International Conference, 31, 2014, Rio de Janeiro. Quality and safety along the health and social care continuum. [S.I.]: International Society for Quality in Health Care; 2014.

Sá RAM, Mendes W. Adverse events and lesions related to the use of the MRI equipment. Trabalho apresentado no IUPESM WC2015. 
Schwab SA, Kuefner MA, Anders K et al. Peripheral intravenous power injection of iodinated contrast media: the impact of temperature on maximum injection pressures at different cannula sizes. Acad Radio. 2009; 16: 1502-1508.

Vergara M, Seguel S. Adverse reactions to contrast media in CT: effects of temperature and ionic property. Radiology. 1996; 199: 363-366.

Wells PN. Physics and bioeffects. In: Mcgahan JP, Goldberg BB. editor. Diagnostic ultrasound: a logical approach. Philadelphia: Lppincott-Raven Publ.; 1998, p. 1-19.

World Federation for Ultrasound in Medicine and Biology. Statements on thermal effects and clinical applications. Ultrasound Med Bio. 1992; 18: 731.

Zaremba LA. FDA guidelines for magnetic resonance equipment safety. [Local desconhecido]: Center for Devices and Radiological Health, Food and Drug Administration, [2005]. Disponível em: https://www.aapm.org/meetings/02AM/pdf/8356-48054.pdf. 


\section{A segurança do paciente no cuidado odontológico}

Claudia Dolores Trierweiler Sampaio de Oliveira Corrêa

Neste capítulo, será apresentado um panorama sobre o atual estágio da segurança do paciente em odontologia. As características do cuidado odontológico e sua implicação para a segurança do paciente, algumas pesquisas/investigações que vêm sendo realizadas a respeito do assunto, os principais eventos adversos (EA) apontados na literatura, bem como as sugestões para mitigar o problema serão destacadas.

\section{Características do cuidado odontológico que implicam a segurança do paciente}

A odontologia é uma atividade prioritariamente invasiva, desenvolvida mediante a execução de procedimentos numerosos e repetitivos que, se aliados à complexidade tecnológica e ao contato bem próximo com sangue e saliva, têm grande capacidade para provocar EA - incidente com dano desnecessário oriundo do cuidado. A profissão apresenta singularidades que podem implicar diretamente a segurança do paciente (Perea-Pérez et al. 2011 a; Yamalik, Perea-Pérez 2012). A seguir, abordaremos algumas delas.

\section{Fragmentação do cuidado}

Distintas categorias profissionais atuam na área odontológica. No Brasil, as categorias profissionais habilitadas são: cirurgião-dentista, técnico em saúde bucal, auxiliar em saúde bucal, técnico em prótese dentária e auxiliar em prótese dentária. O cirurgião-dentista, o técnico e o auxiliar em saúde bucal lidam diretamente com o paciente; os dois últimos, porém, unicamente sob a supervisão do cirurgião-dentista. O técnico e o auxiliar em prótese dentária executam a parte mecânica 
No Capítulo 7, "Comunicação entre os profissionais de saúde e a segurança do paciente", do livro Segurança do paciente: criando organizações de saúde seguras, você poderá avaliar aspectos da comunicação entre todos os envolvidos no cuidado, seus impactos na segurança do paciente e as sugestões de estratégias e técnicas para melhorar a comunicação. dos trabalhos odontológicos solicitada pelo cirurgião-dentista, sendo-lhes vedado prestar cuidado direto ao paciente (Conselho Federal de Odontologia 2012).

Além do envolvimento dessas categorias profissionais, o conhecimento se expandiu muito. Hoje, a profissão de cirurgião-dentista se divide em várias especialidades. É muito comum o paciente consultar mais de um especialista a fim de dar continuidade e concluir seu tratamento. Algumas vezes, essa movimentação ocorre em uma mesma unidade, com múltiplas especialidades; em outras, o paciente precisa deslocar-se entre consultórios distantes um do outro. Compreende-se, portanto, que promover a articulação do cuidado odontológico não é tarefa simples. Muitas vezes ocorre a perda de continuidade e a fragmentação do processo de trabalho, favorecendo o acontecimento de EA.

\section{Prática solitária e afastamento da discussão sobre o assunto}

O cuidado odontológico é de modo predominante ambulatorial. O atendimento realizado em ambiente hospitalar é reservado, principalmente, aos procedimentos relacionados às especialidades de cirurgia e traumatologia bucomaxilofacial e odontologia hospitalar. Como a discussão sobre a segurança do paciente tem se intensificado nos hospitais (mais afeito a campanhas, cursos e maior controle dos EA que nos ambientes ambulatoriais), em tese, apenas essa reduzida parcela dos profissionais de odontologia, a que trabalha em hospitais, teria maior proximidade com o assunto, e a maior parte se encontraria apartada do debate.

Ainda em relação ao ambiente de trabalho, de forma distinta do hospital, onde os casos clínicos, em geral, costumam ser conversados entre os pares, na prática odontológica, predominantemente solitária, muitas vezes, o cirurgião-dentista se vê obrigado a tomar decisões durante o atendimento em seu consultório, prescindindo de outro olhar, o que poderia ser valioso para dirimir dúvidas, ajudar a direcionar condutas e até evitar erros. 

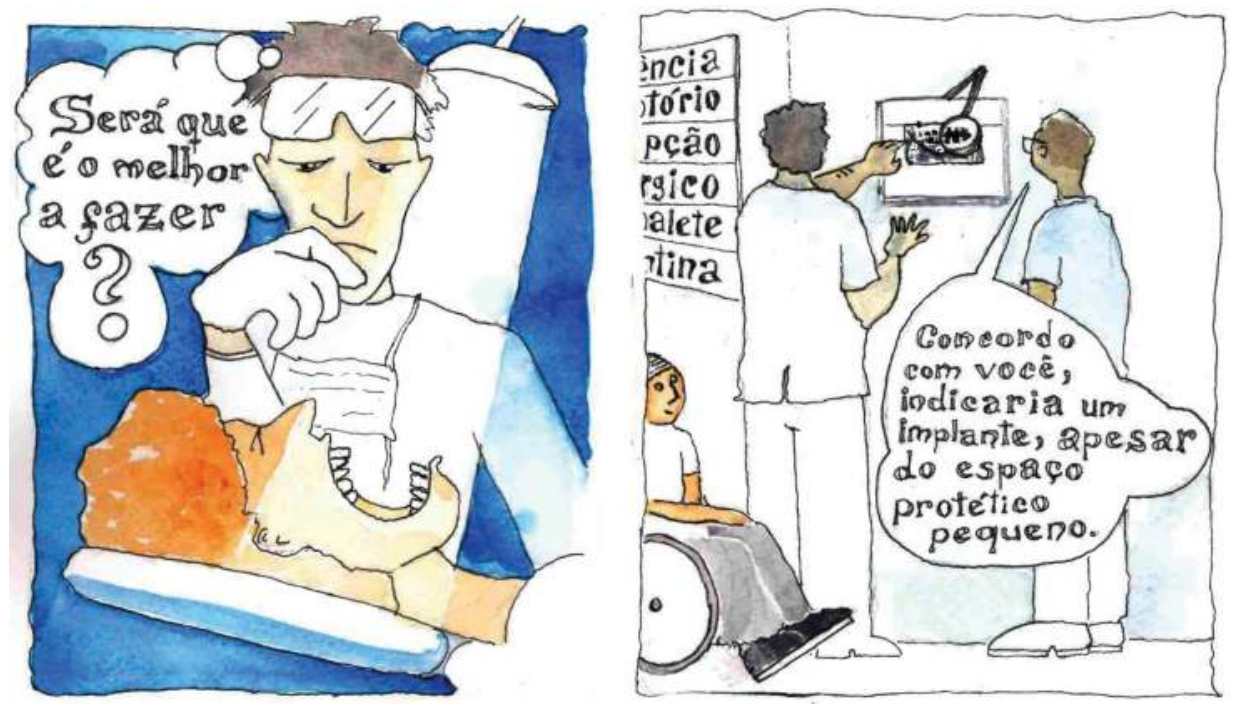

Por outra vertente, em relação a seu processo de trabalho, ainda que o ideal seja dispor de um técnico ou um auxiliar em saúde bucal para realizar o trabalho a quatro mãos, muitas vezes, o cirurgião-dentista trabalha sozinho e em consultórios individualizados. Esse isolamento dificulta a discussão sobre os incidentes que, quando ocorrem, diversas vezes, ficam restritos ao conhecimento do profissional e do paciente, em especial quando resolvidos sem que se pare para compreender os motivos da ocorrência.

Outro aspecto é que, diante de uma complicação do tratamento ou uma urgência odontológica, o paciente, muitas vezes, não volta ao mesmo profissional, recorre às unidades de emergência hospitalar ou a outro cirurgião-dentista. Nesse caso, o profissional que possa ter cometido um erro e ocasionado um EA não tomará conhecimento do problema e, dessa forma, não terá oportunidade de reavaliar e compreender a situação de modo a buscar evitar novos acontecimentos.

Por último, apesar de amplamente utilizado o bordão "errar é humano", nem mesmo para o profissional de saúde é simples internalizar que o erro é inerente à sua condição humana. Assim, a inadmissão do erro, que obscurece a discussão do EA, também pode estar associada ao medo do afastamento da clientela e à perda de credibilidade, posto que, na maior parte dos países, o cuidado odontológico é de modo predominante privado, e a escolha do cirurgião-dentista embute a confiança do paciente na sua capacidade e qualificação técnica, diretamente associada ao ideário vigente de que o bom profissional não erra. 


\section{A crescente complexidade tecnológica}

Conforme as demais áreas da Saúde, a complexidade tecnológica em odontologia só vem aumentando ao longo do tempo. Se, por um lado, isso é bom, porque facilita diagnósticos e agiliza a terapêutica, por outro, é preocupante, uma vez que toda a sofisticação que faz parte do dia a dia do atendimento odontológico implica ampliação do risco da ocorrência de EA.

Alarga-se, a cada dia, a gama de dispositivos essenciais à prática odontológica. Hebballi et al. (2015) utilizaram, como fonte de dados, o sistema Manufacturer and User Facility Device Experience (Maude), mantido pela agência estadunidense Food and Drug Administration (FDA), e realizaram um levantamento dos problemas relacionados aos dispositivos utilizados em odontologia, notificados no período de $1^{\circ}$ de janeiro de 1996 a 31 de dezembro de 2011 . O estudo identificou que aqueles relativos aos dispositivos para implantes dentários foram os mais frequentes; encontrados, todavia, problemas mais raros, ou pelo menos pouco conhecidos, como hematológicos e neurológicos, atribuídos à utilização de adesivos com zinco para a fixação de próteses removíveis.

Outros exemplos podem ilustrar a problemática:

* a sedação consciente, usada para reduzir a ansiedade e aumentar a colaboração do paciente diante do tratamento odontológico, envolve riscos, tais como: complicações respiratórias, danos aos sistemas imunológicos e hematológicos, alucinações; havendo, ainda, como desvantagem, a possibilidade de mascarar os sintomas de uma emergência médica (Corcuera-Flores et al. 2016);

* exames de imagem utilizados constantemente para auxiliar nos diagnósticos e conduzir terapêuticas expõem profissionais e pacientes à radiação ionizante (Nenad et al. 2016);

熯 equipamentos criados a fim de agilizar procedimentos, como os instrumentos rotatórios, para tratamentos endodônticos, e os equipamentos ultrassônicos, para remoção de tártaro, por exemplo, precisam de muita habilidade e treinamento para seu manejo; e

路os registros do atendimento odontológico, por meio eletrônico, agilizam a comunicação, mas exigem, porém, padronização e informações completas para que a comunicação inadequada não prejudique a segurança do paciente (Tokede et al. 2016). 


\section{Para refletir}

Como você avalia que as peculiaridades do cuidado odontológico discutidas até este momento poderiam ser administradas em benefício da segurança do paciente odontológico?

\section{Os eventos adversos no cuidado odontológico}

A literatura revela que muitos danos podem advir do cuidado odontológico. Entre outros estudos, destaca-se o de Perea-Pérez et al. (2014), no qual os autores analisaram 4.149 ações judiciais na Espanha, nos anos de 2000 a 2010. Nessas ações, 415 incidentes foram atribuídos à odontologia. O dano mais comum foi a perda de elementos dentários. Também encontrados danos permanentes aos troncos nervosos, lesões ao globo ocular, perda óssea significativa, lesão crônica do seio maxilar e, até mesmo, a morte do paciente. Os autores também citam dois outros amplos estudos: Thusu, Panesar, Bedi (2012) e Hiivala, Mussalo-Rauhamaa, Murtomaa (2013). No primeiro, analisados 2.339 incidentes, reportados anonimamente na Inglaterra, de janeiro a dezembro de 2009. Desses, 327 relacionados à odontologia. No segundo, os autores analisaram questionários respondidos por 1.041 dentistas finlandeses, em que se perguntou o número e o tipo de incidente ocorrido nos últimos 12 meses, em sua prática. Como resultado, quase um terço dos dentistas relatou algum incidente, dos quais pouco mais da metade foi considerado EA.

Outro estudo importante foi uma revisão de literatura que reuniu 182 artigos científicos e identificou 270 danos odontológicos temporários ou permanentes, inclusive óbito. Muitos EA levaram à necessidade de tratamento hospitalar de emergência ou à internação/internamento. Os EA mais frequentes estavam associados ao tratamento tardio, desnecessário ou a progressão da doença por erro de diagnóstico. Encontradas reações alérgicas/hipersensibilidades e infecções sistêmicas, injeção acidental de substâncias, aspiração de corpo estranho, anorexia nervosa associada ao tratamento ortodôntico, entre outras (Obadan, Ramoni, Kalenderian 2015).

Em 2013, Kalenderian et al. (2013), inspirados na ferramenta sugerida pelo Institute for Healthcare Improvement (IHI) para rastreamento de EA ambulatoriais, propuseram e testaram um conjunto de rastreadores para detectar EA em registros odontológicos (triggers tools dental)
No Capítulo 10 deste livro, "A segurança do paciente e o diagnóstico", você poderá recordar conceitos importantes relacionados ao erro diagnóstico. 
por meio de nova análise retrospectiva de registros em prontuários/ processos clínicos eletrônicos, mas que, segundo os autores, também se aplicariam aos prontuários/processos clínicos físicos. O instrumento foi testado durante um semestre em todos os pacientes atendidos em uma faculdade de odontologia, ao mesmo tempo que foi levantada uma amostra aleatória de 50 pacientes para comparação. Os rastreadores acionaram 315 registros, dos quais 158 (50\%) foram positivos para um ou mais EA, enquanto dos 50 registros selecionados, 17 (34\%) foram positivos para pelo menos um EA (Kalenderian et al. 2013).

Tomando por base uma revisão desses estudos e de outros, além das complicações relacionadas em livros didáticos da área, Corrêa e Mendes (2017) propuseram uma classificação dos tipos de EA, disposta no Quadro 1, a seguir.

Quadro 1 - Classificação dos tipos de eventos adversos em odontologia

\begin{tabular}{|l|l|}
\hline $\begin{array}{l}\text { Tipos de eventos adversos em } \\
\text { odontologia }\end{array}$ & Exemplos de evento adverso \\
\hline $\begin{array}{l}\text { Infecção associada ao cuidado } \\
\text { odontológico }\end{array}$ & $\begin{array}{l}\text { Alveolite, perimplantite, infecção endodôntica que podem agravar-se para infecçães } \\
\text { odontogênicas complexas, como a angina de Ludwig. }\end{array}$ \\
\hline $\begin{array}{l}\text { Dano por intervenção } \\
\text { odontológica }\end{array}$ & $\begin{array}{l}\text { Danos por aspiração/deglutição de corpo estranho, danos por extravasamento ou deglutição } \\
\text { de substâncias químicas, descalcificação de esmalte/cáries relacionadas ao tratamento } \\
\text { ortodôntico, distúrbios de articulação temporomandibular, exodontia de dente trocado, } \\
\text { fraturas ósseas e dentárias, hemorragia/hematoma, enfisema subcutâneo, necrose óssea } \\
\text { e de estruturas moles, lesão de seio maxilar, lesão neurológica, lesão de músculos da face/ } \\
\text { da gordura de Bichat, luxação dentária, maceração/laceração/abrasão/queimaduras orais/ } \\
\text { periorais, reabsorção/perfuração radicular. }\end{array}$ \\
\hline $\begin{array}{l}\text { Dano por atraso ou falha no } \\
\text { diagnóstico }\end{array}$ & $\begin{array}{l}\text { Danos pulpares, sinusite, reabsorção radicular, evolução cariosa, doenças periodontais } \\
\text { (gengivite, perda de suporte ósseo, perda de gengiva inserida). }\end{array}$ \\
\hline Alergia & \begin{tabular}{l} 
Alergia ao látex, choque anafilático, alergia ao anestésico local. \\
\hline
\end{tabular}
\end{tabular}

Fonte: Corrêa, Mendes (2017).

O objetivo dos autores foi construir, com a ajuda de um painel de especialistas, um instrumento que contivesse um conjunto de elementos para rastrear EA em odontologia, conforme disposto no Quadro 2, a seguir.

Quadro 2 - Rastreadores de eventos adversos em odontologia ambulatorial

1. Necessidade de retratamento de um mesmo dente ou necessidade de refazer um mesmo procedimento concluído há menos de 12 meses.

2. Lesões ocorridas no ambiente (ambulatório/consultório de odontologia) que não foram causadas pelo tratamento odontológico, propriamente dito (por exemplo, quedas da própria altura ou choque entre o corpo do paciente e equipamentos/instrumentos). 
Quadro 2 - Rastreadores de eventos adversos em odontologia ambulatorial (cont.)

3. Complicações na área do procedimento durante o tratamento odontológico (por exemplo: parestesia, exodontia de dente errado, laceração de tecidos moles, lesão por extravasamento de substâncias químicas, lesão ao globo ocular, aspiração e/ou deglutição de corpo estranho).

4. Complicações sistêmicas durante ou após o tratamento odontológico.

5. Infecções decorrentes do cuidado odontológico.

6. Retorno para atendimento de urgência seja por dor e/ou edema ou outro motivo.

7. Complicações relacionadas à prescrição medicamentosa.

8. Insatisfação expressa ou documentada pelo paciente ou por sua família (incluir documentos, queixas documentadas, conflitos entre o paciente/família e profissionais).

9. Alteração não planejada de plano terapêutico.

10. Óbito.

11. Falha ou fratura de instrumento durante o tratamento.

12. Cirurgia de Caldwell-Luc/acesso ao seio maxilar.

13. Realização de enxerto ou uso de agregado de trióxido mineral (MTA).

14. Quaisquer outras complicações que não se incluam nos itens anteriores.

Fonte: Corrêa, Mendes (2017)

Kalenderian et al. (2017) também propuseram uma classificação para EA em odontologia, acessível por intermédio do artigo publicado por eles e recomendado para leitura na lateral desta página. Os autores fizeram um teste-piloto utilizando a classificação e, em uma revisão retrospectiva de 958 prontuários/processos clínicos, encontraram 101 EA, nos quais a dor e a infecção foram os tipos mais comuns.

\section{Para refletir}

Qual sua percepção acerca dos danos ocasionados pelo atendimento odontológico? Como você agiria a fim de tentar minimizar esses acontecimentos em instituições ambulatoriais e hospitalares?

\section{Recomendações para mitigar os incidentes no cuidado odontológico}

Diferentemente da manufatura obtida no processo de trabalho em uma fábrica, por exemplo, o resultado do trabalho manual empreendido na busca do reestabelecimento das funções mastigatórias não acontece de maneira uniforme, por mais que o processo seja padronizado.
Pesquisadores/investigadores estão trabalhando para catalogar os tipos de EA que ocorrem no consultório odontológico num repositório central/fundamental.

O projeto é intitulado Developing a patient safety system for dentistry e está disponível em: https://projectreporter.nih.gov/ project_info_description.cfm?aid= 8588913\&icde=19506063\&ddpara $m=\& d d v a l u e=\& d d s u b=\& c r=1 \& c s b=$ default\&cs=ASC

No artigo a seguir, constam planilhas com a classificação dos EA quanto ao tipo e à gravidade, que podem ser muito úteis aos serviços: Classifying Adverse Events in the Dental Office, de Kalenderian E et al. J Patient Saf. 2017 Jun 30. doi: 10.1097/ PTS.0000000000000407. [Epub ahead of print] 
O cuidado odontológico é muito dependente do profissional que atua de forma direta sobre o paciente, sendo de extrema importância valorizar o momento do atendimento. Além da capacitação e atualização constante, o profissional precisa de um ambiente estruturado e tranquilo, com material e tempo suficientes para a execução dos procedimentos. Outras medidas, no entanto, também possibilitam dirimir o problema ou reduzir o dano produzido pelo incidente. A seguir, se discorrerá sobre algumas recomendações que pretendem alcançar este objetivo.

\section{Interação entre os profissionais de saúde}

A interação entre o cirurgião-dentista e outros profissionais da saúde é imprescindível em benefício da segurança do paciente. Essa aproximação, desejável em quaisquer casos, é fundamental em algumas ocorrências específicas, tais como:

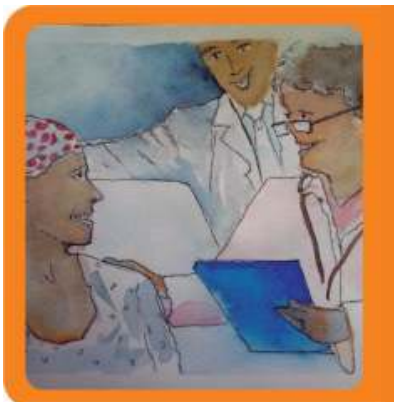

Pacientes em tratamento oncológico - o paciente submetido ao tratamento antineoplásico tem a chance de desenvolver complicações, como: i) xerostomia, que é frequente quando ocorrem danos às glândulas salivares; ii) infecção por cândida, especialmente quando o paciente usa prótese bucal; iii) cárie de radiação, favorecida também quando há baixo fluxo salivar; iv) lesões inflamatórias e/ou ulcerativas na mucosa oral e/ou gastrointestinal, denominadas mucosite, que resultam em grande desconforto ao paciente e prejuízo a sua capacidade do comer, deglutir e falar; v) osteonecrose de mandíbula/maxila que pode ocorrer de forma espontânea, mas também associada aos procedimentos orais invasivos (exodontia, cirurgia periodontal, implantes osteointegrados) em pacientes que fizeram ou fazem uso de bisfosfonatos.

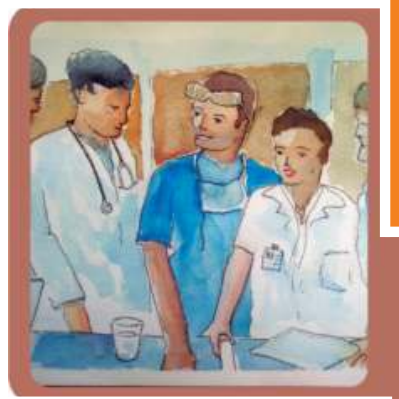

Portanto, em conjunto com outros profissionais, a saúde oral do paciente oncológico deve ser muito bem avaliada antes e acompanhada durante e após a instituição de terapia antineoplásica, a fim de evitar ou reduzir a necessidade de posteriores intervenções odontológicas, em especial, as mais invasivas (Figueiredo et al. 2017.)

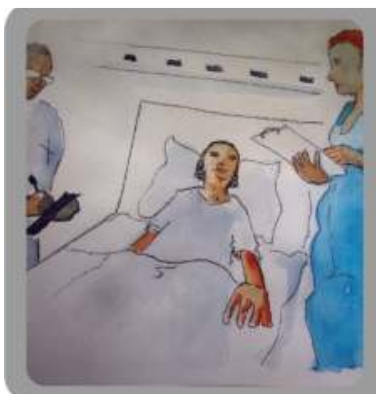

Pacientes acompanhados por múltiplos especialistas - um bom exemplo de problema que pode acontecer quando um paciente passa de um cirurgião-dentista para outro é a exodontia trocada. É muito comum o encaminhamento para exodontia de elementos dentários com finalidade ortodôntica ou protética, sendo imprescindível a transferência meticulosa da informação do campo clínico para o local operatório.

Pacientes internados - em especial aqueles que se encontram em unidades fechadas (UTI), ou aqueles que não estão internados, mas que estão sistemicamente comprometidos, principalmente no que tange à interação entre as múltiplas terapias a que estão sujeitos, visando a diminuir agravos em sua saúde geral. 


\section{Investimento na cultura de segurança do paciente}

Diante de um EA, a tradição dominante é buscar a culpa no profissional que prestou diretamente o cuidado, e atribuir a esse indivíduo o ônus do problema com restrições e punições. Mas há outro enfoque, o que leva em conta o sistema no qual os erros humanos são considerados parte, e não causas únicas para a ocorrência de incidentes. Nesse, incluem-se as "armadilhas" do local de trabalho e dos processos organizacionais que podem propiciar erro. São as referidas "condições latentes", conforme denominou Reason (2000).

Sob esse enfoque, assume-se a premissa que, embora não se possa mudar a condição humana, é possível mudar as condições em que os seres humanos trabalham. A ótica de culpabilidade do indivíduo favorece a tendência de se omitir os erros, o que isso dificulta o combate e o gerenciamento/gestão da questão. No entanto, ao se reconhecer as falhas do sistema e estimular a exposição dos erros e seus fatores contribuintes, abre-se espaço para o investimento em barreiras de defesa para evitar o problema (Reason 2000).

Todavia, mesmo sob o enfoque sistêmico, que é mais favorável, há uma situação que merece destaque, pois pode fragilizar sobremaneira a segurança do paciente odontológico: a diferença de perspectiva entre os que tomam as decisões financeiras e aqueles que não o fazem. Ramoni et al. (2014) apontam para essa situação e reforçam a importância de se identificar e buscar reduzir as condições latentes para a ocorrência do erro. É importante salientar que, mesmo sob pontos de vistas diferentes, deve prevalecer a convergência do foco direcionada à saúde do paciente. Uma economia equivocada na aquisição de equipamentos e de material de consumo, ou mesmo na redução de tempo clínico de atendimento com o objetivo de atender à demanda, pode se converter em EA e ter custos elevados, não somente em recurso monetário, mas também para a integridade física do paciente e a credibilidade da organização e de seus profissionais.

Outro ponto de fragilidade na cultura do atendimento em saúde, que possibilita a ocorrência do EA, é o pouco envolvimento do paciente e de seus familiares. Um estudo realizado na Finlândia demonstrou que os pacientes e seus familiares são capazes de identificar vários incidentes e circunstâncias perigosas que não seriam capturados de outro modo. A autora frisa a importância do estímulo aos relatos de incidentes não somente por parte dos profissionais, como também dos pacientes e de
No Capítulo 4 deste livro, "O erro e as violações no cuidado de saúde", você poderá relembrar o referencial teórico para compreender a importância da identificação precoce das situações vulneráveis à ocorrência do erro. 
No Capítulo 4 do livro Segurança do paciente: criando organizações de saúde seguras, você poderá relembrar os conceitos de cultura de segurança, assim como a importância de sua implementação para o cuidado de saúde. seus familiares, além do desenvolvimento de maneiras proativas para intervir rapidamente mediante a queixa (Hiivala et al. 2016).

Importante acrescentar que a disposição de leis e/ou regulamentações nacionais relativas à segurança dos pacientes aponta para o nível de conscientização do problema, conforme colocam Yamalik e Van Dijk (2013). Os autores relatam que muitos países não dispõem de regulamentação própria, mesmo diante do entendimento de que, para a prática odontológica segura, são imprescindíveis o envolvimento e a familiarização de toda a sociedade com o assunto. De acordo com os autores, investir na cultura é essencial, e o primeiro passo seria sua contínua avaliação com instrumentos confiáveis. Para o desenvolvimento da cultura de segurança do paciente, apostam na implementação de medidas, tais como:

䗉 introdução e desenvolvimento de programas de gestão de recursos e adoção de práticas clínicas baseadas em evidências, com a elaboração de protocolos;

partilha de experiências bem-sucedidas;

橉 treinamento com equipe multidisciplinar, com a participação da liderança;

* imposição de limites que não poderiam ser ultrapassados na prática diária (a não ser por uma excepcionalidade, e com a justificativa para a transposição desse limite registrada em prontuário/processo clínico), por exemplo: não realizar tratamento endodôntico sem isolamento absoluto, não reutilizar recipientes descartáveis, não prescrever nenhuma droga sem consultar o registro clínico do paciente e sem perguntar diretamente a ele sobre alergias ou outros problemas de saúde, e nunca fazer uma tomada radiográfica em mulher em idade fértil sem proteção e sem perguntar sobre possível gravidez.

Esses mesmos autores preconizam, ainda, a redução da influência hierárquica e consideram a promoção da segurança do paciente uma obrigação ética, que a qualidade do cuidado está diretamente ligada ao sucesso do resultado e, por conseguinte, à redução da probabilidade de ocorrência de EA e seus custos econômicos associados, inclusive os de litígio.

Merece destaque a Espanha, que conta com o Observatorio Español para una Seguridad del Paciente Odontológico (Oespo) e um plano para o gerenciamento/gestão do risco no cuidado odontológico, composto dos seguintes objetivos: 
* promover a cultura de segurança dos pacientes no cuidado odontológico;

*ampliar os termos de segurança do paciente;

滕 criar uma estrutura nacional para a gestão de riscos;

* desenvolver ferramentas para a identificação, análise e avaliação dos riscos;

路 estabelecer linhas de informação oriundas de diferentes fontes (bibliográficas, organizações semelhantes ao Oespo, queixas ou reclamações, denúncias anônimas voluntárias);

* estabelecer medidas para prevenir os riscos tanto em nível de um local específico (quando a existência de um risco específico é resultante de circunstância em particular, que foi verificada em determinado local), como em nível geral (quando envolve riscos conhecidos como: prevenção de infecções em consultórios odontológicos, prevenção de erro cirúrgico, prevenção de erro na prescrição de medicamentos), e que possam ser traduzidas em recomendações simples de boas práticas clínicas;

綵 promover a formação contínua em segurança do paciente;

* promover a pesquisa/investigação na área (Perea-Pérez et al. 2011a).

\section{Algumas intervenções propostas para a melhoria da segurança do paciente odontológico}

A literatura aponta algumas intervenções adotadas nas diversas áreas da Saúde que podem ser implementadas na clínica odontológica. São elas: 


\section{Listas de verificação}

-Instrumento que leva em conta conceitos básicos para a padronização do procedimento a fim de evitar erros ou distrações. Estudos buscando construir listas têm sido empreendidos não somente nos tratamentos mais invasivos, como o tratamento endodôntico (DÍAZ-FLORES-GARCÍA et al. 2014) e a exodontia (PEREA-PÉREZ et al. 2011b), mas também na prevenção de erros no diagnóstico de trismo ocasionado por câncer (BEDDIS et al. 2014) e na busca de melhoria da qualidade da imagem radiográfica, a fim de reduzir exposições desnecessárias (NENAD et al. 2016). Vale ressaltar que em uma revisão sistemática realizada por Bailey et al. (2015) com o objetivo de encontrar intervenções para a melhoria da segurança do paciente odontológico, a lista de verificação para a realização de exodontia foi considerada o único instrumento comprovadamente eficaz.

\section{Notificações de incidentes}

-Promover um ambiente amigável e seguro à notificação de incidentes e dar o feedback das ações tomadas diante das notificações são práticas essenciais para que os profissionais se sintam estimulados a notificar incidentes e EA. As notificações contribuem para o real dimensionamento do problema e ajudam a pensar no direcionamento e na priorização das medidas que devem ser tomadas para combater o problema (LEONG et al. 2008).

\section{Painel de controle}

- Um painel demonstrativo exposto no ambiente interno ao serviço para que os profissionais acompanhem a evolução dos incidentes odontológicos pode aumentar a conscientização sobre o problema, incentivar uma cultura de segurança do paciente e dar foco a questões relevantes (PEMBERTON et al. 2014).

\section{Treinamento e suporte para emergências médicas}

-As emergências médicas, embora não rotineiras, quando acontecem costumam gerar muitos transtornos. Importante que o local de atendimento odontológico tenha suporte medicamentoso e se promova treinamentos dos profissionais para esse tipo de ocorrência (TAN 2011).

No Reino Unido, na Universidade de Manchester, Bailey (2015) reuniu um grupo de 12 cirurgiões-dentistas muito experientes (25 anos de prática docente e clínica, em média) com o propósito de extrair opi niões e ideias para manter ou melhorar as práticas de segurança. O autor colheu que uma das maiores dificuldades desse grupo estava em lidar com a história médica dos pacientes (polifarmácia e comorbidades/comorbilidades); e esses cirurgiões-dentistas consideram importante elevar níveis de habilidades e competências, acreditam no uso de salvaguardas e de ferramentas para aumentar a segurança do paciente, na importância de uma comunicação eficaz e da prática reflexiva. As melhorias sugeridas foram: melhor compartilhamento de informações com outros profissionais da saúde; maior acesso a orientações e ferramentas educacionais; adoção de protocolos de prática clínica, trabalho em equipe e uso de sistemas de gráficos universais para limitar a ambiguidade. 
Por último, vale trazer o estudo de Perea-Pérez et al. (2015), que corrobora algumas medidas já referidas e apresenta outras. Os autores analisaram uma série de danos oriundos do cuidado odontológico e verificaram que grande parte era devido a um pequeno número de circunstâncias. A partir disso, sugeriram 11 procedimentos básicos para a prática da segurança do paciente odontológico. São eles:

路 desenvolver uma cultura de segurança do paciente e um sistema de cuidados de saúde focado na priorização da segurança do paciente;

橉 cuidar da qualidade dos registros clínicos;

* checar procedimentos para a limpeza, desinfecção, esterilização e preservação dos instrumentos clínicos;

蝶 exercer extremo cuidado quando for prescrever medicamentos;

* limitar a exposição do paciente à radiação ionizante ao extremamente necessário;

滕 nunca reutilizar embalagens ou substâncias indicadas para um único uso clínico;

proteger os olhos do paciente durante os procedimentos;

䗉 estabelecer barreiras para prevenção de ingestão ou inalação de materiais e pequenos instrumentos;

usar listas de verificação em todos os procedimentos cirúrgicos;

monitorar o início e a progressão da infecção na cavidade oral; e

滕 ter um protocolo para emergências de ameaça de vida na clínica dentária.

\section{A necessidade de pesquisas/investigação na área de segurança do paciente odontológico}

A segurança na execução dos procedimentos sempre foi motivo de preocupação na condução do cuidado odontológico. De fato, o foco na melhoria da prática clínica e no desenvolvimento de materiais odontológicos é necessário ao aprimoramento dos cuidados com a saúde bucal e não se pode prescindir disso. Mas, somente a intervenção na interface direta entre o paciente e o profissional, por exemplo, a padronização de procedimentos e/ou o aprimoramento de tecnologias, não se mostra suficiente para solucionar o problema do EA. 
A segurança do paciente, como disciplina, se propõe a iluminar outras facetas do incidente, tais como: a necessidade do envolvimento do paciente e seus familiares no cuidado, o papel da liderança e da gestão clínica, a necessidade do envolvimento da indústria de material odontológico, a cultura da culpa. A odontologia, em especial nos últimos anos, vem caminhando nessa direção.

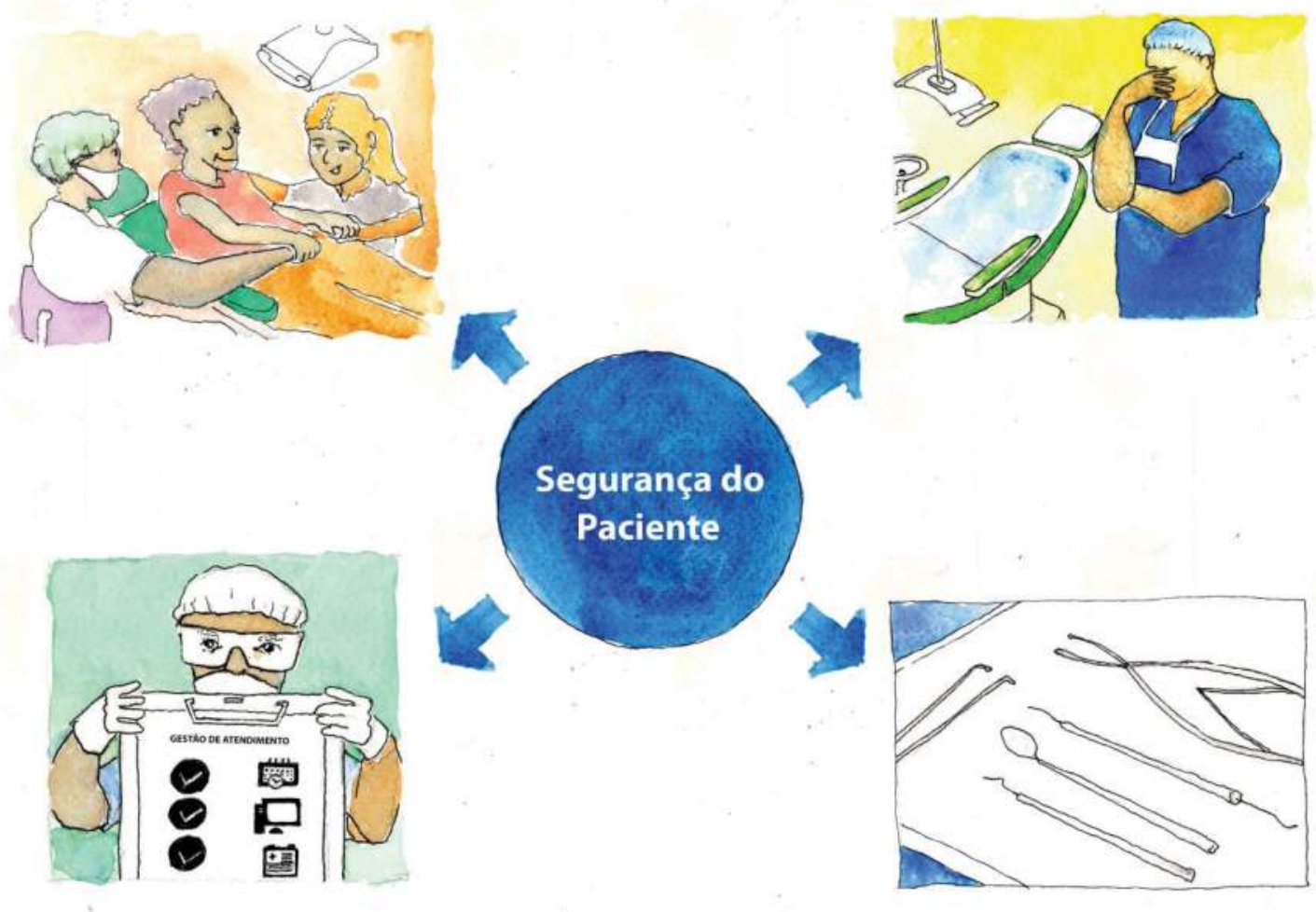

Exemplos de estudos encontrados apresentam fontes e técnicas diversas congruentes com estudos realizados nas demais áreas da Saúde e confirmam a importância dessas ferramentas e de métodos para a evolução do aprendizado na área. Cita-se alguns deles:

慕análise de bases de dados administrativos/judiciais (Perea-Pérez et al. 2014; Thusu, Panesar, Bedi 2012);

* revisões de prontuários (Kalenderian et al. 2013, 2017);

路 respostas a inquéritos e questionários (Leong et al. 2008; Ramoni et al. 2014; Tan 2011);

opiniões de especialistas/grupos focais (Bailey 2015; Yamalik, Van Dijk 2013);

橉 estudo de casos (Beddis et al. 2014); 
revisão de literatura (Bailey et al. 2015; Obadan, Ramoni, Kalenderian 2015);

análise de resultado de projeto de intervenção (Nenad et al. 2016).

Entretanto, ainda existem hiatos no conhecimento para os quais novos estudos devem ser direcionados, principalmente nos países em desenvolvimento e nas economias de transição, tais como o aprofundamento no conhecimento da magnitude e da tipologia dos EA em odontologia, o crescimento e avaliação de iniciativas para a segurança do cuidado odontológico, a participação da indústria e das escolas de formação profissional.

Fica como alerta, no entanto, o cuidado que se deve ter com as dificuldades e os vieses comuns às pesquisas/investigações sobre segurança do paciente em todas as áreas (nos sistemas de notificação/reporte voluntária, em geral, há subnotificação/reporte; os processos judiciais costumam identificar, principalmente, os relatos mais graves; os registros clínicos, muitas vezes, estão incompletos dificultando as revisões retrospectivas de prontuários/processos clínicos; os estudos com grupos focais se restringem às experiências dos participantes; entre outros), que podem ser mais nítidos na odontologia pelas características próprias da profissão já discutidas anteriormente.

\section{Considerações finais}

Conhecer os tipos e compreender as causas dos EA são passos fundamentais que objetivam desenvolver barreiras, cujo propósito é prevenir ou minimizar os danos decorrentes do cuidado odontológico. É essencial a realização de pesquisas/investigações não somente no âmbito da clínica, mas também em políticas públicas, na indústria, na gestão dos serviços e nas escolas de formação para que o cuidado odontológico possa caminhar junto aos demais no aprimoramento da qualidade dos serviços de saúde.

Essencial, também, que os profissionais que atuam na área da Saúde Bucal tenham condições de trabalho adequadas a fim de que possam desempenhar suas funções, do mesmo modo que o paciente e seus familiares precisam estar engajados no processo, pois a manutenção da saúde oral é diretamente dependente do cuidado desenvolvido em casa.
No Capítulo 9, "Investigação/ pesquisa em segurança do paciente", do livro Segurança do paciente: criando organizações de saúde seguras, você poderá compreender melhor a relevância da pesquisa/investigação em segurança do paciente para os serviços de saúde, bem como encontrar referências e apoio para seu desenvolvimento. 


\section{Referências}

Bailey E. Contemporary views of dental practitioners' on patient safety. Br Dent J. 2015 Dec;219(11):535-40.

Bailey $\mathrm{E}$, et al. Systematic review of patient safety interventions in dentistry. BMC Oral Health. 2015;15(1):152.

Beddis HP, et al. Temporomandibular disorders, trismus and malignancy: development of a checklist to improve patient safety. Br Dent J. 2014;217(7):351-5.

Conselho Federal de Odontologia (BR). Consolidação das normas para procedimentos nos Conselhos de Odontologia. Basília, DF: CFO; 2012 [citado 2019 jan 5]. Disponível em: http://cfo. org.br/wp-content/uploads/2009/10/consolidacao.pdf.

Corcuera-Flores JR et al. Current methods of sedation in dental patients - a systematic review of the literature. Med Oral Patol Oral Cir Bucal. 2016 Sep 1;21(5): e579-86.

Corrêa CDTSO, Mendes W. Proposta de um instrumento para avaliar eventos adversos em odontologia. Cad. Saúde Públ. 2017;33(11):e00053217.

Diaz-Flores-Garcia, V. et al. Proposal of a "checklist" for endodontic treatment. J Clin Experim Dent. 2014;6(2):e104-e109.

Figueiredo PTS, et al. Odontologia em oncologia. In: Santos M, et al. Diretrizes oncológicas. Rio de Janeiro: Elsevier; 2017.

Hebballi N B, Ramoni R, Kalenderian E, Delattre V F, Stewart D C, Kent K, et al. The dangers of dental devices as reported in the Food and Drug Administration Manufacturer and User Facility Device Experience Database. J Am Dent Assoc. 2015 Feb;146(2):102-10. doi: 10.1016/j. adaj.2014.11.015.

Hiivala N. Patient safety incidents, their contributing and mitigating factors in dentistry [tese]. Helsinki: Faculty of Medicine, University of Helsinki; 2016.

Hiivala N, Mussalo-Rauhamaa H, Murtomaa H. Patient safety incidents reported by finnish dentists: results from an internet-based survey. Acta Odontol Scand. 2013;71(6):1370-7.

Kalenderian $\mathrm{E}$, et al. An adverse event trigger tool in dentistry: a new methodology for measuring harm in the dental office. J Am Dent Assoc. 2013 July; 144(7):808-14.

Kalenderian $\mathrm{E}$, et al. Classifying adverse events in the dental office.

J Patient Saf. 2017 Jun 30. doi: 10.1097/PTS.0000000000000407. [Epub ahead of print]

Leong $\mathrm{P}$, et al. Attitudes toward patient safety standards in U.S. dental schools: a pilot study. Dent Educ. 2008 Apr;72(4):431-7.

Nenad MW. et al. A dental radiography checklistas a tool for quality improvement. Journal of Dental Hygiene 2016;90(6):386-93.

Obadan EM, Ramoni RB, Kalenderian E. Lessons learned from dental patient safety case reposts. J Amer Dental Assoc. 2015;146(5):318-26.

Pemberton MN, et al. Measuring patient safety in a UK dental hospital: development of a dental clinical effectiveness dashboard. Br Dent J. 2014 Oct;217(7):375-8.

Perea-Pérez B, et al. Analysis of 415 adverse events in dental practice in Spain from 2000 to 2010. Med Oral Patol Oral Cir Bucal. 2014;19(5):500-5. 
Perea-Pérez B, et al. Patient safety in dentistry: dental care risk management plan. Med Oral Patol Oral Cir Bucal. 2011s Sept.;16(6):e805-9.

Perea-Pérez B, et al. Proposal for a 'surgical checklist' for ambulatory oral surgery. Int J Oral Maxillofacial Surg. 2011b Sept;40(9):949-54.

Perea-Pérez B, et al. Eleven basic procedures/practices for dental patient safety. J Patient Saf. 2015 Oct.

Ramoni $\mathrm{R}$, et al. Open wide: looking into the safety culture of dental school clinics. J Dent Educ. 2014 May;78(5):745-56.

Reason J. Human error: models and management. West J Med. 2000;172(6):393-6.

Tan GM. A medical crisis management simulation activity for pediatric dental residents and assistants. J Dent Educ. 2011;75(6):782-90.

Thusu S, Panesar S, Bedi R. Patient safety in dentistry: state of play as revealed by a national database of errors. Br Dent J. Online2012 Aug;213(3): E3. Disponível em: https://www. researchgate.net/publication/230644947_Patient_Safety_in_Dentistry_state_of_play_as_revealed_ by_a_national_database_of_errors.

Tokede O, Ramoni RB, Patton M, Da Silva JD, Kalenderian E. Clinical documentation of dental care in an era of EHR use. J Evid Based Dent Pract. 2016; 16(3):154-60. doi:10.1016/j. jebdp.2016.07.001.

Yamalik N, Perea-Pérez B. Patient safety and dentistry: what do we need to know?: Fundamentals of patient safety, the safety culture and implementation of patient safety measures in dental practice. Int Dent J 2012;6 (4):189-96.

Yamalik N, Van Dijk W. Analysis of the attitudes and needs/demands of dental practitioners in the field of patient safety and risk management. Int Dent J. 2013;63(6):291-7. 
Anexos 


\title{
Anexo A - Diretriz clínica para prevenção de tromboembolismo venoso
}

\author{
Isabela Ribeiro Simões de Castro, Maria Celia Andrade ${ }^{1}$, \\ Maurício Diuana Saud e Ronaldo Franklin de Miranda
}

A trombose venosa profunda e a embolia pulmonar são os agravos mais comuns de tromboembolismo venoso e constituem um importante problema de saúde pública pelo seu impacto em termos de morbimortalidade, custos e consumo de recursos. As consequências da trombose venosa profunda podem ser desde o desconforto, a síndrome pós-trombótica, os inconvenientes e os efeitos colaterais do tratamento até o desenvolvimento de embolia pulmonar, hipertensão pulmonar tromboembólica e morte. Segundo o American College of Chest Physicians (ACCP 2012), o risco aproximado de trombose venosa profunda em pacientes hospitalizados nos serviços de cirurgia geral varia entre 15 e $40 \%$.

O objetivo da diretriz clínica nos casos de tromboembolismo venoso é estabelecer a avaliação do risco e as ações de prevenção dessa complicação do cuidado hospitalar. O risco deve ser avaliado em todos os pacientes internados. A tromboprofilaxia irá depender do risco e do tipo de paciente que será analisado. A conduta sempre deve ser individualizada, atribuindo o risco trombótico versus o risco de sangramento. O nível de evidência (Cochrane) dos resultados com o uso dessa diretriz é alto. O custo de implantação da diretriz depende da gestão da organização. O tempo para implantação da diretriz é menor que 12 meses. A dificuldade de implantação da diretriz é média e depende de diversas questões, dentre elas, a cultura existente na organização de saúde.

Grau de recomendação e força da evidência:

Grau de recomendação

1 = Deve ser realizado.

2 = Provavelmente benéfico.

3 = Não é conhecido se é benefício ou malefício.

4 = Provavelmente maléfico.

5 = Maléfico.

\footnotetext{
${ }^{1}$ Maurício Diuana Saud e Ronaldo Franklin de Miranda colaboraram na atualização deste trabalho, na ausência da saudosa Maria Celia Andrade.
} 
Força da evidência

$A=$ Estudos experimentais e observacionais de melhor consistência.

$B=$ Estudos experimentais e observacionais de menor consistência.

$C=$ Relatos ou séries de casos.

D = Publicações baseadas em consensos ou opiniões de especialistas.

\section{Itens relevantes da diretriz da ACCP}

滕 Recomenda-se o uso de anticoagulantes ou de aspirina para reduzir o tromboembolismo venoso sintomático e embolia pulmonar fatal em pacientes clínicos e cirúrgicos.

* Recomenda-se o uso da heparina não fracionada para reduzir o risco de embolia pulmonar fatal em cerca de dois terços em pacientes cirúrgicos.

* Recomenda-se o uso de antagonistas da vitamina $\mathrm{K}$ para reduzir o risco de tromboembolismo venoso sintomático em cerca de quatro quintos em pacientes submetidos à artroplastia de quadril ou de joelho ou à cirurgia de fratura de quadril/fratura de anca.

Recomenda-se o uso de heparina de baixo peso molecular com duração estendida ou varfarina para reduzir o risco de trombose venosa profunda sintomática em cerca de três quintos dos pacientes submetidos à artroplastia de quadril/anca ou de joelho.

繗 Recomenda-se o uso de heparina de baixo peso molecular, danaparoide ou fondaparinux para reduzir o risco de embolia pulmonar em cerca de dois a três quintos dos pacientes clínicos, com maior risco de uso de heparina não fracionada.

* Recomenda-se o uso de heparina de baixo peso molecular para reduzir o risco de trombose venosa profunda sintomática em cerca de quatro quintos dos pacientes submetidos à cirurgia abdominal ou pélvica.

* Recomenda-se o uso de terapia antiplaquetária como eficaz para a prevenção de tromboembolismo venoso, pois reduz o risco de embolia pulmonar pela metade e de trombose venosa profunda em três quintos dos pacientes clínicos e cirúrgicos de maior risco.

* Recomenda-se o uso de heparina de baixo peso molecular, ou de baixa dose de heparina não fracionada, ou fondaparinux (grau de evidência 1B) em pacientes clínicos hospitalizados em estado grave e com aumento do risco de trombose. 
Não é recomendável o uso de profilaxia farmacológica ou profilaxia mecânica (grau de evidência lB) em pacientes com baixo risco de trombose.

滕 Não se deve prolongar a duração da tromboprofilaxia para além do período de imobilização do paciente, ou de internação aguda (grau de evidência 1B).

Recomenda-se a tromboprofilaxia mecânica com meias de compressão graduada ou compressão pneumática intermitente (grau de evidência 2C) em pacientes com maior risco de trombose, com sangramento ou alto risco de hemorragia grave.

蹸 Recomenda-se o uso de heparina de baixo peso molecular ou heparina não fracionada (grau de evidência 2C) em pacientes em estado crítico.

* Recomenda-se a tromboprofilaxia mecânica pelo uso de meias de compressão graduada, compressão pneumática intermitente e bomba de pé, pois têm a vantagem de não aumentar o sangramento. São medidas melhores que nenhuma outra profilaxia.

䟕 A hemorragia pode ocorrer: na região intracraniana, nas articulações e na ferida operatória.

* A estratificação de risco no paciente cirúrgico não ortopédico considera as cirurgias abdominais e pélvicas, bariátrica, vascular, plástica estética e plástica reconstrutiva.

滕 Consideram-se como de baixo risco os procedimentos de laparoscopia, colecistectomia, apendicectomia, prostatectomia transuretral, herniorrafia inguinal, mastectomia uni ou bilateral.

蹸 Consideram-se como de alto risco as cirurgias abdominais e pélvicas, principalmente em pacientes com neoplasia.

滕 Consideram-se fatores de risco independentes: idade $>60$ anos, história prévia de tromboembolismo venoso, câncer/cancro, anestesia maior que duas horas, repouso no leito/cama maior que quatro dias, sexo masculino, alta pontuação no escore de comorbidades/comorbilidades de Charlson, sepse, gravidez, puerpério e presença de acesso venoso central.

滕 Os escores de Caprini e de Roger podem ser utilizados como estratificação de risco de tromboembolismo venoso na população de cirurgia não ortopédica.

* Não se recomenda a profilaxia de rotina com heparina de baixo peso molecular ou heparina não fracionada (grau de evidência 2B), nem o uso profilático de antagonistas da vitamina K (grau de evidência 
2B) em pacientes ambulatoriais com câncer/cancro que não têm outros fatores de risco para tromboembolismo venoso.

Não se recomenda a tromboprofilaxia farmacológica ou a mecânica (grau de evidência 1B), ou apenas a deambulação precoce (grau de evidência 2C) em cirurgia não ortopédica com risco de tromboembolismo venoso muito baixo $(<0,5 \%)$.

跣 Recomenda-se a profilaxia mecânica, de preferência com compressão pneumática intermitente (grau de evidência 2C) em pacientes com baixo risco de tromboembolismo venoso $(\sim 1,5 \%)$.

Recomenda-se o uso de heparina de baixo peso molecular, ou a heparina não fracionada em baixa dose (grau de evidência 2B), ou a profilaxia mecânica com o compressor pneumático intermitente (grau de evidência 2C) em pacientes com risco moderado para tromboembolismo venoso $(\sim 3 \%)$, sem alto risco para complicações hemorrágicas.

* Recomenda-se a profilaxia farmacológica com heparina de baixo peso molecular ou heparina não fracionada em baixa dose (grau de evidência 1B), ou a profilaxia mecânica com meias elásticas ou compressor pneumático intermitente (grau de evidência 2C) em pacientes com alto risco de tromboembolismo venoso $(\sim 6 \%)$, sem alto risco para complicações hemorrágicas.

膦 Recomenda-se a profilaxia farmacológica (4 semanas) com heparina de baixo peso molecular (grau de evidência 1B) em pacientes com alto risco para tromboembolismo venoso submetidos à cirurgia abdominal ou pélvica por câncer/cancro.

* Recomenda-se o uso da profilaxia mecânica, até o risco da hemorragia diminuir (grau de evidência 2C), em pacientes com risco moderado a alto de tromboembolismo venoso e alto risco de complicações hemorrágicas importantes, ou nos quais as consequências da hemorragia sejam particularmente graves.

路 Recomenda-se o não uso de filtro de veia cava inferior para prevenção de tromboembolismo venoso primário e não realizar a vigilância com doppler venoso (grau de evidência $2 \mathrm{C}$ ) em pacientes de todos os grupos de risco.

踧 Recomenda-se o uso de heparina de baixo peso molecular, fondaparinux, dabigatran, apixaban, (a rivaroxabana para a artroplastia total do quadril/anca ou do joelho), baixa dose de heparina não fraccionada, antagonista de vitamina K, aspirina (grau de evidência 1B) ou o uso do dispositivo de compressão pneumática intermitente por período mínimo de 10 a 14 dias (grau de evidência 1C) em pacientes submetidos à cirurgia ortopédica de grande porte. 
* Recomenda-se o uso preferencial de heparina de baixo peso molecular, mas pode ser usado fondaparinux, apixaban, dabigatrana, rivaroxabana e heparina não fracionada (grau de evidência 2B) ou o uso dos antagonistas da vitamina $\mathrm{K}$ (grau de evidência 2C) em pacientes submetidos à artroplastia de quadril/anca e joelho.

路 Recomenda-se o apixaban e dabigatran bem como o uso de outras modalidades de profilaxia farmacológica (grau de evidência 1B), em pacientes que não aceitam injeção subcutânea de heparina de baixo peso molecular. A rivaroxabana será usada se as duas primeiras drogas não estiverem disponíveis.

路 Recomenda-se o uso de compressão pneumática intermitente durante a permanência no hospital, tendo como objetivo uma aderência de, no mínimo, 18 horas por dia (grau de evidência 2C) nos pacientes submetidos à artroplastia de quadril e joelho.

蛈 Recomenda-se o uso estendido de profilaxia após a alta hospitalar até o $35^{\circ}$ dia com as seguintes drogas, com grau de evidência 2B: heparina de baixo peso molecular e como alternativa fondaparinux, apixaban, dabigatrana, rivaroxabana, heparina não fracionada, antagonistas da vitamina $\mathrm{K}$ e aspirina em pacientes submetidos à artroplastia de quadril/anca e joelho.

路 Recomenda-se o uso de profilaxia estendida até $35^{\circ}$ dia, com as seguintes drogas: heparina de baixo peso molecular e, como alternativa, fondaparinux, heparina não fracionada, antagonistas da vitamina $\mathrm{K}$ e aspirina (grau de evidência $2 \mathrm{~B}$ ) em pacientes submetidos à correção de fratura de quadril/fratura de anca. Vale ressaltar que os novos anticoagulantes orais não estão aprovados para o uso em profilaxia de tromboembolismo venoso na cirurgia de fratura de quadril/fratura de anca.

Apesar de os fatores individuais colaborarem para o risco adicional de desenvolvimento de tromboembolismo venoso em pós-operatório de cirurgia ortopédica, sua aplicação é limitada pela falta de validação de um score de risco apropriado para a população ortopédica. Portanto, os fatores de risco individuais não são considerados seguros o suficiente para a estratificação do risco de tromboembolismo venoso nesses pacientes. A intervenção cirúrgica de grande porte determina por si só a categoria de alto risco; portanto, na ausência de contraindicação, todos os pacientes submetidos à artroplastia de quadril, joelho e fratura de quadril/ fratura de anca devem receber heparina de baixo peso molecular.

䠌 Recomenda-se o uso de compressão pneumática (grau de evidência 2C) em pacientes com risco aumentado de hemorragia. 
跐 Recomenda-se o uso de apixaban ou dabigatran (grau de evidência 1B) em pacientes que recusam injeções.

橉 Não se recomenda o uso de filtro de veia cava inferior para a prevenção primária (grau de evidência 2C) em pacientes com contraindicações para tromboprofilaxia.

Não se recomenda o uso de doppler de triagem antes da alta hospitalar (grau de evidência 1B).

静 Não se recomenda o uso de tromboprofilaxia (grau de evidência 2B) em pacientes com lesões de membros inferiores que necessitam de imobilização da perna.

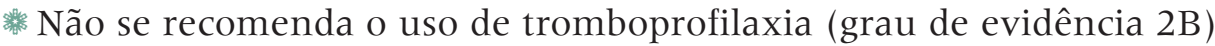
em pacientes submetidos à artroscopia do joelho, sem história de tromboembolismo venoso.

\section{Indicadores utilizados para monitorar a profilaxia do tromboembolismo venoso}

路 Porcentual de pacientes admitidos e avaliados quanto ao risco de tromboembolismo venoso.

* Porcentual de pacientes com orientações quanto à tromboprofilaxia na alta.

滕 Porcentual de pacientes que receberam tromboprofilaxia de forma adequada (quanto ao tempo e à dose) ou têm justificativa para não realizar.

\section{Referências}

American College of Chest Physicians. Evidence-based clinical practice guidelines. antithrombotic therapy and prevention of thrombosis, 9th ed. Chest. 2012; 141(2_suppl).

Michael KG, David AG, Sherry MW, et al. Prevention of VTE in nonorthopedic surgical patients: antithrombotic therapy and prevention of thrombosis. American College of Chest Physicians. Evidence-based clinical practice guidelines. antithrombotic therapy and prevention of thrombosis, 9th ed. Chest. 2012; 141(2_suppl): e227S-e277S. Disponível em: www.chestjournal.chestpubs.org

Reis A, Rocha N, coordenadores, Santos M, Gonçalves F, Soares A, Marques I et al. Normas para a prevenção, diagnóstico e tratamento do tromboembolismo venoso no doente médico. Lisboa: Sociedade Portuguesa de Medicina Interna; 2009 [citado 2014 Ago 11]. 


\section{Outras fontes para estudar as diretrizes clínicas de tromboprofilaxia:}

Agency for Healthcare Research and Quality (AHRQ)

Centers for Medicare \& Medicaid Services (CMS)

National Priorities Partnership (NPP) Safety

National Quality Forum (NQF) Safe Practice for Better Healthcare - 2009 Update Safe Practice 28:

Venous Thomboembolism Prevention

The Joint Commission (TJC) Venous Thromboembolism (VTE) Core Measure Set

Society of Hospital Medicine Preventing Hospital-Acquired Venous Thromboembolism A Guide for Effective Quality Improvement Version 3.0

Venous Disease Coalition

American College of Chest Physicians (ACCP) Antithrombotic and Thrombolytic Therapy, 8th Ed: ACCP Guidelines, Table of Contents

Agency for Healthcare Research and Quality (AHRQ) Diagnosis and Treatment of Deep Venous Thrombosis and Pulmonary Embolism

Map of Medicine Venous Thromboembolism Risk Assessment

The Commonwealth Fund Why Not the Best? Comparative performance data on surgical care, including VTE prevention

National Blood Clot Alliance Stop the Clot

Scottish Intercollegiate Guidelines Network (SIGN) Prevention and management of venous thromboembolism: A national clinical guideline

NICE Pathways NICE Pathways is an interactive tool for health and social care professionals providing fast access to NICE guidance and associated products.

Agency for Healthcare Research and Quality (AHRQ) National Guideline Clearinghouse Synthesis on Preventing Venous Thromboembolism (VTE)

Agency for Healthcare Research and Quality (AHRQ) National Guideline Clearinghouse

US Department of Health and Human Services Partnership for Patients

Centers for Disease Control and Prevention (CDC) Deep Vein Thrombosis/Pulmonary Embolism (DVT/PE). 


\section{Anexo B - Diretriz clínica de avaliação pré-operatória para prevenção de complicações cardiológicas ${ }^{1}$}

\section{Isabela Ribeiro Simões de Castro e Ronaldo Franklin de Miranda}

Orientações para melhorar a segurança da assistência cirúrgica foram abordadas no Capítulo 9, "Cirurgia Segura", do livro Segurança do paciente: conhecendo os riscos nas organizações de saúde.
A avaliação criteriosa do estado de saúde do paciente prévia à cirurgia permite que sejam realizados os cuidados necessários, de forma a reduzir os riscos de complicações e postergações. Algumas premissas são importantes. É necessário obter história médica completa, compreendendo a singularidade de cada paciente, que deve incluir a história de alergias (abrangendo látex) e o uso de medicamentos. Os critérios para a realização de reavaliações e suspensão de cirurgia devem estar definidos para toda a organização de saúde, e as informações disponíveis para a equipe antes das cirurgias

A existência de acidente vascular encefálico ou complicação cardíaca em pós-operatório de cirurgia não cardíaca podem ter origem em causas semelhantes.

\section{Diretriz clínica para prevenção de complicações cardiológicas em cirurgias não cardíacas}

A realização do procedimento cirúrgico com maior brevidade e com menor quantidade de exames complementares deve ser o objetivo a ser perseguido. Todo profissional de saúde envolvido no cuidado perioperatório (pré, per e pós) deve lembrar deste objetivo.

O risco de um procedimento cirúrgico é classificado conforme a possibilidade de complicações cardiológicas do procedimento - alto risco, risco intermediário ou baixo risco. Nos procedimentos de alto risco, espera-se um risco de evento cardiológico maior que 5\%, os de risco intermediário até 5\% e os de baixo risco até 1\% (Quadro 1).

\footnotetext{
${ }^{1}$ A atualização deste trabalho contou com a valiosa colaboração de Maurício Diuana Saud.
} 
Quadro 1 - Estratificação do risco cardíaco para procedimentos cirúrgicos não cardíacos

\begin{tabular}{|c|c|}
\hline $\begin{array}{l}\text { Alto risco: eventos cardíacos } \\
\text { maior que } 5 \%\end{array}$ & $\begin{array}{l}\text { Alto intermediário: eventos } \\
\text { entre } 1 \% \text { e } 5 \%\end{array}$ \\
\hline $\begin{array}{l}\text { Grandes cirurgias de emergência, idosos } \\
\text { Cirurgia aórtica e outras vasculares maiores } \\
\text { Cirurgia vascular periférica } \\
\text { Cirurgias prolongadas em que se antecipam } \\
\text { grandes mobilizações de fluidos e/ou } \\
\text { perdas sanguineas }\end{array}$ & $\begin{array}{l}\text { Endarterectomia carotídea } \\
\text { Cirurgia intraperitoneal e intratorácica } \\
\text { Cirurgia ortopédica } \\
\text { Cirurgia de próstata }\end{array}$ \\
\hline \multicolumn{2}{|c|}{ Risco baixo: eventos maior que $1 \%$} \\
\hline $\begin{array}{l}\text { Procedimentos endoscópicos } \\
\text { Cirurgia de catarata }\end{array}$ & $\begin{array}{l}\text { Cirurgias superficiais } \\
\text { Cirurgia de mama }\end{array}$ \\
\hline
\end{tabular}

Fonte: Eagle e colaboradores (2002, p. 1262).

\section{Avaliação laboratorial padrão}

Apesar de haver uma tendência atual à diminuição dos exames complementares, visando tanto a diminuição de custos desnecessários como também a retirada desnecessária de sangue do paciente, exemplificaremos, a seguir, os exames complementares que deverão ser feitos nos pacientes que irão se submeter a um procedimento cirúrgico. Descrevemos, assim, uma proposta de rotinização de exames laboratoriais em todo paciente que irá se submeter a uma cirurgia de médio ou grande porte.

\section{Hemograma com contagem de plaquetas}

Apesar de ser possível diagnosticar a presença de anemia no exame clínico e a presença de hipotensão postural (queda na pressão sistólica maior que $20 \mathrm{mmHg}$ ), o hemograma é fundamental para monitorar o paciente no pós-operatório. Indivíduos com anemia sintomática devem ter o sangue reposto (grau de recomendação I nível de evidência D). Paciente com hemoglobina abaixo de $7 \mathrm{~g} / \mathrm{dl}$ em quadro de anemia aguda deve ter o sangue reposto (grau de recomendação I nível de evidência A). No caso de indivíduo com mais de 65 anos, portador de doença coronariana/coronária estável e insuficiência ventricular esquerda, a reposição deve ser feita de acordo com o caso e o tipo de cirurgia. Apesar da tendência de tentar manter o hematócrito em 30\% e a hemoglobina em $10 \mathrm{~g} / \mathrm{dl}$, a situação deve sempre ser avaliada.
Grau de evidência foi abordado no Anexo A deste livro. 


\section{Glicemia em jejum}

Nos diabéticos, as complicações pós-operatórias são maiores que nos não diabéticos. O diabetes mellitus, conforme a Associação Americana de Diabetes, é caracterizado da seguinte forma: presença de glicemia de jejum (após oito horas) maior que $126 \mathrm{mg} / \mathrm{dl}$; presença de poliúria ou polidipsia com glicemia maior que $200 \mathrm{mg} / \mathrm{dl}$; presença de glicemia maior que $200 \mathrm{mg} / \mathrm{dl}$, duas horas após uma ingestão de $75 \mathrm{~g}$ de glicose, ou por meio da medida da hemoglobina glicosilada (HbAlc) maior ou igual a 6,5\% pelo método HPLC (American Diabetes Association 2005). No paciente assintomático, todos esses exames devem ser repetidos mais uma vez para confirmação do diagnóstico. É importante assegurar que o indivíduo permaneceu oito horas sem se alimentar, e orientá-lo para que não tome nem um cafezinho na manhã do dia da coleta/ recolha do exame de sangue, o que pode falsear uma hiperglicemia.

\section{Creatinina}

A creatinina é resultado do metabolismo da creatina relacionada com a massa muscular. A concentração sérica em indivíduos normais é praticamente constante, apresentando uma variação em relação ao sexo e ao volume de massa muscular, sendo, portanto, maior nos homens e nos atletas do que nas mulheres, crianças e idosos. O diagnóstico de insuficiência renal é de fundamental importância, pois portadores de creatinina maior que $2 \mathrm{mg} / \mathrm{dl}$ apresentam maior mortalidade peroperatória.

\section{Tipo sanguíneo e Fator Rh}

Todo paciente deve fazer sua classificação sanguínea para que o banco de sangue seja avisado e se organize com o objetivo de efetuar a reserva para pacientes, em especial os de tipos sanguíneos mais raros.

\section{Tempo e Atividade de Protrombina (TAP) e Tempo de} Tromboplastina Parcial Ativado (TTPA)

Esses exames possibilitam avaliar os defeitos da via intrínseca da coagulação, podendo constatar a deficiência dos fatores VIII, IX, XI e XII. Pode apresentar-se alterado também quando ocorre comprometimento da via final comum (X, V, II e I). O achado de TTPA prolongado na presença de TAP normal indica a possível deficiência dos fatores XII, XI, IX e VIII. Ao contrário, TTPA normal na presença de TAP prolongado indica comprometimento do fator VII. Quando ambos (TTPA e TAP) estão alterados, indicam comprometimento da via final comum, ou seja, dos fatores X, V, II e I. Se ambos estiverem normais, indicam 
pacientes sem alterações ou comprometimento do fator XIII. Esses exames, assim como o número de plaquetas ajudam na diminuição da possibilidade de sangramento por causas hematológicas. A história clínica busca se, em uma extração dentária, por exemplo, houve sangramento prolongado e, caso exista menção a esse fato, torna a realização do exame de coagulograma completo indispensável.

\section{Urinocultura}

A coleta/recolha de urinocultura deve ser feita sempre nos candidatos a procedimentos com colocação de material de síntese, em especial as próteses (artroplastias, endopróteses, marca-passos ou desfibriladores).

\section{Teste de gravidez}

Todas as mulheres em idade fértil (13-45 anos) devem realizar o exame imunológico de gravidez.

\section{Eletrocardiograma (ECG)}

O ECG deve ser feito:

路 em todo paciente do sexo masculino assintomático com mais de 45 anos;

普 em mulheres com mais de 55 anos ou que apresentem mais de dois fatores de risco para doença coronariana/coronária; e

踪 nos indivíduos menores que 45 anos se houver referência a qualquer doença cardiológica.

\section{Raios X de tórax}

O American College of Physicians (Qaseem et al. 2006) enfatiza que apenas os pacientes que se submeterão à cirurgia que apresenta risco de desenvolver complicações pulmonares - presença de doença pulmonar obstrutiva crônica ou ser tabagista; cirurgias que usam o tórax como acesso, procedimentos na cavidade abdominal superior - devem realizar raios $\mathrm{X}$ de tórax. O hábito de solicitar raios $\mathrm{X}$ de tórax no pré-operatório vem desde o período da Segunda Guerra Mundial, com o objetivo de diagnosticar precocemente a tuberculose pulmonar. Muitos médicos continuam solicitando raios $\mathrm{X}$ de tórax de forma rotineira para qualquer tipo de cirurgia. 


\section{História clínica e o exame clínico}

A história clínica é o ponto inicial para avaliar a necessidade de exames complementares minuciosos no pré-operatório. A história clínica deve ser feita com ênfase na existência de comorbidades/comorbilidades que possam aumentar o risco cirúrgico, como história de hipertensão arterial, diabetes ou coronariopatia. Deve-se investigar a existência de cirurgias prévias, alergias, intolerância medicamentosa e a inexistência de doenças.

As complicações cardiológicas observadas em uma cirurgia são originadas de: um infarto/enfarte agudo do miocárdio, uma crise hipertensiva, arritmias ventriculares malignas e insuficiência ventricular esquerda (edema agudo de pulmão). A doença coronariana/coronária pode ser avaliada por meio de diferentes exames, entretanto a história clínica é o principal instrumento para seu diagnóstico. A avaliação da capacidade funcional de um indivíduo pode ajudar na previsão da probabilidade de doença coronariana/coronária e na determinação do risco cirúrgico cardiológico.

O risco cirúrgico deve ser considerado sempre como a consequência de uma consulta clínica. O simples fato de se submeter a uma cirurgia não coloca o paciente em situação especial, na qual exames especiais necessitarão ser feitos. A solicitação de exames complementares deve ser feita independentemente da realização da cirurgia. Toda avaliação deve ser feita levando-se em conta a história clínica colhida e o porte da cirurgia a ser realizada. É possível realizar a avaliação pré-operatória de pacientes que farão cirurgias de pequeno porte apenas por meio de uma boa história clínica e um exame clínico minucioso. A capacidade funcional de uma pessoa é medida por sua história clínica, perguntando ao paciente sobre as atividades que realiza em seu dia a dia, avaliando a capacidade funcional (Quadro 2).

A unidade utilizada para se estimar a capacidade funcional é o equivalente metabólico, o chamado Metabolic Equivalente of Task (MET), que significa medir consumo de oxigênio (VO2). A quantidade de oxigênio consumida no repouso é de $3,5 \mathrm{ml}$ de oxigênio por quilo de massa corporal. A partir da unidade de consumo em repouso, é possível estimar o consumo em diferentes atividades cotidianas, e, desse modo, o paciente poderá ser liberado para fazer o procedimento cirúrgico ou exames complementares (Figura 1). O Quadro 2 define as atividades e o equivalente em MET habitualmente gasto. Essa tabela serve como orientação sumária para se estimar a capacidade funcional do paciente. As estratégias para se reduzir o risco de uma complicação cardiológica em uma cirurgia não cardíaca, baseada na capacidade funcional, estão esquematizadas na Figura 1. 
Quadro 2 - Relação entre atividade e consumo de oxigênio

\begin{tabular}{|c|c|c|c|}
\hline Intensidade & Atividades em casa & $\begin{array}{l}\text { Atividades } \\
\text { de trabalho }\end{array}$ & Atividade física \\
\hline $\begin{array}{l}\text { Muito leve } \\
3 \text { METs }\end{array}$ & $\begin{array}{l}\text { Tomar banho, fazer a } \\
\text { barba, vestir. } \\
\text { Trabalho de escritório. } \\
\text { Conduzir um } \\
\text { automóvel. }\end{array}$ & $\begin{array}{l}\text { Trabalho sentado (de } \\
\text { escritório). } \\
\text { Trabalho em pé } \\
\text { (garçom, vendedor). }\end{array}$ & $\begin{array}{l}\text { Caminhar (em terreno } \\
\text { plano, a } 3 \mathrm{Km} / \mathrm{h} \text { ). } \\
\text { Bicicleta fixa, sem } \\
\text { resistência. } \\
\text { Esteira ligeira. }\end{array}$ \\
\hline $\begin{array}{l}\text { Leve } \\
\text { 3-5METs }\end{array}$ & $\begin{array}{l}\text { Limpar janelas, juntar } \\
\text { folhas no jardim. } \\
\text { Cortar o gramado com } \\
\text { máquina. }\end{array}$ & $\begin{array}{l}\text { Solda ligeira. } \\
\text { Marcenaria ligeira. } \\
\text { Empapelamento. } \\
\text { Conserto de } \\
\text { automóvel. }\end{array}$ & $\begin{array}{l}\text { Caminhar (5-6 Km/h). } \\
\text { Bicicleta em terreno plano. } \\
\text { Esteira muito ligeira. }\end{array}$ \\
\hline $\begin{array}{l}\text { Pesada } \\
\text { 7-9 METs }\end{array}$ & $\begin{array}{l}\text { Serrar, subir escadas } \\
\text { (velocidade moderada). } \\
\text { Carregar objetos. }\end{array}$ & $\begin{array}{l}\text { Cavar fossas. } \\
\text { Trabalhos com pá. }\end{array}$ & $\begin{array}{l}\text { Futebol, patinar (no gelo ou } \\
\text { sobre rodas), cavalgar. } \\
\text { Montanhismo, esgrima, } \\
\text { tênis. }\end{array}$ \\
\hline $\begin{array}{l}\text { Muito pesada } \\
\text { superior a } 9 \\
\text { METs }\end{array}$ & $\begin{array}{l}\text { Carregar objetos por } \\
\text { uma escadaria. } \\
\text { Carregar objetos de } \\
\text { mais de } 45 \mathrm{Kg} \text {. } \\
\text { Subir escadas rápido. }\end{array}$ & $\begin{array}{l}\text { Lenhador, trabalho } \\
\text { muito pesado. }\end{array}$ & $\begin{array}{l}\text { Futebol americano, beisebol } \\
\text { squash, esquiar, basquete } \\
\text { vigoroso. }\end{array}$ \\
\hline
\end{tabular}

Fonte: Eagle et al. (2002, p. 1257-67).

Figura 1 - Fluxograma para risco cirúrgico

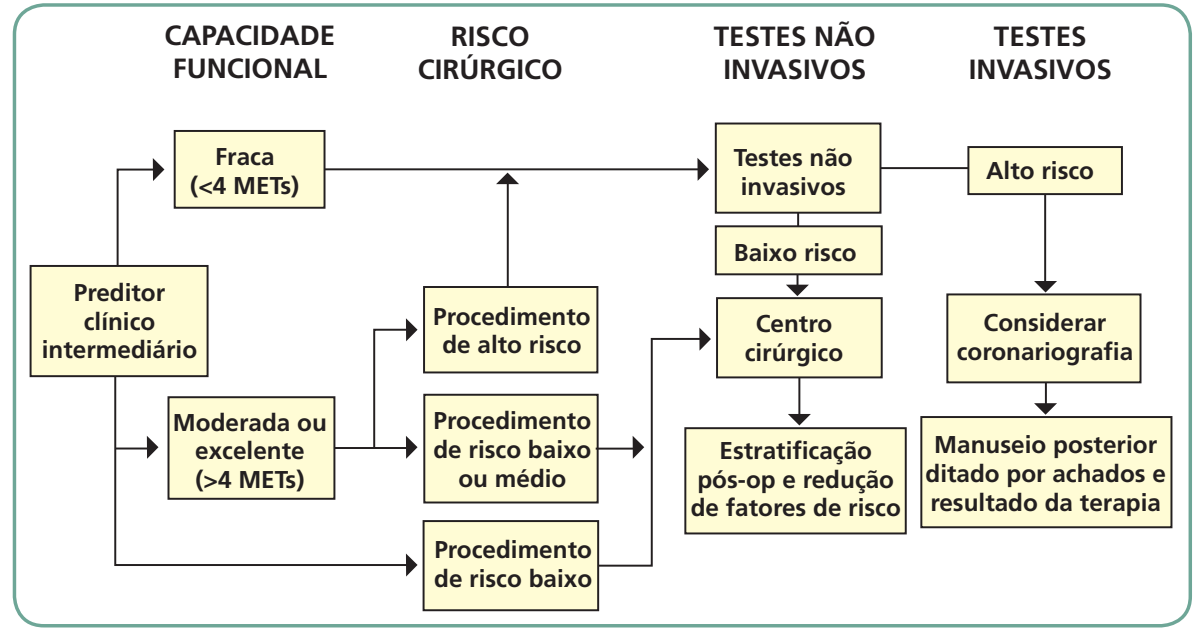

Fonte: Eagle e colaboradores (2002, p. 1260). 
Conhecer a reserva miocárdica possibilita que o manuseio per e pós-operatório seja feito com segurança. O mais importante é definir o grau de comprometimento cardíaco, e não apenas se existe ou não obstrução coronariana/coronária.

A necessidade de revascularizar um paciente deve ser orientada independentemente da realização de um ato cirúrgico. Havendo indicação para uma revascularização, o ato cirúrgico será adiado por, no mínimo, 30 dias. Kaluza e colaboradores (2000), do Hospital Metodista em Houston, Texas, relataram os efeitos desastrosos de um procedimento cirúrgico realizado próximo a uma angioplastia coronariana/coronária.

A fisiopatologia da síndrome coronariana/coronária aguda no contexto pós-operatório é diferente da que ocorre usualmente. Apenas metade dos infartos/enfartes que ocorrem no pós-operatório é proveniente da ruptura de placa com consequente reação trombótica e oclusão no vaso. A outra metade ocorre em razão da perda do equilíbrio entre a oferta e a demanda, diminuindo a perfusão coronariana/coronária; ocorre geralmente entre o primeiro e o quarto dia do pós-operatório. Nesse contexto, o controle da anemia e da hipotensão é primordial para se evitar uma lesão isquêmica aguda. A investigação deve ser feita considerando a presença de sintomatologia isquêmica pré-operatória, a função sistólica e se o paciente está sendo tratado clinicamente de forma plena.

O uso de betabloqueadores pode ser utilizado no pré, ou nos per e pós-operatórios dos pacientes com maior risco de desenvolver uma síndrome coronariana/coronária aguda.

A maioria dos adiamentos dos procedimentos cirúrgicos é devido à hipertensão arterial em função da sua frequência na população. A hipertensão arterial com níveis abaixo de $180 \mathrm{mmHg}$ de sistólica e $110 \mathrm{mmHg}$ de diastólica não representa um risco maior. No tratamento da hipertensão, sempre que possível, deve-se usar betabloqueadores, inibidores de enzima de conversão (Ieca) ou bloqueadores do canal de cálcio. A droga usada como primeira escolha é o betabloqueador. Como segunda escolha, usa-se um bloqueador do canal de cálcio, como nifedipina ou amlodipina, ou um Ieca, como captopril, enalapril, lisinopril ou clonidina. O uso do diurético deve ser evitado, quando possível, para que o paciente não entre hipovolêmico no centro cirúrgico. Os inibidores da Angiotensina 2 podem ser utilizados nos portadores de intolerância aos Ieca. 
A avaliação dos pacientes que fazem uso crônico de diurético deve ser cuidadosa, considerando-se evidências clínicas de hipovolemia - boca seca, hipotensão postural, mucosas hipo-hidratadas.

\section{A influência da idade}

A literatura médica relata a idade como um fator de risco em qualquer procedimento cirúrgico; porém, ao se buscar as evidências para essa afirmação, verificamos que os dados são conflitantes. Os dados registrados no Medicare (Cram et al. 2011), nos EUA, relatam maior mortalidade nos pacientes acima de 70 anos e do sexo masculino. A mortalidade geral descrita nesse registro é de $1 \%$ na artroplastia primária e cerca de $2,5 \%$ na revisão de artroplastia primária. Lowe e colaboradores (2011) defendem a ideia de se avaliar o paciente não pela sua idade cronológica, e sim pela biológica. Goldman e colaboradores (1997), em seu clássico trabalho sobre risco cirúrgico, estabelecem como 70 anos a idade em que o risco é aumentado, o que não foi confirmado por Djokovic e Heddley-White, em 1979, e Hosking e colaboradores em 1989. As diferenças encontradas pelos três autores já citados, certamente, são provenientes das comorbidades/comorbilidades presentes em alguns grupos, fazendo com que apenas o aumento da idade seja um fator confundidor.

Jack e colaboradores (2011) demonstraram que a realização de treinamento pré-operatório diminuía as complicações pulmonares. Quando é feita a história clínica e definida as comorbidades/comorbilidades de cada indivíduo, é possível julgar melhor a importância da idade na liberação para um procedimento ao se estimar qual seria a expectativa de vida do paciente e qual seria a mortalidade do ato cirúrgico.

\section{Uso prévio de antiadesivo plaquetário}

A junção da doença coronariana/coronária e a necessidade de antiagregação plaquetária tem sido um desafio no manuseio do paciente coronariopata que necessita de um procedimento cirúrgico. Alguns cenários clínicos são apresentados abaixo:

䟕 Caso o paciente tenha colocado um stent e necessite de uma intervenção cirúrgica, deve-se realizar um planejamento da estratégia medicamentosa em comum acordo entre o cirurgião e o cardiologista.

踪 Caso haja estabilidade clínica e o stent farmacológico tenha sido colocado há mais de um ano, pode-se suspender o clopidogrel ou prasugrel ou ticagrelor e manter apenas ácido acetilsalić́lico 100mg/dia. 
Caso haja necessidade de se realizar uma coronariografia com posterior colocação de stent, dá-se preferência, sempre que possível, à colocação de um stent não farmacológico, o que permitiria a realização de dupla antiagregação por apenas 30 dias.

踏 Caso haja instabilidade clínica e a cirurgia deva ser feita em até 15 dias, opta-se por realizar, apenas, angioplastia do vaso acometido sem colocação de stent. Essa estratégia só é feita se houver uma instabilidade cardiológica grande, aliada com uma necessidade de procedimento cirúrgico em até 15 dias.

O Quadro 3 a seguir traz, de forma resumida, as principais recomendações para avaliação pré-operatória para a prevenção de complicações cardiológicas em procedimentos não cardíacos.

Quadro 3 - Recomendações resumidas para avaliação pré-operatória

\begin{tabular}{|l|l|}
\hline Urgência & $\begin{array}{l}\text { Recomendações de manuseio, tentar } \\
\text { otimizar ao máximo terapia clínica }\end{array}$ \\
\hline $\begin{array}{l}\text { RVM/angioplastia entre seis meses e cinco anos, } \\
\text { sem sintomas de isquemia }\end{array}$ & Não precisa investigar \\
\hline $\begin{array}{l}\text { Avaliação extensa de coronariopatia < dois } \\
\text { anos, sem novos sintomas }\end{array}$ & Não precisa investigar \\
\hline Paciente de alto risco (um fator) & Avaliar doença cardíaca no pré-operatório \\
\hline $\begin{array}{l}\text { Paciente de risco intermediário } \\
\text { Conforme a capacidade funcional e o risco da } \\
\text { cirurgia }\end{array}$ \\
\hline $\begin{array}{l}\text { Capacidade baixa ou moderada com cirurgia de } \\
\text { alto risco }\end{array}$ & Avaliação não invasiva \\
\hline $\begin{array}{l}\text { Paciente de baixo risco, capacidade funcional } \\
\text { baixa e cirurgia de risco maior }\end{array}$ & Avaliar individualmente \\
\hline Recomendações & Angiografia, RVM, uso de drogas \\
\hline $\begin{array}{l}\text { A RVM e a angioplastia não devem ser recomendadas apenas para diminuir o risco da cirurgia não } \\
\text { cardíaca em pacientes que não têm indicação para esses procedimentos. }\end{array}$ \\
\hline
\end{tabular}




\section{Referências}

American Diabetes Association. Diagnosis and classification of diabetes mellitus. Diabetes Care. 2005;28(suppl): S37-42.

American Society of Anesthesiologists. Basic standards for preanesthesia care. ASA; 2010.

Cram P, Xi L, Kaboli PJ, Vaughan SM, Cai X, Wolf BR et al. Clinical characteristics and outcomoes of medicare patients undergoing total hip arthroplasty, 1991-2008. JAMA 2011;305:1560-67.

Djokovic JL, Hedley-White J. Prediction of outcome of surgery and anaesthesia in patient over 80 years. JAMA 1979;242:2301-06.

Eagle KA, Berger PB, Calkins H, Chaitman BR, Ewy GA, Fleischmann KE, et al. ACC/AHA guideline update for perioperative cardiovascular evaluation for noncardiac surgery: a report of the American College of Cardiology. American Heart Association Task Force on Practice Guidelines (Committee to Update the 1996 Guidelines on Perioperative Cardiovascular Evaluation for Noncardiac Surgery). Circulation, 2002;105:1257-67. Disponível em: http:/www.acc.org/clinical/guidelines/perio/dirlndex.htm.

Goldman L, Caldera DL, Nussbaum SR et al. Multifactorial índex of cardiac risk in non-cardiac surgical procedures. New Engl J Med. 1977;297:845-50.

Gualandro DM, Yu PC, Caramelli B, Marques AC, Calderaro D, Luciana S. Fornari LS et al. $3^{\text {a }}$ Diretriz de Avaliação Cardiovascular Perioperatória da Sociedade Brasileira de Cardiologia. Arq Bras Cardiol 2017; 109(3Supl.1):1-104

Hosking MP, Warner MA, Lodbell CM et al. Outcomes of surgery and anaesthesia in patients 90 years of age and older. JAMA 1989;242:1909-15.

Jack S, West M, Grocott MP. Perioperative exercise training in elderly subjects. Best Pract Res Clin Anaesthesiol. 2011 Sep;25(3):461-72.

The Joint Commission [JC]. Updated universal protocol. Washington, DC: JC; 2013 [citado 2013 Out 20]. Disponível em: http://www.jointcommission.org.

Kaluza GL, Joseph J, Lee JR, Raizner ME, Raizner AE. Catastrophic outcomes of noncardiac surgery soon after coronary stenting. J Am Coll Cardiol. 2000;35:1288-94.

Lowe JA, Crist BD, Bhandari M, Fergunson TA. Optimal treatment of femoral neck fractures according to patient's physiologic age:an evidence based review. Best Pract Res Clin Anaesthesiol $2011 ; 25,461-72$.

Levine BD. Fisiologia do exercício para o clínico. In: Thompson P (ed.). O exercício e a cardiologia do esporte. Barueri: Manole, 2004.

Maddox TM. Preoperative cardiovascular evaluation for noncardiac surgery. Mt Sinai J Med. 2005 May;72(3):185-92.

Miranda RF. Risco coronariano para cirurgia não cardíaca. Revista da Socerj. 2006; 12:170.

National Health Service, National Institute for Health and Clinical Excellence. Preoperative tests guideline. London: Nice; 2003.

National Priorities Partnership [NPP]. Safety [citado 2013 Out 20]. Disponível em: http://www. qualityforum.org.

Practice advisory for preanesthesia evaluation: an updated report by the American Society of Anesthesiologists Task Force on Preanesthesia Evaluation. Anesthesiology. 2012 Mar;116(3):522-38. 
Qaseem A, Snow V, Fitterman N, et al. Clinical Efficacy Assessment Subcommittee of the American College of Physicians: risk assessment for and strategies to reduce perioperative pulmonary complications for patients undergoing noncardiothoracic surgery. Ann Intern Med. 2006;144(8):575-80.

Stephen M, Salerno SM, Daniel W, Carlson DW, Eugene K, Soh EK, et al. Impact of perioperative cardiac assessment guidelines. Am J Med. 2007 Feb;120(2):185.e1-6.

Smettana GW, Lawrence VA, Cornell JE. Preoperative pulmonary risk stratification for noncardiothoracic surgery: systematic review for the American College of Physicians. Ann Intern. Med.2006;144:581-95. 


\section{Anexo C - Diretriz clínica para} prevenção de Acidente Vascular Cerebral perioperatório em cirurgias que não sejam cardíacas, carotídeas
ou neurológicas

\section{Isabela Ribeiro Simões de Castro e Ronaldo Franklin de Miranda}

Acidente Vascular Encefálico ou Cerebral (AVE ou AVC) é definido como déficit neurológico focal ou global de causa vascular cerebral, que persiste por mais de 24 horas ou seguido de morte dentro de 24 horas. Trata-se de uma importante causa de mortalidade, principalmente nos idosos.

O AVC perioperatório (durante ou até 30 dias de cirurgia não cardíaca) tem incidência que varia de 0,05 a 8\%; após cirurgias cardíacas, carotídeas ou neurológicas, essa incidência pode ser ainda mais elevada, variando de 2,2 a 5,2\%. A etiologia mais frequente é de origem tromboembólica.

A mortalidade intra-hospitalar no período perioperatório pode ser 2 a 8 vezes maior que a dos AVCs que não ocorrem no período perioperatório, provavelmente pelo atraso no diagnóstico. Vale ressaltar que as alterações inflamatórias desencadeadas nesse período ocasionam agravamento da lesão isquêmica cerebral por causa de alteração na função endotelial, induzindo à hipercoagulabilidade nesse período (Kam, Calcroft 1997).

A hipotensão arterial deve ser sempre tratada, pois é uma causa direta de AVC, provocando também aumento na lesão já existente. O estudo Poise (Devereaux 2008), ao utilizar uma dose elevada de betabloqueador no pré-operatório, ocasionou prevalência maior de hipotensão arterial e aumento na incidência de AVC no grupo que utilizou metropolol. Desse modo, devemos ser cautelosos com o uso de betabloqueador pré-operatório. A diretriz brasileira de avaliação pré-operatória (Gualandro 2011) enfatiza a importância do betabloqueador como cardioprotetor, bem como outras medidas em pacientes com isquemia miocárdica sintomática ou evidenciada por prova funcional em pacientes que já recebem betabloqueadores e, com menor evidência, os com risco cardíaco intermediário. O uso do betabloqueador não deve ser descartado pelo receio de o paciente ter um AVC. O uso do betabloqueador deve ser titulado no pré-operatório, devendo-se evitar o envio imediato para o centro cirúrgico após sua prescrição. 
A mortalidade precoce no AVC ocorre por edema cerebral e hipertensão intracraniana, e a mortalidade tardia por broncoaspiração, pneumonia, distúrbio metabólico, sepse, ou infarto/enfarte agudo do miocárdio. A maioria dos AVCs perioperatórios ocorre entre o segundo e sétimo dia de pós-operatório. Os fatores predisponentes mais consistentemente ligados ao AVC perioperatório estão listados no Quadro 1.

Quadro 1 - Fatores de risco para AVC no perioperatório

\begin{tabular}{|l}
\hline Fatores pré-operatórios (relacionados ao paciente) \\
\hline $\begin{array}{l}\text { Idade }>70 \text { anos (marcador de diminuição de reserva cerebrovascular e de coexistência de } \\
\text { patologias) }\end{array}$ \\
\hline Sexo feminino \\
\hline $\begin{array}{l}\text { História de hipertensão arterial sistêmica, diabetes mellitus, insuficiência renal (creatinina > } \\
2 \text { mg/dl), tabagismo, doença pulmonar obstrutiva crônica, doença arterial periférica, doença } \\
\text { cardíaca/doença de foro cardíaco - coronariopatia, arritmia, insuficiência cardíaca, disfunção } \\
\text { sistólica (fração de ejeção < } 40 \%, \text { principalmente nos submetidos à cirurgia de revascularização } \\
\text { miocárdica) }\end{array}$
\end{tabular}

História de AVC ou de acidente isquêmico transitório (AIT)

Estenose carotídea (em especial se sintomática)

Aterosclerose de aorta ascendente (em pacientes em pré-operatório de cirurgia cardíaca)

Parada/paragem abrupta de terapia antitrombótica prévia à cirurgia

Fatores intraoperatórios (relacionados ao procedimento)

Tipo e natureza do procedimento cirúrgico

Tipo de anestesia

Duração da cirurgia. Em procedimentos cardíacos, duração do bypass cardiopulmonar e tempo de clipagem aórtica.

Manipulação de lesões arterioscleróticas de aorta proximal

Arritmias, hiperglicemia, hipo ou hipertensão

Fatores de risco pós-operatórios

Insuficiência cardíaca, fração de ejeção baixa, infarto/enfarte agudo do miocárdio ou arritmias (fibrilação/fibrilhação atrial)

Desidratação e perda sanguínea

Hiperglicemia

Fonte: Selim (2007) 
Com relação ao tipo de cirurgia e incidência de AVC, a literatura é controversa. A presença de uma lesão carotídea assintomática pode se instabilizar no perioperatório e ocasionar um AVC; entretanto, o manuseio de uma lesão carotídea pré-operatória deve ser semelhante ao recomendado se o indivíduo não for realizar um procedimento cirúrgico (Augoustides 2012).

Há relato de menor incidência e mortalidade em pacientes submetidos à artroplastia de quadril (Mashour 2014), podendo refletir a anticoagulação precoce que geralmente ocorre nesses pacientes. Outros fatores, como cirurgia em posição sentada, administração prévia de radioterapia, rotação do pescoço, ainda não tiveram suas contribuições ao risco claramente definida, mas os cuidados nessas situações, com alterações bruscas de pressão arterial, devem ser redobrados considerando o percentual de queda em relação ao valor basal da pressão arterial mais que os números absolutos de pressão arterial a serem atingidos.

As medidas de prevenção para minimizar o risco de AVC são: cessação do tabagismo; controle da pressão arterial e manutenção da terapêutica em uso (mesmo betabloqueadores, se já vinham sendo utilizados, mas evitar começá-los no pré-operatório por período inferior a 7 dias (Foex Sear, 2014); a anticoagulação para fibrilação/fibrilhação atrial e manutenção dos antiarrítmicos em uso; administração de hipolipemiantes e terapia antiplaquetária; manejo da anticoagulação oral que vinha sendo utilizada por qualquer que seja a causa (retirar, usar anticoagulante que permita manejo com períodos mais curtos etc.); evitar alterações bruscas de glicemia. A técnica anestésica geral ou regional não é um fator de risco a ser considerado, não havendo diferença significativa que beneficie uma ou outra, nem técnicas ventilatórias específicas (Gualandro 2011 ).

\section{Medidas de prevenção em pacientes com maior risco de acidente vascular encefálico}

Nesses casos, as medidas são:

*m pacientes com história de AVC prévio: adiar o procedimento preferencialmente por três meses, otimizar a perfusão cerebral, realização de doppler transcraniano, se necessário, em razão de cirurgia em período anterior. 
静 Em pacientes com sopro carotídeo: endarterectomia de carótidas, em paciente sintomático e assintomático, se obstrução for maior que $50 \%$ de acordo com os critérios do Nascet (Augoustides 2012).

镂 Em pacientes com fibrilação/fibrilhação atrial recente: controlar a frequência cardíaca e anticoagulação.

\section{Resumo das medidas de prevenção de acordo com o período perioperatório}

As medidas de prevenção para minimizar o risco de AVC devem variar de acordo com o período perioperatório da seguinte forma:

* No período pré-operatório: normalização da hipertensão arterial sistêmica, manutenção da glicemia < 180 e uso de estatinas em caso de hipercolesterolemia, associado com dieta (evidência 1A), interrupção de alcoolismo e tabagismo (evidência 1A). Evitar início de diurético nesse período. O uso de diurético deve ser reservado para os portadores de congestão venosa sistêmica.

踪 No período intraoperatório: controle hemodinâmico, visando especial atenção ao surgimento de hipotensão arterial que deve ser evitada. O controle glicêmico deve ser realizado tentando evitar hiper ou hipoglicemia, manutenção de normocarbia.

嚗 No período pós-operatório: equilíbrio eletrolítico é de fundamental importância para se evitar o surgimento de arritmias, potencialmente emboligencias, hidratação, controle glicêmico, anticoagulação.

\section{Manuseio da anticoagulação}

O uso de anticoagulantes tem sido cada vez mais frequente, tendo em vista a profilaxia de eventos tromboembólicos. Ao avaliarmos um paciente nesse contexto, precisamos saber o risco das complicações hemorrágicas no período per e pós-operatório. O Quadro 2 descreve os riscos no manuseio do indivíduo em uso de terapia anticoagulante referente ao procedimento cirúrgico. 
Quadro 2 - A anticoagulação em função do risco de sangramento

\begin{tabular}{|c|c|c|}
\hline $\begin{array}{l}\text { Risco de } \\
\text { sangramento }\end{array}$ & Pré-operatório & Pós-operatório \\
\hline Baixo ou moderado & $\begin{array}{l}\text { - Parar HBPM que vinha sendo } \\
\text { utilizada como ponte de } \\
\text { anticoagulação em dose } \\
\text { terapêutica de manhã, 20-24 } \\
\text { horas antes da cirurgia. } \\
\text { - Omitir dose da noite se regime } \\
\text { de duas vezes ao dia. } \\
\text { - Dar } 50 \% \text { da dose total se } \\
\text { regime de uma vez ao dia. }\end{array}$ & $\begin{array}{l}\text { - Dar dose terapêutica de HBPM } 24 \\
\text { horas após a cirurgia e se houver } \\
\text { hemostasia adequada. }\end{array}$ \\
\hline Alto risco & $\begin{array}{l}\text { - Parar HBPM que vinha sendo } \\
\text { utilizada como ponte de } \\
\text { anticoagulação em dose } \\
\text { terapêutica de manhã, 20-24 } \\
\text { horas antes da cirurgia. } \\
\text { - Omitir dose da noite se regime } \\
\text { de duas vezes ao dia. } \\
\text { - Dar } 50 \% \text { da dose total se } \\
\text { regime de uma vez ao dia. }\end{array}$ & $\begin{array}{l}\text { - Dar dose terapêutica de HBPM } \\
48 \text { a } 72 \text { horas após a cirurgia e se } \\
\text { houver hemostasia adequada. } \\
\text { - Administrar dose baixa de HBPM } \\
\text { ou não fazer a medicação. }\end{array}$ \\
\hline
\end{tabular}

Fonte: Traduzido de Darvish-Kazem e Douketis (2012)

O uso de trombolítico para tratamento do acidente vascular embólico no período pré-operatório segue os mesmos critérios de inclusão e exclusão para pacientes com AVC isquêmico agudo, de três horas de início dos sintomas, conforme critérios que vêm sendo propostos pela Society for Neuroscience in Anesthesiology and Critical Care, chamado SNACC Task:

* Critérios de inclusão: diagnóstico de acidente vascular cerebral isquêmico causando déficit neurológico mensurável, início dos sintomas $<3$ horas antes do início do tratamento, $\geq 18$ anos.

* Critérios de exclusão: traumatismo craniano significativo ou AVC prévio em três meses anteriores; sintomas que sugerem hemorragia subaracnoide; punção arterial em local não compressível nos sete dias anteriores; hemorragia intracraniana anterior; neoplasia; malformação arteriovenosa ou aneurisma intracraniano; cirurgia intracraniana recente; pressão arterial elevada (sistólica > 185 $\mathrm{mm} \mathrm{Hg}$ ou diastólica > $110 \mathrm{mmHg}$ ); sangramento interno do Active; diátese hemorrágica aguda, incluindo, mas não limitado a plaquetas $<100$ 000/mm3; TTPA maior que o limite superior do normal, tendo recebido heparina nas últimas 48 horas, uso atual do anticoagulante com INR > 1,7 ou PT > 15 segundos; uso de 
inibidores diretos da trombina ou inibidores do fator Xa direto, com testes laboratoriais alterados (tais como TTPA, INR, contagem de plaquetas etc.); glicemia < $50 \mathrm{mg} / \mathrm{dL}$; CT demonstra infarto/enfarte multilobar (hipodensidade $>1 / 3$ hemisfério cerebral).

* Critérios de exclusão relativa: com cuidadosa consideração e ponderação de risco, alguns pacientes podem receber tratamento fibrinolítico, apesar de uma ou mais contraindicações relativas: sintomas pequenos ou melhorando rapidamente, gravidez, início com convulsão, cirurgia de grande porte ou trauma grave nos últimos 14 dias, hemorragia gastrointestinal ou urinária recente (nos últimos 21 dias), infarto/enfarte agudo do miocárdio recente (nos últimos três meses).

É importante que as organizações de saúde padronizem um protocolo validado para lidar com esse evento, definindo: a equipe que deverá ser acionada em caso de sinais e sintomas neurológicos, o treinamento do profissional que trabalha na instituição para reconhecer a escala de magnitude de déficit neurológico provocado pelo AVC, que será utilizada para realização do diagnóstico precoce, e a prioridade em setor de imagem para realizar uma tomografia computadorizada de crânio o mais precocemente possível. A equipe de saúde deve estar treinada para as seguintes condutas de cuidados básicos:

橉 administração do trombolítico após discussão interdisciplinar, pesando risco de sangramento;

滕 administração de aspirina, se possível (exceto nas primeiras 24 horas se for realizada trombólise);

monitorização cardíaca por pelo menos 24 horas;

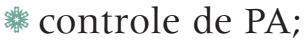

噒 uso de oxigênio para manter saturação maior que 94\%;

uso de ventilação mecânica se houver grande comprometimento ventilatório;

prevenção de complicações clínicas associadas, incluindo a solicitação de eletrocardiograma e enzimas cardíacas.

A existência de indicadores da evolução de portadores de acidente vascular encefálico pode ser utilizada para se aferir a qualidade dos serviços prestados em diferentes unidades de saúde. A seguir, são apresentados três exemplos de indicadores que podem ser utilizados no acompanhamento do atendimento prestado ao paciente: 
*úmero de pacientes com resultados diagnósticos disponíveis para os anestesistas.

紫 Número de pacientes com sintomas instáveis tratados antes da cirurgia.

滕 Número de pacientes com complicações cardiológicas no pósoperatório (insuficiência cardíaca, AVE, IAM, arritmias).

Esses indicadores têm baixo custo de implantação e podem ser realizados em períodos menores de 12 meses. Entre as dificuldades em sua implantação estão: a coleta/recolha em múltiplas unidades, a mudança de cultura institucional e a evidência, que é pequena (nível III), disponível apenas em estudos publicados, alguns com grupo controle.

\section{Referências}

Augoustides JG. Advances in the management of carotid artery disease: focus on recent evidence. J Cardiothorac Vasc Anesth. 2012 Feb;26(1):166-71.

Darvish-Kazem S, Douketis JD. Perioperative management of patients having noncardiac surgery who are receiving anticoagulant or antiplatelet therapy: an evidence-based but practical approach. Semin Thromb Hemost 2012; 38:652-660. doi: 10.1055/s-0032-1326781

Devereaux PJ, Yang H, Yusuf S, et al. Effects of extended-release metoprolol succinate in patients undergoing non-cardiac surgery (POISE trial): a randomized controlled trial: POISE Study Group. Lancet. 2008 May 31;371(9627):1839-47. DOI: 10.1016/S0140-6736(08)60601-7.

Foex P, Sear JW. 囚-Blockers and cardiac protection: 5 yr on from POISE Br. J. Anaesth. 2014;112 (2):206-10.

Gualandro DM, Yu PC, Calderaro D, Marques AC, Pinho C, Caramelli B, et al. $2^{\text {a }}$. diretriz de avaliação perioperatória da Sociedade Brasileira de Cardiologia. Arq Bras Cardiol. 2011; 96(3 supl.1):1-68.

Kam PCA, Calcroft RM. Peri-operative stroke in general surgical patients. Anaesthesia. 1997, $52: 879-83$

Kikura M, Bateman BT, Tanaka KA. Perioperative ischemic stroke in non-cardiovascular surgery patients. J Anesth. 2010 Oct;24(5):733-8.

Mashour G. Perioperative care of patients at high risk for stroke after non-cardiac, non-neurologic surgery: guidelines from the Society for Neuroscience in Anesthesiology and Critical Care. SNACC Task. 2014 Jan 20. In comments. Draft version.

$\mathrm{Ng} J$, Chan MT, Gelb AW. Perioperative stroke in noncardiac, nonneurosurgical surgery. Anesthesiology. 2011 Oct;115(4):879-90

Selim M. Perioperative stroke. N Engl J Med. 2007 Feb 15;356 (7):706-13. 


\section{Anexo D - Diretriz clínica para gerenciamento/gestão da dor}

\section{Elaine da Hora dos Santos, Isabela Ribeiro Simões de Castro e Marcio Curi Rondinelli}

A dor é um sintoma frequente no ambiente hospitalar e ambulatorial, e seu controle e alívio do sofrimento são de responsabilidade do profissional de saúde. O desconhecimento sobre doses eficazes, tempo de ação dos analgésicos, técnicas analgésicas disponíveis, o receio quanto à depressão respiratória, o hábito de agir da mesma forma contribuem para que ela seja subtratada, além de outros fatores.

O inadequado alívio da dor no pós-operatório é um problema na prática clínica. Em estudo da Associação Internacional para Estudo da Dor (AIED) sobre a avaliação em pós-operatório de cirurgia cardíaca e abdominal, observou-se que, em todas as prescrições, havia algum analgésico em regime "se necessário", mas cerca da metade dos pacientes não o utilizou, e aqueles que receberam a medicação permaneceram com dor, sugerindo subdose.

A avaliação da dor e o registro sistemático e periódico de sua intensidade são fundamentais para que se acompanhe a evolução dos pacientes e se realizem os ajustes necessários no tratamento. O tratamento da dor minimiza, elimina o desconforto, facilita a recuperação, evita efeitos colaterais, gera menores custos, previne complicações e diminui o período de internação.

O tratamento da dor tem como alicerces a monitorização padronizada, os protocolos para uso de analgésicos e controle dos efeitos colaterais, além do treinamento dos profissionais responsáveis pela analgesia. Iniciativas de tratamento antálgico sem orientação médica especializada podem resultar em dano grave à saúde.

\section{A diretriz clínica}

O objetivo da diretriz clínica é implantar a Dor como $5^{\circ}$ sinal vital nas organizações de saúde. A necessidade de a dor ser reconhecida como $5^{\circ}$ sinal vital foi citada pela primeira vez em 1996, por James Campbell (Presidente da Sociedade Americana de Dor), e seu objetivo foi o de elevar a conscientização entre os profissionais de saúde sobre o tratamento da dor. Campbell (1996 apud Almeida 2011) refere que "se a dor fosse aliviada com o mesmo zelo que os outros sinais vitais, haveria melhor chance de promover tratamento adequado". O nível 
de evidência (Cochrane) dos resultados com o uso da diretriz é alto. O custo de implantação exige apenas esforço e treinamento. O tempo para implantação é menor que 12 meses. A dificuldade de implantação é média e depende de diversas áreas e da cultura existente no serviço de saúde.

A diretriz clínica orienta:

Adotar uma rotina de avaliação de ocorrência e intensidade da dor para todos os pacientes usando escala específica para pacientes adultos, pediátricos, com déficit cognitivo ou sedados (por exemplo: escala EVA; escala CRIES);

䟕 Documentar as intervenções planejadas para o tratamento e controle da dor, bem como o período determinado para a reavaliação.

Realizar um planejamento/planeamento para o seu efetivo desenvolvimento, preferencialmente designando um membro da equipe que fique responsável pela coordenação da implantação do $5^{\circ}$ sinal vital.

滕 Estabelecer um plano de ação com prazos e designação de responsáveis para a sua implantação em todas as unidades da organização.

Definir a folha para o registro da avaliação, intervenção e reavaliação.

滕 Definir o instrumento de avaliação que será utilizado.

橉 Estabelecer normas e procedimentos para avaliação e reavaliação da dor para os pacientes em que a dor seja identificada.

* Educar a equipe quanto à avaliação da dor (componentes de uma avaliação, aplicação da escala específica, registro adequado e reavaliação) e seu manejo (intervenções farmacológicas e não farmacológicas).

輠 Desenvolver um plano para educação do paciente e seus familiares quanto à avaliação e o manejo da dor.

\section{O processo de avaliação da dor}

O processo de avaliação deve incluir o histórico e exame físico do paciente, bem como os aspectos psicossociais e familiares relacionados. A avaliação também deve envolver os componentes sensoriais da dor, porém deve-se ter em mente que o indivíduo que vivencia a dor é 
o "expert" sobre seu padrão, localização, intensidade e natureza, bem como o grau de alívio obtido pela terapia.

O padrão da dor é avaliado pelo uso de palavras que descrevem seu ritmo. O paciente será questionado se a dor é constante, intermitente ou breve, sobre a data e horário do seu início e quando foi o último episódio.

A especificação da localização da dor pode auxiliar na determinação de sua etiologia. Pode ser utilizado um diagrama corpóreo para que o paciente demonstre, assinalando em um desenho, as áreas dolorosas (Figura 1). De outra forma, o profissional questiona o paciente sobre quais locais do corpo que doem e registra ou assinala no diagrama de localização. Novos locais dolorosos que apareçam devem ser registrados, porque podem sinalizar uma nova complicação.

Figura 1 - Mapa de localização da dor em regiões do corpo

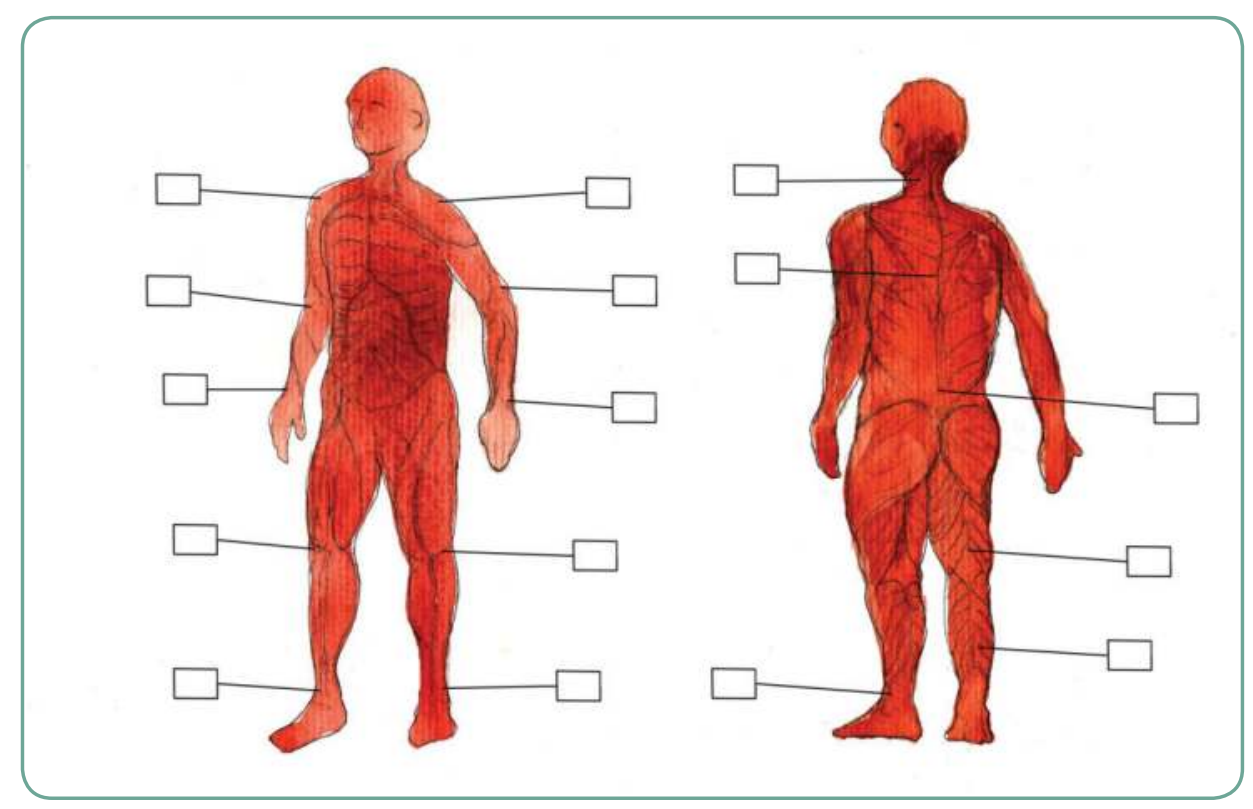

Fonte: Adaptado de Bueno, Vianna (2010).

A intensidade da dor pode ser avaliada por meio de uma escala visual analógica (EVA). Uma das versões dessas escalas compreende uma linha horizontal de $10 \mathrm{~cm}$, com as extremidades indicando "ausência de dor" e "a pior dor possível". Poderá ser determinado um valor numérico utilizando-se uma régua e medindo-se a distância entre a marcação do indivíduo, que está sendo avaliado, e o extremo inferior, em uma escala em centímetros. Outra escala utilizada é de 0 a 4, caracterizando ausência de dor, dor leve, moderada, forte ou intensa (Figuras 2, 3 e 4). 
Figura 2 - Escala linear analógica visual

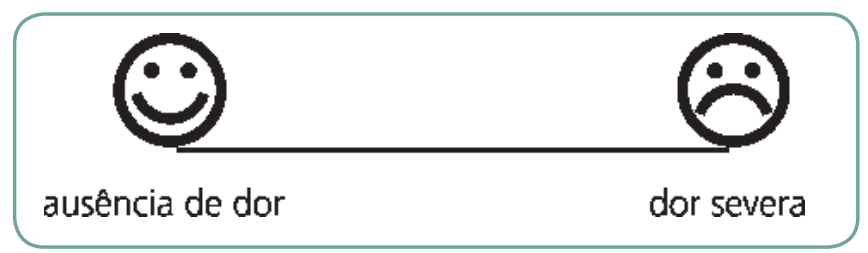

Fonte: Schechter (1990)

Figura 3 - Escala linear analógica não visual

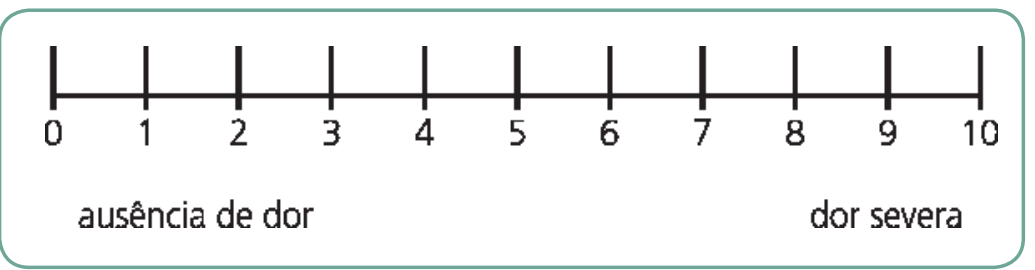

Fonte: Schechter (1990).

Figura 4 - Escala de faces masculina e feminina
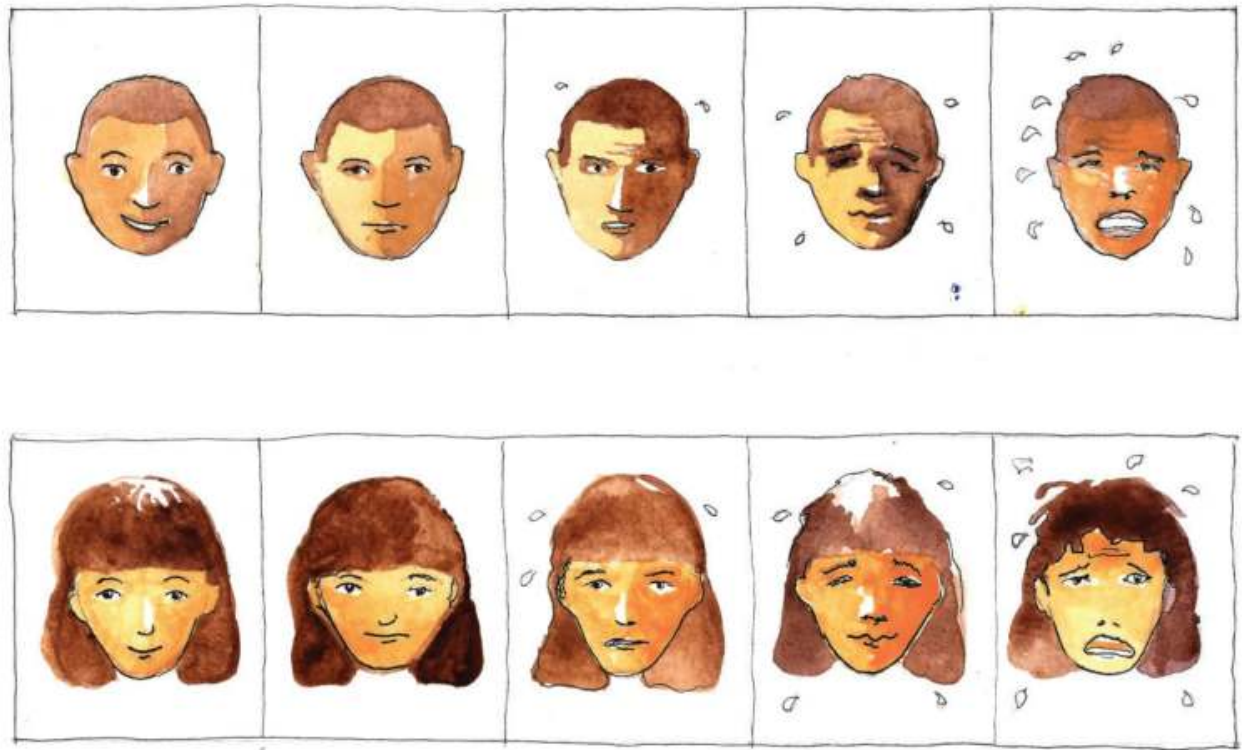

Os prejuízos nas atividades de vida diária como sono, apetite, movimentação, higiene e deambulação, além do humor também devem ser avaliados. Podem ser indicativos do desconforto causado pela dor e auxiliam na avaliação da qualidade da analgesia. A identificação da natureza da dor poderá ser definida pelas suas características utilizando-se descritores verbais (Quadro 1). 
Quadro 1 - Tipos de dor

\section{Somática}

Visceral

Neuropática
Constante e bem localizada, por ativação de nociceptores; por exemplo, dor óssea por vasoclusão.

Constante, mal localizada, referida a sítios cutâneos. Seu mecanismo envolve a ativaçāo de nociceptores e/ou componente autonômico. Exemplo: dor no gradil costal em pacientes com síndrome torácica aguda.

Em salvas ou paroxismos, tipo choque, queimação ou disestesia. Seu mecanismo não é nociceptivo, mas por descargas paroxísticas do Sistema Nervoso Central, Sistema Nervoso Periférico e do componente autonômico.

Fonte: Lobo, Marra, Silva (2007).

A frequência de avaliação da dor é um aspecto importante da implantação da dor como $5^{\circ}$ sinal vital e pode variar de acordo com o cenário clínico.

Para pacientes internados, a dor deve ser avaliada na admissão, junto com os outros sinais vitais e, posteriormente, de acordo com a rotina da organização e as condições do paciente (pós-operatório imediato, pós-operatório tardio, dor crônica, pacientes fora de possibilidade terapêutica em fase avançada da doença, entre outras), que podem determinar maior ou menor frequência a ser estabelecida. Rotinas para avaliação sistemática da dor em ambulatórios, consultórios e no domicílio também podem ser estabelecidas.

A padronização do registro de avaliação é fundamental na implantação da dor como $5^{\circ}$ sinal vital. O registro da avaliação pode ser feito no papel (impresso próprio) ou realizado eletronicamente em programas de computadores específicos. É necessário que seja demonstrado o valor da intensidade da dor na hora da avaliação, a intervenção adotada e a intensidade da dor na hora da reavaliação (Quadro 2). Os valores que representam a intensidade da dor também podem ser expressos em gráfico, demonstrando uma curva de melhora ou piora ou ausência de dor, de acordo com valores encontrados. 
Quadro 2 - Folha de registro

\begin{tabular}{|l|l|l|l|l|}
\hline Data & Hora & Intensidade da dor & Intervenção & Reavaliação \\
\hline & & & & \\
\hline & & & & \\
\hline & & & & \\
\hline & & & & \\
\hline & & & & \\
\hline & & & & \\
\hline
\end{tabular}

Fonte: Oliveira et al. (2012).

\section{Tratamento medicamentoso}

Após a identificação da intensidade do processo doloroso, a analgesia é iniciada contemplando três níveis:

路 Nível 1 (Dor leve): Iniciar com analgésicos e anti-inflamatórios não esteroides com adição de drogas adjuvantes/auxiliares (antidepressivos tricíclicos, anticonvulsivantes, corticoides), utilizados para pacientes com dor leve respeitando-se os intervalos recomendados para cada fármaco.

* Nível 2 (Dor moderada): Acrescentar anti-inflamatório não esteroide ao esquema, alternando os dois fármacos em intervalo de oito horas para cada medicamento. Utiliza-se, dessa forma, um medicamento a cada quatro horas alternadamente.

* Nível 3 (Dor forte ou intensa): Acrescentar codeína (opioide fraco) a cada quatro horas. Com a implantação dessa estratégia, o paciente estará, nesse momento, utilizando três analgésicos intercalados. Dipirona e anti-inflamatório não esteroide a cada oito horas e codeína a cada quatro horas. Utilizar-se-á, dessa forma, um medicamento a cada duas horas alternadamente.

Em todos os estágios, o tratamento deve ser monitorado com a escala da dor e mantido até o desaparecimento do sintoma. Os fármacos devem ser então retirados, um de cada vez, a cada 24 horas. Após 24 horas do início do tratamento apropriado, em caso de piora ou ausência de controle do sintoma, o paciente deve procurar atendimento médico hospitalar, se for o caso. 
Durante as crises, deve-se estimular a ingestão de líquidos $(60 \mathrm{ml} /$ $\mathrm{kg} / 24 \mathrm{~h}$ para adultos). Quando o paciente faz uso de opioide, deve-se ainda monitorar a necessidade de administrar laxantes em razão de constipação intestinal. A administração concomitante de opioide com os outros analgésicos da escala da Organização Mundial da Saúde (Quadro 3), por exemplo, dipirona e anti-inflamatórios, é recomendada. Seu uso potencializa o efeito analgésico do opioide. Nunca deverá ser associado opioide com outro opioide, ou anti-inflamatório com outro anti-inflamatório. Deve-se utilizar, preferencialmente, a via oral. A via parenteral está indicada quando se deseja alcançar mais rápido as concentrações plasmáticas.

Quadro 3 - Escala analgésica da OMS

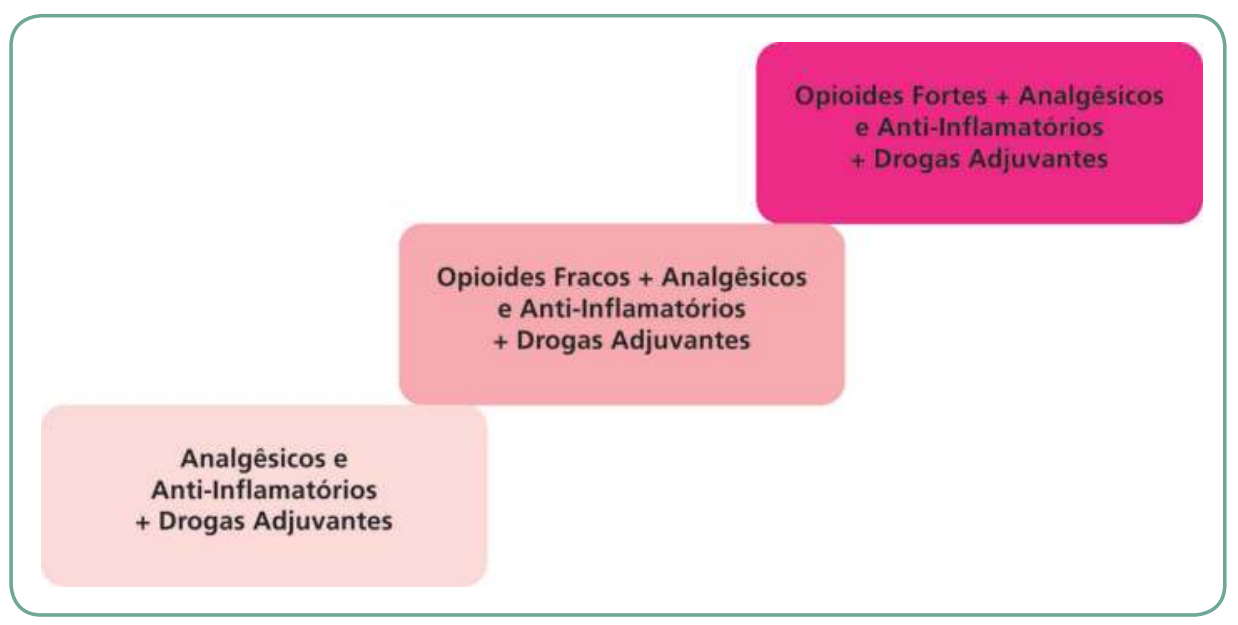

Fonte: http://www.isaudebahia.com.br

Além do tratamento medicamentoso, as estratégias adjuvantes/auxiliares são úteis no tratamento da crise de dor, tais como: estimulação nervosa transcutânea (TEEN) e acupuntura. Algumas outras medidas educativas também podem apresentar resultados positivos, entre elas as técnicas de autoajuda e hipnose.

\section{Considerações sobre a anemia falciforme}

É muito importante que os profissionais que cuidam de paciente com doença falciforme reflitam sobre a efetividade do tratamento não só do ponto de vista técnico, como também sob a ótica do paciente, de sua família e da sociedade. Deve-se partir da premissa que a doença é crônica, permeada por crises agudas e ainda não pode ser curada. É também fundamental buscar conhecer e entender os processos 
pelos quais esses indivíduos são conduzidos a viver. Há um sofrimento intenso, com o estigma da doença, possibilidade de limitação, perda da capacidade de trabalho e sentimento de inutilidade. Não há dúvida de que apenas a abordagem técnica não nos permitirá resolver as questões centrais sem considerar a profundidade dos significados da doença e da dor para aquele indivíduo. O modelo médico tradicional, no qual o paciente adota uma atitude passiva, deve ser rejeitado dando lugar a uma relação mais participativa, na qual o paciente passa a ser considerado parte ativa na tomada de decisões de seu tratamento.

O envolvimento do paciente nas decisões sobre seu tratamento foi abordado no Capítulo 8, "Envolvimento e segurança do paciente: desafios e estratégias", do livro Segurança do paciente: criando organizações de saúde seguras.

\section{Referências}

Almeida SARM. A avaliação e registro da dor como $5^{\circ}$ sinal vital por parte dos enfermeiros da urgência pediátrica do CHTV [dissertação]. Viseu: Instituto de Viseu, Escola Superior de Saúde de Viseu; 2011 [citado 2014 Ago 25]. Disponível em: http://hdl.handle.net/10400.19/1575.

Bueno FF, Vianna HB. Ginástica laboral: avaliação de dores localizadas nos colaboradores de uma empresa de teleatendimento. EFDeportes.com. 2010 Nov [citado 2014 Ago. 11];15(150). Disponível em: http://www.efdeportes.com/efd150.jpg.

Castilho EE. El dolor en los ninõs. Rev. Educ Enfermeria, Medelin. 1987 Sep;2:40-41.

Claro MT. Escala de faces para avaliação da dor em crianças: etapa preliminar [dissertação]. Ribeirão Preto: Escola de Enfermagem de Ribeirão Preto, Universidade de São Paulo; 1993.

Delgado GL. A dor em oncologia. São Paulo: Atheneu; 1988.

Lavigne JV, et al. Psychological aspects of painful medical condictions in children. Pain. $1986 ; 27: 133-46$.

Lobo C, Marra VN, Silva RMG. Crises dolorosas na doença falciforme. Rev Bras Hematol Hemoter. 2007;29(3):247-258.

McGrath PJ, et al. Report of the Subcommithes on assement and methodologic issues in the management of pain in childhood cancer. Pediatrics. 1990 Nov;86(5):814-7.

Melzack R. The Mc Gill pain questionnaire: major properties and scoring methods. Pain. 1975;1:277-99.

Oliveira RM, Silva LMS, Pereira MLD, Gomes JMA, Figueiredo SV, Almeida PC. Dor e analgesia em pacientes com síndrome da imunodeficiência adquirida. Rev. dor. 2012 Dez;13(4): 332-7.

Portenoy RK, Foley KM, Stulman J, et al. Plasma morphine and morphine-6-glucoronide during chronic morphine therapy for cancer pain: plasma profiles, steady state concentrations and the consequences of renal failure. Pain. 1991;47:13-9. 
Schechter NL, et al. Report of the Consensus Conference on the Management of pain in childhood cancer. Pediatrics. 1990 Nov;86(5):818-34.

Wilson J, Barnete, Lynn B. A research base for nursing care. London: Scrittori Press London; 1991. p.118-127. 


\section{Anexo E - Uso único para os dispositivos de injeção}

\section{Barbara Ventura Fontes e Sandra Regina Ferreira Vasconcelos}

Segundo a Organização Mundial da Saúde (OMS 2015), em seu guia de orientações que promove o uso seguro de dispositivos de injeção (2003), o procedimento de cuidado de saúde mais utilizado em todo o mundo são as injeções. Países em desenvolvimento administram, por ano, aproximadamente 16 milhões de injeções.

Medicamentos injetáveis são utilizados nos mais diversos tipos de cuidado de saúde e com objetivos distintos, tais como: prevenção, diagnóstico e tratamento de várias doenças (Centers for Disease Control and Prevention's - CDC).

Seringas e agulhas hipodérmicas estéreis, de uso único, são classificadas como produtos médicos, devendo assim obedecer à regulamentação aplicável aos órgãos regulamentadores e, por serem usados no corpo humano de forma invasiva (penetra em um ou mais tecidos do corpo), podem apresentar riscos associados ao uso, havendo a necessidade de ser garantida sua esterilidade antes e durante o uso, bem como outras características definidas em normas técnicas pertinentes.

Em estudo patrocinado pela OMS, observou-se que cerca de 1,7 milhão de pessoas foram infectadas com o vírus da hepatite $\mathrm{B}, 315.000$ pelo vírus da hepatite C e 33.800 pelo HIV, devido ao uso de práticas inseguras no preparo e administração de medicamentos injetáveis (OMS 2007). Em muitos casos, essas injeções são desnecessárias ou poderiam ser substituídas por medicamentos orais, mas, geralmente, os pacientes acreditam na eficácia maior de medicamentos injetáveis.

Com o intuito de prevenir a propagação de doenças infecciosas fatais pela reutilização de seringas, é recomendável a utilização de dispositivos de único uso, termo utilizado pela Anvisa para indicar que a reutilização é proibida.

Uma política de segurança para injeções foi lançada pela OMS objetivando auxiliar os países a atuar na questão relacionada a injeções inseguras. Novos protocolos para a segurança em injeções foram propostos, fornecendo recomendações detalhadas, com ênfase no valor dos recursos de segurança para seringas, incluindo, ainda, dispositivos que protegem os profissionais da saúde de acidentes por agulhas com consequente exposição à infecção, além da necessidade de redução do número de injeções desnecessárias (OMS 2015).

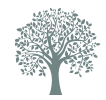

Estas são algumas normas técnicas da Anvisa, importantes sobre o tema, que podem ser facilmente encontradas na internet:

- RDC n. 45, de 12 de março de 2003

- RDC n. 3, de 4 de fevereiro de 2011

- RDC n. 4, de 4 de fevereiro de 2011

- RDC n. 5, de 4 de fevereiro de 2011 
São consideradas práticas seguras no uso de injeções:

* utilizar técnica asséptica no preparo e administração de injeções,

*uando o rótulo do medicamento indicar uso único ou dose única, utilizar em apenas um paciente,

繗 não utilizar seringas ou agulhas em mais de um paciente, e

路 não aspirar medicamentos de frascos multidoses com agulha ou seringa usadas, mesmo que sejam doses adicionais para o mesmo paciente (Kossover-Smith et al. 2017).

\section{Reutilização de seringas e agulhas por profissionais de saúde}

Nos Estados Unidos da América (EUA), desde 2001, foram notificados ao CDC (Centro de Controle e Prevenção de Doenças) mais de 50 surtos de doenças relacionados à má prática no uso de medicamentos injetáveis, como reutilização de seringas e agulhas (Kossover-Smith et al. 2017). Dessas 50 ocorrências, 56\% foram por infecções bacterianas, e $44 \%$ por hepatite viral; e, em sua maioria, ocorreram durante atendimento ambulatorial (CDC 2017). Nesse mesmo período, mais de 150 mil pacientes nos EUA foram notificados quanto a potencial exposição ao vírus da Hepatite B, Hepatite C e HIV, relacionado a não utilização de práticas básicas de controle de infecção por profissionais de saúde.

Entre os anos 2003 e 2004, o CDC foi notificado quanto a surtos de Hepatite B em pacientes de três instituições de longa permanência, associados ao uso compartilhado de canetas lancetadoras para realização de hemoglicoteste. Apesar da troca da lanceta entre um paciente e outro, ainda há o risco de transmissão cruzada de doenças transmitidas pelo sangue, pois o reservatório da caneta pode conter sangue (CDC,2005). É possível ocorrer a mesma situação quando as canetas de aplicação de insulina são compartilhadas; embora a agulha seja trocada, o risco de transmissão de vírus da hepatite, HIV ou qualquer outro patógeno de transmissão sanguínea existe (FDA 2009).

Logo, tanto as canetas lancetadoras quanto às de aplicação de insulina só devem ser utilizadas por um paciente, nunca compartilhadas. 
Estudos realizados pela American Society of Anesthesiologists (ASA), na década de 1990, revelaram que 19\% dos anestesistas usavam seringas com droga residual em mais de um paciente. No Canadá, um estudo similar, realizado em 1996, demonstrou que 61\% dos anestesistas relatavam essa prática, e pesquisas/investigações mais recentes, realizadas no Reino Unido e Nova Zelândia, mostraram que respectivamente $54 \%$ e $2,2 \%$ dos anestesistas participantes da pesquisa/investigação não trocavam todo circuito intravenoso antes de cada paciente e/ou utilizavam seringas contendo droga residual em mais de um paciente (Sikora et al. 2010).

Organizações governamentais, como o CDC nos EUA e a Anvisa no Brasil, orientam que seringas e agulhas são estéreis e artigo de uso para único paciente. Medicações em seringas não devem ser administradas em mais de um paciente, mesmo que a agulha seja trocada entre um paciente e outro. Após a entrada ou conexão com a infusão intravenosa (IV) de um paciente (equipo), a seringa e a agulha devem ser consideradas contaminadas e usadas apenas para este paciente, pois germes, como o da Hepatite C, staphylococcus ou MRSA, não são visíveis a olho $\mathrm{nu}$, mas podem facilmente infectar um paciente quando presentes em quantidade microscópica.

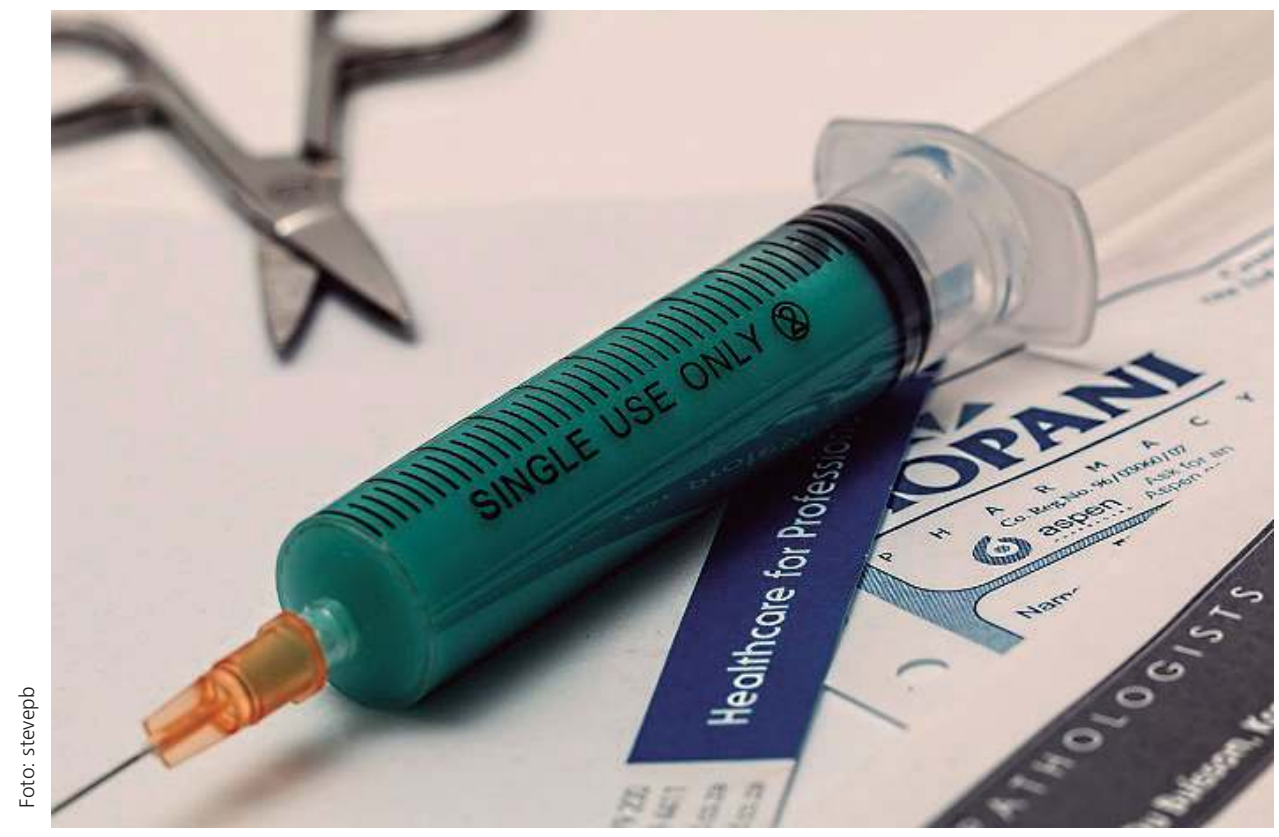

Fonte: https://pixabay.com/pt/seringa-inje\%C3\%A7\%C3\%A3o-droga-medicina-435809/ 


\section{Reutilização de seringas e agulhas por diabéticos insulinodependentes}

O número de pessoas com diabetes no mundo aumentou de 108 milhões em 1980 para 422 milhões em 2014 (WHO 2015).

A Pesquisa/Investigação Nacional de Saúde de 2013, realizada pelo Ministério da Saúde (MS) em parceria com o IBGE, mostra que o diabetes atinge cerca de 9 milhões de brasileiros, o que corresponde a $6,2 \%$ da população adulta (IBGE 2013).

Pacientes com diabetes tipo 1 necessitam de aplicação de injeções diárias de insulina, pois seu corpo já não produz mais insulina ou sua produção é insuficiente. Segundo a Sociedade Brasileira de Diabetes o "reuso de agulhas e/ou seringas está relacionado à conveniência, economia, falta de insumo e preocupação ambiental", sendo uma prática que ocorre em todo o mundo (SBD 2017).

O fornecimento de seringas, fitas glicêmicas e insulina para a população diabética do Brasil, pelo Ministério da Saúde, não ocorre de forma regular, agravando as condições econômicas da família e, com isso, incrementando progressivamente a prática da reutilização (Castro, Grossi 2007).

Os gastos envolvidos nesse tratamento podem alcançar até $70 \%$ da renda mensal de pessoas diabéticas. Por isso, a reutilização dos artigos injetáveis descartáveis é uma forma de economizar recursos (Araujo et al. 2009).

O reaproveitamento de agulhas pode levar à perda da lubrificação, da afiação, alterações no bisel, quebra e bloqueio do fluxo devido à cristalização da insulina. Com a reutilização das seringas, a graduação apaga, possibilitando ocorrer o erro de dose (SBD 2017).

Castro e Grossi (2007) relatam que pacientes diabéticos reutilizam a agulha para aplicação da insulina de 2 a 4 vezes, e somente param de reutilizá-la quando perde o seu corte, o que leva à sensação dolorosa pela dificuldade de penetração na pele.

Zabaleta-del-Olmo et al. (2016) referiram estudos por Puder et al. (2005), que apontaram para a possibilidade de economia na reutilização de agulhas para a mesma pessoa, caso houvesse a garantia de segurança na sua reutilização. Segundo os autores, poderiam ser economizados 100 milhões de euros na Europa. No entanto, não existe evidência científica sólida que recomende a reutilização de agulhas, seringas ou canetas de insulina (Zabaleta-del-Olmo et al. 2016). 


\section{Uso de medicamentos em frascos de dose única e multidoses}

Dados do CDC, desde 2007, relatam que, nos EUA, dezenas de surtos de infecção por bactéria ou patógenos de transmissão sanguínea, associados à utilização de frascos de medicamentos de dose única para mais de um paciente e mau uso de frascos multidoses, ocorreram em consultórios ambulatoriais, em sua maioria em clínicas para tratamento da dor, onde medicamentos injetáveis são utilizados.

The Joint Commission, com base em um evento sentinela ocorrido em 2014, lançou alerta para a utilização de medicamentos em mais de um paciente, a partir de um único frasco. A simples troca de agulha ou a administração em ejetor lateral de equipo não garantem a total segurança contra contaminação por sangue após o uso.

Segundo Sikora et al. (2010), estudos realizados identificaram, por meio de técnicas de ionização por laser, a presença de sangue no circuito intravenoso, e, após o uso, 50\% das seringas com substância salina foram contaminadas por sangue.

Frascos de medicamentos, denominados dose única, foram fabricados para serem utilizados em apenas um paciente e, após seu uso, devem ser descartados mesmo que contenham alguma dose residual, pois, na formulação desses medicamentos, não há conservante antimicrobiano que permita sua guarda após seu uso, como ocorre nos medicamentos presentes em frascos multidoses.

Os medicamentos em frascos multidoses podem ser utilizados em mais de um paciente, mas, para isso, técnicas assépticas devem ser seguidas, tais como:

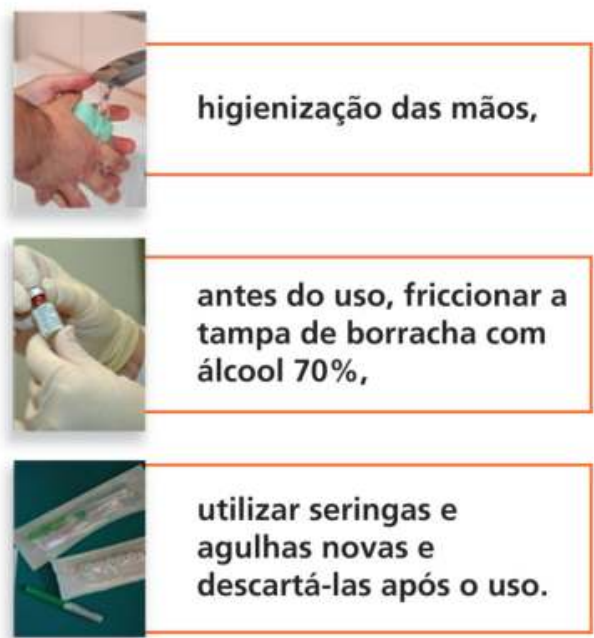


Sendo assim, profissionais de saúde devem sempre seguir medidas seguras nos processos de injeção e atentar para a prevenção e controle de infeção durante sua prática, tais como: técnica asséptica, higiene das mãos e uso único para seringas e agulhas.

\section{Práticas profissionais que contribuem para falhas}

1. Reinserção de agulhas usadas em frascos de multidoses ou recipiente de soluções (bolsa de solução salina).

2. Uso de uma única agulha/seringa para administrar medicamento intravenoso para múltiplos pacientes.

3. Falta de adesão, por parte dos profissionais, aos princípios básicos das técnicas assépticas para preparação e administração de medicamentos parenterais - uso de agulhas e seringas estéreis, de único uso e descartáveis para cada injeção realizada, e práticas preventivas de contaminação dos equipamentos de injeção e dos medicamentos.

\section{Para refletir}

Na sua vivência profissional, você já se deparou com alguma das falhas listadas? O que você acredita ser possível fazer para melhorar essas práticas? Se você manipula agulhas, seringas e outros equipamentos de injeção, o que tem feito para evitar possíveis contaminações?

\section{Recomendações}

1. Práticas seguras de injeção - Uso de técnica asséptica para evitar contaminação de equipamentos estéreis para injeções.

2. Administração de medicamentos injetáveis - Não administrar medicamentos de uma seringa para múltiplos pacientes, mesmo que a agulha ou cânula seja trocada. Usar conjuntos de administração para infusão de fluidos somente para um único paciente e descartálos apropriadamente após o uso. Usar frascos de uma dose, sempre que possível, para medicamentos parenterais. Se frascos de multidoses forem utilizados, tanto a agulha ou cânula como a seringa usadas para acesso ao frasco devem ser estéreis.

3. Treinamento - O treinamento continuado de profissionais da saúde, baseado na segurança em injeções, também merece destaque como estratégia-chave. 
4. Novos dispositivos - Incentivo à produção de seringas inteligentes para adequação a padrões de desempenho de qualidade e segurança. Elas apresentam características que previnem seu reuso, sendo, portanto, recomendáveis pela OMS tanto para injeções intramusculares como para injeções dérmicas. Esses tipos de seringas também são projetadas objetivando proteger profissionais de saúde contra acidentes por agulhas, com lesões resultando em infecções. Alguns modelos da nova seringa incluem um ponto fraco no êmbolo, que o faz quebrar se o usuário tentar puxá-lo após a injeção. Existem também outros modelos que apresentam um clip de metal que bloqueia o êmbolo, não permitindo que ele possa se mover para trás. Já num terceiro modelo, a agulha se retrai para dentro da seringa ao final da injeção. A meta da OMS é que, até 2020, os países façam a transição para o uso exclusivo das novas seringas inteligentes, exceto para algumas circunstâncias, por exemplo, se o bloqueio da seringa, após o único uso, interferisse com o procedimento, como no caso de seringas em bomba infusora.

\section{Referências}

American Society of Anesthesiologists. Recommendations for infection control for the practice of anesthesiology. 3rd. ed. Park Ridge (III): ASA; 2016 [citado 2017 out 4]. Disponível em: https:// www.asahq.org/coveo.aspx?q=recommendations $\% 20$ for $\% 20$ infection $\% 20$ control.

AkI L, Ballout R, Batoul D, Harb A, Khamassi S, Tarabay R. Reuse prevention syringes. York: Prospero; 2014 [citado 2017 set 10]. Disponível em: http://www.crd.york.ac.uk/PROSPERO_ REBRANDING/display_record.asp?ID=CRD42014006953.

Araujo $\mathrm{M}$ et al. Reutilização de agulhas e seringas descartáveis por um grupo de diabéticos. Ciência. Cuid Saude. 2009 [citado 2014 mar. 11];8(1):93-100. Disponível em:

http://basesbireme.br/.

Castro A, Grossi S. Reutilização de seringas descartáveis no domicílio de crianças e adolescentes com diabetes mellitus. Rev Esc Enferm USP. 2007 [citado 2017 out 4];41(2):187-95. Disponível em: http//www.ee.usp.br/reeusp/.

Centers for Disease Control and Prevention's. Infection prevention during blood glucose monitoring an insulina administration. Atlanta: CDC; 2017 June 8 [citado 2017 set 20]. Disponível em: https:// www.cdc.gov/injectionsafety/blood-glucose-monitoring.html.

Centers for Disease Control and Prevention's. The one and only campaign. Atlanta: CDC; 2017 [citado 2017 out 10]. Disponível em: http//oneandonlycampaign.org/.

Centers for Disease Control and Prevention's. Protect patients against preventable harm from improper use of sinngle-dose/singles-use vials. Atlanta: CDC; 2016 Aug 30 [citado 2017 set 20]. Disponível em: http://www.cdc.gov/.

Centers for Disease Control and Prevention's. Transmission on hepatite B virus among persons undergoing blood glucose monitoring in long-term care facilities - Mississipi, North California and Los Angeles County, California, 2003-2004. MMWR Weekly. 2005 Mar 11 [citado 2017 out 4];54(09):220-3. Disponível em: https://www.cdc.gov/mmwr/preview/mmwrhtml/mm5409a2.htm. 
Food and Drugs Administration. Risk of Transmission of Blood-borne Pathogens from Shared Use of Insulin Pens. Silver Spring: FDA; 2009 [citado 2017 out 4]. Disponível em: https:// www.fda.gov/Drugs/DrugSafety/PostmarketDrugSafetylnformationforPatientsandProviders/ DrugSafetylnformationforHeathcareProfessionals/ucm133352.htm.

Gisselquist D, et al. HIV infections in sub-Saharan Africa not explained by sexual or vertical transmission. Int J STD AIDS, 2002;13(10):657-666.

Grossi SAA. Tratamento insulinoterápico da pessoa com diabetes mellitus. In: Duarte YAO, Diogo MJD. Atendimento domiciliar: um enfoque gerontológico. São Paulo: Atheneu; 2000. cap. 24.2, p. 336-47.

IBGE. Pesquisa nacional de saúde 2013: percepção do estado de saúde, estilo de vida e doenças crônicas. Rio de Janeiro: IBGE; 2013 [citado 2017 out 5]. Disponível em: ftp://ftp.ibge.gov.br/ PNS/2013/pns2013.pdf.

Kossover-Smith RA, Coutts K, Hatfield KM, Cochran R, Akselrod H, Schaefer MK, et al. One needle, one syringe, only one time? A survey of physician and nurse knowledge, attitudes, and practice around Injection safety. Am J Infect Control. 2017 Sep 1;45(9):1018-1023.

Sikora et al. Population risk of syringe reuse: estimating the probability of transmitting bloodborne disease. Infect Control Hosp Epidemiol. 2010 July;31(7):748-54.

Sociedade Brasileira de Diabetes. Recomendações sobre o tratamento injetável do diabetes: insulinas e incretinas. São Paulo: SBD; 2017 [citado 2017 set 30]. (Posicionamento oficial SBD; n. 1/2017). Disponível em: http://www.diabetes.org.br/publico/images/2017/posicionamento-oficialsbd-01-2017.pdf.

Joint Commission. Sentinel event alert: preventing infection from the misuse of vials. Oakbrook Terrace (III): JC, 2017 [citado 2017 out 5]. Disponível em: http//www.jointcomission.org/

World Health Organization. Diabetes. Geneva: WHO; 2018 Oct 30 [citado 2017 Out 4]. Disponível em: http://www.who.int/mediacentre/factsheets/fs312/en/.

World Health Organization. Guiding principles to ensure injection device security. Geneva: WHO; 2015 [citado 2017 Out 4]. Disponível em: http://www.who.int/infection-prevention/tools/injections/ GuidingPrinciple-injection-device-security.pdf?ua=1.

World Health Organization. Single use of injection devices. Geneva: WHO; 2007 May. (Patient Safety Solutions; vol. 1; solution 8).

World Health Organization. WHO calls for worldwide use of "smart syringes. Geneva: WHO; 2015 Feb 23 [citado 2017 Set 10]. Disponível em: http://www.who.int/mediacentre/news/releases/2015/ injection-safety/en/.

Zabaleta-del-Olmo E, et al. Safety of reuse of needles for subcutaneous insulin injection: a systematic review an meta-analysis. Int J Nurs Stud. 2016 Aug 20;60:121-32. 
Anexo F - Diretriz clínica para a prevenção de falhas relacionadas a conexões de linhas de infusão e cabos

\section{Bárbara Ventura Fontes e Sandra Regina Ferreira Vasconcelos}

Na administração de medicamentos e fluidos para pacientes, deparamo-nos com a presença constante de conexões de circuitos e cabos de infusão de medicamentos, além de outros fluidos. O uso de dispositivos para acesso venoso é universalmente usado no cuidado de saúde; estima-se que pelo menos $85 \%$ dos pacientes hospitalizados nos Estados Unidos da América recebam terapia intravenosa (Mattox 2017).

Esse emaranhado de conectores pode facilitar o erro de vias que não eram aquelas pretendidas. São falhas evitáveis, mas ocorrem com muita frequência. Erros em conexões de tubos e cateteres acontecem quando um dispositivo médico é conectado a outro que está sendo utilizado para uma função totalmente diferente, como conectar equipo de alimentação enteral em algum acesso venoso (Mattox 2017). Um único paciente pode estar conectado a vários cabos e linhas usados para diagnóstico, terapêutica ou monitoramento, como demonstrado na figura a seguir, aumentando o potencial de falhas em conexões.

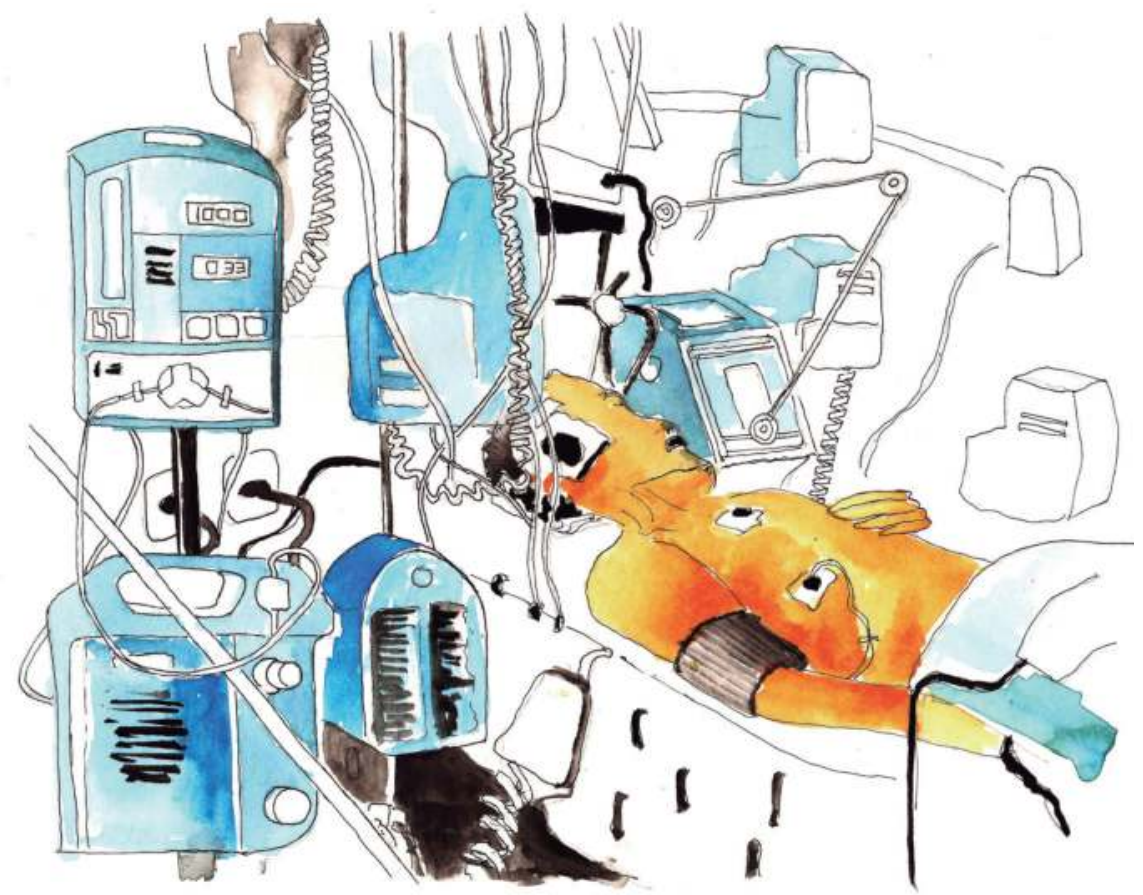

A profusão de conectores apresenta uma desordem visual que, aliada ao estresse, fadiga e distração, tão típicos do ambiente hospitalar, pode causar confusão e levar a falhas nas conexões.
O termo dispositivo médico (medical device) significa equipamento médico, sendo definido pelo Food and Drug Administration (FDA 2013) como: instrumento, aparato, implemento, máquina, aparelho, implante, reagente in vitro, ou outro artigo similar ou relacionado, incluindo qualquer componente, peça ou acessório que seja usado no diagnóstico de doenças ou outras condições, ou na cura, alívio, tratamento e prevenção de doenças.

\section{oor ApoloAn}




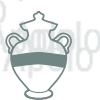

A maioria das falhas são near miss, ou seja, ocorrem sem atingir os pacientes, mas também é possivel ocasionar eventos adversos e mesmo a morte.
Os tipos de conectores mais frequentemente envolvidos nas notificações de incidentes, para The Joint Commission (Guenter et al. 2008), são os cateteres venosos centrais, cateteres venosos periféricos, cateteres nasogástricos para alimentação, cateteres entéricos percutâneos para alimentação, cateteres peritoneais para diálise, conexão para inflação do cuff de traqueostomia e conexões para insuflação do cuff de pressão sanguínea.
Embora tubos, catéteres e seringas façam parte da rotina de profissionais de saúde para a administração de medicamentos e fluidos em pacientes, a administração não intencional desses fluidos a destinos equivocados ocorre com frequência significativa (ainda que sua incidência seja desconhecida) e pode ocasionar eventos adversos, por exemplo, perda permanente de função ou até mesmo a morte do paciente.

O objetivo da diretriz clínica é a implementação de medidas para a prevenção do erro de conexões e mitigação dos riscos de administração de medicamentos e outros fluidos em vias erradas.

A literatura científica, as bases de dados como MAUDE, do FDA, e o sistema de relatos de problemas do E CRI (Emergency Care Research Institute) citam numerosos casos de conexões erradas. O óxido nitroso (N2O) tem sido erroneamente administrado no lugar do oxigênio, por exemplo, como também a solução para alimentação enteral administrada por via intravenosa.

A seguir, abordamos alguns dos elementos mais frequentemente relacionados ao acontecimento falhas, referentes a conexões de linhas de infusão e cabos.

\section{Fatores desencadeantes de falhas de conexões}

繗 Design - Existem fatores que podem contribuir para falhas de conexão, como uso de conectores universais, os quais são utilizados para uma variedade de aplicações na conexão de dispositivos médicos, incluindo administração de fluidos por via enteral, intravascular, espinhal e epidural e insuflação de gás em balões de catéteres, cuffs endotraqueais e dispositivos de pressão sanguínea. Esse tipo de conector permite que se liguem conectores de tubos ou cateteres funcionalmente diferentes. Os conectores Luer, por exemplo, conectam de modo fácil muitos componentes médicos, acessórios e sistemas de administração, levando profissionais a conectarem, inadvertidamente, os dispositivos errados e, como consequência, aplicarem substâncias através da via errada.

繗 Indicação dos dispositivos - Outro fator desencadeante de falha é a utilização de tubos ou cateteres para uso diferente de seus propósitos.

* Proximidade de dispositivos - A proximidade de tubos instalados no paciente com propósitos diferentes também pode ser apontada como um risco de conexão errada, por exemplo, a proximidade de um cateter para alimentação enteral com um cateter intravenoso central. 
* Falta de protocolo de comunicação nos handovers - A movimentação interna do paciente dentro da instituição e a falta de protocolos para gerenciar essa tranferência de cuidados podem contribuir para falhas relacionadas a conexões erradas.

Sobrecarga de trabalho (burnout) - A fadiga da equipe, associada a vários plantões, é também contribuinte para ocorrência desse tipo de falha.

滕 Falhas relacionadas à estrutura - Pouca iluminação, recursos humanos subdimensionados e sem treinamento adequado.

Baixo grau de maturidade da cultura de segurança - As falhas ocorridas não são tratadas como oportunidade de aprendizado para a prevenção de novas falhas similares.

\section{Tipos de conexões erradas}

As conexões erradas variam de acordo com o tipo e gravidade do dano causado. Vejamos os tipos de falha de conexões que podem ocorrer:

能 Falha de conexões entre cabos - Cabos são frequentemente ligados a pacientes para monitoramento ou usados para conectar dispositivos médicos em fontes de energia. As conexões erradas podem trazer resultados como queimaduras e danos ao equipamento. Eletrocussão é também possível, embora muito menos provável.

滕 Falha de conexões gás-gás - Linhas de gases são comumente usadas para suporte respiratório ou equipamento médico pneumático. Pelo fato de a ventilação ser crítica, a conexão errada de linhas de um circuito respiratório ou o fornecimento errado de um gás respiratório pode causar sérios danos ao paciente. Conexões erradas de gás que não envolvem ventilação também possibilitam sérios danos, por exemplo: paciente com dano resultante de linha de gás pressurizado; a linha pode ser confundida com linhas de sucção.

紫 Falha de conexões líquido-líquido - Linhas com líquidos são primariamente aquelas que fornecem nutrientes ou medicação para pacientes, como as linhas de infusão e aquelas usadas para circulação de banhos de água. Em razão de as linhas para a administração de líquidos serem, com frequência, direcionadas a pontos de acesso no corpo, conexões erradas podem resultar na entrada de substâncias em parte errada, possivelmente com consequências mortais. 
踏Falha de conexões gás-líquido - Ocorrem quando linhas de gás e líquido são, de forma errada, conectadas juntas. Conexões erradas de gás-líquido são tipicamente graves e, em geral, resultam em gás sendo introduzido no sistema vascular ou líquido introduzido no trato respiratório.

Segundo Mattox (2017), sinais e sintomas da infusão não intencional de líquidos ou gases variam amplamente, mas alguns foram listados com base em estudo de casos relatados, sendo eles: dor nas costas, febre, dor no peito, dispneia, anafilaxia, parada/paragem cardiopulmonar, alteração mental, convulsões, sepse, coagulopatia. Esses sinais e sintomas podem ser sutis ou catastróficos, com início variando entre o insidioso ou abrupto.

\section{Ações específicas de prevenção}

É possível dividir as ações preventivas em ações essenciais, que devem ser realizadas, e estratégias adicionais, que devem ser consideradas.

\section{Ações essenciais: soluções relacionadas a práticas de trabalho}

䠌 Tracione todas as linhas, a partir da sua origem, antes de realizar conexões. Isso evitará erros, como a conexão de uma linha de gás respiratório para uma linha intravenosa do paciente. Apesar de um tempo extra na tração de cada linha, essa é uma medida necessária a fim de prevenir erros.

滕 Não force conexões, utilize somente para seu propósito, não adaptando-o ou modificando-o. Se uma conexão está difícil de ser feita, ou seja, se requer muita força, é sinal que não é a correta. E, ainda, se você perceber que a conexão não é segura, cheque para ver se os componentes certos estão sendo conectados.

镂 Não use adaptadores, a não ser que sejam claramente necessários para a aplicação. Esteja ciente de que seu uso possibilita a conexão de dois componentes inapropriados. A necessidade de um adaptador pode ser sinal de que a conexão que você está tentando fazer não deve ser realizada.

Tenha certeza de que você recebeu treinamento antes de usar um equipamento.

Rechear conexões e tracionar todas as linhas a cada transição de cuidado, como a chegada do paciente a novas unidades e nas trocas de plantão/turno. 
Notifique qualquer ocorrência de falha ou near miss em conexões. As notificações ajudam a demonstrar a frequência de conexões erradas e podem levar indústrias a realizar mudanças.

暍 Assegure iluminação apropriada quando estiver fazendo conexões.

膦 Desenvolva uma rotina de posicionamento diferente (em relação ao paciente) para linhas de diferentes finalidades, mantendo sempre um padrão para essas localizações. Colocar constantemente as mesmas linhas no mesmo lado cria uma rotina, e pode facilitar para que os profissionais identifiquem corretamente e as conectem de forma apropriada. Esse é o caso da padronização da fixação de tubos e cateteres que possuam finalidades diferentes, em posições opostas, por exemplo: cateter venoso posicionado no sentido da cabeça e cateter nasoenteral posicionado no sentido dos pés.

蹸 Identificação com rótulos para cateteres de alto risco, como epidural, intratecal e arterial. Além disso, os cateteres não devem possuir entradas secundárias para injeção.

普 Implemente um procedimento de dupla checagem durante a administração de medicamentos de alto risco como drogas intratecais, além de outros procedimentos com maior frequência de eventos adversos. Procedimentos independentes de dupla checagem podem consumir mais tempo de trabalho, mas devem ser aplicados como procedimentos de rotina.

* Armazene medicações para diferentes vias de administração em locais diferentes (por exemplo, manter medicações intratecais em local separado das medicações intravenosas).

\section{Estratégias adicionais - Relacionadas a lideranças}

蛇 Fornecer treinamento periódico aos profissionais de saúde para identificação e prevenção de riscos de erros de conexão. Os profissionais necessitam de lembretes sobre práticas de segurança no trabalho, e toda a equipe deve saber das consequências de conexões erradas.

Realize treinamento de acompanhantes dos pacientes e visitantes a fim de não conectarem ou reconectarem linhas de infusão, solicitando assistência à equipe de saúde.

滕 Reveja o uso de adaptadores no hospital e desencoraje sua rotina de uso. Somente adaptadores claramente necessários para aplicações especializadas devem ser estocados e usados.

滕 Reveja políticas de compra com a intenção de assegurar que, sempre que possível, somente equipamento com design efetivo seja 
adquirido e, ainda, disponibilizar apenas seringas específicas para diferentes tipos de vias de administração, assegurando que seringas para infusão de soluções enterais sejam incompatíveis com cateteres venosos.

Reveja critérios de inspeção e manutenção para questões relacionadas a conectores.

蝶 O responsável pela engenharia clinica deve assegurar que os técnicos de manutenção estejam cientes de questões relacionadas a conexões e evitem a modificação de dispositivos nos locais em que podem facilitar conexões erradas.

繙 Acompanhar o processo de administração de soluções e dietas por meio de indicadores.

静 Todas as conexões erradas devem ser notificadas a fim de identificar novas áreas de preocupação no hospital.

\section{Estratégias proativas que conduzem a soluções relacionadas a políticas de segurança dos pacientes, à engenharia clínica, ao gerenciamento/gestão de riscos e gerenciamento/gestão de compras}

Barreiras físicas - O design ajuda a eliminar a possibilidade de interconectividade entre diferentes conexões e cateteres, pois a alteração física dos conectores terminais impede conexões entre diferentes aplicações. Uma série de padronizações podem ser desenvolvidas para que, quando implementadas, tornem praticamente impossível as conexões de tubos que envolvam conectores de pequeno diâmetro, porque o design do conector não será mais universal, e sim específico da sua aplicação (AMMI 2013). O desenvolvimento de novos padrões internacionais de design para conectores está sendo realizado por associações, em parceria com lideranças de organizações industriais importantes (Mundi, EPP, Hurt 2016).

* Marcação específica de entradas a fim de evitar conexões de linhas intravenosas para o cateter de cuffs ou balões.

Conexões dedicadas à infusão de bombas para aplicações específicas, como infusão epidural. 
謷 Usar somente seringas oral/enteral para administrar medicações oral/enteral, evitando uso de adaptadores e "three-way".

滕 As cores de linhas e conexões devem ser padronizadas, como a utilização de apenas equipo de cor azul para infusão de dietas enterais ou de etiquetas com cores diferentes para marcar as linhas de infusão.

No decorrer da formação acadêmica de profissionais de saúde, promover discussões a respeito do risco de erros de conexões de cateteres e sondas durante o cuidado de saúde.

\section{Referências}

Association for the Advancement of Medical Instrumentation. Ambitious standards initiative on small-bore connectors moves forward. News and Views Articles \& Press Releases. 2013 April 24.

Center for Clinical Standards and Quality, Survey \& Certification Group. Memorandum para: State Survey Agency Directors. Assunto: Luer misconnections adverse events. 2013 Mar 8.

Conexões e conectores: a mudança do bem? BIT: Bol Inf Tecnovigilância. 2012 abr./jun.;3(2).

ECRI Institute. Preventing misconnections of lines and cables. Health Devices. 2006 Mar;35(3):81-95.

Food and Drug Administration (US). Preventing tubing and luer misconnections: tips for health care providers. Silver Spring: FDA; 2013.

Food and Drug Administration (US). Safety considerations to mitigate the risks of misconnections with small-bore connectors intended for enteral applications: guidance for Industry and Food and Drug Administration staff. 2015 Feb 11 [citado 10 jul 2017]. Disponível em: https://www.fda.gov/ downloads/medicaldevices/deviceregulationandguidance/guidancedocuments/ucm313385.pdf.

Guenter P, Hicks RW, Simmons D, Crowley J, Joseph S, Croteau R et al. Enteral feeding misconnections: a consortium position statement. Jt Comm J Qual Patient Saf. 2008 May;34(5):285-92.

Institute for Safe Medication Practices. Preventing catheter/tubing misconnections: much needed help is on the way. ISMP Medication Safety Alert. 2010 Jul 15;15:1-2. Disponível em: http://www. ismp.org.

Instituto para Práticas Seguras no Uso de Medicamentos. Erros de conexão: praticas seguras e riscos na administração de soluções por sondas enterais e cateteres vasculares. Bol ISMP. 2013 [citado 2017 jul 4];2(3). Disponível em: http://www.ismp-brasil.org/site/wp-content/uploads/2015/07/ V2N3.pdf.

Mattox E. Complications of peripheral venous access devices: prevention, detection, and recovery strategies. Crit Care Nurse. 2017;37(2):e1-e14.

Mundi, MS, EPP, L., Hurt, RT. Increased Force with proposed standardized enteral feed conector in blenderized tube feeding.. Nutr Clin Pract. 2016;20(10).

Trindade $\mathrm{E}$, et al. Modos de falhas de artigos médico-hospitalares: análise das queixas técnicas envolvendo equipos de infusão notificadas à ANVISA em 2007 e 2008. BIT Bol Inf Tecnovigilancia. 2010 dez.

WHO Collaborating Centre for Patient Safety Solutions. Avoiding Catheter and Tubing MisConnections. Patienty Safety Solutions, 2007 May; 1, solution 7.
Three-way é um duplicador de acesso venoso, também chamado torneirinha. Trata-se de um dispositivo intermediário (entre o acesso venoso e diversos equipos instalados), descartável, estéril, que auxilia a instalação de infusões múltiplas de soluções IV (intravenosa) e/ou medicamentos; é constituído de um volante giratório com setas indicativas que controlam o direcionamento do fluxo. 


\section{Anexo G - Diretriz clínica para prevenção e tratamento do delirium em pacientes internados em serviços de pacientes em condições agudas e de cuidados gerais}

\section{Luciana Santos de Carvalho e Isabela Ribeiro Simões de Castro}

O delirium é um distúrbio neurocognitivo comum, marcado pela desatenção e falha da consciência, que se desenvolve em um curto período de tempo. Dois fatores de risco marcam a predisposição comum para o delirium: a idade avançada e a demência. Em geral, a prevalência de delirium em ambientes hospitalares varia de 18 a 35\%, de 26 a $62 \%$ em unidades de cuidados paliativos, e de 30 a $70 \%$ em cuidados intensivos, dependendo do perfil de pacientes e dos métodos de avaliação (Bush et al. 2017).

O objetivo da diretriz clínica para prevenção e tratamento do delirium é identificar pacientes com fatores de risco para delirium, diagnosticar e tratar prontamente as causas do delirium seguindo protocolos. O nível de evidência (Cochrane) dos resultados com o uso da diretriz é III. O tempo para implantação do protocolo é de um a dois anos. A dificuldade de implantação é média e depende de diversas áreas e da cultura existente na organização de saúde. Os impactos do uso da diretriz são:

Redução de custo

Redução de danos

滕 Redução de tempo de internação em unidades intensivas (medido nos últimos seis meses)

䟕 Redução de readmissões (no período de 30 dias)

As consequências do delirium são déficits anatômicos, desequilíbrio (em razão de alterações nos níveis de serotonina, acetilcolina e deficiência de dopamina). Essas alterações podem ser secundárias a: redução no metabolismo cerebral; doença intracraniana primária; doenças sistémicas; infecção secundária do cérebro; agentes tóxicos exógenos; retirada de drogas e substâncias de uso crônico, tais como álcool ou agentes sedativo-hipnóticos; hipoxemia; distúrbios metabólicos; e a administração de medicamentos psicoativos, como os benzodiazepínicos. 


\section{Itens relevantes das diretrizes clínicas do Critical Care Medicine sobre delirium}

\section{As ações estratégicas são:}

繗 Avaliar o risco de todos os pacientes internados em unidades agudas e de cuidados gerais.

滕 Reconhecer sinais e sintomas precocemente.

Tratar farmacologicamente o delirium.

\section{As ações mais operacionais são:}

噄 Identificar pacientes com fatores de risco:

- variáveis não controláveis: idade e gravidade da doença existente (pré-existência de demência);

- variáveis controláveis: coma, uso de benzodiazepínicos, histórico de alcoolismo.

Manter familiares e cuidadores próximos o maior tempo possível.

橉 Restituir óculos e aparelho auditivo o mais cedo possível.

Manter ambiente silencioso e com janelas para percepção de luz do dia.

蝶 Evitar excesso de claridade ou escuridão total à noite.

Manter relógios, calendários e itens pessoais.

滕 Não acordar à noite para administrar medicação ou aferir sinais vitais, a menos que seja estritamente necessário.

Não interromper medicamentos psicoativos de uso habitual.

滕 Proporcionar analgesia e hidratação adequada no pós-operatório.

* Evitar contenção no leito/cama, a não ser quando for estritamente necessário para preservar a segurança do paciente.

Mobilizar o paciente precocemente no leito/cama.

滕 Utilizar, preferencialmente, as ferramentas validadas para monitoramento do delirium em pacientes internados em unidades intensivas e clínicas como: The Confusion Assessment Method for the ICU - CAM-ICU ou The Intensive Care Delirium Screening Checklist - ICDSC.

Familiarizar o paciente com o ambiente, reforçando as orientações de uso de óculos e aparelhos auditivos, conforme necessário.
Resultados de estudos demonstram que altos níveis de ruídos, incluindo aqueles oriundos dos alarmes, não apenas interferem no cuidado, mas possuem, também, efeitos deletérios para a recuperação dos pacientes internados em terapia intensiva e na saúde dos profissionais que atuam nesses setores (Sampaio Neto et al. 2010). 
噄 Promover sono aos pacientes (principalmente àqueles internados em unidades intensivas).

Monitorar a retirada do ventilador avaliando nível de consciência, nos casos de pacientes internados em unidades intensivas.

\section{As ações farmacológicas:}

* Evitar o uso de benzodiazepínicos em pacientes em risco de delirium, exceto se houver suspeita de abstinência desse tipo de droga.

橉 Não usar rivastigmina para reduzir a duração do delirium.

Não utilizar haloperidol ou psicóticos atípicos para prevenir delirium.

* Evitar o uso de antipsicóticos em pacientes com prolongamento do segmento QT, história de Torsades de Pointes (taquicardia ventricular caracterizada por flutuação dos complexos QRS, tipicamente causada por um intervalo QT prolongado e podendo estar associada à administração de antipsicóticos) e em pacientes que recebem medicações para o prolongamento de segmento QT.

䠌 Usar dexmedetomidina em vez de infusões de benzodiazepínicos, quando a sedação for necessária em pacientes críticos com delirium, a menos que esteja relacionado ao álcool ou à retirada de benzodiazepínicos.

*studos recentes apontam efeitos positivos da melatonina na prevenção do delirium em pacientes idosos. Entretanto, a evidência científica ainda é considerada insuficiente para recomendar o seu uso para redução da incidência do delirium em pacientes internados, com 65 anos ou mais (CADTH 2016).

\section{Indicadores utilizados para monitorar a prevenção e tratamento do delirium em pacientes internados em unidades agudas e de cuidados gerais:}

䟕 Percentual de pacientes com risco de desenvolver delirium.

膦 Percentual de pacientes monitorados diariamente para delirium.

蝶 Percentual de pacientes com delirium conduzidos por protocolos. 


\section{Referências}

Agency for Healthcare Research and Quality. Making health care safer: a critical analysis of patient safety practices. Rockville (MD): AHRQ; 2001 [citado 2014 ago 25]. Disponível em: ttp://www.ahrq. gov/research/findings/evidence-based-reports/ptsafetyuptp.html.

Agostini JV, Baker DI, Inouye SK, Bogardus Jr, ST. Prevention of delirium in older hospitalized patients. In: Agency for Healthcare Research and Quality. Making health care safer: a critical analysis of patient safety practices. Rockville (MD): AHRQ; 2001 [citado 2014 ago 25]. Chapter 28. Disponível em: http://archive.ahrq.gov/clinic/ptsafety/chap28.htm

Barr J, Fraser GL, Puntillo K. Clinical practice guidelines for the management of pain, agitation, and delirium in adult patients in the intensive care unit. Crit Care Med. 2013 Jan;41(1):263-306.

Bush $\mathrm{SH}$, Marchington $\mathrm{KL}$, Agar M, et al. Quality of clinical practice guidelines in delirium: a systematic appraisal. BMJ Open 2017;7:e013809. doi: 10.1136/bmjopen-2016-013809.

Canadian Agency for Drugs and Technologies in Health. Sleep medications for the treatment or prevention of delirium: clinical effectiveness and guidelines. Ottawa: CADTH; 2016 Dec 9 [citado 2018 out 20]. Rapid response report. Disponível em: https://www.cadth.ca/sites/default/files/pdf/ htis/2016/RB1046\%20Sleep\%20Medications\%20for\%20Delirium\%20Final.pdf

Centers for Disease Control and Prevention. Medication Safety Program. Atlanta: CDC; 2014 [citado 2014 ago 25]. Disponível em: http://www.cdc.gov/medicationsafety/

Joint Commission. Advancing effective communication, cultural competence, and patientcentered care: a roadmap for the hospital. Oakbrook Terrace (IL): Joint Commission, 2010 [citado 2014 ago 25]. Disponível em: http://www.jointcommission.org/assets/1/6/ ARoadmapforHospitalsfinalversion727.pdf

National Priorities Partnership. Palliative care and end-of-life care. Washington, DC: National Quality Forum; 2010 [citado 2014 ago 25]. Disponível em: www.qualityforum.org/Publications/2010/11/ Palliative_Care_and_End-of-Life_Care_Convening_Meeting.aspx

Hughes RG, editor. Patient safety and quality: an evidence-based handbook for nurses. Rockville (MD): Agency for Healthcare Research and Quality; 2008 Apr.

Kleinpell RM, Fletcher K, Jennings BM. Reducing functional decline in the hospitalized elderly. In: Hughes RG, editor. Patient safety and quality: an evidence-based handbook for nurses. Rockville (MD): Agency for Healthcare Research and Quality; 2008 Apr [citado 2014 ago 25]. Disponível em: http://www.ahrq.gov/professionals/clinicians- providers/resources/nursing/resources/nurseshdbk/ KleinpellR_RFDHE.pdf

Vanderbilt University, Center for Health Services Research. ICU Delirium and Cognitive Impairment Study Group: training manual and instructional video. Nashville, TN: VUMC; 2013 [citado 2014 ago 25]. Disponível em: http://www.icudelirium.org/delirium/monitoring.html

Yale University. The Hospital Elder Life Program (HELP). New Haven, CT: School of Medicine; 2000 [citado 2014 ago 25]. Disponível em: http://www.hospitalelderlifeprogram.org/public/patientfamily.php 


\section{Anexo $\mathrm{H}$ - Fadiga de alarmes}

\section{Adriana Carla Bridi}

O desenvolvimento e a contínua incorporação de tecnologia com fins diagnósticos e terapêuticos nas unidades de terapia intensiva (UTI) têm inúmeros benefícios para o paciente grave. Contudo, estudos vêm apontando que o elevado número de alarmes de equipamentos médico-assistenciais (EMA) aumenta o risco do paciente grave na terapia intensiva (Blum; Tremper 2010, Cvach 2012, Graham, Cvach 2010, Korniewicz et al. 2008, Siebig et al. 2010). Pesquisadores/investigadores demonstram crescente preocupação quanto ao uso seguro desse aparato nessas unidades, especialmente no que diz respeito aos problemas relacionados ao uso inadequado dos sistemas de alarmes dos equipamentos, levando a incidentes com pacientes graves.

Nesse contexto, discute-se a fadiga de alarmes, fenômeno que ocorre quando grande número deles encobre os clinicamente significativos, possibilitando que alarmes de relevância clínica sejam desabilitados, silenciados ou ignorados pela equipe. O número excessivo de alarmes acarreta sobrecarga sensorial e dessensibilização da equipe, reduz seu estado de alerta e confiança no sentido de urgência dos alarmes, levando à falta de resposta ou demora em atendê-los em tempo hábil. Alarmes de relevância clínica, quando subestimados, podem resultar em graves consequências relacionadas às condições clínicas do paciente, pois alterações não detectadas impedem a adoção de medidas terapêuticas apropriadas (Blum; Tremper 2010, Cvach 2012, Graham, Cvach 2010, Korniewicz et al. 2008, Siebig et al. 2010).

Reconhecidas organizações como Association for the Advancement of Medical Instrumentation (AAMI), American College of Clinical Engineering (ACCE), American Association of Critical Care Nurses (AACN), Healthcare Technology Foundation (HTF), Joint Commission (JC) e o Emergency Care Research Institute (ECRI Institute) divulgam relatórios, estudos e recomendações, direcionados aos profissionais envolvidos com o cuidado de saúde, acerca da fadiga de alarmes e da problemática abrangendo-os, além de suas implicações para a segurança do paciente. Essa última organização tem destacado os alarmes entre os principais perigos da tecnologia em saúde desde 2007, consecutivamente (Top 10 Health Technology Hazards). 
De 2005 a 2008, a Food and Drug Administration (FDA) e a Manufacturer and User Facility Device Experience (MAUDE) receberam 566 relatos de mortes de pacientes relacionadas com alarmes de monitorização em hospitais dos Estados Unidos (Cvach 2012). Entre março e junho de 2010, houve registro, no MAUDE, de mais 73 mortes relacionadas com alarmes, sendo 33 com monitores multiparamétricos (Cvach 2012). No período de 2009 a 2012, a Joint Commission relatou 98 eventos sentinela envolvendo alarmes de equipamentos em unidades de terapia intensiva; todos resultaram em algum tipo de dano aos pacientes, incluindo óbito (Joint Commission 2013). Esses incidentes levaram a JC, em 2014, a apresentar, como proposta a ser implementado, o gerenciamento/gestão de alarmes clínicos de forma sistemática aos hospitais, com programas de acreditação, objetivando melhorar a segurança do paciente no uso desses sistemas.

Dentre os fatores contribuintes à fadiga de alarmes, considerando sua complexidade e como um fenômeno multifacetado, multifatorial, multidisciplinar, podemos citar:

滕 alta complexidade da programação e configuração dos sistemas de alarmes nos dispositivos;

滕 ausência de manutenção dos acessórios e equipamentos e de envolvimento entre a equipe de saúde e a engenharia clínica nas instituições;

䟕 déficit de recursos humanos nas unidades e pouca aderência das equipes para configuração e programação correta dos sistemas de alarmes;

能 elevada incidência de falsos alarmes (ocorrem na ausência de um evento válido, gerados devido a dados ruins ou ausentes, por movimentação do paciente, instalação inadequada de eletrodos, sensores, cabos) ou não acionáveis (sinalizam corretamente, mas não requerem intervenção clínica, são de curta duração e se autocorrigem), por conta de sistemas de monitorização com alta sensibilidade e baixa especificidade;

犈 falta de padronização sonora e visual das variáveis em alarmes e de recursos de prioridade dos alarmes nos monitores e ventiladores mecânicos por parte dos fabricantes;

滕 inexistência de programas contínuos para capacitação dos profissionais, tendo em vista o manuseio correto dos aparelhos e de seus recursos;
Resultados de estudos demonstram que altos níveis de ruídos, incluindo aqueles oriundos dos alarmes, não apenas interferem no cuidado, mas possuem, também, efeitos deletérios para a recuperação dos pacientes internados em terapia intensiva e na saúde dos profissionais que atuam nesses setores (Sampaio Neto et al. 2010).
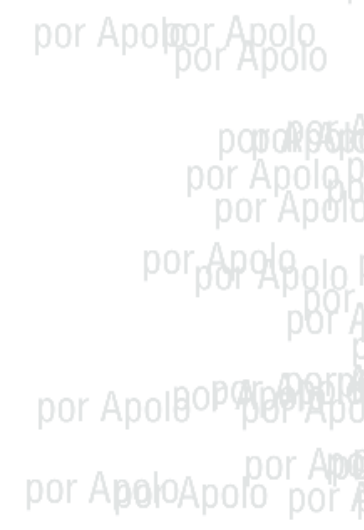
踏 falta de política de incorporação de tecnologias com foco na capacitação do profissional para correto manuseio e utilização dos recursos, de sua usabilidade e sua obsolescência;

* linguagem pouco compreensível dos manuais dos fabricantes, uma vez que não são direcionados para os profissionais que utilizam o equipamento;

planta física das terapias intensivas inadequadas ao atendimento dos alarmes.

Listamos algumas recomendações a fim de minimizar a fadiga de alarmes e tornar o gerenciamento/gestão e resposta da equipe aos alarmes mais seguros, em especial nas unidades de terapia intensiva:

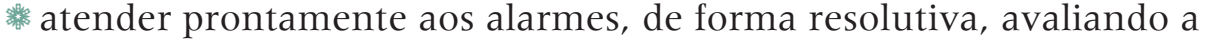
causa do alerta, e não silenciá-los somente;

* atentar ao uso correto de eletrodos, cabos, sensores de oximetria, acessórios, sistemas de transdução, evitando interferências e falsos alarmes;

* capacitar periodicamente os profissionais objetivando o manuseio correto dos diferentes equipamentos, seus recursos e sistemas de alarmes (por meio de demonstração e/ou simulação);

橉 contar com uma equipe interdisciplinar na unidade, incluindo engenheiros clínicos;

噒 definir rotina dos parâmetros fisiológicos de real necessidade a serem monitorizados nos pacientes (evitar duplicidade de variáveis monitoradas e alarmes);

* desenvolver processos de melhoria contínua com a equipe e a engenharia clínica, para adequada utilização dos sistemas de alarme, valendo-se de protocolos voltados a programações e configurações: de parâmetros de alarmes; de níveis de prioridade; de delays de alarmes (aumento do tempo para disparo de 10s a fim de evitar alarmes não acionáveis e falsos, permitindo autocorreção antes do disparo); dos níveis de volume e tons; considerando as condições e necessidades da unidade, o perfil e criticidade dos pacientes;

disponibilizar os recursos humanos necessários nos setores, de acordo com a complexidade dos pacientes e dos recursos tecnológicos utilizados;

documentar, no prontuário do paciente/processo clínico, os parâmetros de alarme definidos; 
繗 familiarizar-se com os equipamentos disponíveis, conhecer de que forma configurar, programar e ajustar as variáveis fisiológicas e os parâmetros dos sistemas de alarmes, objetivando melhor usabilidade dos EMA;

gerenciar e fiscalizar as tecnologias disponíveis na unidade (manutenção adequada);

manter os manuais dos aparelhos em uso disponíveis no setor para consulta da equipe;

䠝 minimizar os ruídos extras no ambiente;

滕 notificar os eventos adversos relacionados ao uso dos EMA (tecnovigilância);

* padronizar as práticas de monitoramento com diretrizes para configurações e ajustes dos limites de alarmes: como rotina, verificar e manter os equipamentos com alarmes ativados, em volume audível; parametrizar e configurar os alarmes de acordo com a condição clínica dos pacientes, suas necessidades e perfil da unidade de internação (individualização ou personalização dos parâmetros de alarmes);

畨 participação da equipe da unidade fim no processo de aquisição de novas tecnologias;

* preparar de modo adequado a pele do paciente e realizar a troca dos eletrodos rotineiramente.

\section{Referências}

ACCE Healthcare Technology Foundation. Impact of clinical alarms on patient safety. Plymouth Meeting (PA): ACCE; 2006 [citado 2012 nov 2]. Disponível em: http://thehtf.org/White\%20Paper. pdf.

American Association of Critical-Care Nurses. Practice alert: alarm management. Crit Care Nurse. 2013 [citado 2013 nov. 4];33(5):83-6. Disponível em: http://ccn.aacnjournals.org/content/33/5/83. full.pdf+html.

Association for the Advancement of Medical Instrumentation. Clinical alarms: 2011 summit. Arlington (VA): AAMl; 2011 [2012 out 12]. Disponível em: http://www.aami.org/publications/ summits/.

Association for the Advancement of Medical Instrumentation. Clinical alarm management compendium. Arlington (VA): AAMI; 2015 [citado 2017 out 10]. Disponível em: http:// s3.amazonaws.com/rdcmsaami/files/production/public/FileDownloads/Foundation/Reports/Alarm_ Compendium_2015.pdf.

Association for the Advancement of Medical Instrumentation. Horizons: Biomed Instrum Technol. 2017 [citado 2017 set 25];51(s2): 76. Disponível em: http://www.aamibit.org/toc/bmit/51/s2. 
Blum JM, Trember KK. Alarms in the intensive care unit: too much of a good thing is dangerous: is it time to add some intelligence to alarms? Crit Care Med. 2010 [citado $2010 \mathrm{abr}$ 30];3(2):7023. Disponível em: http://ovidsp.ovid.com/ovidweb.cgi?T=JS\& PAGE=fulltext\& D=ovft\& NEWS=N\& LINKOUT $=Y \&$ CSC $=Y \& A N=00003246-201002000-00054$

Bridi AC. Fatores determinantes do tempo estímulo-resposta da equipe de enfermagem aos alarmes dos monitores multiparamétricos em terapia intensiva: implicações para a segurança do paciente grave [dissertação]. Rio de Janeiro: Universidade Federal do Estado do Rio de Janeiro; 2013 [citado 2017 out 10]. 176 f. Disponível em: http://web02.unirio.br/sophia_web/.

Bridi AC, Louro TQ, Silva RCL. Alarmes clínicos em terapia intensiva: implicações da fadiga de alarmes para a segurança do paciente. Rev Lat Am Enferm. 2014 [citado dez 3];22(6):1034- 40. Disponível em: http://www.scielo.br/pdf/rlae/v22n6/pt_0104-1169-rlae-22-06-01034.pdf.

Bridi AC, Silva RCL, Farias CCP, Franco AS, Santos VLQ. Tempo estímulo-resposta da equipe de saúde aos alarmes de monitorização na terapia intensiva: implicações para a segurança do paciente grave. Rev Bras Ter Intensiva. 2014 [citado 2014 abr 23];26(1):28-35. Disponível em: http://rbti.org. br/artigo/detalhes/0103507X-26-1-05.

Bridi AC, Silva RCL, Monteiro JL. Fadiga de alarmes em terapia intensiva: descrevendo o fenômeno através da revisão integrativa da literatura. J Res: Fundam Care Online. 2013 [2013 jul 1];5(3):2741. Disponível em: http://www.seer.unirio.br/index.php/cuidadofundamental/article/view/2308/ pdf_810.

Cosper, P. et al. Clinical alarm management: guidance and strategies. Biomed Instrum Technol. 2017 [citado 2017 out. 11]:109-15. Disponível em: http://s3.amazonaws.com/rdcmsaami/files/ production/public/Libraries/Alarms/2017_BIT_MA_ClinicalAlarmManagement.pdf.

Cvach, M. Monitor alarm fatigue: an integrative review. Biomed Instrum Technol. 2012 [citado 2012 set 15];46(4):268-77. Disponível em: http://www.aami.org/publications/bit/2012/JA_alarm_ fatigue.pdf.

Cvach, M. et al. Customizing alarm limits based on specific needs of patients. Biomed Instrum Technol. 2017 May/June [citado 2017 set 25]:227-34. Disponível em: https://www.researchgate. net/publication/317127644_Customizing_Alarm_Limits_Based_on_Specific_Needs_of_Patients.

Cvach, M. et al. Daily electrode change and effect on cardiac monitor alarms an evidence-based practice approach. J Nurs Care Qual. 2013 [citado 2017 out 7];28(3):265-71. Disponível em: https://www.researchgate.net/profile/Maria_Cvach/publication/233787951_Daily_Electrode_ Change_and_Effect_on_Cardiac_Monitor_Alarms_An_Evidence-Based_Practice_Approach/ links/54d8b2370cf24647581b1 dc6/Daily-Electrode-Change-and-Effect-on-Cardiac-Monitor-AlarmsAn-Evidence-Based-Practice-Approach.pdf.

Cvach, M. et al. Effect of altering alarm settings: a randomized controlled study. Biomed Instrum Technol. 2015 [citado 2017 out 3];49(3):214-22. Disponível em: https://www.researchgate.net/ publication/277084121_Effect_of_Altering_Alarm_Settings_A_Randomized_Controlled_Study.

ECRI Institute. Clinical alarms. Plymouth Meeting (PA): ECRI Institute; 2013 [citado 2014 jan 12]. p. 1-25. Disponível em: https://www.ecri.org/components/HRC/Pages/CritCare5.aspx.

Graham KC, Cvach M. Monitor alarm fatigue: standardizing use of physiological monitors and decreasing nuisance alarms. Am J Crit Care. 2010 [citado 2010 maio 3];19(1):28-37. Disponível em: http://ajcc. aacnjournals.org/cgi/search?sortspec=relevance\&author $1=$ graham\&fulltext=critical+ care+nursing \&pubdate_year $=2010 \&$ volume $=19 \&$ firstpage $=28$.

Healthcare Technology Foundation. 2011 national clinical alarms survey: perceptions, issues, improvements and priorities of healthcare professionals. Plymouth Meeting (PA): HTF; 2011 [citado 2011 out 11]. Disponível em: http://thehtf.org/documents/2011_HTFAlarmsSurveyOverallResults. pdf.

Hyman WA. Clinical alarm effectiveness and alarm fatigue. R Pesq: Cuid Fundam Online. 2012 [citado 2012 abr 1];4(1). 
Joint Commission. Sentinel event alert: Medical device alarm safety in hospitals. Oakbrook Terrace (III): Joint Commission; 2013 Apr 8 [citado 2013 abr 28]. Disponível em: https://www. jointcommission.org/assets/1/6/SEA_50_alarms_4_26_16.pdf.

Korniewicz D, Clark T, David Y. A national online survey on the effectiveness of clinical alarms. Am J Crit Care. 2008 [citado 2010 maio 22];17(1):36-41. Disponível em: http://ajcc.aacnjournals. $\mathrm{org} / \mathrm{cgi} / \mathrm{content} /$ full/17/1/36? maxtoshow=\&hits=10\&RESULTFORMAT=\&author $1=$ korniewicz \&andorexactfulltext=and\&searchid=1\&FIRSTINDEX=0\&sortspec=relevance\&volume $=17$ \&firstpage $=36 \&$ resourcetype $=$ HWCIT.

Paine CW, Goel VV, Ely E, Stave CD, Stemler S., Zander M, et al. Systematic review of physiologic monitor alarm characteristics and pragmatic interventions to reduce alarm frequency. J Hosp Med. 2016 [citado 2017 out 13];11(2):136-144. Disponível em: https://www.ncbi.nlm.nih.gov/pmc/ articles/PMC4778561/pdf/nihms761586.pdf.

Pergher AK, Silva RCL. Fadiga de alarmes: revisão integrativa. R Enferm [Universidade Federal de Pernambuco]. 2013 [citado 2013 jun 4];7(4):1241-7. Disponível em: http://www.revista.ufpe.br/ revistaenfermagem/index.php/revista/article/view/3589/pdf_2442.

Sampaio Neto RA et al. Ruídos na unidade de terapia intensiva: quantificação e percepção dos profissionais de saúde. Rev Bras Ter Inten. 2010 [citado 2016 maio 4];22(4):369-74. Disponível em: http://rbti.org.br/artigo/detalhes/0103507X-22-4-10.

Siebig, S. et al. Intensive care unit alarms: how many do we need? Crit Care Med. 2010 [citado $2010 \mathrm{abr}$ 30];38(2):451-56. Disponível em: http://link.periodicos.capes.gov.br/ sfxlc|3?url_ver=Z39.88-2004\&url_ctx_fmt=infofi/fmt:kev:mtx:ctx\&ctx_enc=info:ofi/enc:UTF8\&ctx_ ver=Z39.882004\&rfr_id=info:sid/sfxit.com:azlist\&sfx.ignore_date_threshold=1\&rft.object_ $i d=954925461121$.

Sowan AK, Reed CC. A complex phenomenon in complex adaptive health care systems: alarm fatigue. JAMA Pediatr. 2017 [citado 2017 out 13];171(6):515-6. Disponível em: http://jamanetwork. com/journals/jamapediatrics/article-abstract/2614070.

\section{Sugestão de estudos complementares}

American Association of Critical-Care Nurses. Alarm Management resources. Disponível em: http:// www.aacn.org/clinical-resources/clinical-toolkits/strategies-for-managingalarm-fatigue?sc_camp=2 DC6BA0C943B44E597A70E5E9400512B

Association for the Advancement of Medical Instrumentation. Disponível em: http://www.aami.org/ thefoundation/content.aspx? ItemNumber $=1730$

Association for the Advancement of Medical Instrumentation. Toolkit for hospitals focuses on alarm management. AAMI News. 2016 Jan [citado 2019 jan 5]. Disponível em: www.aami.org/ productspublications/articledetail.aspx? ItemNumber $=2961$

ECRI Institute. Disponível em: https://www.ecri.org/topics/Pages/TopicLanding.aspx?k=*\&Page=1\&P ageSize=20\&Sort=relevance $\&$ mo=false $\&$ rf=ECRItopics:equals(\%27Alarm\%20Management\%27)\&to picid $=c 56 c 9 f 6 e 174 \mathrm{e} 405795 a 4 d f 49 a 04 e 6605$

Health Technology Foundation. Clinical alarm hazards and management. Disponível em: http:// thehtf.org/clinical.asp

Joint Commission. Medical Device Alarm Safety. Disponível em:

www.jointcommission.org/assets/1/6/medical_device_alarm_safety_infographic.pdf.

National Association of Clinical Nurse Specialists Alarm Fatigue Toolkit. Disponível em: www.nacns. org/docs/NACNSFatigueToolkit.pdf 


\title{
Anexo I - Interrupções do trabalho da equipe de enfermagem
}

\author{
Adriana Carla Bridi
}

O fenômeno das interrupções foi definido como uma quebra no desempenho de uma atividade, iniciada por fonte interna (do próprio indivíduo) ou externa (outros indivíduos, sinais físicos de equipamentos) para o receptor, resultando na suspensão da tarefa inicial, começando uma nova tarefa não programada, com o pressuposto de retomada da tarefa inicial (Brixey et al. 2007).

Falhas operacionais, tais como a falta de materiais, equipamentos e pessoal, deficiências estruturais do sistema e da divisão de trabalho, favorecem as interrupções no fluxo de trabalho, que, combinadas com a realização de diversas tarefas simultâneas, interferem na resolução de problemas, na tomada de decisões e facilitam a ocorrência de erros pelos profissionais envolvidos (Kalisch, Aebersold 2010; Tucker, Spear 2006).

Na literatura internacional, os termos distractions, break-in-task, disruption são, por vezes, utilizados como sinônimos de interrupções. Contudo, a distração é definida como o afastamento dos pensamentos de um ponto para outro ou momentos em que eventos sonoros ou visuais captam a atenção; elas chamam nossa atenção para um objeto diferente, enquanto as interrupções nos impedem de completar uma atividade, invadindo totalmente o processo (Brixey et al. 2007).

A primeira referência acerca das repercussões das interrupções no cuidado de enfermagem foi realizada por Florence Nightingale (1859) em seu livro Notas sobre Enfermagem: o que é e o que não é. Na publicação, a autora afirma que a interrupção prejudica os doentes e os sadios; declara, ainda, de forma visionária: “Nunca soube de pessoas expostas durante anos a interrupções constantes que não desenvolvessem, ao final, e por causa disso, entorpecimento ou confusão mental" (Nightingale 1989, p. 58).

Na década de 1940, na aviação militar e civil, constatou-se que a falta de atenção causada por interrupções levava os pilotos ao erro; posteriormente, a preocupação se estendeu para a indústria automobilística e outras atividades de alto risco, como as usinas nucleares (McGinley 2010). 
No campo da saúde, o estudo das interrupções é relativamente novo, em comparação a outros domínios. Todavia, desde 2000, o tema das interrupções tem sido bastante explorado por pesquisadores/investigadores; esse interesse é, em grande parte, devido à publicação do relatório To Err is Human: building a safer health system pelo Institute of Medicine (IOM 2001), que destacou as interrupções como possíveis contribuintes para a ocorrência de erros em saúde e falhas relacionadas ao ambiente de trabalho. Em razão de as interrupções serem muito comuns em instituições hospitalares, elas impactam negativamente esse cenário e seus profissionais e, consequentemente, a segurança do paciente (Rivera 2014).

Além de induzirem ao erro nas tarefas, as interrupções têm sido reconhecidas por especialistas em fatores humanos como condições que geram atrasos na produção, reduzem a eficiência, a produtividade, a criatividade e acarretam custos diretos e indiretos (Brogan 2012).

Tanto as evidências dos estudos observacionais, dos experimentais, como as investigações laboratoriais controladas e com o uso de simuladores demonstram que as interrupções causam esquecimento nos profissionais, falta de concentração, atrasos no cuidado, tarefas inacabadas, piora do desempenho, o que pode ter implicações negativas significativas para a segurança do paciente (Grundgeiger et al. 2010).

Em relação às implicações cognitivas das interrupções, quando os indivíduos são interrompidos, sua atenção é desviada da tarefa primária (inicial) para realizar outra tarefa (secundária). Uma vez que essa mudança de atenção ocorre, a memória da tarefa primária tem um declínio, a fim de "abrir espaço" para os processos necessários para lidar com a tarefa de interrupção. Assim, quando a tarefa primária é reiniciada, o indivíduo pode não lembrar que parte da tarefa já foi concluída. A quantidade de perda de memória da tarefa primária depende, principalmente, das características e complexidade das tarefas (primária e secundária). Quanto mais complexa e duradoura a tarefa que interrompe a tarefa primária, mais prejudicial será aos processos cognitivos (Rivera, Karsh 2010).

Quando mudamos rápido entre tarefas, existem os "custos de troca", pois temos que nos afastar cognitivamente de uma atividade, para acionar as habilidades necessárias à nova tarefa; as mudanças predispõem a erros. Além disso, uma vez interrompido, um trabalhador pode levar de 15 a 20 minutos para voltar ao que estava fazendo de forma efetiva originalmente, visto em parte, às limitações da memória (Brogan 2012). 


\section{Para refletir}

Você já havia pensado em como as interrupções podem atrapalhar sua dinâmica profissional? Faça um teste. Pare de ler agora este material e vá fazer algo totalmente diferente. Volte e tente ler o texto a partir desse ponto. Você acha que conseguirá retomar a informação do local exato de onde parou, sem ter que reler, pelo menos, os dois últimos parágrafos? O que significa ter que reler parte do que você já havia lido?

Dentre os principais fatores que interferem nos efeitos da interrupção, podemos considerar:

路 aspectos cognitivos do indivíduo (como atenção e carga de memória de trabalho);

momento e duração da interrupção;

滕 necessidade de deslocamento físico do profissional;

䋛 similaridade entre a atividade primária e secundária;

腾 características e complexidade das atividades;

utilização do mesmo estímulo sensorial nas tarefas;

prática e experiência do profissional interrompido;

滕 gerenciamento/gestão da interrupção;

踩 fatores ambientais.

Portanto, conclui-se que os efeitos das interrupções são resultado de um complexo conjunto de variáveis (Li, Magrabi, Coiera 2012).

Burnout é uma síndrome disparada por excessivos e prolongados níveis de estresse no trabalho. Características individuais, somadas às do ambiente e às do trabalho, propiciam o aparecimento de fatores multidimensionais característicos da síndrome, que são: exaustão emocional, distanciamento afetivo e baixa realização profissional.
Mais um agravante na ocorrência de interrupções são os efeitos manifestados psicologicamente no profissional que as vivencia, tais como irritação, burnout, insatisfação, frustração, ansiedade e estresse (Monteiro, Avelar, Pedreira 2015, Prates, Silva 2016).

A análise dos relatórios apresentados à Pennsylvania Patient Safety Authority, nos EUA, em 2010 e 2011, identificou 1.015 relatos de erros atribuídos a distrações e interrupções. A maioria dos eventos foi classificada como erros de medicação $(59,6 \%)$, relacionados aos procedimentos, tratamentos e testes $(27,8 \%)$. Treze eventos resultaram em danos ao paciente (Feil 2013). 
Resultados de pesquisas/investigações demonstram que o trabalho dos profissionais de saúde, principalmente em áreas críticas, requer altas exigências de atenção e memória, ocasionadas pela complexidade e a grande quantidade de informações que devem ser processadas. Nessas circunstâncias, as distrações e interrupções podem ser de modo particular prejudiciais ao desempenho, com impacto negativo na segurança do paciente (Feil 2013).

Artigo de revisão demonstra que, majoritariamente nos artigos analisados, a amostra foi composta de enfermeiros, e, dentre os profissionais da equipe de saúde, são eles os mais interrompidos. O número de interrupções vivenciadas por eles variou de 0,4 a 13,9 por hora, de acordo com o tipo de unidade observada, e foram mais frequentes durante atividades de cuidado direto ao paciente (terapia medicamentosa) e de registro. Constatou-se que o enfermeiro raramente é capaz de completar uma atividade sem ser interrompido, sendo com frequência acionado para o fornecimento de informações e por falhas operacionais na unidade. As principais fontes de interrupção de enfermeiros foram outros membros da equipe de enfermagem, profissionais de saúde, telefone, pacientes, visitantes e a autointerrupção. Quanto às implicações da interrupção para a segurança do paciente, os trabalhos científicos identificaram que próximo a 90\% das interrupções resultaram em consequências negativas, como atraso no tratamento, perda de concentração do profissional e erros de medicação (Monteiro, Avelar, Pedreira 2015).

Embora distrações e interrupções nos cuidados de saúde não possam ser completamente eliminadas, podemos citar algumas recomendações de práticas seguras a fim de minimizá-las e criar um ambiente mais seguro para a execução de tarefas críticas:

a alertas, alarmes e ruídos: reduzir a frequência de alertas de computador; configurar adequadamente parâmetros de alarmes de equipamentos médico-assistenciais para notificações críticas e necessárias; minimizar o ruído de conversas desnecessárias em áreas clínicas;

繗 corrigir falhas operacionais que levem a interrupções evitáveis;

* dizer "não" e "não abraçar o mundo": deixar de assumir trabalho adicional a fim de evitar muitas prioridades concorrentes;

漛 educação do pessoal quanto às repercussões das interrupções e distrações, principalmente em tarefas complexas, e como lidar com elas, alertando também sobre os riscos do uso dos dispositivos móveis pessoais durante tarefas; 
碀incentivar a adoção da rotina de checagem da cirurgia segura com a equipe, incluindo minimização de interrupções durante cirurgias;

歎 não perturbe: utilização, pelo profissional, de um sinal visual durante o preparo e a administração de medicamentos, como coletes coloridos, faixas, aventais, para demonstrar que eles não devem ser interrompidos;

* preparação adequada de material e documentos antes de realizar tarefas, a fim de evitar interrupções durante procedimentos;

踏priorizar tarefas;

政 promover uma cultura de segurança justa e não punitiva;

䓶 realizar programas de capacitação interdisciplinar em segurança do paciente;

* utilizar listas de verificação (checklists), procedimentos padronizados e pistas sinalizadoras para verificação de pontos importantes durante tarefas críticas longas;

菊 zona de não interrupção ou no interruption zone (NIZ) ou zonas de silêncio: são áreas em que o silêncio é recomendado para não interferir na atenção do profissional, principalmente onde tarefas críticas são realizadas. A área é isolada com burocracia, marcadores visuais no chão (como na ilustração) ou paredes e divisórias, para significar que falas e interrupções não são permitidas naquele local.

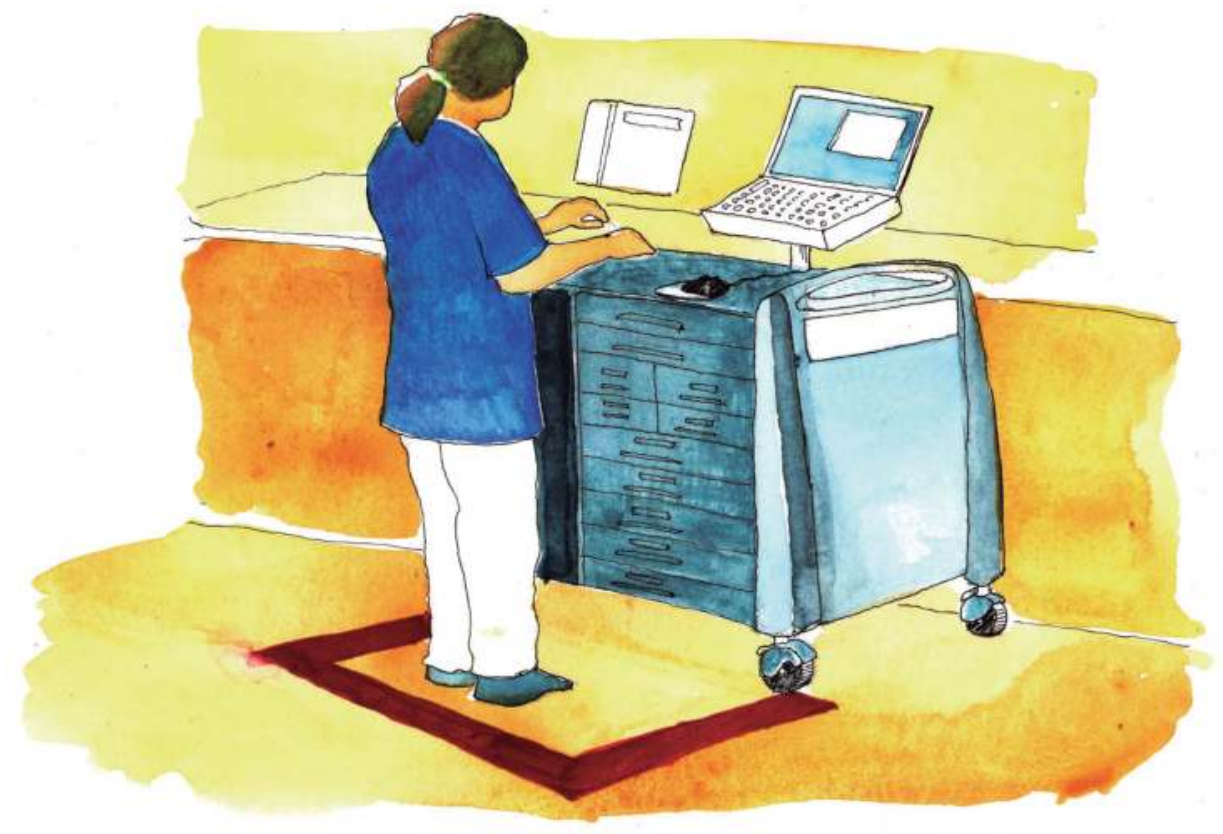


Reason (2000) sugere que identificar as condições que causam interrupções do processo de trabalho possibilita desenvolver estratégias que visam evitar essa ocorrência e minimizar seus impactos para a assistência.

\section{Referências}

Biron AD, Loiselle CG, Lavoie-Tremblay M. Work interruptions and their contribution to medication administration errors: An evidence review. Worldviews Evid Based Nurs. 2009 [citado 2013 ago 4];60(2):70-86. Disponível em: http://onlinelibrary.wiley.com/doi/10.1111/j.17416787.2009.00151.x/pdf.

Bridi AC. Interrupções nas atividades de enfermagem em terapia intensiva: repercussões na atenção e memória dos enfermeiros [tese]. Rio de Janeiro: Universidade Federal do Estado do Rio de Janeiro, Programa de Pós-Graduação em Enfermagem e Biociências; 2017 [citado 2017 out 12]. $318 f$. Disponível em: http://web02.unirio.br/sophia_web/.

Brixey JJ, et al. A concept analysis of the phenomenon of interruption. ANS Adv Nurs Sci. 2007 [citado 2013 ago 1];30(1):E26-E42. Disponível em: http://journals.Iww.com/ advancesinnursingscience/pages/articleviewer.aspx?year $=2007 \&$ issue $=01000 \&$ article $=00012 \&$ type $=$ abstract.

Brogan J. Constant distractions can take a toll. Boston Globe, 2012 Feb 12 [citado 2016 out 12]. Disponível em: http://archive.boston.com/lifestyle/health/articles/2012/02/27/constant_distractions_ can_take_a_toll/?page $=2$.

Elfering A, Grebner S, Ebener C. Workflow interruptions, cognitive failure and near-accidents in health care. Psychol Health Med. 2015 [citado 2016 nov 26];20(2):39-47. Disponível em: https:// www.ncbi.nlm.nih.gov/pubmed/24787909.

Feil M. Distractions and their impact on patient safety. Pa Patient Saf Advis. 2013 [citado 2016 nov 5];10(1). Disponível em: https://www.researchgate.net/publication/237154749_Distractions_and_ Their_Impact_on_Patient_Safety.

Grundgeiger T, Sanderson P. Interruptions in healthcare: theoretical view. Int J Med Inform. 2009 [citado 2013 jul 31];78(5):293-307. Disponível em: http://www.ijmijournal.com/article/S13865056\%2808\%2900179-2/abstract.

Grundgeiger T, Sanderson PM, Beltran Orihuela C, Thompson A, MacDougall HG, Nunnink L, et al. Interruption management in the intensive care unit: predicting resumption times and assessing distributed support. J Exp Psychol: Appl. 2010 [citado 2016 nov 8];16(4): 317-334. Disponível em: http://citeseerx.ist.psu.edu/viewdoc/download?doi=10.1.1.380.7184\&rep=rep1\&type=pdf

Hanson D. Reducing interruptions. Patient Saf Qual Healthc. 2010 Mar/Apr [citado 2012 nov 13];7(2): 24-30. Disponível em: http://viewer.zmags.com/publication/8441c6ae\#/8441c6ae/26.

Hopkinson SG, Jennings BM. Interruptions during nurses' work: a state-of-the-science review. Res Nurs Health. 2013 [citado 2013 jul 31];36(1):38-53. Disponível em: http://onlinelibrary.wiley.com/ doi/10.1002/nur.21515/pdf.

Institute for Safe Medication Practices. Side tracks on the safety express: interruptions lead to errors and unfinished... wait, what was I doing? Horsham (PA): Institute for Safe Medication Practices; 2012 [2016 nov 7]. Disponível em: https://www.ismp.org/newsletters/acutecare/showarticle. aspx?id=37.

Institute of Medicine (US). Keeping patients safe: transforming the work environment of nurses. Washington, DC: The National Academies Press; 2004 [citado 2016 out 12]. p. 23-49. Disponível em: https://www.nap.edu/read/10851/chapter/1. 
Kalisch BJ, Aebersold M. Interruptions and multitasking in nursing care. Jt Comm J Qual Patient Saf 2010 [citado 2016 nov 27];36(3):126-32. Disponível em: https://www.researchgate.net/ Playstation/42253476_Interruptions_and_multitasking_in_nusing_care.

Li YW, Magrabi F, Coiera E. A systematic review of the psychological literature on interruption and its patient safety implications. J Am Med Inform Assoc. 2012 [citado 2013 ago 30];19(1):6-12. Disponível em: http://www.ncbi.nlm.nih.gov/pmc/articles/PMC3240749/pdf/amiajnl-2010-000024. pdf.

Liberto R. Quiet Zones. Patient Saf Qual Healthc. 2010 Mar/Apr [citado 2012 nov 13];7(2):24-30. Disponível em: http://viewer.zmags.com/publication/8441c6ae\#/8441c6ae/26.

Magrabi F. et al. Challenges in measuring the impact of interruption on patient safety and workflow outcomes. Methods Inf Med. 2011 [citado 2013 ago 30];50(5):447-53. Disponível em: https://www.researchgate.net/profile/Farah_Magrabi/publication/51524195_Challenges_ in_Measuring_the_Impact_of_Interruption_on_Patient_Safety_and_Workflow_Outcomes/ links/54ba3f2b0cf29e0cb049d258.pdf.

Magrabi F. et al. Why is it so difficult to measure the effects of interruptions in healthcare? Stud Health Technol Inform. 2010 [citado 2013 ago 30];160(Pt1):784-8. Disponível em: http://www. ncbi.nlm.nih.gov/pubmed/20841793.

McGinley P. Studies and strategies to reduce interruptions and improve care. Patient Saf Qual Healthc. 2010 [citado 2016 nov 7]:24. Disponível em: http://www.psqh.com/analysis/distractionsand-interruptions-impact-on-nursing/.

Monteiro C, Avelar AFM, Pedreira MLG. Interrupções de atividades de enfermeiros e a segurança do paciente: revisão integrativa da literatura. Rev. Latino-Am. Enferm. 2015 [citado 2015 jun 25];23(1):169-179. Disponível em: http://www.scielo.br/pdf/rlae/v23n1/pt_0104-1169rlae-23-01-00169.pdf.

Nightingale F. Notas sobre a Enfermagem: o que é e o que não é. Tradução de Amália Correa de Carvalho. 1. ed. Ribeirão Preto: Cortez, 1989. Ruídos; p. 52-66.

Pape TM et al. Innovative approaches to reducing nurses' distractions during medication administration. J Contin Educ Nurs. 2005 [citado 2017 jan 18];36(3):108-16. Disponível em: http:// interruptions.net/literature/Pape-JCEN05.pdf.

Potter P. Impact of interruptions on the cognitive work of nursing rooms. Patient Saf Qual Healthc. 2010 [citado 2012 nov 13];7(2): 24-30. Disponível em: http://viewer.zmags.com/publication/8441c 6ae\#/8441c6ae/26.

Potter P. et al. Understanding the cognitive work of nursing in the acute care environment. J Nurs Adm. 2005 [citado 2013 ago 18];35(7-8):327-335, 2005. Disponível em: http://citeseerx.ist.psu. edu/viewdoc/download?doi=10.1.1.78.3548\&rep=rep1\&type=pdf.

Prates DO, Silva AEBC. Interruptions of activities experienced by nursing professionals in an intensive care unit. Rev. Latino-Am. Enferm. 2016 [citado 2016 out 14]; 24: 2802-9. Edição especial. Disponível em: http://www.scielo.br/pdf/rlae/v24/pt_0104-1169-rlae-24-02802.pdf.

Raban M. Z.; Westbrook, J. I. Are interventions to reduce interruptions and errors during medication administration effective?: a systematic review. BMJ Qual Saf. 2013 [citado 2016 ago 17]: 1-8. Disponível em: http://qualitysafety.bmj.com/content/early/2013/08/26/ bmjqs-2013-002118.full.pdf.

Reason J. Human error: models and management. Brit Med J. 2000 [citado 2016 out 12];320: 76870. Disponível em: http://www.galliera.it/20/58/strutture-e-servizi-in-staff-alla-direzione-sanitaria/ ugr/documenti/pubblicazioni/risk_12.pdf.

Redding DA, Robinson S. Interruptions and geographic challenges to nurses' cognitive workload. J Nurs Care Qual. 2009 [citado ago 2013];24(3):194-200. Disponível em: http://interruptions.net/ literature/Redding-JNursCareQual09.pdf. 
Rev. psiquiatr. clín. vol. 34 no. 5 São Paulo 2007. Acesso em: 10 abr. 2018.

Rivera AJ. A socio-technical systems approach to studying interruptions: Understanding the interrupter's perspective. Appl Ergon. 2014 [citado 2016 nov 14];45:747-56. Disponível em: https:// pdfs.semanticscholar.org/0d78/e8455160219767ed3462f494ee62cbc040a4.pdf.

Rivera AJ., Karsh BT. Interruptions and distractions in healthcare: Review and reappraisal. Qual Saf Health Care. 2010 [2013 jul 31];19(4):304-312. Disponível em: http://www.ncbi.nlm.nih.gov/pmc/ articles/PMC3007093/pdf/nihms249161.pdf.

Sanderson PM, Grundgeiger T. How do interruptions affect clinician performance in healthcare? Negotiating fidelity, control, and potential generalizability in the search for answers. Int. J. HumanComputer Studies. 2015 [citado 2016 out 12];(79):85-96. Disponível em: http://interruptions.net/ literature/Sanderson-IntJHumComputStud15.pdf.

Sasangohar $F$, et al. Interruptions experienced by cardiovascular intensive care unit nurses: an observational study. J Crit Care. 2014 [citado 2016 nov. 27];29(5):848-53. Disponível em: https:// www.researchgate.net/publication/263315586_Interruptions_Experienced_by_Cardiovascular_ Intensive_Care_Unit_Nurses_An_Observational_Study.

Tucker AL, Spear SJ. Operational failures and interruptions in hospital nursing. Health Serv Resch. 2006 [citado 2015 jun 22];41(3, part I):643-62. Disponível em: http://www.ncbi.nlm.nih.gov/pmc/ articles/PMC1713207/pdf/hesr041-0643.pdf.

Wickens CM, Toplak ME, Wiesenthal DL. Cognitive failures as predictors of driving errors, lapses, and violations. Accid Anal Prev. 2008 [citado 2016 nov 7];40(3):1223-33. Disponível em: https:// www.ncbi.nlm.nih.gov/pubmed/18460392. 
Formato: $205 \times 260 \mathrm{~mm}$

Tipografia: Meridien LT Std e Frutiger Lt Std

Papel do Miolo: Papermax 90g/m2

Papel e Acabamento Capa: Papel Cartão supremo 250g/m2

Ctp Digital: COAN Indústria Gráfica

Impressão e acabamento: COAN Indústria Gráfica

Rio de Janeiro, maio de 2019. 